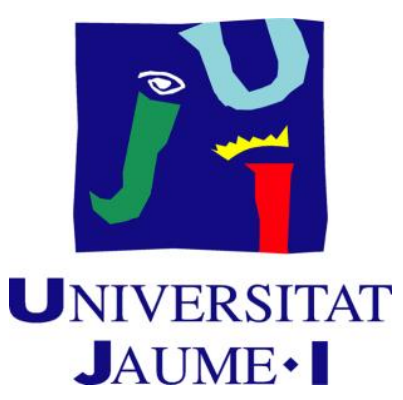

UNIVERSITAT JAUME I DE CASTELLÓ

Programa de Doctorado en Tecnologías Industriales y Materiales

Escuela de Doctorado de la Universitat Jaume I

\title{
Estudio de la dispersión de nanopartículas en medio acuoso para su posterior aplicación como fluido térmico
}

\author{
Memoria presentada por \\ MáCarmen Segarra Ferrando
}

para optar al grado de doctora por la Universitat Jaume I

doctoranda:

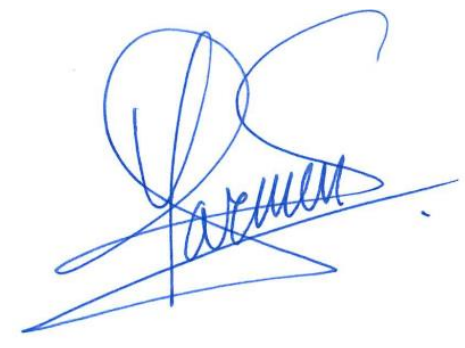

Ma Carmen Segarra Ferrando directores de la tesis:
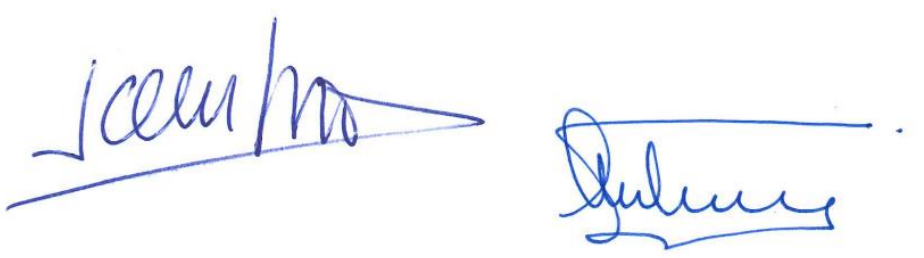

Dr.Juan Carlos Jarque Fonfría y Dr.Antonio Barba Juan 

JUAN CARLOS JARQUE FONFRÍA Y ANTONIO BARBA JUAN, CATEDRÁTICOS DE INGENIERÍA QUÍMICA

CERTIFICAN: que Doña María del Carmen Segarra Ferrando ha realizado bajo su dirección dentro del "Programa de Doctorado en Tecnologías Industriales y de Materiales" de la Universitat Jaume I de Castellón, el trabajo que se presenta con el título "Estudio de la dispersión de nanopartículas en medio acuoso para su posterior aplicación como fluido térmico" y que constituye su tesis para optar al grado de Doctora en Ingeniería Química.

Y para que conste con los efectos oportunos, firman el presente certificado en Castellón, a 20 de octubre de 2020.

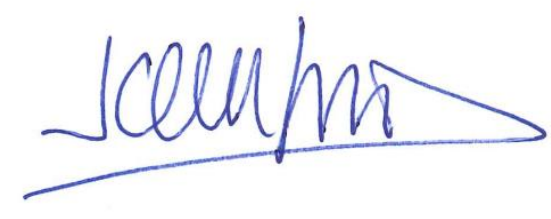

Dr. Juan Carlos Jarque Fonfría

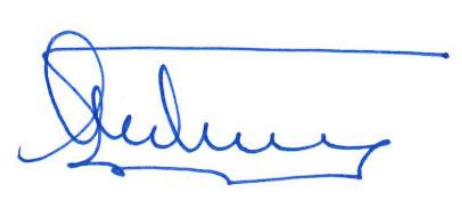

Dr. Antonio Barba Juan 

Este estudio ha sido financiado a través de dos proyectos de investigación:

1) Proyecto: Uso de nanofluidos para la mejora de fluidos térmicos (NANOTHERMAL). Plan Nacional I-D+i 2008-2011 Ministerio de Ciencia e Innovación, Subprograma de Proyectos de Investigación Fundamental.

2) Ayuda complementaría para la ejecución del proyecto:"Caracterización y optimización de nanofluidos para procesos de transferencia de calor por ebullición"dentro de la línea: sol-licitud d'ajudes complementàries per a projectes d'itd acomp/2012 de la Conselleria d’educació. Direcció general de política científica, Genaralitat Valenciana. 

"A la meva familia per la seva ajuda i recolçament a mi tutor por su orientación 

Agradecimientos 

A lo largo de nuestras vidas emprendemos diferentes proyectos, los cuales iniciamos siempre con ilusión y que finalmente debido a su gran embergadura acaban convierténdose en un reto personal difícil de superar. En este documento se recoge todo el trabajo desarrollado en esta tesis a nivel científico, pero no queda reflejado el trabajo humano que acompaña al mismo y el cual quiero hacer constar con las siguientes palabras de agradecimiento.

En primer lugar agradecer a mi familia el apoyo constante a lo largo de estos años, sobre todo a mi hijos que han compartido su infancia con el desarrollo de la tesis, y que no entendían como un trabajo podía llevar tanto tiempo, pero tras el cual han aprendido que las cosas importantes no se consiguen sin esfuerzo.

Gracias a mis directores de tesis, Juan Carlos y Toni, por sus indicaciones, apoyo y consejos pues han sido de gran ayuda en la redacción de este trabajo de investigación.

Gracias al profesor, Dr. Enrique Julián por sus indicaciones y orientaciones como investigador principal del proyecto, como codirector del trabajo final de master presentado sobre nanofluidos de nanotubos de carbono en 2016. Su pérdida fue un duro golpe para todos aquellos investigadores que habíamos trabajado con él, generando a su vez innumerables preguntas sobre la fragilidad de la vida, sobre los retos con los que nos comprometemos y la cuestión más importante, el tiempo con tu familia. La respuesta a esta última cuestión por parte de mi familia fue unánime, este reto ya no era meramente científico, era un reto personal que contaba con el apoyo incondicional por su parte y que lograríamos finalizar todos juntos con la lectura de la tesis.

Agradecer a Rosa Mondragón sus aportaciones en el inicio del trabajo de investigación conjunto a desarrollar durante la ejecución del proyecto NANO-OPT, al igual que a otros compañeros de trabajo como Juan Castelló, Ferran Franch, Marie Arnoult, Juan Miguel Tiscar, Sandra Rodríguez junto con los cuales se consiguió llevar a cabo todo el trabajo experimental del proyecto origen de la tesis.

Agradecer a todos mis compañeros del ITC su incansable interés por la evolución de la tesis, por sus ánimos, y en algunos casos por sus aportaciones, podría citar a tantos... Gracias David por tu asesoramiento informático, gracias Paqui por tu incesable apoyo, gracias Tica ,Adriana Dori y Encarna por vuestros consejos tras la presentación de vuestras tesis. 
Tabla de contenido 



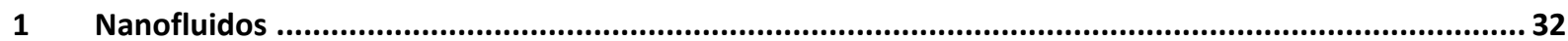

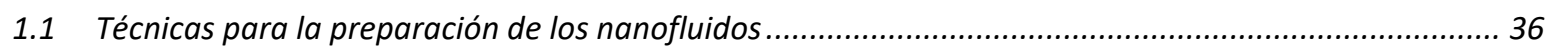

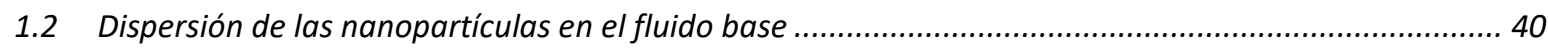

1.3 Estabilidad de las nanopartículas dispersadas en el fluido base ...................................................44

1.3.1 Modificación de la superficie de las nanopartículas; Surfactantes ...........................................47

1.3.2 Modificación de la superficie de las nanopartículas; Funcionalización...................................... 49

1.3.3 Estabilización de los nanofluidos mediante modificación del potencial zeta ............................. 50

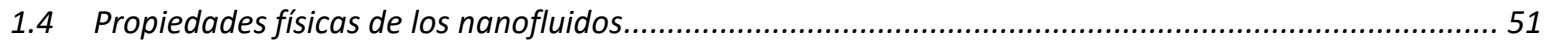

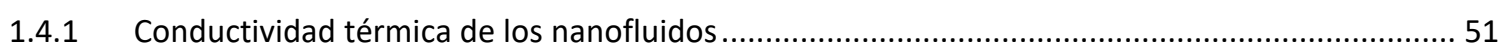

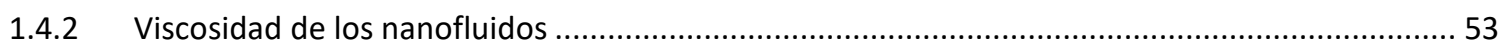

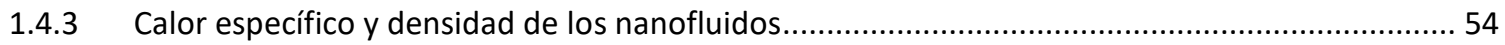

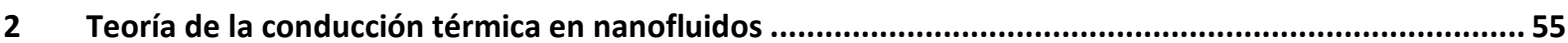

2.1 Mecanismos propuestos por diversos autores para predecir el aumento en conductividad térmica de los nanofluidos 55

2.2 Factores que afectan a la conductividad térmica de los nanofluidos ............................................. 58

3 Mecanismos de transferencia de calor. Aplicación de los nanofluidos como fluidos térmicos. 61

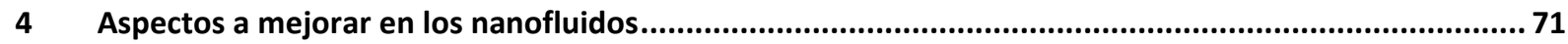

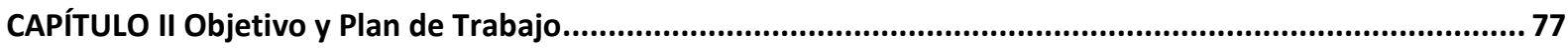

1 Objetivo

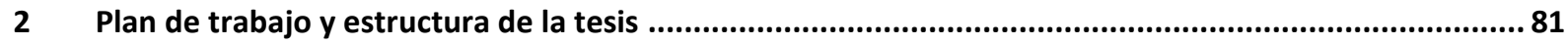

CAPÍTULO III Materiales y metodología experimental ......................................................................... 85

$1 \quad$ Materiales utilizados en la preparación de los nanofluidos .........................................................8

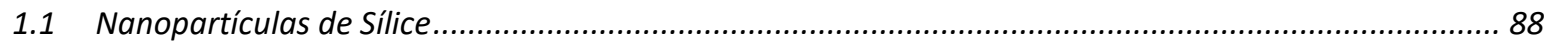

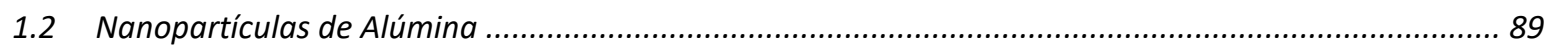

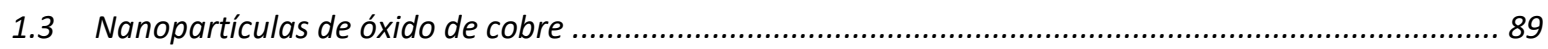




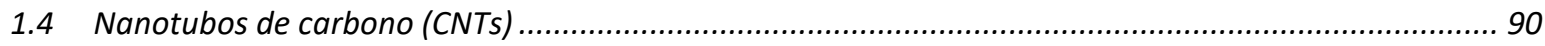

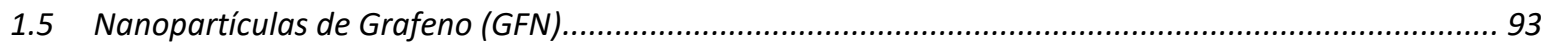

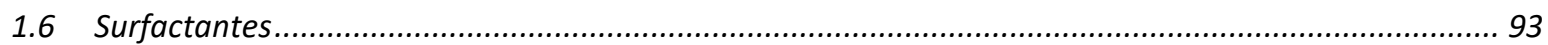

2 Preparación de los nanofluidos: dispersión de nanopartículas en base acuosa ...................................95

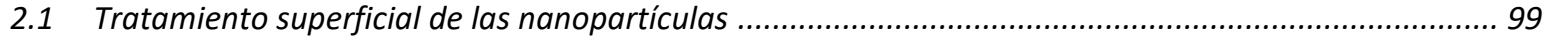

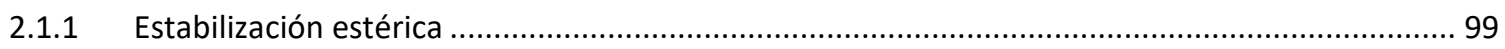

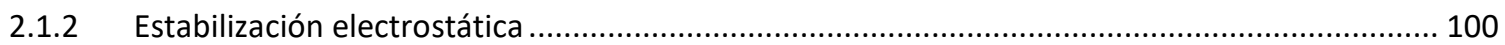

2.1.3 Funcionalización de las nanopartículas .......................................................................... 101

2.2 Dispersión mecánica de las nanopartículas en el fluido base ....................................................... 104

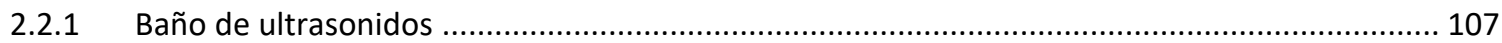

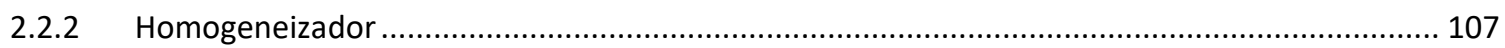

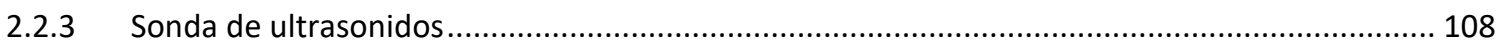

3 Técnicas utilizadas para la caracterización de los nanofluidos ....................................................... 113

3.1 Caracterización de la estabilidad de los nanofluidos .................................................................. 113

3.1.1 Caracterización de la estabilidad de los nanofluidos mediante luz retrodispersada en el equipo

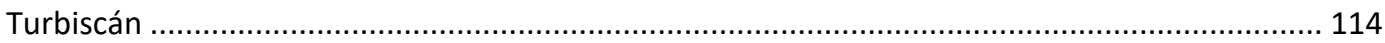

3.1.2 Caracterización de la estabilidad de los nanofluidos mediante espectrofotometría de U.V...... 117

3.2 Medida de la conductividad térmica en los nanofluidos .............................................................. 120

3.2.1 Método transitorio de hilo caliente ...................................................................................... 121

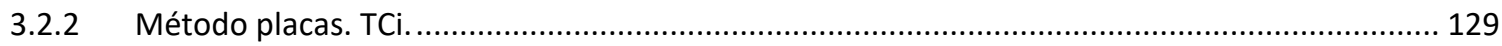

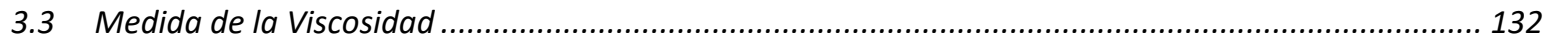

3.3.1 Medida de la viscosidad en un reómetro de rotación ......................................................... 134

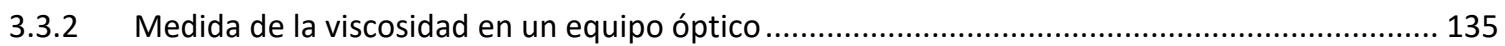

3.4 Caracterización de los nanoflui1dos por análisis de imagen ..................................................... 136

3.4.1 Microscopia electrónica de transmisión TEM .............................................................. 136

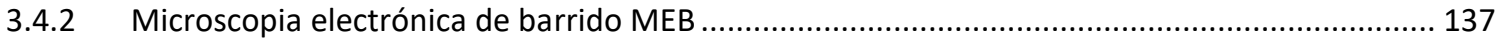

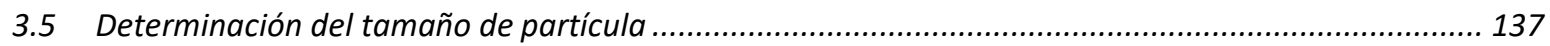

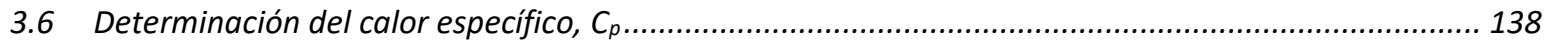

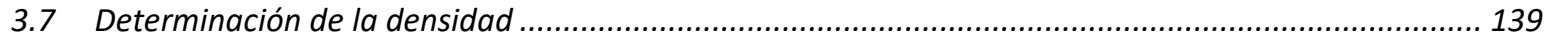

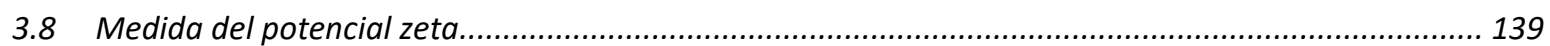

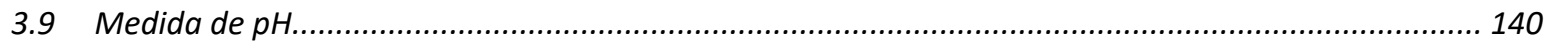


1.1 Caracterización de los nanofluidos preparados con nanopartículas de sílice

1.1.1 Caracterización del material de sílice de partida

1.1.2 Preparación de los nanofluidos de sílice. Resultados de caracterización, dispersión y estabilidad.

1.1.3 Resultados de la medida de la conductividad térmica de los nanofluidos de sílice. 160

1.1.4 Resultados de la medida de la viscosidad de los nanofluidos de sílice: Aerosil y LUDOX ........... 163

1.2 Caracterización de los de los nanofluidos preparados con nanopartículas de alúmina ...................... 171

1.2.1 Caracterización del material de alúmina de partida

1.2.2 Preparación de los nanofluidos de alúmina. Resultados de la caracterización de la dispersión y de la estabilidad

1.2.3 Resultados de la medida de la conductividad térmica de los nanofluidos de alúmina: Aeroxide y Aerodisp

1.2.4 Resultados de la medida de la viscosidad de los nanofluidos de alúmina: Aeroxide y Aerodisp 184

1.3 Caracterización de los de los nanofluidos preparados con nanopartículas de óxido de cobre (II)........ 187

1.3.1 Caracterización del material de óxido de cobre de partida

1.3.2 Preparación y caracterización de la dispersión y estabilidad de los nanofluidos de óxido de cobre

1.3.3 Resultados de la medida de la conductividad térmica de los nanofluidos de óxido de cobre.... 194

1.3.4 Resultados de la medida de la viscosidad de los nanofluidos de óxido de cobre

2.1 Caracterización del grado de dispersión y de la estabilidad de los nanofluidos preparados con nanotubos de carbono

2.1.1 Caracterización de los nanotubos adquiridos ..................................................................... 202

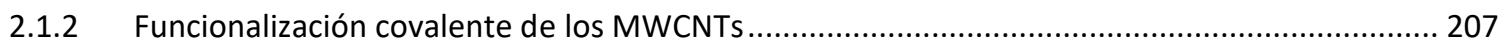

2.1.3 Caracterización del estado de dispersión de los nanotubos en los nanofluidos preparados ..... 211

2.1.4 Caracterización de la estabilidad de los nanofluidos preparados con nanotubos..... 215

2.2 Resultados de la medida de la conductividad térmica de los nanofluidos preparados con nanotubos 224

2.2.1 Influencia del método de dispersión mecánica sobre la conductividad térmica ........................ 225

2.2.2 Influencia de la naturaleza del surfactante sobre la conductividad térmica ............................. 230

2.2.3 Influencia de la fracción volumétrica y la temperatura de trabajo sobre la conductividad térmica 
2.2.4 Influencia de la tipología de nanotubo sobre la conductividad térmica ............................... 232

2.2.5 Influencia del pH del nanofluido sobre la conductividad térmica ......................................... 234

2.3 Resultados de la medida de la viscosidad de los nanofluidos preparados con nanotubos .................. 235

2.3.1 Influencia del método de dispersión mecánica y del tipo de surfactante sobre la viscosidad del nanofluido

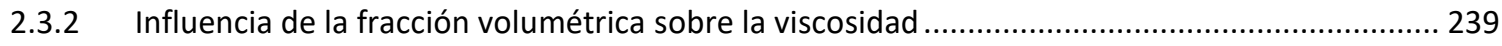

2.3.3 Influencia de la tipología de nanotubo sobre la viscosidad ......................................................240

3 Preparación y caracterización de los nanofluidos con nanopartículas de grafeno

3.1 Caracterización de la dispersión y estabilidad de los nanofluidos preparados con grafeno................ 246

3.1.1 Caracterización de las partículas de grafeno adquiridas .................................................... 246

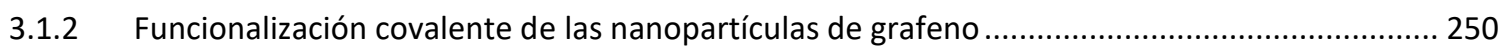

3.1.3 Caracterización del estado de dispersión de las nanopartículas de grafeno en los nanofluidos preparados

3.1.4 Caracterización de la estabilidad de los nanofluidos preparados con grafeno........................ 259

3.2 Resultados de la medida de conductividad térmica de los nanofluidos preparados con nanopartículas de grafeno.

3.2.1 Medida de la conductividad térmica en nanofluidos de grafeno sin funcionalizar 267

3.2.2 Medida de la conductividad térmica en nanofluidos de grafeno funcionalizado con surfactantes .

3.2.3 Medida de la conductividad térmica en nanofluidos de grafeno funcionalizado con método covalente

3.3 Resultados de la medida de viscosidad de los nanofluidos preparados con nanopartículas de grafeno....

3.3.1 Medida de la viscosidad en nanofluidos de grafeno sin funcionalizar .................................. 272

3.3.2 Medida de la viscosidad en nanofluidos de grafeno funcionalizados ...................................... 275

4 Estudio comparativo y de viabilidad de los nanofluidos preparados

4.1 Modelización de la conductividad térmica de los nanofluidos

4.1.1 Modelización y análisis de los resultados de la conductividad térmica de nanofluidos preparados con nanopartículas esféricas (sílice, alúmina, oxido de cobre II) 281

4.1.2 Modelización y análisis de los resultados de la conductividad térmica de nanofluidos preparados con nanopartículas de carbono

4.2 Aplicación de los nanofluidos como fluidos térmicos

4.2.1 Estudio comparativo mediante el módulo de Mouromtseff y de Prandtl de la efectividad de los nanofluidos 


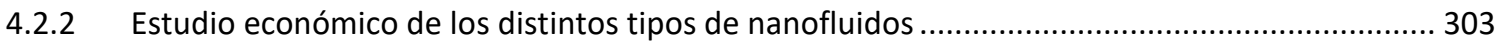

4.2.3 Validación de la transferencia de calor de los nanofluidos en un bucle experimental ............... 313

CAPÍTULO V Conclusiones

1 Conclusiones obtenidas en la metodología aplicada en la preparación y caracterización de los nanofluidos

2 Conclusiones obtenidas en el estudio de las propiedades de los nanofluidos preparados

3 Conclusiones obtenidas sobre modelización y viabilidad tras el estudio comparativo entre nanofluidos .

Futuras líneas de investigación

Publicaciones

1 Artículos

2 Publicaciones a congresos 

Resumen 

En esta última década la mejora de la eficiencia de los sistemas de conversión y transporte de energía ha sido uno de los temas más estudiado con el objetivo de mitigar las emisiones de $\mathrm{CO}_{2}$ y el calentamiento global del planeta. La intensificación y el control de los procesos de transferencia de calor con el objetivo de aumentar su eficiencia y reducir sus consumos focaliza el estudio tanto en el diseño de los intercambiadores como en el de los fluidos térmicos. En este sentido, numerosos trabajos de investigación han centrado sus estudios en encontrar las mejores técnicas que conlleven un aumento significativo en la transferencia de calor de los fluidos. Uno de los métodos propuesto es la adición de nanopartículas con elevada conductividad térmica en el fluido base, obteniéndose de esta forma un nanofluido más eficiente en la transferencia de calor.

Aunque en la teoría las características de los nanofluidos auguran un futuro prometedor en el ámbito de los procesos de transferencia de calor, en la actualidad esto no se ha producido. Todavía hay un importante obstáculo para su comercialización y posterior aplicación industrial, que a escala de laboratorio no se está consiguiendo salvar, y es la estabilidad de las suspensiones con las nanopartículas dispersas. A menudo se encuentran discrepancias entre los resultados obtenidos en estudios similares de nanofluidos obtenidos a partir de nanopartículas del similares características pero preparados por distintos investigadores. Esto se debe a que influye en gran medida la forma de preparación de estas suspensiones. Tanto el pH, la forma, el tamaño y la fracción volumétrica de las nanopartículas, como el fluido base en el que se encuentran inmersas van a tener gran influencia en las propiedades térmicas y reológicas del nanofluido. La tendencia general observada por la mayoría de los estudios es al aumento de la conductividad térmica con el aumento de la fracción volumétrica y la disminución del tamaño de partícula. En cuanto a la viscosidad, propiedad que juega un papel importante en el desempeño de su función como fluido térmico, también se ha observado una tendencia al aumento de esta con el aumento de la carga sólida en el nanofluido. Aun así, el efecto de la aglomeración de partículas, debido a las fuerzas de tipo Van der Waals que surgen por la interacción entre las partículas de tamaño nanométrico, y el grado de afinidad entre éstas y el líquido base hacen que el comportamiento del nanofluido sea algo inestable e impredecible. 
Existen por tanto todavía numerosas barreras en la preparación de nanofluidos, entre las cuales se encuentran el elevado coste de las nanopartículas, la correcta dispersión de las mismas en el fluido base, y la estabilidad de los nanofluidos tras su preparación que hacen que su aplicación industrial sea actualmente un desafío. En este contexto y con el objeto de profundizar en el conocimiento que permita mejorar la estabilidad de dichos nanofluidos se inició el presente estudio de dispersión de nanopartículas en medio acuoso.

El objetivo principal del trabajo de investigación ha sido establecer la metodología óptima de dispersión de nanopartículas en base acuosa a escala de laboratorio para obtener nanofluidos estables para su aplicación como fluido térmico. Se ha seleccionado como fluido base el agua por tratarse de un fluido de bajo coste y respetuoso con el medio ambiente. En el estudio de la bibliografía consultada sobre nanofluidos se ha constatado que:

- existe poca información sobre los principales métodos de dispersión de las nanopartículas en fluidos base como por ejemplo el agua

- y una gran dispersión de los resultados obtenidos en los aumentos de conductividad publicados por diversos autores a idénticas fracciones volumétricas de material.

Este estudio puede ayudar a predecir las condiciones óptimas para preparar nanofluidos estables que conlleven un aumento en la conductividad térmica y esclarecer las causas de esta posible disparidad en los aumentos relativos de conductividad térmica conseguidos.

La conductividad térmica final de un nanofluido va a depender de la estabilidad del mismo y del estado de agregación de las nanopartículas. En este trabajo de investigación se ha analizado el efecto que tiene sobre las propiedades térmicas finales de los nanofluidos dicho estado de agregación, analizando tanto el método de preparación como la tipología y fracción volumétrica de las nanopartículas en el fluido base.

La naturaleza de las nanopartículas elegidas para la preparación de los nanofluidos ha sido diversa incluyéndose óxidos cerámicos (alúmina y sílice), óxidos metálicos (óxido de cobre II) y nanopartículas basadas en carbono (nanotubos y grafeno), todas ellas adquiridas comercialmente. Para lograr la dispersión de dichas nanopartículas en base acuosa a varias fracciones volumétricas, se han utilizado distintos métodos de agitación mecánica, caracterizando posteriormente su conductividad térmica y viscosidad. Además de los mecanismos de agitación mecánica, se ha analizado el efecto que puede tener la 
funcionalización de las nanopartículas, la adición de surfactantes y el pH del medio sobre la dispersión y estabilidad de las suspensiones preparadas.

La tesis se ha estructurado en cinco capítulos. El presente capítulo recoge la introducción y motivaciones del trabajo de investigación, junto con la revisión bibliográfica. En el segundo capítulo se describen los principales objetivos del estudio y el plan de trabajo seguido para su consecución. En el tercer capítulo se describen los diferentes materiales utilizados y la metodología seguida en los ensayos experimentales realizados para la dispersión y caracterización de los nanofluidos. Los resultados obtenidos para cada uno de los tipos de nanofluidos preparados (a partir de nanopartículas de grafeno, nanotubos, sílice, alúmina y óxido de cobre) junto con la discusión de los mismos se resumen en el cuarto capítulo. Además, se ha incluido en dicho capítulo un apartado de modelización y estudio de viabilidad de los nanofluidos preparados para su posterior aplicación industrial. Por último, en el quinto capítulo se presentan las principales conclusiones que pueden extraerse del estudio junto con las líneas futuras de desarrollo que se abren a raíz del mismo. 

CAPÍTULO I

Introducción 

El Quinto Informe AR5 de Evaluación del IPCC (Grupo Intergubernamental de Expertos sobre el Cambio Climático) mostró que el calentamiento es ya un fenómeno global causado por los humanos, "Las emisiones de gases de efecto invernadero y otros impulsores antropógenos han sido la causa dominante del calentamiento observado desde mediados del siglo XX" cita textualmente. En este último informe de síntesis se añade que existe suficiente ciencia y tecnología para mitigar el efecto de los gases invernadero, asimismo, se apunta que una economía basada en bajas emisiones de carbono además de posible es un negocio sostenible. Los procesos de captación, transformación y uso de la energía provocan importantes impactos sobre el medio ambiente, además del propio efecto de agotamiento progresivo de los recursos no renovables. Los daños más significativos suelen estar asociados a las emisiones atmosféricas contaminantes y hay que añadir que cerca del $90 \%$ de las emisiones de $\mathrm{CO}_{2}$ a la atmósfera tienen un origen energético. La respuesta de la comunidad internacional a estos serios problemas ambientales se ha traducido en dos instrumentos jurídicos, la Convención Marco de Naciones Unidas sobre el Cambio Climático, adoptada en 1992 y que entró en vigor en 1994, y el Protocolo de Kioto. El objetivo de ambos instrumentos es luchar contra el cambio climático mediante una acción internacional de reducción de las emisiones de determinados gases de efecto invernadero responsables del calentamiento del planeta. La mejora de la eficiencia de los sistemas de conversión y transporte de energía es una de las cuestiones clave para cumplir con el desafío energético, mitigando dichas emisiones.

Como predice la 2ạ ley de la Termodinámica, en ninguna conversión de energía se puede obtener un rendimiento del $100 \%$, ya que siempre existe una pérdida en forma de calor. La eficiencia energética trata de reducir este porcentaje que en ocasiones puede llegar a ser muy importante mediante la aplicación de procesos más eficientes. Otro de los objetivos de la eficiencia energética se basa en reducir el consumo de recursos energéticos para obtener la misma cantidad final de energía. La eficiencia energética tiene por tanto una doble vertiente:

- Desde el punto de vista de la producción de energía.

- Desde el punto de vista del consumo final de energía.

La intensificación y el control de los procesos de transferencia de calor con el objetivo de aumentar su eficiencia y reducir sus consumos deberían ser las principales tareas en la lucha contra el cambio climático, actuando por ejemplo en los sistemas de refrigeración, los 
reactores nucleares, los sistemas mecánicos, etc. En el enfoque integrado, se reconoce que la refrigeración es una parte esencial de muchos procesos industriales y que debe considerarse un elemento fundamental del sistema global de gestión energética.

Otra herramienta en la lucha contra el cambio climático es a través del aprovechamiento de energías renovables, como la energía termosolar, donde el consumo de combustible es mínimo y los procesos de obtención de energía empiezan a ser eficientes. Dentro de esta línea se engloban las siguientes técnicas;

- colectores solares

- la energía fotovoltaica

- los concentradores solares

Tanto en colectores solares como en concentradores solares la aplicación de fluidos térmicos de elevado coeficiente de transferencia de calor resulta óptima. Los fluidos térmicos que habitualmente se utilizan en los intercambiadores de calor son aceites térmicos para operar a temperaturas elevadas (hasta $300^{\circ} \mathrm{C}$ con aceites térmicos orgánicos y $430^{\circ} \mathrm{C}$ con ciertos sintéticos) y fluidos agua-glicol (excelente opción para procesos de calentamiento indirecto de hasta aproximadamente $150^{\circ} \mathrm{C}$ ), aunque el mejor fluido térmico es el agua, ya que presenta entre sus numerosas ventajas, un coste muy reducido y excelentes prestaciones térmicas.

Existen dos estrategias para mejorar la eficiencia de los intercambiadores, de manera que intercambien la mayor cantidad de calor consumiendo la menor cantidad de energía al operar con el fluido intercambiador. Una primera estrategia es la mejora del diseño del equipo, maximizando el área de contacto, mientras que la segunda es la mejora de las características del fluido intercambiador (objeto del presente estudio doctoral). Fluidos base con mayor conductividad térmica, mejoran los mecanismos de transferencia de calor con su consecuente ahorro energético y reducción en las emisiones de dióxido de carbono [1].

Los nanofluidos se definen como suspensiones diluidas con partículas sólidas de menos de $100 \mathrm{~nm}$ en los cuales gracias a la elevada conductividad térmica de las nanopartículas sólidas se obtiene un fluido térmico de elevada conductividad. Para poder utilizar los nanofluidos como sustitutos de los fluidos térmicos convencionales (fluidos homogéneos como el agua o el etilenglicol), éstos deben cumplir los mismos requisitos técnicos. Los requerimientos básicos de los fluidos térmicos son los siguientes [1]: 
- Resistencia a la degradación a las temperaturas para las cuales están especificados, para asegurar una larga vida de estos sin sedimentación de residuos.

- Estabilidad y homogeneidad a lo largo del tiempo.

- Buenas características de transferencia de calor, alta conductividad térmica.

- Poseer bajas presiones de vapor a las temperaturas de trabajo, para permitir operar en sistemas a bajas presiones (incluso atmosféricas).

- Poseer baja viscosidad, para reducir pérdidas asociadas al bombeo, (pérdidas por fricción o rozamiento), que se traducirán en mayores consumos de energía eléctrica.

- Evitar la corrosión de los materiales en contacto con los fluidos térmicos.

- Tener un precio asequible.

- Poca tendencia a ensuciamiento o "fouling" sobre las paredes del intercambiador, medido como potencial de incrustación.

- Punto de congelación bajo.

- Que sean biodegradables.

En este capítulo se ha realizado una revisión bibliográfica sobre la metodología utilizada por diversos grupos de investigación para la preparación de los nanofluidos y su posterior caracterización térmica, con el objetivo de definir los factores clave en la metodología a utilizar. En primer lugar, resultó necesario profundizar en los mecanismos de transferencia de calor a micro y nano-escala y adquirir los conocimientos necesarios sobre dispersión de nanopartículas en medios acuosos y estabilidad coloidal con el objetivo de preparar nanofluidos con posterior aplicabilidad industrial. 


\section{Nanofluidos}

El concepto de añadir pequeñas partículas sólidas en un fluido base para incrementar su conductividad térmica se ha practicado desde hace 150 años, sin embargo, la mayoría de los estudios iniciales se realizaron utilizando suspensiones de partículas de tamaño milimétrico o micrométrico (suspensiones coloidales). Este tipo de suspensiones presentaron problemas de estabilidad de la suspensión y obstrucción de los microcanales del intercambiador por donde circula el fluido debido a la sedimentación de las partículas, lo cual limitó su aplicación práctica. Pero con el auge de la Nanotecnología experimentado en la última década, han sido muchos los grupos de investigación que han incorporado las nanopartículas a los fluidos base dando origen a una nueva tipología de fluidos térmicos, los nanofluidos [1 a 7].

Maxwell [13] fue el primer investigador en proponer (en 1873) una mejora teórica en la conductividad para las suspensiones con partículas debido a que los sólidos presentan valores de conductividad térmica varios órdenes de magnitud superiores a los valores de los líquidos, (Figura 1 y Figura 2). Como se observa en la Figura 1 la conductividad del fluido base (agua destilada, etilenglicol o aceite mineral) es bastante baja comparada con la conductividad térmica de los sólidos. Entre los sólidos, los que mayor conductividad térmica presentan son los nanotubos de carbono de pared única (SWCNTs) seguidos por las nanopartículas de grafeno y los nanotubos de pared múltiple (MWCNTs), (Figura 2). Por tanto, es de esperar que la conductividad del nuevo fluido con partículas sólidas dispersas presente una conductividad mayor, que según la expresión de Maxwell dependería de las conductividades térmicas de los componentes y de la fracción volumétrica de las nanopartículas sólidas en el fluido:

$$
k_{n f}=\frac{k_{p}+k_{f b}+2\left(k_{p}-k_{f b}\right) \Phi}{k_{p}+2 k_{f b}-\left(k_{p}-k_{f b}\right) \Phi} k_{b f}
$$

Donde:

$\mathrm{k}_{\mathrm{nf}}$ : conductividad térmica del nanofluido $(\mathrm{W} / \mathrm{mK})$

$\mathrm{k}_{\mathrm{p}}$ : conductividad térmica de la partícula sólida(W/mK)

$\mathrm{k}_{\mathrm{fb}}$ : conductividad térmica del fluido base $(\mathrm{W} / \mathrm{mK})$

$\Phi$ : fracción volumétrica de nanopartículas (adimensional) 


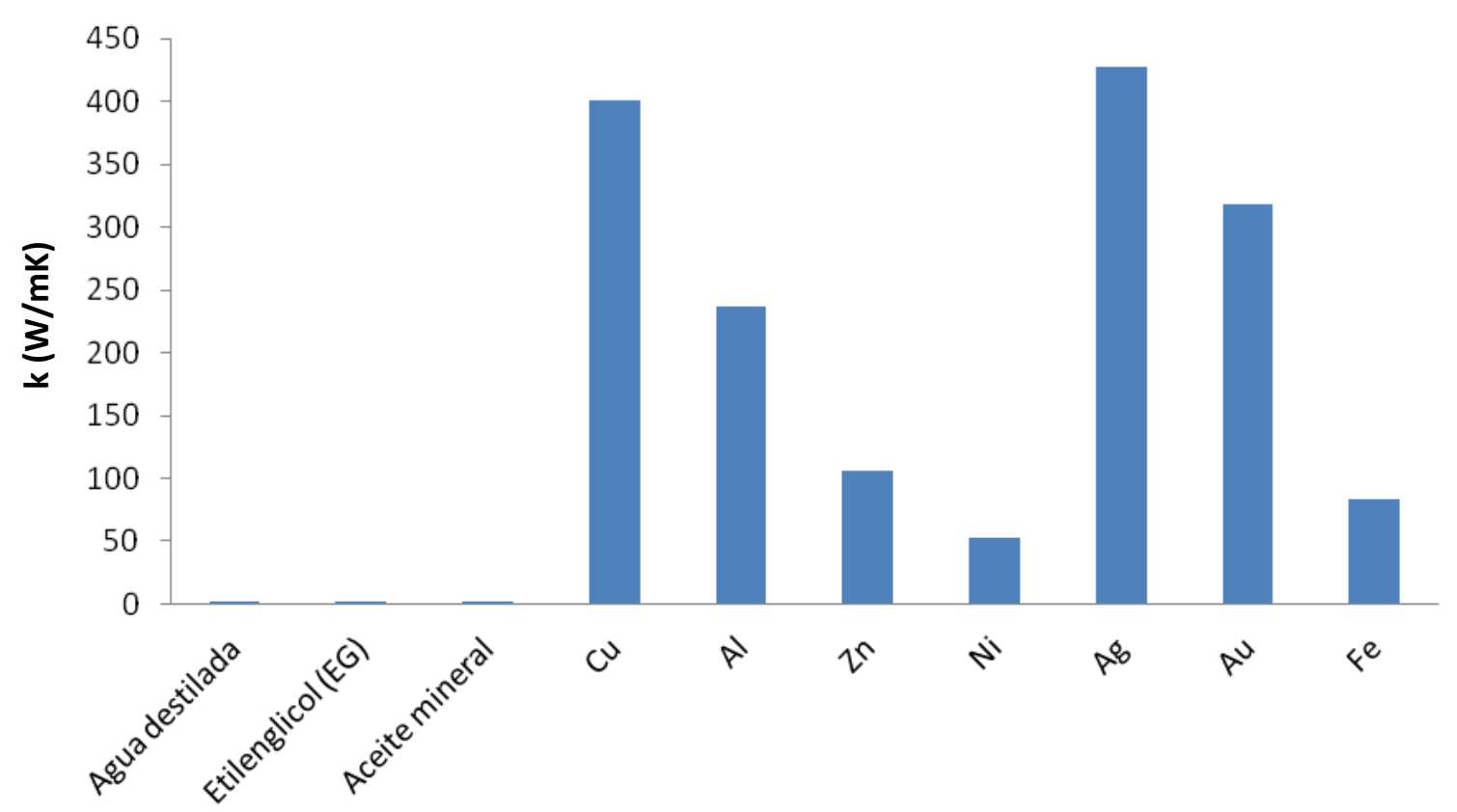

Figura 1. Conductividades térmicas de partículas metálicas comparadas con los fluidos base utilizados como refrigerantes. Fuente [14 y 35].

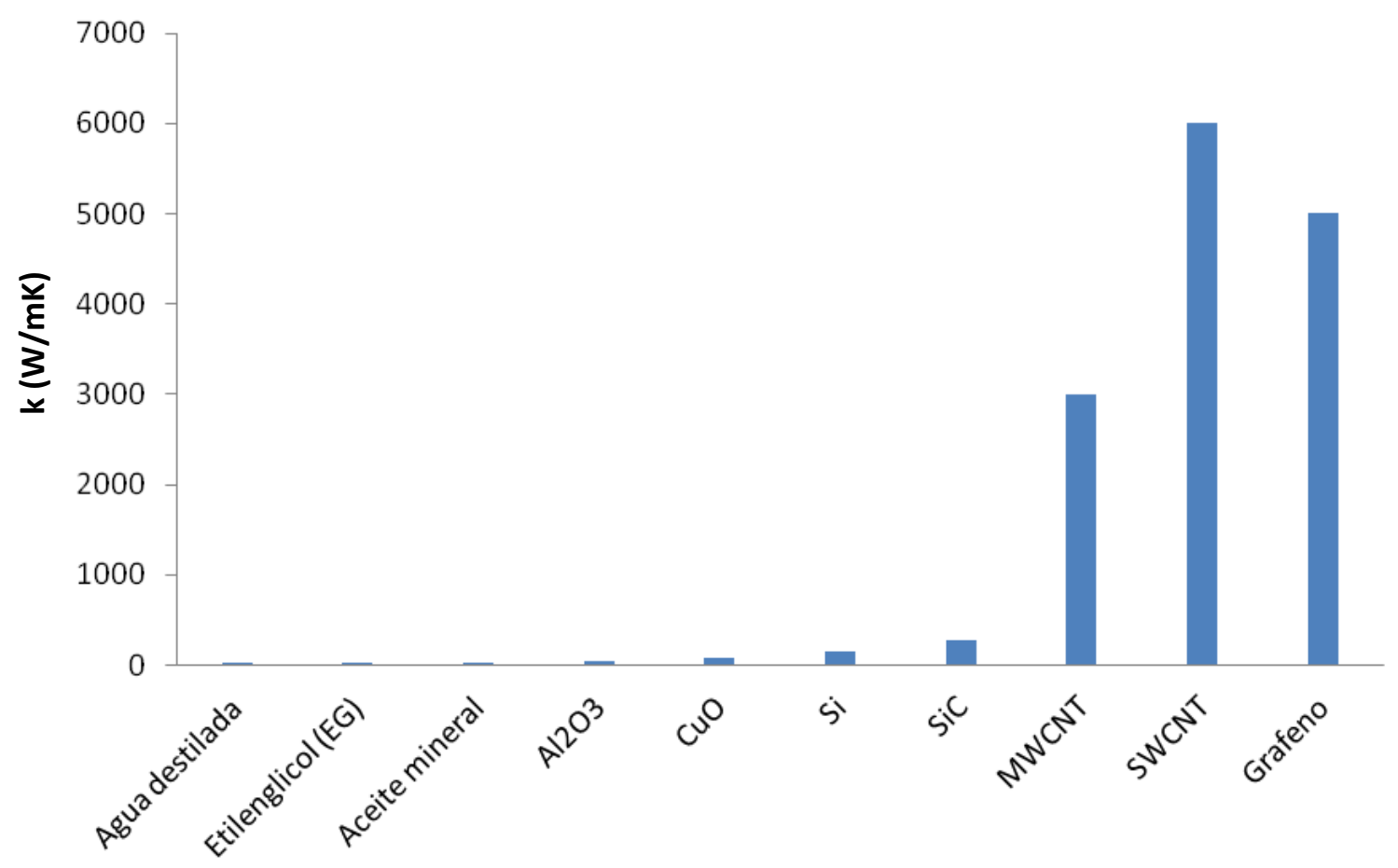

Figura 2. Conductividades térmicas de partículas no metálicas comparadas con los fluidos base utilizados como refrigerantes. Fuente [14 y 35]. 
En los últimos años, los avances en la tecnología han dado origen a partículas de tamaño nanométrico denominadas habitualmente como "nanopartículas". Al introducirse estas nanopartículas en un fluido base, la nueva suspensión obtenida y a la cual el investigador Choi en 1995 dio el nombre de "nanofluido", presenta una serie de ventajas frente a las suspensiones coloidales convencionales con partículas de tamaño del orden de los micrómetros. En los nanofluidos los fenómenos superficiales en las partículas sólidas son los que predominan y este hecho hace posible que las nanopartículas puedan mantenerse suspendidas de forma estable en el nanofluido debido al movimiento Browniano y que, por tanto, no sedimenten [12]. Esta falta de sedimentación en el tiempo otorga una buena estabilidad al nanofluido, que unida a la reducción de la obturación de canales por los que circula el nanofluido gracias al tamaño de las partículas presentes en el mismo, hace que los nanofluidos sean los candidatos ideales para su uso como fluidos térmicos siempre y cuando no se produzcan los fenómenos de aglomeración.

Los resultados obtenidos por distintos grupos de investigación muestran que los nanofluidos tienen propiedades térmicas muy diferentes a los fluidos convencionales. Se han obtenido aumentos en conductividad térmica respecto al fluido base con distintos tipos de nanopartículas a fracciones volumétricas bajas (0,5-4\%). En estas bajas fracciones volumétricas el aumento alcanzado en el coeficiente de conductividad térmica obtenido ha sido de hasta un 25\% [12]. Los investigadores Choi y Eastman [2] fueron los primeros en constatar el aumento en el coeficiente de transferencia de calor (aumento del 20\%) al dispersar nanopartículas de óxido de cobre (II) y de alúmina en agua y etilenglicol. También se ha constatado una fuerte dependencia de las propiedades térmicas de los nanofluidos con la temperatura, tendencia mucho más acusada que en los fluidos térmicos convencionales sin nanopartículas.

El principal objetivo de los nanofluidos es alcanzar las óptimas propiedades térmicas con la menor fracción de nanopartículas para así asegurar una buena dispersión y estabilidad, evitando la sedimentación de las nanopartículas por aglomeración. Se han realizado innumerables estudios con diversos materiales sólidos, desde óxidos cerámicos hasta materiales mucho más innovadores como el grafeno con el objetivo de obtener nanofluidos con elevada conductividad térmica [1] y [13]. 
En la Figura 3 puede observarse los diferentes materiales sólidos utilizados para la preparación de nanofluidos así como su histórico comparativo. Puede observarse como los óxidos sólidos $\mathrm{Al}_{2} \mathrm{O}_{3}, \mathrm{TiO}_{2}$ y $\mathrm{CuO}$ han sido los más utilizados en los estudios de preparación de nanofluidos realizados hasta la actualidad.

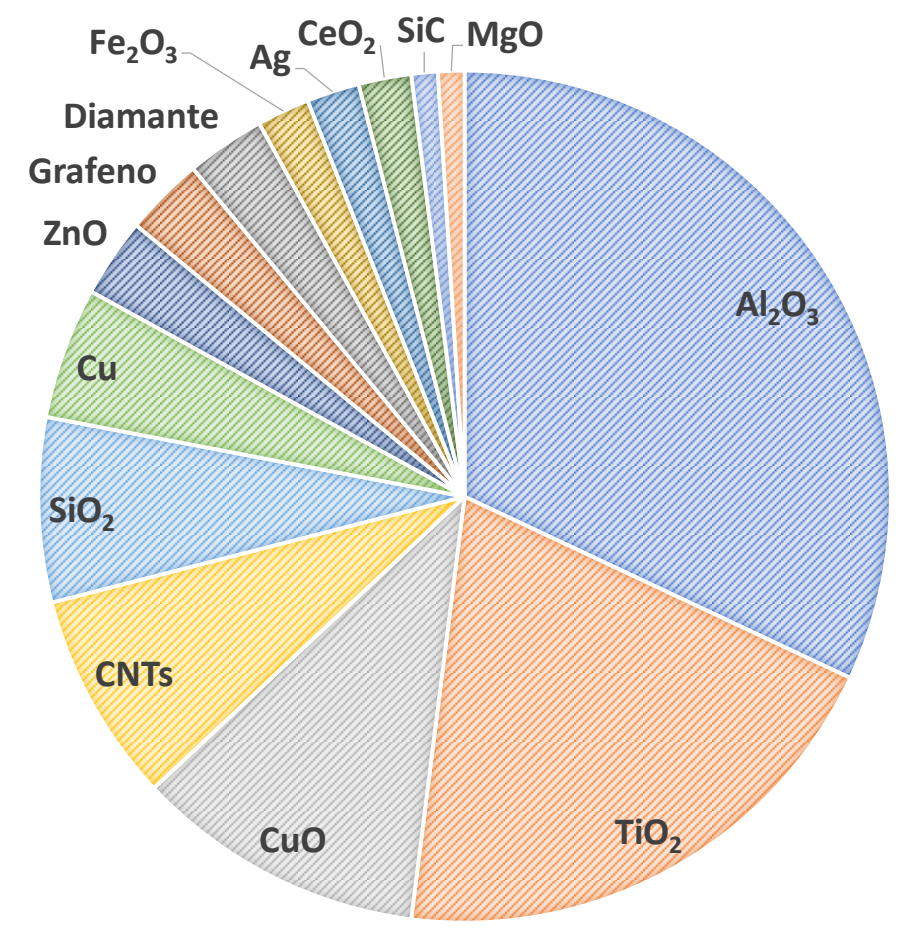

Figura 3. Uso de los distintos materiales en la preparación de nanofluidos, Fuente [112]

Como se observa en la tabla resumen obtenida a partir de la revisión bibliográfica realizada Tabla $1[1,62]$, se han utilizado desde metales a óxidos y polímeros para la preparación de nanofluidos en distintos fluidos base (agua, etilenglicol, agua/EG,) y a distintas fracciones volumétricas (mayores de 1\% para los óxidos y menores del 1\% para los nanotubos de carbono de pared múltiple, MWCNTs). En la mayoría de los estudios se han constatado los incrementos en conductividad térmica a temperaturas cercanas al ambiente $[3,20,62]$. 
Tabla 1. Estudios realizados con distintos tipos de nanopartículas y fluidos. Fuente $[1,4,6,62]$

\begin{tabular}{cccc}
\hline $\begin{array}{c}\text { Tipo de muestra de } \\
\text { nanofluido }\end{array}$ & $\begin{array}{c}\text { Fracción } \\
\text { volumétrica }\end{array}$ & Autor & $\begin{array}{c}\text { Aumento relativo } \\
\text { conductividad térmica } \\
\left(\mathbf{k}_{\text {naf }} / \mathbf{k}_{\text {base }}\right) \text { o (\%) }\end{array}$ \\
\hline $\mathrm{Al}_{2} \mathrm{O}_{3}$-agua & 4,3 & Masuda et al. [1] & $30 \%$ \\
$\mathrm{Al}_{2} \mathrm{O}_{3}$-agua & 5 & Xie et al. [1] & $21 \%$ \\
$\mathrm{Al}_{2} \mathrm{O}_{3}$-agua & 0,4 & Wang et al. [6] & $13 \%$ \\
$\mathrm{SiO}_{\text {-agua }}$ & 2 & Masuda et al. [62] & 1,01 \\
TiO ${ }_{2}$-agua & $1-5$ & Murshed et al. [4] & $20-30 \%$ \\
CuO-agua & 0,4 & Zhou et I. [1] & $17 \%$ \\
CuO-agua & 3,4 & LeeS, Choi [1] & $12 \%$ \\
Cu-agua & 2,0 & Xuan et al.[62] & 1,24 \\
Cu-agua & 0,1 & Liu et all [62] & 1,006 \\
Cu-etilenglicol & 0,56 & Eastman et al [62] & 1,10 \\
Ag-agua & 0,4 & Kang et al. [62] & 1,11 \\
Ag-etlenglicol & 0,12 & Qiao [62] & 1,07 \\
MWCNTs-agua & 0,05 & Diang et al.[62] & 1,07 \\
MWCNTs-agua & 1,5 & Liu et al.[62] & 1,17 \\
MWCNTs-EG & 1,0 & Liu et al.[62] & 1,12 \\
Grafeno-agua & 0,2 & Qiao [62] & 1,17 \\
Grafeno-aceite & 1,3 & Qiao [62] & 1,36 \\
\hline
\end{tabular}

\subsection{Técnicas para la preparación de los nanofluidos}

En la bibliografía son muchos los artículos en los que proponen diferentes técnicas para la preparación de los nanofluidos [14],[15],[21],[23] y [24]. Independientemente de la naturaleza del material, las diferentes técnicas para la preparación de los nanofluidos pueden clasificarse principalmente en dos: "two step" o "single step".

\section{- Técnica de preparación de nanofluidos en dos etapas. "Two-step technique".}

En esta técnica las nanopartículas en polvo (obtenidas por métodos de síntesis en una primera etapa independiente del proceso) se dispersan en una segunda etapa en el fluido base elegido [6]. Debido a la alta carga superficial de las mismas tienden a aglomerarse, 
por lo cual resulta necesario aplicar una agitación mecánica considerable o ultrasonidos en esta segunda etapa para alcanzar un elevado grado de dispersión.

Esta técnica es muy atractiva para su posterior aplicación industrial, por ser un método simple, pues se pueden adquirir las nanopartículas ya sintetizadas y tan solo proceder a su dispersión. Sin embargo, hay que señalar que la dispersión completa hasta que las nanopartículas estén totalmente individualizadas en el fluido base resulta muy difícil pues las nanopartículas inicialmente presentan un estado de agregación elevado. Por este motivo (las nanopartículas no logran dispersarse completamente), resulta necesario ir a fracciones volumétricas elevadas para obtener aumentos en conductividad térmica significativos.

Este método en dos etapas puede tener más éxito si se modifican las nanopartículas superficialmente mediante métodos químicos como:

- Surfactantes. Mediante la adsorción del surfactante sobre la superficie de la partícula se modifica su carga superficial. Una vez cargadas las nanopartículas superficialmente se producen los fenómenos de repulsión si las cargas son del mismo signo.

- Control del pH de la suspensión con el objetivo de alejarse del punto isoeléctrico donde el potencial zeta es cero y la atracción entre partículas es máxima, para estar en potenciales de repulsión elevados.

- Funcionalización de las nanopartículas. Con este método se consigue la modificación de la estructura de las partículas mediante la introducción de átomos o grupos funcionales en su superficie y se logra una mayor afinidad con el medio acuoso.

\section{- Técnica de preparación de nanofluidos en una etapa. "Single step technique"}

En esta técnica la obtención de las nanopartículas y del nanofluido se realizan al mismo tiempo (por métodos físicos como "physical vapor deposition" PVD o por métodos químicos"), es decir en una única etapa $[6,57]$. Con la técnica de obtención de nanofluidos en una sola etapa se evita el secado, almacenamiento, transporte y posterior dispersión de las nanopartículas en el fluido base, minimizando los procesos de aglomeración. La desventaja de este método es la dificultad de su aplicación industrial. Los métodos físicos 
de síntesis de nanopartículas como la técnica PVD no permiten la producción en gran escala mientras que los métodos químicos presentan una serie de desventajas, como por ejemplo los residuos de los reactivos que pueden quedar en el nanofluido debido a una reacción incompleta. Resulta difícil conocer la influencia en la conductividad térmica de este tipo de impurezas.

Como ventajas a destacar se ha constatado que la conductividad térmica y la estabilidad de los nanofluidos obtenidos mediante una única etapa química son mayores que los obtenidos por otros métodos [30 y 57]. Además, con esta técnica se puede variar la microestructura del nanofluido gracias al ajuste de los parámetros de síntesis.

Como se ha mencionado en el punto anterior las propiedades de transporte (conductividad térmica y viscosidad final) de un nanofluido van a depender del estado de agregación de las nanopartículas y de su estabilidad. Por esta razón el método utilizado en la preparación de los nanofluidos va a tener una gran influencia en las propiedades finales del nanofluido.

Según la bibliografía consultada el método más utilizado para la preparación de nanofluidos es el de dos etapas, ya que permite preparar el nanofluido en el fluido base elegido, con los aditivos seleccionados independientemente del método de síntesis utilizado para la obtención de las nanopartículas. Se ha observado en algunos casos que los reactivos utilizados en la síntesis permanecen como impurezas en los nanofluidos preparados afectando a su comportamiento final. En la Tabla 2 se resumen a modo de ejemplo las técnicas utilizadas por diversos autores para la preparación de nanofluidos, puede observarse como cuando de utiliza la técnica de single step las fracciones volumétricas que presentan los nanofluidos son más bajas, y que de entre las dos técnicas, la más utilizada en los estudios es la de dos pasos (twostep).

Aunque la técnica en dos etapas es el método para la obtención de nanofluidos más económico (debido a que las técnicas de síntesis de nanopartículas ya se han escalado a niveles de producción industrial) las características estructurales de las nanopartículas, como por ejemplo su tamaño de partícula medio, la distribución de tamaños o aglomerados, la forma, dependen del proceso de producción industrial e influyen en las propiedades del nanofluido preparado. Todavía no se ha clarificado si la dispersión de los datos experimentales observados en la bibliografía consultada es debido a los métodos de medida de conductividad 
térmica o a la distinta naturaleza de las nanopartículas en función de su método de síntesis [52].

Tabla 2. Tabla resumen nanofluidos preparados a partir de una o dos etapas. Fuente [14].

\begin{tabular}{|c|c|c|c|c|}
\hline $\begin{array}{l}\text { Tipo de muestra } \\
\text { de nanofluido }\end{array}$ & $\begin{array}{l}\text { Método de } \\
\text { preparación }\end{array}$ & $\begin{array}{c}\text { Fracción } \\
\text { volumétrica } \\
\text { (\%) }\end{array}$ & $\begin{array}{c}\text { Tamaño de } \\
\text { partícula } \\
\text { (nm) }\end{array}$ & $\begin{array}{c}\text { Aumento relativo } \\
\text { conductividad } \\
\text { térmica (\%) }\end{array}$ \\
\hline $\mathrm{Cu} / \mathrm{EG}$ & Single-step & 0,3 & 10 & 40 \\
\hline $\mathrm{Cu} / \mathrm{H}_{2} \mathrm{O}$ & Single-step & 0,1 & $75-100$ & 23,8 \\
\hline $\mathrm{Cu} / \mathrm{H}_{2} \mathrm{O}$ & Two-step & 7,5 & 100 & 78 \\
\hline $\mathrm{Fe} / \mathrm{EG}$ & Single-step & 0,55 & 10 & 18 \\
\hline $\mathrm{Ag} /$ tolueno & Two-step & 0,001 & $60-80$ & 16 \\
\hline $\mathrm{Au} /$ tolueno & Two-step & 0,00026 & $10-20$ & 21 \\
\hline $\mathrm{Ag} /$ etanol & Two-step & 0,6 & 4 & 1,3 \\
\hline $\mathrm{Fe}_{3} \mathrm{O}_{4} / \mathrm{H}_{2} \mathrm{O}$ & Single-step & 4 & 10 & 38 \\
\hline $\mathrm{TiO}_{2} / \mathrm{H}_{2} \mathrm{O}$ & Two-step & 5 & 15 & 30 \\
\hline $\mathrm{Al}_{2} \mathrm{O}_{3} / \mathrm{H}_{2} \mathrm{O}$ & Two-step & 5 & 20 & 20 \\
\hline $\mathrm{CuO} / \mathrm{H}_{2} \mathrm{O}$ & Two-step & 5 & 33 & 11,5 \\
\hline $\mathrm{SiC} / \mathrm{H}_{2} \mathrm{O}$ & Two-step & 4,2 & 25 & 15,9 \\
\hline NCTs/aceite & Two-step & 2 & $20 \times 50$ & 30 \\
\hline NCTs/EG & Two-step & 1 & $15 \times 30$ & 19,6 \\
\hline $\mathrm{NCTs} / \mathrm{H}_{2} \mathrm{O}$ & Two-step & 1 & $15 \times 30$ & 7 \\
\hline
\end{tabular}

El presente estudio se va a centrar en la preparación de nanofluidos a partir de la dispersión de nanopartículas en polvo en el fluido base y posterior agitación (Two-step technique) pero incluyendo el tratamiento superficial de las nanopartículas con surfactantes y funcionalización para así evitar la formación de aglomerados en el tiempo que disminuyan la estabilidad del nanofluido.

Un nanofluido es un sistema coloidal con propiedades térmicas complejas. Los sistemas coloidales incluso en suspensiones diluidas tienden a forman agregados que dependen de las cargas superficiales en las nanopartículas y del movimiento browniano de las mismas. Además, se debe mencionar que este sistema coloidal es inestable pues pueden darse al 
mismo tiempo mecanismos que lleven a la coalescencia y formación de agregados, a la sedimentación y a la rotura de agregados [10].

Por estos motivos el principal objetivo del presente estudio, tal y como se describirá detalladamente en el capítulo II de esta memoria ha sido, además de dispersar adecuadamente las nanopartículas en el agua, lograr que el estado de dispersión alcanzado en la preparación del nanofluido permanezca estable en el tiempo, asegurando que las propiedades térmicas del nanofluido permanezcan invariables. La estabilidad de los nanofluidos preparados $[5,6]$ se ve influenciada por los siguientes factores:

- Los nanofluidos son termodinámicamente inestables por ser sistemas multifásicos con alta carga superficial.

- Las nanopartículas dispersas tienen un elevado movimiento browniano, que puede originar su sedimentación por coalescencia y gravedad.

- $\quad$ Con el tiempo, las fuerzas de Van der Waals pueden llevar a la agregación de las nanopartículas.

- No debe existir reacción entre las partículas y el fluido base, que pueda originar la solubilización o cambios de las mismas.

Se puede afirmar que hay dos fenómenos críticos en la preparación de los nanofluidos; la dispersión de las nanopartículas y los fenómenos de agregación y posterior sedimentación que afectan a la estabilidad de los mismos. En los apartados 1.2. y 1.3 del presente capitulo se resumen las distintas técnicas aplicadas por distintos investigadores con el objetivo de mejorar la dispersión de las nanopartículas y la estabilidad de los nanofluidos.

\subsection{Dispersión de las nanopartículas en el fluido base}

El proceso por el cual las partículas se dispersan en el líquido juega un papel importante en las propiedades finales de los nanofluidos ya que el incremento en conductividad térmica obtenido gracias a la elevada conductividad de las partículas sólidas respecto al fluido base, es función de su movimiento browniano el cual depende del grado de dispersión alcanzado al suspender las nanopartículas en el fluido y de su posterior estabilidad evitando formar de nuevo agregados. 
Cuando se utiliza la técnica en dos pasos para la preparación de los nanofluidos, el proceso de dispersión puede considerarse una de las etapas más críticas. En la mayoría de los casos, al adquirir las nanopartículas en polvo éstas se encuentran bastante aglomeradas y la dispersión de dichos aglomerados en el fluido base va a depender de la resistencia de los mismos y de la afinidad de las nanopartículas con dicho fluido base.

\section{Métodos mecánicos para dispersar las nanopartículas en el fluido base}

La dispersión y desaglomeración de nanopartículas en líquidos depende de la intensidad de la energía utilizada para la dispersión y el tiempo de aplicación de dicha energía. Según la bibliografía consultada la energía aplicada en la dispersión puede llevarse a cabo en baños de ultrasonidos [6, 9-12], sondas de ultrasonidos [13-16], agitadores magnéticos, "agitadores de alta cizalla" [8], molinos de bolas [26] y homogeneizadores [59]. Si se comparan los resultados obtenidos por los investigadores al utilizar distintos procedimientos de dispersión de nanopartículas se observa como el tratamiento con sonda de ultrasonidos es el más efectivo de todos $[15,18,55]$.

El tiempo necesario para alcanzar un determinado grado de dispersión depende también del tipo de tratamiento utilizado y de la intensidad de la energía que aplica cada uno de ellos [17, 55]. Así pues, en el caso de los turbodesleidores y de los agitadores magnéticos, el tamaño de aglomerado se modifica de forma gradual, dejando de producirse cambios significativos en el tamaño de aglomerado cuando la energía no es suficiente para romper los clusters. En cambio, en el caso de las sondas de ultrasonidos, altamente energéticas, el tiempo necesario para que la dispersión sea completa y reproducible es mucho menor, manteniéndose prácticamente invariable el tamaño de los agregados a partir del primer minuto de tratamiento.

Se ha realizado una revisión bibliográfica para ver qué técnicas de dispersión mecánica se utilizan en la dispersión de nanopartículas en base acuosa y aplicarlas en la medida de lo posible en el presente estudio [6, 15- 17, 19,21- 24, 26, 28,31,59, 118 y 123]. Los resultados obtenidos tras dicha revisión se resumen en la Tabla 3. Entre los distintos métodos de dispersión mecánica se han elegido los siguientes para su aplicación en el trabajo de investigación:

- $\quad$ Baño de ultrasonidos

- $\quad$ Agitación magnética 
- Homogeneizador

- $\quad$ Sonda de ultrasonidos

Tabla 3. Tabla resumen ejemplos nanofluidos preparados con distintos mecanismos de dispersión. Fuentes $[6,17,55,59,118,123]$.

\begin{tabular}{|c|c|c|c|c|c|}
\hline Autor & $\begin{array}{c}\text { Tipo de } \\
\text { muestra de } \\
\text { nanofluido }\end{array}$ & $\begin{array}{c}\text { Fracción } \\
\text { volumétrica } \\
\text { (\%) }\end{array}$ & $\begin{array}{l}\text { Método de } \\
\text { preparación }\end{array}$ & $\begin{array}{l}\text { Tiempo de } \\
\text { dispersión }\end{array}$ & Observaciones \\
\hline$[55]$ & $\mathrm{Al}_{2} \mathrm{O}_{3}$ & 0,8 a $5 \%$ & Baño de ultrasonidos & 6 a $15 \mathrm{~h}$ & $\begin{array}{l}\text { Sedimentan a los } \\
\text { pocos minutos }\end{array}$ \\
\hline$[55]$ & $\mathrm{Al}_{2} \mathrm{O}_{3}$ & 0,08 & $\begin{array}{c}\text { Sonda de ultrasonidos } \\
\text { +surfactante }+ \text { ajuste } \\
\text { pH }\end{array}$ & $15 \mathrm{~min}$ & No sedimentan \\
\hline$[55]$ & $\mathrm{Al}_{2} \mathrm{O}_{3}$ & 1 & Sonda de ultrasonidos & $30 \mathrm{~min}$ & No sedimentan \\
\hline [6] & $\mathrm{SiO}_{2}$ & 1 & Sonda de ultrasonidos & $2 \mathrm{~h}$ & No sedimentan \\
\hline$[55]$ & $\mathrm{CuO}$ & 0,003 & Sonda de ultrasonidos & $2 \mathrm{~h}$ & No sedimentan \\
\hline$[55]$ & $\mathrm{CuO}$ & 0,1 & $\begin{array}{c}\text { Sonda de ultrasonidos } \\
\text { +surfactante }\end{array}$ & $1 \mathrm{~h}$ & No sedimentan \\
\hline$[17]$ & MWCNTS & 0,2 & $\begin{array}{l}\text { Sonda de ultrasonidos } \\
+ \text { surfactante }\end{array}$ & 30 & No sedimentan \\
\hline [59] & CNTs & 0,2 & $\begin{array}{l}\text { Baño ultrasonidos, } \\
\text { Sonda, } \\
\text { Homogeneizador }\end{array}$ & $\begin{array}{c}120 \\
60 \\
3 \text { pasadas } \\
18000\end{array}$ & $\begin{array}{l}\text { Sedimentan } \\
\text { Reduce el } \\
\text { tamaño y no } \\
\text { sedimentan }\end{array}$ \\
\hline$[123]$ & Grafeno & 0,5 & Sonda de ultrasonidos & - & $\begin{array}{c}\text { Estables por más } \\
\text { de dos años }\end{array}$ \\
\hline [118] & Grafeno & 0,2 & $\begin{array}{l}\text { Sonda de ultrasonidos } \\
\qquad+ \text { surfactante }\end{array}$ & $30 \mathrm{~min}$ & No sedimentan \\
\hline
\end{tabular}

Entre todos estos sistemas citados, la sonda de ultrasonidos es el equipo más utilizado por los investigadores debido a su efectividad en la dispersión de las nanopartículas en el fluido base $[72,74,75$ y 77$]$. 
Los agregados pueden romperse por mecanismos de desgaste al aplicar una fuerza de cizalla, o por ruptura de toda la masa debido a los impactos. El mecanismo de ruptura depende del tamaño de los agregados y de la intensidad de energía aplicada. A medida que los agregados se vuelven más pequeños conforme avanza el proceso de desaglomeración, las fuerzas superficiales adquieren mayor importancia. Por lo tanto, la ruptura de los agregados grandes es relativamente simple, mientras que la ruptura de agregados menores de $1 \mu \mathrm{m}$ puede resultar muy complicada, llegando las partículas en 10 y $100 \mathrm{~nm}$ a no poder ser separadas por acción mecánica. En función del tamaño de aglomerado y la forma de la nanopartícula será necesario aplicar una cantidad de energía específica y tiempo determinado para cada caso.

El tiempo de aplicación de la energía mecánica es además una variable crítica pues en algunos estudios también se ha constatado que una vez pasado el tiempo óptimo de agitación se pueden observar incluso problemas de reaglomeración de las nanopartículas [55]. Este impacto negativo puede deberse a que un tiempo excesivo genera coalescencia entre las nanopartículas las cuales si las fuerzas de Van de Waals son considerables formarán agregados. Además, elevados tiempos de aplicación de ultrasonidos implican un aumento de la temperatura del nanofluido debido a la energía aplicada por lo que se producirá un aumento del movimiento browniano, y por tanto se incrementará la colisión entre las nanopartículas. Algunos investigadores han intentado romper los aglomerados de nanopartículas usando la alta energía de cavitación generada con los equipos llamados homogenizadores, como por ejemplo el caso con nanotubos de carbono en base orgánica [59]. La energía de cavitación se consigue al hacer pasar a la suspensión por unos microcanales. Esta reducción de paso genera una alta dispersión de las partículas en el fluido debido a las microburbujas formadas por cavitación.

Una vez se alcanza la dispersión de las nanopartículas tras la aplicación de la energía mecánica, puede darse el caso que las partículas vuelvan a reaglomerarse tras el cese de la energía dispersante debido a que las fuerzas de Van der Waals entre partículas de tamaño nanométrico empiezan a ser significativas. Por lo tanto, una vez concluido el proceso de dispersión, resulta imprescindible estabilizar las suspensiones de nanofluidos si se desea que las partículas se mantengan separadas unas de otras durante un tiempo prolongado [58]. 


\subsection{Estabilidad de las nanopartículas dispersadas en el fluido base}

La estabilidad de una dispersión coloidal se obtiene cuando la relación de número de partículas por unidad de volumen se mantiene constante. El estado coloidal comprende partículas con un tamaño suficientemente pequeño para no verse afectadas por las fuerzas gravitacionales $(\leq 1 \mu \mathrm{m})$ pero suficientemente grande para mostrar diferencias con respecto de las disoluciones reales (>1 nm). Dentro del estado coloidal, se denominan nanopartículas a aquellos materiales con un tamaño inferior a $100 \mathrm{~nm}$. Las suspensiones de partículas sólidas de tamaño nanométrico en un líquido, como el caso de los nanofluidos, reciben el nombre de suspensiones coloidales. "Coloidalmente estable" implica que las partículas sólidas no sedimentan ni se agregan a una velocidad significativa $[10,58]$.

La estabilidad de los nanofluidos es uno de los requerimientos más importantes pues afecta directamente a sus propiedades termofísicas y a la transferencia de calor. Preservar dichas propiedades en el tiempo es esencial, aunque siempre va a existir un inevitable deterioro de los nanofluidos que puede impedir su aplicación. Los estudios de estabilidad de estos sistemas se pueden clasificar en cuatro tipos:

- Estabilidad termodinámica

- Estabilidad cinética

- Estabilidad química

- Estabilidad del grado de dispersión.

Para la aplicación de los nanofluidos debe garantizarse el grado de dispersión y la estabilidad cinética, por lo que el presente estudio se centrará en el análisis de dichas variables. El movimiento de las nanopartículas dispersas está gobernado por el movimiento browniano, que lleva al aumento de colisiones favoreciendo la interacción entre las mismas. Las suspensiones pierden su estabilidad por agregación de las partículas coloidales en el tiempo y su posterior sedimentación debido a las fuerzas gravitacionales. La tasa de agregación de las nanopartículas [57] viene determinada por la frecuencia de colisiones y la probabilidad de la cohesión durante dicha colisión. 
Las nanopartículas pueden unirse o agregarse por distintas causas:

- gelificación (formación de una red coherente de partículas que ocupan todo el volumen, y por mecanismos de capilaridad retiene el líquido)

- $\quad$ coagulación (formación de grupos de partículas compactos en los cuales la fracción es mayor que en la suspensión original)

- floculación (unión de partículas mediante puentes formados por un agente floculante formando una estructura abierta y voluminosa)

Derjaguin, Verway, Landau y Overbeek (DVLO) desarrollaron una teoría que explica la estabilidad coloidal. La teoría DVLO sugiere que la estabilidad de una partícula en solución viene determinada por la suma de las fuerzas atractivas de Van der Waals y las fuerzas repulsivas que existen entre partículas a medida que se acercan entre sí debido al movimiento browniano que están experimentando. Si la fuerza de atracción es mayor que la fuerza repulsiva, las dos partículas chocarán, y se agregarán, formando una suspensión que no será estable en el tiempo.

Para evitar que lleguen a formarse aglomerados es necesario impedir que las partículas entren en contacto. Esto se consigue provocando la aparición en el sistema de fuerzas repulsivas de mayor magnitud y alcance que las atractivas, de forma que mantengan las partículas alejadas unas de otras en la medida de lo posible [58]. Las fuerzas repulsivas provienen de interacciones estéricas o electrostáticas, como se observa en la Figura 4. En general las interacciones electrostáticas son importantes en sistemas acuosos, mientras que las interacciones estéricas son también efectivas en sistemas no acuosos.

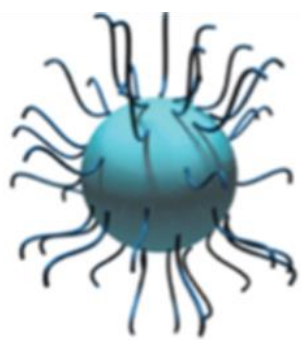

estabilidad estérica

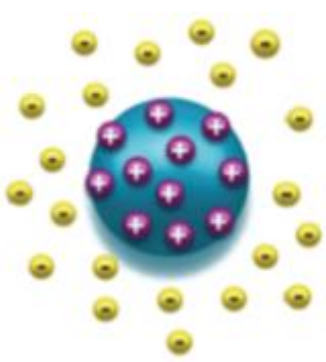

estabilidad electrostática

Figura 4 .Tipos de estabilidad coloidal [57] 
La estabilidad final de las suspensiones de nanofluidos dependerá de estas interacciones, y del resultado del balance entre las fuerzas atractivas y las repulsivas.

A medida que disminuye el tamaño de las nanopartículas se incrementa la superficie específica, mejorándose la transferencia de calor que tiene lugar en la superficie, pero por contra se incrementan las interacciones entre las nanopartículas que afectan a la estabilidad de los nanofluidos [44]. Este fenómeno va a ser crítico en la obtención de los nanofluidos, pues la aglomeración de las nanopartículas en un nanofluido conlleva una disminución de la conductividad térmica de los nanofluidos además de problemas de sedimentación y obstrucción de los microcanales en los intercambiadores al producirse el aumento de tamaño. Por esta razón, los estudios sobre la estabilidad de los nanofluidos son una cuestión clave que influye directamente en las propiedades de los nanofluidos para su posterior aplicación. Resulta por tanto necesario estudiar y analizar los factores que influyen sobre la dispersión y estabilidad de los nanofluidos preparados a partir de nanopartículas en polvo, "técnica en dos pasos", con el objetivo de aplicar soluciones que aumenten la estabilidad [57].

\section{Mecanismos para aumentar la estabilidad de los nanofluidos}

La preparación de nanofluidos homogéneos y estables supone un reto ya que las nanopartículas siempre tienen tendencia a formar agregados debido a las fuertes fuerzas de interacción de Van der Waals [25]. A medida que la fracción volumétrica aumenta, se mejora la conductividad térmica pero las interacciones hidrodinámicas así como la probabilidad de colisión entre las partículas se vuelven importantes, favoreciendo los procesos de agregación en los nanofluidos.

El estado de aglomeración y por tanto la estabilidad de los nanofluidos puede modificarse mediante el control de los factores que afectan a las propiedades superficiales de las partículas y a las fuerzas de interacción entre ellas. Entre estos factores se encuentran, el pH de la suspensión, la presencia de electrolitos, los surfactantes, la viscosidad del fluido base, el diámetro de partícula, la densidad y la fracción volumétrica $[14,47,57]$.

Los mecanismos que pueden mejorar la estabilidad de los fluidos preparados se clasifican en tres tipos:

- $\quad$ Adición de surfactantes 
- Técnicas de modificación de la superficie de las nanopartículas sin surfactantes, mediante funcionalización.

- Modificación del potencial zeta $(\varsigma)$.

\subsubsection{Modificación de la superficie de las nanopartículas; Surfactantes}

Habitualmente se han utilizado agentes dispersantes o surfactantes para conseguir dispersar las nanopartículas en base acuosa [64]. Todos los surfactantes poseen una molécula que presenta a la vez un grupo polar (o hidrofílico) y un grupo apolar (hidrófobo o lipofílico). El grupo polar es en general un grupo funcional que contiene hetero-átomos $(\mathrm{O}, \mathrm{S}, \mathrm{N}, \mathrm{P})$, mientras que el grupo apolar es en la mayoría de los casos un hidrocarburo parafínico o alquilaromático. Los surfactantes en medios acuosos migran hacia las superficies de las partículas para que su componente hidrosoluble permanezca en la fase acuosa y el hidrófobo quede fuera de esa fase en nuestro caso sobre la superficie de la nanopartícula (Figura 5), modificando de esta forma su comportamiento frente a la agregación.

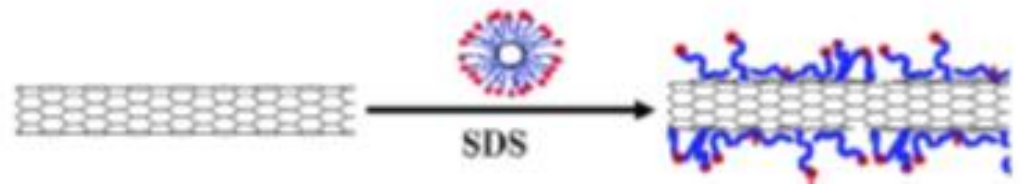

Figura 5. Modificación de la superficie de la partícula mediante la incorporación del surfactante dodecilsulfato sódico, SDS, sobre un nanotubo de carbono

La adición de surfactantes logra estabilizar la dispersión de las nanopartículas en el fluido base impidiendo su aglomeración mediante impedimento estérico o por repulsión electrostática.

Para conseguir una estabilización estérica, habitualmente se utilizan polímeros, los cuales se van a adsorber sobre la superficie de las partículas, produciendo una fuerza de repulsión estérica adicional [57]. Por ejemplo, nanopartículas de óxido de zinc modificadas con polimetilmetacrilato, PMMA, tienen buena compatibilidad con los disolventes polares. Los nanofluidos de plata son muy estables debido a la función protectora del aditivo polivinilpirrolidona, PVP. También se ha constatado que el PVP es un agente eficaz para mejorar la estabilidad de la suspensión de grafito.

Para conseguir una estabilización electrostática, se carga superficialmente las nanopartículas a través de uno o varios de los siguientes mecanismos: adsorción preferencial de iones, 
disociación en la superficie de especies cargadas, sustitución isomórfica de iones, acumulación o agotamiento de los electrones en la superficie y adsorción física de especies cargadas sobre la superficie.

En la Tabla 4 se citan los distintos tipos de surfactantes más utilizados en la preparación de nanofluidos por diversos investigadores.

Tabla 4. Tabla resumen de nanofluidos preparados con distintos tipos de surfactantes.

\begin{tabular}{|c|c|c|}
\hline Autor & Material del nanofluido & Tipo de surfactante \\
\hline [5] Z. Hadad, Jung et al. & $\mathrm{Al}_{2} \mathrm{O}_{3}$ & PVA \\
\hline [5] Z. Hadad, Kim et al. & $\mathrm{Al}_{2} \mathrm{O}_{3}$ & SDS \\
\hline [5] Z. Hadad, Yousefi et al. & $\mathrm{Al}_{2} \mathrm{O}_{3}$ & Triton \\
\hline [31] M.A. Khairul et al. & $\mathrm{Al}_{2} \mathrm{O}_{3}$ & SDBS \\
\hline [72] A. Asadi et al. & $\mathrm{Mg}(\mathrm{OH})_{2}$ & CTAB, SDS \\
\hline [4] S. Murshed et al. & $\mathrm{TiO}_{2}$ & CTAB \\
\hline [5] Z. Hadad, Timofeeva et al. & $\mathrm{SiO}_{2}$ & CTAB \\
\hline [5] Z. Hadad, Byme et al. & $\mathrm{CuO}$ & CTAB \\
\hline [31] M.A. Khairul et al. & $\mathrm{CuO}$ & SDBS \\
\hline [5] Z. Hadad. Kathiravan et al. & $\mathrm{Cu}$ & SDS \\
\hline [71] Ahmad Ghozatloo et al. & CNTs (nanotubos de carbono) & SDS \\
\hline [5] Z. Hadad, Yousefi et al. & CNTs (nanotubos de carbono) & Triton \\
\hline [5] Z. Hadad, Indhuja et al. & CNTs (nanotubos de carbono) & Goma arábiga \\
\hline [17] R.Sadri et al. & CNTs (nanotubos de carbono) & Goma arábiga, SDS \\
\hline [19] A.Nasiri et al. & CNTs (nanotubos de carbono) & SDS \\
\hline [7] S.M. Ablasi et al. & $\begin{array}{l}\text { MWCNTs (nanotubos de } \\
\text { carbono de pared múltiple) }\end{array}$ & Triton \\
\hline [15]M.J. Assael et al. & $\begin{array}{l}\text { MWCNTs (nanotubos de } \\
\text { carbono de pared múltiple) }\end{array}$ & SDS \\
\hline [5] Z. Hadad. Bobbo et al. & $\begin{array}{l}\text { SWCNTS (nanotubos de carbono } \\
\text { de pared única) }\end{array}$ & PEG \\
\hline [118] Nen-Wen Pu et al. & Grafeno & SDS, CATB, CO890 \\
\hline
\end{tabular}


Aunque el método de dispersión y estabilización de las nanopartículas con el uso de surfactantes está muy extendido, se ha constatado experimentalmente que algunas veces el enlace de unión entre el surfactante y la superficie de las nanopartículas se ve afectado por la temperatura, disminuyendo el efecto del mismo [23].

\subsubsection{Modificación de la superficie de las nanopartículas; Funcionalización}

La modificación de la superficie de las nanopartículas mediante su funcionalización es otro de los métodos utilizados para mejorar la dispersión y estabilidad de los nanofluidos. El objetivo de la funcionalización es introducir grupos funcionales hidrofílicos mediante reacciones químico-físicas. Por ejemplo, la funcionalización de nanotubos de carbono es un método bastante utilizado para aumentar la estabilidad de las suspensiones. Los métodos de funcionalización utilizados con los nanotubos incluyen un tratamiento ácido para introducir los grupos funcionales seguido de una operación de lavado. Mesgari S. [7], utilizó como tratamiento ácido nítrico durante 4 horas a $60^{\circ} \mathrm{C}$, y un tratamiento con una mezcla de ácido sulfúrico y ácido nítrico $(3: 1)$ durante 6 horas a $60^{\circ} \mathrm{C}$. Con ambos tratamientos logró preparar suspensiones estables de nanofluidos híbridos (nanotubos de carbono de pared múltiple y $\mathrm{Al}_{2} \mathrm{O}_{3}$ ) en base agua, aunque también constató que el tratamiento afecta a la morfología de los nanotubos y si ésta se ve modificada, puede afectar también a la conductividad térmica.

Z.Talaei estudió el efecto de la cantidad de grupos funcionales introducidos en la superficie de los nanotubos sobre la estabilidad de la dispersión en el fluido base (agua), comprobando que a mayor cantidad de grupos funcionales mayor estabilidad [23].

Aravind S.J. estudió el efecto del tiempo de funcionalización (reflujo de 1 a 4 horas en mezcla ácida 3:1 ácido sulfúrico y ácido nítrico) de los nanotubos sobre la estabilidad de los mismos al dispersarlos en base agua y etilenglicol. Tras el análisis del espectro de absorción UV, se observó que la máxima absorbancia (mejor dispersión de los nanotubos) se obtuvo con los nanotubos funcionalizados durante 2,5 horas [97].

Está técnica es una de las rutas prometedoras ya que no implica la incorporación de ningún aditivo (como por ejemplo un surfactante) en la preparación de los nanofluidos y se ha utilizado ampliamente en la bibliografía consultada obteniéndose buenos resultados en la estabilidad de los nanofluidos [7, 19, 23, 97, 99 y 117]. 


\subsubsection{Estabilización de los nanofluidos mediante modificación del potencial zeta}

Las medidas de potencial zeta proporcionan un análisis inmediato del grado de estabilidad y dispersión de las partículas en suspensión. Las nanopartículas en suspensión en el nanofluido base están cargadas eléctricamente en su superficie, compensándose esta carga con carga de signo opuesto y formando una doble capa eléctrica. El potencial zeta es el potencial eléctrico que existe en el plano de cizalla, que delimita la parte fija de doble capa iónica de la parte móvil [58]. Se trata de una medida directamente proporcional a la carga de las partículas, de forma que cuanto mayor sea su valor, más cargadas estarán éstas y mayor será el potencial electrostático y la consecuente repulsión que impedirá que las partículas se atraigan y permanezcan unidas formándose agregados. Un potencial zeta cercano a cero $(\mathrm{mV})$ indica la aglomeración máxima de las nanopartículas y su precipitación. Un valor absoluto alto (del orden de magnitud de $100 \mathrm{mV}$ ) implica una muy buena estabilidad.

El punto isoeléctrico de una suspensión es el valor del pH al cual el potencial zeta es cero. Este punto puede determinarse midiendo el potencial zeta en función de su pH mediante el ensayo de valorización. Una vez establecido el punto isoeléctrico, los valores altos de potencial zeta podrán alcanzarse con un $\mathrm{pH}$ lejano al pH del punto isoeléctrico.

La modificación del potencial zeta de una suspensión de nanofluidos mediante la regulación de su pH es una técnica muy utilizada por los investigadores para lograr una buena estabilidad de los mismos. Z. Haddad [5] comprobó experimentalmente que nanofluidos con un potencial zeta de $30 \mathrm{mV}$ son ya físicamente estables, mientras que por debajo de $20 \mathrm{mV}$ su estabilidad está limitada y por debajo de $5 \mathrm{mV}$ ya se aglomeran. Pastoriza-Gallego et al. [68] Mondragón et al. [69], demostraron que en nanofluidos de sílice el potencial zeta depende de la fracción volumétrica de nanopartículas. Aumentos en contenido en masa de 0,10 a 0,20 disminuyen el potencial zeta. En nanofluidos preparados a partir de nanotubos de carbono y $\mathrm{CuO}$ el potencial máximo medido fue de $20 \mathrm{mV}$, lo cual indica que las fuerzas de repulsión entre partículas no son suficiente para vencer la atracción entre ellas. En nanofluidos de nanotubos la adición de un surfactante a $\mathrm{pH}=7$ aumenta el potencial zeta a $50 \mathrm{mV}$. 


\subsection{Propiedades físicas de los nanofluidos}

Resulta obvio que la conductividad térmica es una de las propiedades físicas de los nanofluidos más importante, pero existen otras como la viscosidad, la densidad, el calor específico y la estabilidad del fluido que también se van a modificar al dispersar las nanopartículas en el fluido base y que deben estudiarse en paralelo pues son propiedades fundamentales para la posterior aplicación de los nanofluidos. A continuación, se resumen los principales factores que afectan a dichas propiedades en los nanofluidos junto con las técnicas más utilizadas en su caracterización obtenidos tras la revisión bibliográfica.

\subsubsection{Conductividad térmica de los nanofluidos}

La conductividad térmica se considera la propiedad termofísica más importante en el aumento de la transferencia de calor con nanofluidos. La conductividad térmica, $k(\mathrm{~W} /(\mathrm{mK}))$, describe el transporte de energía - en forma de calor - a través de un cuerpo como resultado de un gradiente de temperatura. La conductividad térmica es, por consiguiente, una propiedad específica de cada material, o combinación de materiales, como es el caso de los nanofluidos. El valor de la conductividad térmica puede obtenerse de forma teórica a partir de la expresión de Maxwell (Ec.1) siendo función de las conductividades térmicas de los componentes y de la fracción volumétrica de las nanopartículas sólidas en el fluido, pero diversos autores $[53,54]$ han constatado grandes desviaciones en los valores de conductividad obtenidos experimentalmente frente a los obtenidos de forma teórica.

Para la medida de la conductividad térmica experimental en líquidos con nanopartículas sólidas dispersas los distintos grupos de investigadores [8, 35,36] han utilizado varias técnicas, las cuales pueden clasificarse en dos grupos:

- Técnicas transitorias

○ De la esfera

○ De hilo caliente

- Técnicas en estado estacionario

- Placas paralelas

- Cilindros concéntricos 
La discrepancia de resultados en los aumentos de conductividad térmica en nanofluidos de una misma tipología constatados por distintos grupos de investigadores podría tener relación con la técnica utilizada para su medida [35], de hecho, algunos investigadores han modificado los métodos para desarrollar una técnica mucho más precisa.

La técnica más utilizada para la medida de conductividad térmica en nanofluidos es la técnica transitoria de hilo caliente (Transiet Hot Wire, THW), como puede observarse en los datos de porcentajes de artículos publicados utilizando esta técnica, Figura 6, [8, 18, 25]. La ventaja más atractiva de este método en la aplicación de los nanofluidos es la capacidad para eliminar de forma experimental el error debido a la convección natural, además de ser un método muy rápido, simple y con buena precisión y reproducibilidad. Este método se basa en la medida de la variación de temperatura y tiempo de respuesta de una sonda tras recibir un impulso eléctrico. El cable o sonda se utiliza a la vez como emisor y como receptor. Han aparecido bastantes equipos ya estandarizados basados en esta técnica (transiet hot wire, THW), como por ejemplo el equipo KD2. Esta técnica se explicará con más detalle en el Capítulo III, apartado 2.4 .

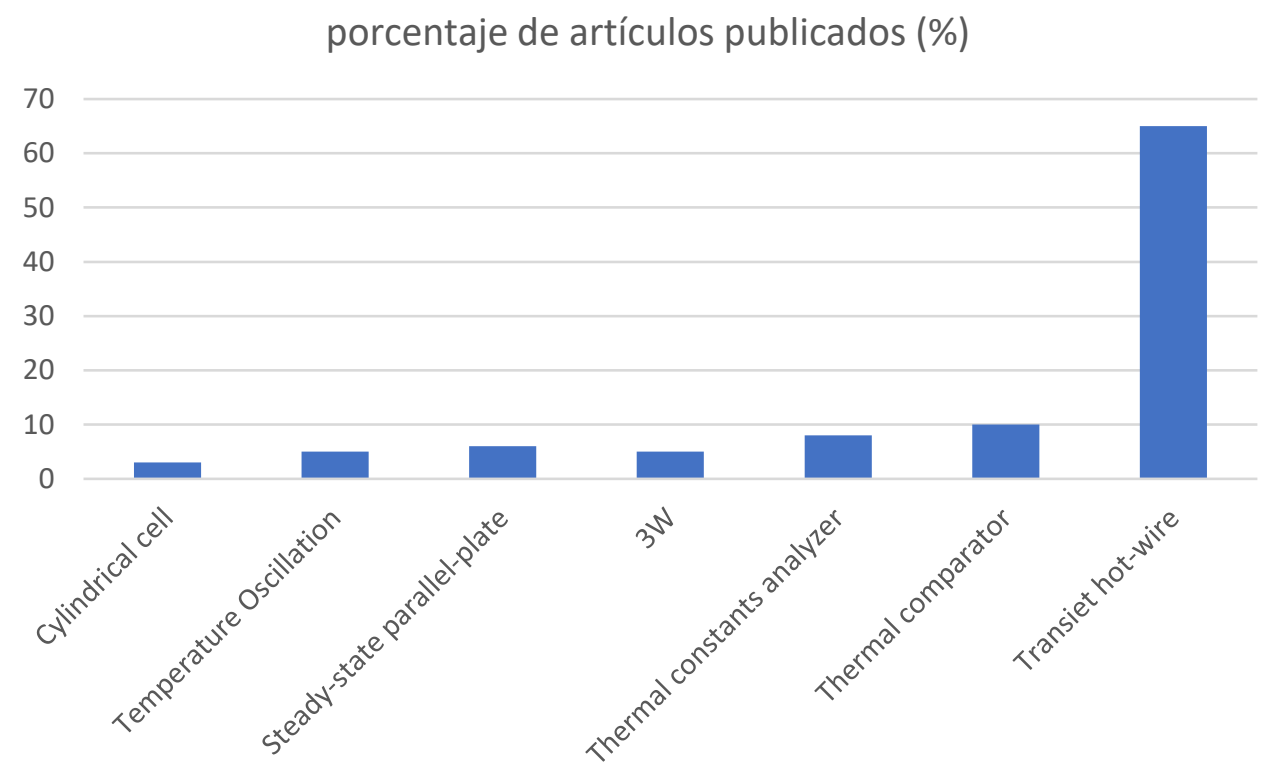

Figura 6. Métodos de medida de la conductividad térmica (\% de utilización en publicaciones científicas) [Fuente 35] 


\subsubsection{Viscosidad de los nanofluidos}

Del mismo modo que la conductividad térmica, la viscosidad tiene un impacto importante sobre el resultado global de la transferencia de calor en los fluidos. El comportamiento reológico de nanofluidos se ve afectado por las fuerzas coloidales presentes entre las partículas y por lo tanto depende de aquellas variables que modifican las cargas superficiales y el potencial de interacción total $[79,29]$. Para las partículas en el intervalo de tamaño nanométricas, las fuerzas de Van der Waals actúan como fuerzas de cohesión y restringen el movimiento relativo de las partículas resultantes. La presencia de estos aglomerados aumenta la viscosidad del fluido.

Algunos investigadores han tratado de obtener una expresión que relacione la viscosidad del nanofluido con la viscosidad del fluido base, siendo una de las expresiones pioneras la sugerida por Einstein [52], para fluidos newtonianos con nanopartículas suspendidas esféricas a bajas fracciones volumétricas:

$$
\eta_{n f}=\eta_{f b}(1+2,5 \phi)
$$

Donde

$\eta_{n f}$ viscosidad del nanofluido (Pa·s)

$\eta_{f b}$ viscosidad del fluido base (Pa.s)

$\Phi$ fracción volumétrica de nanopartículas (adimensional)

Según Murshed, con los modelos clásicos los valores de viscosidad estimados están muy por debajo de los valores experimentales [94]. Generalmente, la viscosidad de un nanofluido aumenta con la fracción sólida, (resultados observados por distintos investigadores en la Tabla 5) y disminuye con la temperatura [92].

Aunque la adición de nanopartículas mejora las propiedades térmicas y capacidades de transferencia de calor de los fluidos, la aplicación industrial en sistemas de transferencia de calor está limitada por el aumento de la viscosidad del fluido (lo que aumenta la potencia de bombeo). Prasher constató con los resultados experimentales obtenidos con nanofluidos de alúmina que, aunque el aumento relativo en viscosidad obtenido con dichos nanofluidos fue elevado, dicho aumento debe ser mayor de un factor 4 para que las propiedades del nuevo nanofluido no sean mejores que las del fluido base [95]. 
Tabla 5. Variación de la viscosidad de los nanofluidos respecto al fluido base agua. Fuente [52].

\begin{tabular}{cccc}
\hline Autor & $\begin{array}{c}\text { Tipo de muestra de } \\
\text { nanofluido }\end{array}$ & $\begin{array}{c}\text { Fracción } \\
\text { volumétrica (\%) }\end{array}$ & $\begin{array}{c}\text { Aumento de } \\
\text { viscosidad (\%) }\end{array}$ \\
\hline Chandrasekar et al. & $\mathrm{Al}_{2} \mathrm{O}_{3}$ & $1-5$ & $14-136$ \\
Niguyen et al. & $\mathrm{Al}_{2} \mathrm{O}_{3}$ & $1-13$ & $12-430$ \\
Anoop et al. & $\mathrm{Al}_{2} \mathrm{O}_{3}$ & $0,5-6$ & $3-77$ \\
Masuda et al. & $\mathrm{TiO}_{2}$ & $1-4,3$ & $11-60$ \\
Chen et al. & $\mathrm{TiO}_{2}$ & $0,25-1,2$ & $3-11$ \\
Duangthongsuk et al. & $\mathrm{TiO}_{2}$ & $0,2-2$ & $4-15$ \\
Pastoriza Gallego et al. & $\mathrm{CuO}$ & $1-10(\mathrm{wt})$ & $0,5-11,5$ \\
Chen et al. & Nanotubos de & $0,12-0,6$ & $3,5-82$ \\
\hline
\end{tabular}

Por estos motivos, el estudio de dispersión de las nanopartículas en medio acuoso para su posterior aplicación como fluido térmico debe contemplar la caracterización reológica del mismo junto con la caracterización térmica, obteniéndose los reogramas a distintas temperaturas (viscosidad del fluido en función del gradiente de velocidad) en un reómetro.

\subsubsection{Calor específico y densidad de los nanofluidos}

El calor específico es una magnitud física que se define como la cantidad de calor que hay que suministrar a la unidad de masa de una sustancia o sistema termodinámico para elevar su temperatura en un grado. En general, el valor del calor específico depende del valor de la temperatura. En los nanofluidos el calor específico puede obtenerse teóricamente a partir del calor específico de las nanopartículas y del fluido base, según la siguiente expresión:

$$
c_{p n f}=\frac{(1-\Phi)\left(\rho c_{p}\right)_{f b}+\Phi\left(\rho c_{p}\right)_{n p}}{(1-\Phi) \rho_{f b}+\Phi \rho_{n p}}
$$

Donde

$\rho_{\mathrm{np}} \quad$ densidad de la nanopartícula $\left(\mathrm{kg} / \mathrm{m}^{3}\right)$

$\rho_{\mathrm{fb}} \quad$ densidad del fluido base $\left(\mathrm{kg} / \mathrm{m}^{3}\right)$ 
$\Phi \quad$ fracción volumétrica de partículas en el fluido base (\%)

Cpnp calor específico de la nanopartícula $(\mathrm{J} /(\mathrm{kgK}))$

Cpnf calor específico del fluido base $(\mathrm{J} /(\mathrm{kgK}))$

El valor de la densidad también puede obtenerse teóricamente según la siguiente expresión, considerando una mezcla binaria:

$$
\rho_{n f}=(1-\Phi) \rho_{f b}+\Phi \rho_{n p}
$$

El valor del calor específico del nanofluido y la densidad también puede obtenerse experimentalmente en un calorímetro diferencial de barrido y en un estereopicnómetro de helio, según el procedimiento descrito posteriormente en el Capítulo III, apartado 3.3 y 3.4.

\section{Teoría de la conducción térmica en nanofluidos}

Para entender mejor el aumento relativo en conductividad térmica que experimentan los nanofluidos respecto al fluido base se resumen a continuación los distintos mecanismos en los cuales se basan los modelos teóricos propuestos por diversos autores para justificar dicho incremento $[3,30,44,60,61$ y 63$]$. Se incluye también a modo de resumen un listado de los factores que inciden sobre la conductividad térmica de los nanofluidos [3, 49,53, 62 y 66].

\subsection{Mecanismos propuestos por diversos autores para predecir el aumento en} conductividad térmica de los nanofluidos

Se ha encontrado gran variedad de teorías que engloban diversos mecanismos de transferencia de calor con el objetivo de predecir el aumento de conductividad térmica que experimenta un fluido cuando se incorporan nanopartículas a la suspensión. Estas teorías se pueden clasificar en la teoría clásica, teorías basadas en mecanismos estáticos y teorías basadas en modelos dinámicos microscópicos.

\section{Teoría clásica}

La primera teoría que se propuso para predecir el aumento en conductividad térmica de los nanofluidos fue la teoría de Maxwell (Ec1.) en 1873 [3,44]. Esta teoría tan sólo se puede aplicar a nanofluidos en los cuales no existe interacción entre las nanopartículas, es decir nanofluidos 
preparados a una baja fracción volumétrica y cuando las nanopartículas presentan forma esférica. Como ya se ha comentado, los incrementos en conductividad predichos por la ecuación de Maxwell no se corresponden con los resultados obtenidos en nanofluidos medidos experimentalmente según la bibliografía [30]. De hecho, los valores de conductividad térmica medidos experimentalmente en los nanofluidos superan los valores límite teóricos en los cuales el único mecanismo de transmisión de calor es la difusión térmica. Asimismo, se ha detectado que la conductividad térmica presenta una dependencia lineal con la temperatura y es inversamente proporcional al tamaño de nanopartícula, y se ha observado dependiendo del tipo de sólido, un límite en el incremento de conductividad térmica cuando se preparan nanofluidos a fracciones volumétricas altas [44].

Por este motivo, diversos autores han propuesto varios mecanismos para explicar las variaciones de conductividad térmica medida experimentalmente respecto a la teoría clásica propuesta por el modelo de Maxwell, [44]. Los mecanismos propuestos se pueden dividir en mecanismos estáticos y mecanismos dinámicos. Los mecanismos estáticos, que consideran los fenómenos de nanocapa y agregación, se desarrollan sobre la base de que las nanopartículas suspendidas en los fluidos base no tienen movilidad. Los mecanismos dinámicos, que consideran las nanopartículas en suspensión en movimiento aleatorio, incluyen el modelo de nanoconvección inducido por el movimiento browniano de las nanopartículas. A continuación, se describen brevemente estos mecanismos propuestos en la bibliografía consultada que intentan explicar el aumento en conductividad obtenido con los nanofluidos [3,30,44,60,61 y 63], y a partir de los cuales se han definido los distintos modelos teóricos.

\section{Teorías basadas en mecanismos estáticos}

\section{Teoría basada en la nanocapa: capa de líquido alrededor de las nanopartículas}

En la interfase entre el líquido y las nanopartículas se produce una resistencia a la transferencia de calor debido a la diferente naturaleza de ambas fases implicadas. Alrededor de esta interfase se forma una capa de moléculas de líquido ordenada. Son estas moléculas ordenadas las que actúan de puente entre la nanopartícula y el líquido mejorando la transferencia de calor a través de la interfase. Se cree que las moléculas de esta nanocapa límite de líquido tiene la capacidad de conducir el calor mejor que el resto de moléculas del líquido. Si hay suficientes nanopartículas y éstas se encuentran muy cerca se formará una 
trayectoria de transporte térmico en forma de cadena. Esta nanocapa fue introducida por Keblinski y Choi como el primer mecanismo estático que explicaba el incremento en conductividad que experimentan los nanofluidos [30].

\section{Teoría basada en la forma y agregación de las nanopartículas}

Las nanopartículas tienden a formar clusters y agregarse debido a las fuerzas atractivas de Van der Waals. Keblinski propuso que dicha aglomeración podía incrementar la conductividad térmica del medio debido a que proporcionan rutas locales por percolación que facilitan el transporte de calor $[3,60,63]$. Se ha demostrado en determinados estudios [49] que el fenómeno de aglomeración y la microestructura de los aglomerados tienen mayor efecto en los aumentos de conductividad que los fenómenos dinámicos de microconvección.

\section{Teorías basadas en modelos dinámicos microscópicos}

\section{$\underline{\text { Teoría basada en el movimiento browniano de las nanopartículas }}$}

El movimiento browniano es el libre movimiento de las nanopartículas suspendidas en un fluido. En esta teoría el transporte de energía se da por la colisión entre nanopartículas debido a dicho movimiento. Este tipo de movimiento fue el primer modelo dinámico que se propuso, sin embargo, Wang y Keblinski demostraron que el aumento de conductividad no era significativo debido a que la velocidad de difusión browniana es más lenta que la térmica [30], por lo que este mecanismo no debe ser el único mecanismo de transferencia de calor que contribuye a los aumentos anómalos en conductividad térmica [3].

\section{Micro-Convección en el fluido base}

Como la difusión entre partículas es más baja que la difusión térmica en el fluido base, Jan y Choi y posteriormente Prasher, propusieron la hipótesis de que el movimiento browniano de las nanopartículas induce una convección a escala nanométrica que puede explicar la dependencia de la conductividad térmica con la temperatura y el tamaño de las nanopartículas $[3,60]$.En esta teoría se suma a la transmisión de calor por el movimiento browniano de las partículas la transmisión por micro-convección.

Cada uno de estos mecanismos o la combinación de todos ellos (estáticos y dinámicos) dan lugar a diversos modelos teóricos que se analizarán en profundidad en el capítulo $\mathrm{V}$, donde se 
presentan los resultados de modelización y estudio de viabilidad de los nanofluidos preparados.

\subsection{Factores que afectan a la conductividad térmica de los nanofluidos}

Según la bibliografía consultada [3,4, 49, 56, 62 y 66] los factores más importantes que afectan a la conductividad térmica de los nanofluidos son;

\section{- $\quad$ Fracción volumétrica de nanopartículas en el fluido}

La conductividad térmica crece de forma lineal con la fracción volumétrica de partículas en la suspensión (Ф). Este parámetro se estudia en la mayoría de los artículos y todos coinciden en esta linealidad. El aumento en cantidad de nanopartículas implica un aumento directo del movimiento browniano y del número de contactos entre partículas, generándose por tanto un aumento en la conductividad térmica [49].

\section{- $\quad$ Tipo de material sólido utilizado}

En la mayoría de los artículos se ha comprobado que cuanto mayor es la conductividad térmica de la nanopartícula sólida que se pone en suspensión en el fluido base, mayor es la conductividad térmica del nanofluido (por ejemplo, con nanofluidos de cobre se obtiene mayor conductividad térmica que con los nanofluidos de alúmina) [66]. La principal razón de este factor es la diferencia en conductividad térmica que ya presentan como sólidos las nanopartículas de distinta naturaleza (valores de $k$ del cobre mayores que los de la alúmina, Figura 2 y 3). Sin embargo, hay que señalar que este factor no es el factor dominante que determina la conductividad térmica final del nanofluido. La naturaleza del material también está relacionada con otros factores como la tendencia a la formación de aglomerados y la viscosidad. De hecho, este factor es mucho más significativo cuando se usan nanotubos de carbono, donde la forma alargada de los mismos favorece la rápida conducción de calor frente a la forma esférica de otras nanopartículas [3].

\section{- Tamaño de la nanopartícula}

El tamaño de nanopartícula es uno de los parámetros más críticos. La conductividad térmica de un nanofluido disminuye cuando aumenta el tamaño de la nanopartícula independientemente de la naturaleza de la misma, dado que al aumentar el tamaño 
disminuye el movimiento browniano (mecanismo que produce un aumento anómalo en la conductividad térmica final del nanofluido). Hay que señalar que, si el tamaño de la partícula es muy pequeño, el sistema puede tener tendencia a formar aglomerados, los cuales al no tener movimiento browniano disminuyen la conductividad térmica generándose finalmente el efecto opuesto. Respecto al tamaño de partícula hay conflicto en cuanto a los resultados experimentales en conductividad obtenidos por diversos autores [66], pues algunos han constatado aumentos en la conductividad térmica al disminuir el tamaño mientras que en otros artículos este factor actúa a la inversa. El tema de la influencia del tamaño de partícula sobre la conductividad final va a depender del mecanismo predominante (que puede ser el dinámico debido al movimiento browniano y la microconvección generada o al mecanismo estático debido a la agregación de las nanopartículas). El efecto de este factor será más notable a bajas fracciones volumétricas [56].

\section{- $\quad$ Forma de la partícula}

Diversos autores han analizado la influencia de la forma de la partícula, laminar o en forma cilíndrica, con el objetivo de analizar la influencia que puede tener dicha variable sobre el incremento en conductividad térmica en el nanofluido. La relación del diámetro de la partícula respecto a su longitud, se utiliza mucho para caracterizar las nanopartículas con forma no esférica, como los nanotubos.

Hamilton y Crosser ya en 1962, propusieron un modelo teórico el cual predice que las nanopartículas cilíndricas producen mayores aumentos en conductividad térmica que las partículas esféricas. Los resultados experimentales obtenidos por Murshed en 2005 con nanotubos [4], ratifican dicha tendencia.

\section{- Fluido base}

Si se aplica la teoría clásica de mezclas binarias, cuanto menor es la conductividad del fluido base mayor es el aumento en conductividad térmica obtenido al añadir nanopartículas al fluido base. Sin embargo, la viscosidad del fluido afecta directamente al movimiento browniano de las partículas y por tanto a su conductividad térmica final. El efecto de la doble capa que se forma alrededor de la partícula depende de la naturaleza del fluido base. Por ejemplo, los mejores resultados experimentales de aumento de conductividad térmica con nanopartículas de $\mathrm{Al}_{2} \mathrm{O}_{3}$ se han obtenido con el etilenglicol como fluido [3]. En nanofluidos 
preparados a partir de nanotubos de carbono de pared múltiple, MWCNTS, se han obtenido mejores valores de conductividad térmica con aceite mineral que con etilenglicol [3].

\section{- $\quad$ Temperatura}

Las suspensiones con nanopartículas presentan una gran variación de la conductividad térmica con la temperatura debido a que la temperatura afecta al movimiento browniano y a la formación de aglomerados. En la bibliografía consultada la variación de la conductividad térmica con la temperatura no se ha analizado de forma aislada, pero en general se ha observado que los incrementos en conductividad térmica son mayores a temperaturas elevadas (aunque pocos autores han medido dichos incrementos a temperaturas mayores de $90^{\circ} \mathrm{C}$ ). Según el modelo de microconvección la velocidad de una nanopartícula aumenta linealmente con la temperatura, por tanto, al elevar la temperatura se aumentará la conductividad térmica debido al movimiento browniano de dichas nanopartículas. Sin embargo, el aumento del movimiento de partículas debido a un incremento de la temperatura puede aumentar la tendencia a formar aglomerados debido al mayor número de contactos entre partículas y afectar a la conductividad térmica resultante. Como ya se ha comentado en la incidencia del tamaño de la partícula, el aumento en conductividad dependerá del mecanismo predominante que lo origine. Algunos autores han constatado que el aumento en conductividad del nanofluido al aumentar la temperatura se debe a la dependencia lineal del nanofluido base y no al tipo de nanopartículas dispersas en él, (estudios de nanofluidos donde el fluido base es el keroseno) $[64,66]$, por lo que en estos casos no se obtienen finalmente un aumento relativo de la conductividad térmica respecto al fluido base. Para estos estudios la única explicación es que el mecanismo de microconvección no es dominante.

\section{- Estado de aglomeración de las nanopartículas}

Como ya se ha comentado uno de los mecanismos que contribuyen al aumento de conductividad térmica es la configuración lineal o con geometría fractal de las nanopartículas disueltas en el fluido base. Esta disposición contribuye mediante el mecanismo de conducción a la transferencia de calor, como así se ha demostrado en diversos estudios en los cuales se ha conseguido un aumento en la conductividad térmica al aplicar un campo magnético en nanofluidos de hierro y conseguir el alineamiento de las nanopartículas [66]. Si los agregados que se forman son muy grandes, pueden llegar a sedimentar y a reducir la conductividad 
térmica. Cuando las nanopartículas tienen tendencia a formar aglomerados y aumentar su tamaño se reduce el movimiento browniano y por tanto la conductividad térmica al reducirse los mecanismos dinámicos. El estado de aglomeración dependerá de la estabilidad de la suspensión de los nanofluidos, de la dispersión de las nanopartículas según el método de preparación y de la fracción volumétrica y es uno de los factores que más puede variar en el tiempo.

- $p H$

La estabilidad de los nanofluidos se ve influenciada por el valor del pH. La modificación del pH de una suspensión puede acercar o alejar a la suspensión del punto isoeléctrico al modificar la carga superficial de las partículas (punto en el cual el potencial de repulsión de las partículas es cero y tienden a formar aglomerados) y por tanto modificar su estado de agregación y su movilidad repercutiendo directamente sobre la conductividad térmica del nanofluido y la reología (viscosidad). Ajustar el pH del nanofluido a un valor óptimo puede llevar a obtener mejores resultados en cuanto estabilidad y conductividad térmica. Sin embargo, cuando ya se está alejado del punto isoeléctrico, modificaciones del pH no implican cambios sustanciales de conductividad $[31,66,68,69,79]$.

\section{Mecanismos de transferencia de calor. Aplicación de los nanofluidos como}

\section{fluidos térmicos.}

La transferencia de calor es determinante en cualquier avance tecnológico en el que esté presente. Su gestión eficiente es necesaria tanto en aquellas operaciones de enfriamiento, en las que hay que eliminar el exceso de calor, como en aquellas en las que interesa transportarlo para aprovechar su valor energético.

Como se ha comentado en la introducción los intercambiadores de calor, son uno de los equipos de mayor importancia en los procesos térmicos, pudiendo actuar como sistemas de refrigeración mejorando así la eficiencia del proceso. Los intercambiadores de superficie (clasificados en flujo paralelo, en contracorriente, mixto o cruzado) son equipos que transmiten el calor entre fluidos por intermedio de una pared que los separa. $[43,44,45]$. Este tipo de configuraciones tienen limitada aplicación práctica debido al gran volumen de ocupación que presentan. Existen otros intercambiadores de estructura más compleja donde 
se consiguen altas superficies de transmisión con tamaños más reducidos, como los intercambiadores de carcasa y haz de tubos. En estos intercambiadores conseguir aumentos en los coeficientes de transmisión de calor ayuda de forma significativa a reducir las altas superficies de contacto necesarias para una óptima transferencia de calor.

El flujo de calor que se transfiere depende, según la expresión de Newton, de la diferencia de temperaturas entre fluido y pared, del área de contacto y del coeficiente de transferencia (intrínseco a las propiedades del fluido). El incremento en el flujo de calor puede obtenerse por tanto aumentando la diferencia de temperatura, aumentando el área y aumentando dicho coeficiente de transmisión de calor. La estrategia más común para aumentar la transferencia de calor es aumentar el área de contacto mediante el diseño de los intercambiadores como por ejemplo los radiadores o los intercambiadores de placas, ya que no siempre resulta posible aumentar el gradiente de temperaturas (por limitaciones de proceso o por la naturaleza de los materiales). Sin embargo, en los nuevos procesos de refrigeración donde se requieren sistemas cada vez más pequeños, el tamaño juega un papel limitante, siendo la única estrategia posible aumentar el coeficiente de transferencia de calor $(h)$.

La transmisión o transferencia de calor en los equipos de intercambio se define como el paso natural de energía térmica desde un cuerpo a mayor temperatura a otro de menor nivel térmico [44]. En los fluidos térmicos la transmisión de calor se dará principalmente por conducción y por convección.

\section{$\underline{\text { Transmisión por conducción }}$}

La ley básica de transmisión de calor por conducción se debe a Fourier, la cual postula que la cantidad de calor que pasa a través de la superficie de un cuerpo, en un intervalo de tiempo, es proporcional al gradiente de temperaturas. El calor se transmite en el sentido de las temperaturas decrecientes.

$$
q=\frac{k A}{x}\left(T_{1}-T_{2}\right)
$$

donde:

$$
\begin{aligned}
& q=\text { calor transmitido por unidad de tiempo }(\mathrm{J} / \mathrm{s}) \\
& A=\text { área de la superficie de contacto }\left(\mathrm{m}^{2}\right)
\end{aligned}
$$




$$
\begin{aligned}
& k=\text { conductividad térmica }(\mathrm{W} / \mathrm{m} \mathrm{K}) \\
& \mathrm{x}=\text { espesor del material }(\mathrm{m}) \\
& \left(\mathrm{T}_{1}-\mathrm{T}_{2}\right)=\text { diferencia de temperatura entre dos puntos o caras de un material }(\mathrm{K})
\end{aligned}
$$

La proporcionalidad de dicha expresión se relaciona con una constante dependiente del material, denominada conductividad " $k$ ", que describe la capacidad que tiene una sustancia de transmitir calor y que se mide en $(\mathrm{W} / \mathrm{mK})$.

\section{$\underline{\text { Transmisión por convección }}$}

La convección es la transferencia de energía que se produce en un fluido en movimiento en contacto con una pared sólida o fluido inmiscible con una temperatura distinta a la del fluido. La transferencia de calor por convección se expresa con la ecuación de enfriamiento de Newton:

$$
q=A h\left(T_{f}-T_{p}\right)
$$

donde:

$$
\begin{aligned}
& A=\text { superficie de transmisión }\left(\mathrm{m}^{2}\right) \\
& \mathrm{h}=\text { coeficiente de transmisión de calor por convección o de película }\left(\mathrm{W} / \mathrm{m}^{2} \mathrm{~K}\right) \\
& T_{p}=\text { temperatura de la pared }(\mathrm{K}) \\
& T_{f}=\text { temperatura del fluido }(\mathrm{K}) \\
& q=\text { flujo de calor intercambiado entre fluido y pared }(\mathrm{J} / \mathrm{s})
\end{aligned}
$$

El coeficiente de transmisión $\mathbf{h}$ depende de múltiples parámetros relacionados con el flujo del fluido a través del cual se da la convección:

- tipo de convección (forzada o natural)

- régimen del fluido (laminar o turbulento)

- velocidad del fluido

- viscosidad del fluido,

- densidad del fluido,

- conductividad térmica del fluido,

- calor específico del fluido, 
- coeficiente de dilatación del fluido,

- forma de la superficie de intercambio,

- rugosidad de la superficie de intercambio,

- temperatura.

Las formas clásicas de estimar el coeficiente de transmisión h o coeficiente de película se basan en el empleo de correlaciones de números adimensionales (número de Nusselt), de manera que en general se dispone de una igualdad entre el número de Nusselt, que es proporcional al coeficiente de convección, y una cierta expresión que involucra al número de Reynolds y al número de Prandtl en convección forzada, y al de Prandtl y al número de Grashof en convección natural. Para obtener el coeficiente de transmisión h o coeficiente de película de forma experimental se aplica la Ec. 7, para la cual resulta necesario conocer el campo de temperaturas en el fluido.

$$
h=-\left.\frac{\kappa}{T_{p}-T_{f}} \frac{\partial T}{\partial l}\right|_{l \rightarrow 0}
$$

Siendo "I" la distancia a la pared.

Pueden distinguirse dos tipos de convección según la causa del movimiento del fluido:

- Convección natural: el movimiento del fluido se debe tan solo a las diferencias de densidad que se producen en el fluido por el gradiente de temperaturas.

- Convección forzada: cuando el movimiento del fluido se produce debido a la existencia de fuerzas externas que actúan sobre el mismo, como ventiladores o bombas.

El coeficiente de transferencia de calor por convección depende de la densidad, viscosidad y velocidad del fluido, así como de sus propiedades térmicas (conductividad térmica y calor específico). Según el tipo de movimiento del fluido tendremos dos tipos de convección: convección en régimen laminar y convección en régimen turbulento. Finalmente, existe una última clasificación de la transmisión por convección en función de si existe cambio de fase o no.

Habitualmente se trabaja con un número adimensional de Nusselt para referirse al coeficiente de transmisión de calor h, cuya expresión es: 


$$
N u=\frac{h L}{\kappa}
$$

Dicho coeficiente de transmisión o de película, "Nu", está relacionado con coeficientes adimensionales con la siguiente ecuación de semejanza:

$$
N u=F(R e, P r)
$$

En convección forzada con velocidades moderadas el coeficiente de película "Nu" depende del número de Reynolds y del número de Prandtl. Es decir, la transferencia de calor por convección forzada depende de los siguientes números adimensionales:

$$
R e=\frac{u_{\infty} \rho L}{\eta}
$$

Donde:

$\mathrm{u}_{\infty}=$ velocidad del fluido

$\eta=$ viscosidad del fluido

L= diámetro conducción

$\rho=$ densidad del fluido

$$
\operatorname{Pr}=\frac{\eta c_{p}}{\kappa}
$$

Donde:

$\eta=$ viscosidad del fluido

$\mathrm{k}=$ conductividad térmica del fluido

$c_{p}=$ calor específico medio del líquido a presión constante

El número adimensional de Reynolds representa la relación de las fuerzas de inercia con la fuerza asociada a la tensión viscosa, mientras que el número de Prandtl relaciona la viscosidad cinemática y la difusividad térmica. El valor del número de Prandtl determina que fenómeno es más significativo en el proceso de convección (números bajos predomina mecanismo de conducción, con números altos predomina el mecanismo de convección).

En el presente estudio el tipo de transmisión de calor entre los fluidos en los intercambiadores de calor va a considerarse que se da por convección forzada en régimen turbulento y sin 
cambio de fase. En el caso de procesos de transferencia de calor en régimen turbulento [2] en tuberías pequeñas el coeficiente de transferencia de calor $(h)$ puede calcularse a partir de la ecuación de Dittus-Boelter con el coeficiente de Nusselt:

$$
N u=0,023 \operatorname{RePr}
$$

Si se mantienen constantes la densidad, viscosidad y capacidad calorífica del fluido de transporte, el coeficiente de transferencia de calor $h$ puede incrementarse si se aumenta la velocidad de circulación del fluido o aumentando el coeficiente de conductividad térmica. El aumento de velocidad implica un aumento de la energía de bombeo. La caída de presión por fricción en una tubería donde se tiene un régimen turbulento depende de la velocidad, longitud y diámetro de la tubería. En intercambiadores con microcanales las pérdidas de carga son elevadas por lo que se incrementa muchísimo la energía utilizada para el bombeo. Por estos motivos los fluidos térmicos utilizados en estos tipos de intercambiadores deben tener una conductividad térmica elevada para no tener que trabajar a velocidades elevadas. Además, la viscosidad de los mismos debe ser mínima para disminuir también la energía utilizada en el bombeo.

La siguiente expresión, fórmula de Darcy Weisbach, permite obtener la pérdida de carga entre dos puntos, expresado como $\Delta \mathrm{p}$ :

$$
\Delta p=f \frac{L}{D} \frac{\rho v^{2}}{2}
$$

Donde
$\Delta \mathrm{p} \quad$ pérdida de carga entre dos puntos $(\mathrm{Pa})$
$\rho \quad$ densidad del fluido $\left(\mathrm{kg} / \mathrm{m}^{3}\right)$
$\mathrm{L} \quad$ longitud de la tubería $(\mathrm{m})$
D diámetro del canal o tubería (m)
v velocidad del fluido $(\mathrm{m} / \mathrm{s})$ 
f factor de fricción adimensional obtenido en función del régimen laminar a partir de la expresión $f=64 / R e$, o en régimen turbulento a partir de la ecuación de Colebrook simplificada

\section{Aplicaciones de los nanofluidos como fluidos térmicos.}

Los nanofluidos presentan algunas ventajas importantes sobre las suspensiones coloidales convencionales [51] como:

- Mejor estabilidad a lo largo del tiempo debido al movimiento browniano de las partículas.

- Alta superficie específica y por tanto mayor superficie en contacto sólido- fluido para el intercambio de calor.

- Mejor conductividad térmica que los fluidos que contienen el mismo tipo de partícula pero con tamaño micrométrico y por tanto mejorando la transferencia de calor.

- Menor posibilidad de obturación en microcanales, promoviendo la miniaturización de los sistemas electrónicos.

- Posibilidad de ajustar las propiedades del nanofluido variando la fracción de nanopartículas.

- Menor coeficiente de fricción y mejora de la resistencia al desgaste.

Todas estas ventajas potenciales han impulsado la investigación en el ámbito de los nanofluidos como así lo demuestra el grafico con la evolución en número de artículos publicados en los últimos años (Figura 7). 


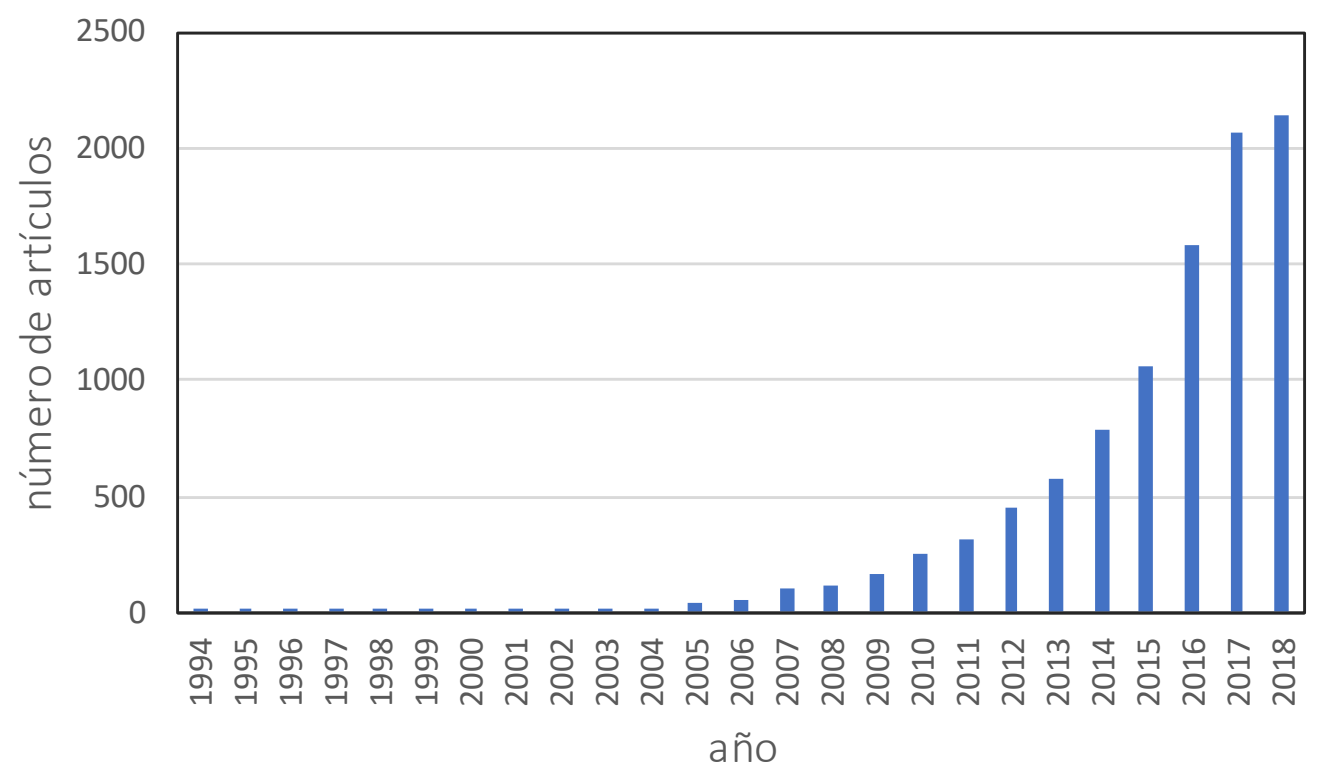

Figura 7. Artículos publicados sobre nanofluidos [fuente Science Direct].

Gracias a los avances en investigación aplicada realizados en este tema, ha sido posible utilizar los nanofluidos en gran número de aplicaciones térmicas, Figura 8 , para mejorar la transferencia del calor en las áreas citadas a continuación:

- Transporte. W.Yu y S.U.S. Choi [12] recogieron en un trabajo de revisión publicado por Argonne las posibles aplicaciones de los nanofluidos en el sector del transporte, concretamente para la refrigeración de motores, como fluido térmico en los radiadores ( base etilenglicol y nanopartículas) o como lubricantes.

- Refrigeración circuitos electrónicos. Esta es una de las aplicaciones en las que los nanofluidos pueden tener un mayor futuro, dado la limitación de espacio en estos equipos para el intercambio de calor, los fluidos de elevada conductividad aumentan notablemente la eficiencia del sistema y además no requieren de un volumen de nanofluido elevado, por lo que el precio y producción del mismo puede ser viable. Diversos autores han recogido en varios artículos la aplicación de los nanofluidos como refrigerantes en micro canales como R.Saidur en 2010 [1, 51] y 2011 [38 y 67], comprobando que los nanofluidos permite disminuir el consumo al mejorar la transferencia y reducir el coeficiente de fricción, aunque en todos los casos se ha observado un aumento en la presión de bombeo.

- Intercambiadores. Gabriela Huminic [50], realizó una revisión de los distintos artículos sobre la aplicación de los nanofluidos en intercambiadores de calor de placas, 
intercambiadores de calor de carcasa y haz de tubos, intercambiadores de calor compactos e intercambiadores de calor de doble tubo, concluyendo que la mayoría de los estudios experimentales mostraron que los nanofluidos muestran un coeficiente de transferencia de calor mejorado en comparación con su fluido base y que aumenta significativamente con el aumento de la fracción de nanopartículas, así como del número de Reynolds. La mejora de la capacidad de transferencia de calor de los nanofluidos hace que su uso en intercambiadores de calor sea una opción interesante, lo que conduce a un mejor rendimiento del sistema y a la consiguiente ventaja en la eficiencia energética. Por otro lado, la estabilidad de los nanofluidos y su coste de producción son factores importantes que dificultan la comercialización de los nanofluidos $[51,67]$.

- Energías renovables. Los nanofluidos también pueden aplicarse en todos los sistemas de aprovechamiento de la energía solar (colectores solares planos, concentradores solar parabólicos, placas fotovoltaicas) o procesos de geotermia que impliquen transferencia de calor. Ali Najah Al-Shamani recoge en su artículo innumerables aplicaciones de los nanofluidos (de alúmina o de óxido de cobre en base agua o etilenglicol) en distintos sistemas para el aprovechamiento de la energía solar [40]. Omid Mahian [48] apunta que el uso de los nanofluidos en los colectores solares permite reducir las emisiones de $\mathrm{CO}_{2}$ al aumentar la eficiencia del sistema, pero que existe una dependencia de la eficacia con la fracción volumétrica y el tamaño de partícula, las cuales pasan por un óptimo. La adición de surfactantes y estabilización con el pH llevan a una mayor estabilidad de los nanofluidos. Siddharth Suman recoge los últimos avances de la aplicación de nanofluidos en el campo de energía solar hasta el 2015 [65].

- Aplicaciones varias. Los nanofluidos pueden tener otras aplicaciones como en cámaras, microdispositivos y pantallas, en frigoríficos domésticos, como refrigerantes en los procesos de mecanizado, para reducir la temperatura de los gases de combustión de la caldera, en transformadores, en tuberías de calor oscilante, en aplicaciones aeroespaciales, en defensa, en medicina, en reactores nucleares, en los procesos de molienda y en pilas de combustible [1]. 
En la Figura 8 se ha representado un mapa conceptual de las posibles aplicaciones de los nanofluidos, siendo los mecanismos de transferencia de calor en refrigeración los más estudiados.

Actualmente, se ha visto ya gran potencial de aplicación de los nanofluidos como aditivos para fluidos de perforación profunda en procesos de geotermia y extracción de petróleo (como fluidos de transferencia de calor o lubricantes) y como medios de almacenamiento de energía térmica (por ejemplo, los nanofluidos de sales fundidas para aplicaciones solares térmicas).

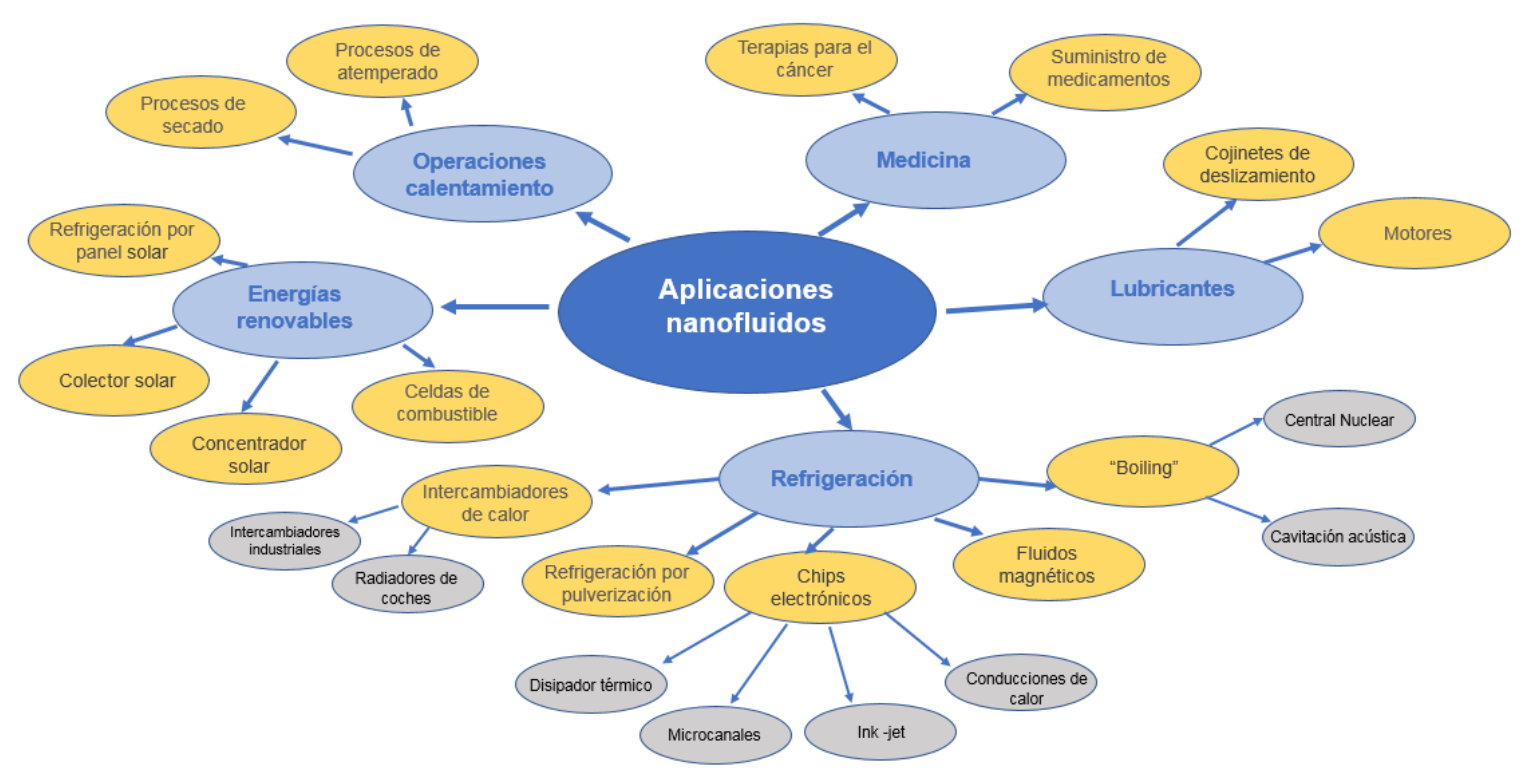

Figura 8. Mapa conceptual de los distintos campos de aplicación de los nanofluidos, fuente $[127,128]$.

A más largo plazo, los nanofluidos pueden ser una solución prometedora en su uso en las pilas de combustible y como nuevos electrolitos para mejorar el almacenamiento de energía en las baterías. La fiabilidad es una cuestión importante en las aplicaciones nucleares y es necesario mejorar por tanto la estabilidad de los nanofluidos para dicha aplicación. También se espera que los nanofluidos generen nuevas aplicaciones energéticas, como la gestión térmica de las baterías eléctricas recargables, las pilas de combustible, las plataformas solares termoeléctricas para la generación de energía y las nuevas estrategias para el almacenamiento de energía [128]. 


\section{Aspectos a mejorar en los nanofluidos}

Tras la revisión bibliográfica se ha visto que los nanofluidos presentan ventajas notables frente a los fluidos base, pero estas ventajas vienen acompañadas de una serie de dificultades que a día de hoy todavía no han sido resueltas. El uso de nanofluidos en una amplia variedad de aplicaciones parece ser prometedor, como se ha comentado en el apartado anterior, pero el desarrollo de los mismos se ha visto obstaculizado por la falta de acuerdo en los resultados obtenidos por los diferentes investigadores, la caracterización deficiente de las suspensiones y por la falta de comprensión teórica de los mecanismos responsables de los cambios en las propiedades. De entre todas las variables implicadas en la preparación de los nanofluidos susceptibles de mejora, se puede considerar que los mayores problemas que presentan los nanofluidos para su definitiva aplicación industrial son la inestabilidad de los mismos y los costes de producción.

A continuación, se resumen los distintos aspectos a mejorar para que sea viable la aplicación de los nanofluidos como fluidos térmicos $[50,51]$.

\section{a) Estabilidad a largo plazo de la dispersión de nanopartículas}

En general, la estabilidad a largo plazo de la dispersión de las nanopartículas es uno de los aspectos más importantes de entre los requisitos básicos de las aplicaciones de los nanofluidos. La preparación de una suspensión homogénea y estable sigue siendo una cuestión técnica a mejorar, como así se ha constatado en la mayoría de los artículos de revisión sobre preparación de nanofluidos [6, 10,14, 26, 28, 41, 55,57, 76 y 78]. La utilización de surfactantes para mejorar la dispersión de las nanopartículas y evitar que se aglomeren, junto con la modificación de la superficie y el ajuste del pH, son los métodos más utilizados. La medida de dicha estabilidad se realiza la mayoría de las veces mediante control visual de la sedimentación, midiendo la coalescencia de las partículas con equipos de espectrofotometría o mediante el control del potencial Z. Autores como Suganthi, Sandur, Xie y Garg han conseguido fluidos estables durante meses utilizando la técnica de preparación en dos pasos, dispersando nanopartículas de $\mathrm{CuO}, \mathrm{Fe}_{3} \mathrm{O}_{4}$ y nanotubos de carbono MWCNTs en fracciones elevadas [111]. Sin embargo, todavía no hay un método estandarizado para medir la estabilidad de los nanofluidos en el tiempo y que permita comparar los nanofluidos preparados con distintas técnicas por diversos autores. 
Últimamente se ha generado un especial interés en estudiar cómo cambiar la forma y la composición de estas nanopartículas, ya que no es fácil controlar la agregación de formas y la composición de la superficie de las mismas, de hecho, muchos resultados obtenidos con nanofluidos son poco productivos debido a la formación de estos clusters de partículas que generan problemas de sedimentación, de ensuciamiento, comportamiento de fluido no newtoniano...[51]. Este comportamiento impredecible con el tiempo de los nanofluidos en su uso debido a la colisión entre nanopartículas obliga a realizar ensayos experimentales previos a su aplicación [62].

\section{b) Elevada viscosidad}

La viscosidad de las suspensiones de nanopartículas en agua aumenta a medida que se aumenta la fracción de partículas en la suspensión. Por este motivo, la fracción volumétrica de las partículas no puede aumentarse ilimitadamente como sería deseable para obtener mayor valor de conductividad térmica. Experimentalmente se han medido aumentos en viscosidad del $250 \%$ en nanofluidos de alúmina, cuando se preparan al 13\% de fracción volumétrica según W. Nguyen et al.[111], que repercuten negativamente en la futura aplicación. Las viscosidades altas afectan a la perdida de carga y a la presión de bombeo, viéndose afectado también el coeficiente de convección $h$, por lo cual el impacto de la viscosidad es un factor a tener muy en cuenta. Además, el carácter no newtoniano de algunos nanofluidos dificulta su aplicación a velocidades diferentes a las caracterizadas experimentalmente.

La viscosidad del nanofluido depende no solo de la fracción y temperatura, sino también del tamaño de partícula y forma, pues diversos autores han obtenido distintos valores de viscosidad para un mismo material a igual fracción volumétrica, [42] por lo que el método de preparación, grado de dispersión y estabilidad alcanzada en un nanofluido producen variaciones en su viscosidad final. El efecto del surfactante sobre la viscosidad es ambiguo, pues se ha constatado que algunos surfactantes logran mejorar la dispersión de las nanopartículas pero sin embargo conllevan un aumento de la viscosidad [62].

Los fenómenos de aglomeración que se pueden producir en un nanofluido poco estable modifican la viscosidad del mismo en el tiempo, por lo que resulta imprescindible obtener un fluido lo más estable posible para garantizar una viscosidad correcta para su aplicación. 


\section{c) Bajo calor específico}

Un refrigerante ideal debe poseer un valor de calor específico alto pues permite que el refrigerante elimine más calor. Sin embargo, en la revisión bibliográfica se ha visto experimentalmente que el calor específico de los nanofluidos es más bajo que el del líquido base. Praveen et al.[76] midieron experimentalmente que los nanofluidos $\mathrm{CuO} / \mathrm{etilenglicol}$, $\mathrm{SiO}_{2}$ /etilenglicol y los nanofluidos de $\mathrm{Al}_{2} \mathrm{O}_{3}$ /etilenglicol presentan menor calor específico comparado con los fluidos base.

\section{d) Discrepancia de resultados de aumentos en conductividad térmica}

Se han observado aumentos relativos dispares para los mismos contenidos de nanopartículas del mismo tipo entre los distintos artículos consultados. El estudio de Tertsinidou et al. [54], proporcionó un análisis crítico de estos resultados contradictorios, afirmando que el estado termodinámico del nanofluido y las técnicas experimentales utilizadas para caracterizar la conductividad térmica, tienen un papel importante en la medida del valor final de dicha propiedad. La adopción de técnicas no probadas y las malas prácticas en el procedimiento experimental podrían llevar a muchos de estos resultados dispares.

Para solucionar esta problemática de la dispersión de los resultados experimentales, los métodos de medida de conductividad térmica deberían estandarizarse y utilizarse distintos equipos o realizar inter-comparaciones. El error de medida ocasionado por los problemas de convección en el interior de la muestra cuando los ensayos se realizan a temperaturas altas debe minimizarse [36]. No se han identificado todavía si los aumentos anómalos en conductividad térmica son reales (ocasionados por los efectos de movimiento browniano, o efectos de doble capa) o son errores en la medida [60 y 62]. Los modelos existentes para predecir las conductividades térmicas no pueden predecir con un error menor del 1\% [11].

\section{e) Elevado coste de los nanofluidos}

El mayor coste de producción de los nanofluidos es una de las razones principales que puede dificultar la aplicación de los nanofluidos en la industria. Los nanofluidos puede producirse por métodos de una o dos etapas, sin embargo, ambos métodos requieren de equipos avanzados y sofisticados. El coste de producción de las nanopartículas se está reduciendo, pero el posterior proceso de dispersión encarece la producción de los nanofluidos a gran escala. De 
hecho, apenas se han encontrado muy pocos artículos en los que se estime la viabilidad económica de los mismos [114 y 116]

Debido al elevado coste actualmente sólo se pueden aplicar en aquellos sitios que se necesite poco volumen y elevada transferencia de calor, y que el sistema sea tan pequeño que no pueda optimizarse la transferencia mediante el área.

\section{f) Dificultades en el proceso de producción}

Como ya se ha comentado anteriormente, para producir nanofluidos existen el proceso de una única etapa (donde se produce la nanopartícula y esta queda dispersa ya en el fluido base) y el proceso de dos etapas (generación de nanopartículas y posterior dispersión en el fluido base). Debido a la tendencia de las nanopartículas a aglomerarse en partículas más grandes, que limita los beneficios de las nanopartículas de alta superficie, se añaden en ambos procesos aditivos para ayudar a la dispersión de partículas Desafortunadamente, esta práctica puede cambiar las propiedades superficiales de las partículas, y los nanofluidos obtenidos pueden contener niveles inaceptables de impurezas $[12,14,31,111]$.

Además, la mayoría de los estudios hasta la fecha se han limitado al tamaño de las muestras de nanofluidos de unos pocos cientos de mililitros. Esto es problemático, ya que se necesitan muestras más grandes para analizar innumerables propiedades y para ver la escalabilidad del proceso. Hoy en día todavía no se conocen productos comerciales de nanofluidos aplicables como fluidos térmicos, de hecho, en el proyecto europeo NANOUPTAKE (Nanouptake Overcoming Barriers to Nanofluids Market Uptake (COST Action CA15119)) se están analizando las posibles barreras que dificultan la llegada de los nanofluidos al mercado.

\section{g) Ensuciamiento, erosión y corrosión}

Cuando los nanofluidos se han aplicado como fluidos térmicos en bucles experimentales y se ha obtenido la transferencia de calor en ebullición, se ha observado que dichos nanofluidos causaron incrustaciones en las paredes, reduciéndose finalmente los coeficientes de transferencia de calor [14]. Además de generar incrustaciones a altas temperaturas, las nanopartículas como ya se ha comentado, pueden aglomerarse y sedimentar si dichos aglomerados alcanzan un tamaño considerable, modificándose finalmente las propiedades del nanofluido. Por lo que también será necesario profundizar en la erosión o corrosión que 
los sedimentos de los nanofluidos pueden ocasionar sobre los conductos de los intercambiadores donde se utilizan [112], sobre todo cuando se trabaja a pH muy ácidos o básicos. 



\section{CAPÍTULO II}

Objetivo y Plan de Trabajo 



\section{Objetivo}

Con la realización del presente trabajo de investigación se pretende alcanzar un mejor y más exhaustivo conocimiento sobre la dispersión de nanopartículas en medio acuoso para obtener nanofluidos térmicos, determinándose aquellas variables del proceso de preparación sobre las cuales es posible actuar para mejorar los valores de las propiedades térmicas de este tipo de materiales.

El objetivo global de este estudio es conseguir un nanofluido estable que conlleve un aumento significativo en conductividad térmica respecto al fluido base utilizado, que ha sido agua destilada. Además, este nanofluido tiene que ser viable técnica y económicamente, es decir, debe cumplir unos requisitos térmicos mínimos para poder utilizarse como fluido en intercambiadores tales como no presentar una viscosidad elevada, no ser corrosivo, ser amigable con el medio ambiente y ser económicamente viable.

Para alcanzar este objetivo global resultará imprescindible alcanzar los siguientes objetivos específicos:

- Objetivo 1 Mejorar la dispersión en base acuosa de las nanopartículas elegidas para la preparación de los nanofluidos.

Para que el nanofluido térmico presente aumentos en la conductividad térmica respecto al fluido base resulta imprescindible que las nanopartículas puedan presentar un movimiento browniano, el cual tan sólo se da cuando las nanopartículas se encuentran perfectamente dispersas en el fluido base y no tiendan a formar aglomerados. Para lograr una buena dispersión de las nanopartículas en agua se estudiarán distintas metodologías:

- Ruta química para modificar las propiedades superficiales de las nanopartículas

- Adición de surfactantes a los nanofluidos

- Estabilización con $\mathrm{pH}$ determinando previamente el punto isoeléctrico de los nanofluidos

- Funcionalización con tratamiento químico ácido o básico 
- Ruta mecánica para la dispersión de las nanopartículas tratadas químicamente
- Agitación
o Homogeneización
- Sonicación con sonda de ultrasonidos

- Objetivo 2 Establecer la metodología correcta para la caracterización de la estabilidad de los nanofluidos para todos los tipos de suspensiones preparadas, definiendo el método más correcto en función de la naturaleza de la nanopartícula dispersa y la fracción volumétrica de la misma en el nanofluido.

- Objetivo 3 Reducir aquellos factores que afectan al método de medida de la conductividad térmica de los nanofluidos.Como ya se ha comentado anteriormente existen discrepancias entre los resultados medidos de conductividad térmica por diversos autores, muy posiblemente debido al método de medida.

- Objetivo 4 Realizar un análisis de las variables de proceso e intrínsecas a los materiales con las que se consigue un aumento de conductividad térmica en los nanofluidos preparados con el objetivo de definir un proceso viable para la preparación del nanofluido.

- Objetivo 5 Realizar un estudio de viabilidad económica y de aplicación a escala de laboratorio con aquellos nanofluidos con los que se haya conseguido un aumento en conductividad térmica óptimo.

- Objetivo 6 Establecer una correlación adimensional que permita evaluar la eficacia del nanofluido teniendo en cuenta el aumento en conductividad térmica y en viscosidad.

- Objetivo 7 Mediante el análisis de modelización ver qué mecanismo de transferencia es el predominante en los nanofluidos preparados en función del tipo de material utilizado con el objetivo de una posterior optimización del nanofluido. 


\section{Plan de trabajo y estructura de la tesis}

De la fase de revisión bibliográfica previa al inicio del trabajo, se concluyó que hay una gran dispersión y heterogeneidad en los resultados de incremento en conductividad térmica obtenidos tras la adición de nanopartículas a un fluido base. Además, los resultados que presentan la mayoría de los artículos no van acompañados de errores, lo cual no permite intercomparar los estudios realizados. Esta disparidad de resultados impuso realizar un estudio exhaustivo de las distintas metodologías aplicadas tanto en la preparación de los nanofluidos como en su caracterización.

De acuerdo con estas premisas, se planificó desarrollar el siguiente plan de trabajo:

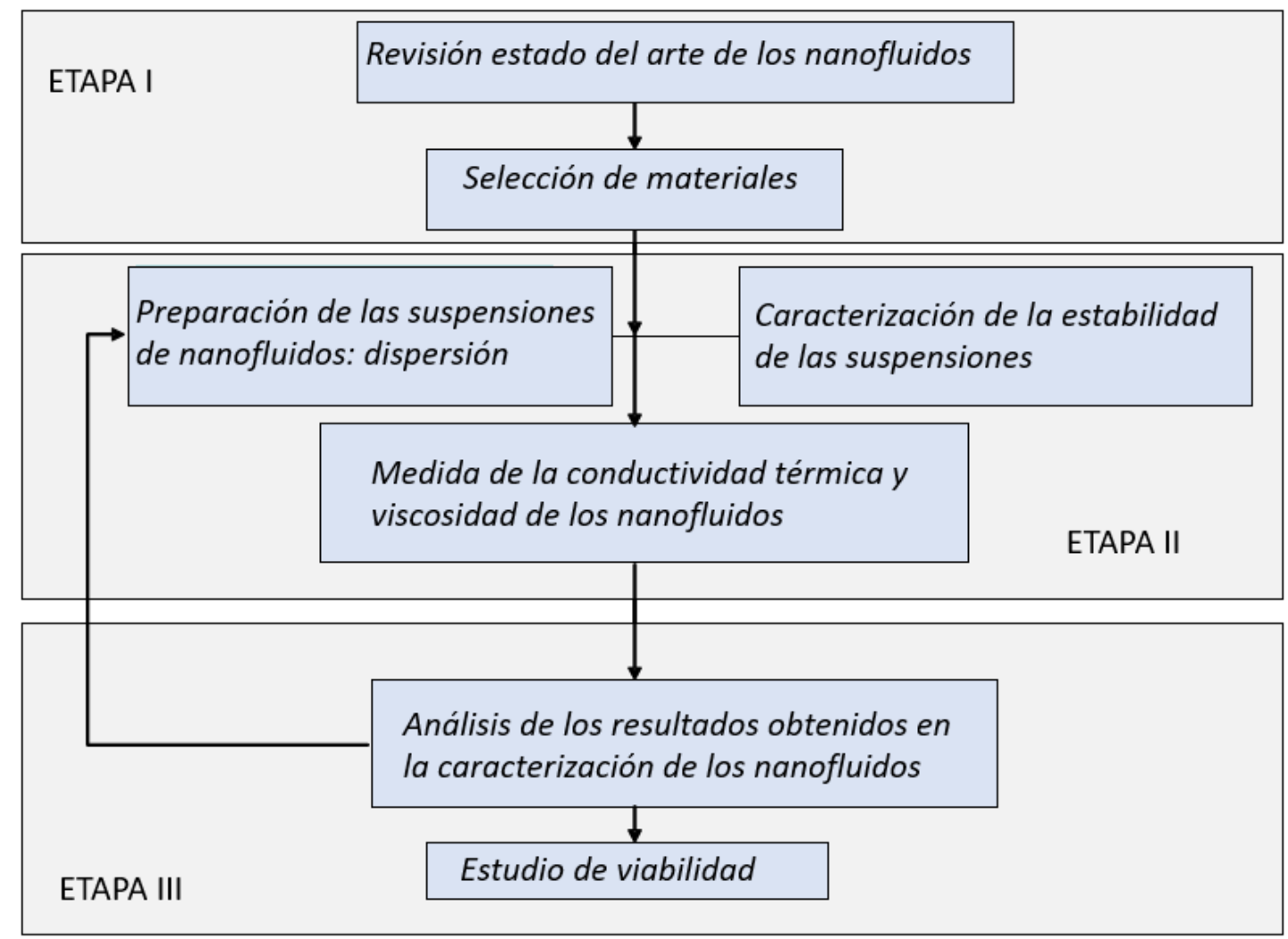

Figura 9. Mapa conceptual de las etapas de trabajo realizadas en el desarrollo del estudio de dispersión 


\section{Revisión estado del arte y selección de materiales}

Se ha realizado una selección de materiales en base a las variables de estudio que pueden afectar a la conductividad térmica de los nanofluidos, como tamaño y forma de la nanopartícula o composición. Se han adquirido tanto nanopartículas comerciales como suspensiones acuosas con nanopartículas ya preparadas.

La naturaleza de las nanopartículas con las que se ha realizado el estudio ha sido la siguiente:

- $\quad$ Óxidos cerámicos (sílice y alúmina)

- $\quad$ Óxidos metálicos (óxido de cobre)

- Nanopartículas en base carbono (nanotubos y nanopartículas de grafeno)

\section{Preparación y caracterización de los nanofluidos}

\section{a) Preparación de las suspensiones}

Definidos los materiales a utilizar en la preparación de los nanofluidos, se ha procedido a la preparación de los mismos, realizándose un análisis comparativo de las distintas técnicas de dispersión que se vienen aplicando hasta la actualidad en la obtención de nanofluidos. EI estudio de las distintas técnicas (baño de ultrasonidos, homogeneizador y sonda de ultrasonidos) va a permitir establecer las ventajas y desventajas de cada uno de los métodos y la viabilidad para su aplicación con cada uno de los tipos de nanopartículas.

b) Selección de las técnicas de caracterización de la estabilidad y el grado de dispersión

En esta fase del trabajo, previa al estudio de aplicabilidad térmica del nanofluido, se ha procedido a establecer la metodología correcta para la caracterización de los materiales suministrados y las suspensiones preparadas a partir de ellos. Para ello, tras una exhaustiva revisión bibliográfica, se han llevado a cabo pruebas con las distintas técnicas más utilizadas en la caracterización de los nanofluidos, profundizando especialmente en la medida de la estabilidad.

c) Medida de la conductividad térmica y la viscosidad de los nanofluidos

El estudio de dispersión se ha completado con la caracterización de los nanofluidos para su aplicación como fluido térmico. Para ello resulta imprescindible medir la conductividad térmica de los mismos a distintas temperaturas y su viscosidad a distintos gradientes de 
velocidad. Además de obtener los valores de conductividad y viscosidad, uno de los objetivos ha sido analizar la influencia que tienen algunas variables sobre los resultados en incrementos de conductividad térmica obtenidos en los nanofluidos. Las principales variables sometidas a análisis han sido:

- método de dispersión

- fracción volumétrica de nanopartículas

- temperatura

- tipo de material

- tamaño de las nanopartículas

- método de modificación superficial de las nanopartículas (funcionalización covalente o no covalente)

- $\quad \mathrm{pH}$ de la suspensión con nanopartículas

\section{Análisis de resultados}

Se ha realizado un estudio de modelización con cada uno de los materiales a partir de los modelos teóricos y empíricos encontrados en la bibliografía consultada, con el objetivo de determinar que mecanismo de transferencia es el responsable del aumento en conductividad obtenido con los nanofluidos. Si se identifican los mecanismos predominantes se podrá optimizar el nanofluido para su posterior aplicación comercial, diseñando aquellas variables que mejoren su aplicación como fluido térmico.

\section{Estudio de viabilidad}

El estudio de la dispersión de las nanopartículas se ha completado con un estudio de la aplicación real de los nanofluidos, para lo cual se han preparado a mayor escala los nanofluidos de laboratorio con los que se han obtenido resultados óptimos. Para proceder a dicho estudio de viabilidad, se han realizado pruebas de transferencia de calor en un bucle diseñado especialmente a escala de laboratorio, con el objetivo de constatar que los aumentos en conductividad térmica conllevan el correspondiente aumento en el coeficiente de transferencia de calor. Este estudio técnico se acompañará de un estudio económico. 


\section{Estructura}

El plan de trabajo descrito se ha recogido en la tesis siguiendo la estructura resumida a continuación:

- En el primer capítulo, visto anteriormente, se ha incluido la introducción de la tesis recogiéndose una visión general de los últimos avances de los nanofluidos y de aquellas variables y métodos que influyen en su aplicación como fluidos térmicos y su estabilidad. Esta revisión bibliográfica permitirá conocer el estado actual del tema de esta tesis.

- $\quad$ En este segundo capítulo se recogen los objetivos de la investigación, el alcance y plan de trabajo seguido.

- En el tercer capítulo se presentan las metodologías utilizadas para la consecución de los objetivos propuestos, describiéndose las principales técnicas de caracterización utilizadas para el desarrollo de las mismas.

- En el cuarto capítulo se presentan los resultados alcanzados en los ensayos experimentales llevados a cabo y el análisis de los mismos. Dichos resultados se han dividido en tres grandes bloques, englobando así las diferentes tipologías de nanopartículas utilizadas en la preparación de los nanofluidos: óxidos, nanotubos de carbono y grafeno.

- En el capítulo quinto se muestran las conclusiones generales obtenidas con cada uno de los nanofluidos a partir de la realización del presente trabajo. En este capítulo se resumen también las futuras líneas de investigación recomendadas para completar los resultados obtenidos.

- Se ha incluido un apartado con las diferentes publicaciones de artículos y conferencias o posters a congresos relacionadas con el trabajo presentado.

- $\quad$ Se ha creído conveniente añadir dos apartados adicionales con el fin de simplificar la lectura de la memoria de la tesis, dedicados a glosario de términos y acrónimos y anexos.

- $\quad$ Finalmente, en los anexos se especificará la bibliografía citada en los diferentes capítulos del presente trabajo. 


\section{CAPÍTULO III}

Materiales y metodología experimental 



\section{Materiales utilizados en la preparación de los nanofluidos}

Las distintas nanopartículas utilizadas para la preparación de nanofluidos según la bibliografía consultada se agrupan en función de su naturaleza en:

- $\quad$ Metales: oro, plata, cobre

- $\quad$ Óxidos de metales: óxidos de cobre, oxido de titanio

- $\quad$ Óxidos cerámicos: sílice y alúmina

- $\quad$ Carbono: grafito, nanotubos de carbono, grafeno

El trabajo de investigación desarrollado se ha centrado en el estudio de dispersión de nanopartículas en base acuosa (agua destilada), preparándose nanofluidos a partir de varios tipos de nanopartículas con el objetivo de estudiar la influencia de las siguientes variables sobre las propiedades termofísicas de los nanofluidos:

- Naturaleza de las nanopartículas (óxidos metálicos, cerámicos y en base carbono)

- Tamaño de las nanopartículas

- $\quad$ Forma de las nanopartículas (esféricas o cilíndricas)

- $\quad$ Forma de distribución comercial (en polvo o en suspensión acuosa)

- Partículas modificadas superficialmente

Una cuidada selección de materiales y su caracterización inicial es crucial para la preparación de los nanofluidos, sobre todo para alcanzar una buena dispersión que garantice la estabilidad de los mismos. Dependiendo del método de síntesis utilizado para la obtención de las nanopartículas o fluidos comerciales, las partículas contienen más o menos impurezas y aunque el tamaño de las partículas según el fabricante sea nanométrico estas se sirven en forma de agregados en algunos casos con un tamaño del orden de los micrómetros, los cuales pueden presentar problemas en la dispersión debido a su resistencia a la rotura.

En el presente estudio se han seleccionado distintos óxidos: alúmina y sílice con un tamaño de unos $10 \mathrm{~nm}$ por su forma esférica y el óxido de cobre con un tamaño de partícula de 30 $\mathrm{nm}$. Como nanopartículas con elevada conductividad térmica y geometría no esférica se han seleccionado los nanotubos de carbono (de pared simple, SWCNTs (single wall carbon 
nanotubes) y de pared múltiple, MWCNTs (multiple wall carbon nanotubes)) y nanopartículas de grafeno.

A continuación, se resumen las propiedades de los distintos materiales utilizados en la preparación de los nanofluidos junto a las propiedades de los surfactantes empleados para mejorar la dispersión y estabilidad de las suspensiones acuosas preparadas a partir de las nanopartículas.

\subsection{Nanopartículas de Sílice}

Las nanopartículas de sílice utilizadas en el estudio, Aerosil 200, se han adquirido en la empresa Degussa, Evonik industries. El material en polvo se compone de nanopartículas de sílice pirogénica hidrófilas con unidades primarias de $\mathbf{1 2} \mathbf{n m}$ y una superficie específica de 200 $\mathrm{m}^{2} / \mathrm{g}$ según el fabricante.

La suspensión de sílice comercial adquirida para la preparación de los nanofluidos a partir de su dilución, fue Ludox TM- 50 suministrado por Sigma - Aldrich. En este nanofluido según el fabricante, las partículas primarias tienen un diámetro de $10 \mathrm{~nm}$ y una superficie específica de $140 \mathrm{~m}^{2} / \mathrm{g}$. Las sílices coloidales LUDOX $^{\circledR}$ son aproximadamente esféricas, no porosas y dispersas en agua. Tienen un núcleo de sílice densa y una superficie recubierta por grupos silanol (Si-OH).

En la Tabla 6 se muestra un resumen de las principales características de ambos materiales de sílice adquiridos y utilizados en el estudio proporcionadas por el suministrador.

Tabla 6. Resumen de las propiedades de las nanopartículas de Sílice según suministrador

\begin{tabular}{lll}
\hline Propiedad & $\mathrm{SiO}_{2}$ en polvo & $\mathrm{SiO}_{2}$ en suspensión acuosa \\
\hline Nombre comercial & AEROSIL 200 & LUDOX TM-50 \\
Fabricante & Aerosil, Degussa & Sigma-Aldrich \\
Diámetro partícula $(\mathrm{nm})$ & 12 & 10 \\
Pureza (\%) & 99,8 & 50 \\
Área superficial $\left(\mathrm{m}^{2} / \mathrm{g}\right)$ & 200 & 140 \\
Densidad real $\left(\mathrm{kg} / \mathrm{m}^{3}\right)$ & 2200 & 1400 a $25^{\circ} \mathrm{C}$ \\
Contenido en sólidos $(\%)$ & - & 50
\end{tabular}




\subsection{Nanopartículas de Alúmina}

Las nanopartículas de alúmina fueron suministradas por la empresa Degussa (Aeroxide Alu C) con un tamaño primario de partícula de $13 \mathrm{~nm}$, según el fabricante.

La suspensión comercial utilizada para la dilución y preparación de los nanofluidos de alúmina fue AERODISP W925 suministrado también por la empresa Degussa. El tamaño de las nanopartículas que forman la suspensión fue de $11 \mathbf{n m}$ según el fabricante.

En la Tabla 7 se muestra un resumen de las principales características, según el suministrador, de los materiales de alúmina adquiridos y utilizados en el estudio.

Tabla 7. Resumen de las propiedades de las nanopartículas de alúmina según suministrador

\begin{tabular}{lll}
\hline Propiedad & $\mathrm{Al}_{2} \mathrm{O}_{3}$ en polvo & $\mathrm{Al}_{2} \mathrm{O}_{3}$ en suspensión acuosa \\
\hline Nombre comercial & Aeroxide R Alu C & Aerodisp W 925 \\
Fabricante & Aerosil, Degussa. & Aerosil, Degussa. \\
Diámetro partícula $(\mathrm{nm})$ & 13 & 11 \\
Diámetro aglomerado, $\mathrm{d}_{50,}(\mathrm{~nm})$ & 128 & 127 \\
Pureza $(\%)$ & 99,60 & - \\
Área superficial $\left(\mathrm{m}^{2} / \mathrm{g}\right)$ & $100 \pm 15$ & - \\
Densidad real $\left(\mathrm{kg} / \mathrm{m}^{3}\right)$ & 3961 & 1200 \\
pH & 0 & $3-5$ \\
Contenido en sólidos $(\%)$ & - & $25 \pm 1,0$ \\
\hline
\end{tabular}

\subsection{Nanopartículas de óxido de cobre}

Las nanopartículas de óxido de cobre (II) (con una pureza del 99\%) se adquirieron a la empresa Nanoestructured \& Amorphous Materials, Inc. Estas nanopartículas presentan un tamaño inicial entre $30-50 \mathrm{~nm}$. En la Tabla 8 se presentan las principales características de las nanopartículas de este material según el fabricante. 
Tabla 8. Resumen de las propiedades de las nanopartículas óxido de Cobre II según suministrador

\begin{tabular}{ll}
\hline Propiedad & Óxido de cobre (II) \\
\hline Diámetro $(\mathrm{nm})$ & $30-50$ \\
Pureza (\%) & 99 \\
Área superficial $\left(\mathrm{m}^{2} / \mathrm{g}\right)$ & 13,1 \\
Densidad real $\left(\mathrm{kg} / \mathrm{m}^{3}\right)$ & $6300-6490$ \\
\hline
\end{tabular}

\subsection{Nanotubos de carbono (CNTs)}

Fundamentalmente existen dos tipos principales de nanotubos de carbono (carbon nanotubes, CNTs) en función del número de capas de grafito, los nanotubos de pared única (single wall carbon nanotubes, SWCNT) y los de pared múltiple donde las capas de grafito están enrolladas sobre ellas mismas (multiple wall carbon nanotubes, MWCNT), como se muestra en la Figura 10.

a)

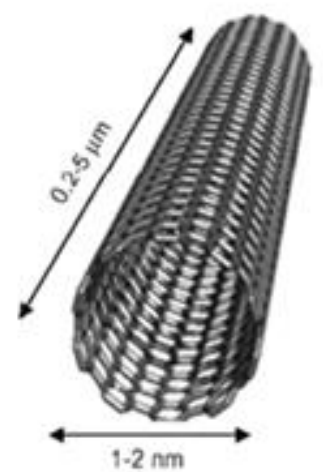

Figura 10 Geometría estándar SWCNT(a) y MWCNTs (b).

Fuente [ Rafael Daza, Departamento ciencias de los materiales. UPM]

Para el presente estudio se han utilizado ambos tipos de materiales, (SWCNTs y MWCNTs) que han sido adquiridos en polvo y como suspensión comercial en base acuosa ya preparada.

En la Tabla 9 se resumen las principales propiedades, según el fabricante, de los materiales tipo SWCNTs adquiridos para el estudio. 
Tabla 9. Resumen de las propiedades de los nanotubos de pared única SWCNTs según suministrador

\begin{tabular}{ll}
\hline Propiedad & SWCNTs Largos \\
\hline Nombre comercial & - \\
Fabricante & Nanostructured \& amorphous Materials INC. \\
Diámetro $(\mathrm{nm})$ & $1-2$ \\
Longitud $(\mu \mathrm{m})$ & $5-30$ \\
Pureza $(\%)$ & con un $90 \%$ pureza en CNTs \\
Tamaño aglomerado medio $(\mu \mathrm{m})$ & 193 \\
Área superficial $\left(\mathrm{m}^{2} / \mathrm{g}\right)$ & $360-400$ \\
Densidad real $\left(\mathrm{kg} / \mathrm{m}^{3}\right)$ & 2100 \\
$-\mathrm{COOH}(\%)$ & 0 \\
wt $(\%)$ & - \\
\hline
\end{tabular}

Los nanotubos de carbono comerciales adquiridos de pared múltiple se han obtenido industrialmente por el método de deposición catalítica en fase vapor. Tienen una pureza del 90\% y se clasifican como nanotubos de carbono de paredes múltiples (MWCNT). Los nanotubos fueron adquiridos a la empresa Nanocyl S.A. y están referenciados como NC7000 A. En la Tabla 10 se resumen sus principales propiedades. Estos MWCNTs se referenciarán como "MWCNTs cortos".

La suspensión comercial adquirida se trata de una suspensión de los mismos MWCNTs cortos nanocyl $7000 \mathrm{~A}$ adquiridos, dispersos en base acuosa al 3\% en peso y con un surfactante (no definido). El nombre comercial de esta suspensión es Aquacyl 0301.

También se han utilizado en este estudio unos nanotubos MWCNTs funcionalizados-COOH, adquiridos a la empresa Nanoamor y que también pueden considerarse por su longitud como cortos. De esta forma se ha pretendido analizar el efecto de la funcionalización en laboratorio con la funcionalización comercial al compararse entre ellos. Estos MWCNTs se referenciarán como "MWCNTs cortos funcionalizados comercial". 
Tabla 10. Resumen de las propiedades de los nanotubos de carbono MWCNTs según suministrador

\begin{tabular}{|c|c|c|c|c|}
\hline Propiedad & $\begin{array}{l}\text { MWCNTs } \\
\text { cortos }\end{array}$ & $\begin{array}{l}\text { MWCNTs-COOH } \\
\text { funcionalizados }\end{array}$ & $\begin{array}{l}\text { MWCNTS } \\
\text { Cortos en } \\
\text { suspensión }\end{array}$ & $\begin{array}{l}\text { MWCNTS } \\
\text { Largos }\end{array}$ \\
\hline Nombre comercial & $\begin{array}{l}\text { Nanocyl } \\
\text { NC7000A }\end{array}$ & $\begin{array}{l}\text { Nanoamor- } \\
\text { funcionalizados } \\
\text { comercial }\end{array}$ & $\begin{array}{c}\text { Aquacyl } \\
0301\end{array}$ & $\begin{array}{l}\text { MWCNTs }(10-30 \\
\text { micras) }\end{array}$ \\
\hline Fabricante & Nanocyl & $\begin{array}{l}\text { Nanostructured } \\
\& \quad \text { amorphous } \\
\text { Materials INC. }\end{array}$ & Nanocyl & $\begin{array}{l}\text { Nanostructured } \\
\& \quad \text { amorphous } \\
\text { Materials INC. }\end{array}$ \\
\hline Diámetro (nm) & 9,5 & $\begin{array}{l}(3-5) \text { interno } \\
(8-15) \text { externo }\end{array}$ & 9,5 & $\begin{array}{l}(5-10) \text { interno } \\
(20-30) \text { externo }\end{array}$ \\
\hline Longitud ( $\mu \mathrm{m})$ & 1,5 & $0,5-2$ & 1,5 & $10-30$ \\
\hline $\begin{array}{l}\text { Tamaño aglomerado } \\
(\mu \mathrm{m})\end{array}$ & 123 & 27 & - & 89 \\
\hline Pureza (\%) & 90 & 95 & 90 & 95 \\
\hline Área superficial $\left(\mathrm{m}^{2} / \mathrm{g}\right)$ & $250-300$ & 233 & $250-300$ & $110-130$ \\
\hline Densidad real $\left(\mathrm{Kg} / \mathrm{m}^{3}\right)$ & $1800-2300$ & - & $1800-2300$ & 2100 \\
\hline$-\mathrm{COOH}(\%)^{*}$ & 0 & 2,5 & 0 & 0 \\
\hline $\begin{array}{l}\text { Contenido en sólidos } \\
\text { (\%) }\end{array}$ & - & - & 3 & - \\
\hline
\end{tabular}

(*) grupos funcionales introducidos

Finalmente, también se han adquirido MWCNTs más largos, con una longitud comprendida entre 10 y $30 \mu \mathrm{m}$, con objeto de analizar el efecto que esta característica geométrica tiene sobre el comportamiento posterior del nanofluido. 


\subsection{Nanopartículas de Grafeno (GFN)}

Las nano-escamas de grafeno son estrechas partículas laminares formando capas de diámetros entre 1-50 $\mu \mathrm{m}$ y con un espesor entre 1-20nm. Se sirven aglomeradas y para alcanzar sus propiedades óptimas deben dispersarse correctamente. Estas partículas de grafeno se han obtenido por métodos no oxidantes, por lo que tienen una superficie de grafito prístina de átomos de carbono con configuración electrónica $\mathrm{sp}^{2}$ que las hace especialmente adecuadas para aplicaciones que requieren una alta conductividad térmica.

Para el estudio se han utilizado dos tipos de grafeno con distinta superficie específica, el GNP750 y el GNP -300 , en la Tabla 11 se resumen las principales características de ambos materiales.

Tabla 11. Resumen de las propiedades de las nanopartículas de Grafeno según suministrador

\begin{tabular}{lll}
\hline Propiedad & $\begin{array}{l}\text { Grafeno de alta superficie } \\
\text { específica }\end{array}$ & $\begin{array}{l}\text { Grafeno de baja superficie } \\
\text { específica }\end{array}$ \\
\hline Nombre comercial & XGnP-C-750 & XGnP-C-300 \\
Fabricante & $1-5$ & XG sciences \\
Espesor $(\mathrm{nm})$ & $1-2$ & $1-5$ \\
Diámetros $(\mu \mathrm{m})$ & 24 & $1-2$ \\
Tamaño aglomerado medio $(\mu \mathrm{m})$ & 100 & 19 \\
Pureza $(\%)$ & 750 & 100 \\
Área superficial $\left(\mathrm{m}^{2} / \mathrm{g}\right)$ & 2200 & 300 \\
Densidad real $\left(\mathrm{kg} / \mathrm{m}^{3}\right)$ & & 2200 \\
\hline
\end{tabular}

\subsection{Surfactantes}

Se han utilizado diferentes tipos de surfactantes, también llamados dispersantes, para la suspensión de las nanopartículas de distinta naturaleza en agua. Los surfactantes afectan a la superficie de la partícula modificando su comportamiento en la interacción con el medio acuoso. Los dispersantes o surfactantes están formados por una parte hidrofóbica 
(normalmente una cadena larga de hidrocarbonos) y una parte polar hidrofílica o soluble en agua. Los surfactantes se dividen en cuatro clases según su estructura molecular:

- Aniónicos. Como cada agente tensioactivo, los tensioactivos aniónicos están formados por una parte polar y una parte no polar. La parte hidrofílica, parte polar de la molécula del tensioactivo posee una carga negativa. Ésta suele tratarse de un grupo carboxilato $\left(-\mathrm{COO}^{-}\right)$, sulfato $\left(\mathrm{SO}_{4}{ }^{2-}\right)$, sulfonato $\left(\mathrm{SO}^{3-}\right)$ o fosfato $\left(\mathrm{PO}_{4}^{3-}\right)$. La parte no polar son grupos alquilo diferentes.

- Catiónicos. La parte hidrofílica de estos tensioactivos posee una carga positiva. Estos tensoactivos suelen tener una alta adherencia en diferentes sustratos y una alta "persistencia" en esa adhesión. Un hecho experimental que caracteriza a estos compuestos es que cambia las propiedades superficiales y convierte una superficie hidrofílica en hidrofóbica y viceversa.

- No-iónicos. Por definición, los tensioactivos no iónicos son tensioactivos que no contienen grupos funcionales disociables (ionizables) y, por lo tanto, no se disocian en el agua en iones. Como todo tensioactivo, se compone de una parte no-polar y una parte polar. La parte no polar es principalmente una cadena alifática (de entre C12-C18), aunque hay tensioactivos no iónicos no alifáticos. Los grupos polares suelen ser un grupo alcohol o éter, como el óxido de polietileno. Se caracterizan por el número HLB (acrónimo inglés de Hydrophilic-Lipophilic Balance), siendo más soluble el surfactante en agua cuando más alto es el número HLB.

- Anfóteros. Por definición, son tensoactivos que poseen tanto un grupo catiónico como un grupo aniónico. El uso del término anfótero lo hace más restrictivo: la carga de la molécula cambia con el pH.

La selección del surfactante depende del solvente, si este es polar, como en nuestro caso de estudio, se eligen surfactantes solubles en agua. A continuación, en la

Tabla 12 se describen las propiedades de los surfactantes utilizados en el presente estudio. 
Tabla 12. Resumen de las propiedades de los surfactantes utilizados en el estudio según suministrador

\begin{tabular}{|c|c|c|c|c|}
\hline Propiedad & SDS & CTAB & GA & TRITONX100 \\
\hline Nombre & $\begin{array}{l}\text { dodecilsulfato } \\
\text { sódico }\end{array}$ & $\begin{array}{l}\text { Bromuro de } \\
\text { cetiltrimetilamonio }\end{array}$ & $\begin{array}{l}\text { Goma arábiga } \\
\text { Polisacárido } \\
\text { natural }\end{array}$ & $\begin{array}{l}\text { Triton }^{\mathrm{TM}} \mathrm{X}-100 \\
\text { polioxietilen octil fenil } \\
\text { eter }\end{array}$ \\
\hline Tipo & aniónico & catiónico & No-iónico & No- iónico \\
\hline \multirow[t]{2}{*}{ Fabricante } & Sigma-Aldrich & Sigma-Aldrich Química & Sigma-Aldrich & Sigma-Aldrich Química \\
\hline & Química SA & SA & Química SA & SA \\
\hline Formula & $\mathrm{C}_{12} \mathrm{H}_{25} \mathrm{NaO}_{4} \mathrm{~S}$ & $\mathrm{CH}_{3}\left(\mathrm{CH}_{2}\right)_{15} \mathrm{~N}(\mathrm{Br})\left(\mathrm{CH}_{3}\right)_{3}$ & $\mathrm{C}_{16} \mathrm{H}_{26} \mathrm{O}_{3}$ & $\left(\mathrm{C}_{2} \mathrm{H}_{4} \mathrm{O}\right)_{n} \mathrm{C}_{14} \mathrm{H}_{22} \mathrm{O}$ \\
\hline PM (g/mol) & 288,38 & 364,45 & 266,38 & 647 \\
\hline
\end{tabular}

\section{Preparación de los nanofluidos: dispersión de nanopartículas en base acuosa}

Como ya se ha comentado en la introducción, la técnica seleccionada en este estudio para la preparación de las suspensiones de nanofluidos es la denominada en ingles "Two-step technique" que consta de dos etapas. En esta técnica las nanopartículas en polvo comerciales adquiridas se dispersan en el fluido base en una segunda etapa [6]. Debido a la alta carga superficial de las mismas, las nanopartículas tienden a aglomerarse, por lo cual resulta necesario aplicar una agitación mecánica considerable o ultrasonidos para alcanzar así la total dispersión. Debido a la complejidad que conlleva la dispersión total de las nanopartículas ya sintetizadas, resulta necesario preparar nanofluidos con una fracción volumétrica más elevada para lograr un aumento en conductividad térmica significativo. La preparación de nanofluidos a mayor fracción implica un aumento en viscosidad en el nanofluido, mayor interacción entre las nanopartículas y un mayor coste [29 y 125].

Cuando las suspensiones de nanofluidos se obtienen en una única etapa, etapa de síntesis de las nanopartículas, las partículas en suspensión están más individualizadas, mejor dispersas pues no se han aglomerado en etapas posteriores de secado, pero esta técnica es la menos utilizada. Los investigadores prefieren la técnica en dos etapas [57], por ser la opción más 
indicada para su posterior aplicación industrial ya que la síntesis de nanopartículas en suspensión no se produce actualmente a gran escala.

El objetivo a tener en cuenta en el diseño y/o elección del sistema de dispersión mecánico se va a centrar en mejorar el grado de dispersión. El grado de dispersión alcanzado es función de la afinidad de las nanopartículas con el fluido base, por lo que se obtienen mejores resultados en base acuosa con nanofluidos preparados a partir de óxidos que con nanotubos de carbono por su carácter hidrofóbico [111]. La dispersión y estabilidad del nanofluido depende por tanto de la naturaleza del fluido base y de las nanopartículas.

La preparación de un nanofluido estable en el tiempo en el cual se evite la aglomeración y posterior sedimentación de las nanopartículas es un requisito indispensable para conseguir propiedades térmicas óptimas, por lo que se requiere el uso de técnicas que una vez bien dispersadas las nanopartículas impidan dicha aglomeración, como es el caso del uso de surfactantes.

En una suspensión en estado estacionario, la velocidad de sedimentación de partículas esféricas en el fluido base sigue la ley de Stokes:

$$
v_{S}=\frac{2}{9} \frac{r^{2} g\left(\rho_{p}-\rho_{f}\right)}{\eta}
$$

Donde $\mathrm{v}_{\mathrm{s}}$ es la velocidad de sedimentación de las partículas (velocidad límite, $\mathrm{m} / \mathrm{s}$ ).

$r$ es el radio equivalente de la partícula $(\mathrm{m})$

$\eta$ es la viscosidad dinámica media del líquido ( $\mathrm{kg} / \mathrm{ms})$

$\rho_{p}$ y $\rho_{f}$ es la densidad de la partícula sólida y la del fluido $\left(\mathrm{kg} / \mathrm{m}^{3}\right)$

g es la aceleración de la gravedad $\left(\mathrm{m} / \mathrm{s}^{2}\right)$

Esta ecuación establece un balance entre las fuerzas de gravedad y la resistencia ocasionada por la viscosidad del medio que actúan sobre las partículas, y de cuyo resultado va a depender que las partículas permanezcan suspendidas o sedimenten. Para evitar la sedimentación de las nanopartículas y por tanto mejorar la estabilidad de los nanofluidos, se pueden adoptar las siguientes pautas: 
- Reducir el tamaño de los aglomerados mediante dispersión para conseguir alcanzar tamaños nanométricos donde el movimiento browniano de las nanopartículas impide su sedimentación. Sin embargo, a menor tamaño mayor superficie específica, por lo cual se incrementa junto con dicho movimiento browniano la posibilidad de contacto entre partículas y posterior agregación debido a las fuerzas de Vander Waals.

- Aumentar la viscosidad del fluido base.

- Disminuir la diferencia de densidad entre las nanopartículas y el fluido base.

La primera de estas tres posibilidades es la más interesante, pues la viscosidad del fluido base es constante o incluso disminuirá a medida que se aumente la temperatura del fluido, con lo que van a aparecer más problemas de sedimentación al aumentar la temperatura. En cuanto a la diferencia de densidad, al tratarse de partículas sólidas va a ser bastante elevada (densidades mayores de $2000 \mathrm{~kg} / \mathrm{cm}^{2}$ ) en comparación con la del líquido base.

Aunque existe mucha bibliografía sobre nanofluidos, todavía no se ha estandarizado un método de preparación (mezcla, ultrasonidos, energía aportada, amplitud, tiempo) para alcanzar una suspensión estable y bien dispersada. En la Figura 11 aparece un ejemplo de metodología propuesta en la bibliografía consultada [7].

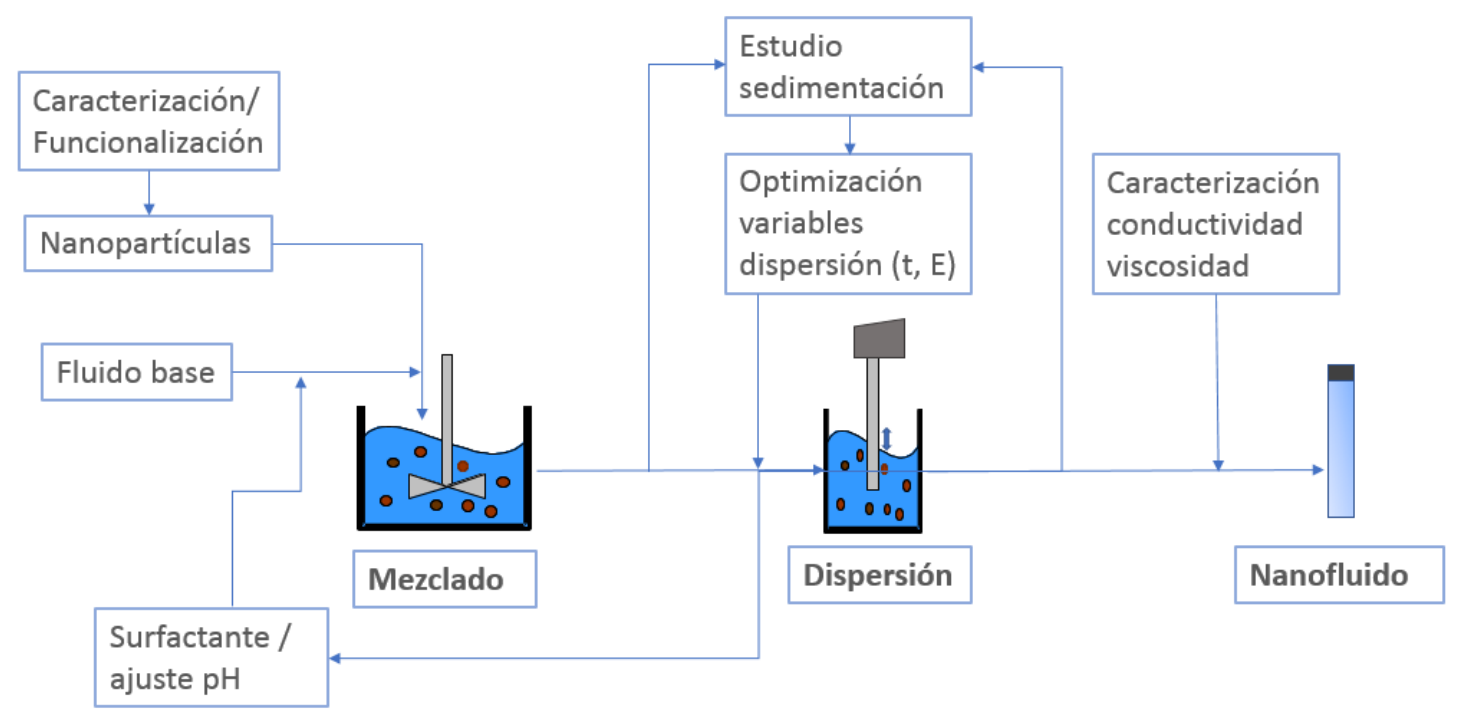

Figura 11. Esquema de preparación de los nanofluidos siguiendo el método de "dos etapas" 
La preparación de nanofluidos en dos etapas, incluye:

- Una primera fase de mezcla del fluido base, las nanopartículas y los surfactantes o ajuste de pH para garantizar la estabilidad tras la dispersión.

- Una segunda fase de dispersión y caracterización de la estabilidad de los nanofluidos preparados, para la optimización del tiempo de sonicación y ajuste de pH en base a los resultados obtenidos.

Finalmente, cuando el nanofluido ya está optimizado se procederá a caracterizar su conductividad térmica.

Una vez preparado el nanofluido tras la dispersión de las nanopartículas, hay que garantizar la estabilidad del mismo para que sea viable su aplicación, y sus características térmicas no se vean modificadas. Un nanofluido estable implica que las nanopartículas sólidas no sedimentan ni se agregan a una velocidad significativa [58]. Las suspensiones coloidales habitualmente pierden su estabilidad al agregarse las partículas por:

- Gelificación: Formación de una red coherente de partículas que ocupan todo el volumen y por acción capilar retienen el líquido.

- Coagulación: Formación de grupos de partículas compactos en los cuales la fracción es mayor que en la suspensión original

- Floculación: Unión de partículas mediante puentes formados por un agente floculante formando una estructura abierta y voluminosa

En el caso de suspensiones de nanopartículas el método predominante por el cual se aglomeran es de tipo coagulación, cuando las partículas se acercan unas a otras por el movimiento browniano y las fuerzas atractivas de Van der Waals las mantienen unidas. El estado de agregación va a influir en la transferencia de calor (según las teorías ya comentadas como movimiento browniano, doble capa, clusters...) y por tanto en el aumento relativo en conductividad térmica que va a experimentar el nanofluido preparado respecto al fluido base [6]. Para cada nanofluido puede existir un estado de agregación que conlleve a un óptimo en aumento de la conductividad térmica, por lo cual va a ser necesario un estudio exhaustivo de las distintas técnicas de dispersión y preparación de los nanofluidos, para así definir el método que aplica a cada tipo de nanofluido. En los siguientes dos apartados se describe los distintos 
tratamientos y técnicas aplicados, conjuntamente o de forma individual, en la preparación de los distintos nanofluidos utilizados en la presente tesis.

\subsection{Tratamiento superficial de las nanopartículas}

La sedimentación de las nanopartículas en los nanofluidos debido a la formación de aglomerados puede evitarse o retrasarse gracias al control del pH y/o a la fracción de iones en el medio. Este método de estabilización recibe el nombre de estabilización electrostática. Otra técnica utilizada para evitar la aglomeración y posterior sedimentación de nanopartículas es la estabilización estérica, en la cual se añade un surfactante para modificar la superficie de las partículas aumentando la distancia efectiva entre partículas. Por último, también se puede modificar la superficie de las partículas mediante la funcionalización. Con este método se modifica la naturaleza hidrofóbica de la nanopartícula pasando a ser hidrófila con lo cual se mejora notablemente su dispersión en agua. A continuación, se describe la metodología seguida para la aplicación de cada uno de los métodos con el objetivo de mejorar la dispersión de las nanopartículas en base acuosa.

\subsubsection{Estabilización estérica}

Como se ha comentado anteriormente, una de las técnicas utilizadas para evitar la aglomeración y posterior sedimentación de nanopartículas es la estabilización estérica, en la cual se añade un tercer componente (habitualmente un surfactante) para modificar la superficie de las partículas. Los surfactantes modifican la superficie de las nanopartículas de naturaleza hidrofóbica, a una superficie hidrófila, previniendo de esta forma la aglomeración de las nanopartículas al dispersarse mejor en medio acuoso [55].

Entre los surfactantes más utilizados en la preparación de nanofluidos podemos citar; el dodecilsulfato de sodio (SDS), el dodecil benzeno sulfonato de sodio (SDBS), el ácido oleico, el bromuro de cetil trimetil amonio (CTAB), el bromuro de dodecil trimetilamonio (DTAB), el octano sódico (SOCT), el polivinil pirroleina (PVP) y la goma arábiga [6]. La elección del surfactante más adecuado es uno de los factores más importantes para alcanzar un buen grado de dispersión de las nanopartículas y una adecuada estabilidad en los nanofluidos. En la elección y aplicación del surfactante hay que tener en cuenta que algunos son termosensibles, por lo que no se pueden aplicar a altas temperaturas $\left(60^{\circ} \mathrm{C}\right)$ [6]. 
La metodología utilizada para la adición del surfactante en el presente estudio ha sido la que se enumera a continuación:

1. Adición del surfactante (\% en peso) al fluido base (agua destilada).

2. Agitación mecánica.

3. Adición de las nanopartículas (\% en volumen)

4. Agitación mecánica.

5. Dispersión enérgica utilizando uno de los tres sistemas: baño de ultrasonidos, homogeneizador o sonda de ultrasonidos.

El estudio de la cantidad óptima de surfactante se ha determinado mediante el análisis de la estabilidad coloidal de las suspensiones preparadas, utilizando para ello diversas técnicas de caracterización como la sedimentación visual, el microscopio electrónico de transmisión (TEM), la dispersión de luz (“Light scattering” con el equipo Turbsican) , y mediante la medición de la conductividad térmica del nanofluido.

\subsubsection{Estabilización electrostática}

Los fenómenos de estabilidad de una suspensión, en la cual las nanopartículas no se agregan y sedimentan rápidamente, van a depender principalmente del equilibrio alcanzado entre dos fuerzas de interacción: las fuerzas de atracción de Van de Waals y las fuerzas de repulsión electrostática. La teoría clásica del DLVO (Derjaguin-Landau-Verwey-Overbeek)) analiza las interacciones en la superficie de las partículas definiéndose el potencial total de interacción (ろ) como la suma de las fuerzas de atracción y las de repulsión [58].

Las fuerzas de Van de Waals son significativas cuando la separación entre partículas es diez veces inferior a su tamaño y este fenómeno se da en los nanofluidos, donde las nanopartículas se acercan debido al movimiento browniano. Esta atracción puede contrarrestarse con las fuerzas repulsivas, las cuales se consiguen cargando superficialmente la nanopartícula. La carga superficial que adquieren las partículas al introducirlas en medio acuoso depende del $\mathrm{pH}$ de dicho medio. Para cada naturaleza de partícula existe un valor de $\mathrm{pH}$ para el que el valor de la carga superficial es cero, denominado punto isoeléctrico (IEP) y que resulta necesario determinar de forma experimental. 
Las variables de la suspensión que permiten actuar sobre este balance de fuerzas son: el pH, la fracción de electrolitos y el contenido en sólidos. De entre todas ellas se ha elegido la modificación del pH para regular el potencial total de interacción potencial zeta (ろ). La disminución o aumento del $\mathrm{pH}$ con respecto al punto isoeléctrico, provoca la adsorción de hidrogeniones o de hidroxilos, adquiriendo las superficies carga positiva o negativa respectivamente. Superficies altamente cargadas, provocan un dominio de las fuerzas de repulsión electrostática sobre las de atracción, aumentando la barrera energética que impide que las partículas se aglomeren. Por lo tanto, cuando mayor sea la diferencia entre el pH del medio y el pH correspondiente al punto isoeléctrico del sistema, mayor será la estabilidad de éste.

La metodología empleada para la estabilización electrostática de las suspensiones de los nanofluidos consta de las siguientes etapas:

- Determinación del punto isoeléctrico del nanofluido, según apartado 3.5 Capitulo III.

- Modificación del pH de la suspensión con el objetivo de alejarnos del punto isoeléctrico (donde el potencial zeta es cero y la repulsión entre partículas es nula) para así potenciar la repulsión entre partículas. Para la medida del pH se ha seguido el procedimiento descrito en el apartado 3.6 Capitulo III.

Para la modificación del pH se han utilizado dos disoluciones:

- Disolución de $\mathrm{HCl}$ al 0,1 M, para conseguir un pH ácido

- Disolución de $\mathrm{NaOH}$ al 0,1 M para conseguir un pH básico

\subsubsection{Funcionalización de las nanopartículas}

La funcionalización es la modificación de la estructura grafítica de las partículas carbonosas mediante la introducción de átomos o grupos funcionales en su superficie. Con la funcionalización de los nanomateriales puede modificarse su comportamiento, ya que:

- Los grupos funcionales sirven como puntos de anclaje para otras moléculas.

- Se logra una mayor afinidad con el medio.

Los principales métodos de funcionalización se pueden clasificar en dos categorías: 
- Funcionalización no covalente. Se refiere a la unión sin enlace covalente de las nanopartículas a distintas moléculas o especies. Por lo general las interacciones que ocurren son débiles, del tipo Van Der Waals.

- Funcionalización covalente. En este caso hay enlace covalente entre la superficie de la nanopartícula y la especie anclada a ella. Puede conseguirse por oxidación química o una reducción de sales de diazonio aromáticas. Dentro de la funcionalización covalente, destacan los diversos métodos como la activación térmica, o la funcionalización por reacción electroquímica o reacción fotoquímica.

La modificación superficial de las nanopartículas (por el método covalente y no covalente) en el presente estudio se ha llevado a cabo en los nanotubos de carbono y las nanopartículas de grafeno. Para conseguir dicha modificación superficial se ha realizado una funcionalización de tipo no covalente utilizando para ello dos técnicas:

\section{- $\quad$ Funcionalización ácida}

El primer método de oxidación aplicado se utiliza para procesos con polímeros y se seleccionó por ser el método de funcionalización más sencillo encontrado en la bibliografía. Este método consiste en agitar 0,5 g de las nanopartículas a funcionalizar (MWCNTs o grafeno) en una mezcla $3: 1$ en volumen de $\mathrm{H}_{2} \mathrm{SO}_{4}(96 \%)$ y $\mathrm{HNO}_{3}(65 \%)$ durante 3 horas a $55^{\circ} \mathrm{C}$. Según la bibliografía consultada $[7,23]$, los tiempos de reflujo aplicados oscilan de $1 \mathrm{~h}$ a $6 \mathrm{~h}$, motivo por el cual se decidió alargar para algunos materiales el tiempo de 3 horas a 9 horas con el objetivo de intentar aumentar la cantidad de grupos hidrofílicos introducidos en la superficie de las nanopartículas.

\section{- Funcionalización alcalina}

El segundo método de oxidación aplicado consiste en colocar en suspensión 0,1 g de las nanopartículas a funcionalizar (MWCNTs o grafeno) en $100 \mathrm{ml}$ de agua a los cuales se añaden 3,5 g de persulfato de potasio (KPS), esta mezcla se lleva a pH 12 con $\mathrm{KOH}$. Cuando se ha alcanzado el pH básico se coloca la mezcla en el sistema de reflujo, Figura 12, durante 8 horas a $75^{\circ} \mathrm{C}[23]$. 

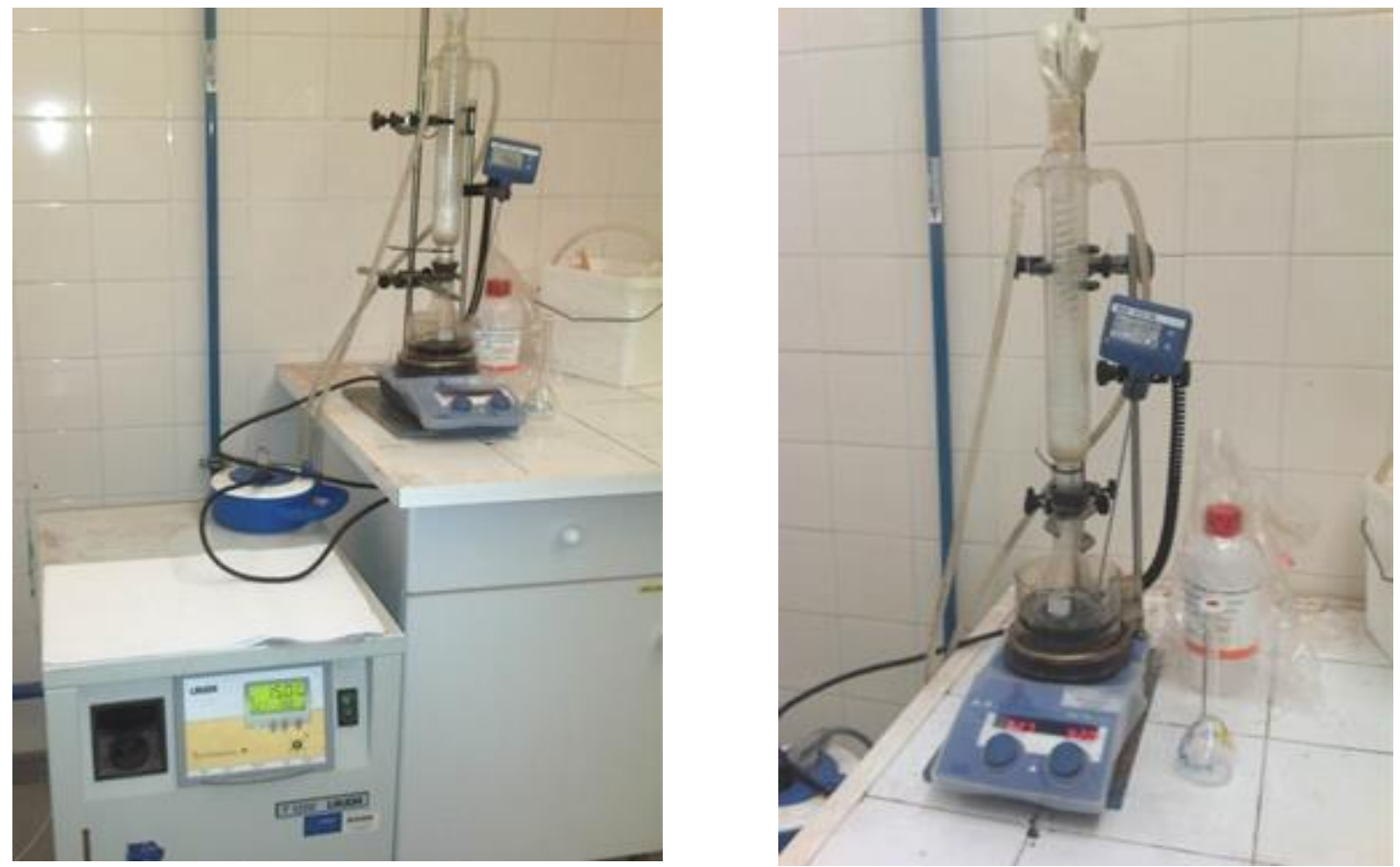

Figura 12. Montaje para la funcionalización de los nanotubos de carbono y el grafeno

Cuando se termina el tratamiento de funcionalización (agitación de los nanotubos o nanopartículas de grafeno en ácido a altas temperaturas Figura 12), se procede al lavado de las nanopartículas con agua hasta llegar al pH del agua destilada (5,5-6). Este proceso se repite varias veces, hasta que se alcanza un $\mathrm{pH}=5$. En esos momentos la suspensión ya no sedimentaba debido al cambio de las cargas superficiales de los nanotubos a este $\mathrm{pH}$, en consecuencia, para proseguir con los lavados hasta alcanzar pH neutro se optó por centrifugar la suspensión para acelerar así la sedimentación de las nanopartículas y conseguir separarlas por decantación.

El equipo de laboratorio utilizado fue una centrifugadora Eppendorf (Figura 13, izda.). Se necesitó un tiempo largo de centrifugación (40 min) y alta velocidad (4000 rpm) para conseguir que las nanopartículas funcionalizadas sedimentaran correctamente. El resultado de las nanopartículas sedimentadas después de la centrifugación se muestra en la Figura 13 (derecha).

Tras el lavado de las nanopartículas funcionalizadas se procedió a su secado por convección en estufa a $60^{\circ} \mathrm{C}$ para guardar el material funcionalizado en bolsas de plástico en espera de su posterior procesamiento en la preparación del nanofluido. 

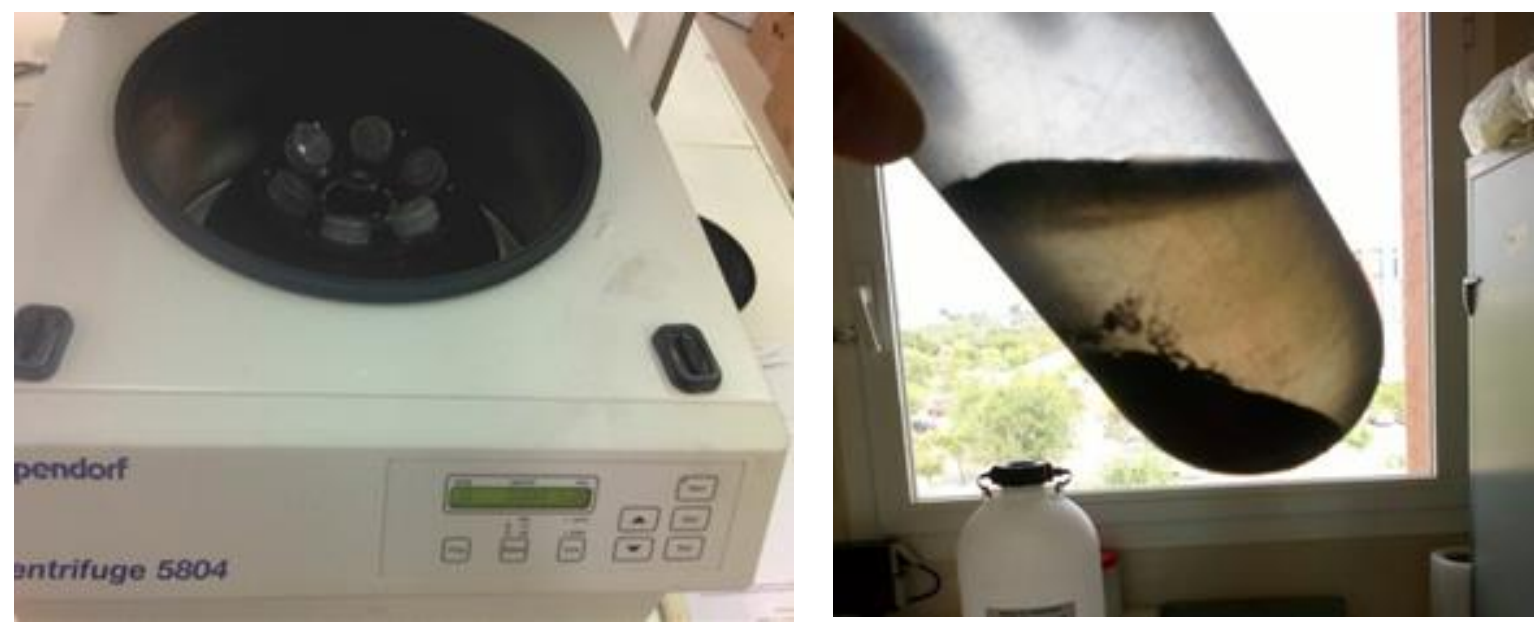

Figura 13. Centrifugadora Eppendorf modelo 5804 (izda.) imagen nanotubos centrifugados (dcha.).

\subsection{Dispersión mecánica de las nanopartículas en el fluido base}

Algunos de los investigadores han preparado los nanofluidos sintetizando ellos mismos las nanopartículas y obteniendo en un único paso el nanofluido, aunque la mayoría utilizan la técnica de dos etapas, mezclando en una primera fase las nanopartículas con el surfactante y dispersando posteriormente la mezcla, como puede observarse en la Tabla 13. En esta tabla se resumen los principales métodos de dispersión utilizados por diversos autores junto con los surfactantes o métodos de estabilización utilizados con nanopartículas no metálicas como las elegidas para el estudio [5].

Para la dispersión de las nanopartículas en el fluido base la cantidad de energía necesaria va a depender de varios factores, tales como, la naturaleza del material, el tamaño de partícula o agregado, la afinidad por el fluido base, etc... Además, si la energía aplicada es excesiva puede tener efectos contraproducentes de reaglomeración de las nanopartículas, deterioro de los aditivos como los surfactantes o rotura de la longitud de las nanopartículas como en el caso de los nanotubos. Puede concluirse que no existe un procedimiento estandarizado para la preparación de los nanofluidos, por lo que dicho procedimiento debe optimizarse para cada caso en particular, siguiendo como base los resultados obtenidos por diversos investigadores. 
Entre los distintos métodos de dispersión utilizados por los investigadores (Tabla 13), en el presente estudio se han elegido tres técnicas para realizar el estudio de dispersión de las nanopartículas de distinta naturaleza en agua:

- Baño de ultrasonidos

- Homogeneizador

- $\quad$ Sonda de ultrasonidos

Tabla 13. Principales métodos utilizados en la dispersión de nanopartículas en un fluido base. Fuente [5]

\begin{tabular}{|c|c|c|c|c|}
\hline Nanofluidos & Investigador & Fluido base & $\begin{array}{l}\text { Surfactante/ } \\
\text { modificación pH }\end{array}$ & Dispersión \\
\hline \multirow[t]{6}{*}{ Sílice $\left(\mathrm{SiO}_{2}\right)$} & Timofeeva & orgánico & $\begin{array}{l}\text { Surfactantes } \\
\text { Cloruro de benzalconio } \\
\text { Cloruro de bencetonio } \\
\text { bromuro de cetiltrimetil } \\
\text { amonio }\end{array}$ & $\begin{array}{l}\text { Sonicación tren } \\
\text { ultrasonidos } 5 \mathrm{~min}, \\
10 \text { veces }\end{array}$ \\
\hline & Yang and Liu & $\begin{array}{l}\text { Agua } \\
\text { destilada }\end{array}$ & $\begin{array}{l}\text { Funcionalizacion de } \\
\text { nanopartículas de sílice } \\
\text { con silanos }\end{array}$ & mezclado \\
\hline & Anoop & $\begin{array}{l}\text { Agua } \\
\text { destilada }\end{array}$ & $\mathrm{pH}=4,5$ & $\begin{array}{l}\text { Baño de } \\
\text { ultrasonidos } 30+ \\
\text { sonicacion } 15 \mathrm{~min}\end{array}$ \\
\hline & Fazeli & $\begin{array}{l}\text { Agua } \\
\text { destilada }\end{array}$ & - & $\begin{array}{l}\text { Baño ultrasonidos } \\
90 \mathrm{~min}\end{array}$ \\
\hline & $\begin{array}{l}\text { Bolukbasi and } \\
\text { Ciloglu }\end{array}$ & $\begin{array}{l}\text { Agua } \\
\text { destilada }\end{array}$ & - & $\begin{array}{l}\text { Agitador magnético } \\
+ \text { sonicación } 2 \mathrm{~h} \\
(600 \mathrm{~W}, 40 \mathrm{kHz})\end{array}$ \\
\hline & Kulkarni & $\begin{array}{l}\text { Mezcla } \\
\text { binaria } \\
\text { (60:40): } \\
\text { etilenglicol; } \\
\text { agua } \\
\text { destilada }\end{array}$ & - & $\begin{array}{l}\text { Baño de } \\
\text { ultrasonidos } 2 \mathrm{~h}\end{array}$ \\
\hline \multirow[t]{5}{*}{ Alúmina $\left(\mathrm{Al}_{2} \mathrm{O}_{3}\right)$} & Suresh & agua & $\mathrm{pH}=4,8$ & $\begin{array}{l}\text { Sonicación } 6 \mathrm{~h} \text {, } \\
\text { pulsos de } 100 \\
\text { W y } 36 \pm 3 \mathrm{kHz}\end{array}$ \\
\hline & Beck & etilenglicol & - & Baño ultrasonidos \\
\hline & $\begin{array}{l}\text { Gharagozloo } \\
\text { and Goodson }\end{array}$ & agua & $\begin{array}{l}\mathrm{pH}=5,5 \text { ajustado con } \\
\text { ácido nítrico }\end{array}$ & $\begin{array}{l}\text { Sonicación } 4 \text { h } 60 \\
\mathrm{~Hz} \text { and } 130 \mathrm{~W}\end{array}$ \\
\hline & Soltani & agua & $\begin{array}{l}\text { Surfactante: } \\
\text { carboximetilcelulosa }\end{array}$ & $\begin{array}{l}\text { Mezcla durante } 6 \mathrm{~h} \\
\text { con agitador }+ \\
\text { sonicación } 1 \mathrm{~h}\end{array}$ \\
\hline & Hung & Agua & $\begin{array}{l}\text { Surfactante catiónico } \\
\text { Chitosan }\end{array}$ & $\begin{array}{l}\text { Homogeneizador } \\
8000 \text { rpm durante } \\
30 \mathrm{~min} / \text { agitador } \\
600 \mathrm{rpm} \text { durante }\end{array}$ \\
\hline
\end{tabular}




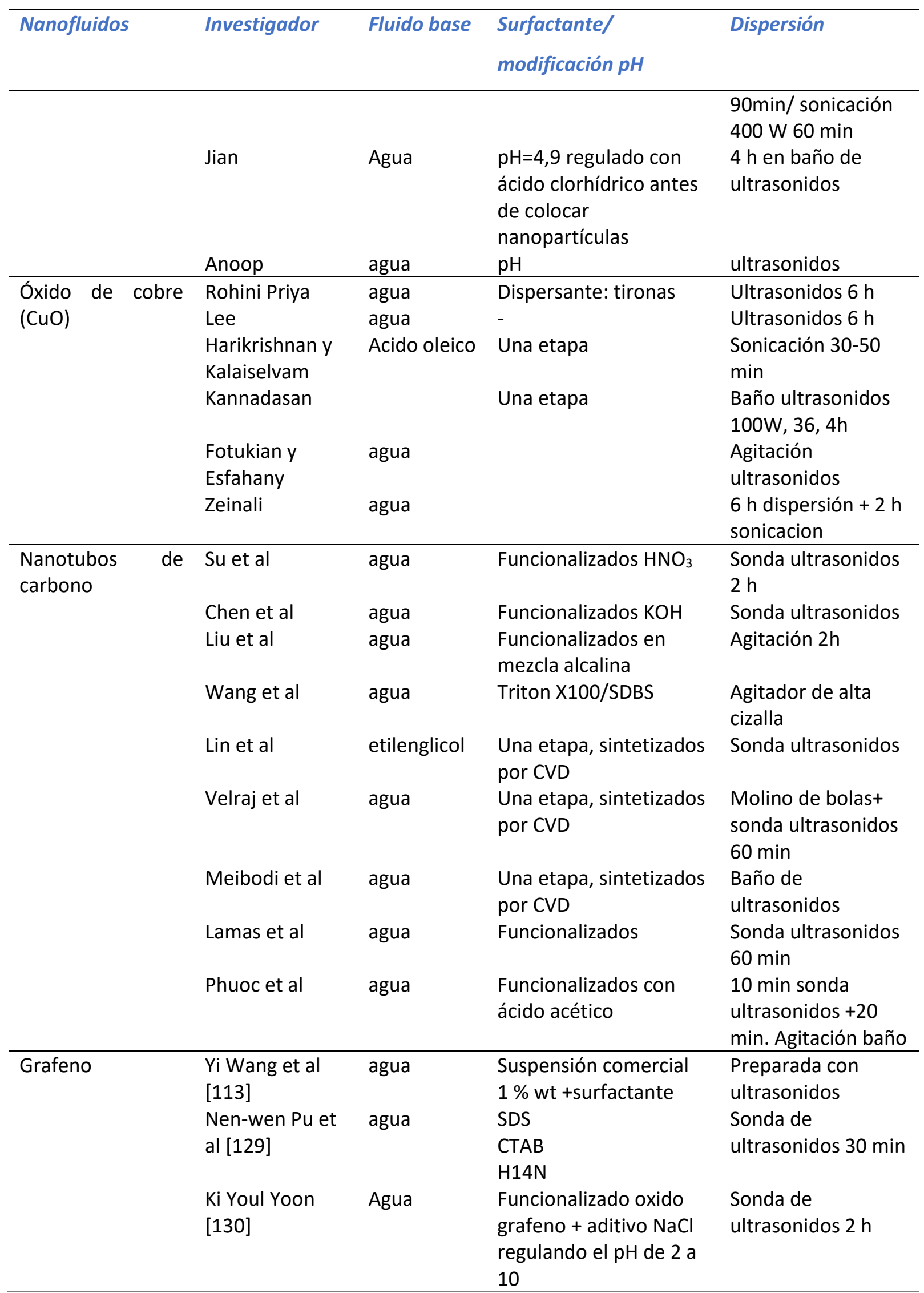


A continuación, se describe la metodología utilizada para la aplicación de cada una de estas técnicas seleccionadas.

\subsubsection{Baño de ultrasonidos}

El método de dispersión mecánico menos agresivo, debido a que aplica una baja potencia, es el baño de ultrasonidos [6]. Esta metodología se aplicó en los nanotubos de carbono, los cuales son susceptibles de romper su estructura longitudinal si se someten a una dispersión mecánica muy enérgica. El baño de ultrasonidos utilizado fue el modelo PSelecta, con una potencia de $50 \mathrm{~W}$. En la Figura 14 se observa el baño utilizado con la muestra de nanofluido sumergida en el mismo durante la ejecución del ensayo de dispersión.

Se estudió la dispersión de los nanotubos de carbono a dos fracciones volumétricas $(0,05 \%$ y $0,1 \%)$, aplicándose diferentes tiempos de permanencia en el baño (10, 30, 60 y $90 \mathrm{~min})$. Todos los ensayos se realizaron con el baño a una temperatura de $40^{\circ} \mathrm{C}$.

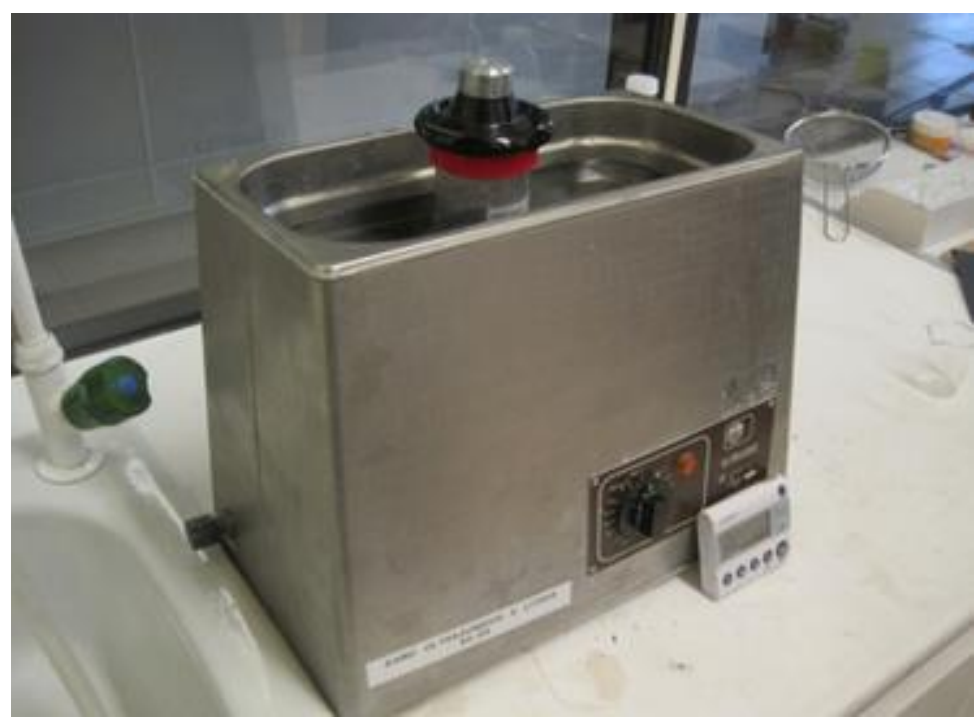

Figura 14. Baño de ultrasonidos con la muestra de nanofluido en su interior

\subsubsection{Homogeneizador}

El segundo método de dispersión menos agresivo y que también se aplicó a los nanotubos de carbono y al grafeno fue el homogeneizador.

La tecnología de homogeneización aplica presión sobre los líquidos para subdividir las partículas presentes en los fluidos y crear una dispersión estable. El paso del fluido a través de un minúsculo espacio en la válvula bajo alta presión lleva al fluido a condiciones de alta 
turbulencia y cizallamiento, logrando su dispersión y micronización. Este mecanismo logra la homogeneización de partículas en el seno de un fluido con la correspondiente rotura de aglomerados y se ha utilizado en la preparación de nanofluidos según la bibliografía consultada [6].

El equipo utilizado para los ensayos de dispersión fue el PANDA Plus 2000, De GEA NIRO Soavi, Figura 15.
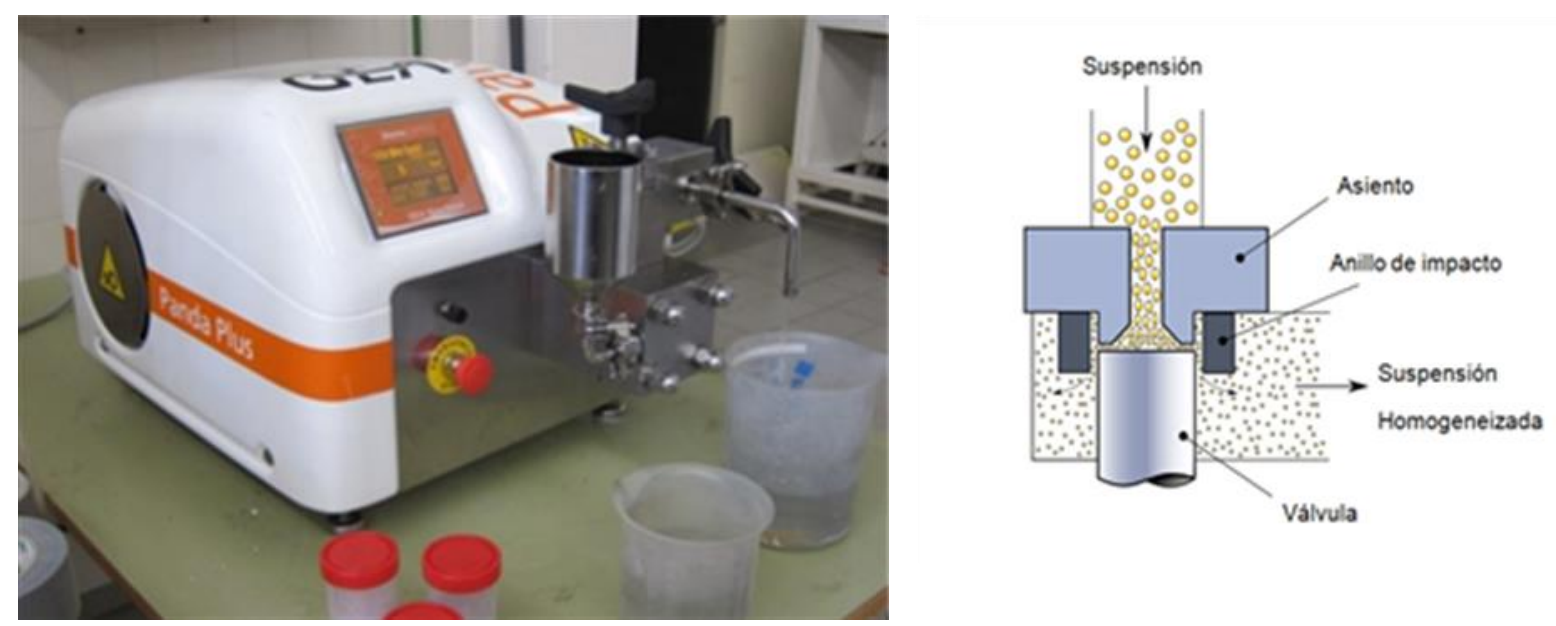

Figura 15. Vista global del homogeneizador Panda Plus de Niro Soavi (izda.). Esquema de la válvula de homogeneización (dcha.).

Para el estudio de su posible aplicación en la preparación y dispersión de nanotubos de carbono en medio acuoso se analizaron las siguientes variables de operación:

- $\quad$ presión

- número de pasadas de la muestra o recirculación de la misma dentro del circuito

Para la cuantificación del efecto de estas variables sobre la dispersión se caracterizó la conductividad térmica de los nanofluidos preparados en distintas condiciones de ensayo.

\subsubsection{Sonda de ultrasonidos}

La sonicación es un proceso físico durante el cual se aplica la energía del sonido (generalmente ultrasonidos) para agitar las partículas de una muestra y que puede romper la aglomeración de nanopartículas e incluso la agregación de éstas [74]. Una corriente eléctrica transmite su energía a un sistema mecánico que la convertirá en vibraciones de alta intensidad que generan las ondas de ultrasonido y que generan a su vez, vibraciones en el material objetivo. Si el 
material es un líquido, dicha vibración generará millones de burbujas microscópicas, las cuales sufren rapidísimos procesos de expansión y colapso transmitiendo de esta forma su energía a otros materiales. Este fenómeno se llama cavitación. La sonicación se utiliza de modo habitual en nanotecnología para dispersar uniformemente las nanopartículas en los líquidos gracias a este mecanismo de cavitación.

La sonda de ultrasonidos está formada por dos componentes principales; el sonicador y el sonotrodo. El sonicador es el dispositivo que transforma la energía eléctrica en energía mecánica. Este equipo genera ondas ultrasónicas gracias a la oscilación de los transductores piezoeléctricos con una frecuencia aproximada de $20 \mathrm{kHz}$ y consiguiendo aplicar una potencia total de 200-400W dependiendo de la naturaleza del sonotrodo.

Las variables que intervienen en el proceso de sonicación y que por tanto pueden someterse a estudio son las siguientes:

- $\quad$ tiempo de aplicación de ultrasonidos

- $\quad$ energía: depende de la potencia aplicada y del tiempo

- $\quad$ amplitud

- $\quad$ continuo o discontinuo (pulsos)

- diseño del sonicador

- $\quad$ volumen de muestra sonicada

- fracción volumétrica de nanopartículas; mayor fracción de partículas necesita mayor tiempo de ultrasonidos

Finalmente se puede establecer un factor dependiente de todas las variables anteriormente citadas:

$$
\text { E ultrasonidos }=(\text { Potencia } \times \text { tiempo }) /(\text { masa nanopartícula })
$$

Por lo cual la variable a estudiar según la ecuación (15) para una fracción volumétrica dada y para un diseño de sonda determinado va a ser el tiempo total de aplicación de los ultrasonidos. Como ya se ha resumido anteriormente en la Tabla 13, el tiempo de aplicación es muy variable, encontrándose gran disparidad en la bibliografía consultada, desde minutos a horas. 
El grado de la dispersión alcanzado tras la aplicación de distintos tiempos de sonda de ultrasonidos se analizará mediante la medida del tamaño de aglomerado, potencial zeta y la conductividad térmica del nanofluido. El estudio del tiempo de dispersión y tipo de sonda se ha llevado a cabo con las nanopartículas de alúmina, pues en los nanotubos la cantidad de energía aplicada puede modificar su relación radio/ longitud, viéndose afectados los mecanismos de transmisión de calor al romperse su longitud bajo largos tiempos de sonicación.

En el estudio de dispersión mediante sondas de ultrasonidos se han utilizado dos tipos de sondas:

- $\quad$ Sonda de baja potencia: modelo UP200Ht de $200 \mathrm{~W}$ y $26 \mathrm{KHz}$ fabricante HIELSCHER

- $\quad$ Sonda de alta potencia: modelo UP400S de 400W y $20 \mathrm{KHz}$ fabricante HIELSCHER

\section{Sonda UP200Ht}

La sonda Up200Ht se utiliza para dispersar mediante sonicación muestras con un volumen de 0,1 a $1000 \mathrm{ml}$. La sonda tiene disponibles varios sonotrodos (de 2 a $40 \mathrm{~mm}$ de diámetro) a utilizar según el volumen de muestra a dispersar y la intensidad que se quiera alcanzar. Con los sonotrodos de mayor diámetro se transfiere suavemente las ondas de ultrasonidos a través de una superficie grande, mientras que con los de menor tamaño se trabaja con una amplitud e intensidades más elevadas. Las características del sonotrodo utilizado (S26d14) junto con la sonda UP200 para la dispersión de las nanopartículas en el presente estudio han sido:

- Sonotrodo fabricado en titanio

- Diámetro de $14 \mathrm{~mm}$ y longitud de $80 \mathrm{~mm}$

- Relación amplitud 1:2

- Aplicable en muestras de $50 \mathrm{ml}$ hasta $500 \mathrm{ml}$

Con este tipo de sonda, resulta imprescindible trabajar siempre con la misma cantidad de muestra y en el mismo recipiente para que el sonotrodo quede sumergido siempre a la misma altura, que se regula mediante el trípode (Figura 16, imagen de la derecha). La capacidad de vaso refrigerado es de $50 \mathrm{ml}$. 

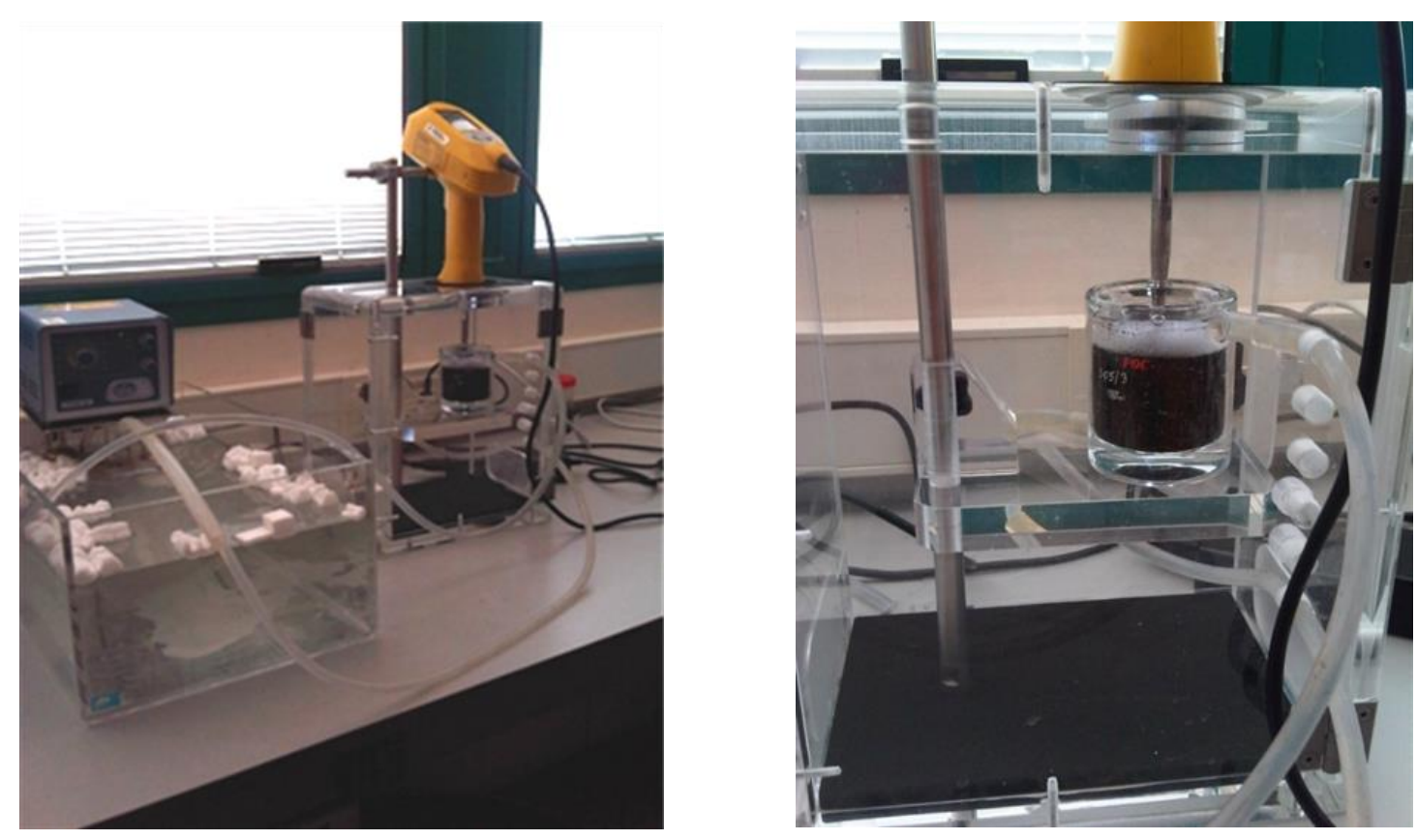

Figura 16. Sonda de ultrasonidos modelo UP200 con baño de agua para refrigerar la muestra y mantenerla a $15 \stackrel{\circ}{\circ} \mathrm{C}$

La metodología utilizada para la preparación de nanofluidos con la sonda de ultrasonidos modelo UP 200 ha sido la siguiente:

1. Dosificación del fluido base, agua destilada, en la cantidad requerida según la fracción volumétrica final deseada.

2. Adición del surfactante si se considera necesario y posterior mezcla con agitador magnético.

3. Adición de las nanopartículas

4. Ajuste de pH, para ayudar a la estabilización de las nanopartículas dispersas, alejándose del punto isoeléctrico.

5. Mezcla del conjunto en agitador magnético para posterior transvase al vaso refrigerado de la sonda de ultrasonidos.

6. Dispersión de las nanopartículas en el fluido base mediante la sonda de ultrasonidos seleccionando potencia y tiempo de aplicación. 


\section{Sonda UP400S}

Con la sonda de mayor potencia (400W) se pueden sonicar muestras de mayor volumen (100 $\mathrm{ml}$ a $2000 \mathrm{ml}$ ) utilizándose el sonotrodo S24d22D, con un diámetro de $22 \mathrm{~mm}$ y una longitud de $1000 \mathrm{~mm}$ (Figura 17). Esta sonda se ha utilizado en el estudio para la preparación de muestras de mayor volumen.

El método seguido para la utilización de esta sonda de mayor potencia es igual al descrito para la sonda UP200, pero con ligeras modificaciones, ya que el sistema de sonicación no incluye el sistema de refrigeración. Todas las muestras se sometieron a ultrasonidos durante dos minutos, tras los cuales resultó necesario refrigerar la muestra en un baño frío durante otros dos. El tiempo total de ultrasonidos aplicado a las muestras según el procedimiento descrito, fue de 12 minutos.
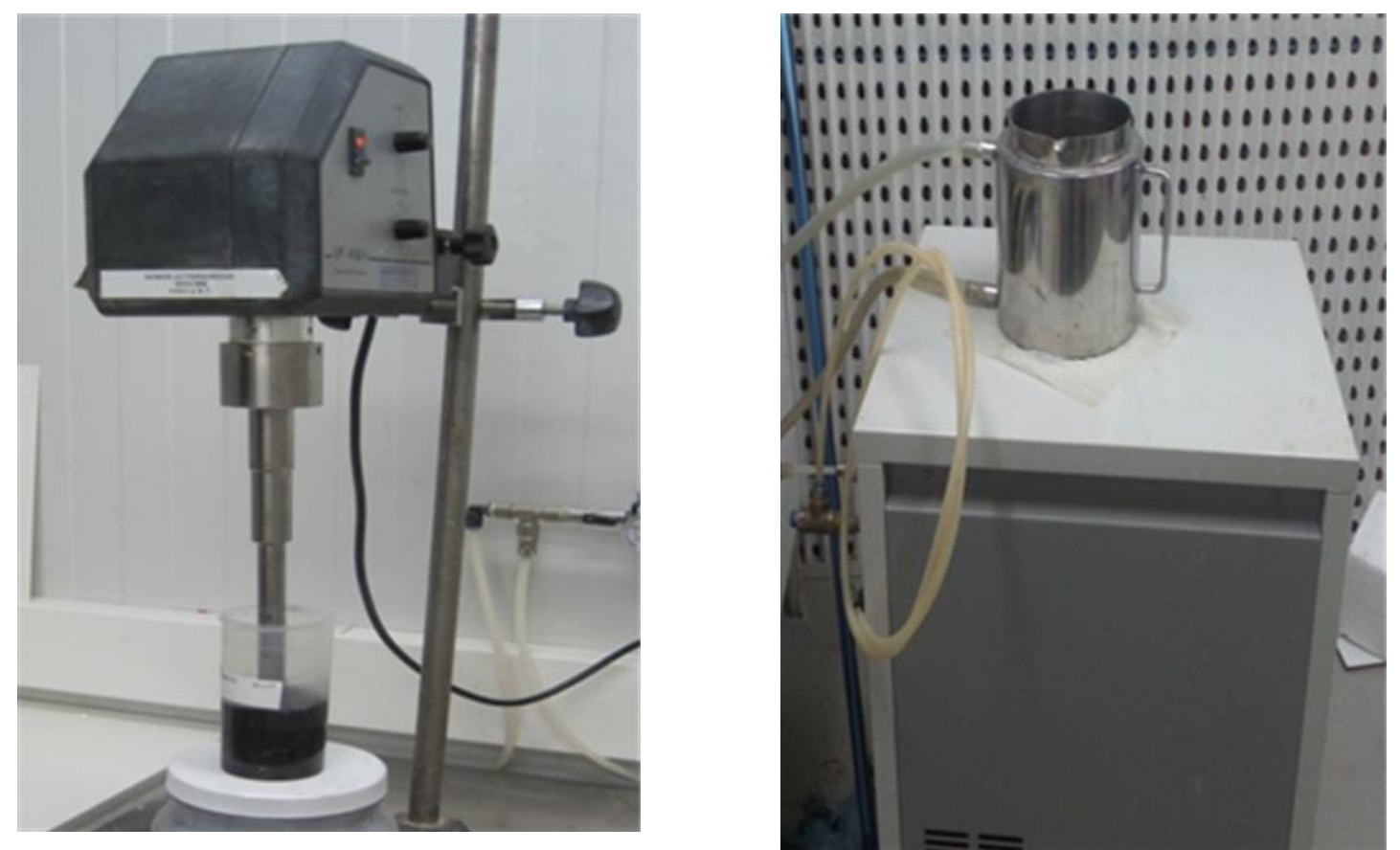

Figura 17. Sonda de ultrasonidos modelo UP 400 s (izda.) y baño refrigerado (dcha.). 


\section{Técnicas utilizadas para la caracterización de los nanofluidos}

A continuación, se describen en este apartado las técnicas utilizadas en la caracterización de la estabilidad, la conductividad térmica, la viscosidad, el tamaño y morfología de partícula dispersada, la capacidad calorífica, la densidad, el pH y el potencial zeta de los nanofluidos. Se describen también la técnica de espectroscopía infrarroja utilizada para determinar el grado de funcionalización de las nanopartículas modificadas químicamente para su mejor dispersión.

\subsection{Caracterización de la estabilidad de los nanofluidos}

Como ya se ha comentado en el punto anterior, la metodología empleada para la obtención de los nanofluidos es la de dos etapas, adquisición de las nanopartículas en polvo y posterior dispersión en medio acuoso mediante agitación; metodología en la cual la estabilidad de los nanofluidos es menor, debido a la tendencia de las nanopartículas a aglomerarse. La efectividad de un nanofluido depende de la sedimentación de las nanopartículas, por lo tanto, debe analizarse la evolución del tamaño de las mismas en el tiempo determinando la tendencia a la aglomeración y posterior sedimentación. En la bibliografía se emplean diversas técnicas para poder medir la estabilidad de los fluidos $[26,71,74,75,77,78,79]$ desde las técnicas visuales, en las cuales se detecta la sedimentación de las suspensiones preparadas mediante imágenes, métodos de centrifugación [74] para acelerar así los procesos de sedimentación, medida de la variación de la fracción volumétrica midiendo la densidad del nanofluido [26], potencial zeta en la doble capa, hasta las técnicas de medida que se basan en la interferencia generada por las partículas en suspensión frente al paso de un haz de luz $[5]$.

Las técnicas de medida de tamaño de partícula o aglomerado mediante dispersión dinámica de luz (DLS, del inglés dynamic light scattering), son utilizadas por varios autores $[55,76]$, para determinar el tamaño de los aglomerados en la suspensión y la evolución de los mismos. Hay que señalar que aunque dichas medidas no permiten una medida directa del tamaño de las nanopartículas dispersas en el nanofluido (la muestra se diluye para así poder realizar la medida, con lo cual se modifican en gran medida las condiciones que afectan a la aglomeración de partículas como $\mathrm{pH}$, dispersante y temperatura), estas medidas son lo 
suficientemente representativas del estado de aglomeración de las nanopartículas en el fluido base y permiten realizar comparaciones del grado de dispersión alcanzado en los nanofluidos. La estabilidad de las suspensiones con nanopartículas preparadas se ha caracterizado finalmente mediante los dos métodos que se describen a continuación (medida de la luz retrodispersada en el equipo Turbiscán y medida de la absorbancia en espectrofotómetro de UV), aplicándose cada uno en función de la naturaleza de las nanopartículas. La estabilidad o sedimentación de las distintas muestras de nanofluidos preparadas se ha caracterizado también mediante análisis visual.

\subsubsection{Caracterización de la estabilidad de los nanofluidos mediante luz retrodispersada en} el equipo Turbiscán

Uno de los métodos de medida de la estabilidad de los nanofluidos es la técnica de dispersión de luz en el equipo Turbiscán, de la empresa LabExpert [6, 59, 71, 77, 78 y 79].

La tecnología del Turbiscán consiste en medir las intensidades de luz en Transmisión (definida como T) y Reflexión (definida como BS), más comúnmente denominada retrodispersión en función de la altura de la muestra para detectar el cambio de tamaño de partícula en procesos de coalescencia y floculación, y la separación de fases en procesos de sedimentación o flotación. Para ello, el equipo dispone de un cabezal óptico con una fuente de luz infrarroja (880 nm) y dos detectores (uno de transmisión, T, y otro que detecta la reflexión BS) que recorren toda la altura de la muestra que se encuentra en el interior de una celda de cristal. En la Figura 18 se muestra el equipo utilizado para la medida de estabilidad.

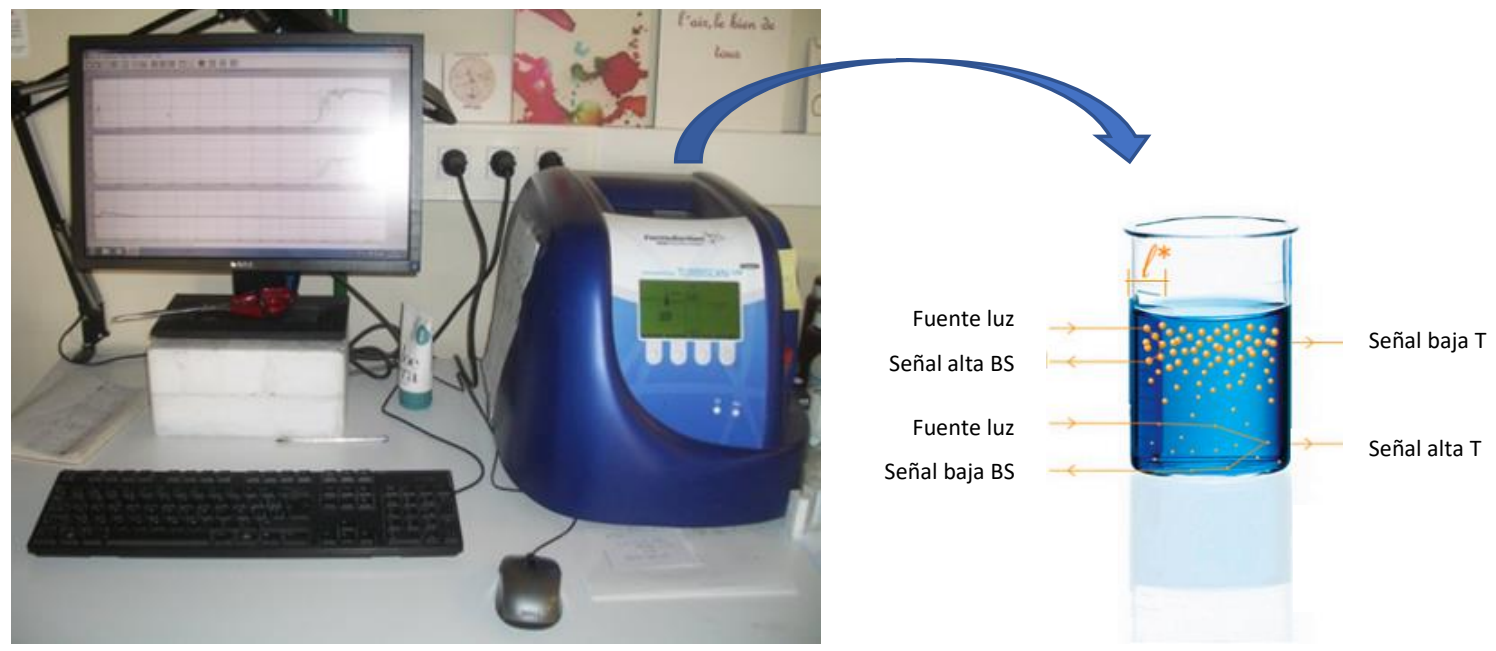

Figura 18. Imagen Turbiscán utilizado para los ensayos de estabilidad de nanofluidos. 
Con los datos recogidos de intensidad de luz, se obtienen unos perfiles de absorbancia respecto al tiempo que permiten caracterizar la estabilidad de la suspensión y detectar procesos como sedimentación, floculación, coalescencia, etc.

Para cada nanofluido, se obtienen los perfiles de retrodispersión (luz dispersada a 45ํำ del haz incidente) y de luz transmitida ( $0^{\circ}$ en relación a fuente de luz) a lo largo de la altura de toda la celda. Para el análisis de estabilidad se utilizará la retrodispersión, ya que el valor de la misma es directamente proporcional a la fracción de partículas en cada posición, realizándose medidas a diferentes tiempos. Los ensayos se realizarán a dos temperaturas, para así analizar también el efecto de la temperatura sobre la estabilidad del nanofluido, eligiéndose 40 y $60^{\circ} \mathrm{C}$ ( $60^{\circ} \mathrm{C}$ es la temperatura máxima del equipo).

Posteriormente se analiza el porcentaje de retrodispersión (\% BS), con el tiempo para dos alturas diferentes de la celda, a $2 \mathrm{~mm}$ (en el fondo de la celda) y a $20 \mathrm{~mm}$ (en el centro de la celda), descartándose la parte superior de la celda porque pueden existir burbujas y los resultados obtenidos no serían reales.

Al analizar las medidas de estabilidad en el equipo turbiscán, se pueden dar tres situaciones diferentes $[14,135]$ :

- Estabilidad. Esta situación se da cuando la cantidad de luz retrodispersada por la muestra es estable en el fondo y en el centro de la celda, sin presentar variaciones en el tiempo en los valores de retrodispersión o transmisión, (Figura 19). 


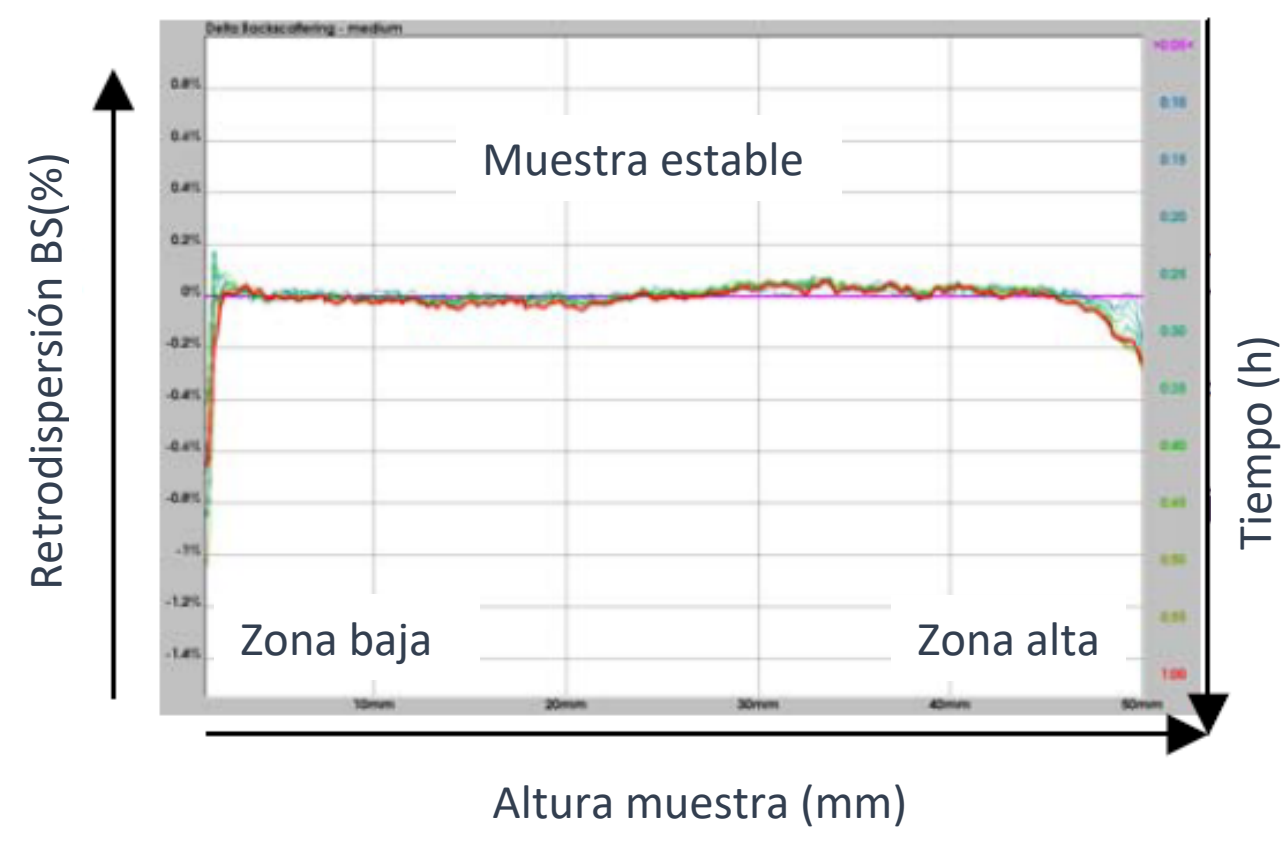

Figura 19. BS tipo de una muestra estable en el tiempo. Fuente [135]

- Sedimentación. El porcentaje de retrodispersión (\% BS) en el fondo de la celda aumenta con el tiempo al aumentar la fracción de partículas y, en cambio, disminuye en la parte superior de la celda. En este caso las nanopartículas al sedimentar se colocan en el fondo de la celda dejando pasar menos luz, midiendo el detector mayor retrodispersión. En cambio, en la parte superior de la celda hay menos partículas, menor fracción y por lo tanto, menor \% BS, (Figura 20).

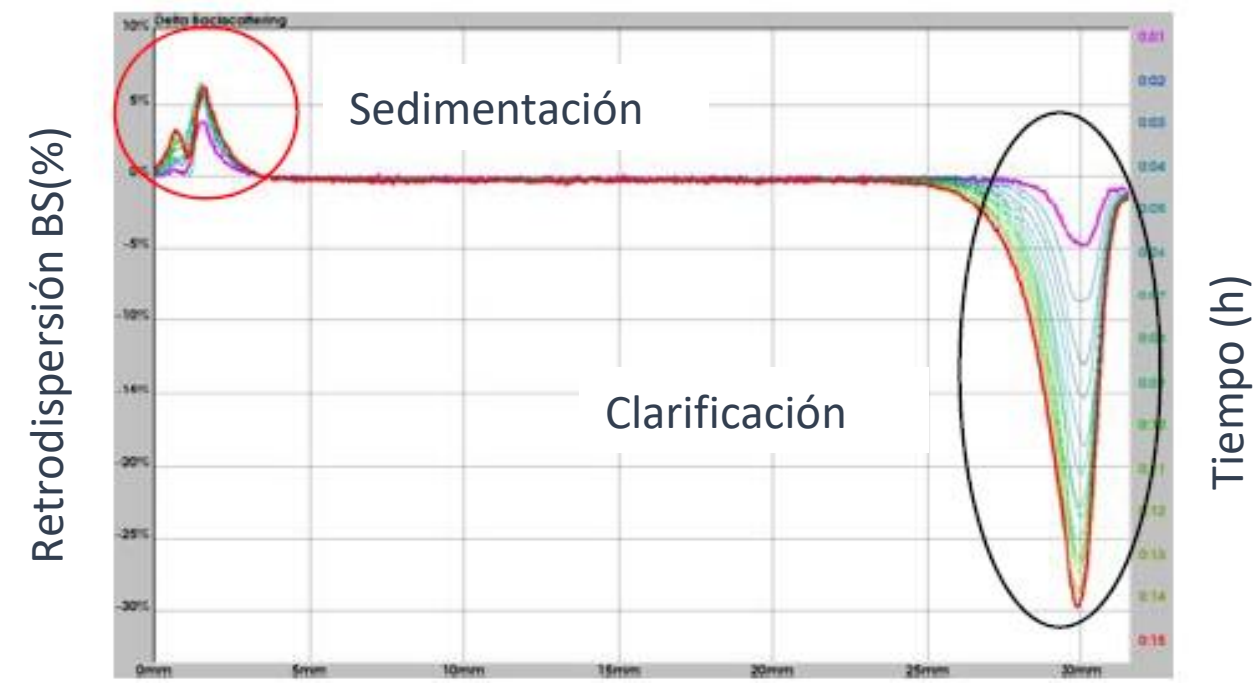

Figura 20. BS tipo de una muestra que sedimenta. Fuente [135] 
- Aglomeración o floculación. La cantidad de luz retrodispersada disminuye con el tiempo, cuando el tamaño de las partículas es mayor que el tamaño del haz incidente $600 \mathrm{~nm}$ por lo que se obtiene una gráfica como la que aparece en la Figura 21. Si el tamaño de las partículas al aglomerarse es menor que el haz incidente (600 nm) tendríamos un aumento de señal de retrodispersión BS (\%).

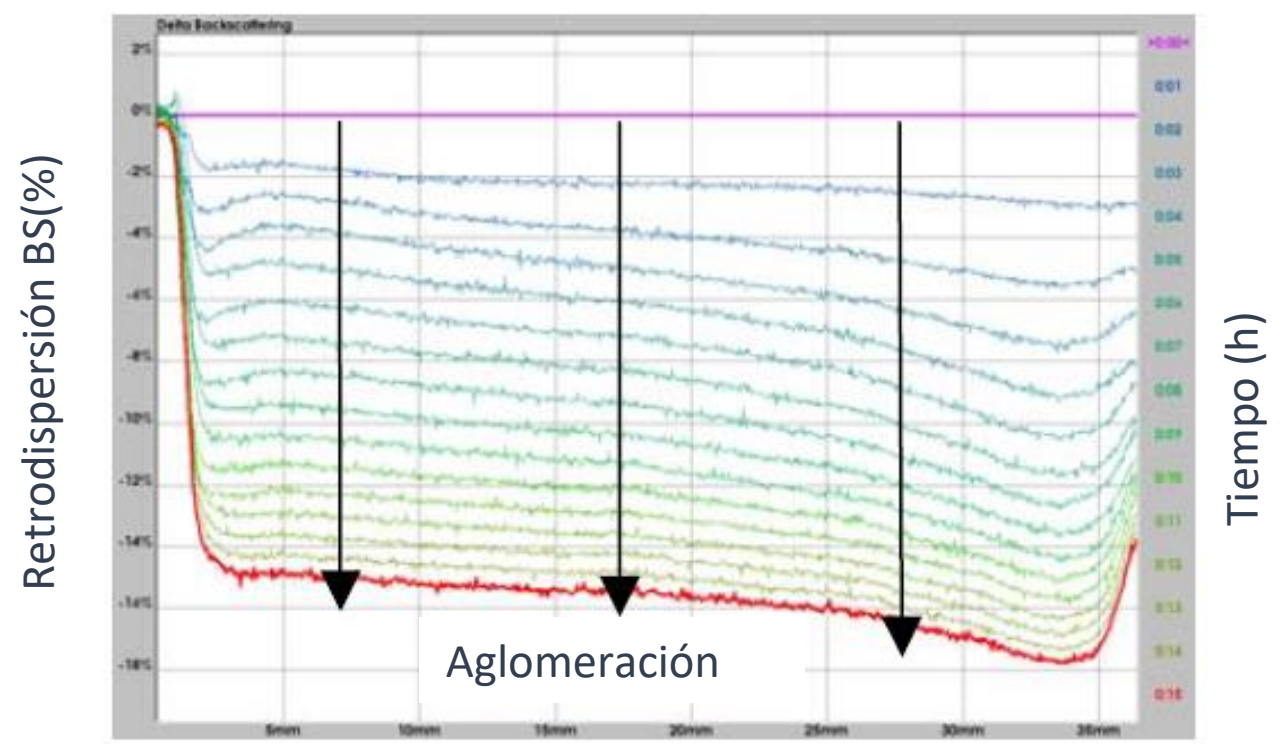

Figura 21. BS tipo de una muestra que se aglomera. Fuente [135]

Para poder analizar la estabilidad de las muestras en tiempos largos, y al no disponer el equipo de un porta-muestras automático, las cubetas con las muestras una vez finalizada la medida se sacaban del equipo y se mantenían en estufa a la temperatura del ensayo hasta el momento de realizar una nueva medida. Tan sólo aquellas muestras analizadas para tiempos cortos (48 h), se mantuvieron en el interior del equipo durante el tiempo total de análisis.

\subsubsection{Caracterización de la estabilidad de los nanofluidos mediante espectrofotometría de} U.V.

La caracterización de la estabilidad del nanofluido mediante la técnica de espectrofotometría es posible, siempre que las nanopartículas tengan las bandas de absorción características dentro del rango 200-1100 nm. Esta técnica es un método fácil para determinar la fracción de nanopartículas en la zona superior del recipiente que contiene el nanofluido y evaluar su variación con el tiempo de sedimentación $[84,85]$. La estabilidad de los nanofluidos puede obtenerse a partir de la evolución de la cantidad de partículas sedimentadas, la cual puede 
medirse en el tiempo si se pipetea una muestra de la zona alta de la muestra y se mide la absorbancia. Los valores de absorbancia medidos en la muestra dependen de la cantidad de partículas, cuanto menor es dicho valor, la muestra tiene menor cantidad de partículas, es decir está más clarificada debido al proceso de sedimentación.

La fracción de partículas en la superficie es proporcional a la absorbancia ya que la absorbancia está relacionada con la fracción de la sustancia, c, por la ley de Lambert-Beer, que se resume con la ecuación:

$$
A=\varepsilon b c
$$

donde

c es la fracción de la sustancia ( $\mathrm{mol} / \mathrm{l})$

b es la longitud del camino óptico (anchura de la célula que contiene la disolución de la sustancia) (cm)

$\varepsilon$ es la absortividad molar, propiedad característica de cada sustancia correspondiente a la cantidad de radiación que absorbe a una longitud de onda determinada por unidad de fracción, $(\mathrm{I} /(\mathrm{mol} \mathrm{cm})$

Para poder aplicar la ley de Lambert-Beer es necesario seleccionar previamente una longitud de onda puesto que tanto la absorbancia, A, como la absortividad, $\varepsilon$, varían con ella. Para ello se obtiene previamente el espectro de absorción de la sustancia, que consiste en una representación de los valores de absorbancia frente a la longitud de onda expresada en nanómetros $(\mathrm{nm})$. Del espectro de absorción puede seleccionarse el valor de longitud de onda para el cual la absorbancia es máxima y realizar los ensayos a lo largo del tiempo en esa longitud de onda fijada.

Para realizar en ensayo de caracterización de la estabilidad de los nanofluidos por espectrofotometría se utilizó el espectrofotómetro T60, de PG Instruments, (Figura 22). 


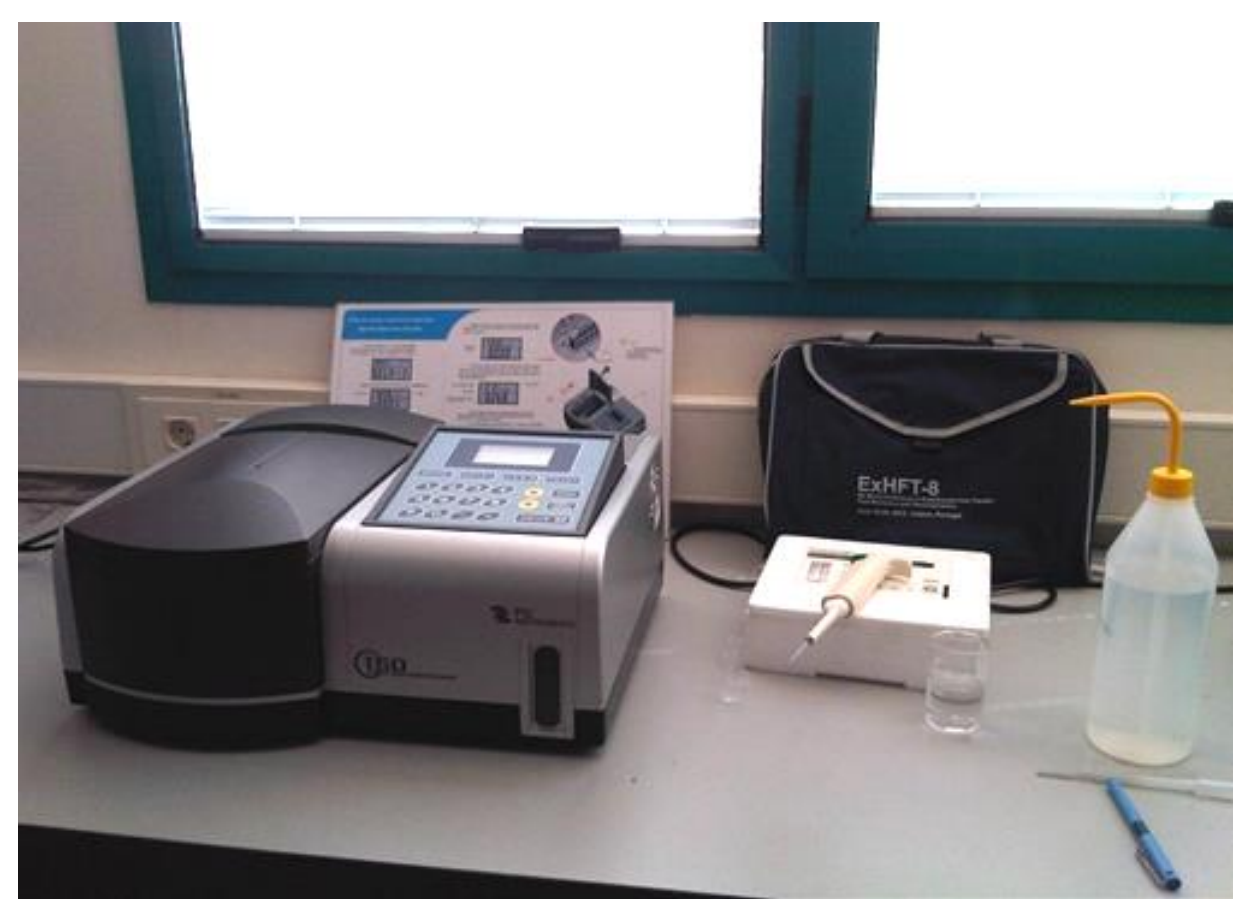

Figura 22. Espectrofotómetro para las medidas de estabilidad de los nanofluidos.

La metodología seguida para poder obtener valores de absorbancia reproducibles fue la siguiente:

- Preparación de la muestra: se pipetean 10 picolitros de la superficie de la muestra a testear y posteriormente se diluyen en agua destilada hasta enrasar la cubeta del equipo de medida.

- Se mide la absorbancia de la muestra a la longitud de onda seleccionada.

- Se realizan varias lecturas con el objeto de obtener un promedio de la medida y asignar la absorbancia para el tiempo en el que se ha tomado la muestra.

- Se repite el proceso de toma de muestra, preparación y medida, en la periodicidad fijada.

- Representación de la evolución de los valores de absorbancia relativos en el tiempo de muestreo y medida (>72 h). 


\subsection{Medida de la conductividad térmica en los nanofluidos}

Para la medida de conductividad térmica se utiliza la ley de Fourier suponiéndose un flujo de calor en una dimensión. Por tanto, midiendo la temperatura en dos puntos conocidos a lo largo de la dirección de la transmisión de calor y conociendo el calor aplicado, se puede estimar la conductividad térmica según la ecuación de transmisión del calor por conducción (5), donde la proporcionalidad de dicha expresión se relaciona con la conductividad,k.

La conductividad térmica es una de las propiedades termofísicas más estudiadas de los nanofluidos y necesita ser medida de forma experimental ya que los modelos empíricos propuestos para describir el comportamiento térmico de estas suspensiones no se ajustan de forma rigurosa.

Las técnicas utilizadas para la medida de la conductividad térmica se clasifican en función del método de medida elegido:

- Método transitorio; aplican este método la técnica de hilo caliente ("hot strip method"), el método de temperatura oscilatorio y el método $3 \mathrm{~W}$.

- Método estacionario; método entre placas.

Como se puede deducir de la dispersión de resultados en la medida de la conductividad constatada por diversos investigadores según la bibliografía consultada [54], donde para un mismo material se encuentran diferencias del orden del $10 \%$ entre autores, la medida de conductividad térmica debe realizarse de forma minuciosa minimizando en lo posible los errores debido a las variables que pueden afectar en función del método de medida elegido [35].

Para una correcta medida de la conductividad térmica los nanofluidos deben permanecer en estado estacionario durante los ensayos. En caso de los líquidos deben evitarse los posibles gradientes en temperatura que pueden generar mecanismos de convección y que pueden ocasionar errores en la medida de la conductividad. Además, los nanofluidos pueden presentar gradientes de homogeneidad si las nanopartículas no están bien dispersas o si se producen fenómenos de aglomeración y sedimentación cuando los nanofluidos son poco estables [6]. Por estos motivos los tiempos de medición de la conductividad térmica deben ser 
lo más cortos posibles para evitar en la medida de lo posible cualquier gradiente o tipo de convección.

De entre todos los métodos utilizados para medida de la conductividad el método más usado por los investigadores en la bibliografía consultada sobre nanofluidos [6, $25,35,36,44]$, es el método transitorio de hilo caliente, por ser un método rápido.

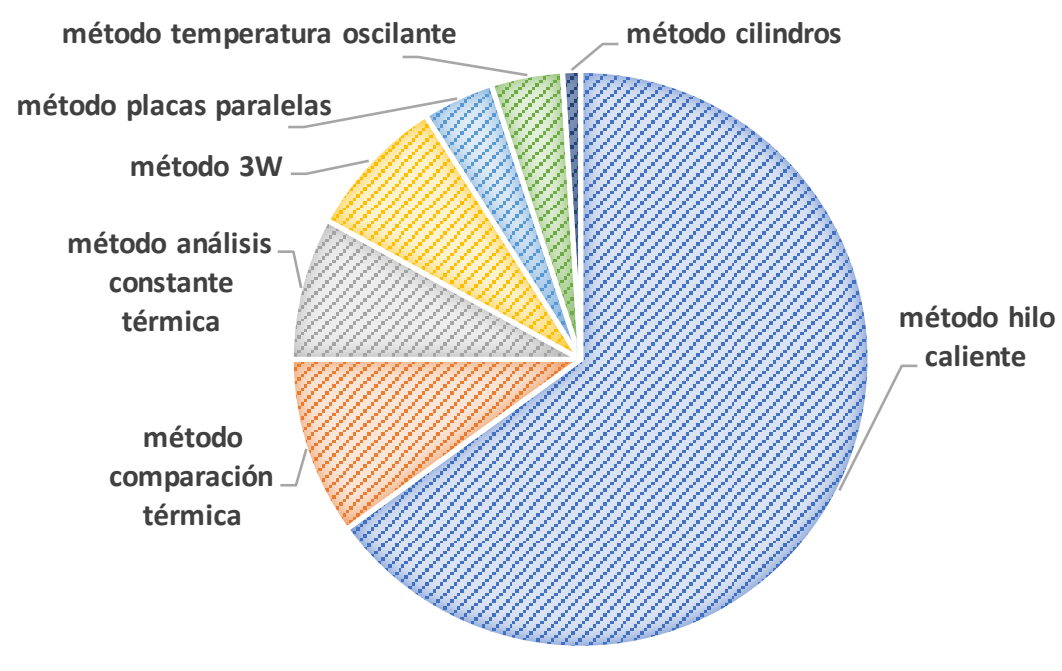

Figura 23. Porcentaje de uso de los distintos métodos de medida de conductividad térmica en base a los artículos publicados.

La técnica de medida de conductividad térmica basada en el método transitorio del hilo caliente va a ser uno de los métodos transitorios elegido junto con la técnica de placas paralelas (método estacionario) para evaluar la idoneidad de los mismos y llevar a cabo las medidas de conductividad térmica en los nanofluidos.

\subsubsection{Método transitorio de hilo caliente}

Como se ha comentado en apartados anteriores de entre todas las técnicas, el método transitorio de hilo caliente (THW, siglas en inglés) es la técnica más utilizada para la medida de conductividad térmica en fluidos. Este método está basado en la evolución del valor de temperatura respecto al tiempo de un alambre muy delgado. La evolución en el valor de temperatura o incremento se logra debido al efecto Joule en el alambre. Se asume en el 
modelo ideal que la disipación de calor debido al efecto Joule es solamente conductiva y de forma radial a través del fluido que rodea al alambre de forma que dicha disipación es función de la conductividad térmica del fluido, (Figura 24).

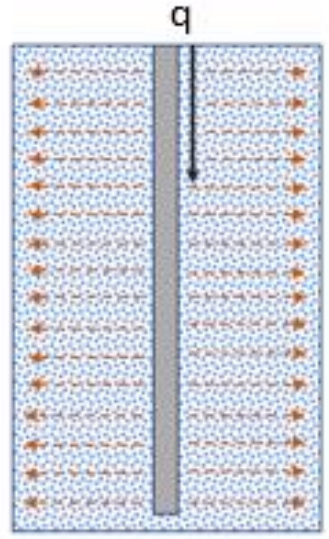

nanofluido

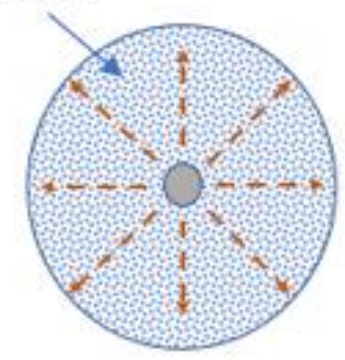

Figura 24. Disipación del calor de forma radial a través del fluido.

En el modelo se considera que la transferencia de calor es solamente conductiva, pero en ensayos llevados a cabo por investigadores que han desarrollado equipos de medida con dicha técnica se han detectado fenómenos de transferencia de calor por convección, sin embargo, este efecto puede evitarse realizando la medición de evolución de la temperatura en tiempos muy cortos. Además, los efectos de transferencia de calor por convección pueden detectarse y despreciarse, ya que cuando se dan estos fenómenos se observan desviaciones en la linealidad de la gráfica de variación de temperatura, (Figura 25), [35, 131].

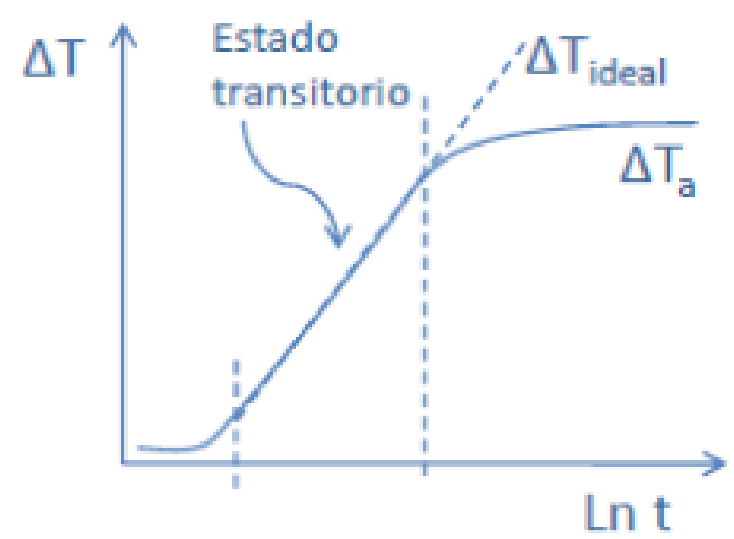

Figura 25. Evolución de la temperatura del fluido cuando se aplica un pulso de calor. Fuente [137] 
Para obtener el valor de conductividad térmica, $k$, se debe medir el aumento de temperatura del alambre con respecto a la temperatura inicial o de equilibrio, el tiempo y el flujo de calor por unidad de longitud que disipa el alambre por efecto Joule (q). Esto requiere de un flujo de calor constante, midiendo en tiempos muy cortos. La relación entre el incremento de temperatura en el líquido y la conductividad térmica de la suspensión viene dada por la siguiente ecuación:

$$
\Delta T=\frac{q}{4 \pi k} \ln \left(\frac{4 \alpha t}{r^{2} C}\right)
$$

Donde

q potencia disipada por unidad de longitud del alambre $(\mathrm{W} / \mathrm{m})$

t $\quad$ tiempo de medición (s)

$r \quad$ radio del alambre $(\mathrm{m})$

C constante

$\alpha \quad$ difusividad térmica $\left(\mathrm{m}^{2} / \mathrm{s}\right)$, que se la relaciona con la conductividad térmica según la ecuación:

$$
\alpha=\frac{k}{\rho c_{p}}
$$

Donde

$$
\begin{aligned}
& \mathrm{k} \text { conductividad térmica }(\mathrm{W} / \mathrm{mK}) \\
& \rho \text { densidad del sólido }\left(\mathrm{kg} / \mathrm{m}^{3}\right) \\
& \mathrm{C}_{\mathrm{p}} \quad \text { calor específico }(\mathrm{J} / \mathrm{kgK})
\end{aligned}
$$

Se han desarrollado varios modelos de equipos en las últimas décadas basados en esta técnica THW. Todos ellos cuentan con un alambre metálico, habitualmente de platino que tiene la función de fuente lineal de calor. 
Metodología experimental seguida para la medida de la conductividad térmica con el equipo KD2. Diseño del dispositivo experimental o accesorio.

En este apartado se ha verificado y desarrollado un método de medida de la conductividad térmica de nanofluidos, utilizando la técnica transitoria de hilo caliente con el equipo KD2 de Decagon Services. Se ha analizado la fiabilidad del mismo para establecer las principales fuentes de incertidumbre con el objetivo de mejorar el procedimiento de medida para reducirlas en la medida de los posible.

El equipo KD2 ha sido diseñado para medida de conductividad térmica usando como base la técnica transitoria de hilo caliente. El equipo dispone de varios sensores siendo el sensor con referencia KS1 un alambre de 1,3 $\mathrm{mm}$ de diámetro y $6 \mathrm{~cm}$ de longitud el sensor indicado por el fabricante por tener el diámetro más fino para la medida de la conductividad térmica en muestras líquidas.

El equipo KD2 ha desarrollado un modelo matemático siguiendo el modelo presentado en la ecuación anterior (Ec.17), gracias al cual tras aplicar un pulso de calor y medir la temperatura del alambre en función del tiempo, se obtiene la conductividad térmica del nanofluido. La conductividad térmica es proporcional al flujo de calor por unidad de longitud del alambre e inversamente proporcional a la pendiente de la región lineal de la curva de incremento de temperatura frente al logaritmo del tiempo.

Durante el impulso de calentamiento la ecuación que ajusta los valores de temperatura obtenidos respecto al tiempo es:

$$
T=m_{0}+m_{2} t+m_{3} \ln (t)
$$

Donde:

mo es la temperatura inicial de la etapa de calentamiento

$\mathrm{m}_{2}$ es el gradiente de variación de la temperatura

$\mathrm{m}_{3}$ es la pendiente de la recta del incremento de temperatura frente al logaritmo del tiempo

Durante el enfriamiento sigue el siguiente ajuste: 


$$
T=m^{\prime}{ }_{0}+m^{\prime}{ }_{2} t+m^{\prime}{ }_{3} \ln \left(t / t-t_{h}\right)
$$

Donde:

$\mathrm{m}_{0}{ }_{0}$ es la temperatura inicial de la etapa de calentamiento

$\mathrm{m}_{2}{ }_{2}$ es el gradiente de variación de la temperatura

$\mathrm{m}_{3}{ }_{3}$ es la pendiente de la recta del incremento de temperatura frente al logaritmo del tiempo

$t_{h}$ es el tiempo en el cual se deja de aplicar el pulso de calor y comienza el enfriamiento Finalmente se obtiene la conductividad térmica como la media obtenida en la etapa de calentamiento como en enfriamiento a partir de la siguiente ecuación;

$$
k=\frac{q}{4 \pi m_{3}}
$$

Donde:

k es la conductividad térmica $(\mathrm{W} / \mathrm{mK})$

q es el impulso de calentamiento aplicado por unidad de longitud $(\mathrm{W} / \mathrm{m})$

En el sensor de medida del equipo KD2 el mismo hilo de platino cumple una doble función, porque además de actuar como fuente de calor también sirve como detector resistivo de la temperatura permitiendo medir las variaciones de temperatura del hilo.

El primer dispositivo que se ha diseñado en el desarrollo de esta fase (Figura 26 imagen a), permite mantener el sensor de medida centrado y vertical dentro del porta-muestras gracias a la nivelación con los tres ejes verticales. Además de la verticalidad del sensor, la temperatura de la muestra mientras se realizan los ensayos debe permanecer constante a la temperatura de ensayo programada. Con el objeto de alcanzar dicho fin, se utilizó un baño termostatado en el cual se sumergió la celda porta-muestras con el sensor, (Figura 26 imagen b). 


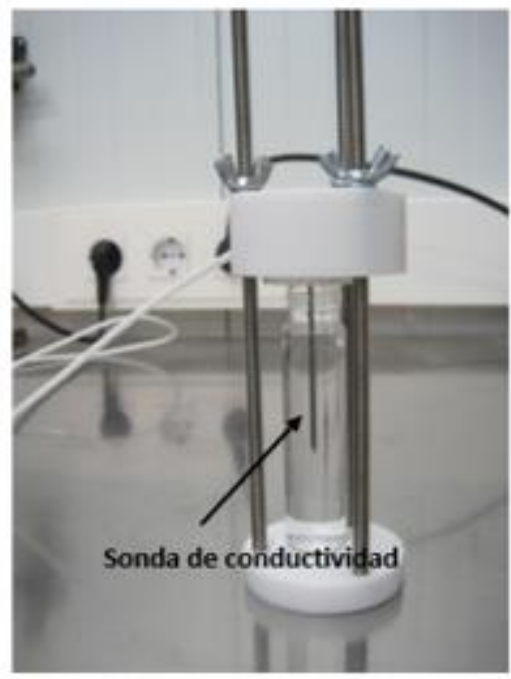

a)

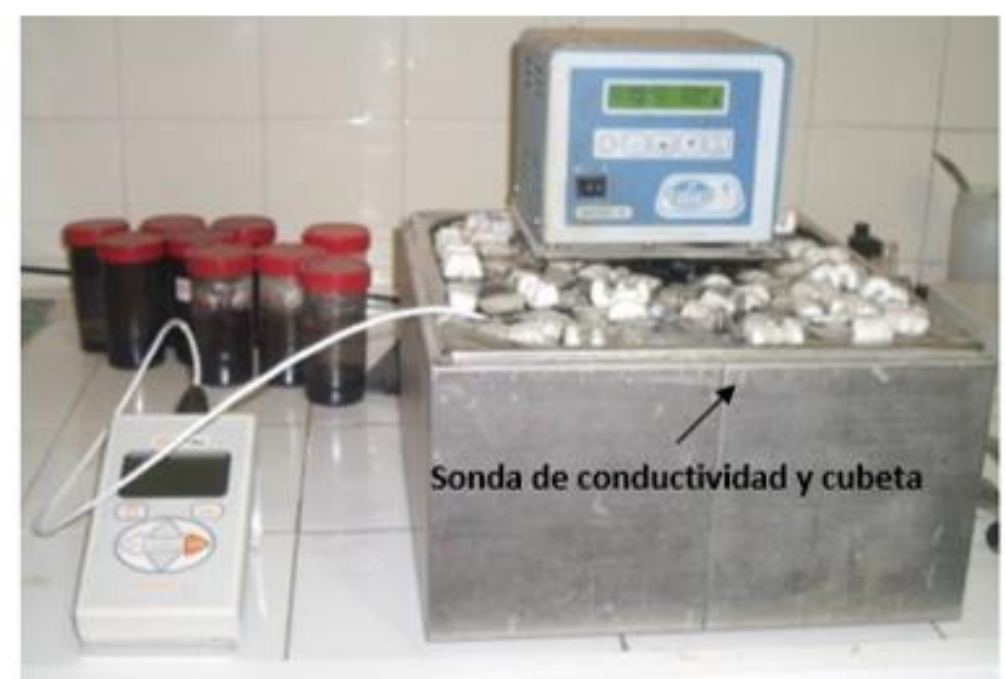

b)

Figura 26. a) Celda diseño experimental inicial con el recipiente porta muestras b) sensor KD2 y baño termostatado para realizar las medidas a distintas temperaturas de ensayo.

Se analizó la influencia de las vibraciones que produce el baño sobre el error de medida que se obtiene en el equipo y en la reproducibilidad, observándose una desviación significativa y que debe minimizarse en la medida de lo posible. Por dicho motivo se propuso un segundo diseño del sistema de acondicionamiento térmico de las muestras en el cual se minimizarán las vibraciones y que se muestra en la Figura 27. El sistema está formado por un vaso con doble camisa por el cual circula el agua atemperada del baño. Este vaso encamisado se sitúa fuera del baño en un soporte independiente minimizando de esta forma las vibraciones y no resultando necesario apagar el baño durante el ensayo. En este nuevo diseño también se optimizó el sistema de colocación de la sonda para garantizar su verticalidad en muestras de nanofluidos preparadas con nanotubos y en las cuales no resulta posible detectar la correcta colocación de la sonda visualmente. En la Figura 28 se muestra el conjunto del equipo de medida, baño y celda de medición con la sonda, utilizado en la caracterización térmica de los nanofluidos. 


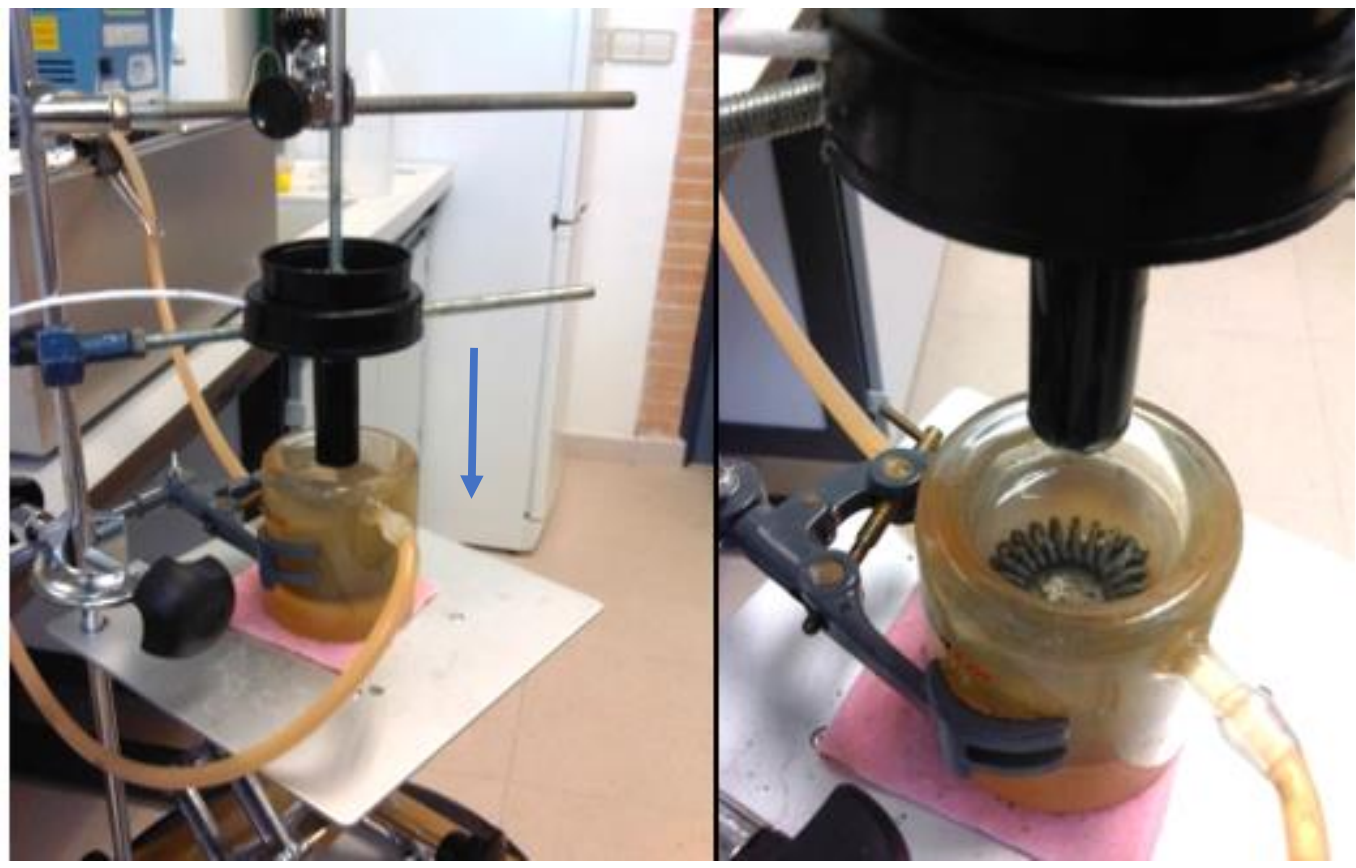

Figura 27. Vista del recipiente encamisado y de la espiral que permite centrar y mantener en posición vertical el porta muestras

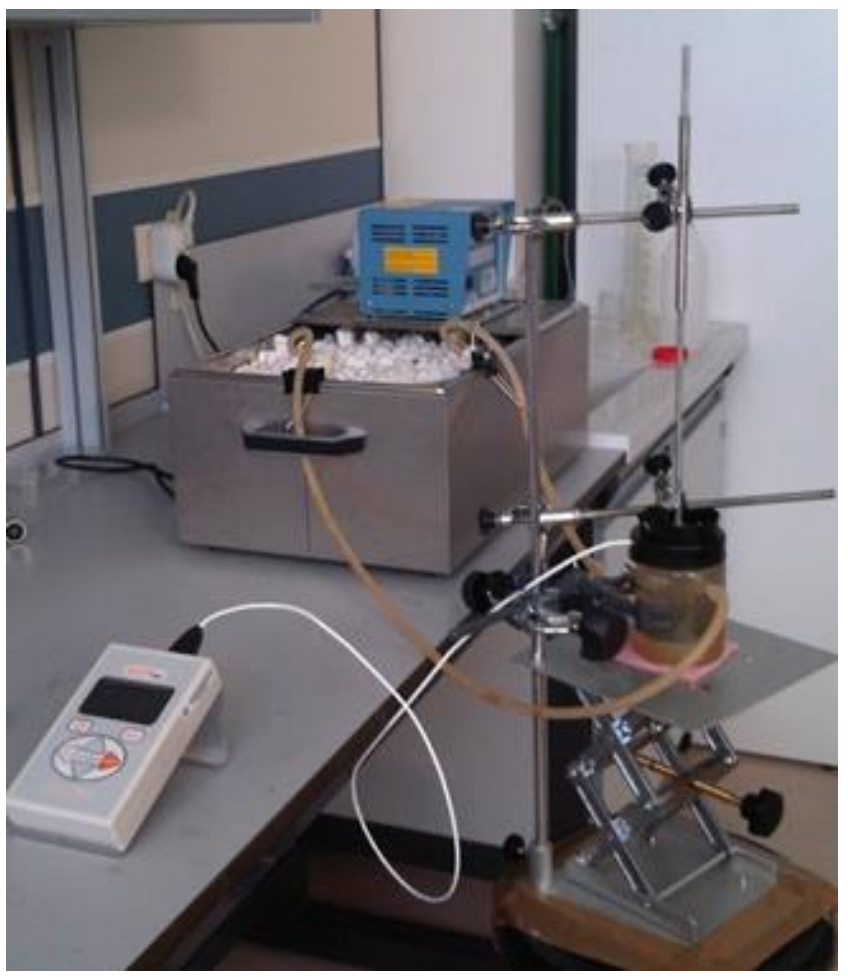

Figura 28 . Vista del montaje final para la medida de la conductividad térmica de los nanofluidos 
Los valores finales de la conductividad térmica se han obtenido a partir del promedio de un mínimo de seis medidas, tomadas cada 15 minutos para que el pulso de calor que el hilo caliente transmite a la muestra durante el ensayo influya mínimamente y las condiciones iniciales de medida sean reproducibles.

El error de medida o repetibilidad del ensayo se ha calculado a partir de la desviación típica (s) de un mínimo de 10 lecturas como:

$$
\text { error }=t \frac{S}{\sqrt{n}}
$$

Siendo t la variable estadística t-student calculada con un grado de confianza del $95 \%$ y un número de grados de libertad igual al tamaño de la muestra menos uno (n-1).

Se tomaron como correctas las medidas indicadas en el equipo KD2 con un error en el ajuste interno de lectura en el equipo menor del 0,01\%.

El error total del método de medida se ha obtenido teniendo en cuenta el error de repetibilidad obtenido en la medida (21), siendo éste el error que se utilizará para el análisis de los resultados. Si se quiere obtener el valor de conductividad térmica absoluta del nanofluido, en el error de medida sería necesario introducir el error del equipo que viene especificado por el fabricante del KD2, y que está fijado para líquidos en un 5\%.

Junto con las medidas de conductividad de los nanofluidos preparados se llevaron a cabo medidas del fluido base, agua destilada a $25^{\circ} \mathrm{C}$ y $40^{\circ} \mathrm{C}$, para así validar el correcto funcionamiento de la sonda.

La conductividad térmica se ha expresado como medida absoluta o como medida relativa (efectiva o incremento) según la ecuación;

$$
k_{\text {efectiva }}=\frac{k_{\text {nanolfuido }}}{k_{\text {fluido base }}} \quad 0 \quad k_{\text {incremento }}(\%)=\left(\frac{k_{\text {nanolfuido }}-k_{\text {fluido base }}}{k_{\text {fluido base }}}\right) * 100
$$

La conductividad térmica como medida relativa efectiva o incremento se ha acompañado del error de medida calculado este según la ley de propagación de errores. 


\subsubsection{Método placas. TCi.}

Dentro de los métodos estáticos, el método de medida de conductividad entre placas paralelas puede evitar los posibles errores en la medida de conductividad por los gradientes en fracción ocasionados por la sedimentación de las nanopartículas debido al poco volumen de muestra. En este método el hueco entre las placas donde se coloca la suspensión es pequeño (sobre $1 \mathrm{~mm}$ ) y minimiza dicho efecto. Sin embargo, los tiempos de medida son más largos que en la técnica transitoria del hilo caliente (THW) por lo cual pueden aparecen problemas de medida por convección [6].

Para la medida de conductividad térmica por este método se ha utilizado el analizador de conductividad térmica C-Therm TCi de la casa Mathis Instrumentos Ltd Figura 30, con la técnica de fuente plana transitoria modificada. Este analizador de conductividad térmica se basa en la medida experimental de la efusividad térmica de la muestra. Para realizar esta determinación, un sensor de área perfectamente conocida induce, mediante una resistencia eléctrica, un cambio en la temperatura, tanto del sensor como de la muestra, que varía con el tiempo. La variación de la temperatura con el tiempo se relaciona con la efusividad del sensor (conocida mediante calibración) y de la muestra, lo que permite la determinación de la misma. A partir del dato de efusividad de la muestra es posible calcular varios valores indirectos, como por ejemplo el valor de la conductividad térmica, si se conocen la densidad y capacidad calorífica del material analizado.

Para la medida de conductividad térmica en estado estacionario en los nanofluidos se utilizó el kit de testeo de pequeños volúmenes (Figura 29). Los ensayos se realizaron a distintas temperaturas llevando todo el kit a la temperatura fijada dentro de la cámara climática como se muestra en la Figura 30. 


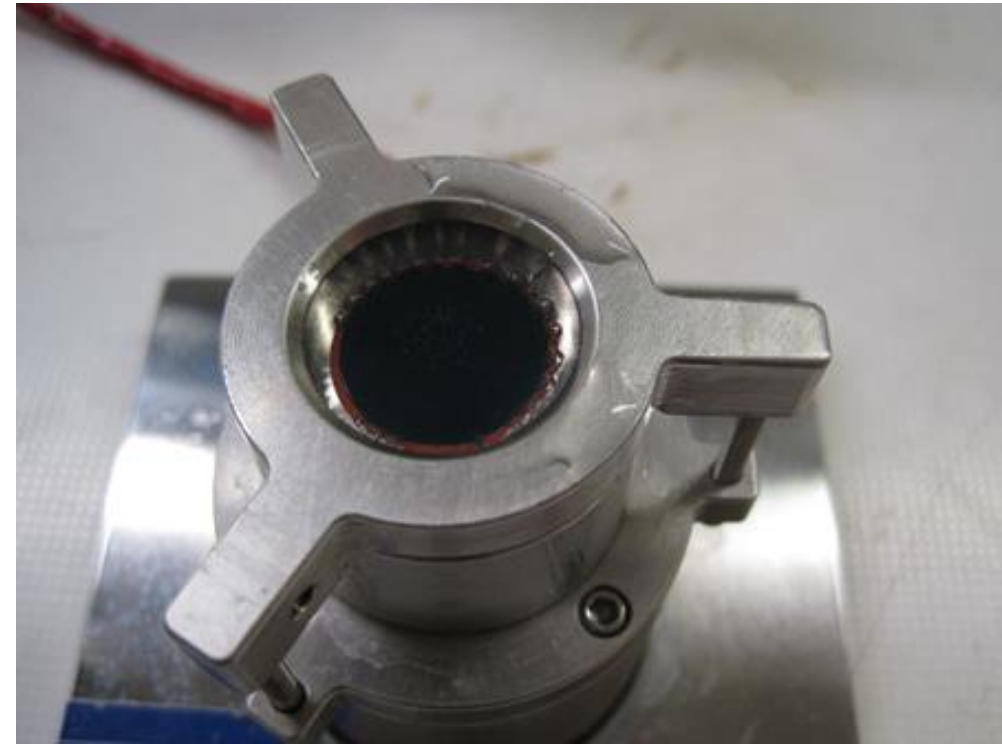

Figura 29. Kit de testeo en pequeños volúmenes

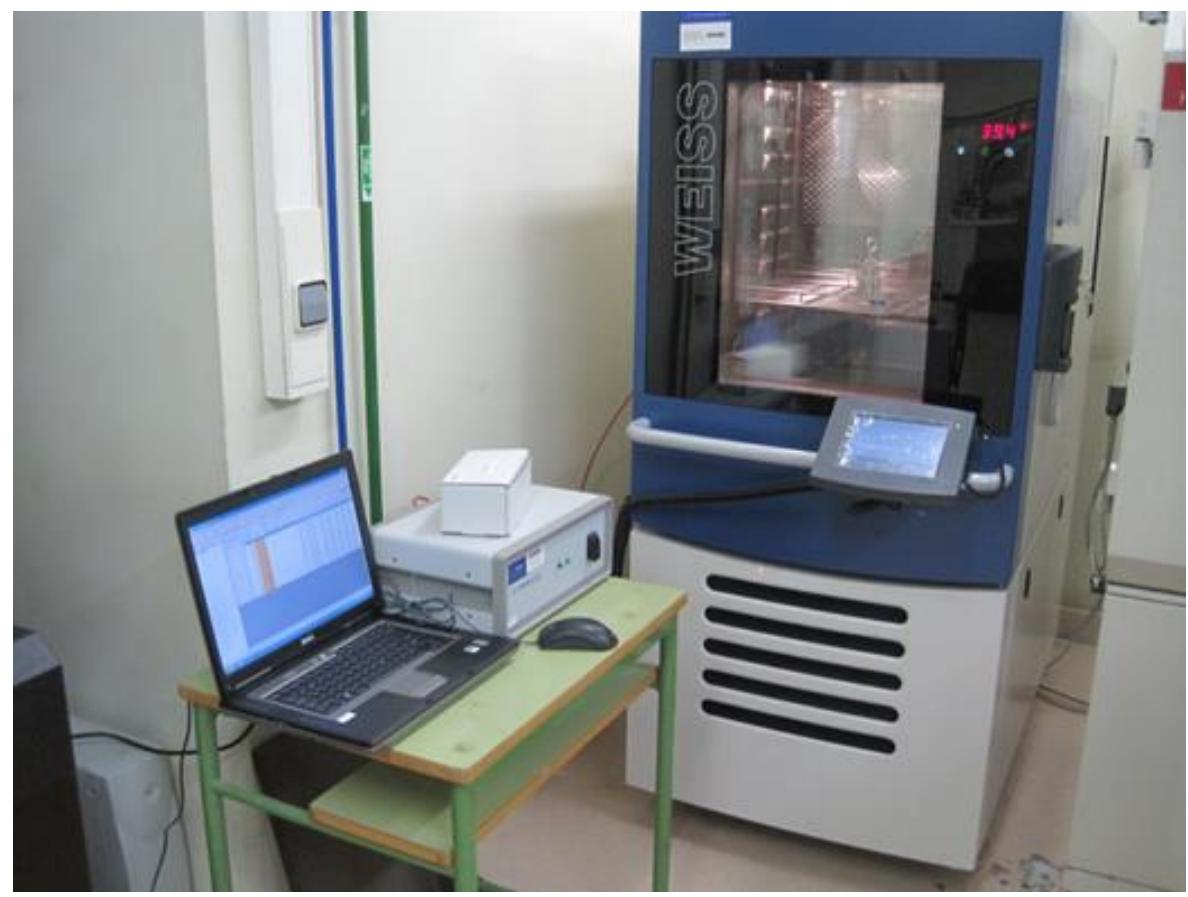

Figura 30. Analizador de conductividad térmica TCi de C-Therm dentro de la cámara climática

Esta técnica no cuenta con un dispositivo para calefactar las muestras por lo que presenta un problema para realizar los ensayos a distintas temperaturas. Cuando se mide la conductividad térmica en el TCi la muestra durante el ensayo no se puede mantener constante la temperatura de la muestra, por lo cual tan solo se pueden hacer medidas con repeticiones a temperatura ambiente. Se intentó mantener la temperatura colocando todo el equipo en el interior de una cámara climática, como puede apreciarse en la imagen, pero esta medida no fue suficiente para poder fijar la temperatura del ensayo. 
En la Figura 31 se ha representado los valores de conductividad obtenidos con el material de sílice y la muestra de agua destilada a distintas temperaturas. Las medidas de la serie 1 y 2 con los nanofluidos de sílice se iniciaron a $50^{\circ} \mathrm{C}$ y se observa que, aunque el ensayo se llevó a cabo dentro de una cámara climática, la muestra se enfría y va disminuyendo su temperatura progresivamente, disminuyendo hasta los $40^{\circ} \mathrm{C}$ a medida que transcurre el tiempo de ensayo (serie 2). Este hecho es más acusado cuando las medidas de conductividad se realizan a $65^{\circ} \mathrm{C}$ (series 3 y 4), donde la pérdida de temperatura durante la realización del ensayo es de $15^{\circ} \mathrm{C}$. Además, las medidas de conductividad térmica obtenidas para el agua presentan valores mucho más altos que los teóricos a los mostrados en la revisión bibliográfica, posiblemente por los mecanismos de convección originados en la muestra al utilizar este método tiempos más largos de medida y que se acusan mucho más a temperaturas mayores de $60^{\circ} \mathrm{C}$.

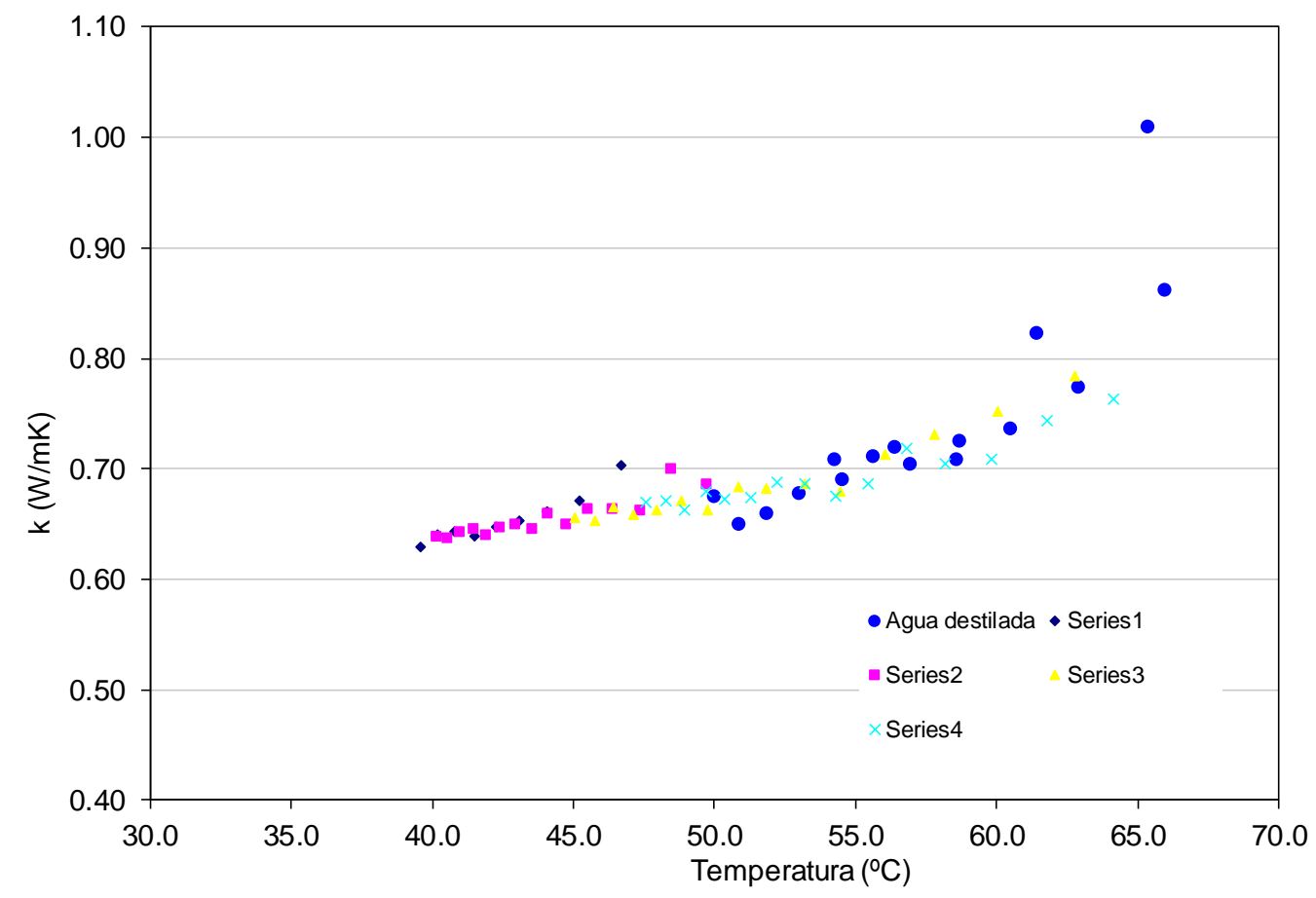

Figura 31. Medida conductividad LUDOX $1 \% \mathrm{pH}=9$

Por este motivo se consideró más adecuado realizar las medidas con el método transitorio de hilo caliente, con el equipo KD2, donde si se pueden realizar las medidas de temperatura en un baño termostatado pues el diseño del equipo con la sonda sí que lo permite, como se ha mostrado en la imagen Figura 28. 


\subsection{Medida de la Viscosidad}

La caracterización reológica de los nanofluidos es un requisito indispensable para su aplicación como fluido térmico ya que la introducción de nanopartículas en el fluido con el objetivo de mejorar su conductividad térmica conlleva un aumento de la viscosidad del mismo $[1,2]$.

Para medir la viscosidad de un fluido del cual se desconoce a priori si es un fluido newtoniano o no newtoniano se utilizan los reómetros. En este equipo se aplica un esfuerzo y se mide el comportamiento del material. Si el esfuerzo aplicado $(\sigma)$ es mayor que el límite de resistencia que el material puede soportar se puede romper la estructura de la muestra y ésta comienza a fluir. En este caso la muestra se comportará como un líquido y seguirá la ley de Newton, según la cual al aplicar una tensión o esfuerzo cortante $(\sigma)$ sobre un fluido se genera en este un gradiente de velocidad $(\nu)$ proporcional al esfuerzo aplicado:

$$
\sigma=\eta \cdot \gamma
$$

Donde $\eta$ es la viscosidad del fluido (Pa.s).

Esta ecuación define el comportamiento en condiciones de flujo estacionario.

La viscosidad de un fluido puede verse afectada por su naturaleza, su temperatura, la presión, la velocidad de cizalla, e incluso la presencia de campos eléctricos y magnéticos. De todas estas variables, la más significativa, es la velocidad de cizalla. Cuando se hacen circular los fluidos térmicos en los intercambiadores las velocidades de cizalla pueden llegar a alcanzar valores de $10^{3}-10^{4} \mathrm{~s}^{-1}$.

\section{Efecto de la velocidad de cizalla}

El modelo de Newton asume que existe una proporcionalidad directa entre el esfuerzo cortante y el gradiente de velocidad producido. Existen habitualmente dos formas de representar el comportamiento al flujo:

- Curvas de flujo; representación gráfica del esfuerzo cortante o tensión en función de la velocidad de cizalla

- Curvas de viscosidad; representación gráfica de la viscosidad en función de la velocidad de cizalla. 
En un líquido Newtoniano la curva de flujo es una línea recta, que comienza en el origen y tiene como pendiente la viscosidad $(\eta)$. Si se representa la viscosidad frente al gradiente de velocidad de un fluido newtoniano se obtiene una recta paralela al eje de abcisas, ya que la viscosidad no varía con la velocidad de cizalla. Un fluido que se desvía de estas características es un fluido no-newtoniano. Debido a que la mayor parte de los materiales son nonewtonianos, tendremos siempre una viscosidad de cizalla o viscosidad aparente dependiente de la velocidad y que necesitaremos medir de forma experimental.

\section{Efecto de la temperatura}

La viscosidad depende de la temperatura, concretamente para los fluidos newtonianos disminuye al aumentar la temperatura, siguiendo aproximadamente la ley de Arrhenius:

$$
\eta=A e^{-B / R T}
$$

Donde T es la temperatura y A y B son constantes características de cada fluido. En general cuanto mayor es la viscosidad más dependiente es de la temperatura.

En el caso de que el fluido térmico sea un nanofluido, además de las variables ya mencionadas, existen otras variables que van a afectar a la viscosidad del nanofluido [3]. Los nanofluidos están formados por nanopartículas y en función del grado de dispersión y el tamaño y fracción de las mismas o de lo aglomerados [4], el nanofluido puede tener un comportamiento muy diferente, pasando por ejemplo de ser un fluido newtoniano a uno no newtoniano.

Por todos estos factores que afectan a la viscosidad del nanofluido se han programado para la caracterización de su comportamiento reológico ensayos a varias velocidades de cizalla y distintas temperaturas para cada una de las muestras en las que se ha ido variando el grado de dispersión, fracción volumétrica de nanopartículas, pH, tipología y tamaño.

Los equipos más utilizados en la medida de viscosidad de los nanofluidos documentados en la bibliografía revisada son los siguientes [6]:

- Reómetro de cilindros coaxiales (Haake Rheostress RS600)

- Viscosímetro cono-plato de Brookfield (LVDV-I PRIME C/P)

- Reómetro Bohlin CVO

- Vicosímetro de capilaridad Ubbeholder (Fisher Scientific) 
- También se han utilizado equipos experimentales como el viscosímetro tipo pistón basado en el flujo de Couette dentro de una cámara de medida cilíndrica acondicionada térmicamente para realizar los ensayos a temperatura [93].

Entre todos estos métodos el equipo seleccionado para realizar la medida de la viscosidad en los nanofluidos ha sido el reómetro de rotación.

\subsubsection{Medida de la viscosidad en un reómetro de rotación}

Para medir la viscosidad de los nanofluidos se utilizará un reómetro de rotación que aplica la deformación por cizallamiento controlado a la muestra. Este equipo permite medir las propiedades de un flujo o de un material y obtener los valores de viscosidad en función del gradiente de velocidad. El modelo utilizado para efectuar la caracterización del comportamiento reológico de los nanofluidos fue el Kinexus de Malver Phanalitical, Figura 32 imagen izquierda.

Para los ensayos de viscosidad de los nanofluidos (de los cuales esperamos que tengan un comportamiento en viscosidad parecido al del agua sobre todo a bajas fracciones volumétricas), se utilizó el dispositivo de medida "de doble hueco", Figura 32, imagen derecha. Este sistema es el que se utiliza generalmente para suspensiones de baja viscosidad, ya que su alta superficie aporta una buena sensibilidad y por tanto permite obtener datos de viscosidad con una baja deformación por cizallamiento.

En este sistema de cilindros concéntricos, la cantidad de muestra a utilizar mínima es de 20 ml. Para los ensayos se llena la celda con el nanofluido a caracterizar y se programa la temperatura a la cual se quiere medir la viscosidad del fluido (el reómetro dispone de una placa peltier que permite un ajuste muy rápido de la muestra a la temperatura de consigna). Una vez alcanzada la temperatura, se inicia el ensayo programado a diferentes velocidades de cizalla. 

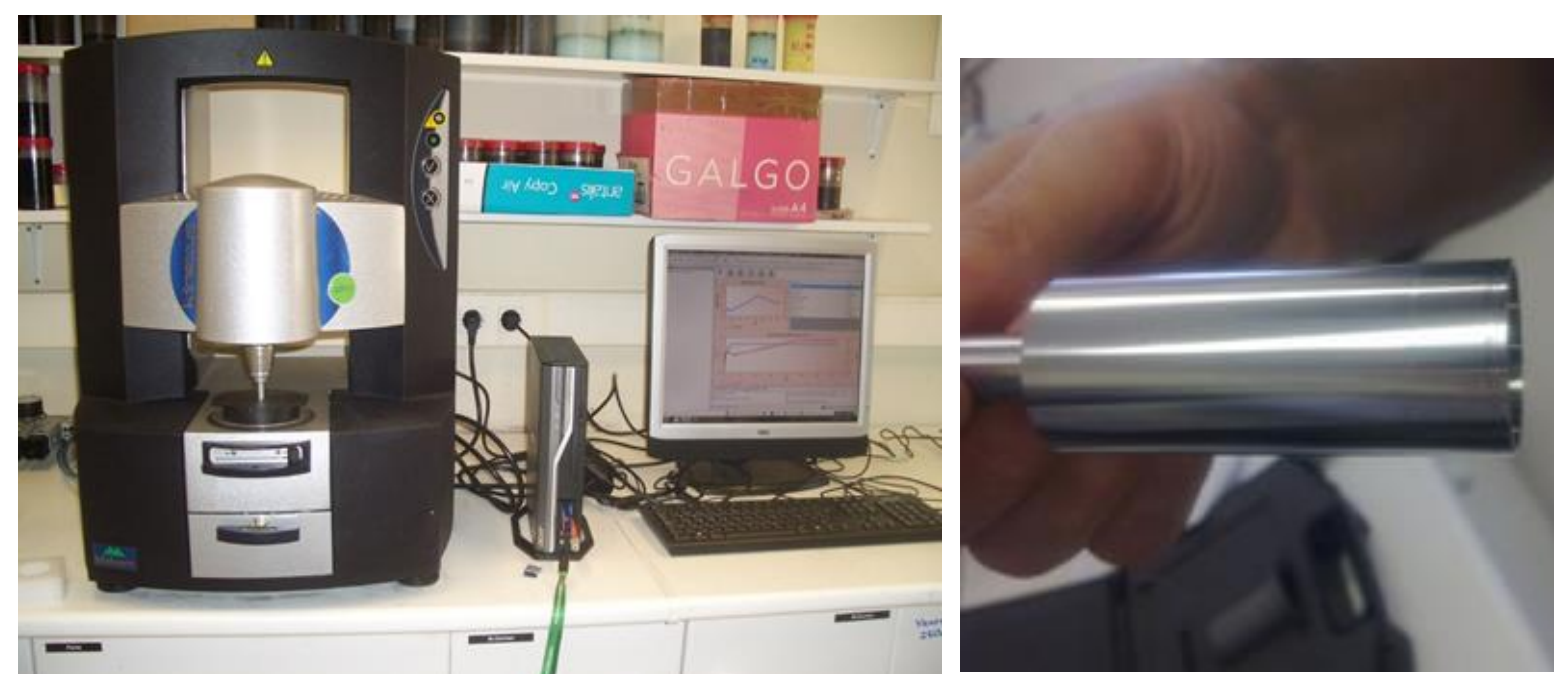

Figura 32. Imagen reómetro Kinexus y accesorio de doble gap utilizado para la medida de la viscosidad

\subsubsection{Medida de la viscosidad en un equipo óptico}

El equipo Fluidicam es un reómetro óptico que permite obtener la viscosidad de un fluido a elevados gradientes de cizalla.

La muestra a medir y un estándar newtoniano de viscosidad conocida, se impulsan a la vez mediante el uso de dos jeringuillas (Figura 33 )a)) por unos conductos hasta alcanzar el chip de cristal en forma de "Y" (Figura 33 c)) a una velocidad de flujo controlada. Un sistema óptico adquiere la imagen del flujo laminar de ambas muestras a su paso por el chip. La posición de la interfase (línea naranja en Figura 33 b)) está relacionada con la viscosidad y las diferencias entre las velocidades de flujo de la muestra y el estándar newtoniano de viscosidad conocida. A través de los cálculos del equipo se obtiene la viscosidad de la muestra en función de la temperatura. 


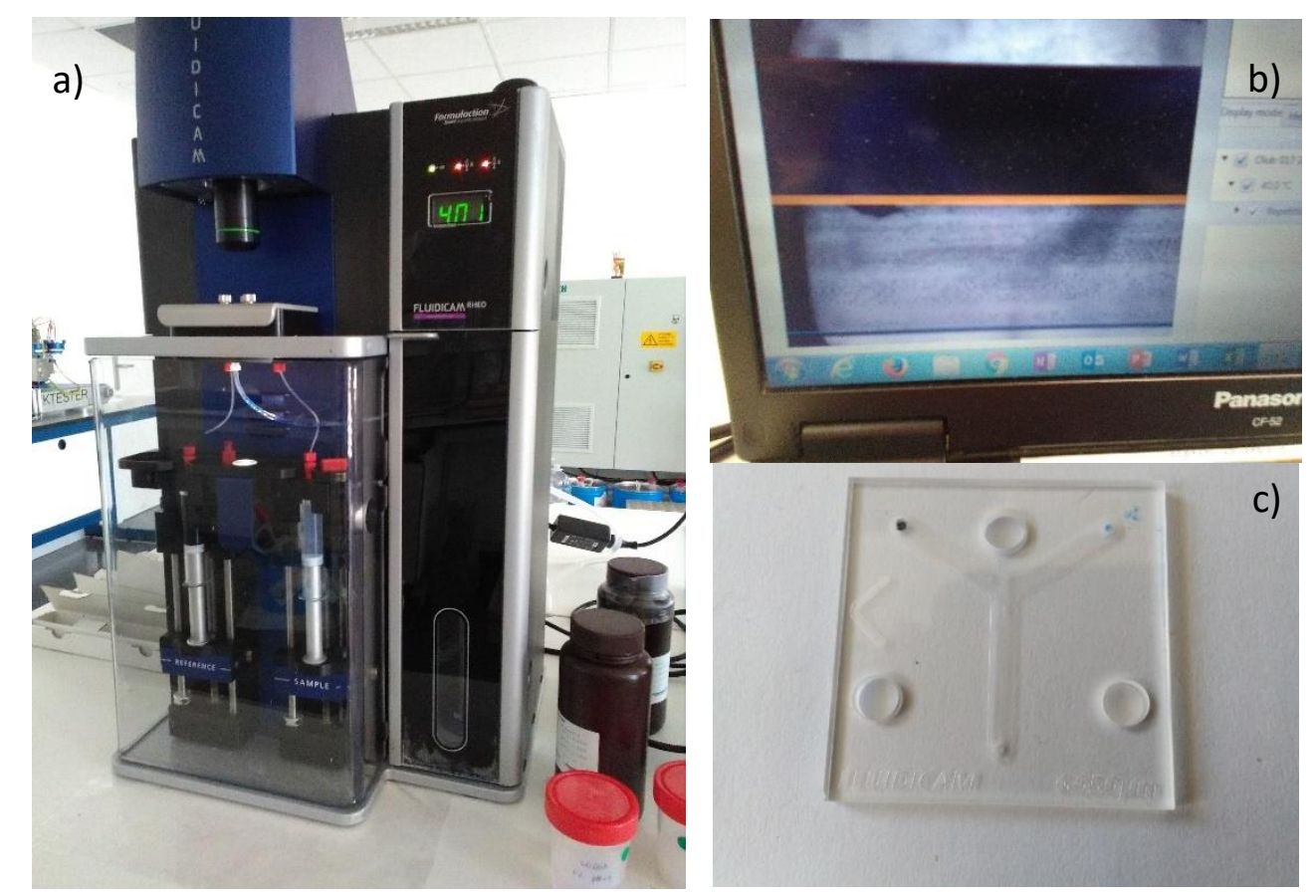

Figura 33. Imagen reómetro óptico Fluidicam y accesorio para la medida de la viscosidad

\subsection{Caracterización de los nanofluidos por análisis de imagen}

\subsubsection{Microscopia electrónica de transmisión TEM}

La microscopía electrónica de transmisión (TEM) es una técnica muy utilizada para la caracterización estructural y química de los materiales en el campo de la Química Inorgánica, Química Orgánica, Ingeniería de Materiales, Biología y Biomedicina.

En el microscopio electrónico de transmisión, una muestra es irradiada con un haz de electrones con una energía entre 100 y $200 \mathrm{KeV}$. Entre las diferentes interacciones que se producen cuando los electrones inciden sobre la materia, se utiliza la transmisión / dispersión para la formación de la imagen, la difracción de electrones para obtener información cristalográfica, y la emisión de rayos $\mathrm{X}$ característicos para determinar la composición elemental de la muestra. Se utilizó para los ensayos el microscopio electrónico de transmisión JEOL 2100. 


\subsubsection{Microscopia electrónica de barrido MEB}

Las muestras se observaron y fotografiaron con la señal de electrones retrodispersados y electrones secundarios del microscopio electrónico de barrido de emisión de campo (FEG Quanta 200F).

La señal de electrones retrodispersados proporciona información sobre la topografía y composición; siendo más intensa cuanto mayor es el número atómico medio de la muestra, de manera que las zonas más claras contienen elementos más pesados (contraste de composición).

La señal de electrones secundarios es más superficial de manera que proporciona información sobre la morfología de la muestra, resaltando las irregularidades de la superficie, como grietas, poros, bordes de grano o de cristales...

La observación se ha realizado con electrones acelerados con dos potenciales distintos, $10 \mathrm{y}$ $20 \mathrm{keV}$, de manera que cuanto menor es el potencial de aceleración de los electrones, más superficial es la señal.

\subsection{Determinación del tamaño de partícula}

La distribución de tamaños de partícula de los sólidos en los nanofluidos preparados se ha determinado utilizando un equipo de difracción de láser MASTERSIZER 2000 de la firma MALVERN. En este equipo, las partículas atraviesan un haz de luz láser y la luz que dispersan es recogida en 52 detectores.

Los cálculos se han realizado con el software que incorpora el equipo, utilizando la teoría de Mie para interpretar la señal de dispersión de luz recogida por los detectores. Los cálculos se han efectuado considerando el índice de refracción respectivo para cada tipo de muestra y su correspondiente valor de coeficiente de absorción.

La muestra se ha dispersado en agua, introduciendo una porción de la muestra en la cubeta del equipo, donde se ha sometido a ultrasonidos y agitación mecánica durante la caracterización de su tamaño.

Las distribuciones de tamaños de partícula de las muestras con tamaño nanométrico se han determinado utilizando el equipo ZETASIZER NANO de la firma MALVERN. El método utilizado 
se basa en la difracción dinámica de luz (Dynamic Light Scattering, DLS). Esta técnica analiza tamaños submicrónicos basándose en el movimiento Browniano. La relación entre el tamaño de partícula y la velocidad debido al movimiento Browniano se define en la ecuación EinsteinStokes. Las suspensiones se introducen en una cubeta de plástico. El ensayo se lleva a cabo a una temperatura de $25^{\circ} \mathrm{C}$, ya que la viscosidad del medio vendrá influenciada por la temperatura, dejando un tiempo de equilibrio antes de realizar la medida de 10 segundos, ya que tiempos de estabilización mayores influyen en la estabilidad de la suspensión. Los cálculos se han efectuado considerando el índice de refracción y valor del coeficiente de absorción específicos para cada muestra.

\subsection{Determinación del calor específico, $\mathrm{C}_{\mathrm{p}}$}

El calor específico de una muestra describe la cantidad de calor requerida para incrementar la temperatura (a presión constante). La capacidad calorífica viene definida según la siguiente expresión:

$$
c_{p}=\frac{d H}{d t} \frac{1}{\beta_{s} m_{0}}
$$

siendo $\mathrm{dH} / \mathrm{dt}=$ Flujo de calor de la muestra $(\mathrm{kJ} / \mathrm{s})$

$$
\begin{aligned}
& \beta_{\mathrm{s}}=\text { velocidad de calentamiento de la muestra }(\mathrm{K} / \mathrm{s}) \\
& \mathrm{m}_{0}=\text { masa de la muestra }(\mathrm{kg})
\end{aligned}
$$

Los experimentos se han realizado en un Calorímetro Diferencial de Barrido (DSC), modelo DSC1 (Mettler Toledo, USA).

El cálculo del calor específico se ha realizado según normas DIN (DIN 51007), que define la secuencia de la temperatura del programa de acuerdo con las siguientes etapas: tramo isotermo, tramo dinámico y por último, tramo isotermo. Según la norma DIN 51007, los valores de $C_{p}$ son obtenidos tras la comparación de la curva de DSC obtenida por la muestra ensayada con la obtenida por medio de un zafiro patrón. 
Como consecuencia de la naturaleza de la muestra (líquida), el crisol (Aluminio) se tiene que sellar con objeto de evitar pérdidas de material por evaporación y el calor específico se calcula a temperaturas inferiores a las de ebullición.

Seguidamente se cita la secuencia de temperaturas utilizadas en la determinación del calor específico de las suspensiones:

- Tramo isotermo de 5 minutos a $25^{\circ} \mathrm{C}$.

- Subida de $25^{\circ} \mathrm{C}$ a $95^{\circ} \mathrm{C}$ a una velocidad de calentamiento de $10^{\circ} \mathrm{C} / \mathrm{min}$.

- Tramo isotermo de 5 minutos a $95^{\circ} \mathrm{C}$.

\subsection{Determinación de la densidad}

La densidad real de las muestras se ha determinado empleando un estereo-picnómetro de helio de Quantachrome. La técnica se basa en la determinación del volumen real que ocupa el polvo mediante diferencia entre el volumen de la celda y el que ocupa el helio que se introduce para acabar de llenar dicha celda. La densidad real se calcula teniendo en cuenta la masa del polvo utilizado.

\subsection{Medida del potencial zeta}

El potencial zeta es una medida de la estabilidad de una dispersión coloidal, debido a que es un buen índice de la magnitud de la interacción repulsiva entre partículas coloidales.

Para medir el potencial zeta (ל) de una suspensión, se utiliza el Zetasizer Nano ZS de la casa Malvern Instruments. Es un equipo que analiza el potencial zeta aplicando un campo eléctrico a través de la suspensión, de modo que las partículas cargadas migran hacia el electrodo de carga opuesta con una velocidad proporcional a la magnitud del potencial zeta. Esta velocidad es medida utilizando la técnica Velocimetría Doppler de Láser (LDV, Láser Doppler Velocimetry) midiendo la movilidad electroforética de las partículas. La medida de potencial zeta se obtiene a partir de la ecuación de Smoluchowsky :

$$
U E=(2 \cdot \varepsilon \cdot z \cdot f(k a)) /(3 \cdot \eta)
$$

Donde: 
z Potencial Zeta $(\mathrm{mV})$

UE Movilidad electroforética ( $\mu \mathrm{mcm} / \mathrm{Vs})$

$\varepsilon \quad$ Constante dieléctrica

$\eta \quad$ viscosidad (cP)

$f(k a) \quad 1,5$

Para determinar el potencial zeta de la suspensión, se realiza un barrido de $\mathrm{pH}$ (utilizando ácido clorhídrico $10 \%$ y $\mathrm{NaOH} 0,1 \mathrm{~N}$ ) y el accesorio Titrator de Malvern Instruments, a $25^{\circ} \mathrm{C}$. Para el agua como base, se utiliza una constante dieléctrica de 78,5 y una viscosidad de 0,8872 cP $\left(\right.$ a $\left.25^{\circ} \mathrm{C}\right)$.

\subsection{Medida de $\mathrm{pH}$}

Para estudiar la influencia del $\mathrm{pH}$ sobre la conductividad de las muestras de nanofluidos preparados con MWCNTs se utilizó un pH-metro Crison. El pH de las suspensiones se modificó añadiendo gotas de disoluciones ácidas de $\mathrm{HCl}$ al $10 \%$ o de $\mathrm{NaOH} 0,1 \mathrm{~N}$ hasta alcanzar el pH deseado.

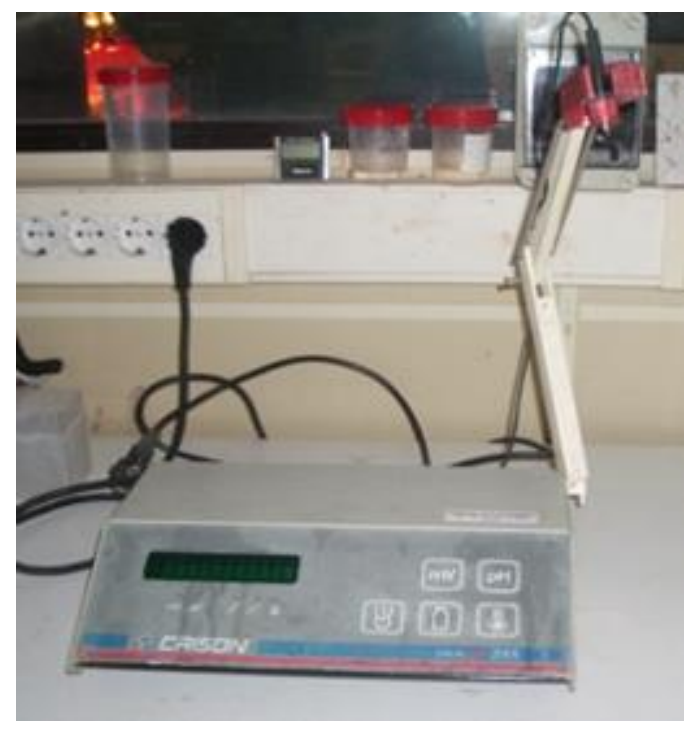

Figura 34. pH-metro Crison utilizado para la medida de pH de los nanofluidos 


\subsection{Espectroscopía infrarroja, FTIR}

Cuando la radiación infrarroja incide sobre una muestra es capaz de provocar cambios en los estados vibracionales de las moléculas que la constituyen. La absorción de radiación por parte de una muestra es indicativa del tipo de enlaces y grupos funcionales presentes en ésta.

Se utilizó para los ensayos un espectrómetro de infrarrojo por transformada de Fourier de la marca Jasco, modelo FT / IR -6200. Este espectrofotómetro permite la medida de las transiciones vibracionales moleculares que se encuentran en el intervalo de longitudes de onda de $15000 \mathrm{~cm}^{-1}$ hasta $50 \mathrm{~cm}^{-1}$. Presenta una resolución máxima de $0,25 \mathrm{~cm}^{-1}$ y una relación $\mathrm{S} / \mathrm{N}$ de $45000: 1$.

El equipo está acoplado a un microscopio FT-IR de la marca Jasco, modelo IRT -3000. Este microscopio permite la observación tanto por reflexión como para transmisión. En la zona observada, permite la medida de transiciones vibracionales en el intervalo de 5000 hasta 600 $\mathrm{cm}^{-1}$. Se pueden utilizar dos objetivos; $\times 16$ y $\times 32$. Además, permite realizar un "mapping" de las transiciones de IR con movimiento en las tres direcciones del espacio. 



\section{CAPÍTULO IV}

Resultados y discusión 



\section{Preparación y caracterización de los nanofluidos preparados con óxidos}

\section{cerámicos y metálicos}

Los primeros materiales elegidos para iniciar el estudio de dispersión acuosa de nanopartículas con el objetivo de obtener nanofluidos de elevada conductividad térmica fueron los óxidos cerámicos. Como ya se ha mencionado en el capítulo de materiales, los dos óxidos cerámicos seleccionados fueron el dióxido de silicio $\left(\mathrm{SiO}_{2}\right)$, llamado comúnmente sílice y el óxido de aluminio $\left(\mathrm{Al}_{2} \mathrm{O}_{3}\right)$, llamado comúnmente alúmina. Además de estos dos óxidos cerámicos el estudio se llevó a cabo también con un óxido metálico, concretamente el óxido de cobre (II) (CuO), para así analizar la influencia de la distinta naturaleza de estos óxidos sobre la conductividad térmica del nanofluido.

En la Tabla 14 se resumen todos los nanofluidos preparados con los distintos tipos de nanopartículas de óxidos cerámicos y metálicos adquiridos (Capítulo III apartado materiales 1.), junto con el sistema de dispersión y estabilización aplicado y los ensayos de caracterización realizados para cada caso. Se ha medido su capacidad calorífica, viscosidad y conductividad térmica a tres temperaturas $\left(40,60\right.$ y $\left.80^{\circ} \mathrm{C}\right)$ con el objetivo de analizar el efecto de la temperatura sobre las propiedades finales de los nanofluidos siguiendo el procedimiento de ensayo descrito en el Capítulo III (apartado 2.4 y 2.5). También se ha caracterizado la estabilidad de los nanofluidos mediante el turbiscán, así como el grado de dispersión de las nanopartículas en el medio acuoso mediante los equipos TEM y láser (Malvern), (Capitulo III 2.3). 
Tabla 14. Tabla resumen de la preparación y caracterización de los nanofluidos preparados con nanopartículas de sílice, alúmina y óxido de cobre

\begin{tabular}{|c|c|c|c|c|}
\hline Ref. muestra & $\begin{array}{c}\text { Estado nanopartícula } \\
\text { adquirida }\end{array}$ & $\begin{array}{c}\text { Tiempo de } \\
\text { ultrasonidos } \\
\text { (min) }\end{array}$ & $\begin{array}{c}\text { Fracción } \\
\text { volumétrica } \\
\Phi(\%)\end{array}$ & Ajuste $\mathrm{pH}$ \\
\hline Sílice AEROSIL & Polvo & 12 & 0,5 & 9 \\
\hline Sílice AEROSIL & Polvo & 12 & 1 & 9 \\
\hline Sílice AEROSIL & Polvo & 12 & 5 & 9 \\
\hline Sílice LUDOX & Suspensión & 12 & 0,5 & 9 \\
\hline Sílice LUDOX & Suspensión & 12 & 1 & 9 \\
\hline Sílice LUDOX & Suspensión & 12 & 5 & 9 \\
\hline Alúmina AEROXIDE & Polvo & 10 & 0,5 & 4 \\
\hline Alúmina AEROXIDE & Polvo & 10 & 1 & 4 \\
\hline Alúmina AEROXIDE & Polvo & 10 & 5 & 4 \\
\hline Alúmina AERODISP & Suspensión & 10 & 0,5 & 4 \\
\hline Alúmina AERODISP & Suspensión & 10 & 1 & 4 \\
\hline Alúmina AERODISP & Suspensión & 10 & 5 & 4 \\
\hline Óxido de cobre II & Polvo & 12 & 0,5 & 4 \\
\hline Óxido de cobre II & Polvo & 12 & 1 & 4 \\
\hline Óxido de cobre II & Polvo & 12 & 5 & 4 \\
\hline
\end{tabular}

Para una mejor compresión de los ensayos realizados en este apartado de caracterización de los nanofluidos obtenidos a partir de óxidos, se muestra en la Figura 35 un diagrama de flujo el procedimiento seguido con cada tipo de óxido. 

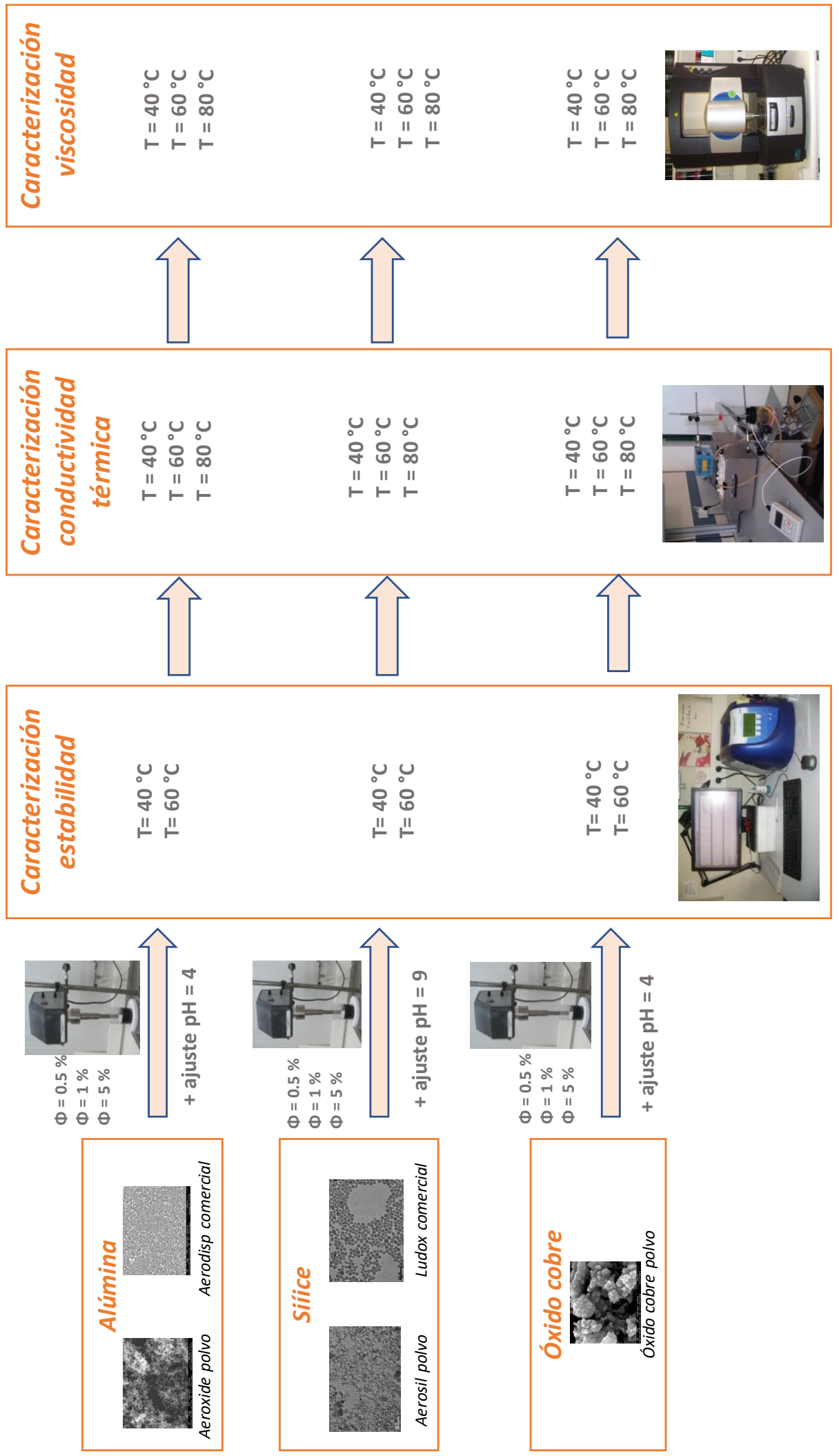

Figura 35. Diagrama de flujo donde se muestra el procedimiento seguido con cada tipo de material para la preparación y caracterización de los nanofluidos 


\subsection{Caracterización de los nanofluidos preparados con nanopartículas de sílice}

Para la preparación de los nanofluidos de sílice se utilizaron dos tipos de materiales. Un óxido de sílice en polvo (Aerosil 200) y una suspensión de nanopartículas de sílice en medio acuoso (LUDOX) como se ha descrito en el capítulo III Materiales y metodología experimental. A continuación, se describe el método seguido en la preparación de los nanofluidos de sílice y la caracterización de su estabilidad, conductividad térmica y viscosidad.

\subsubsection{Caracterización del material de sílice de partida}

Para poder analizar la influencia que puede tener el estado de aglomeración de las nanopartículas utilizadas en la preparación de los nanofluidos se caracterizó en primer lugar la forma y el tamaño de los agregados de las nanopartículas de sílice adquiridas. Para dicho estudio se utilizaron dos técnicas, el análisis de imagen obtenida mediante microscopía de barrido (MEB) y el análisis de tamaño de partícula mediante difracción láser (equipo MALVERN).

En la Figura 36 se muestran las imágenes de la sílice en polvo adquirida Aerosil 200, obtenidas en el Microscopio óptico de barrido a distintos aumentos. Como se observa en ambas fotografías, aunque las partículas de sílice en origen tienen tamaño nanométrico según el fabricante, el estado de agregación de las mismas es elevado (aglomerados con tamaño medio superior a $200 \mathrm{~nm}$ ).
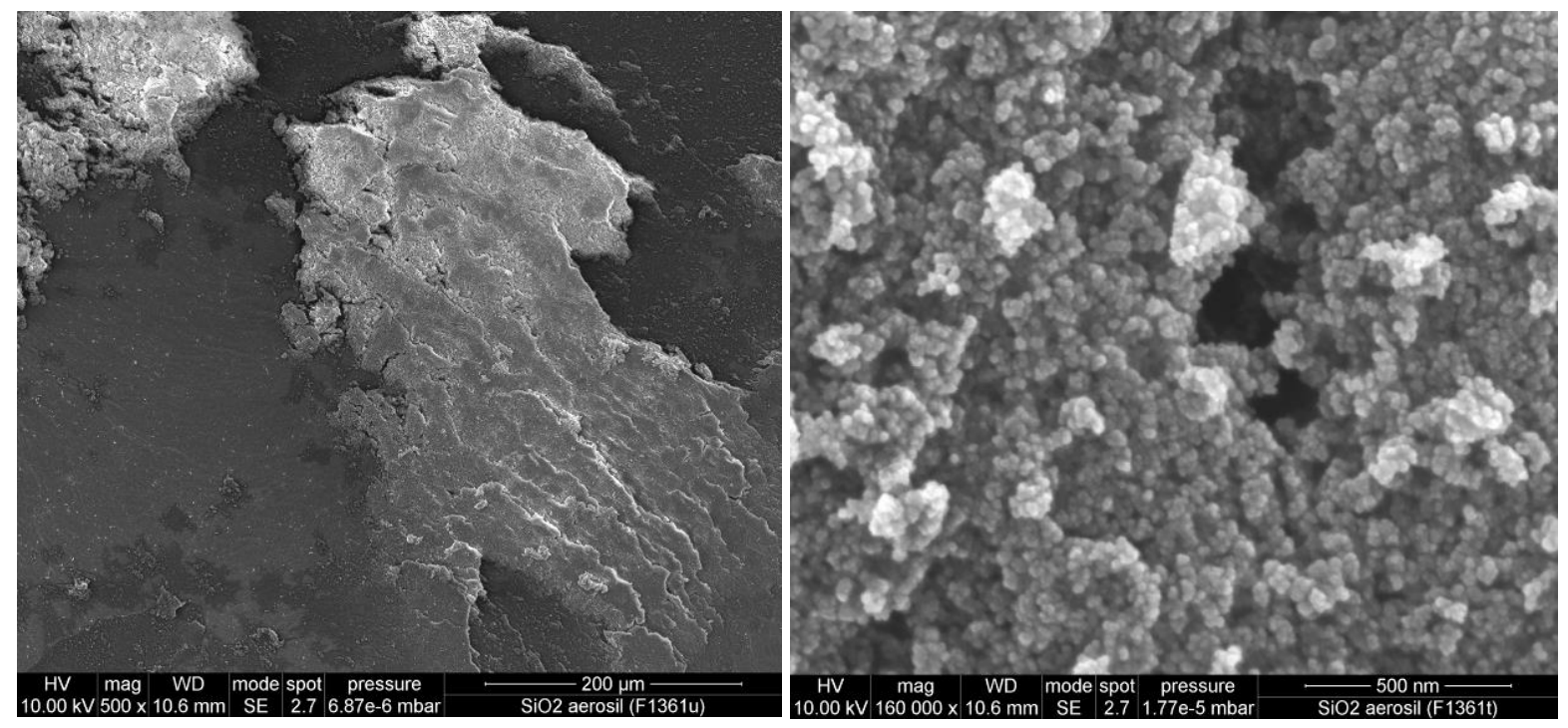

Figura 36. Imagen MEB de Sílice aerosil x500 aumentos (izquierda) y x160000 aumentos (derecha) 
Tras el análisis de las imágenes obtenidas en el MEB de las nanopartículas en polvo de sílice adquiridas, puede concluirse que éstas se encuentran aglomeradas. El tamaño de aglomerado de la sílice en polvo suministrada puede influir en la etapa de dispersión de las nanopartículas en base acuosa, pues el tamaño final de la nanopartícula en el fluido dependerá de la energía aplicada para su correcta dispersión y de la resistencia del aglomerado a disgregarse $[3,31$, 49,78].

Por esta razón y con el objetivo de determinar el tamaño de los aglomerados suministrados, se midió el tamaño de estos mediante difracción láser, para así determinar la diferencia existente entre el tamaño medio de partícula ofrecido por el fabricante y el tamaño final del aglomerado cuando éste se dispersa en agua.

Para dicho análisis se midió el tamaño de partícula a los 10 min de mezcla en agua con agitación suave, aplicándose posteriormente ultrasonidos en el equipo Malvern. Se fueron tomando medidas de tamaño de partícula a medida que se incrementó el tiempo de aplicación de ultrasonidos. En la Figura 37 se muestran los resultados obtenidos, representándose el tamaño de las partículas sólidas dispersas en función del tiempo y del tipo de agitación aplicada. Se han representado conjuntamente las tres series $d_{10}, d_{50}$ y $d_{90}$ (donde $d_{10}$ representa el tamaño de partícula por debajo del cual están el 10\% de partículas en la muestra analizada, y el $d_{50}$ y $d_{90}$ los tamaños por debajo de los cuales están el $50 \%$ y $90 \%$ de partículas respectivamente).

En dicho estudio de dispersión, puede observarse como la agitación suave por bombeo consigue reducir el tamaño del aglomerado, pero es con la agitación más enérgica por ultrasonidos con la que se consigue la mayor reducción. Tras 10 min de aplicación de ultrasonidos se alcanzó el tamaño mínimo de aglomerado. Una vez superado este tiempo si se continúa aplicando ultrasonidos no se reduce el tamaño de aglomerado. Puede concluirse que un tiempo excesivo de aplicación de ultrasonidos en lugar de reducir el tamaño de aglomerado conlleva una reagrupación de las partículas, aglomerándose de nuevo y aumentando finalmente el tamaño (el tamaño medido tras 25 minutos de dispersión es mayor que el medido tras 20 minutos de dispersión). 


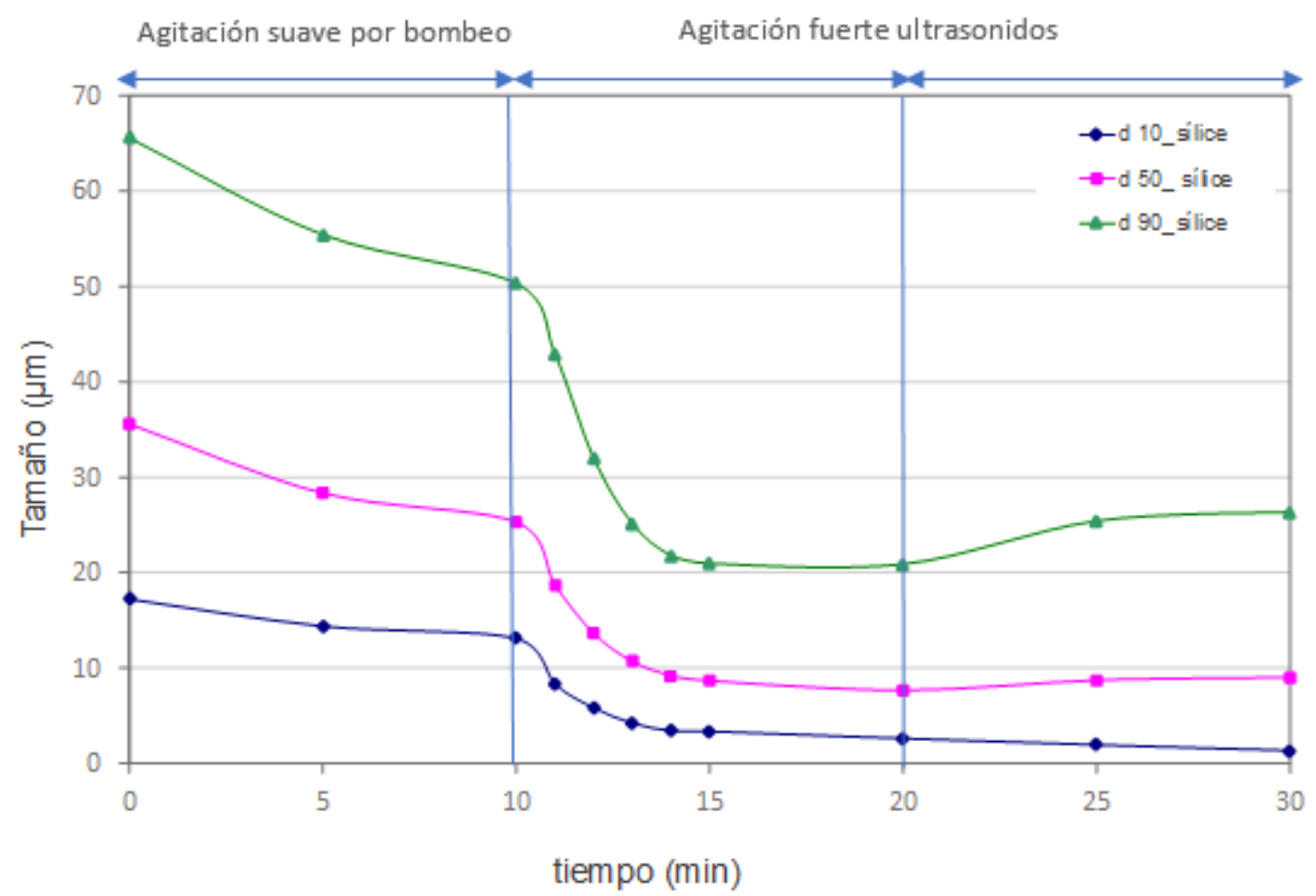

Figura 37. Evolución del tamaño de partícula en dispersión tras la aplicación de agitación suave por bombeo y la aplicación de ultrasonidos

Por esta razón la energía total aplicada (tiempo de aplicación e intensidad) va a ser una variable crítica en el proceso de dispersión, dependiente de la técnica utilizada al aplicar la energía de dispersión y de la naturaleza del aglomerado de nanopartículas a dispersar. En el caso de los nanofluidos de sílice, el tiempo de aplicación de ultrasonidos óptimo se sitúa sobre los $10 \mathrm{~min}$, no resultando recomendable superar el tiempo crítico de $15 \mathrm{~min}$.

Además de medir el tamaño de aglomerado inicial, se caracterizó la friabilidad del mismo mediante un coeficiente que relaciona el tamaño de aglomerado cuando éste se mezcla con agua y el tamaño final tras aplicar dispersión con ultrasonidos. En la Tabla 15 se muestran los valores obtenidos para $d_{10}, d_{50}, d_{90}$ y friabilidad.

Este coeficiente de friabilidad del aglomerado da una idea de la dificultad para dispersar totalmente las nanopartículas en agua dependiendo del tamaño inicial del aglomerado y del método de síntesis con el que se ha obtenido el material nanoparticulado, que dependerá del proveedor. El coeficiente de friabilidad de los materiales de sílice tras aplicar 10 minutos de ultrasonidos es alto, alcanzando un coeficiente de reducción de tamaño del 96\%. 
Tabla 15. Distribución de tamaños de los aglomerados iniciales de sílice medidos en el equipo por difracción laser

\begin{tabular}{|c|c|c|c|c|}
\hline $\begin{array}{c}\text { Tamaño de los aglomerados } \\
\text { de sílice }\end{array}$ & $\begin{array}{c}d_{10} \\
(\mu m)\end{array}$ & $\begin{array}{l}d_{50} \\
(\mu \mathrm{m})\end{array}$ & $\begin{array}{l}d_{90} \\
(\mu m)\end{array}$ & $\begin{array}{l}\text { C.f. }{ }^{*} \\
\text { (\%) }\end{array}$ \\
\hline agitación suave & 10,83 & 21,83 & 40,6 & 48 \\
\hline dispersión U.S. 1 min & 8,61 & 18,04 & 36,8 & 53 \\
\hline dispersión U.S. 10 min & 1,08 & 1,52 & 2,9 & 96 \\
\hline
\end{tabular}

*coeficiente de friabilidad calculado para el d9o como

$$
\text { c. } f .=\frac{\text { tamaño inicial }- \text { tamaño final }}{\text { tamaño inicial }} * 100
$$

\subsubsection{Preparación de los nanofluidos de sílice. Resultados de caracterización, dispersión y} estabilidad.

Las nanopartículas de sílice adquiridas se dispersaron en medio acuoso con una sonda de ultrasonidos según la metodología descrita en el procedimiento Capitulo III, 2.2.3. El tiempo total aplicado para alcanzar una dispersión correcta de las nanopartículas fue de 12 minutos, realizando una batería de repeticiones de 2 minutos y enfriando la muestra en un baño termostatado para evitar en la medida de lo posible un calentamiento excesivo de la misma.

Una vez dispersadas de forma mecánica las nanopartículas se aplicó la técnica de estabilización de las nanopartículas mediante el ajuste del pH de la suspensión preparada con el objetivo de aumentar la estabilidad de los nanofluidos obtenidos. Según la bibliografía $[10,55]$ cuando más alejado esté el pH de la suspensión preparada de su punto isoeléctrico ( $\mathrm{pH}$ en el cual el potencial de repulsión entre las partículas es cero) menores serán las fuerzas de atracción entre las nanopartículas dispersas en el medio y su tendencia a la aglomeración en el tiempo.

El equipo utilizado para la medida de potencial zeta fue el Zetasizer Nano ZS de la casa Malvern Instruments, que analiza el potencial zeta aplicando un campo eléctrico a través de la suspensión, de modo que las partículas cargadas migran hacia el electrodo de carga opuesta con una velocidad proporcional a la magnitud del potencial zeta. En la Figura 38 se muestran los resultados de punto isoeléctrico obtenido para la muestra de sílice. Como puede observarse en dicho gráfico el punto en el cual el potencial de repulsión entre partículas es 
nulo es para un $\mathrm{pH}=2$. Por esta razón, para poder obtener un nanofluido de sílice estable, el pH de la suspensión se modificó hasta alcanzar un pH lo más alejado posible del punto isoeléctrico. El pH elegido para lograr que la repulsión entre las nanopartículas puestas en suspensión fuese máxima fue $\mathrm{pH}=9$.

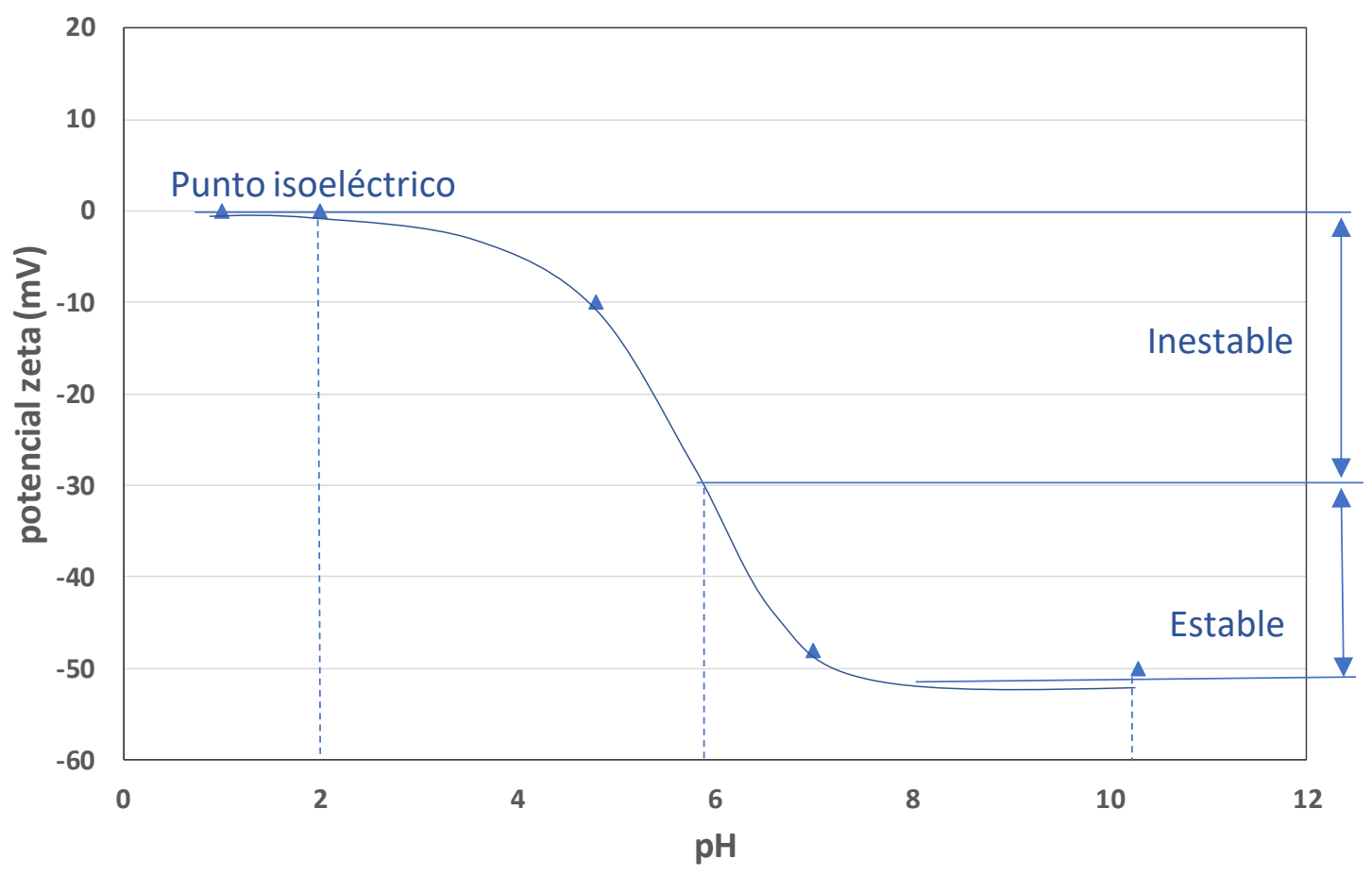

Figura 38.Variación del potencial zeta del nanofluidode sílice (Aerosil 200) en función del pH de la suspensión

Una vez preparados los distintos nanofluidos de sílice (resumidos en la Tabla 14) se procedió a caracterizar su grado de dispersión y estabilidad.

\subsubsection{Caracterización del estado de dispersión de las nanopartículas de sílice en los} nanofluidos preparados

Tras la preparación de los nanofluidos de sílice según la metodología descrita en el Apartado 2.2 Capitulo III, mediante agitación por ultrasonidos (12 $\mathrm{min}$ ) y ajuste de $\mathrm{pH}$, se procedió a la caracterización del estado de dispersión de las nanopartículas en el fluido base. Para dicha caracterización se utilizó en primer lugar el microscopio electrónico de transmisión (TEM). Para poder utilizar dicha técnica resulta necesario acondicionar las muestras sobre un soporte especial, pues las muestras no pueden analizarse con el líquido por lo que requieren de un secado controlado que minimice una posible reaglomeración de las nanopartículas ya dispersas. 
Comparación del método de preparación de las muestras para el TEM: secado natural o por liofilización

En las siguientes dos imágenes, Figura 39, se compara el efecto del método usado para preparación de la muestra de la suspensión acuosa de $\mathrm{SiO}_{2}$ en polvo (AEROSIL 200) a un $1 \%$ de fracción volumétrica para su visualización en el TEM. Se seleccionaron dos métodos para preparar la muestra: liofilización y secado natural. En el método de liofilización una vez depositada la gota pipeteada de la suspensión a analizar se procede al secado de esta mediante un ciclo de liofilización, con el objetivo de que no se produzca una aglomeración de las partículas debido al efecto de contracción que se produce en el secado natural. Como se puede apreciar en las imágenes las partículas se ven menos aglomeradas cuando se utiliza esta técnica de liofilización, Figura 39 (izda.).
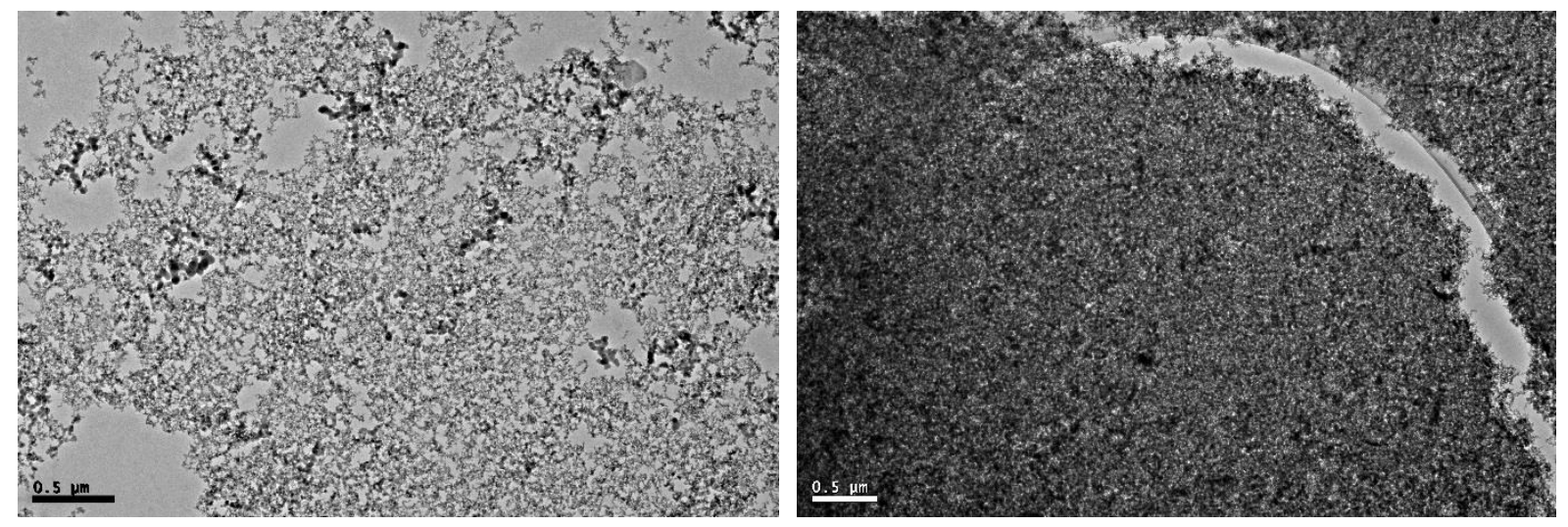

Figura 39. Imagen TEM. Muestra sílice x 6000 aumentos secada por liofilización (izda) y secada natural (dcha).

Pudo comprobarse también que dependiendo de si se toma la foto en el centro o en el borde de la gota Figura 40 , izda. o dcha., se obtienen distintos resultados. En los bordes de la gota se produce una fracción de nanopartículas debido a la migración de estas durante el propio proceso de secado de las gotas de nanofluido que puede no coincidir con el estado real de dispersión de las mismas en la suspensión acuosa. 

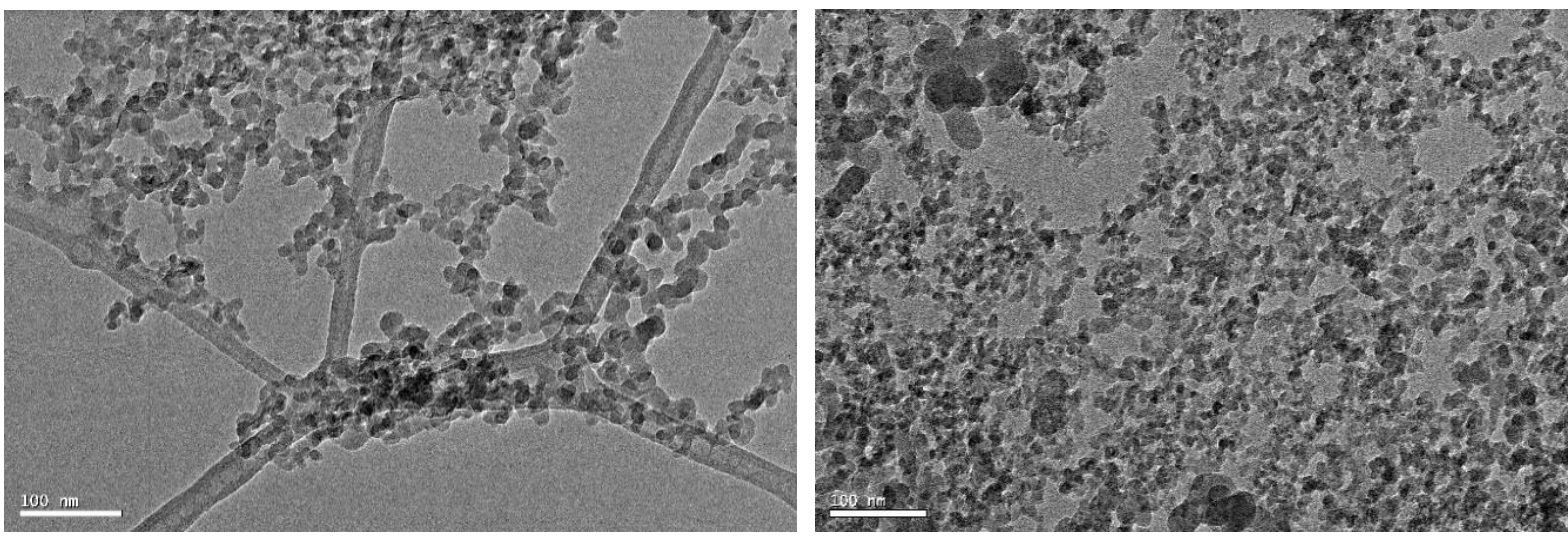

Figura 40. Imagen TEM de una muestra de nanofluido de sílice secado por liofilización. Vista central de la gota (izda.) y vista del borde de la gota (dcha.).

Tras los resultados obtenidos se puede concluir que el método de preparación de la muestra influye en gran medida sobre los resultados finales, al igual que el análisis en el borde o en el centro de la gota. Por esta razón, para el análisis del estado de dispersión en el TEM, se seleccionó la opción de preparar las muestras por liofilización y se determinó observar el centro de la gota para comparar entre distintos nanofluidos.

Comparación de las muestras en TEM de nanofluidos estabilizados mediante el $\mathrm{pH}$ y nanofluidos no estabilizados

Si se analiza una muestra no estabilizada (preparación del nanofluido de sílice sin ajustar el $\mathrm{pH}$, con un $\mathrm{pH}=2$ ) ,Figura 41 (izda.), y se compara con una muestra estabilizada (con un $\mathrm{pH}=9$ lejos de su punto isoeléctrico) Figura 41 (dcha.), puede observarse como en la muestra no estabilizada las nanopartículas están mucho más aglomeradas que en la muestra estabilizada a $\mathrm{pH}=9$.
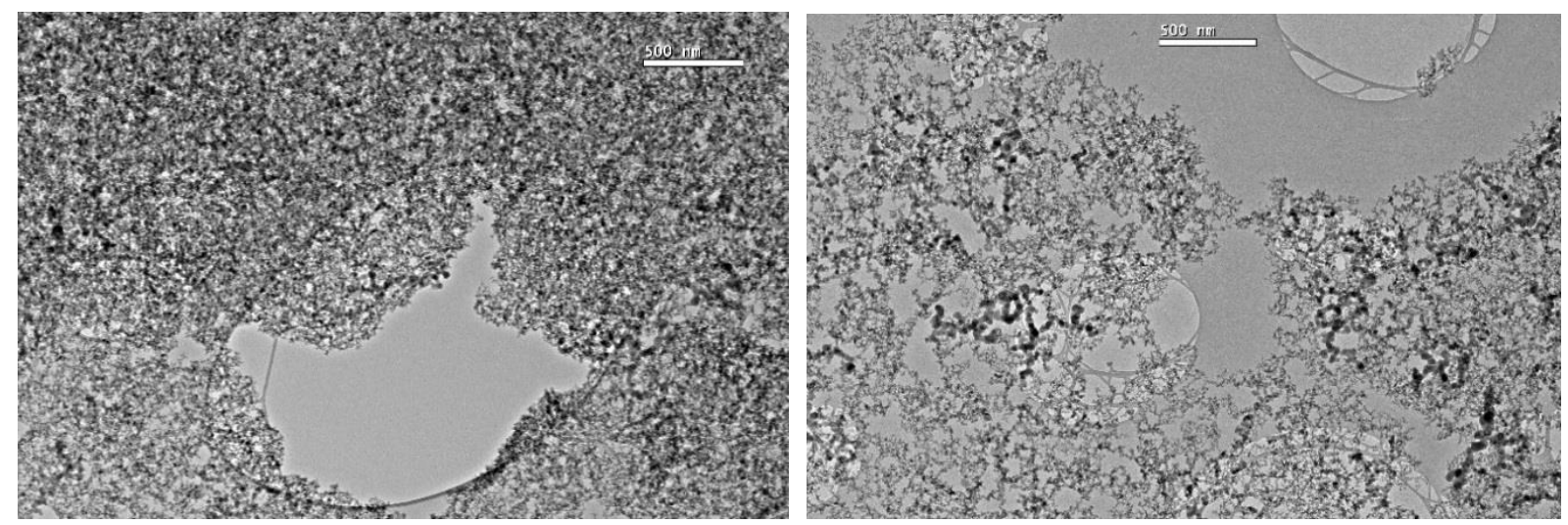

Figura 41. Imagen TEM a 6000 aumentos de nanofluido de sílice al 1\%, no estabilizado un pH=2 (izda.) y estabilizado a $\mathrm{pH}=9$ (dcha). 
Puede concluirse tras el análisis de las muestras de sílice que el método de estabilización mediante ajuste de $\mathrm{pH}$ a un valor lejano al punto isoeléctrico permite que las nanopartículas dispersas presenten menor tendencia a reagruparse.

\section{Análisis del tipo de material: dispersión sílice en polvo y dilución suspensión sílice comercial}

En las imágenes Figura 42 a Figura 45, se muestran fotografías a distintos aumentos de los dos tipos de nanofluidos de sílice preparados:

- $\quad$ Nanofluido de sílice (aerosil nanopartículas en polvo) al $1 \%$ en volumen preparado por ultrasonidos y estabilizado a pH=9 (Figura 42 y Figura 43).

- $\quad$ Nanofluido de sílice preparado a partir de dilución comercial (Ludox) al 1\% en volumen mediante ultrasonidos y estabilizado a pH=9 (Figura 44 y Figura 45).
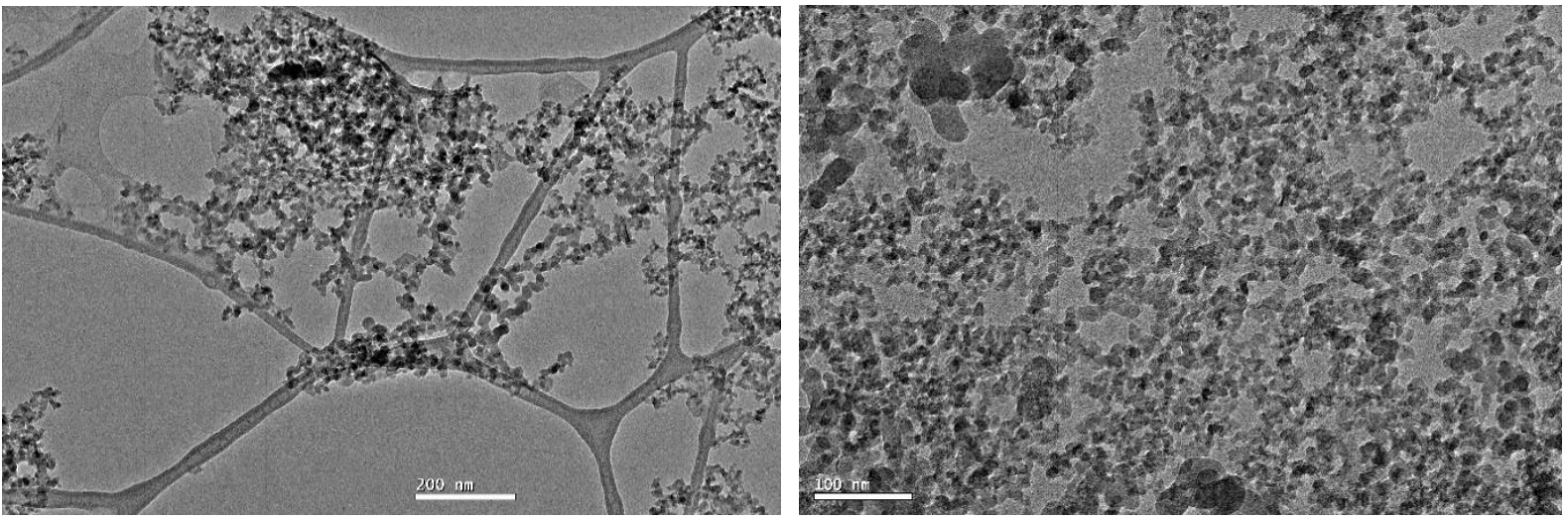

Figura 42. Imagen TEM de nanofluido de sílice al $1 \%$ y ajustado a un $\mathrm{pH}=9$, a 1500 aumentos (izda.) y a 3000 aumentos (dcha)
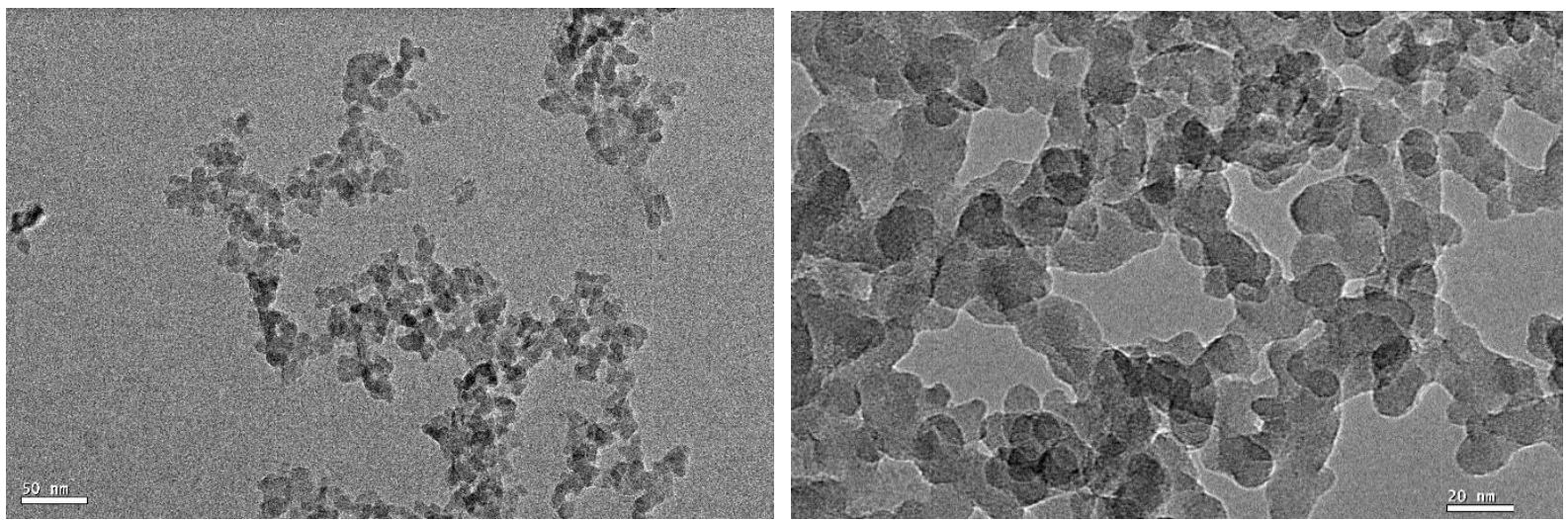

Figura 43. Imagen TEM de nanofluido de sílice al $1 \%$ y ajustado a un $\mathrm{pH}=9$, a 40000 aumentos (izda.) y a 100000 aumentos (dcha.) 

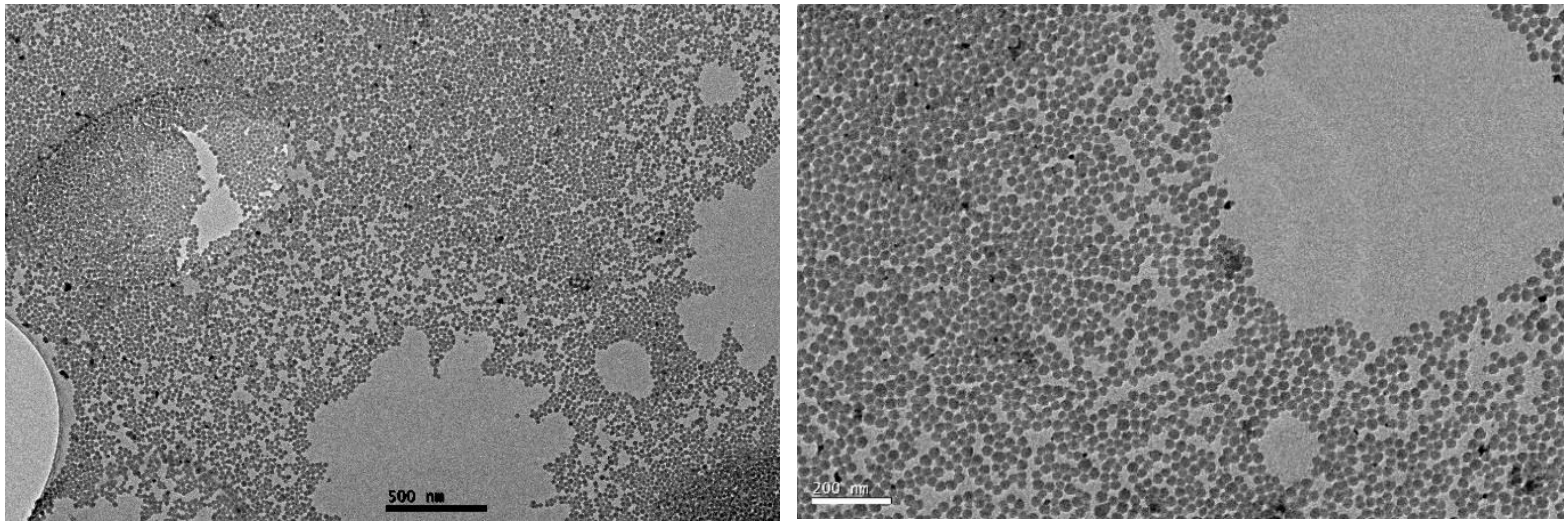

Figura 44. Imagen TEM de nanofluido de sílice Ludox (suspension comercial) al $1 \%$ y ajustado a un pH=9, a 6000 aumentos (izda.) y a 12000 aumentos (dcha.)
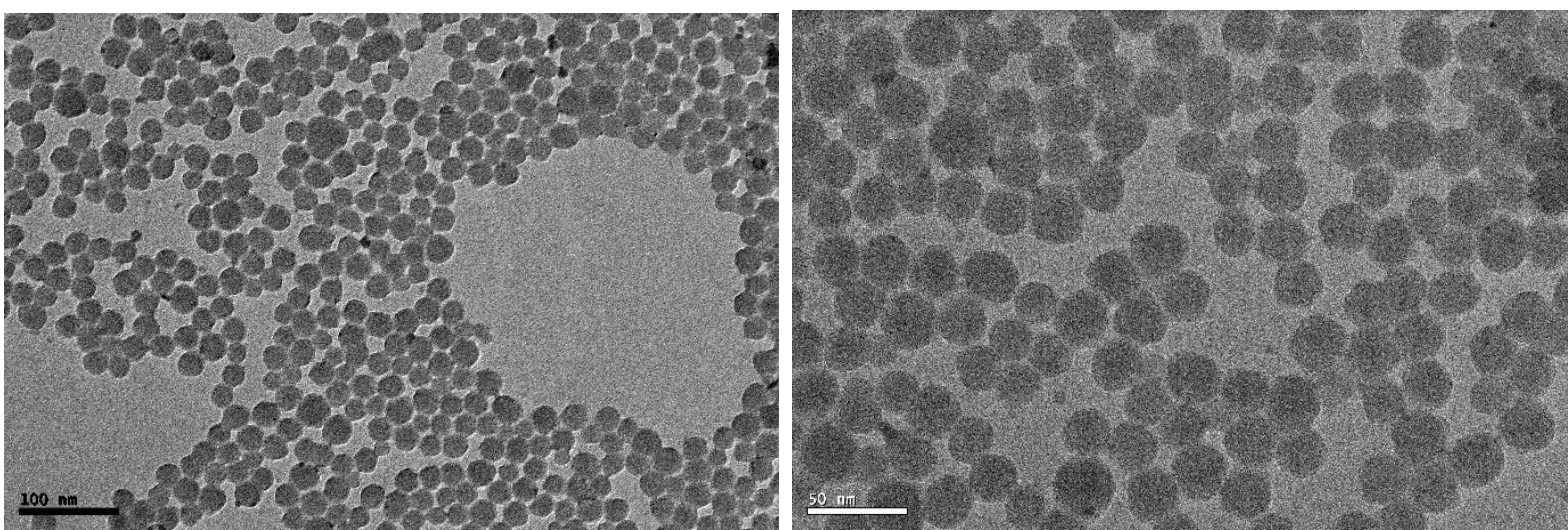

Figura 45. Imagen TEM de nanofluido de sílice Ludox (suspension comercial) al 1\% y ajustado a un pH=9, a 30000 aumentos (izda.) y a 60000 aumentos (dcha.)

Aunque en la caracterización del estado de dispersión mediante la técnica del TEM en el proceso de secado y preparación de las muestras pudo producirse la fracción de partículas, en las figuras anteriores sí que se observan diferencias significativas entre los nanofluidos preparados a partir de nanopartículas en polvo y los nanofluidos preparados mediante dilución de suspensiones comerciales. En los nanofluidos comerciales (Ludox, Figura 44 y Figura 45) las nanopartículas se aprecian bien dispersas, con forma esférica e individualizadas, mientras que en los nanofluidos preparados a partir de nanopartículas de sílice aerosil, Figura 42 y Figura 43, las nanopartículas se observan más aglomeradas.

Las nanopartículas del fluido comercial Ludox según el proveedor tienen el mismo diámetro que las nanopartículas de sílice aerosil, unos $12 \mathrm{~nm}$, pero como ya se ha comentado en el apartado anterior, las nanopartículas en polvo aerosil se suministran aglomeradas. Esta diferencia en el tamaño inicial del aglomerado puede explicar los resultados obtenidos tras la preparación de los nanofluidos por dispersión mecánica que se aprecian en las imágenes, 
donde las nanopartículas de sílice aerosil se observan mucho más ramificadas y menos esféricas, y con un tamaño mayor que las de sílice comercial.

\section{Análisis del tamaño final de las nanopartículas de sílice en polvo y suspensión comercial} dispersadas en los nanofluidos preparados

La distribución de tamaños de partícula presentes en los distintos tipos de nanofluidos preparados se determinó utilizando el equipo ZETASIZER NANO con la técnica Dynamic Light Scattering, DLS. Esta técnica analiza tamaños inferiores a la micra basándose en el movimiento Browniano. En las Figura 46 y Figura 47 se muestran los resultados obtenidos para los dos tipos de muestras de sílice. Como puede observarse el tamaño medio de las partículas $\left(d_{50}\right)$, en los nanofluidos preparados a partir de la sílice en polvo (Aerosil, Figura 46) se encontraba en torno a $201 \mathrm{~nm}$, estando el $90 \%$ de las partículas por debajo de $345 \mathrm{~nm}$, tamaño mucho mayor que los $12 \mathrm{~nm}$ de partícula primaria.

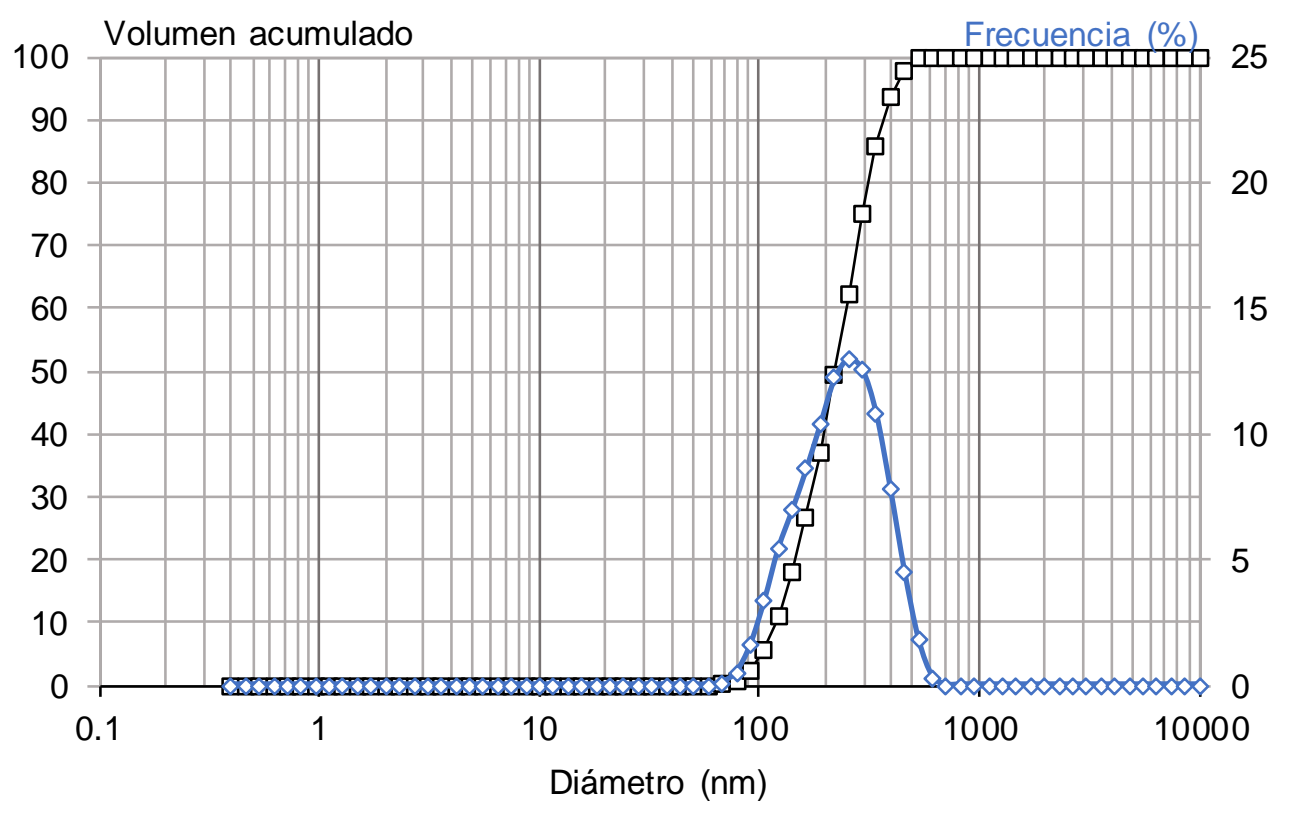

Figura 46. Distribución de tamaño de partícula de la muestra Aerosil medida en Zetasizer-Nano

También se caracterizó el tamaño de partícula y de agregado de la suspensión de sílice comercial adquirida para la preparación de los nanoflluidos, Ludox TM- 50. En este nanofluido según el fabricante, las partículas primarias tienen un diámetro de $10 \mathrm{~nm}$. Tras el análisis, Figura 47, se observó que el diámetro medio de tamaño de partícula era de $39 \mathrm{~nm}$, algo mayor que el tamaño que proporciona el fabricante. En los resultados obtenidos se observa que la distribución de tamaño de partícula es estrecha, por lo cual se puede concluir que, en estas 
suspensiones comerciales, las nanopartículas están muy bien dispersas y presentan un estado de agregación menor que las nanopartículas Aerosil 200.

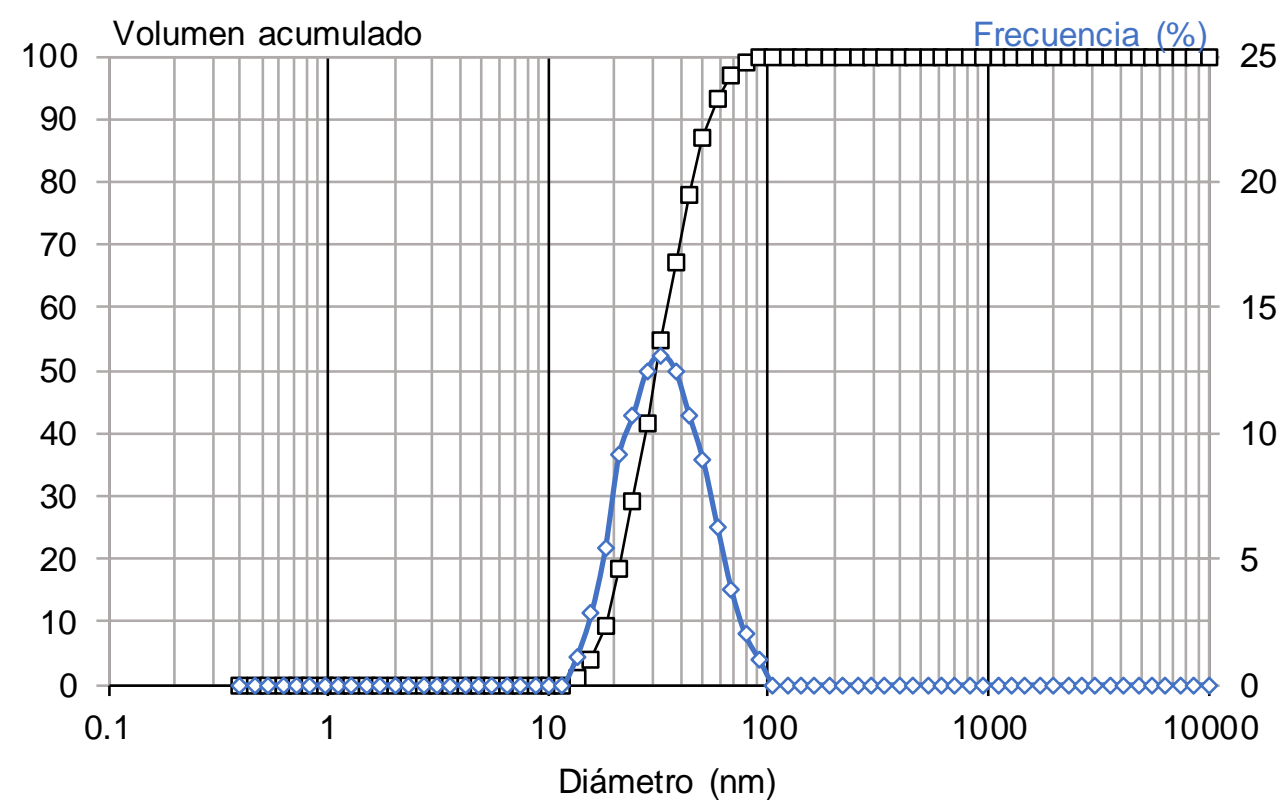

Figura 47. Distribución de tamaño de partícula de la muestra Ludox medida en Zetasizer-Nano

Se puede concluir que el tamaño final de nanopartícula alcanzado en la preparación de los nanofluidos tras la agitación en ultrasonidos es mucho menor en los nanofluidos obtenidos por dilución (tamaño $\mathrm{d}_{50}$ de $40 \mathrm{~nm}$ ) que en los nanofluidos preparados a partir de la sílice en polvo, donde las nanopartículas no se encuentran totalmente individualizadas y forman aglomerados con un tamaño $d_{50}$ entre $200-300 \mathrm{~nm}$.

\subsubsection{Caracterización de la estabilidad de los nanofluidos de sílice}

A continuación, se resumen los resultados de los ensayos de estabilidad realizados a las distintas suspensiones de nanofluidos de sílice preparadas. Además de analizar la estabilidad visual de las muestras de los nanofluidos en el tiempo en la cual no debe apreciarse sedimentación alguna de las nanopartículas, se utilizó la técnica de dispersión de luz para caracterizar la estabilidad de los nanofluidos preparados, como ya se ha descrito en el apartado 3.3.3 del capítulo III. En todas las muestras de sílice analizadas mediante esta técnica, no se observó a priori sedimentación alguna mediante observación visual. 
Para el estudio de los perfiles de retrodispersión obtenidos con esta técnica se tomó como representativa la lectura de porcentaje de retrodispersión (BS) tomada en el centro de la muestra, comparándose los resultados obtenidos con los distintos tipos de nanofluidos de sílice preparados (aerosil y ludox) a distintas fracciones volumétricas y a dos temperaturas de ensayo.

En la Figura 48, puede observarse que todos los nanofluidos preparados permanecen estables en el tiempo de ensayo (72 h). Se observó un ligero aumento del valor de retrodispersión (BS) al aumentar la fracción, debido al aumento de la cantidad de nanopartículas sólidas presentes en el fluido, permaneciendo dicho valor estable en el tiempo.

En los ensayos realizados a distintas temperaturas $\left(40^{\circ} \mathrm{C}\right.$ y $\left.60^{\circ} \mathrm{C}\right)$ se obtienen comportamientos en estabilidad muy similares (Figura 48 y Figura 49), por lo que se puede concluir que el efecto de la temperatura sobre la estabilidad final del nanofluido no es significativo para estas muestras analizadas, siendo los nanofluidos de sílice preparados estables en el tiempo tanto a $40^{\circ} \mathrm{C}$ como a $60^{\circ} \mathrm{C}$.
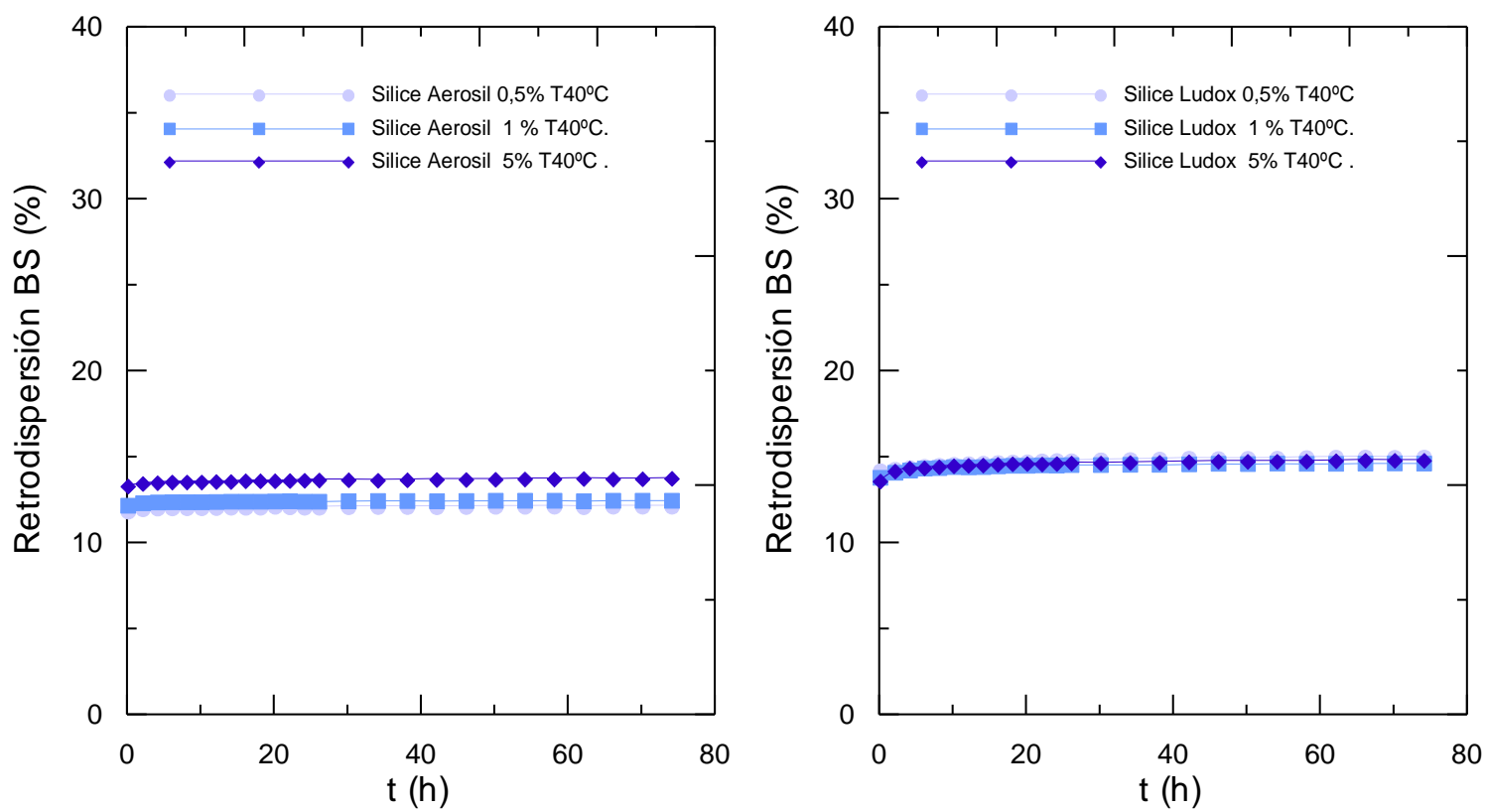

Figura 48. Estabilidad de suspensiones sílice (aerosil 200 izda. y comercial Ludox dcha.) preparadas a distinta fracción volumétrica con ultrasonidos medida en el centro y a $40^{\circ} \mathrm{C}$ 

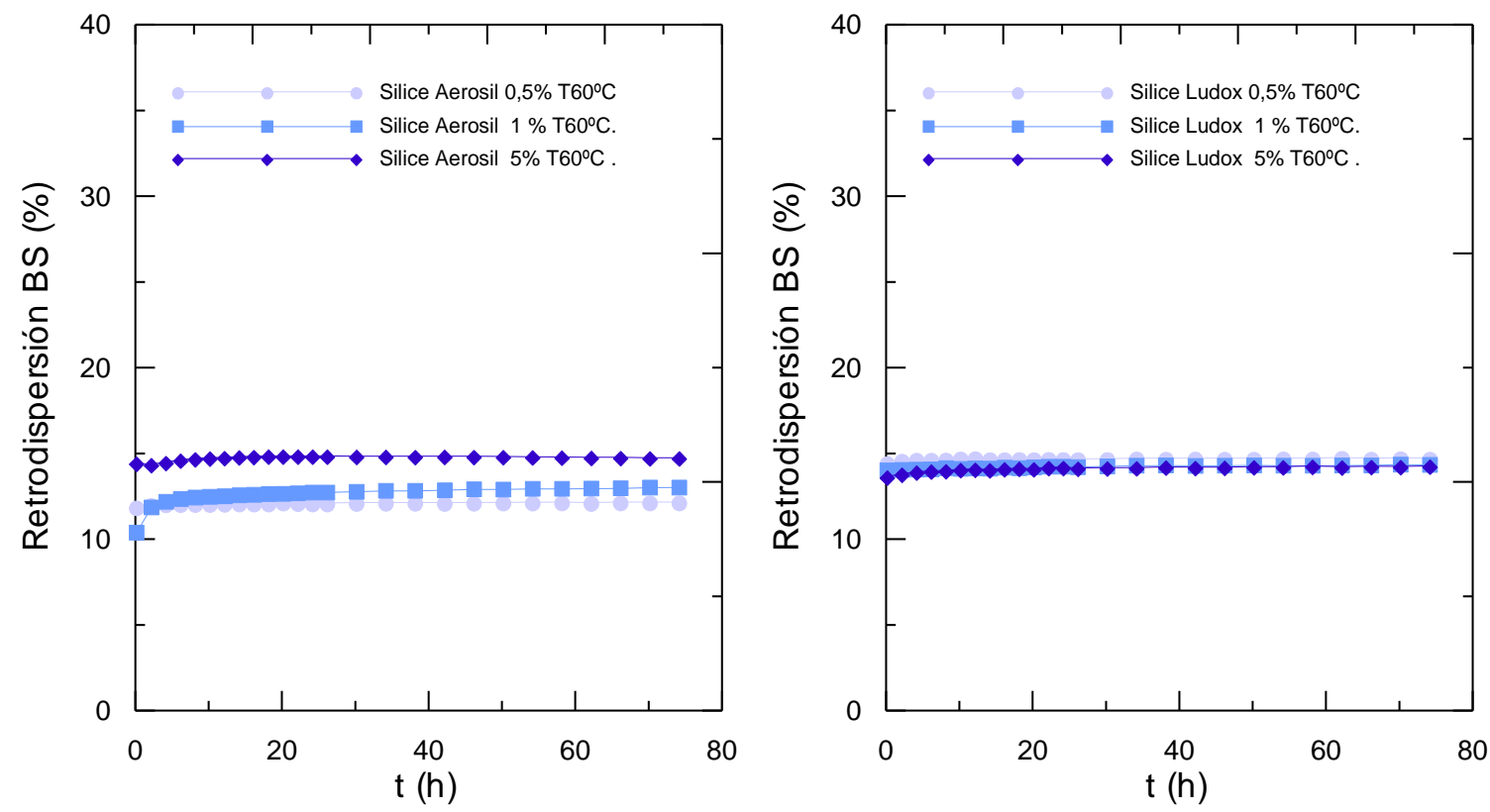

Figura 49. Estabilidad de suspensiones sílice (aerosil 200 izda. y comercial Ludox dcha.) preparadas a distinta fracción volumétrica con ultrasonidos medida en el centro y a $60^{\circ} \mathrm{C}$

\subsubsection{Resultados de la medida de la conductividad térmica de los nanofluidos de sílice}

Se ha medido la conductividad térmica con el equipo KD2 (método 2.4.1. Capitulo III) de los distintos nanofluidos preparados a partir de sílice, Aerosil y Ludox. Se han caracterizado los nanofluidos preparados a distintas fracciones volumétricas $(0,5,1$ y $5 \%)$ con el objetivo de analizar la influencia de la fracción volumétrica de nanopartículas sobre el aumento en conductividad térmica, realizándose los ensayos a tres temperaturas $\left(40,60\right.$ y $\left.80^{\circ} \mathrm{C}\right)$.

En las figuras Figura 50 y Figura 51 se han representado conjuntamente los resultados en aumento de conductividad respecto al fluido base obtenidos a distintas fracciones para cada uno de los tipos de sílice estudiados. En dichos gráficos se ha incluido el error en cada punto calculado según la ley de propagación de errores a partir de los errores experimentales obtenidos en las medidas de conductividad del nanofluido y el agua. Se ha tomado el error cuadrático de las medidas, siempre que este haya sido mayor que el error instrumental (con un valor del $2 \%$ para la técnica del hilo caliente).

Como puede observarse en la Figura 50, tan sólo se aprecian aumentos de conductividad para los nanofluidos preparados a partir de sílice en polvo (Aerosil), a fracciones volumétricas elevadas ( 1 y $5 \%$ ). Además, dichos incrementos son mayores a medida que aumenta la 
temperatura de ensayo, pues como ya se ha comentado en el capítulo II, el factor temperatura genera incrementos en la conductividad térmica de los nanofluidos al aumentar el movimiento browniano de las nanopartículas. El incremento máximo obtenido con los nanofluidos de sílice preparados a partir de nanopartículas en polvo (Aerosil) ha sido del 9\% a una temperatura de $80^{\circ} \mathrm{C}$ y del $7 \%$ a $60^{\circ} \mathrm{C}$, obtenidos para una fracción volumétrica del $5 \%$.

Los nanofluidos preparados a partir de dilución de una suspensión comercial (Ludox) Figura 51, no muestran aumentos significativos respecto al fluido base. En estos nanofluidos las nanopartículas están mejor dispersas (como ya se ha observado en las imágenes del TEM y en análisis del tamaño de partícula de las muestras) que en las suspensiones de sílice en polvo Aerosil, sin embargo, los aumentos en conductividad térmica han sido inferiores a los esperados. Este hecho podría explicarse si el mecanismo predominante en los fenómenos de transferencia de calor por conducción es de tipo estático (modelos de la nanocapa o modelo de agregación comentados en la introducción en mayor detalle) en lugar de tipo dinámico (debido al movimiento de las nanopartículas como el modelo browniano y el de nanoconvección). Entre los mecanismos estáticos el mecanismo que puede explicar las diferencias entre los nanofluidos de sílice preparados a partir de dilución de una suspensión comercial Ludox con los nanofluidos de material en polvo (Aerosil) con los que se obtiene nanofluidos con mayor incremento en conductividad térmica a pesar de que las nanopartículas en suspensión no están totalmente dispersas y se observan aglomerados con un tamaño de $345 \mathrm{~nm}$, sería el mecanismo de agregación el que definiría el mecanismo preferente de conducción. El modelo de la nanocapa sólo aplica para partículas menores de 10 nanómetros por lo que el mecanismo que puede explicar el comportamiento es el mecanismo de agregación.

Hay que añadir que se desconoce a priori el tipo de aditivos que se han podido utilizar en la preparación del LUDOX comercial los cuales pueden afectar al comportamiento térmico de los nanofluidos preparados a partir de la dilución de esta suspensión. 


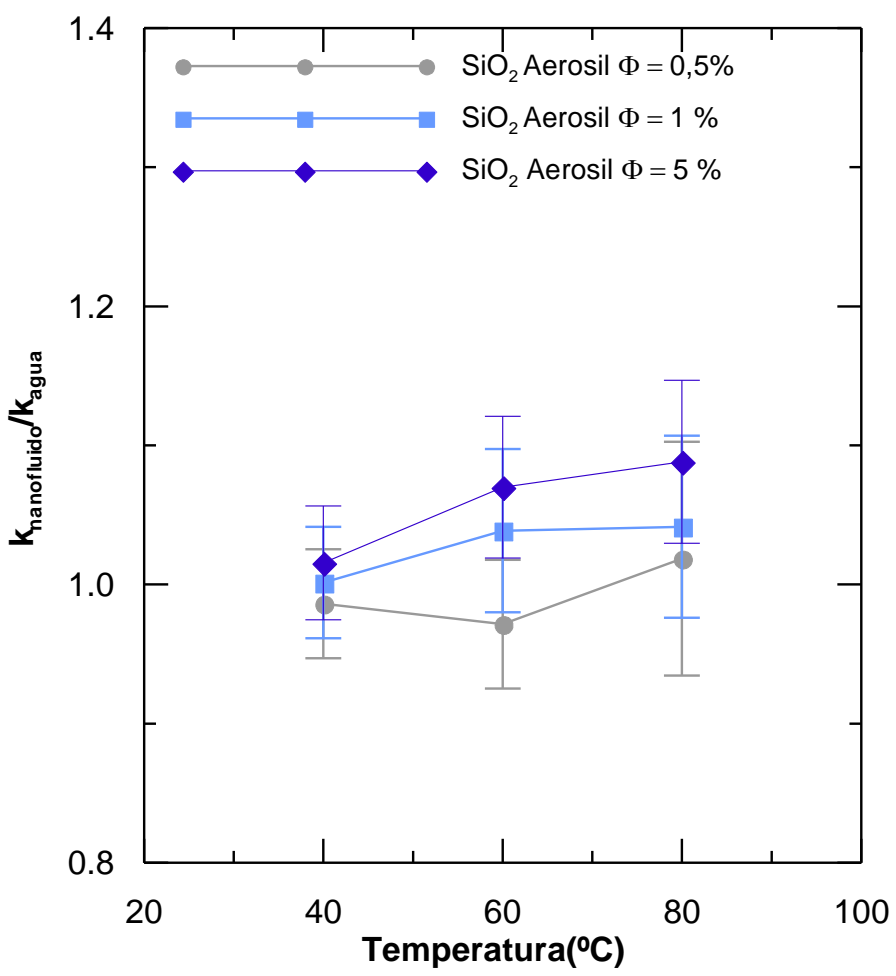

Figura 50. Conductividad térmica relativa para los nanofluidos preparados a distintas fracciones con la sílice en polvo Aerosil. Ensayos realizados a tres temperaturas $\left(40,60\right.$ y $\left.80^{\circ} \mathrm{C}\right)$

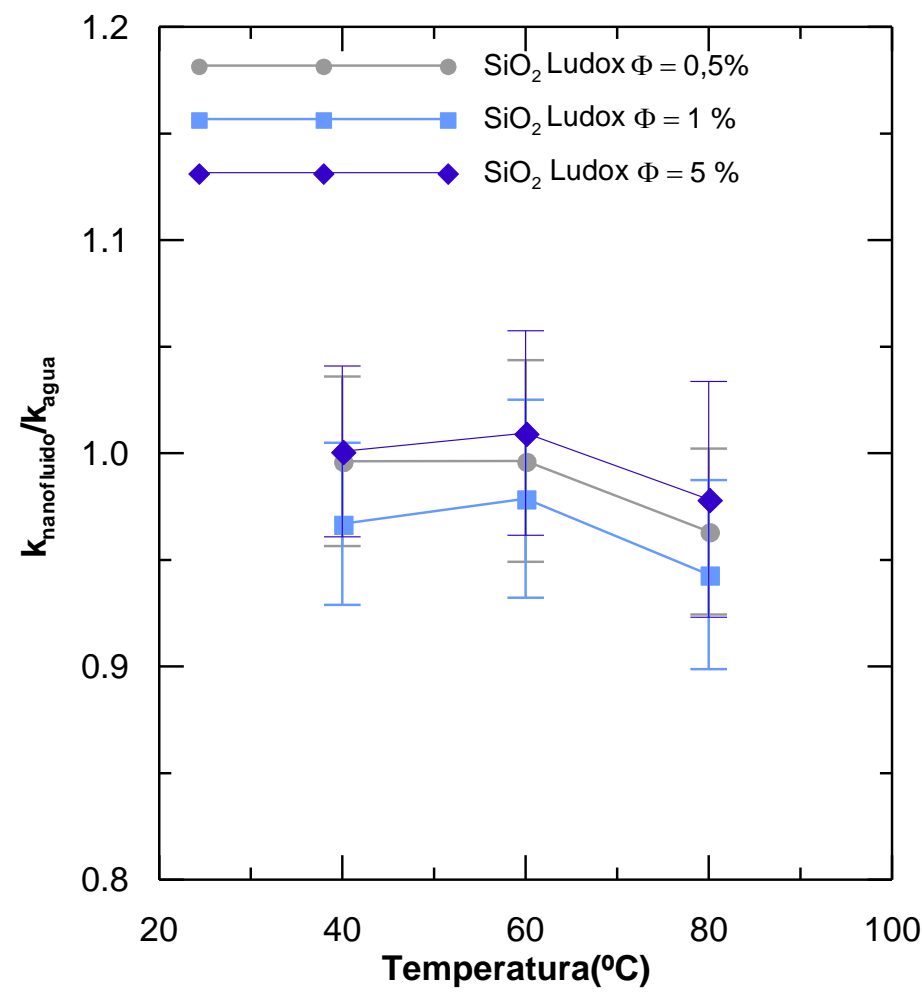

Figura 51. Conductividad térmica relativa para los nanofluidos preparados mediante dilución de la suspensión comercial Ludox a distintas fracciones. Ensayos realizados a tres temperaturas $\left(40,60\right.$ y $\left.80^{\circ} \mathrm{C}\right)$ 
Respecto a los incrementos en conductividad y los errores obtenidos en la medida de conductividad se observa tras el análisis de los resultados que a medida que se caracterizan los nanofluidos a temperaturas elevadas (mayores de $50^{\circ} \mathrm{C}$ ), los incrementos relativos en conductividad disminuyen y los errores aumentan, a medida que aumenta la temperatura de ensayo. La justificación de dichas desviaciones podría deberse a los fenómenos de convección que aparecen a temperaturas elevadas. Se ha observado que en los nanofluidos preparados a bajas fracciones volumétricas la viscosidad es parecida a la del agua, mientras que a mayor fracción la mayor viscosidad ralentiza el fenómeno de convección, pudiéndose llegar a medir la conductividad térmica con un error aceptable (no mayor del $2 \%$ ) con el equipo KD2 en nanofluidos muy viscosos a temperaturas altas $\left(80^{\circ} \mathrm{C}\right)$, como el nanofluido de sílice aerosil al $5 \%$ en fracción volumétrica. En nanofluidos de baja fracción resulta más difícil aislar el fenómeno de transmisión por conducción del fenómeno de convección por lo que las medidas de conductividad presentan mayor error cuando se realizan a temperaturas elevadas (mayores de $50^{\circ} \mathrm{C}$ ).

\subsubsection{Resultados de la medida de la viscosidad de los nanofluidos de sílice: Aerosil y LUDOX}

La viscosidad de los nanofluidos de sílice preparados se midió con el reómetro rotacional Kinexus, siguiendo el método descrito en el apartado 2.5.1., Capitulo III. Los ensayos de flujo se han realizado a una temperatura de 40,60 y $80^{\circ} \mathrm{C}$, al igual que los ensayos de caracterización de conductividad térmica. Con estos ensayos de flujo se determina la variación de la viscosidad con respecto a la velocidad de cizalla, que va aumentando de forma logarítmica desde 1 a 100-200 $\mathrm{s}^{-1}$ en los ensayos de flujo creciente y decreciente, para determinar si existe histéresis en los valores de viscosidad. Estos ensayos tienen como objetivo determinar en qué gradientes de velocidad los nanofluidos se comportan como un fluido newtoniano y en cuáles no.

Cuando los fluidos presentan una viscosidad baja o muy parecida a la del agua, a medida que se aumenta el gradiente de velocidad se observa como la viscosidad sube drásticamente presentando un comportamiento no newtoniano (Figura 52 y Figura 53). Esta subida de viscosidad no se debe al comportamiento del fluido, pues en el caso del agua debería ser newtoniano (cumpliendo la ley de Newton, que establece una proporcionalidad entre el esfuerzo cortante y la velocidad de deformación a través de la viscosidad dinámica), sino a un 
error de medida debido al flujo secundario producido por la geometría del equipo de medida (cilindro concéntrico doble hueco) [47].

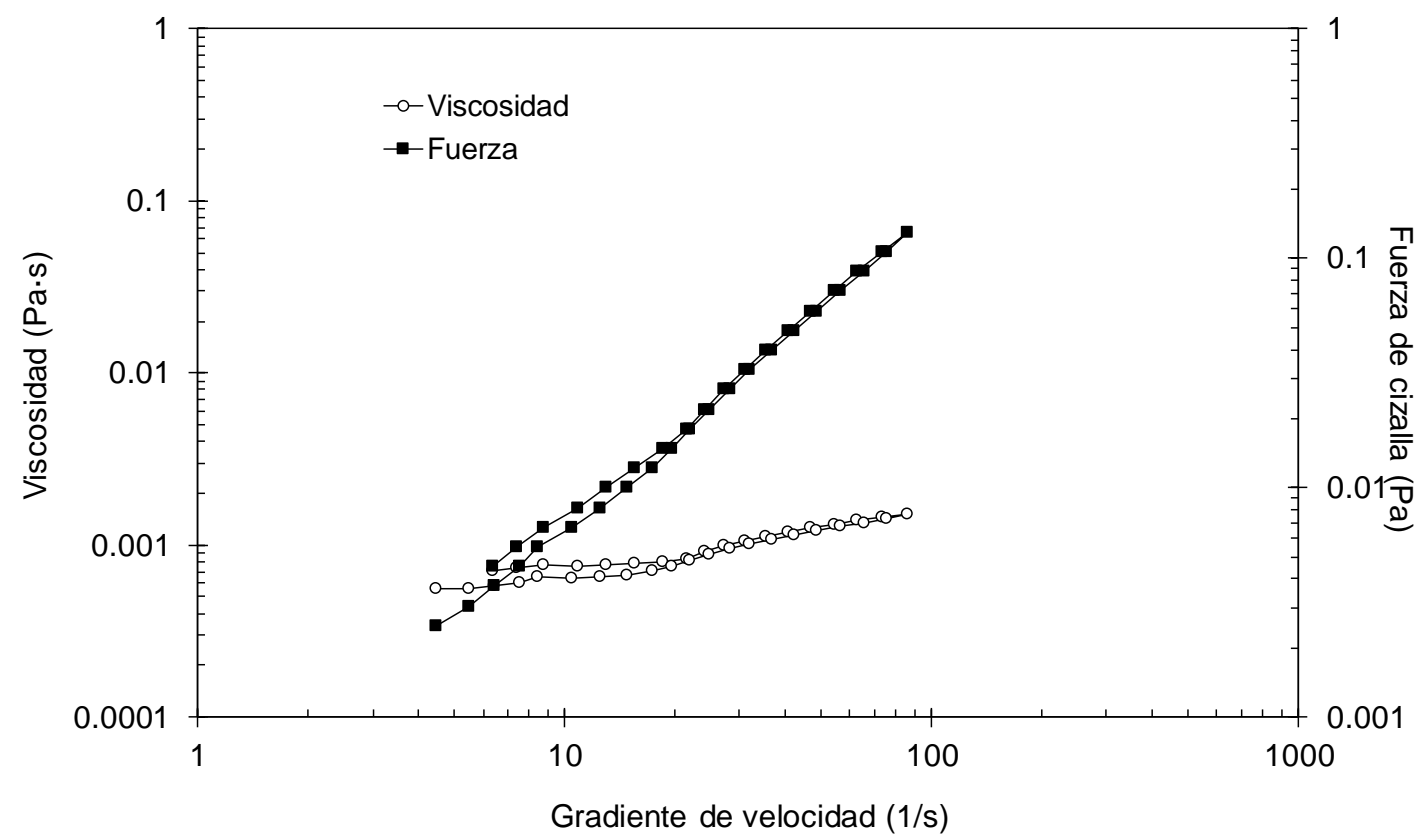

Figura 52. Curva de flujo del agua destilada a la temperatura de $40^{\circ} \mathrm{C}$ en el reómetro Kinexus

En la Figura 53 a Figura 55, se muestran los resultados de las curvas de flujo en función del gradiente de velocidad aplicado a las tres temperaturas de ensayo (40, 60 y $\left.80^{\circ} \mathrm{C}\right)$. En los tres reogramas se observa que el comportamiento del nanofluido es newtoniano a bajos gradientes de velocidad y para temperaturas de 40 y $60^{\circ} \mathrm{C}$, mientras que a gradientes de velocidad elevados $\left(20 \mathrm{~s}^{-1}\right)$, la viscosidad empieza a aumentar debido al efecto de centrifugación. A medida que se aumenta la temperatura, ensayo a $80^{\circ} \mathrm{C}$ (Figura 55), el nanofluido presenta un comportamiento dilatante incluso a bajos gradientes de velocidad debido a este fenómeno de centrifugación, por lo que no se considera adecuado medir con el reómetro la viscosidad de los nanofluidos a altas temperaturas para aquellos nanofluidos con viscosidades bajas inicialmente. 


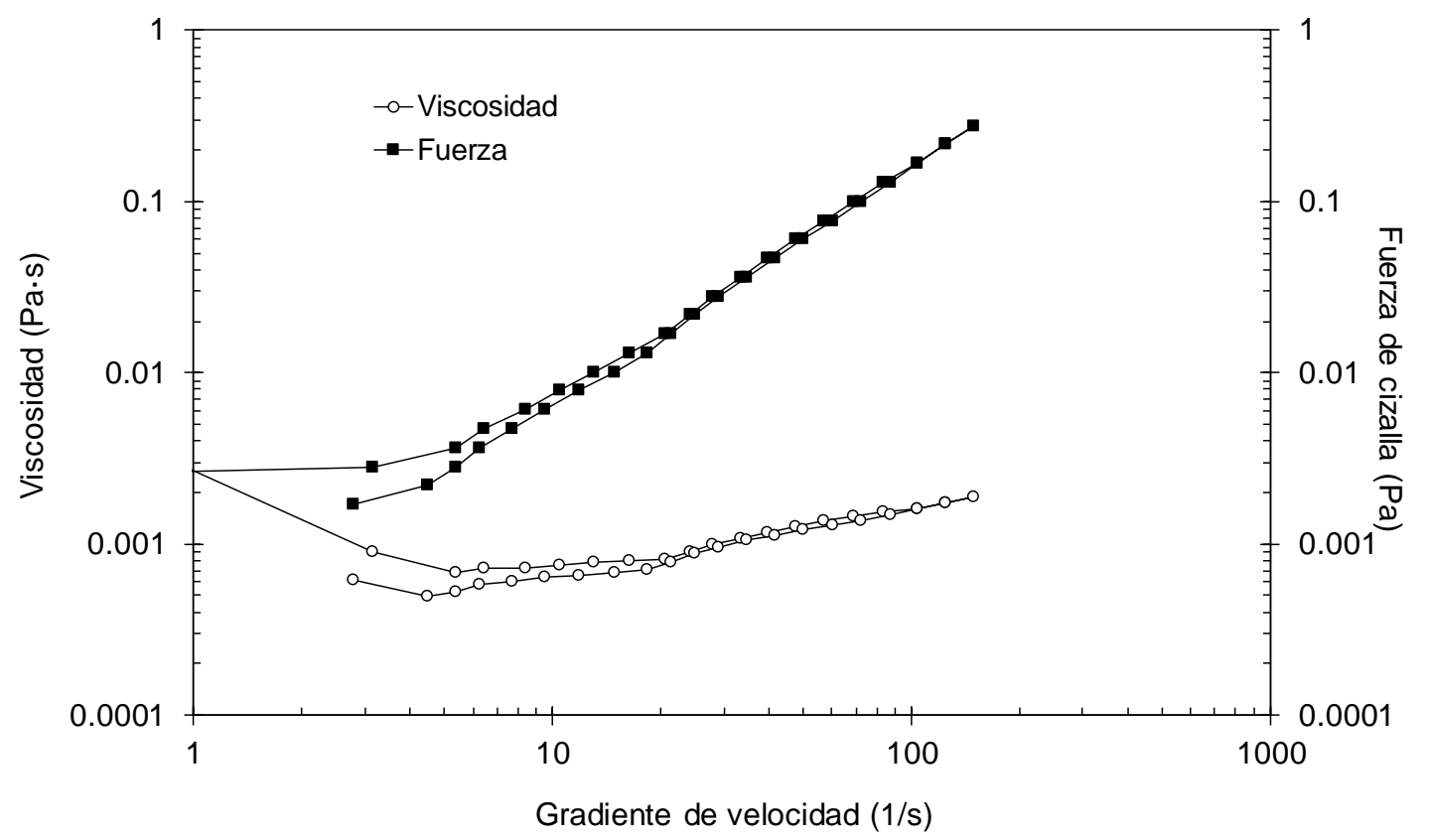

Figura 53. Curva de flujo para el nanofluido de sílice LUDOX al $1 \%$ de fracción volumétrica y a una temperatura de $40^{\circ} \mathrm{C}$

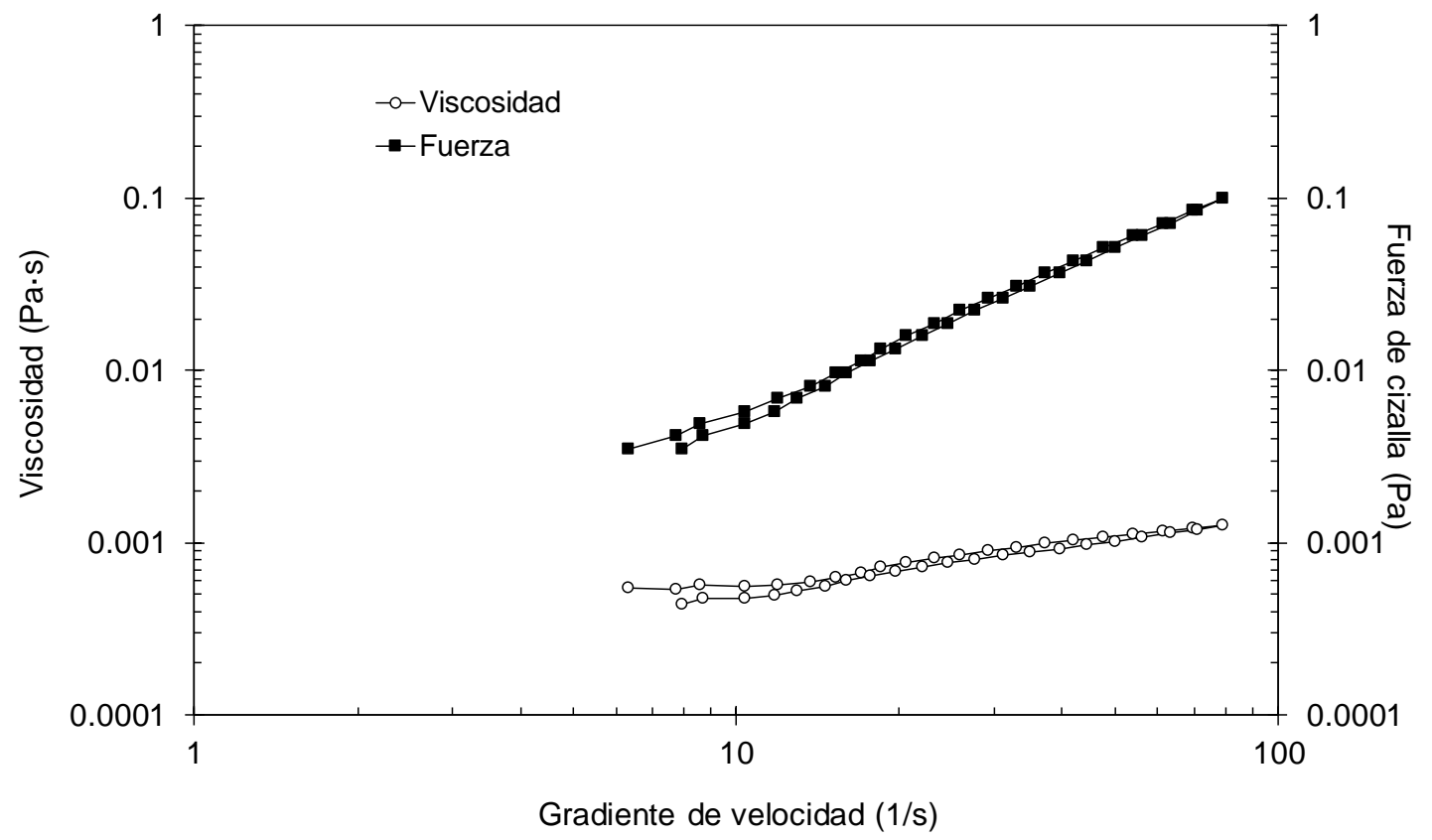

Figura 54. Curva de flujo para el nanofluido de sílice LUDOX al $1 \%$ de fracción volumétrica y a una temperatura de $60^{\circ} \mathrm{C}$ 


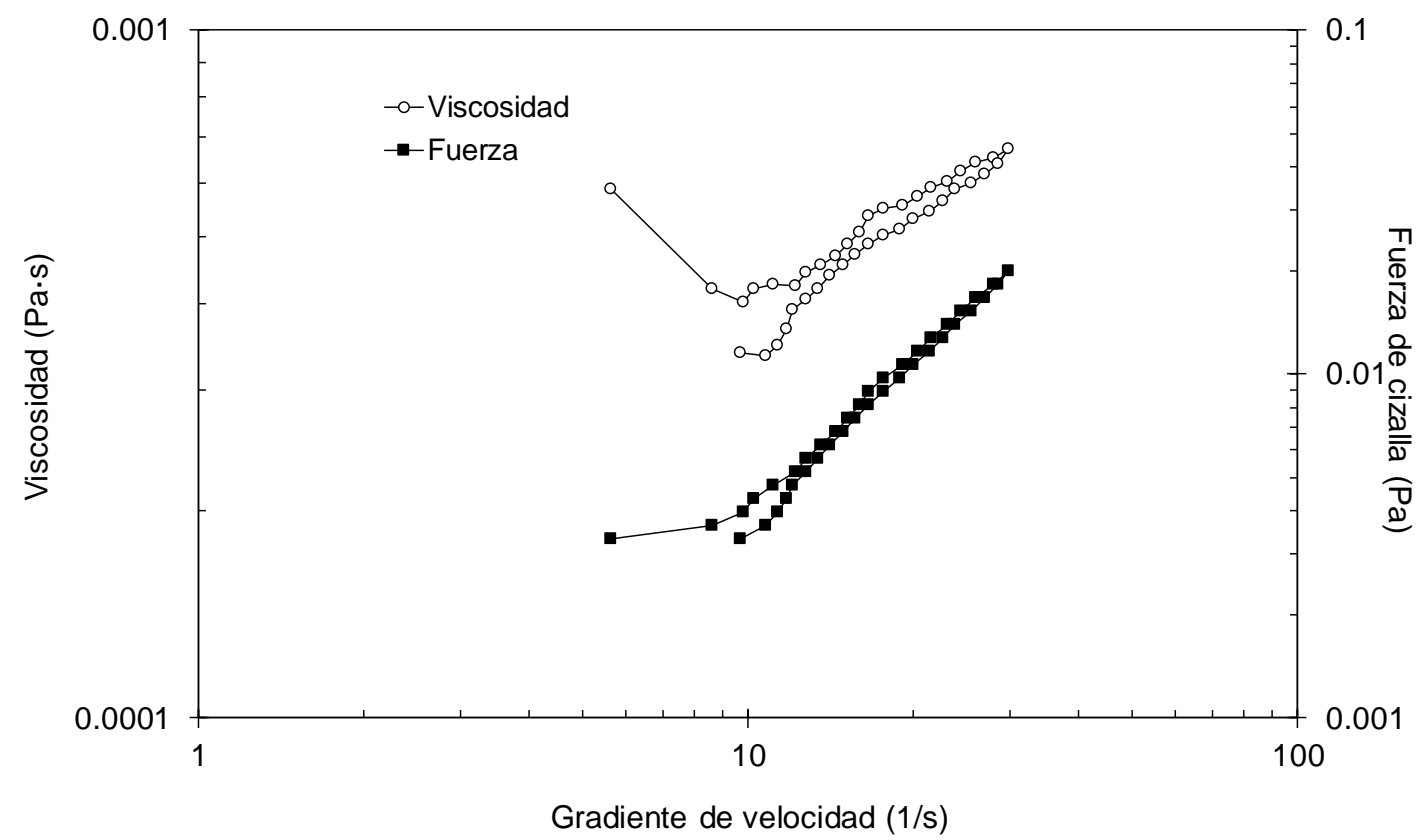

Figura 55. Curva de flujo para el nanofluido de sílice LUDOX al $1 \%$ de fracción volumétrica y a una temperatura de $80^{\circ} \mathrm{C}$

Este incremento de la viscosidad a gradientes de velocidad superiores a $20 \mathrm{~s}^{-1}$ se reprodujo para ambos tipos de los nanofluidos de sílice (Figura 57). Para determinar el comportamiento de los nanofluidos a altas velocidades se determinó la viscosidad con el equipo FLUIDICAM, con el cual pudo comprobarse que el comportamiento de ambos tipos de nanofluidos es newtoniano pues se mantiene la viscosidad constante incluso a velocidades elevadas, tanto para los nanofluidos preparados con sílice en polvo (Aerosil) como para los nanofluidos preparados a partir de dilución (Ludox).

La medición con el equipo FLUIDICAM (Figura 56) evita las turbulencias que aparecen en los reómetros rotacionales al trabajar con el cilindro coaxial en fluidos poco viscosos, pues el fluidicam es un reómetro óptico que proporciona un análisis de viscosidad preciso incluso para muestras muy poco viscosas. La medida de la viscosidad en este reómetro óptico, tipo capilar, se realiza midiendo las imágenes del co-flujo laminar del fluido que pasa por un canal microfluidico junto con un líquido de referencia. La posición de la interfase resultante está relacionada con la velocidad y la diferencia de velocidades de flujo de la muestra y el fluido de referencia . 


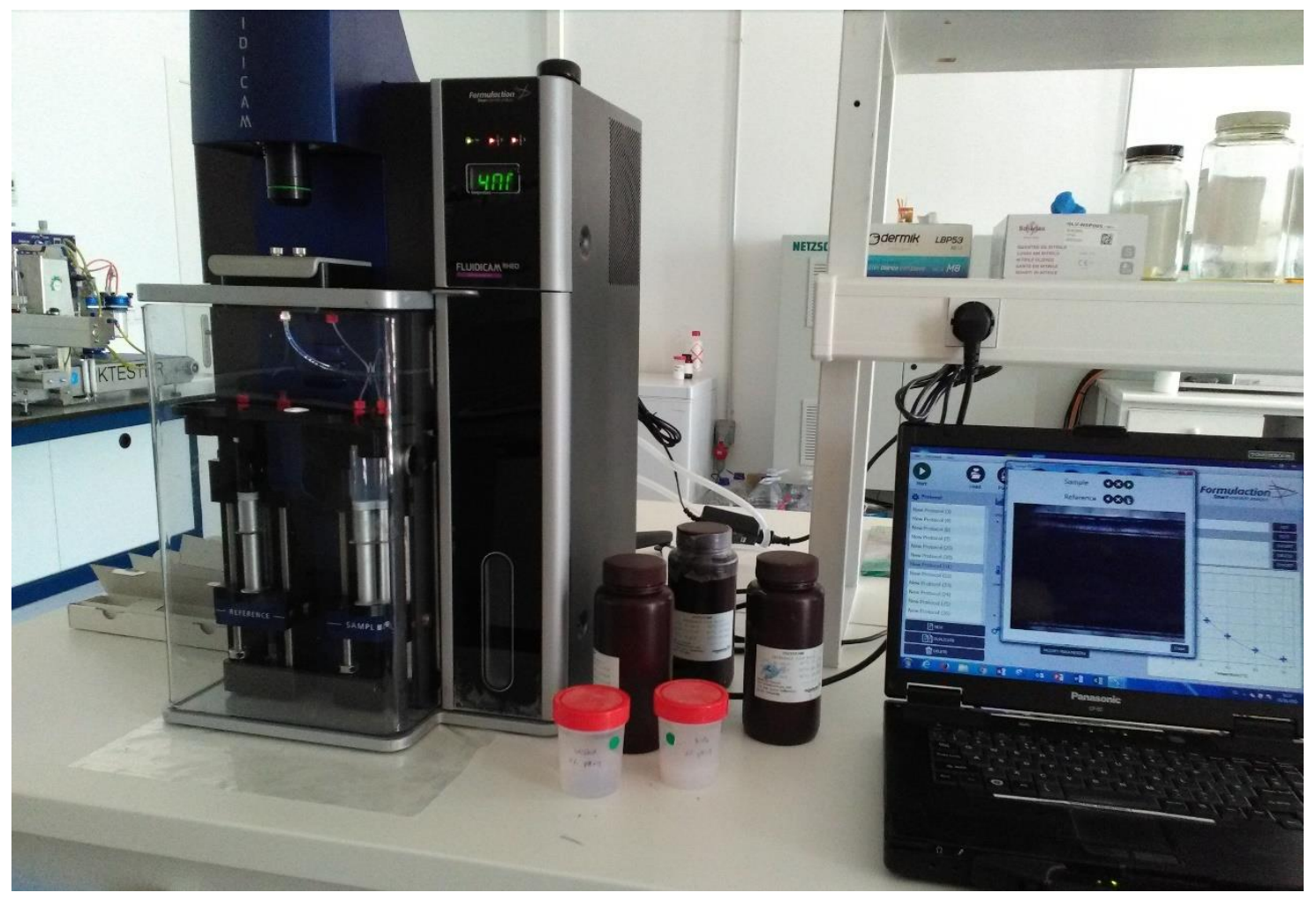

Figura 56. Imagen del equipo Fluidicam en el que se realizaron los ensayos ópticos de medida de viscosidad

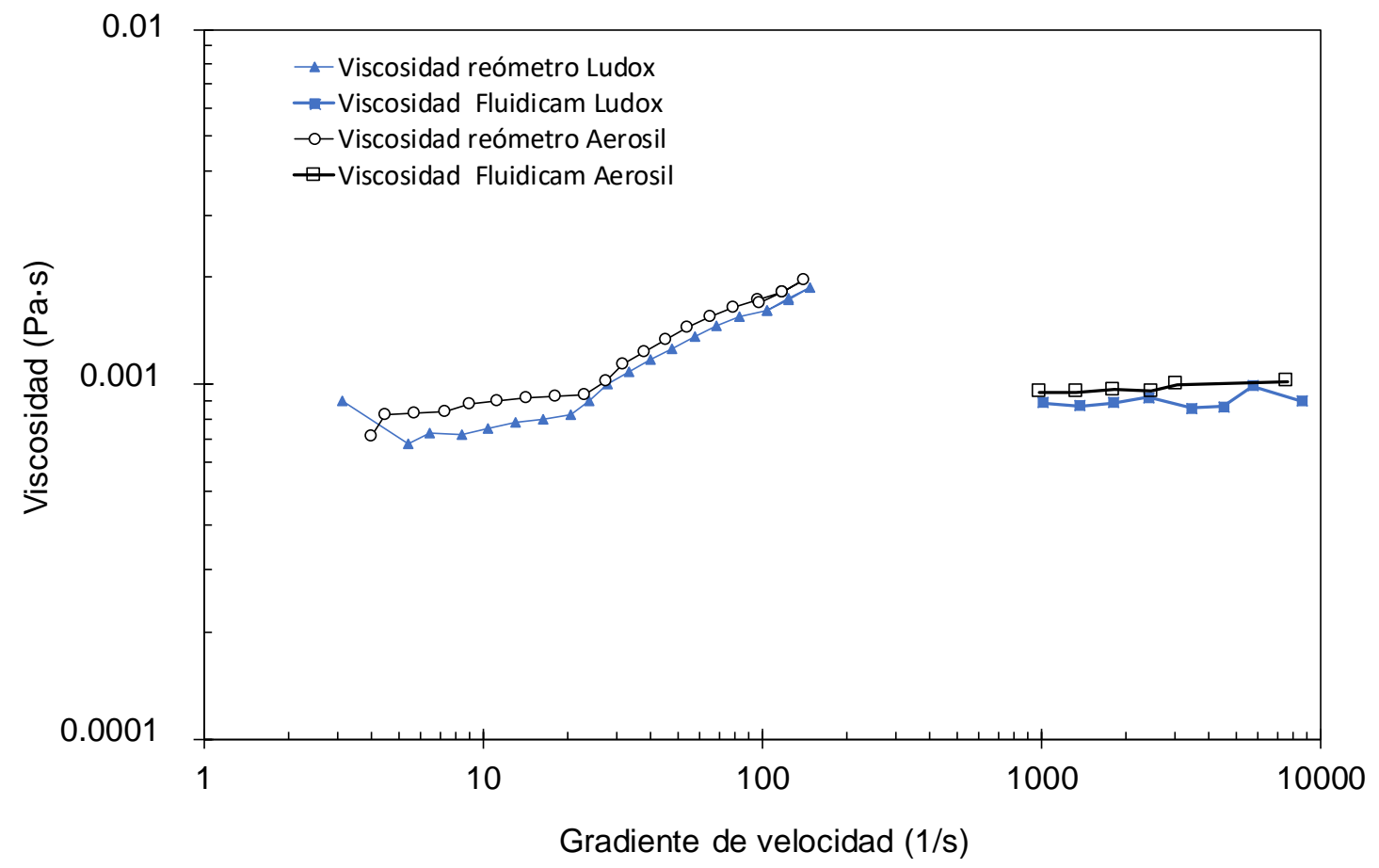

Figura 57. Comparación métodos de medida de viscosidad a una temperatura de $40^{\circ} \mathrm{C}$ (nanofluidos LUDOX y Aerosil al $1 \%$ de fracción volumétrica, $\mathrm{pH}=9$ ) 
Si comparamos las curvas de viscosidad obtenidas con los nanofluidos de sílice preparados a una misma fracción (Figura 57), se observa que los nanofluidos preparados a partir de dilución (Ludox) presentan una viscosidad menor que la de los nanofluidos preparados a partir de la dispersión de las nanopartículas de sílice en polvo.

En la siguiente figura se muestran las curvas de viscosidad obtenidas con el nanofluido preparado a partir de nanopartículas de sílice en polvo (Aerosil) a las tres temperaturas de ensayo. La curva de flujo obtenida con este nanofluido de sílice aerosil muestra un comportamiento similar a los nanofluidos preparados mediante dilución (Ludox) excepto en el ensayo a $80^{\circ} \mathrm{C}$. En este ensayo a mayor temperatura no se reproduce el incremento en viscosidad observado con el nanofluido Ludox a gradientes de velocidad mayores de $20 \mathrm{~s}^{-1}$, posiblemente debido a que el fluido es más viscoso y minimiza el error por centrifugación de la muestra.

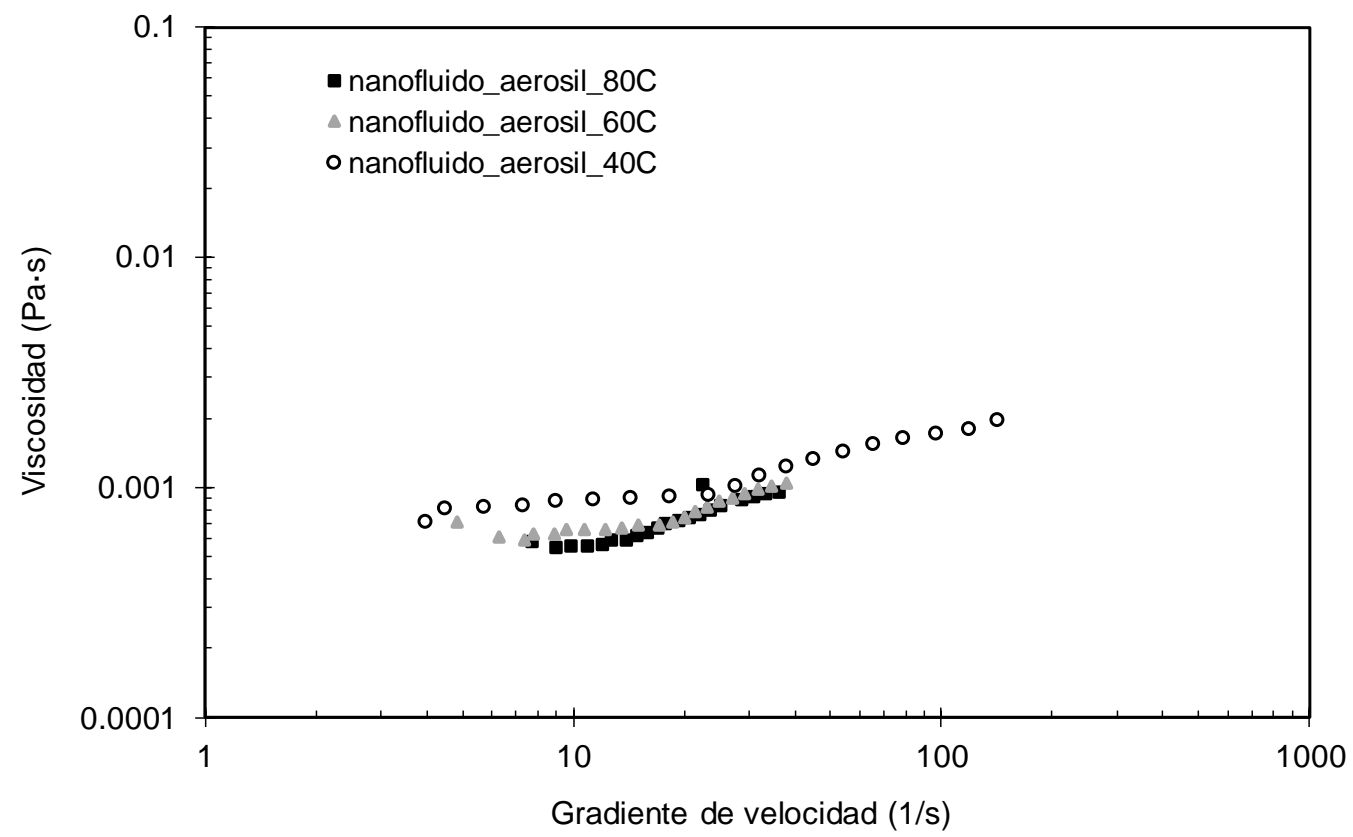

Figura 58. Curva de flujo para el nanofluido AEROSIL al $1 \%$ de fracción volumétrica, a 40,60 y $80^{\circ} \mathrm{C}$

En la Figura 59 se muestran conjuntamente las viscosidades absolutas obtenidas con los nanofluidos de sílice Aerosil y Ludox a distintas fracciones a las tres temperaturas $(40,60$ y $80^{\circ} \mathrm{C}$ ). En todos los nanofluidos de sílice caracterizados las viscosidades disminuyen a medida que se aumenta la temperatura del ensayo. Se observa además, como una mayor fracción volumétrica de nanopartículas conlleva a un aumento significativo de la viscosidad, excepto 
para el nanofluido obtenido a partir de dilución de una suspensión comercial, obteniéndose viscosidades elevadas para los nanofluidos de Aerosil preparados al $5 \%$ en volumen. Como ya han constatado algunos investigadores [62], la viscosidad del nanofluido preparado aumenta a medida que aumenta la cantidad de sólido, pues finalmente la superficie específica de interacción de las nanopartículas con el fluido base es mayor.

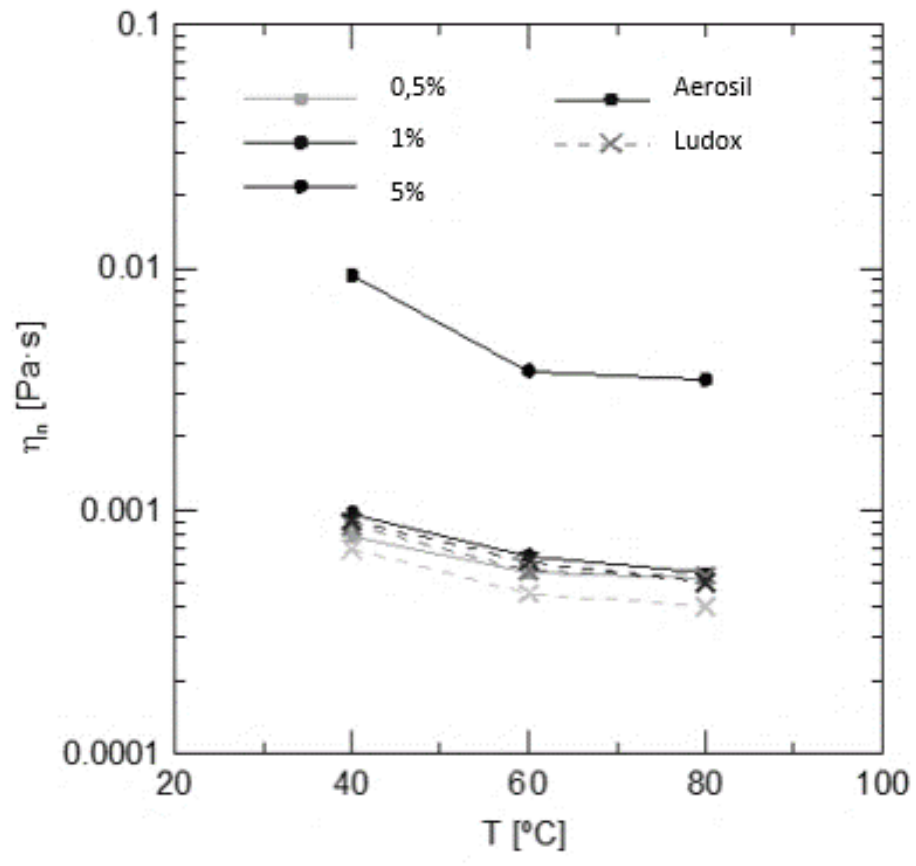

Figura 59. Comparación viscosidades Aerosil y Ludox a distintas fracciones en las tres temperaturas estudiadas

En la Tabla 16 se adjuntan los valores promedio de viscosidad obtenidos en el tramo de gradiente de velocidad en el cual la viscosidad se ha mantenido constante junto con sus errores. Los valores de viscosidad aumentan a medida que aumenta la fracción de nanopartículas dispersas lo cual origina un incremento en viscosidad respecto al fluido base que puede ocasionar problemas en el bombeo de los nanofluidos en los canales del intercambiador, como por ejemplo en el caso de los nanofluidos al $5 \%$ en fracción volumétrica. 
Tabla 16. Aumento relativo de la viscosidad absoluta para los nanofluidos de sílice. Ensayo realizado a $40^{\circ} \mathrm{C}$ y $60^{\circ} \mathrm{C}$.

\begin{tabular}{lcccc}
\hline $\begin{array}{l}\text { Tipo de } \\
\text { muestra }\end{array}$ & $\begin{array}{c}\text { Promedio de la } \\
\text { viscosidad } 40^{\circ} \mathrm{C} \\
\text { (Pa.s) }\end{array}$ & $\begin{array}{c}\text { Incremento } \\
\text { relativo } 40^{\circ} \mathrm{C} \\
(\%)\end{array}$ & $\begin{array}{c}\text { Promedio de la } \\
\text { viscosidad } 60^{\circ} \mathrm{C} \\
(\text { Pa.s) }\end{array}$ & $\begin{array}{c}\text { Incremento } \\
\text { relativo } 60^{\circ} \mathrm{C} \\
(\%)\end{array}$ \\
\hline Agua & $7,1 \mathrm{E}-04 \pm 2,2 \mathrm{E}-05$ & - & $5,3 \mathrm{E}-04 \pm 2,8 \mathrm{E}-05$ & - \\
Aerosil 0,5 \% & $7,5 \mathrm{E}-04 \pm 2,7 \mathrm{E}-05$ & 5,3 & $5,4 \mathrm{E}-04 \pm 1,7 \mathrm{E}-05$ & 1,8 \\
Aerosil 1 \% & $8,2 \mathrm{E}-04 \pm 3,1 \mathrm{E}-05$ & 15,4 & $6,4 \mathrm{E}-04 \pm 1,2 \mathrm{E}-05$ & 20,7 \\
Aerosil 5\% & $7,5 \mathrm{E}-03 \pm 4,2 \mathrm{E}-04$ & 950 & $3,7 \mathrm{E}-03 \pm 1,4 \mathrm{E}-04$ & 590 \\
Ludox 0.5\% & $7,5 \mathrm{E}-04 \pm 2,3 \mathrm{E}-05$ & 6,0 & $5,4 \mathrm{E}-04 \pm 3,1 \mathrm{E}-05$ & 1,8 \\
Ludox 1\% & $7,7 \mathrm{E}-04 \pm 2,5 \mathrm{E}-05$ & 8,4 & $5,8 \mathrm{E}-04 \pm 3,7 \mathrm{E}-05$ & 9,4 \\
Ludox 5\% & $8,8 \mathrm{E}-04 \pm 3,9 \mathrm{E}-05$ & 23,9 & $6,2 \mathrm{E}-04 \pm 4,1 \mathrm{E}-05$ & 16,9 \\
\hline
\end{tabular}




\subsection{Caracterización de los de los nanofluidos preparados con nanopartículas de alúmina}

Para la preparación de los nanofluidos de alúmina se utilizaron dos tipos de materiales, al igual que con los nanofluidos preparados con nanopartículas de sílice. Los materiales seleccionados fueron: un óxido de alúmina en polvo (Aeroxide) y una suspensión de nanopartículas de alúmina en medio acuoso (Aerodisp) con las características ya descritas en el capítulo III.

A continuación, se describen los resultados obtenidos en la caracterización inicial de los materiales utilizados para la preparación de los nanofluido, y en la caracterización de los nanofluidos de alúmina preparados (estabilidad, conductividad térmica y viscosidad).

\subsubsection{Caracterización del material de alúmina de partida}

Para conocer la morfología y estado de agregación de las nanopartículas de alúmina adquiridas (Aeroxide y Aerodisp) se caracterizó en primer lugar la forma mediante análisis de imagen en microscopio óptico de barrido (MEB), y el tamaño de los agregados de nanopartículas por difracción laser con el equipo MALVERN.

En la Figura 60, se muestran las imágenes obtenidas en el MEB a distintos aumentos para el material en polvo de alúmina Aeroxide Alu C (izda.), y para el Aerodisp (dcha.). Como se observa en ambas fotografías, los materiales se presentan aglomerados (con un tamaño mucho mayor que el indicado por el proveedor de $13 \mathrm{~nm}$ para la partícula individual), al igual que ocurría con el material de sílice adquirido. En estas fotografías se observa que la morfología de las partículas dentro de estos aglomerados de la alúmina es esférica y con un tamaño nanométrico. En primer lugar, se midió el tamaño de aglomerado que presentaban las nanopartículas adquiridas de alúmina en polvo pues el tamaño de estos agregados, así como, la resistencia o dureza de los mismos puede afectar a la dispersión de las nanopartículas en el fluido base. 

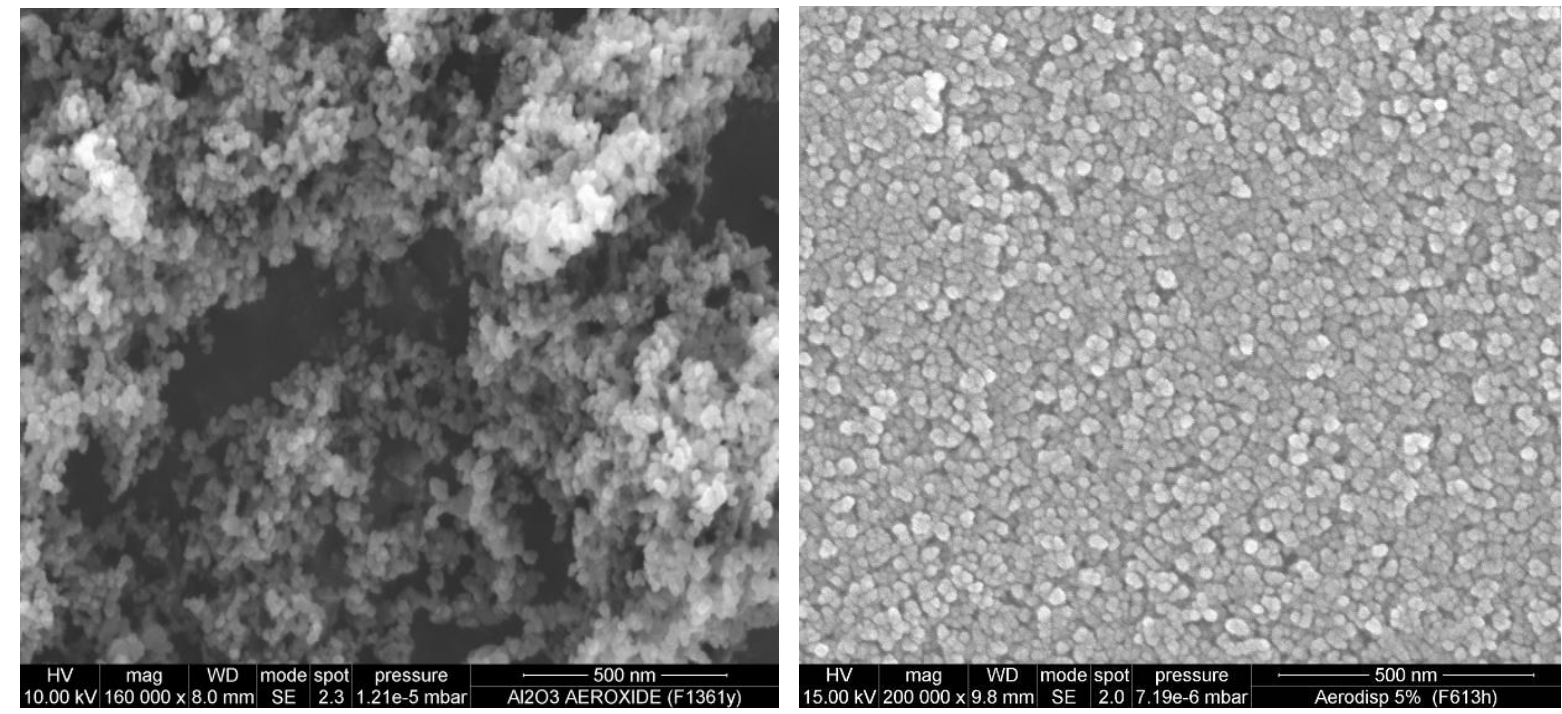

Figura 60. Imagen tomadas en MEB de la alúmina: nanofluido preparado a partir de alúmina en polvo Aeroxide (izda.) y nanofluido preparado por dilución de la suspensión comercial Aerodisp (dcha.)

Para caracterizar la dureza de los aglomerados se midió el tamaño de partícula tras 10 minutos de dispersión en agua con agitación suave (agitación proporcionada por el bombeo del equipo Malvern en el proceso de medición de tamaño por difracción laser), y tras la aplicación de una agitación más enérgica con ultrasonidos en el equipo. Se caracterizó la medida del tamaño de los aglomerados dispersados en función del tiempo y tipo de energía de dispersión aplicada.

Este estudio se realizó a un $\mathrm{pH}=7$ (cercano al punto isoeléctrico de la alúmina) y a un $\mathrm{pH}=4$ ( $\mathrm{pH}$ más alejado del punto isoeléctrico). En los gráficos de la Figura 61 y Figura 62 se muestran los resultados obtenidos para los dos ensayos, representándose el tamaño de agregados de partículas (caracterizado por el $d_{10}, d_{50}$ y $d_{90}$ ) en función del tiempo y tipo de agitación aplicada.

Como puede observarse en ambos gráficos, en la etapa de agitación suave por bombeo los agregados de alúmina se van dispersando, reduciendo su tamaño, tanto a pH=7 como a pH=4. Cuando se inicia la etapa de aplicación de ultrasonidos los agregados se dispersan mejor reduciendo su tamaño hasta un determinado tiempo, a partir del cual la agitación intensa conlleva a que las nanopartículas se reagreguen aumentando el tamaño de aglomerado medido. 


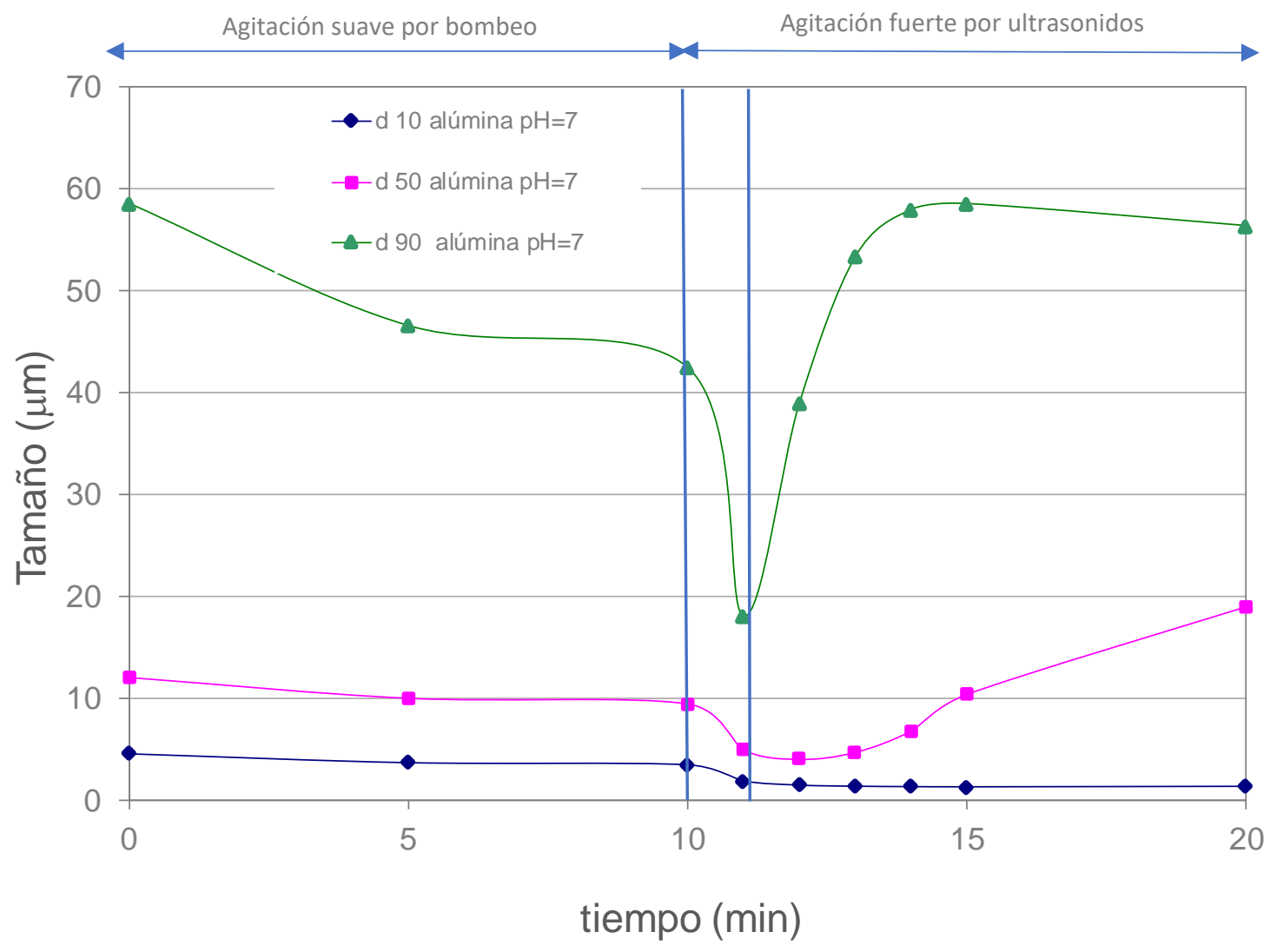

Figura 61. Caracterización del tamaño de los aglomerados de aeroxide en suspensión acuosa a un pH=7

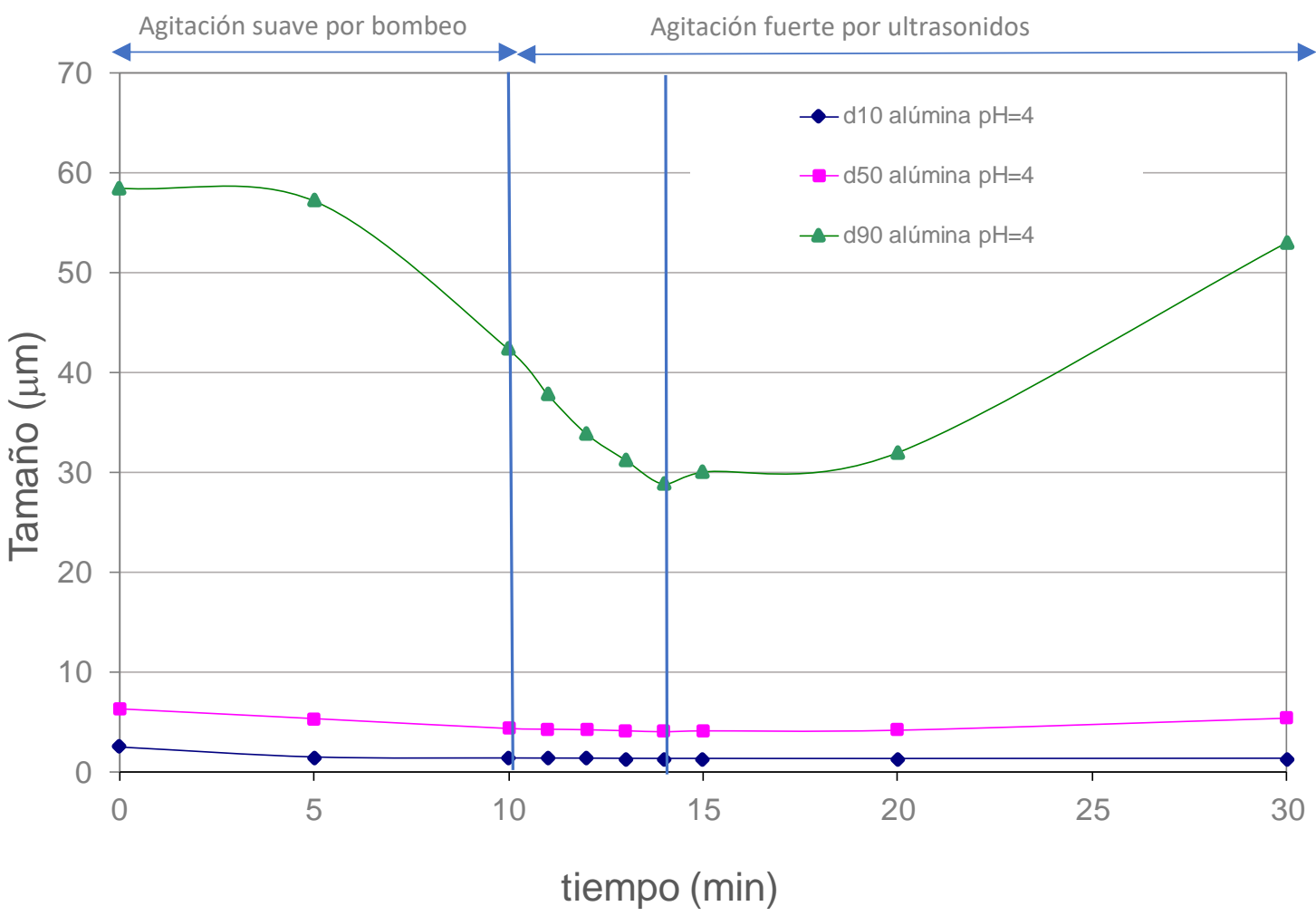

Figura 62. Caracterización del tamaño de los aglomerados aeroxide en suspensión acuosa a un pH=4 
Dicho comportamiento se reproduce tanto a $\mathrm{pH}=7$ donde predominan las fuerzas de atracción entre nanopartículas como a $\mathrm{pH}=4$ donde predominan las fuerzas de repulsión, aunque en el caso de estabilización mediante $\mathrm{pH}$ ácido las partículas dispersadas tras la aplicación de los ultrasonidos permanecen más estables reaglomerándose tras un tiempo de aplicación de ultrasonidos mayor (tras quince minutos de U.S.).

Tras el análisis de evolución del tamaño de los aglomerados en función de la cantidad y tipo de energía aplicada puede concluirse, al igual que se constató con la sílice, que la energía total aplicada en los procesos de dispersión pasa a ser de nuevo una variable crítica en este tipo de materiales.

En la Tabla 17 se muestran los resultados del coeficiente de friabilidad de aglomerado (c.f.) obtenidos para el material Aeroxide a un pH neutro y uno ácido. Puede observarse que para un pH neutro la agitación óptima se obtiene mediante la aplicación de ultrasonidos obteniéndose un coeficiente de friabilidad máximo tras un minuto de aplicación. Se observa que, una vez alcanzado este punto, la aplicación continuada de ultrasonidos conlleva un efecto opuesto pues se obtiene una reaglomeración de las partículas, debido posiblemente al aumento de colisiones entre partículas y a los bajos potenciales de repulsión entre las mismas a este $\mathrm{pH}$. El comportamiento de la cinética de dispersión cuando el fluido se acidifica es totalmente distinto, obteniéndose un tiempo óptimo de aplicación de ultrasonidos entre 5-10 minutos, sin observarse el efecto de reaglomeración por mantener la agitación por ultrasonidos.

Tabla 17. Tamaño de aglomerado tras agitación y coeficiente de friabilidad del material alúmina (Aeroxide)

\begin{tabular}{lcccc}
\hline \multirow{2}{*}{ Sistema de agitación aplicado } & \multicolumn{3}{c}{$p H=7$} & \multicolumn{3}{c}{$p H=4$} \\
\cline { 2 - 5 } & $d_{90}$ & $c_{0} f_{0}{ }^{*}$ & $d_{90}$ & $c_{.} f_{0}{ }^{*}$ \\
& $(\mu \mathrm{m})$ & $(\%)$ & $(\mu \mathrm{m})$ & $(\%)$ \\
\hline Alúmina tras agitación suave & 42,45 & 27 & 42,67 & 28 \\
dispersión U.S. 1 min & 18,08 & 69 & 37,9 & 35 \\
dispersión U.S. 10 min & 56,37 & 4 & 32,05 & 45 \\
\hline
\end{tabular}

* coeficiente de friabilidad calculado como

$$
\text { c. } f .=\frac{\text { tamaño inicial }- \text { tamaño final }}{\text { tamaño inicial }} * 100
$$


Se puede concluir que además de la intensidad y el tiempo de aplicación de energía, el estado de dispersión alcanzado, así como la estabilidad en los nanofluidos preparados va a depender del potencial zeta. En el caso del material de alúmina es recomendable ir a pH ácidos, $\mathrm{pH}=4$, donde los potenciales de repulsión entre partículas alcanzan valores altos, aplicando la agitación mecánica por sonda de ultrasonidos con un tiempo total máximo de 10 minutos tras una agitación suave previa.

1.2.2 Preparación de los nanofluidos de alúmina. Resultados de la caracterización de la dispersión y de la estabilidad.

Las nanopartículas de aeroxide se dispersaron en medio acuoso con una sonda de ultrasonidos según la metodología descrita en el procedimiento 2.2.3 Capitulo III. El tiempo total aplicado para alcanzar una dispersión correcta de las nanopartículas tras su mezcla con agitación suave, fue de 10 min de agitación fuerte en sonda de ultrasonidos a intervalos de 2 minutos, al igual que el utilizado en la preparación de los nanofluidos de sílice.

Una vez dispersadas de forma mecánica las nanopartículas se estabilizó la suspensión mediante el ajuste del pH. Para la alúmina, el punto isoeléctrico que corresponde al valor de $\mathrm{pH}$ en el cual el potencial zeta se hace cero, corresponde a un valor de $\mathrm{pH}$ igual a 8, (Figura 63). Para la estabilización de los nanofluidos de alúmina preparados se eligió un $\mathrm{pH}=4$, bastante alejado de su punto isoeléctrico para lograr así una repulsión máxima entre las nanopartículas dispersadas. 


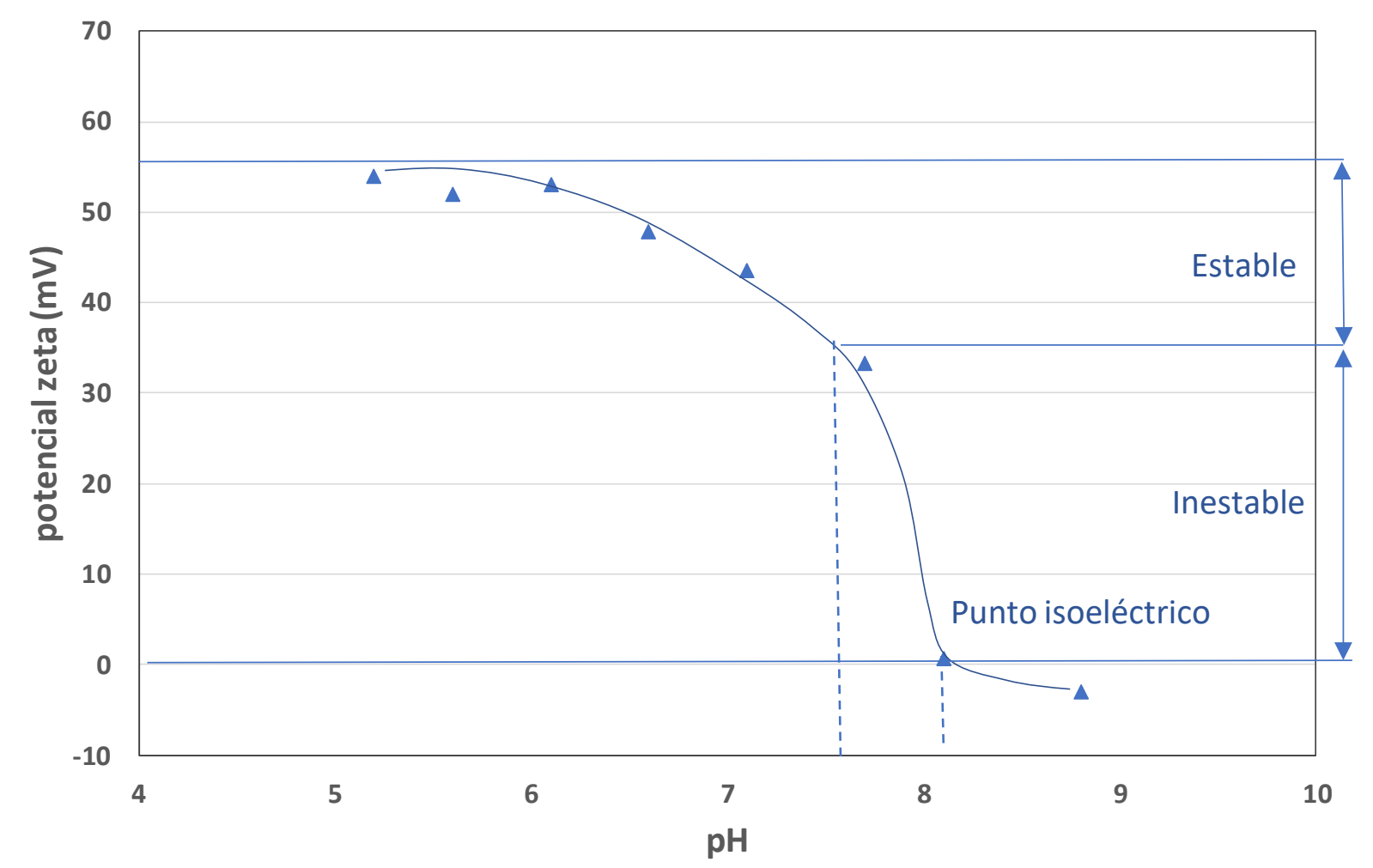

Figura 63 . Variación del potencial zeta del nanofluido de alúmina (Aeroxide) en función del pH de la suspensión

Una vez preparados los distintos nanofluidos de alúmina se procedió a caracterizar su grado de dispersión y estabilidad.

Tras la preparación de los nanofluidos de alúmina según la metodología descrita en el apartado 2.2.3 Capítulo III, se procedió a la caracterización del estado de dispersión de las nanopartículas en el fluido base. Para dicha caracterización se utilizó el microscopio electrónico de transmisión (TEM), siendo el método de preparación de las muestras el mismo método descrito ya en la caracterización de los nanofluidos de sílice. Las muestras una vez depositadas en la gradilla se liofilizaron y se analizó la parte central de la gota.

\section{Caracterización del estado de dispersión de las nanopartículas en los nanofluidos de alúmina} mediante análisis de imagen en el TEM

En las figuras Figura 64 y Figura 65, se muestran las imágenes obtenidas en el microscopio de transmisión óptico a distintos aumentos de los dos tipos de nanofluidos de alúmina caracterizados: 
- Aeroxide: nanofluido de alúmina preparado a partir de nanopartículas en polvo, con una fracción volumétrica del 1\% y agitado con sonda de ultrasonidos. Estabilizado a $\mathrm{pH}=4$ (Figura 64)

- Aerodisp: nanofluido de alúmina comercial diluido al $1 \%$ en volumen, agitado mediante sonda de ultrasonidos ultrasonidos y estabilizado a pH=4 (Figura 65).

No se han encontrado diferencias significativas entre las muestras de alúmina caracterizadas en el TEM. Tanto las nanopartículas en polvo Aeroxide dispersadas como la dilución de la alúmina comercial Aerodisp presentan agregados con tamaño mayor a $20 \mathrm{~nm}$ formados por una cadena de nanopartículas de 5 a $10 \mathrm{~nm}$. La forma de dichos agregados es arracimada, no esférica.
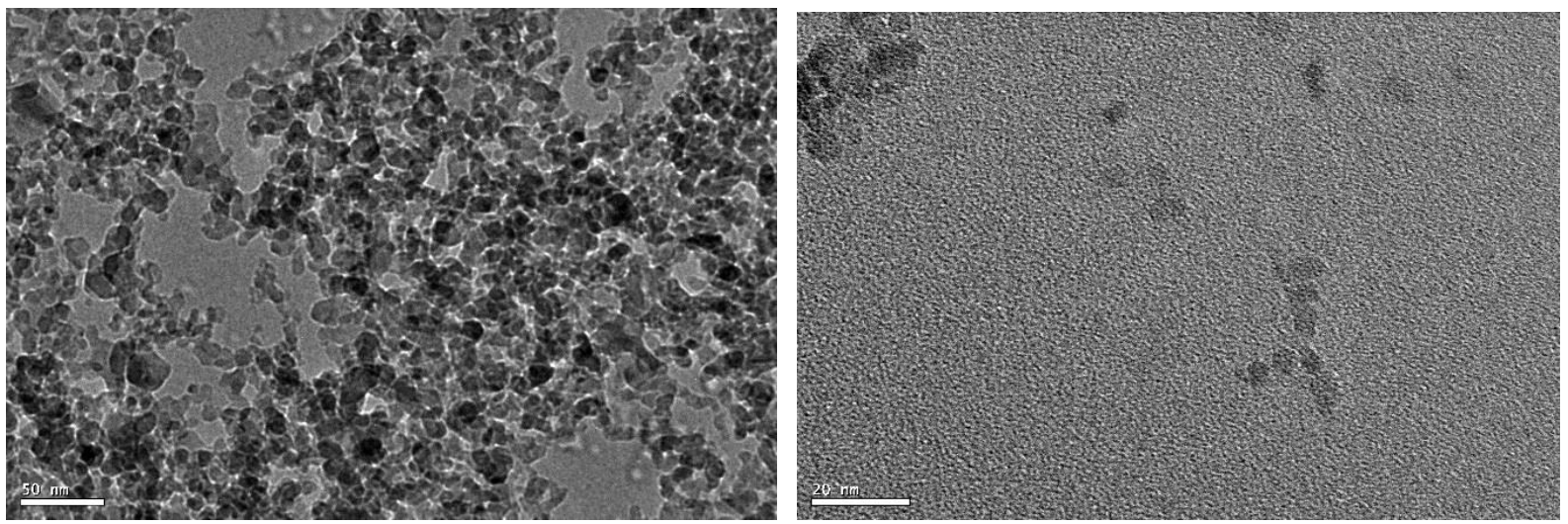

Figura 64. Imagen TEM del nanofluido preparado a partir de alúmina en polvo Aeroxide al $1 \%$ en volumen y ajustado a un pH=4 a 50000 aumentos (izda.) y a 150000 aumentos (dcha.).
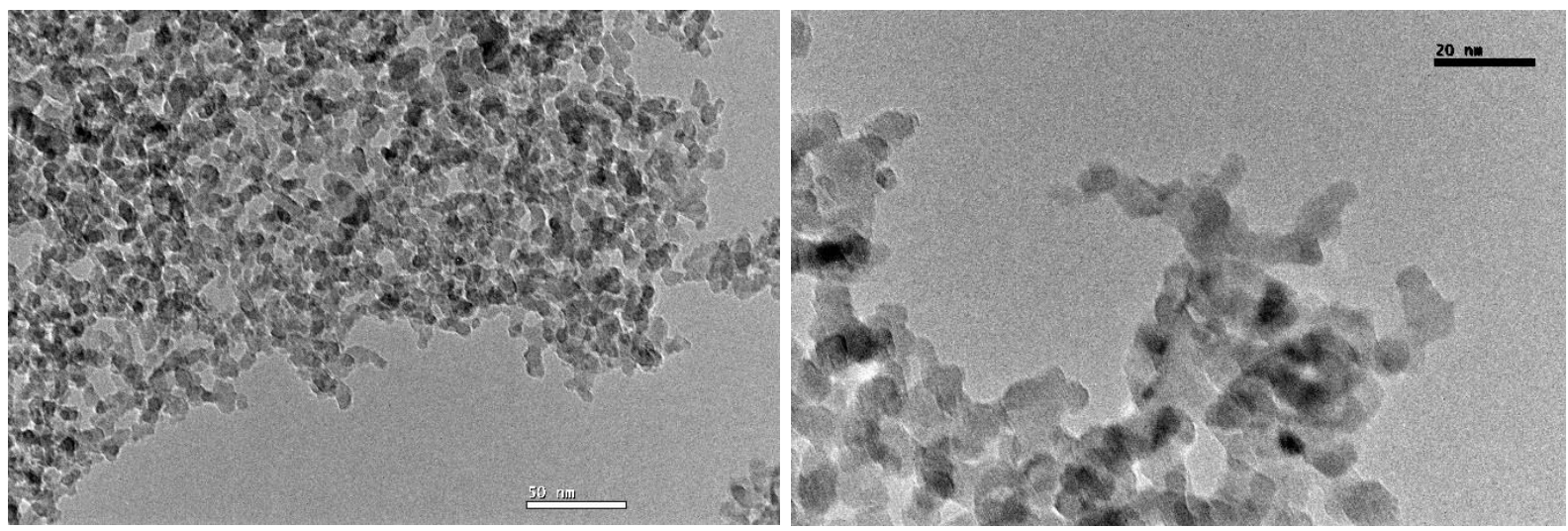

Figura 65. Imagen TEM del nanofluido preparado a partir de dilución de suspensión comercial Aerodisp al $1 \%$ en volumen y ajustado a un pH=4 a 60000 aumentos (izda.) y a 150000 aumentos (dcha.). 


\section{Análisis del tamaño final de las nanopartículas de alúmina en polvo y suspensión comercial}

\section{dispersadas}

Tras la caracterización del grado de dispersión de las nanopartículas de alúmina en los nanofluidos preparados mediante el análisis de imagen en TEM, se procedió a medir el tamaño final de las nanopartículas o agregados en las suspensiones de nanofluidos mediante la técnica de difracción laser, según el método descrito en el apartado 3.5 Capitulo III en el equipo Nanosizer.

En las Figura 66 y Figura 67 se muestran los resultados obtenidos de la distribución de tamaño de las nanopartículas dispersas para los dos tipos de nanofluidos preparados a partir de distintos tipos de material (Aeroxide y Aerodisp). Como puede observarse tras el análisis de tamaños, las nanopartículas de alúmina no se han conseguido dispersar en su totalidad, pues no se han alcanzado los tamaños de nanopartícula que indica el proveedor del orden de 10 $\mathrm{nm}$. Las partículas dispersadas se encuentran formando aglomerados de tamaño medio alrededor de los $100 \mathrm{~nm}$, tanto en los nanofluidos preparados a partir de las nanopartículas en polvo (Aeroxide) como en los nanofluidos preparados a partir de la dilución de una muestra comercial ( Aerodisp).

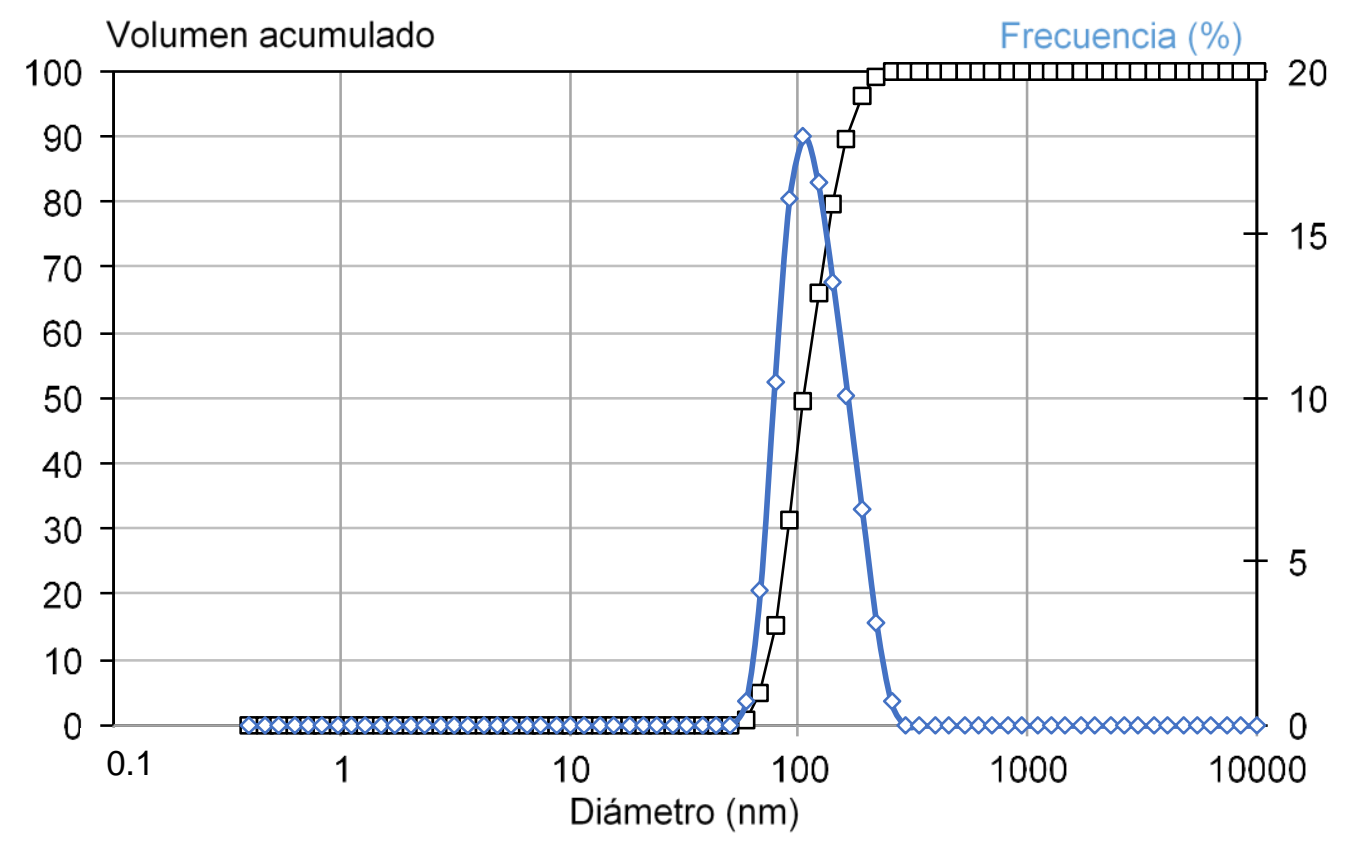

Figura 66. Distribución de tamaño de partícula de la muestra de $\mathrm{Al}_{2} \mathrm{O}_{3}$ (Aeroxide) al $1 \%$ en volumen y a un $\mathrm{pH}=4$ 


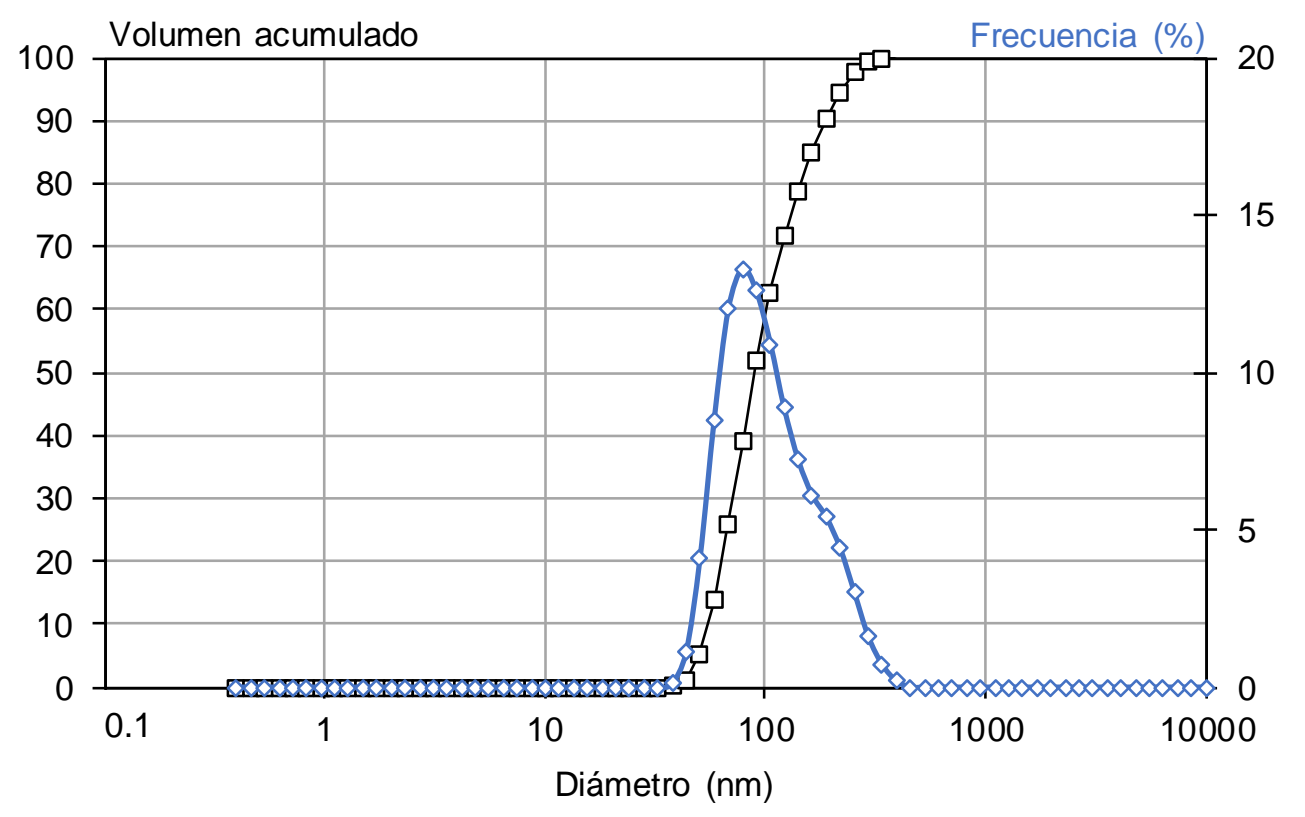

Figura 67. Distribución de tamaño de partícula de la muestra de $\mathrm{Al}_{2} \mathrm{O}_{3}$ (Aerodisp) al $1 \%$ en volumen y a un $\mathrm{pH}=4$

Los nanofluidos de alúmina preparados presentan un tamaño (dgo) de aglomerados de nanopartículas de unos $200 \mathrm{~nm}$, muy superiores a los $13 \mathrm{~nm}$ indicados por el proveedor, (Tabla 18).

Tabla 18. Distribución de tamaños de los aglomerados de alúmina en los nanofluidos preparados

\begin{tabular}{cccc}
\hline Material nanofluido & $d_{10}(\mathrm{~nm})$ & $d_{50}(\mathrm{~nm})$ & $d_{90}(\mathrm{~nm})$ \\
\hline $\mathrm{Al}_{2} \mathrm{O}_{3}$ AEROXIDE & 78,7 & 115 & 181 \\
$\mathrm{Al}_{2} \mathrm{O}_{3}$ AERODISP & 59,2 & 96,9 & 206 \\
\hline
\end{tabular}

\section{Caracterización de la estabilidad de los nanofluidos de alúmina}

A continuación, se resumen los resultados obtenidos en los ensayos de estabilidad realizados a las distintas suspensiones de nanofluidos de alúmina preparadas. Se ha utilizado la técnica de dispersión de luz para el análisis de la estabilidad en el tiempo, como ya se ha descrito en el apartado 2.3.1, del Capítulo III.

En primer lugar, se analizó el efecto de la temperatura sobre la estabilidad de los nanofluidos, ensayándose todos los nanofluidos a dos temperaturas ( 40 y $60^{\circ} \mathrm{C}$ ). En la Figura 68 se muestran los datos de retrodispersión (B.S., "back-scattering") registrados durante 72 horas en la zona centro (zona elegida para comparar la estabilidad de los nanofluidos). Como puede 
observarse no existen diferencias significativas al aumentar la temperatura del ensayo, al igual que lo observado en el comportamiento de los nanofluidos de sílice. Sí se ha observado que a medida que aumenta la fracción volumétrica de nanopartículas en el fluido base, el retrodispersión (BS \%) recogido también es mayor al tener más partículas que dispersan el haz de luz emitido, pero este se mantiene constante durante todo el ensayo, indicando que no hay sedimentación ni reaglomeración en el tiempo de las nanopartículas dispersadas.
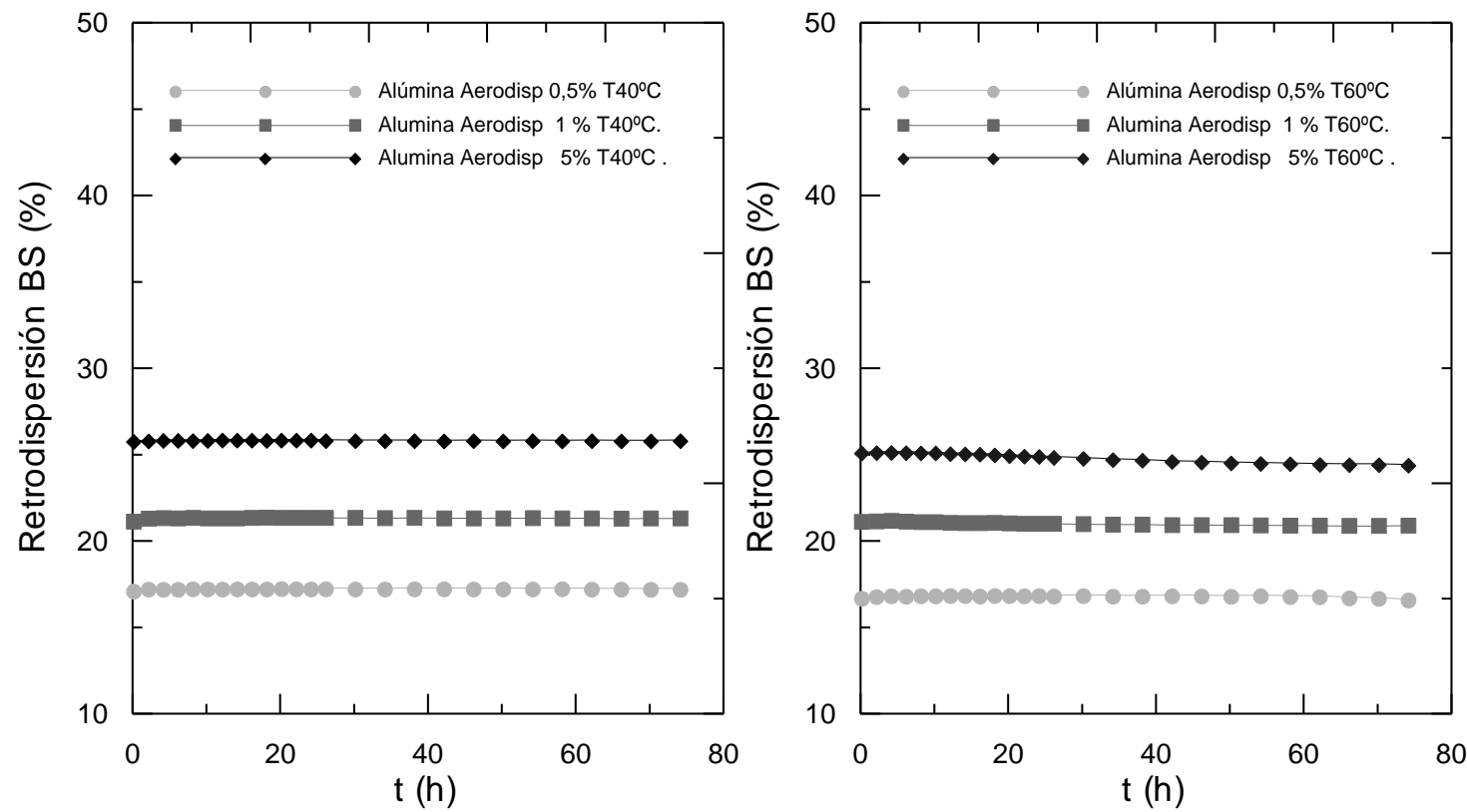

Figura 68. Estabilidad de suspensiones de alúmina Aerodisp a distinta fracción volumétrica a 40 y $60^{\circ} \mathrm{C}$

Para todas las muestras analizadas de nanofluidos de alúmina preparadas con distinta metodología, técnica en dos etapas (aeroxide) o dilución (aerodisp), a las tres fracciones volumétricas $(0,5,1$ y $5 \%$ ) y a un $\mathrm{pH}$ ajustado de 4 , la estabilidad de las mismas se ha mantenido constante pues no se ha detectado cambios en la retrodispersión (BS) a lo largo del tiempo, como puede observarse en el gráfico comparativo de la Figura 69. Los nanofluidos de alúmina preparados presentan una estabilidad adecuada para su posterior aplicación como fluido térmico. 


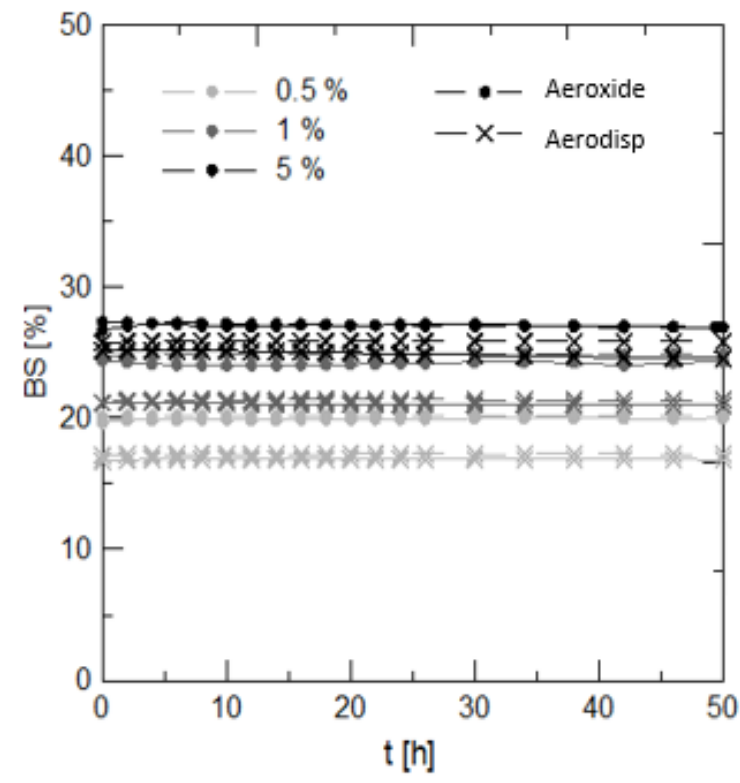

Figura 69. Estabilidad de suspensiones de alúmina preparadas a partir del Aerodisp y del Aeroxide a distinta fracción volumétrica

1.2.3 Resultados de la medida de la conductividad térmica de los nanofluidos de alúmina: Aeroxide y Aerodisp

Al igual que con los nanofluidos de sílice se ha medido la conductividad térmica de los nanofluidos de alúmina preparados a partir de nanopartículas en polvo (Aeoroxide) y de suspensión comercial (Aerodisp). Los nanofluidos se han caracterizado a distintas fracciones realizándose los ensayos a tres temperaturas de trabajo $\left(40,60\right.$ y $\left.80^{\circ} \mathrm{C}\right)$ para analizar también el efecto de la temperatura.

Los incrementos en conductividad respecto al fluido base obtenidos se han representado en dos gráficos:

- En el primer gráfico se ha representado la conductividad térmica relativa ( $k_{\text {nanofluido }} / k_{\text {agua }}$ ) obtenida en función de la temperatura en los nanofluidos Aeroxide preparados a distintas fracciones volumétricas, (Figura 70).

- $\quad$ En el segundo gráfico, Figura 71 , se comparan la conductividad térmica relativa ( $k_{\text {nanofluido/ }}$ agua ) obtenidos con cada tipología de material preparados a distintas fracciones y a una misma temperatura de ensayo. 
Tras el análisis de los resultados puede concluirse que para los nanofluidos de Aeroxide los aumentos en conductividad térmica respecto al fluido base agua son significativos a fracciones elevadas (5\%), como puede observarse en la Figura 70. Para esta fracción se obtiene mayor incremento en la conductividad térmica a temperaturas elevadas, alcanzándose un valor de un $11,8 \%$ a $80^{\circ} \mathrm{C}$.

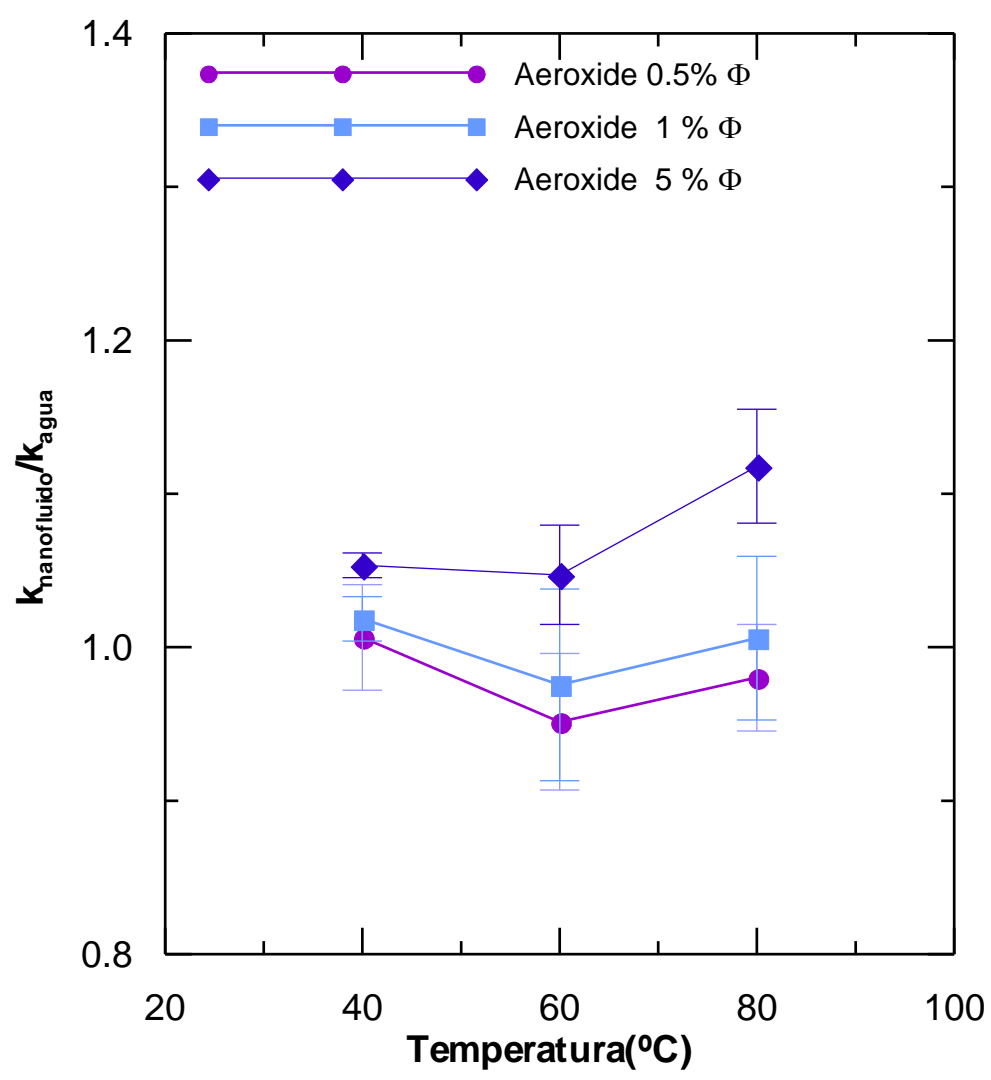

Figura 70. Estudio de aumento de conductividad térmica para nanofluido de alúmina aeroxide preparado a distinta fracción volumétrica a 40,60 y $80^{\circ} \mathrm{C}$

Si comparamos los nanofluidos de alúmina preparados con distinta metodología: técnica en dos etapas o dilución, (aeroxide material en polvo y aerodisp suspensión comercial) Figura 71, los aumentos en conductividad térmica, a una temperatura de $40^{\circ} \mathrm{C}$, son parecidos, obteniéndose el mejor resultado con la preparación del nanofluido en dos etapas a partir del material en polvo aeroxide al $5 \%$. 


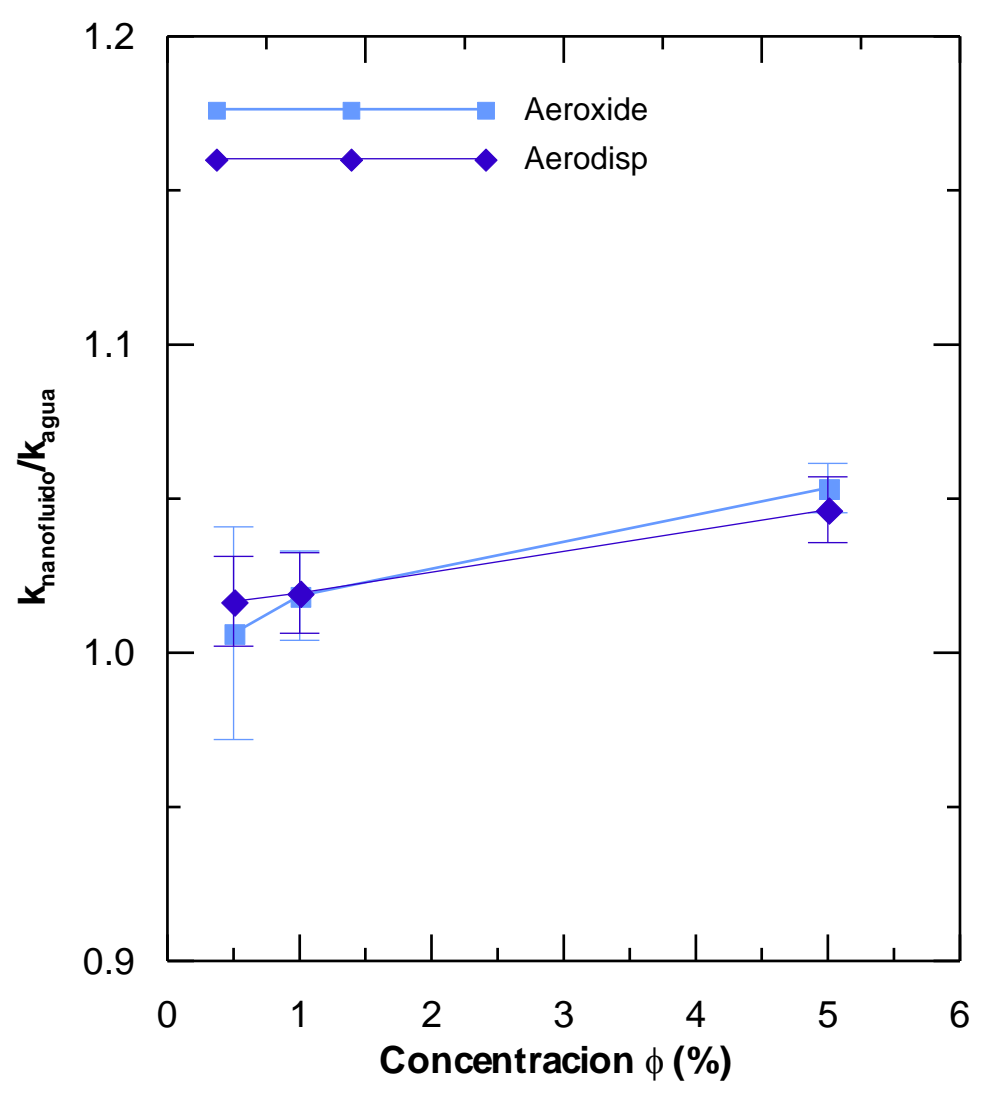

Figura 71. Comparación conductividad térmica a distinta fracción volumétrica medida en nanofluidos Aeroxide y Aeorodisp a $40^{\circ} \mathrm{C}$

Sin embargo, a temperaturas elevadas el mayor incremento en conductividad se ha obtenido con el nanofluido de aerodisp al 5\%, (Figura 72), debido posiblemente a la menor viscosidad del nanofluido comercial que puede aumentar el fenómeno de transferencia de calor añadiendo a los mecanismos de conducción los mecanismos de convección.

Puede concluirse que los mejores resultados en comportamiento térmico se obtendrán con los nanofluidos preparados al $5 \%$ de fracción volumétrica, tanto si se preparan a partir de suspensión comercial o muestra en polvo, presentando ambos un incremento en el rango de temperaturas de 40 a $80^{\circ} \mathrm{C}$, y una buena estabilidad como ya se ha resumido anteriormente. El aumento máximo logrado en conductividad térmica ha sido del $18,5 \%$ y se ha obtenido con el nanofluido Aerodisp al 5\%. 


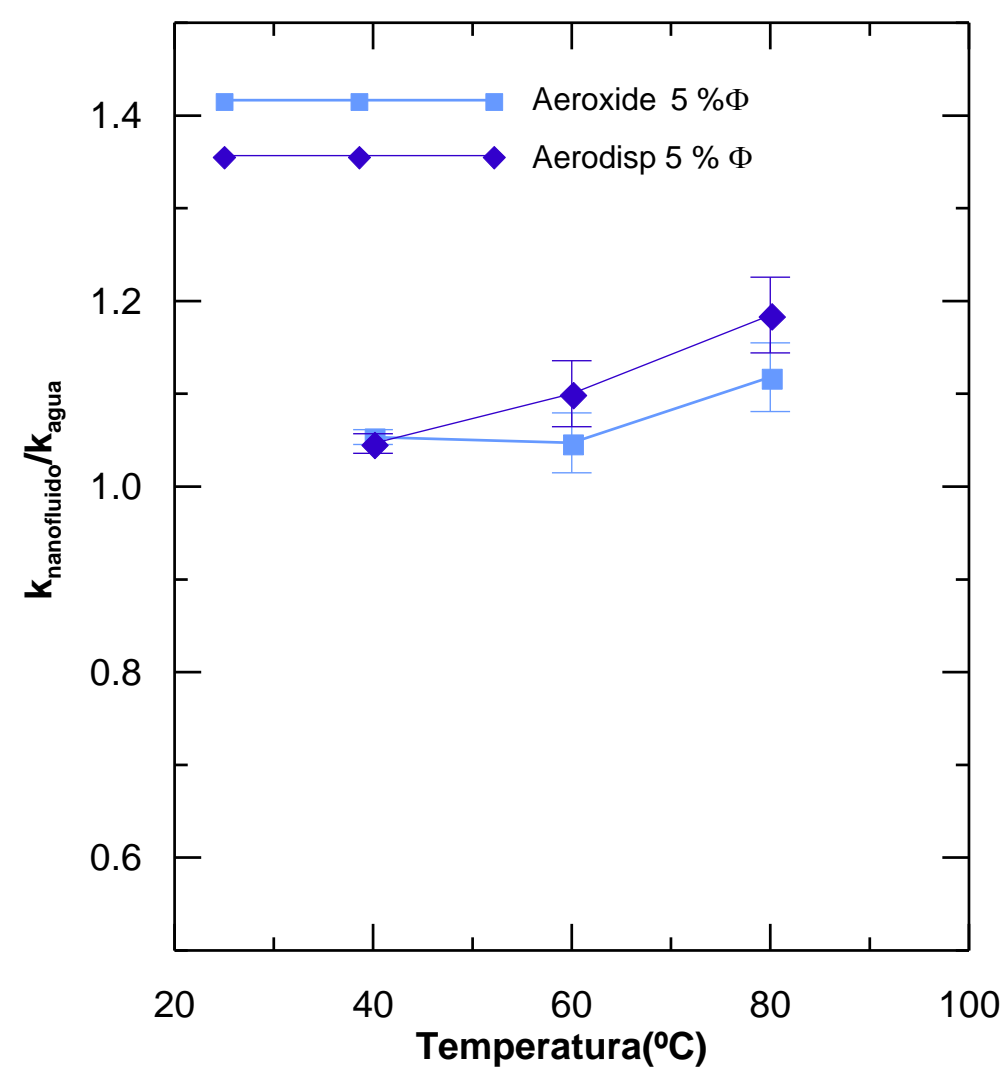

Figura 72. Comparación del aumento de conductividad térmica a varias temperaturas para nanofluidos preparados a partir de alúmina aeroxide y nanofluido obtenido por dilución comercial Aeorodisp, al 5\% de fracción volumétrica

\subsubsection{Resultados de la medida de la viscosidad de los nanofluidos de alúmina: Aeroxide y} Aerodisp

Si se observa el reograma obtenido tras la caracterización del comportamiento reológico de uno de los nanofluidos de alúmina, Figura 73 , se puede observar que el comportamiento que caracteriza a estos nanofluidos es no newtoniano dependiente del gradiente de velocidad aplicado, al igual que el comportamiento observado en los nanofluidos de sílice. Como ya se indicó, este comportamiento puede deberse a un error en el reómetro por efecto de las turbulencias generadas en el viscosímetro cilíndrico coaxial. Sin embargo, en los nanofluidos de sílice este error aparecía a gradientes altos de velocidad (mayores de $10 \mathrm{~s}^{-1}$ ) mientras que en los nanofluidos de alúmina se observa ya a bajos gradientes de velocidad. Para minimizar dicho efecto la viscosidad absoluta se obtendrá como promedio de la viscosidad medida a bajos gradientes de cizalla. 


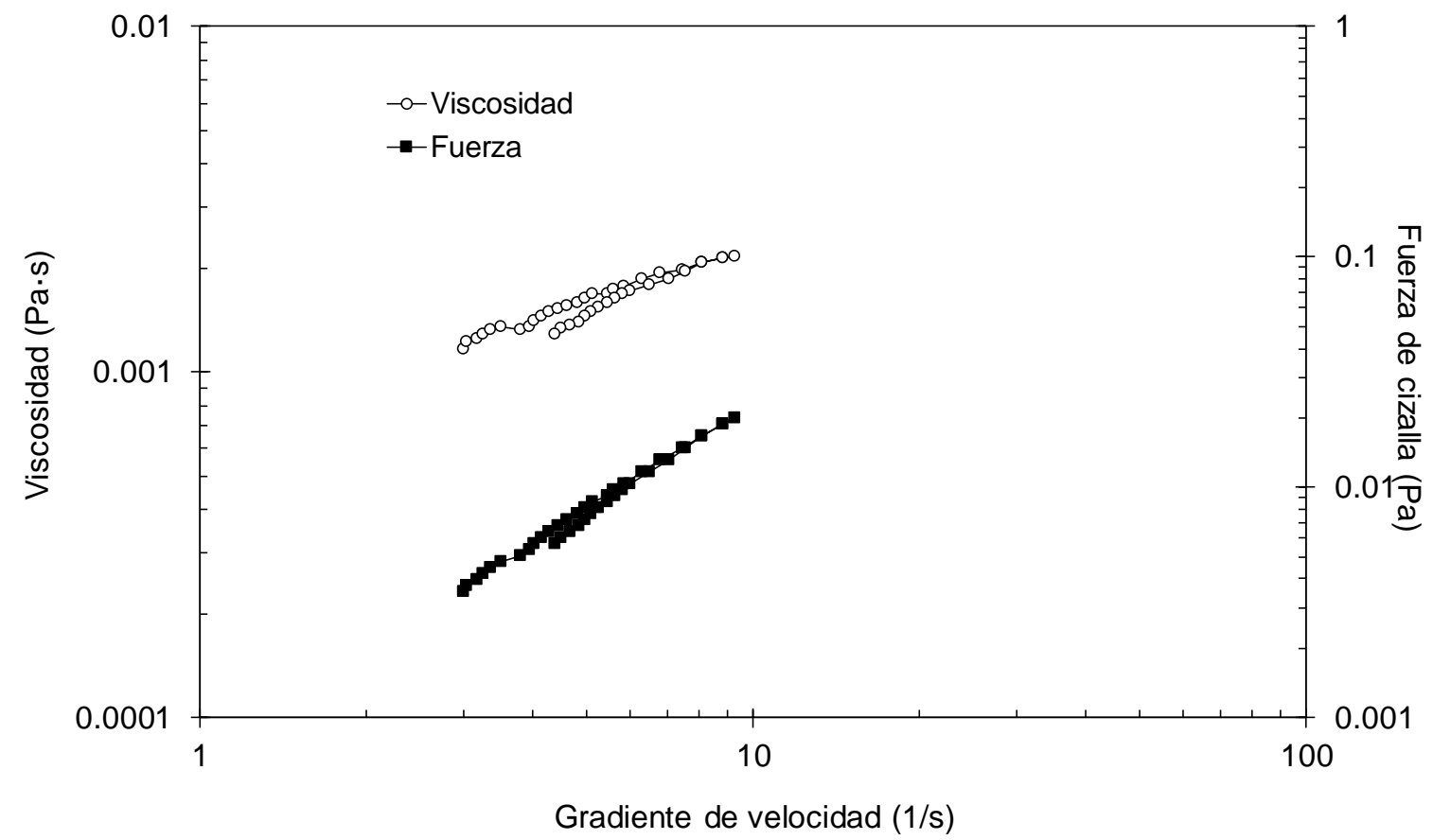

Figura 73. Valores de viscosidad y fuerza de cizalla medidos para el nanofluido Aerodisp $5 \%$ a distintos gradientes de velocidad y a una temperatura de ensayo de $40^{\circ} \mathrm{C}$

En la Figura 74 se comparan las viscosidades absolutas obtenidas a distintas fracciones con los nanofluidos de alúmina Aeroxide y Aerodisp, ensayadas a las tres temperaturas $(40,60$ y $80^{\circ} \mathrm{C}$ ). Las viscosidades de todos los nanofluidos de alúmina disminuyen a medida que se aumenta la temperatura del ensayo, acorde con el comportamiento del fluido base. Cuando se produce un aumento de la fracción volumétrica de nanopartículas se observa como la viscosidad del nanofluido aumenta, tanto para las muestras de nanofluidos preparados a partir de nanopartículas de Aeroxide como para los obtenidos por dilución, de Aerodisp, alcanzando valores de viscosidad más elevados para las fracciones más altas ( $5 \%$ en volumen). 


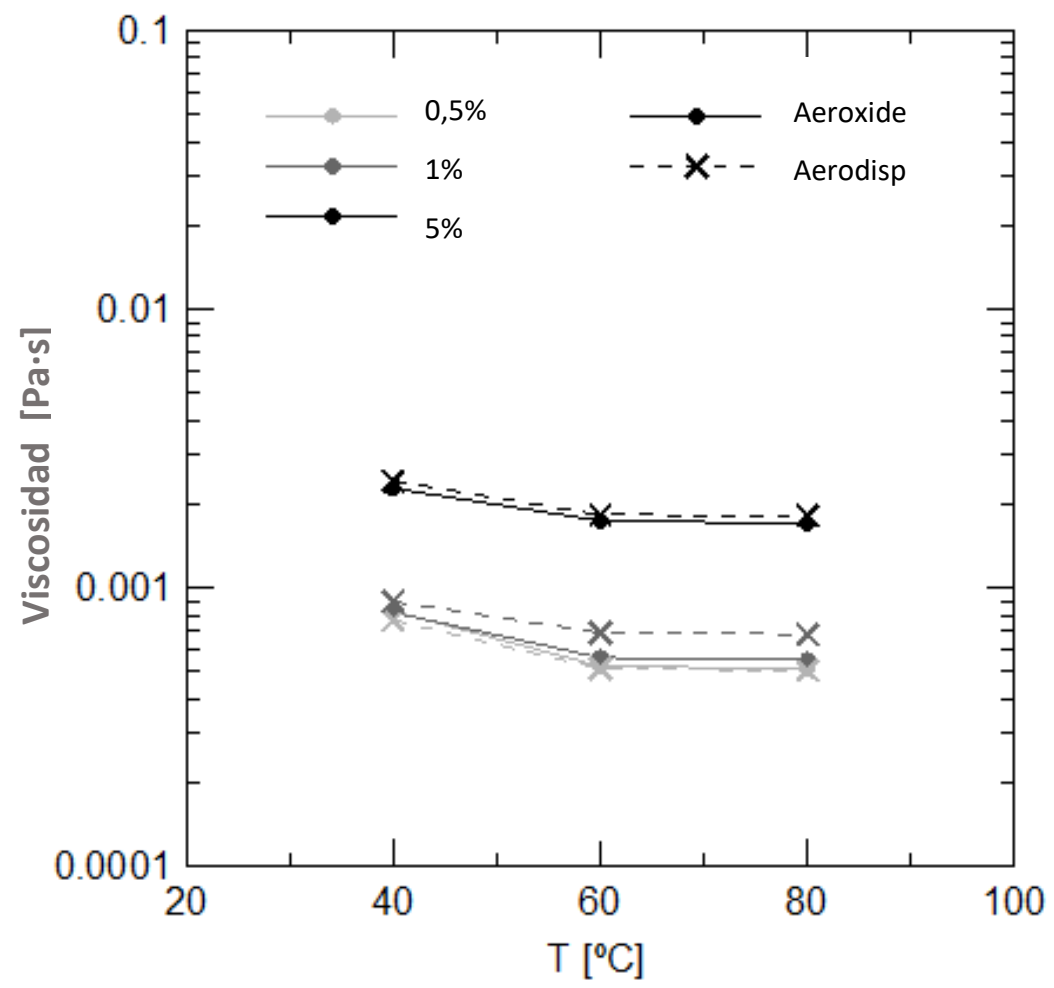

Figura 74. Resultados de viscosidad media obtenidos para los distintos tipos de nanofluidos de alúmina ( Aerodisp y Aeroxide) preparados a distintas fracciones y ensayados a tres temperaturas $\left(40,60\right.$ y $\left.80^{\circ} \mathrm{C}\right)$

Si se observan los incrementos de viscosidad del nanofluido de alúmina respecto al fluido base, Tabla 19 , se observa como a fracciones bajas ( 0,5\%) la viscosidad del nanofluido apenas se ve afectada, pero a fracciones elevadas (5\%) el aumento experimentado en viscosidad es muy elevado ( incrementos del orden del $200 \%$ ) pudiendo generar problemas en el transporte de los nanofluidos en los canales del intercambiador debido a la pérdida de carga que generan y el aumento en la presión de bombeo que resulta necesario aplicar para mantener la velocidad. Este aumento de viscosidad en los nanofluidos de alúmina al $5 \%$ puede ser un factor limitante en cuanto a su aplicación industrial, al igual que ocurría con los nanofluidos de sílice. Los incrementos en viscosidad alcanzados con los nanofluidos de alúmina a elevada fracción volumétrica (del orden del 200\%) son menores que los incrementos en viscosidad obtenidos con los nanofluidos de sílice preparados a partir de nanopartículas en polvo Aerosil (del orden del $600 \%$ ). En los nanofluidos de alúmina se obtienen aumentos en viscosidad en ambos métodos de preparación (método dos etapas, Aeroxide o por dilución, Aerodisp). Sin embargo 
en los nanofluidos de sílice cuando estos se preparaban a partir del método de dilución, apenas se apreciaron incrementos de viscosidad respecto al fluido base.

Tabla 19. Aumento relativo de la viscosidad absoluta para los nanofluidos de alúmina. Ensayo realizado a $40^{\circ} \mathrm{C}$ y $60^{\circ} \mathrm{C}$.

\begin{tabular}{lcccc}
\hline $\begin{array}{l}\text { Tipo de } \\
\text { muestra }\end{array}$ & $\begin{array}{c}\text { Promedio de la } \\
\text { viscosidad } 40^{\circ} \mathrm{C} \\
(\text { Pa.s) }\end{array}$ & $\begin{array}{c}\text { Incremento } \\
\text { relativo } 40^{\circ} \mathrm{C} \\
(\%)\end{array}$ & $\begin{array}{c}\text { Promedio de la } \\
\text { viscosidad } 60^{\circ} \mathrm{C} \\
(\text { Pa.s) }\end{array}$ & $\begin{array}{c}\text { Incremento } \\
\text { relativo } 60^{\circ} \mathrm{C} \\
(\%)\end{array}$ \\
\hline Agua & $7,1 \mathrm{E}-04 \pm 2,2 \mathrm{E}-05$ & - & $5,3 \mathrm{E}-04 \pm 2,8 \mathrm{E}-05$ & - \\
Aeroxide 0,5 \% & $7,5 \mathrm{E}-04 \pm 2,7 \mathrm{E}-05$ & 5,6 & $5,3 \mathrm{E}-04 \pm 1,7 \mathrm{E}-05$ & 0,9 \\
Aeroxide 1 \% & $8,2 \mathrm{E}-04 \pm 3,1 \mathrm{E}-05$ & 15,4 & $6,3 \mathrm{E}-04 \pm 1,2 \mathrm{E}-05$ & 18,8 \\
Aeroxide 5 \% & $2,2 \mathrm{E}-03 \pm 3,2 \mathrm{E}-04$ & 209 & $1,7 \mathrm{E}-03 \pm 1,4 \mathrm{E}-04$ & 220 \\
Aerodisp 0,5\% & $7,6 \mathrm{E}-04 \pm 2,7 \mathrm{E}-05$ & 7,0 & $5,3 \mathrm{E}-04 \pm 3,1 \mathrm{E}-05$ & 0,6 \\
Aerodisp 1\% & $8,9 \mathrm{E}-04 \pm 2,8 \mathrm{E}-05$ & 25,3 & $6,9 \mathrm{E}-04 \pm 2,7 \mathrm{E}-05$ & 30,1 \\
Aerodisp 5\% & $2,4 \mathrm{E}-03 \pm 2,7 \mathrm{E}-04$ & 238 & $1,8 \mathrm{E}-03 \pm 3,2 \mathrm{E}-04$ & 239 \\
\hline
\end{tabular}

\subsection{Caracterización de los de los nanofluidos preparados con nanopartículas de óxido de} cobre (II)

Para la preparación de los nanofluidos de óxido de cobre (II) se utilizó la técnica en dos etapas, preparando los nanofluidos a partir de la dispersión de las nanopartículas de óxido de cobre en polvo adquiridas con las características ya descritas en el capítulo III.

A continuación, se describen los resultados obtenidos en la caracterización inicial del material de óxido de cobre y en la caracterización de la estabilidad, conductividad térmica y viscosidad de los nanofluidos preparados.

\subsubsection{Caracterización del material de óxido de cobre de partida}

Las nanopartículas de óxido de cobre (II) se adquirieron a la empresa Nanoestructured \& Amorphous Materials, Inc. Estas nanopartículas presentan un tamaño inicial de $50 \mathrm{~nm}$ según el fabricante.

En las imágenes obtenidas en el microscopio electrónico de barrido, MEB, (Figura 75) se puede observar que el tamaño de las partículas de óxido de cobre con una morfología esférica es 
nanométrico. Sin embargo, al analizar la imagen con menores aumentos se observa que dichas nanopartículas se agrupan formando aglomerados de tamaños mayores, (imagen izda.).
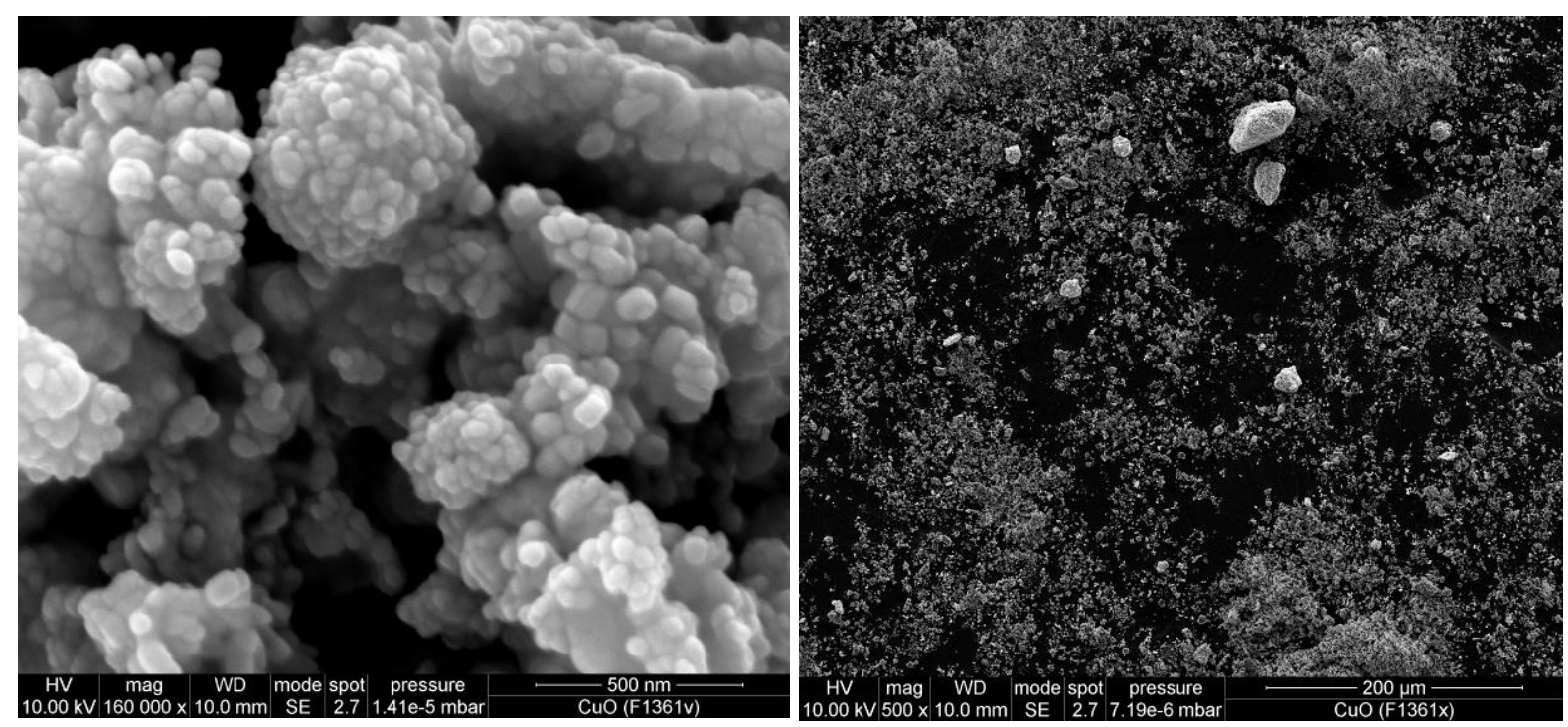

Figura 75. Imagen MEB del nanofluido de óxido de cobre a 160000 aumentos (izda.) y 5000 aumentos (dcha.)

Por esta razón se procedió a medir el tamaño de los aglomerados del material de óxido de cobre adquirido y a caracterizar la facilidad de dispersión de dichos aglomerados al igual que se ha estudiado con los materiales de sílice y de alúmina.

En la Tabla 20 se muestra la distribución de tamaños de aglomerados que inicialmente presentan las partículas suministradas de óxido de cobre cuando estas se mezclan en medio acuoso y no se aplica ningún tipo de dispersión mecánica. Hay que resaltar que, aunque estas nanopartículas también se encuentran en su origen aglomeradas el tamaño de dichos aglomerados ( $5 \mu \mathrm{m}$ ) es mucho menor que el tamaño de las partículas aglomeradas de otros materiales adquiridos (40 $\mu$ m sílice y alúmina) .

Tabla 20. Distribución de tamaños de los aglomerados del óxido de cobre, medidos inmediatamente tras la mezcla en agua

\begin{tabular}{cccc}
\hline Material & $d_{10}$ & $d_{50}$ & $d_{90}$ \\
& $(\mu \mathrm{m})$ & $(\mu \mathrm{m})$ & $(\mu \mathrm{m})$ \\
\hline CuO & 0,87 & 2,05 & 4,52 \\
\hline
\end{tabular}

Si se aplica algo de agitación mecánica (tipo ultrasonidos) en el equipo de medida de tamaño de partícula (DLS) mientras se realiza el ensayo, los resultados obtenidos de tamaño de partícula se reducen respecto a los obtenidos con agitación suave. La rotura de los aglomerados ocurre en los primeros minutos de aplicación de ultrasonidos no resultando ya 
significativo el cambio obtenido al aumentar el tiempo de aplicación (Figura 76). En este tipo de material, no aparece un tiempo crítico de aplicación de ultrasonidos en el cual las partículas se reaglomeran aumentando de nuevo su tamaño.

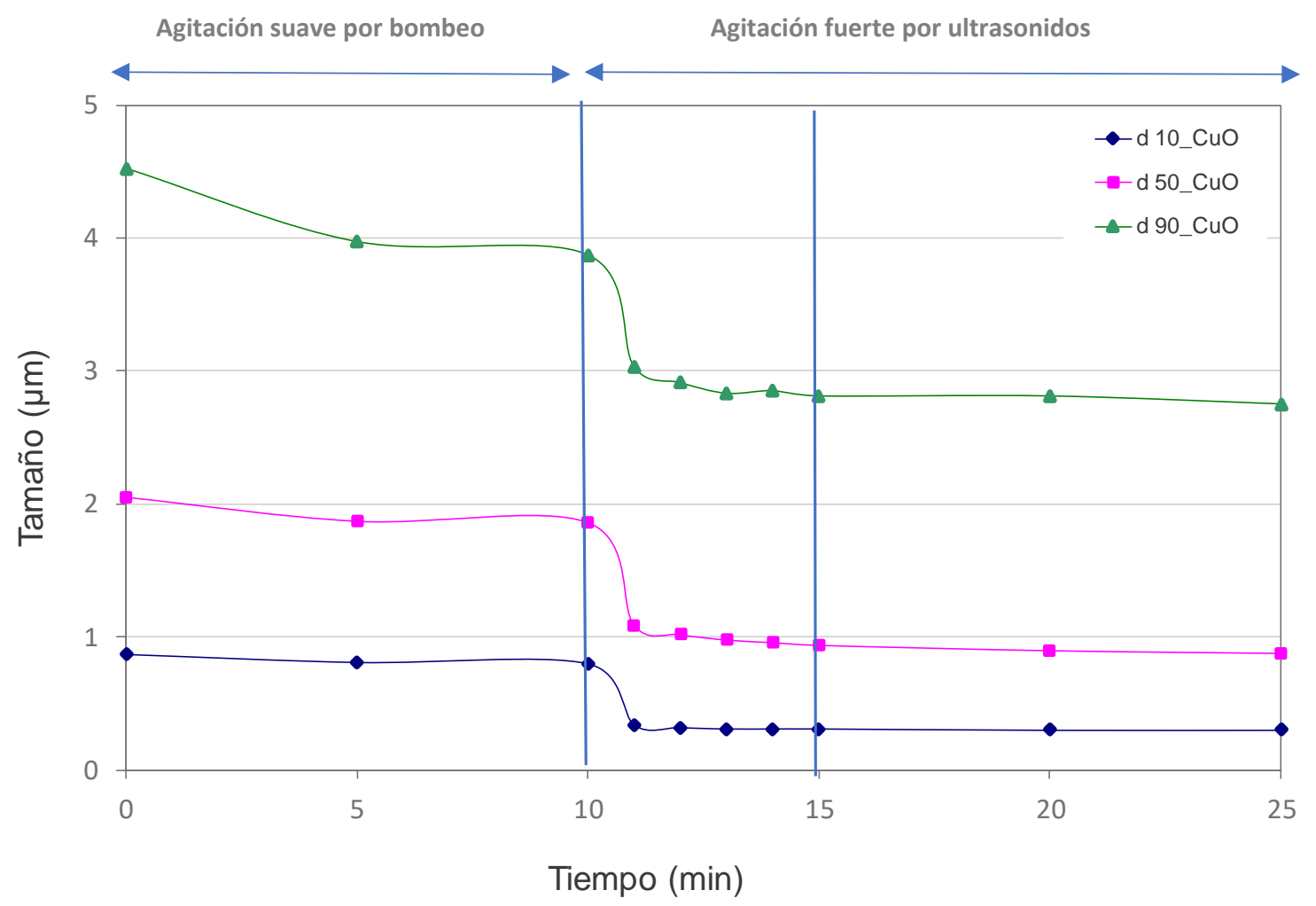

Figura 76. Caracterización del tamaño de los aglomerados de óxido de cobre en suspensión acuosa

En la Tabla 21 se presentan los tamaños de aglomerado de partículas en suspensión para el óxido de cobre tras aplicar la agitación suave y los ultrasonidos (US). El coeficiente de friabilidad alcanza su valor óptimo tras la aplicación de ultrasonidos durante un tiempo de 10 minutos.

Tabla 21. Tamaño de aglomerados y coeficiente de friabilidad del óxido de cobre

\begin{tabular}{ccccc}
\hline $\begin{array}{c}\text { Sistema de agitación } \\
\text { aplicado }\end{array}$ & $\begin{array}{c}d_{10} \\
(\mu \mathrm{m})\end{array}$ & $\begin{array}{c}d_{50} \\
(\mu \mathrm{m})\end{array}$ & $\begin{array}{c}d_{90} \\
(\mu \mathrm{m})\end{array}$ & $\begin{array}{c}\text { c.f. }_{\circ}{ }^{*} \\
(\%)\end{array}$ \\
\hline tras agitación suave & 0,8 & 1,86 & 3,87 & $\mathbf{1 4}$ \\
dispersión US 1 min & 0,34 & 1,09 & 3,09 & $\mathbf{3 3}$ \\
dispersión US 10 min & 0,30 & 0,9 & 2,81 & $\mathbf{3 8}$ \\
\hline
\end{tabular}

* coeficiente de friabilidad calculado como

$$
\text { c.f. }=\frac{\text { tamaño inicial }- \text { tamaño final }}{\text { tamaño inicial }} * 100
$$


1.3.2 Preparación y caracterización de la dispersión y estabilidad de los nanofluidos de óxido de cobre

Los nanofluidos de óxido de cobre se prepararon a partir de nanopartículas de óxido sólidas, por el método de dos etapas. En este caso no se prepararon nanofluidos a partir de una suspensión comercial.

El procedimiento seguido para la preparación de los nanofluidos fue el mismo que el seguido para preparar los nanofluidos de alúmina y sílice. Agitación mediante sonda de ultrasonidos para una correcta dispersión, con un tiempo total de 10 minutos, y posterior estabilización del $\mathrm{pH}$ a un valor de 4.

El estado de dispersión de las nanopartículas de cobre se caracterizó, al igual que con los nanofluidos de sílice y alúmina, mediante observación de la morfología en el microscopio electrónico de transmisión, TEM y la medición del tamaño de partícula dispersa en el fluido base mediante el equipo de dispersión de luz, DLS de MALVERN.

\section{Caracterización del estado de dispersión de las nanopartículas en los nanofluidos de óxido} de cobre mediante análisis de imagen en el TEM

En las siguientes imágenes, (Figura 77 y Figura 78) se muestran las fotografías a distintos aumentos realizadas en el microscopio óptico de transmisión para la caracterización óptica del estado de dispersión de las nanopartículas de CuO en los nanofluidos preparados.
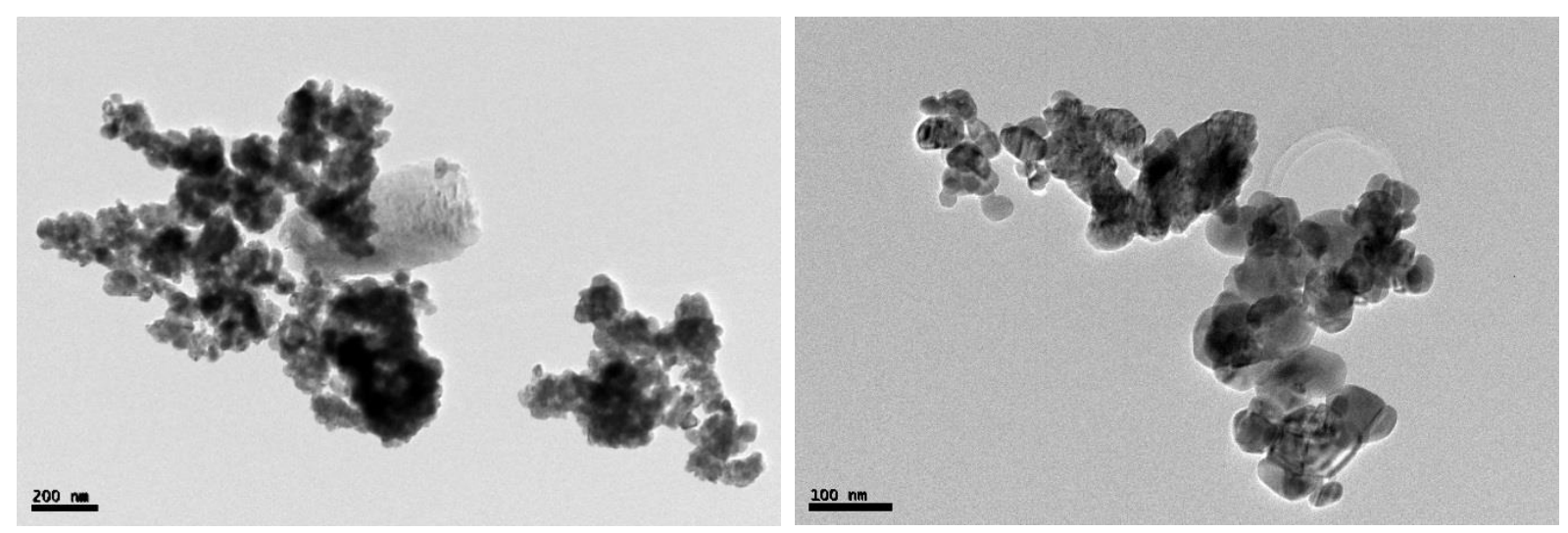

Figura 77. Imagen TEM del nanofluido de $\mathrm{CuO}$ al $1 \%$ en volumen y ajustada a pH=4, 10000 aumentos (izda.) y 20000 aumentos (dcha.) 

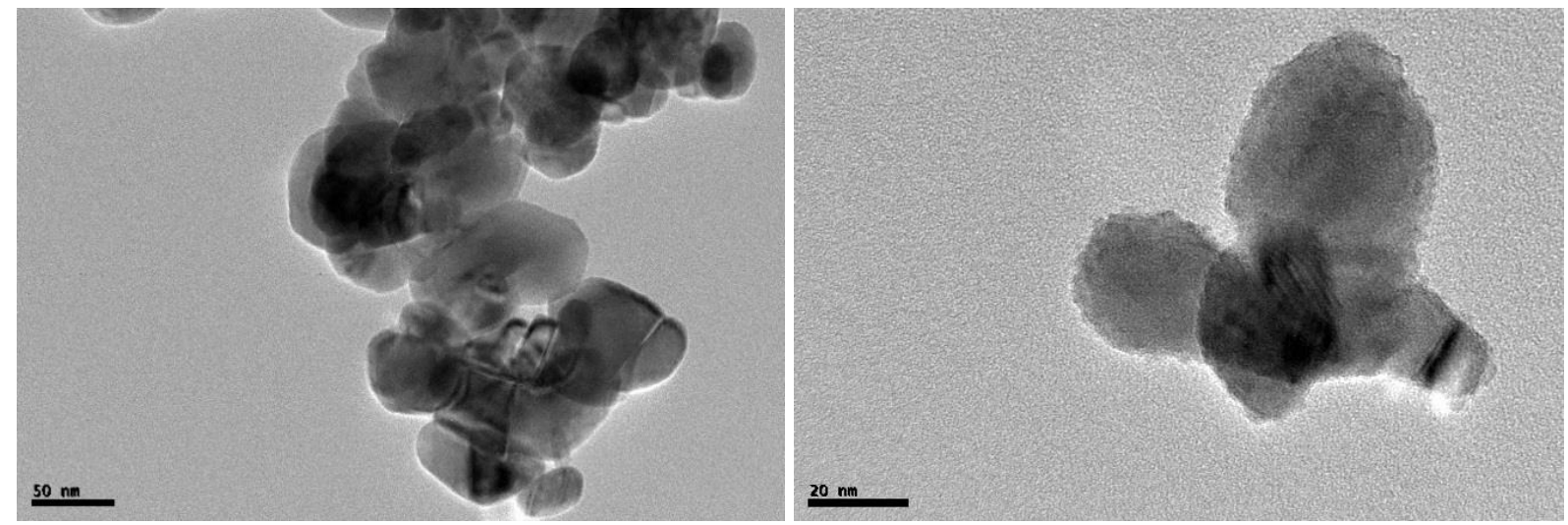

Figura 78. Imagen TEM del nanofluido de CuO al $1 \%$ en volumen y ajustada a pH=4, 50000 aumentos (izda.) y 150000 aumentos (dcha.)

Como se observa en las imágenes, las nanopartículas de óxido de cobre no se encuentran totalmente individualizadas pues están arracimadas formando aglomerados del orden de cientos de nanómetros.

\section{Análisis del tamaño final de las nanopartículas de óxido de cobre en polvo dispersadas en el}

\section{fluido base}

Como puede observarse tras el análisis de tamaño mediante difracción laser, Figura 79, en los nanofluidos de óxido de cobre (II) preparados las nanopartículas no se han conseguido dispersar en su totalidad, pues no se han alcanzado los tamaños de nanopartícula que indica el proveedor 30-50 $\mathrm{nm}$.

Los nanofluidos de óxido de cobre preparados presentan un tamaño medio de partícula $\left(d_{50}\right)$ de unos 1,18 $\mu \mathrm{m}$ (Tabla 22), tamaño superior a los 30-50 nm indicados por el proveedor. Estos resultados confirman los resultados anteriormente comentados en el análisis de imagen con el TEM. 


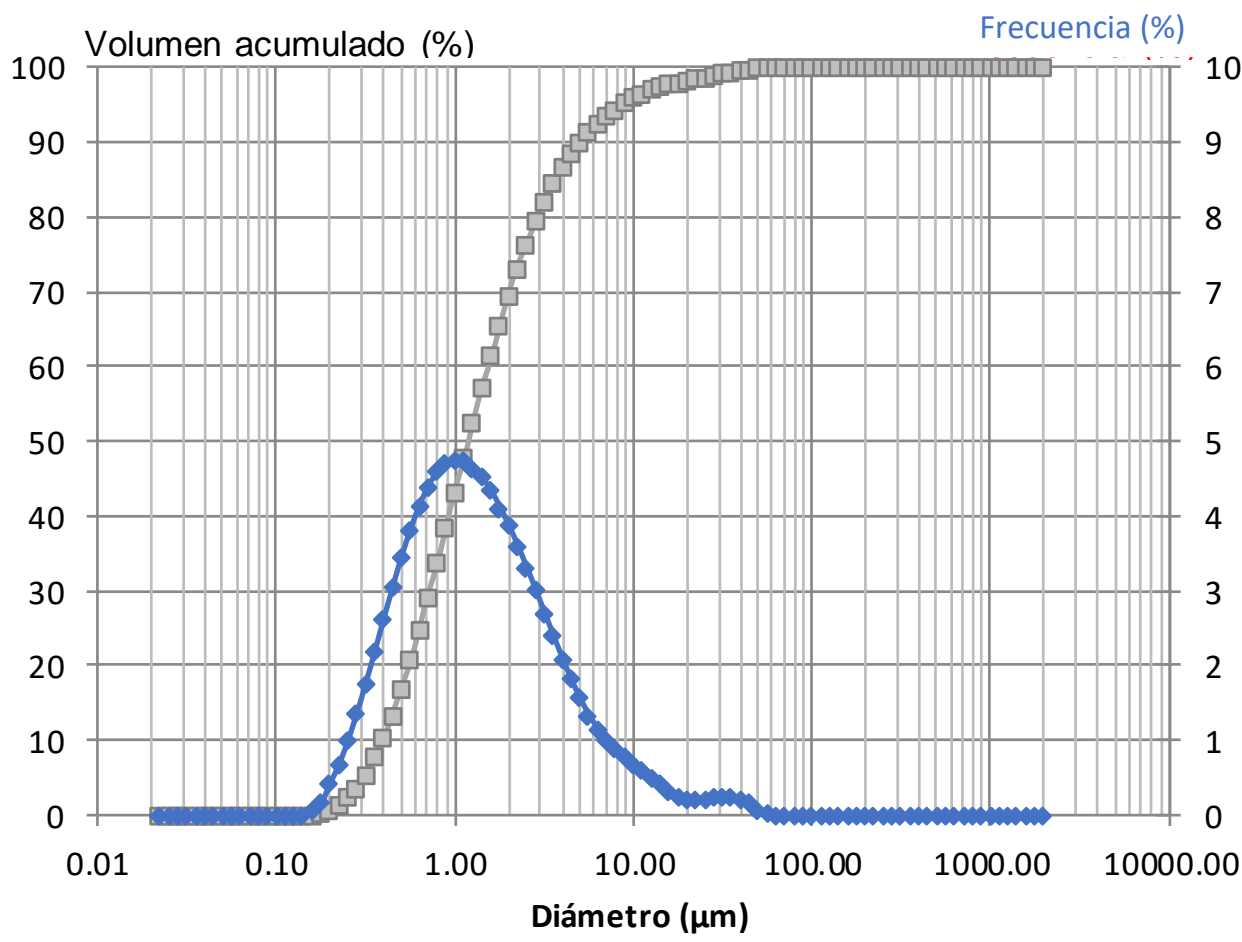

Figura 79. Análisis granulométrico de la suspensión acuosa de CuO al 0,5\% en volumen.

Tabla 22. Distribución de tamaños de los aglomerados óxido de cobre una vez dispersados

\begin{tabular}{cccc}
\hline $\begin{array}{c}\text { Tamaño partículas } \\
\text { nanofluido 0,5\% }\end{array}$ & $d_{10}(\mu \mathrm{m})$ & $d_{50}(\mu \mathrm{m})$ & $d_{90}(\mu \mathrm{m})$ \\
\hline CuO & 0,39 & 1,18 & 4,99 \\
\hline
\end{tabular}

\section{Caracterización de la estabilidad de los nanofluidos de óxido de cobre}

Al igual que con las muestras de sílice y alúmina se midió la evolución en el tiempo de la retrodispersión de muestras a diferentes temperaturas para los tres tipos de nanofluidos de óxido de cobre $(0,5,1$ y $5 \%$ en fracción volumétrica) con el objetivo de analizar su estabilidad. La medición del la retrodispersión se efectuó a tres alturas (Figura 80), observándose que al igual que con las otras muestras de nanofluidos la zona centro y fondo de la probeta son las más representativas para el muestreo, pues en la superficie siempre se produce al inicio una bajada del valor de la retrodispersión debido a las burbujas que se generan al colocar la muestra en el tubo de ensayo.

Como puede observarse en la Figura 81 no existen diferencias significativas al aumentar la temperatura del ensayo, y aunque en todas las muestras ensayadas la retrodispersión (B.S.) 
permanece estable en el tiempo, se observa una disminución del mismo en la fracción diluida de $0,5 \%$ para los ensayos realizados a una temperatura de $40^{\circ} \mathrm{C}$, mientras que para los ensayos realizados a $60^{\circ} \mathrm{C}$ la tendencia es un aumento de los valores de retrodispersión (B.S.). Esto indica poca estabilidad en la suspensión más diluida de los nanofluidos de óxido de cobre preparados.

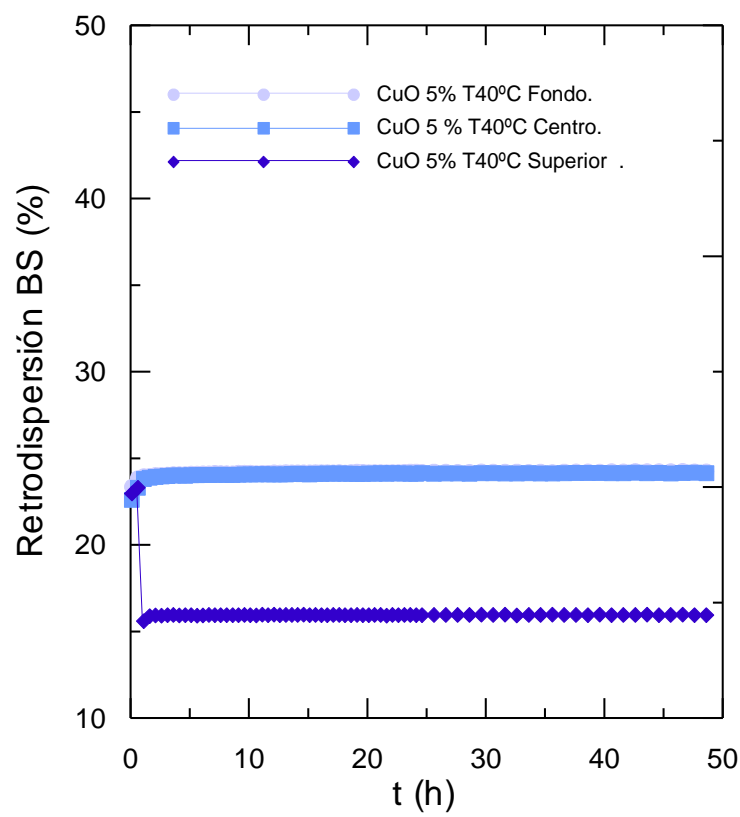

Figura 80. Valores de retrodispersión de un nanofluido de óxido de cobre al $5 \%$. Ensayo realizado a $40^{\circ} \mathrm{C}$
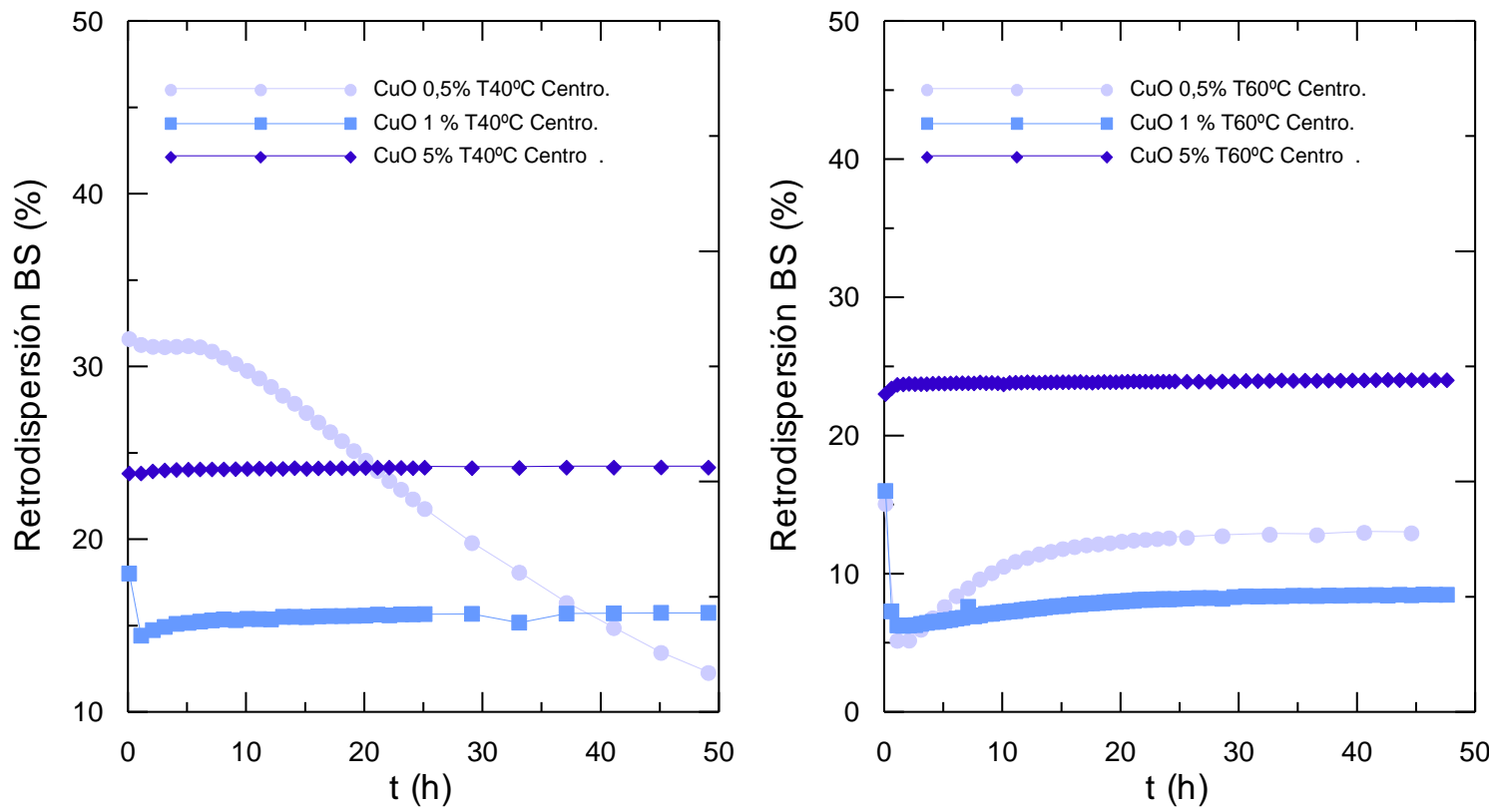

Figura 81. Valores de retrodispersión de un nanofluido de óxido de cobre a distintas fracciones. Temperatura ensayo $40^{\circ} \mathrm{C}$ (izda.) y Temperatura de ensayo a $60^{\circ} \mathrm{C}$ (dcha.) 
Esta poca estabilidad de los nanofluidos de óxido de cobre preparados a baja fracción volumétrica $(0,5 \%)$ puede deberse a una incorrecta dispersión de los mismos como ya se ha constatado en el análisis de tamaño de aglomerado obtenido en la caracterización de estos nanofluidos por difracción laser. El tamaño de las nanopartículas de óxido de cobre según el proveedor era de $50 \mathrm{~nm}$ mientras que el tamaño de los aglomerados medidos se obtiene un d 90 de $5 \mu \mathrm{m}$. La incorrecta dispersión alcanzada en estos nanofluidos al 0,5\% puede originar problemas de agregación y de sedimentación modificándose la estabilidad de los mismos. Cuando se han preparado los nanofluidos a una fracción volumétrica mayor ( 1 y 5 \%) la señal de la retrodispersión del nanofluido se ha mantenido constante en el tiempo ensayado, indicando una mejor estabilidad de los nanofluidos.

\subsubsection{Resultados de la medida de la conductividad térmica de los nanofluidos de óxido de} cobre

Se ha medido la conductividad térmica de los nanofluidos de óxido de cobre preparados a distintas fracciones volumétricas $(0,5,1$ y $5 \%)$ ensayándose también a distintas temperaturas $\left(40,60\right.$ y $\left.80^{\circ} \mathrm{C}\right)$ para analizar el efecto de la temperatura sobre el incremento en conductividad térmica final.

En la Figura 82 se han representado conjuntamente los incrementos en conductividad respecto al fluido base (agua) de los nanofluidos a distintas fracciones. Los aumentos más significativos se han obtenido con el nanofluido preparado a mayor fracción volumétrica, al igual que para los nanofluidos de alúmina, alcanzándose en este caso un incremento en la conductividad térmica del 15 \% con los nanofluidos preparados a mayor fracción volumétrica, $5 \%$.

La temperatura del ensayo influye en la conductividad térmica medida. Puede observarse como en todos los casos un aumento en la temperatura de 40 a $60^{\circ} \mathrm{C}$ implica un aumento en los incrementos relativos de conductividad coincidiendo con los artículos $[3,49,56]$ debido a la mayor movilidad de las nanopartículas. Sin embargo, este aumento no sigue la misma tendencia cuando se ensayan los nanofluidos a $80^{\circ} \mathrm{C}$. A esta temperatura la conductividad térmica del fluido base se puede ver incrementada por los mecanismos de convección, los cuales aparecen debido a que la viscosidad es menor a temperaturas altas, obteniéndose finalmente un menor incremento en la conductividad relativa. 


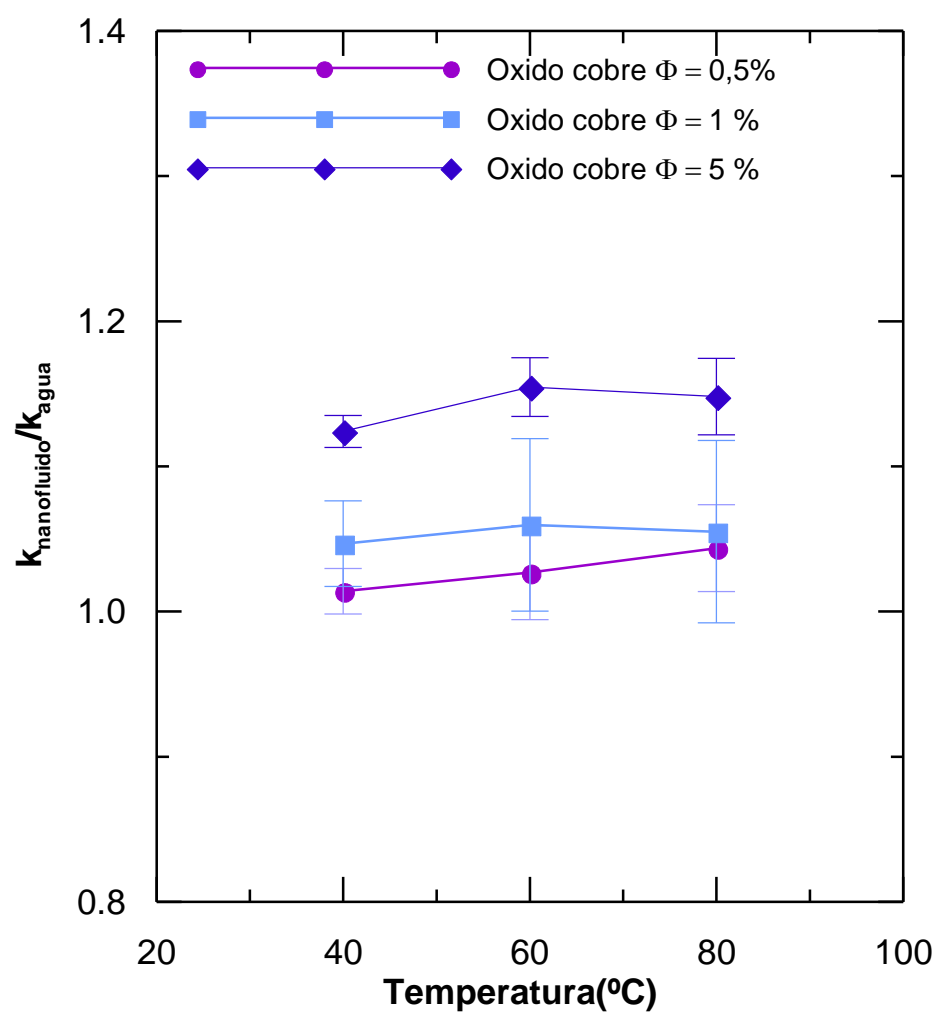

Figura 82. Resultados de aumentos en conductividad térmica de los nanofluidos de óxido de cobre preparados a distintas fracciones

\subsubsection{Resultados de la medida de la viscosidad de los nanofluidos de óxido de cobre}

En la Figura 83 se comparan los incrementos en viscosidad absoluta obtenidos al caracterizar los nanofluidos de óxido de cobre preparados a distintas fracciones, ensayados a tres temperaturas $\left(40,60\right.$ y $\left.80^{\circ} \mathrm{C}\right)$. Las viscosidades de los nanofluidos preparadas a 0,5 y $1 \%$ son bastantes parecidas, aumentando drásticamente la viscosidad para los nanofluidos preparados al 5\%, debido al incremento en el número de contactos al aumentar la superficie específica a fracciones elevadas de sólidos en suspensión.

Se observa en todos los nanofluidos de cobre preparados como a medida que se aumenta la temperatura disminuye la viscosidad absoluta por disminuir la viscosidad del fluido base. 


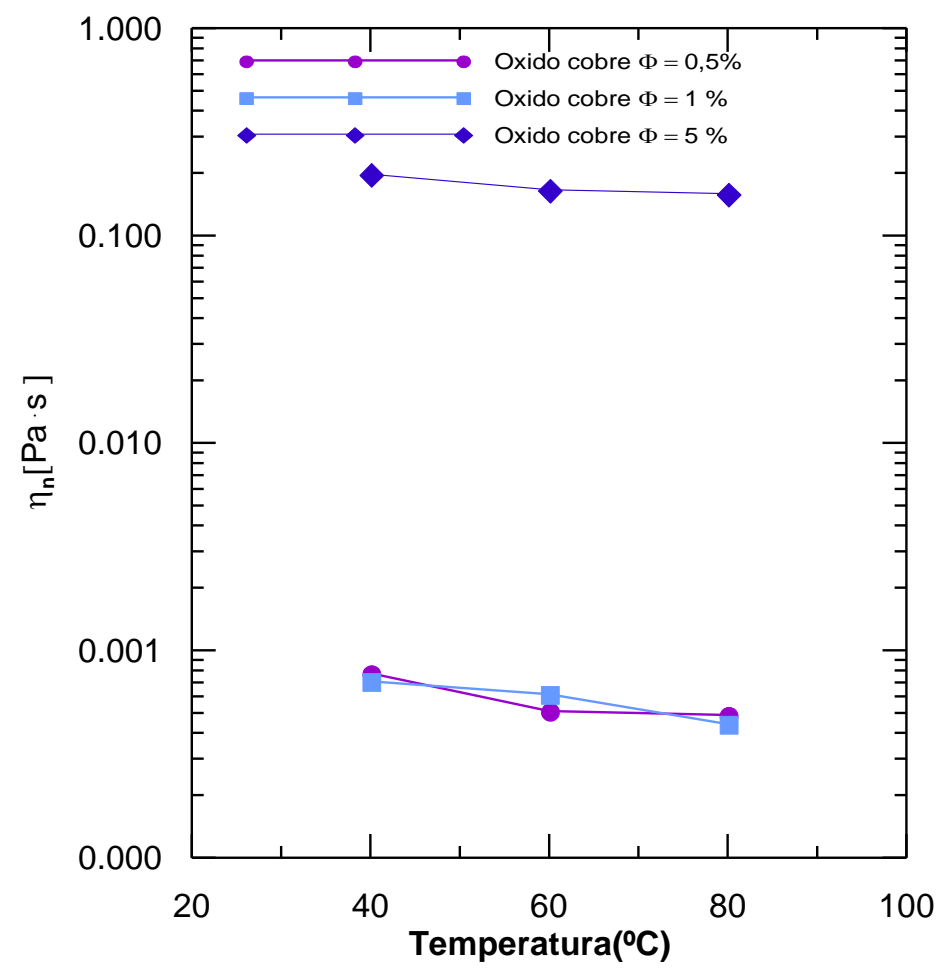

Figura 83. Resultados de aumentos en viscosidad de los nanofluidos de óxido de cobre preparados a distintas fracciones Al igual que con los nanofluidos preparados de sílice y alúmina, al aumentar la cantidad de nanopartículas presentes en nanofluido, aumentar la fracción volumétrica, se produce un aumento en la viscosidad del nanofluido como se recoge en la Tabla 23. Estos aumentos en el caso del óxido de cobre son altos, parecidos a los de la alúmina, alcanzándose incrementos en la viscosidad respecto al fluido base de casi el $300 \%$ cuando se preparan los nanofluidos en dos etapas.

Tabla 23. Aumento relativo de la viscosidad absoluta para los nanofluidos de sílice. Ensayo realizado a $40^{\circ} \mathrm{C}$ y $60^{\circ} \mathrm{C}$.

\begin{tabular}{lcccc}
\hline Tipo de muestra & $\begin{array}{c}\text { Promedio de la } \\
\text { viscosidad } 40^{\circ} \mathrm{C} \\
\text { (Pa.s) }\end{array}$ & $\begin{array}{c}\text { Incremento } \\
\text { relativo } \\
40^{\circ} \mathrm{C}(\%)\end{array}$ & $\begin{array}{c}\text { Promedio de la } \\
\text { viscosidad } 60^{\circ} \mathrm{C} \\
\text { (Pa.s) }\end{array}$ & $\begin{array}{c}\text { Incremento } \\
\text { relativo } 60^{\circ} \mathrm{C} \\
\text { (\%) }\end{array}$ \\
\hline Agua & $7,1 \mathrm{E}-04 \pm 2,2 \mathrm{E}-05$ & - & $5,3 \mathrm{E}-04 \pm 2,8 \mathrm{E}-05$ & - \\
Óxido de cobre 0,5 \% & $7,7 \mathrm{E}-04 \pm 2,2 \mathrm{E}-05$ & 7,8 & $5,3 \mathrm{E}-04 \pm 1,4 \mathrm{E}-05$ & 0,2 \\
Óxido de cobre 1\% & $7,1 \mathrm{E}-04 \pm 2,0 \mathrm{E}-05$ & 1,4 & $6,2 \mathrm{E}-04 \pm 1,8 \mathrm{E}-05$ & 9,9 \\
Óxido de cobre 5\% & $1,9 \mathrm{E}-01 \pm 3,5 \mathrm{E}-03$ & 274 & $1,6 \mathrm{E}-01 \pm 1,6 \mathrm{E}-03$ & 295 \\
\hline
\end{tabular}




\section{Preparación y caracterización de los nanofluidos preparados con}

\section{nanotubos de carbono}

Se han preparado distintos tipos de nanofluidos con nanotubos de carbono (CNTs) en laboratorio utilizándose las siguientes técnicas;

- dilución con agua destilada de suspensiones concentradas hasta la fracción volumétrica deseada. En este caso se ha utilizado como material base el Aquacyl.

- Técnica dos etapas; mezcla del material en polvo con el fluido base (agua destilada) hasta la fracción volumétrica deseada mediante diferentes técnicas de dispersión.

Los materiales en polvo utilizados en el presente estudio han sido:

- $\quad$ Nanotubos de pared única de longitud larga SWCNT-L

- $\quad$ Nanotubos de pared múltiple MWCNT

- cortos, MWCNT-S

- cortos funcionalizados comercialmente, MWCNT-S-Func.comercial

- funcionalizados en el laboratorio mediante métodos ácido y alcalino: MWCNT-S-F.ácida y MWCNT-S-F.básica

- largos, MWCNT-L

- largos funcionalizados en el laboratorio, MWCNT-L-F.ácida

En las siguientes tablas (Tabla 24 y Tabla 25) se resumen las principales características (fracción volumétrica $\Phi$, sistema de dispersión y estabilización) de los nanofluidos preparados a partir los distintos tipos de nanotubos adquiridos (Capítulo III apartado materiales 1.1.4). Se ha estudiado la estabilidad de los nanofluidos así preparados mediante observación visual de la sedimentación y la evolución de la retrodispersión en el Turbiscán o evolución de la absorbancia según los procedimientos de ensayo descritos en los apartados 3.1. del Capítulo III. Para el análisis del grado de dispersión de las nanopartículas en el fluido base se han utilizado las técnicas de análisis de imagen utilizando los microscopios electrónicos de transmisión y de barrido (TEM y el MEB) junto con el análisis de tamaño de partícula por difracción láser (Malvern). Finalmente, para analizar el estudio de las propiedades térmicas de los nanofluidos preparados se ha determinado el calor específico, la viscosidad y la conductividad térmica a varias temperaturas. 
Tabla 24. Tabla resumen de los ensayos realizados con MWCNTs cortos

\begin{tabular}{|c|c|c|c|}
\hline Tipo de material & Sistema dispersión & $\begin{array}{c}\text { Fracción } \\
\text { volumétrica } \Phi\end{array}$ & $\begin{array}{c}\text { Aditivo* } \\
\text { (\%) }\end{array}$ \\
\hline MWCNTs en polvo & Homogeneizador & 0,01 & - \\
\hline Funcionalizados comerciales & Homogeneizador & 0,05 & - \\
\hline \multirow[t]{12}{*}{ NANOAMOR } & Homogeneizador & 0,1 & - \\
\hline & Homogeneizador & 0,1 & $1 \% S D S$ \\
\hline & Sonda Ultrasonidos & 0,01 & - \\
\hline & Sonda Ultrasonidos & 0,01 & $1 \% S D S$ \\
\hline & Sonda Ultrasonidos & 0,05 & - \\
\hline & Sonda Ultrasonidos & 0,05 & $1 \% S D S$ \\
\hline & Sonda Ultrasonidos & 0,1 & - \\
\hline & Sonda Ultrasonidos & 0,1 & $1 \% S D S$ \\
\hline & Sonda Ultrasonidos & 0,5 & $1 \% S D S$ \\
\hline & Sonda Ultrasonidos & 1 & $1 \% S D S$ \\
\hline & $\begin{array}{l}\text { Baño de } \\
\text { ultrasonidos }\end{array}$ & 0,05 & $1 \% S D S$ \\
\hline & $\begin{array}{l}\text { Baño de } \\
\text { ultrasonidos }\end{array}$ & 0,1 & $1 \% S D S$ \\
\hline MWCNTs en polvo & Sonda Ultrasonidos & 0,01 & $1 \%$ SDS \\
\hline cortos comerciales & Sonda Ultrasonidos & 0,05 & $1 \%$ SDS \\
\hline \multirow[t]{4}{*}{ NANOCYL } & Sonda Ultrasonidos & 0,1 & $1 \% S D S$ \\
\hline & Sonda Ultrasonidos & 0,1 & $0.025 \% \mathrm{GA}$ \\
\hline & Sonda Ultrasonidos & 0,1 & $0.01 \%$ CTAB \\
\hline & Homogeneizador & 0,1 & - \\
\hline MWCNTs en suspensión & Sonda Ultrasonidos & 0,1 & - \\
\hline cortos comerciales & Sonda Ultrasonidos & 1 & - \\
\hline AQUACYL & & & \\
\hline
\end{tabular}

\footnotetext{
*El porcentaje en peso del aditivo se ha referido respecto a la masa total de la suspensión
} 
Tabla 25. Tabla resumen de los ensayos realizados con CNTs largos

\begin{tabular}{llcc}
\hline Tipo de material & Sistema dispersión & $\begin{array}{c}\text { Fracción } \\
\text { volumétrica }\end{array}$ & $\begin{array}{c}\text { Aditivo* } \\
\text { (\%) }\end{array}$ \\
\hline MWCNTs en polvo & Sonda Ultrasonidos & 0,1 & $0,15 \%$ Triton X-100 \\
largos comerciales & Sonda Ultrasonidos & 0,1 & $0,25 \%$ Triton X-100 \\
& Sonda Ultrasonidos & 0,1 & $0,15 \%$ GA \\
& Sonda Ultrasonidos & 0,1 & $0,25 \%$ GA \\
& Sonda Ultrasonidos & 0,1 & $0,50 \%$ GA \\
& Sonda Ultrasonidos & 0,1 & Funcionalización ácida \\
& Sonda Ultrasonidos & 0,1 & Funcionalización alcalina \\
\hline largos comerciales & Sonda Ultrasonidos & 0,1 & $0,25 \%$ Triton X-100 \\
\hline
\end{tabular}

* El porcentaje en peso del aditivo se ha referido respecto a la masa total de la suspensión

Al contrario que con las nanopartículas de óxidos cerámicos resulta muy difícil preparar nanofluidos de nanotubos de carbono estables a fracciones altas si estos se preparan con el método en dos etapas, es decir poniendo en suspensión nanotubos en polvo. La máxima fracción volumétrica de nanotubos que se puede tener en suspensión en agua sin tener una elevada sedimentación según la bibliografía consultada es del $1 \%[17,24,28]$.

Para mejorar la estabilidad de los nanofluidos preparados se ha determinado la curva de potencial zeta de los nanotubos de carbono en agua, para así proceder al ajuste del pH que permita obtener una suspensión alejada del punto isoeléctrico. En la Figura 84 se muestran los resultados obtenidos en las medidas de potencial zeta de la suspensión acuosa de MWCNTs. Como puede observarse en el gráfico el punto isoeléctrico para este tipo de suspensiones está cercano a pH=2. 


\section{Punto isoeléctrico}

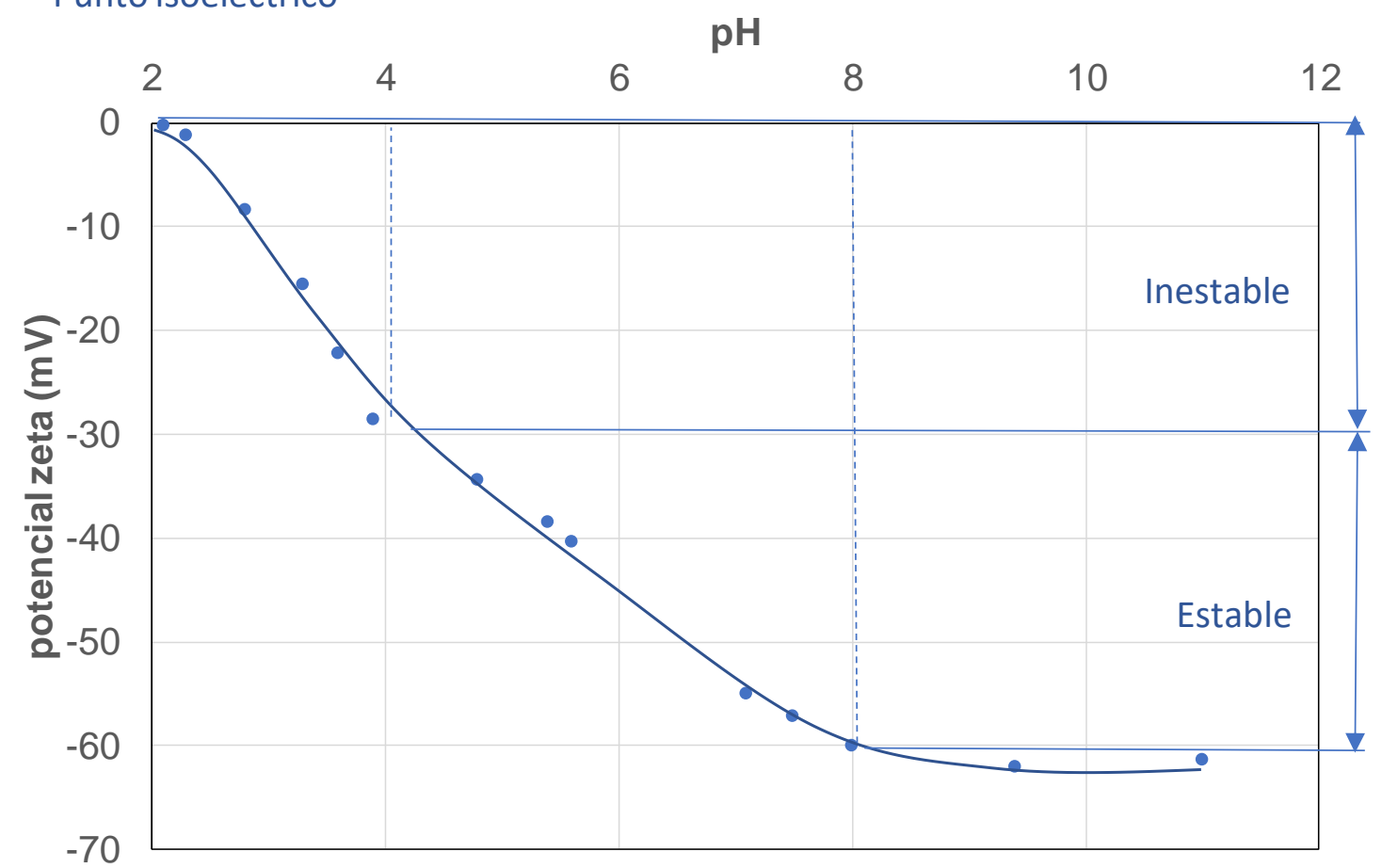

Figura 84. Variación del potencial zeta en función del pH de la suspensión ensayada 0,1\% MWCNTs cortos Func.comercial +SDS

Para la estabilización de los nanofluidos preparados a partir de los nanotubos, ya sean de pared múltiple o de pared única, se ha elegido un $\mathrm{pH}$ de 6 , considerándose que a este $\mathrm{pH}$ el valor del potencial de repulsión entre partículas ya es suficientemente elevado (-50 mV). Este pH=6 se consigue tras la mezcla de los nanotubos con el fluido base, por lo que no resultó necesario un ajuste posterior del pH, simplificándose el proceso de preparación y dispersión de los nanofluidos.

Para una mejor compresión de los ensayos realizados en este subcapítulo de los nanofluidos con nanotubos de carbono se muestra en un diagrama de flujo (Figura 85) el procedimiento seguido con cada tipo de material. 

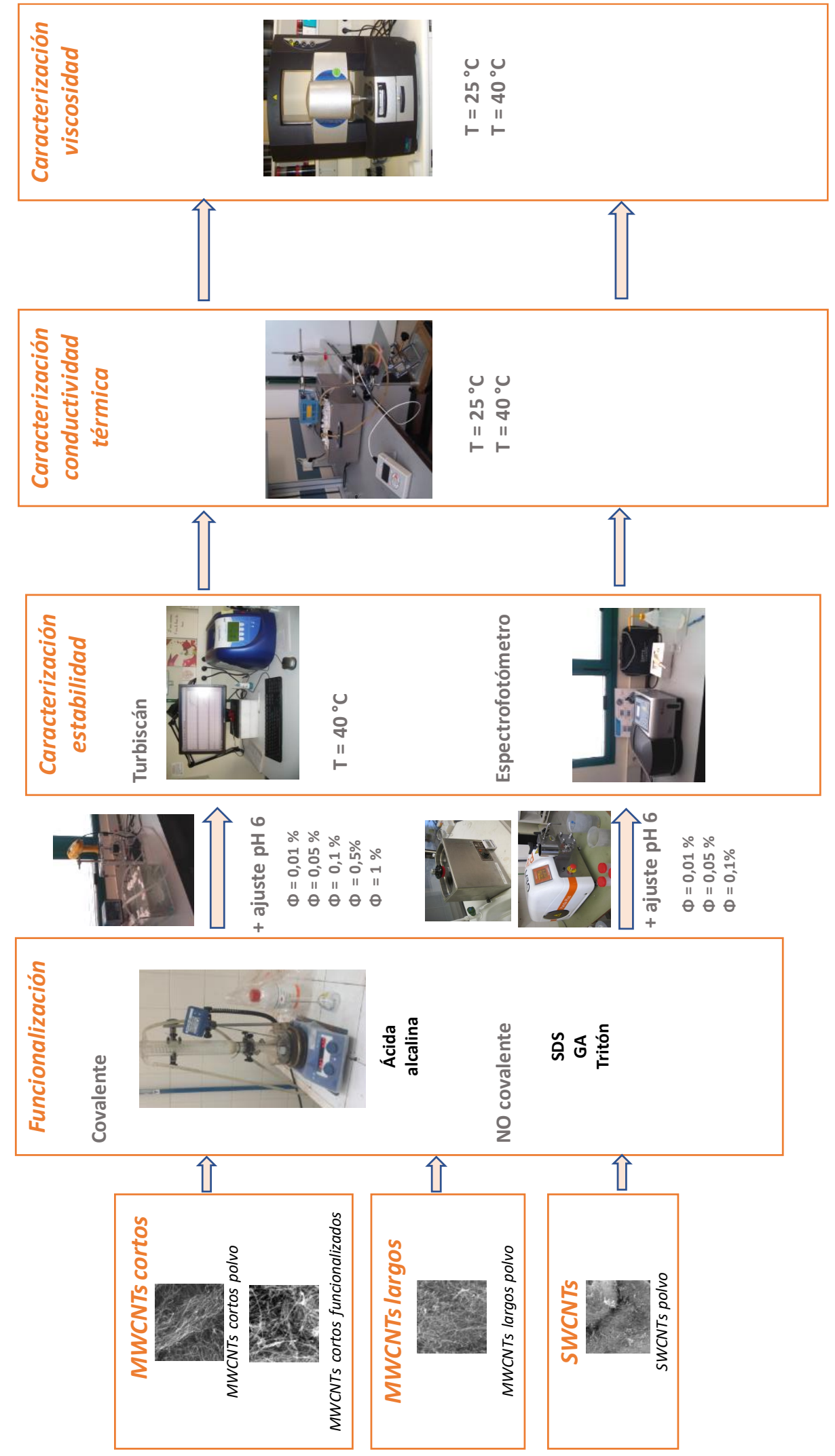

Figura 85. Diagrama de flujo donde se muestra el procedimiento seguido con cada tipo de material para la preparación y caracterización de los nanofluidos de nanotubos de carbono 


\subsection{Caracterización del grado de dispersión y de la estabilidad de los nanofluidos} preparados con nanotubos de carbono

Para poder analizar la influencia que puede tener el estado de aglomeración de los nanotubos adquiridos en la preparación de los nanofluidos se caracterizó en primer lugar la forma y el tamaño de agregado, además de la resistencia de estos a ser dispersados en base acuosa. Para mejorar la dispersión de lo nanotubos de carbono de carácter hidrófobo en el fluido base polar, se han utilizado dos métodos: adición de surfactantes y funcionalización de la superficie del sólido. En los siguientes apartados se resumen los principales resultados obtenidos de dispersión y estabilidad de los nanofluidos preparados con los nanotubos de carbono siguiendo estos dos métodos.

\subsubsection{Caracterización de los nanotubos adquiridos}

Para la caracterización de la forma y tamaño de los nanotubos adquiridos se utilizaron dos técnicas, el análisis de imagen mediante microscopía de barrido (MEB) y el análisis de tamaño de partícula mediante difracción láser (equipo MALVERN).

En las siguientes figuras (Figura 86 a Figura 89), se muestran las imágenes tomadas en el microscopio electrónico de barrido para cada uno de los materiales a diferentes aumentos. En dichas figuras puede observarse como los nanotubos adquiridos se encuentran aglomerados (imágenes en la izquierda de cada figura), siendo el tamaño de aglomerado variable en función de la tipología de material. Los nanotubos que presentan mayor tamaño de aglomerado son los MWCNTs cortos (con tamaños de aglomerados superiores a las $500 \mu \mathrm{m}$ como puede observarse en la Figura 89). Este tamaño de aglomerado tan grande puede dificultar el proceso de dispersión del material en agua en el momento de preparar el nanofluido si además de su mayor tamaño el aglomerado presenta cierta resistencia a la fractura.

En las imágenes del MEB tomadas a mayores aumentos, se observa que los nanotubos no se encuentran de origen de forma individualizada, sino que debido a su longitud se disponen enmarañados, dificultando con ello su posterior dispersión. 


\section{Nanotubos de pared única SWCNT-L}
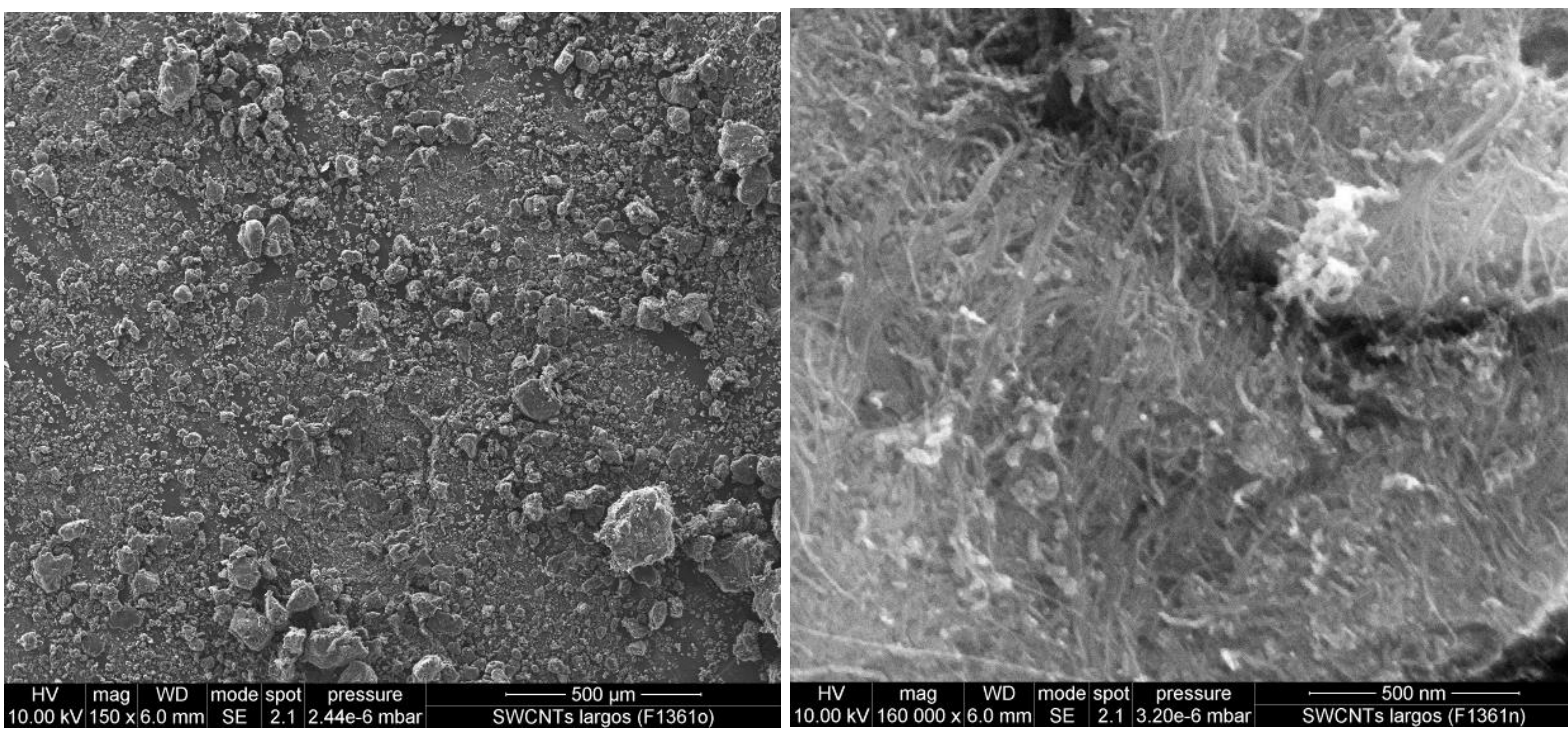

Figura 86. Imagen MEB SWCNT-L a 150 aumentos (izda.) y a 160000 (dcha.)

Nanotubos de pared múltiple MWCNT (cortos, largos y funcionalizados comerciales)
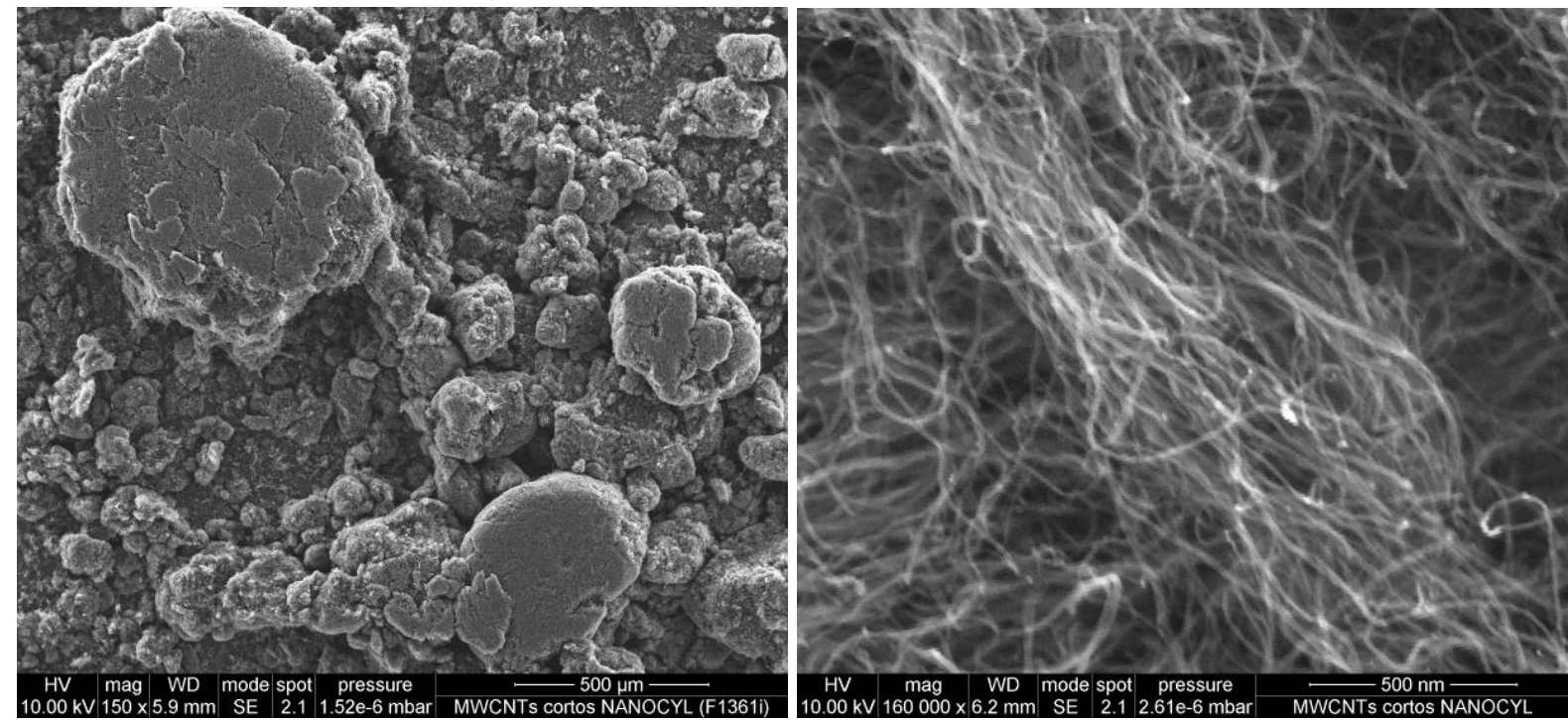

Figura 87. Imagen MEB MWCNT-S a 150 aumentos (izda.) y a 160000 aumentos (dcha.) 

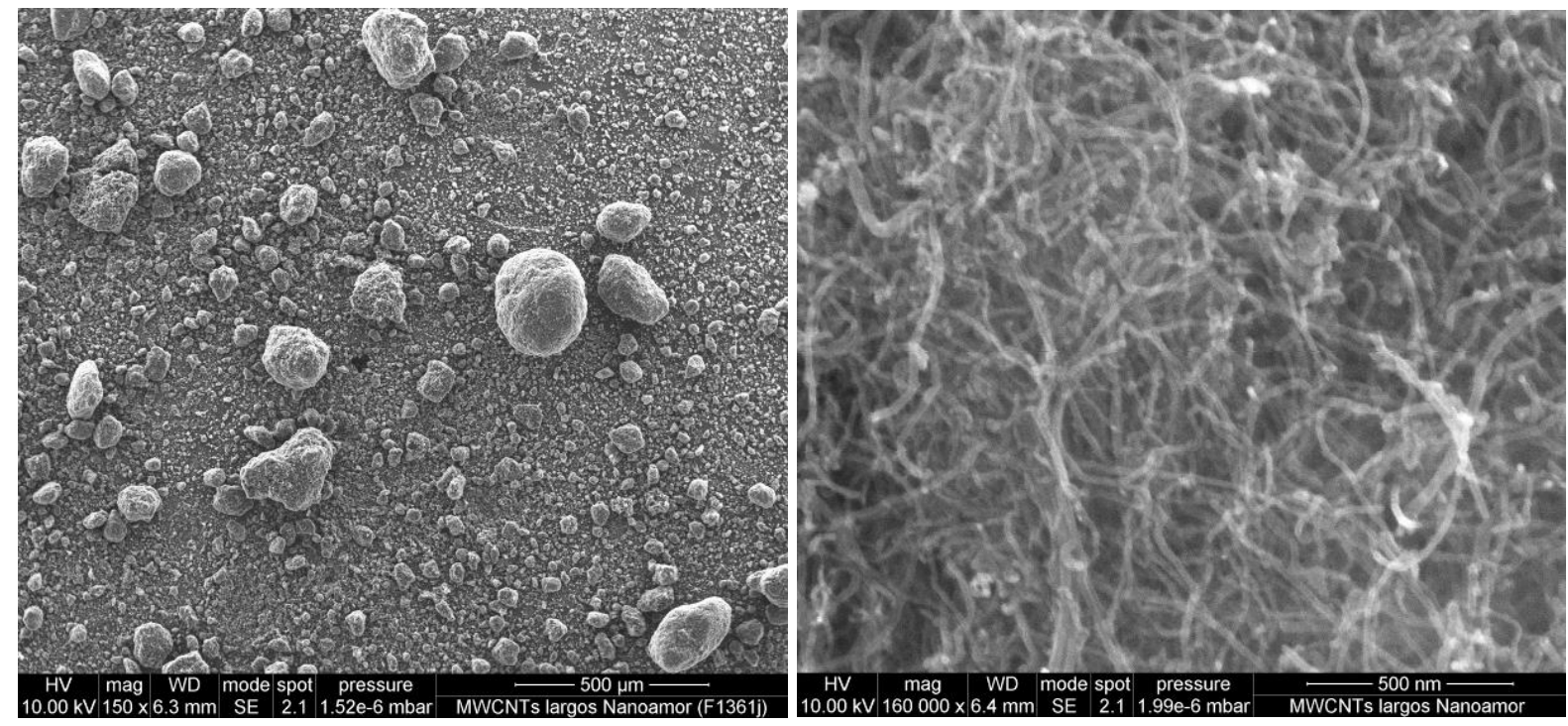

Figura 88. Imagen MEB MWCNT-L a 150 aumentos (izda.) y a 160000 aumentos (dcha.)
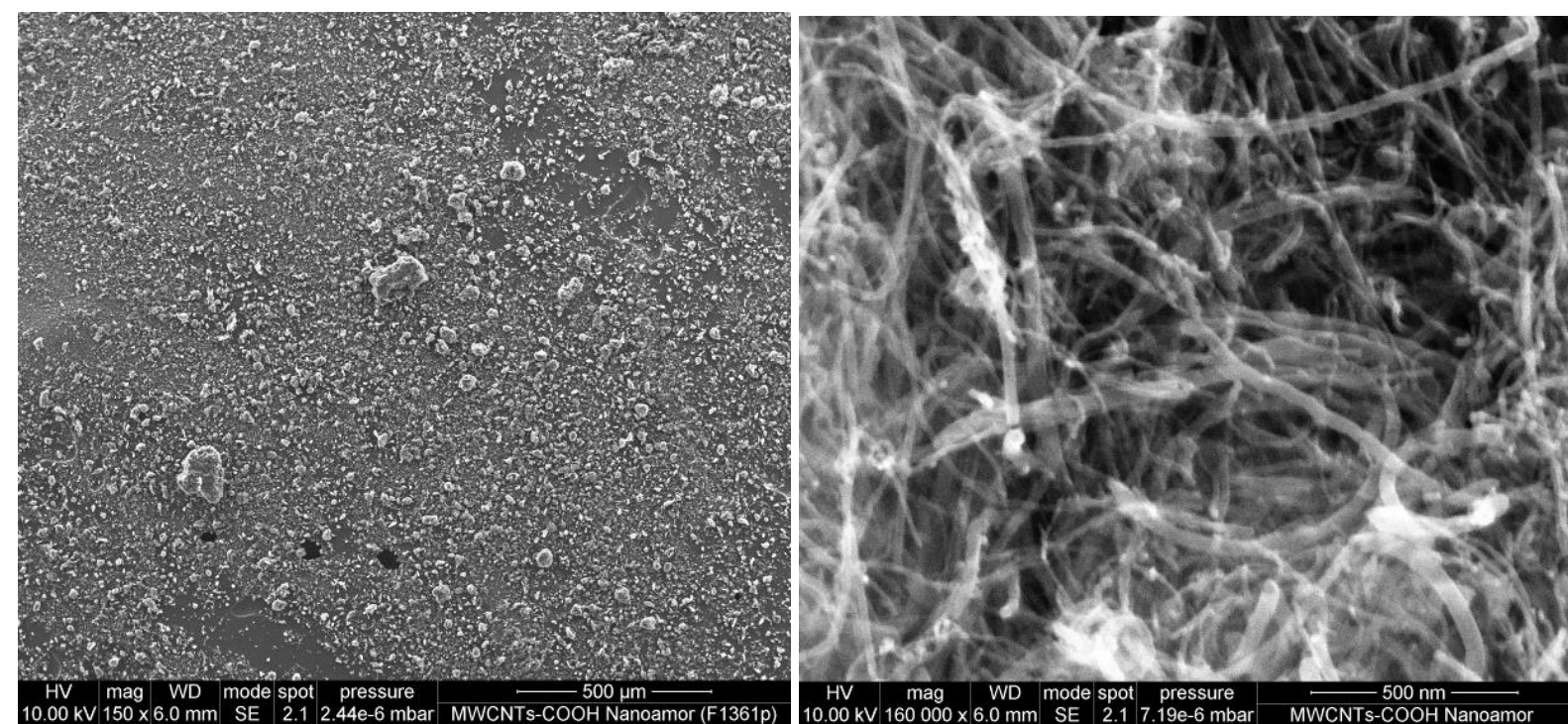

Figura 89. Imagen MEB MWCNT-cortos-Func.comercial a 150 aumentos (izda.) y a 160000 aumentos (dcha.)

En la Tabla 26 se muestran los resultados de distribución de tamaños de los aglomerados caracterizados mediante difracción laser tras cinco minutos de agitación suave para cada uno de los distintos tipos de materiales de nanotubos adquiridos. Se observa que los MWCNTs cortos presentan un tamaño de aglomerado mucho mayor que los otros tipos de nanotubos de carbono tanto de pared múltiple como única. Los nanotubos MWCNTs cortos funcionalizados son los que presentan un tamaño medio de aglomerado menor, como también se ha observado en las imágenes anteriores del MEB. 
Tabla 26. Distribución de tamaños de los aglomerados de los distintos tipos de CNTs adquiridos

\begin{tabular}{lccc}
\hline \multicolumn{1}{c}{ Tamaño aglomerado } & $d_{10}(\mu \mathrm{m})$ & $d_{50}(\mu \mathrm{m})$ & $d_{90}(\mu \mathrm{m})$ \\
\hline SWCNT largos & 32,52 & 193,18 & 470,67 \\
MWCNT cortos & 21,66 & 123,38 & 523,3 \\
MWCNT cortos-funcionalizados & 8,61 & 27,78 & 360,21 \\
MWCNT largos & 10,2 & 89,7 & 418 \\
\hline
\end{tabular}

\section{Estudio de dispersión de los aglomerados en los nanotubos adquiridos}

Además de caracterizar visualmente la morfología y tamaño de los nanotubos adquiridos, se realizó también un estudio de dispersión en agua con los distintos tipos de nanotubos adquiridos, al igual que con los óxidos estudiados anteriormente. En este estudio se analiza la reducción de tamaño de los aglomerados una vez dispersados en agua en función de la energía mecánica de dispersión aplicada. Se midió, en cada tipo de material, el tamaño tras la aplicación de una agitación suave mediante recirculación con la bomba dentro de la cubeta de análisis, y tras la aplicación de una agitación más enérgica con ultrasonidos. En la Figura 90 se han representado conjuntamente el tamaño ( $d_{90}$ ) medido para cada material a distintos tiempos. Puede observarse como en los nanotubos la agitación suave no consigue disgregar apenas los aglomerados. Resulta necesario aplicar ultrasonidos para reducir su tamaño.

En la Tabla 27 se resumen los valores de los coeficientes de friabilidad de los aglomerados obtenidos para cada uno de los tipos de nanotubos. Este coeficiente de friabilidad o rotura del aglomerado nos puede dar una idea de la resistencia del mismo y por tanto de la dificultad para dispersar totalmente los nanotubos en agua. Este coeficiente dependerá del tamaño inicial del aglomerado y del método de síntesis con el que se ha obtenido el material nanoparticulado, distinto en función del proveedor.

Puede observarse que en todos los tipos de nanotubos resulta necesario aplicar una alta energía, con sonda de ultrasonidos, para obtener así coeficientes altos de rotura que garanticen una buena dispersión. Tras la aplicación de un minuto de ultrasonidos ya se alcanzan los resultados óptimos en la mayoría de las tipologías de nanotubos, excepto para el caso de los nanotubos cortos (MWCNTs cortos Nanocyl), para los que resulta necesario aplicar 
más de 10 minutos de ultrasonidos para obtener un coeficiente de rotura alto. Este estudio permitió establecer el tiempo de ultrasonidos mínimo a aplicar en la preparación de los nanofluidos a los materiales de nanotubos para alcanzar un grado de dispersión adecuado.

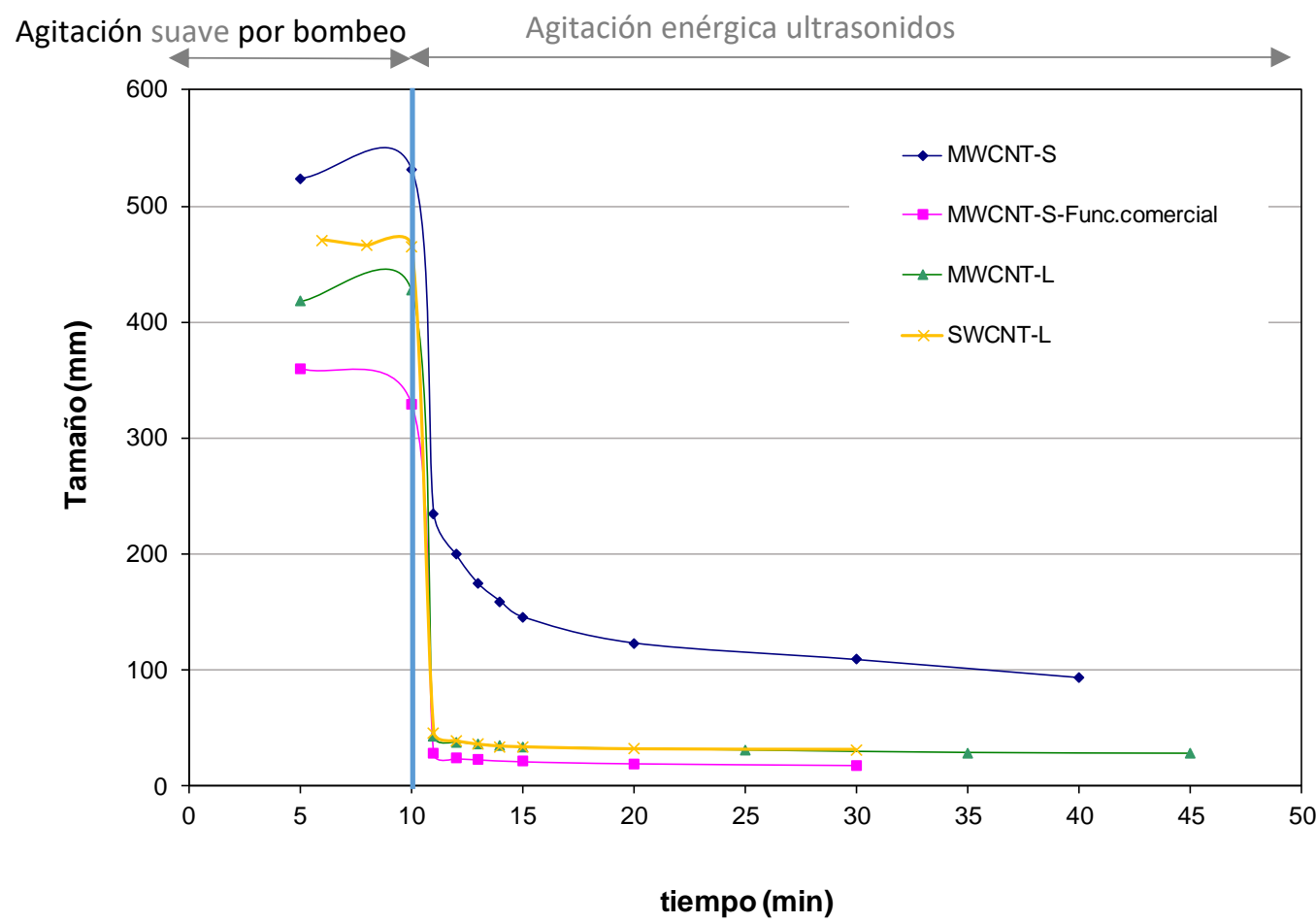

Figura 90. Estudio de dispersión mediante medida de la evolución del tamaño de partícula cuando se aplica agitación enérgica

Tabla 27. Evolución del coeficiente de rotura (\%) de los nanotubos en función del tipo de agitación aplicada

\begin{tabular}{|c|c|c|c|c|}
\hline \multirow[t]{2}{*}{ Material } & \multirow{2}{*}{$\begin{array}{c}\text { c.f. }_{.}^{*} \\
\text { tras agitación suave } \\
10 \mathrm{~min}\end{array}$} & \multicolumn{2}{|c|}{$\begin{array}{c}\text { c.f. }_{.}^{*} \\
\text { tras agitación } \\
\text { Ultrasonidos }\end{array}$} & \multirow{2}{*}{$\begin{array}{c}\text { Tamaño final } \\
\text { aglomerado } d_{50} \\
(\mu \mathrm{m})\end{array}$} \\
\hline & & $1 \mathrm{~min}$ & $20 \mathrm{~min}$ & \\
\hline SWCNTS & 1 & 90 & 93 & 31 \\
\hline MWCNTs cortos & 0 & 56 & 82 & 93 \\
\hline MWCNTs largos & 0 & 90 & 93 & 28 \\
\hline $\begin{array}{l}\text { MWCNTs cortos } \\
\text { Func.comercial }\end{array}$ & 8 & 91 & 94 & 18 \\
\hline
\end{tabular}

*coeficiente de friabilidad calculado como

$$
\text { c. } f .=\frac{\text { tamaño inicial }- \text { tamaño final }}{\text { tamaño inicial }} * 100
$$


Entre los distintos tipos de nanotubos adquiridos se observa que los MWCNTs cortosFunc.comercial, al estar funcionalizados se dispersan más fácilmente en agua, presentando siempre los coeficientes más altos de rotura y alcanzándose con ellos el menor tamaño final de aglomerado. Los nanotubos que presentan mayor tamaño de aglomerado y cierta resistencia a ser disgregados son los MWCNTs-S cortos (con menor valor de c.f.), por lo que es de esperar que presenten mayor dificultad a ser dispersados.

Este resultado parece indicar la conveniencia de funcionalizar la superficie tanto de los MWCNTs largos como de los MWCNTs cortos adquiridos, para así mejorar la dispersión de estos en agua.

\subsubsection{Funcionalización covalente de los MWCNTs}

El proceso de funcionalización covalente permite que los nanotubos con su superficie modificada puedan dispersarse fácilmente en agua sin la adición de otro tipo de surfactante. Esta propiedad se hará evidente si la cantidad de grupos funcionales tipo (- $\mathrm{COOH})$ incorporados en el proceso de funcionalización es suficiente [7]. Los nanotubos de carbono de pared múltiple (cortos y largos) y los de pared única se funcionalizaron según la metodología descrita en el Capítulo III, apartado 2.1.3.

El grado de funcionalización de su superficie se caracterizó mediante espectrofotometría infrarroja, FT-IR, con el equipo descrito en el Capítulo III, apartado 3.10. Los espectros FT-IR de los nanotubos analizados se muestran en los siguientes gráficos de las figuras Figura 91 a Figura 93 . Los resultados del FT-IR evidencian que los grupos hidrofílicos (hidroxílicos y carboxílicos) han sido introducidos en la superficie de los distintos tipos de nanotubos funcionalizados. Las bandas cercanas 1500 y $1000 \mathrm{~cm}^{-1}$ no está claro si están ligadas a grupos sulfóxidos o carboxílicos. Presumiblemente están ligados a la funcionalización ácida y a la funcionalización alcalina respectivamente.

\section{- Funcionalización de los nanotubos de pared múltiple largos}

Para la funcionalización superficial de los MWCNTs largos se aplicaron dos técnicas: la funcionalización alcalina y la funcionalización ácida, siguiendo el método descrito en el Capítulo III, apartado 2.1.3. En la Figura 91 se han representado conjuntamente los espectros FT-IR obtenidos para los MWCNTs-largos con cada tipo de funcionalización. Puede observarse 
que los picos más fuertes (con mayor transmitancia) se han obtenido con la funcionalización ácida, concluyéndose que la funcionalización con ácidos es una funcionalización más agresiva que la funcionalización alcalina.

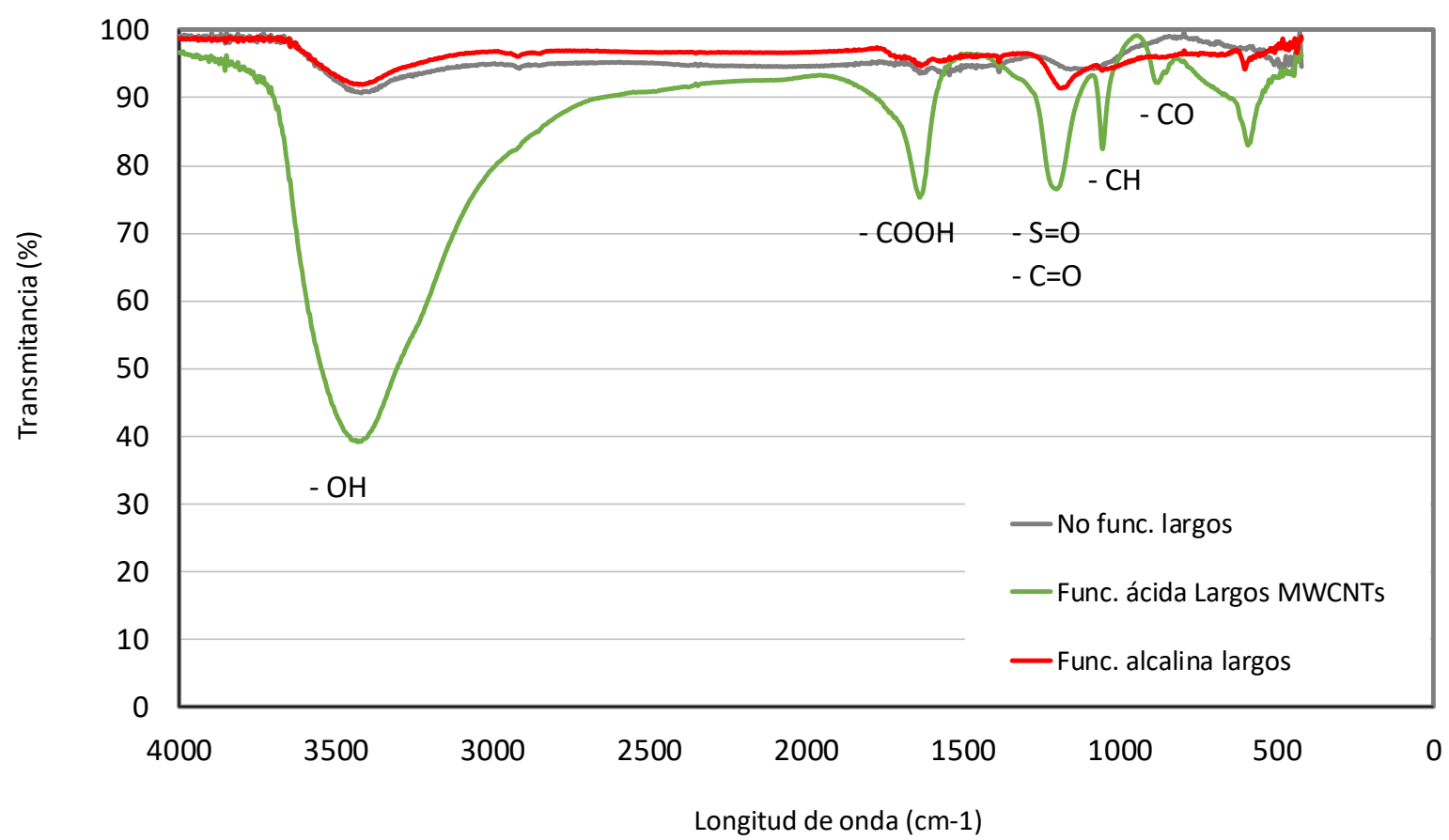

Figura 91. Espectros FT-IR para MWCNT largos originales, funcionalizados por el método ácido y el método alcalino

\section{- Funcionalización de los nanotubos de pared múltiple cortos}

Dentro de los MWCNTs cortos se han comparado los adquiridos ya funcionalizados y los funcionalizados en el laboratorio. Como puede observarse en la Figura 92 los nanotubos comerciales ya adquiridos "MWCNTs funcionalizados cortos" presentaban un espectro muy suavizado sin apenas picos, debido posiblemente a que el método de funcionalización seguido comercialmente no haya sido adecuado. Tan sólo la funcionalización ácida de los MWCNTs cortos realizada experimentalmente en los laboratorios mostró picos más fuertes.

También se ha analizado el efecto del tiempo de funcionalización (tiempo que permanecen los nanotubos en contacto con la mezcla ácida a una determinada temperatura), estudiándose dos tiempos de permanencia, a 3 y 9 horas. Los resultados obtenidos en los espectros con el FT-IR, Figura 93, evidencian que los grupos hidrofílicos como hidroxilos y carboxílicos han sido introducidos sobre la superficie de los nanotubos tratados, y que estos picos son mayores cuando la funcionalización ácida se ha aplicado durante más tiempo (9 horas). 


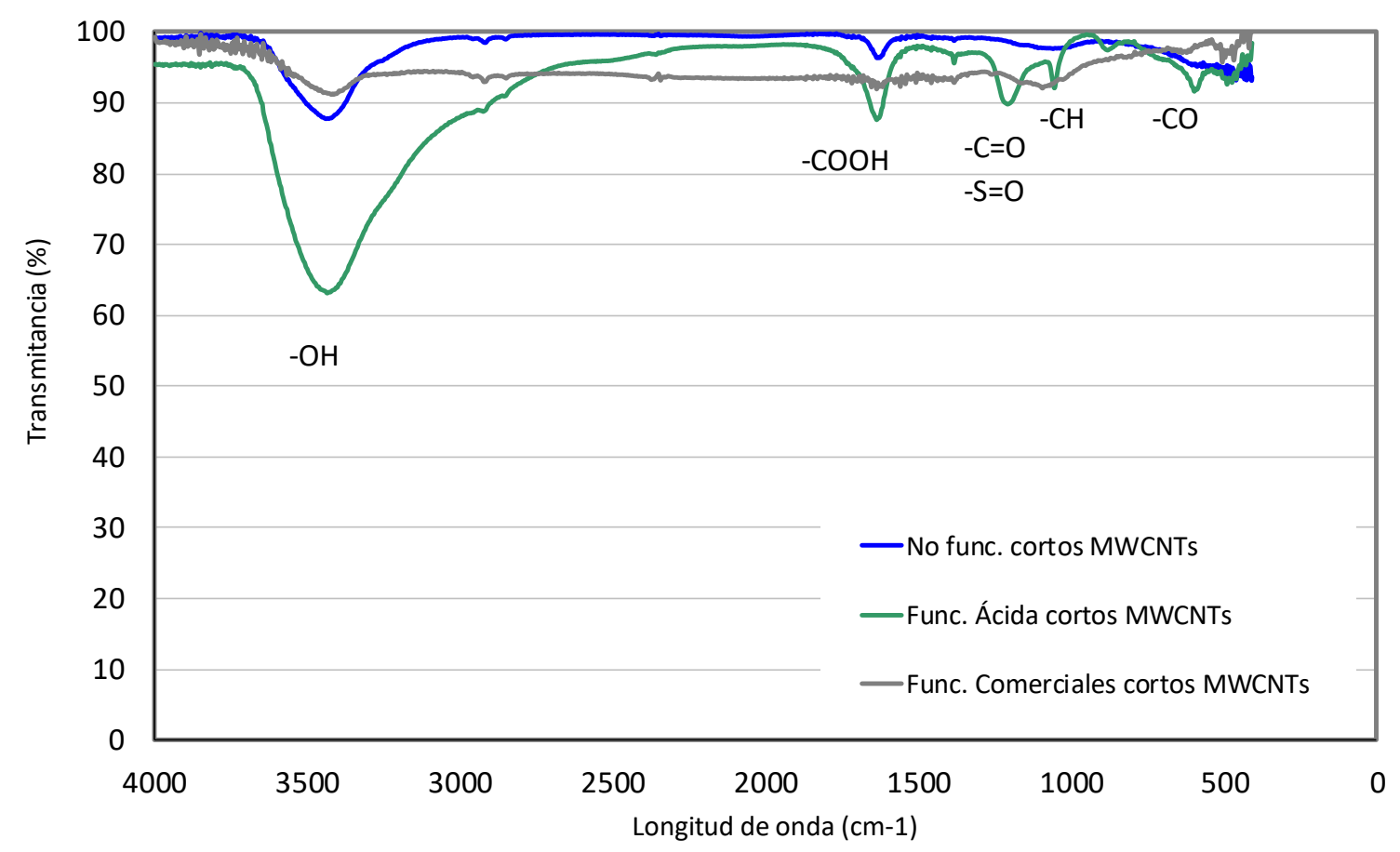

Figura 92. Espectros FT-IR para MWCNT cortos originales, funcionalizados y comerciales funcionalizados

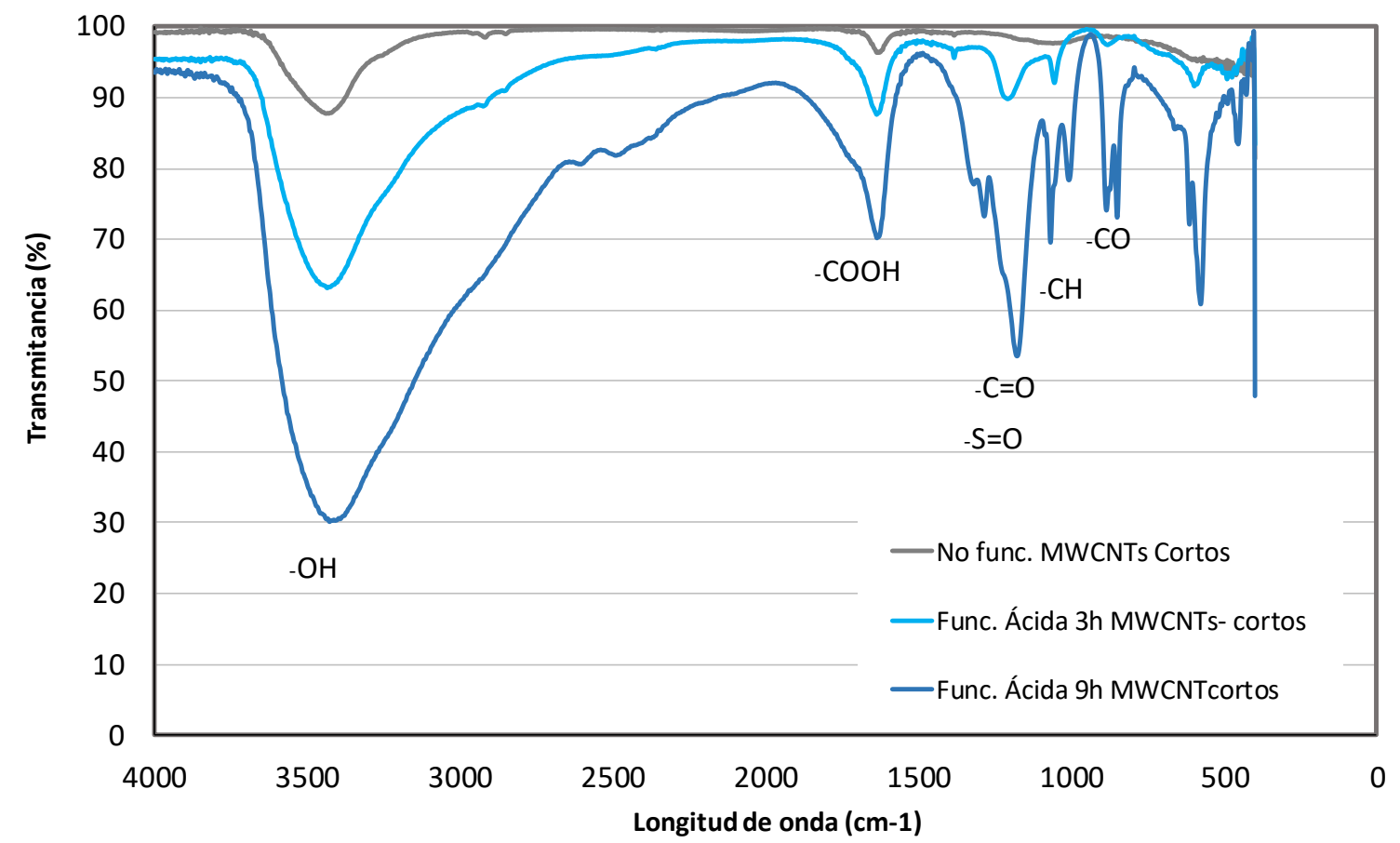

Figura 93. Espectro FT-IR para MWCNT cortos para distintos tiempos de funcionalización ácida

Tras la funcionalización de los nanotubos se caracterizó su estado de aglomeración, pues los nanotubos una vez funcionalizados hay que someterlos a un proceso de lavado y filtrado, de separación mediante centrifugado y finalmente secado que pueden llevar a una 
reaglomeración de las partículas, por lo que su estado de aglomeración puede diferir respecto al estado inicial previo a la funcionalización. Dicha caracterización se llevó a cabo con el análisis de imagen obtenida mediante microscopía de barrido (MEB).

\section{Análisis de imagen de los nanotubos de pared múltiple funcionalizados}

Como puede apreciarse en las siguientes imágenes tomadas en el MEB, la morfologia y tamaños de los agregados de nanotubos obtenidos tras la funcionalización es diferente a la que presentaban inicialmente. La estructura de estos aglomerados es laminar, formando plaquetas, más compactada que los aglomerados que presentaba el material inicialmente.

Esta tipología de agregado puede afectar al proceso de dispersión en base acuosa.
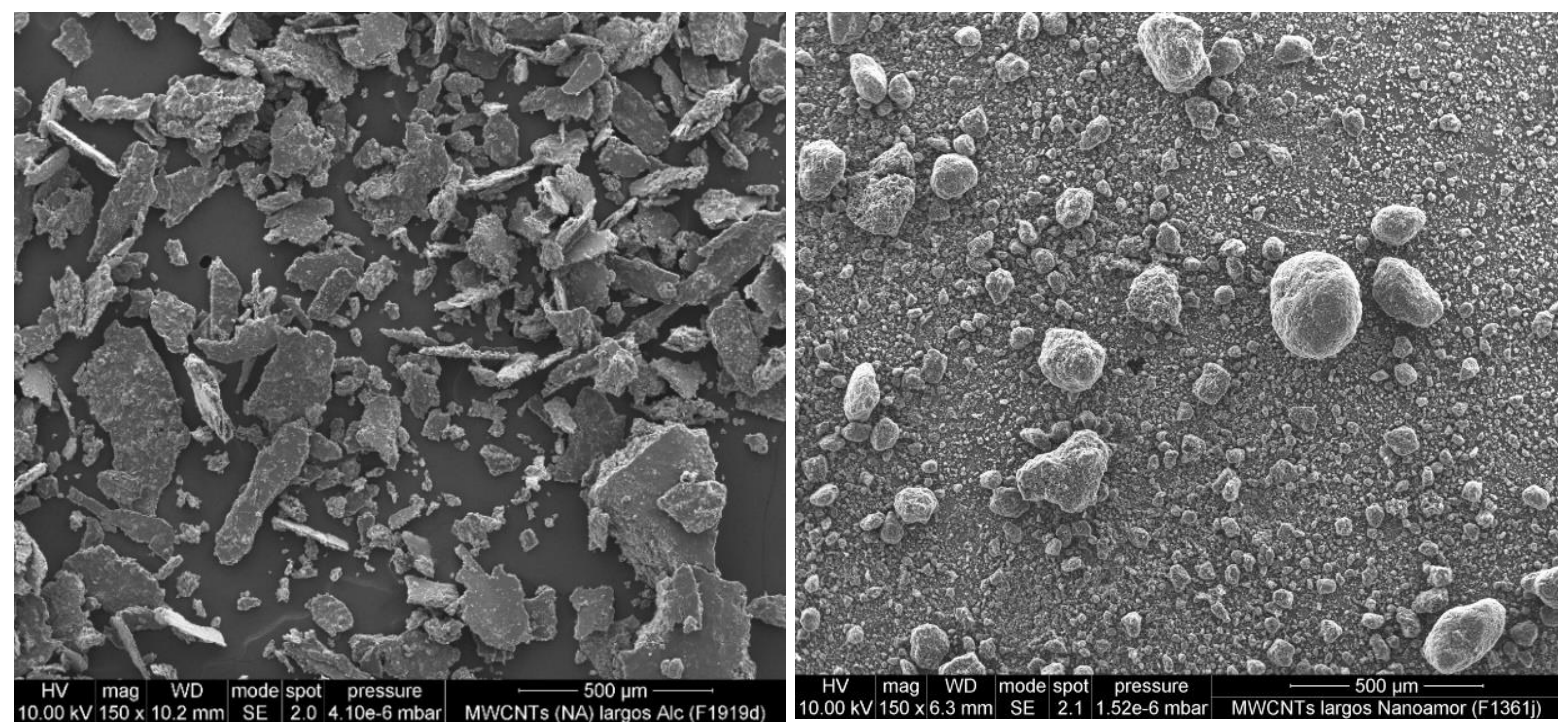

Figura 94. Imagen MEB x150 aumentos MWCNTs largos: a) funcionalizados b) sin funcionalizar
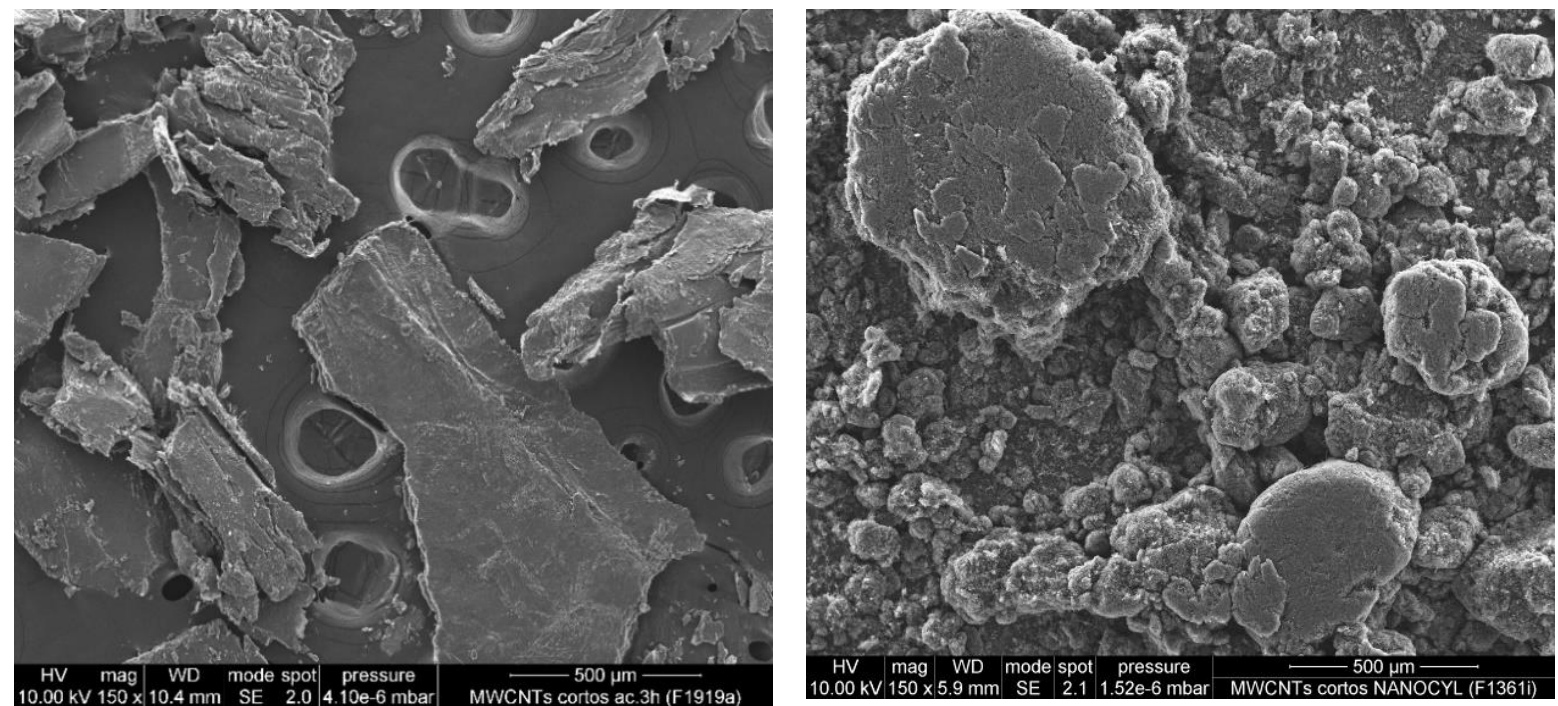

Figura 95. Imagen MEB x150 aumentos MWCNTs cortos: a) funcionalizados b) sin funcionalizar 
Si se observa a mayores aumentos la estructura de estas plaquetas (Figura 96), puede apreciarse que los nanotubos conservan su estructura inicial, por lo que cabe esperar que una vez desaglomerada y dispersada en agua la plaqueta, las características que aportan estos nanotubos funcionalizados van a ser las mismas que los nanotubos iniciales pero mejorando, gracias a la funcionalización, su dispersión en un fluido polar como el agua.
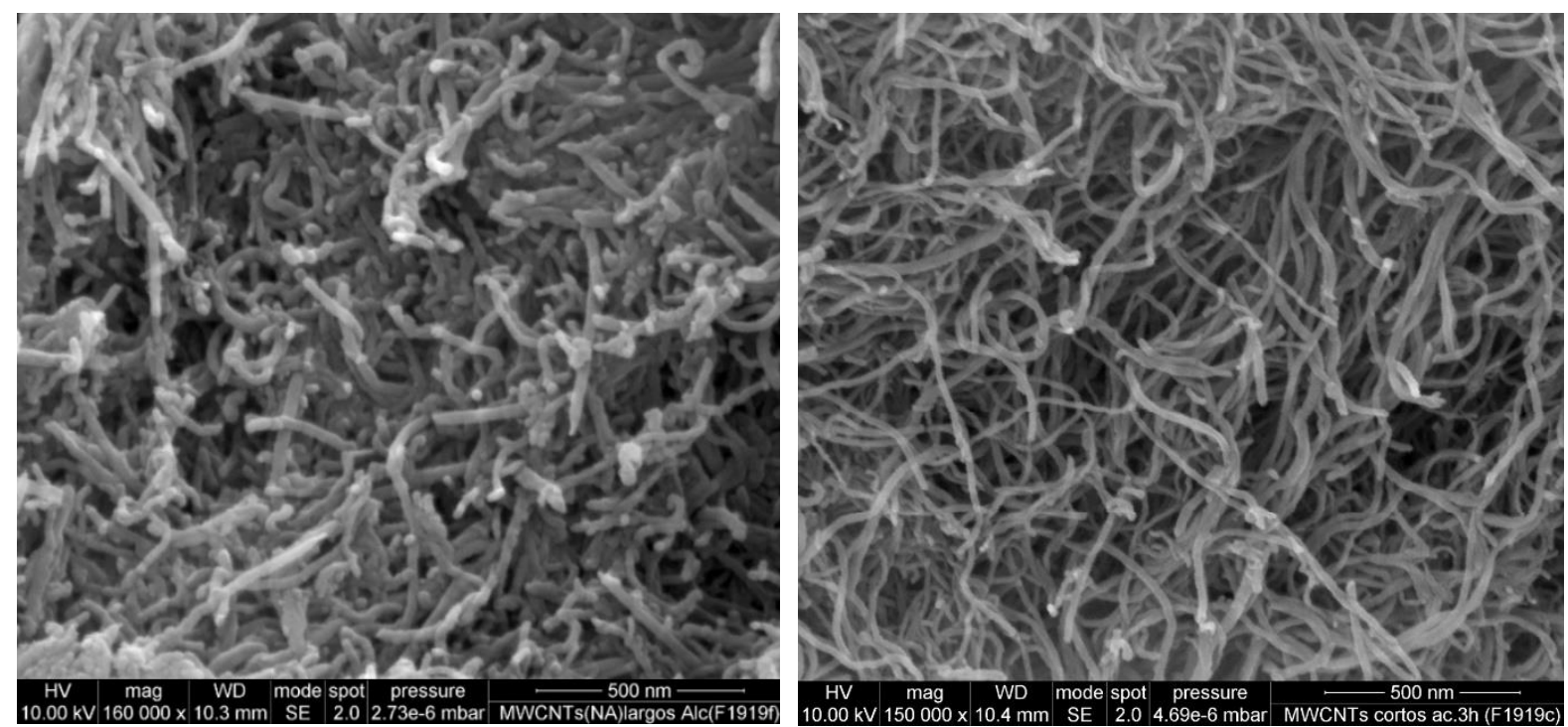

Figura 96. Imagen MEB x160.000 aumentos MWCNTs largos a) funcionalizados b) sin funcionalizar

2.1.3 Caracterización del estado de dispersión de los nanotubos en los nanofluidos preparados

A continuación, se resumen los ensayos realizados para la caracterización de las suspensiones de nanotubos preparados por las técnicas de agitación mecánica por sonda de ultrasonidos y homogeneizador. Además, también se ha estudiado el estado de dispersión de las suspensiones ya preparadas comercialmente y se ha analizado la dispersión conseguida cuando se trata la superficie con surfactantes.

Análisis del estado de dispersión de los nanotubos en los nanofluidos preparados.

Tras la preparación de los nanofluidos con nanotubos, se procedió a la caracterización del estado de dispersión de las nanopartículas en el fluido base. Para dicha caracterización se utilizó el microscopio electrónico de transmisión (TEM). 
Las imágenes obtenidas tras la caracterización de las muestras en el TEM se muestran en las Figura 97 a la Figura 101 . Tras el análisis de las imágenes se puede concluir que no se aprecian diferencias significativas entre los nanofluidos preparados al 0,1 \% de fracción volumétrica mediante distintas técnicas (método de dilución y método de dispersión mecánica a partir de material en polvo, Figura 97 y Figura 98).

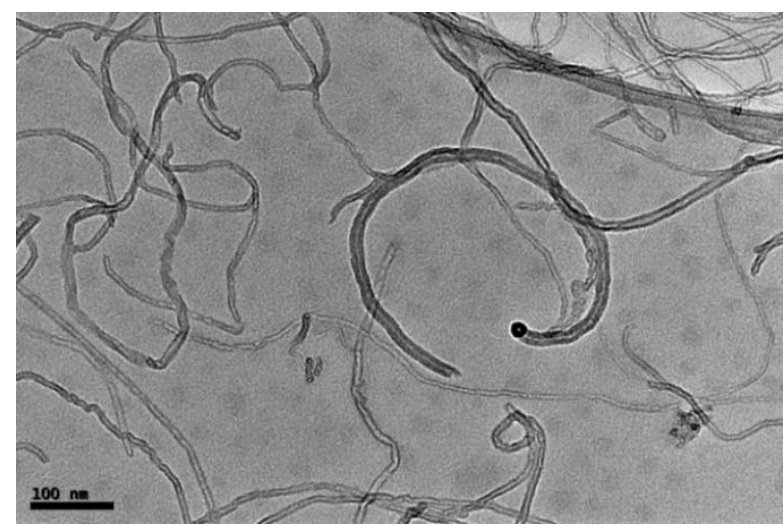

Figura 97. MWCNT-S nanofluido preparado por dilución de una suspensión comercial

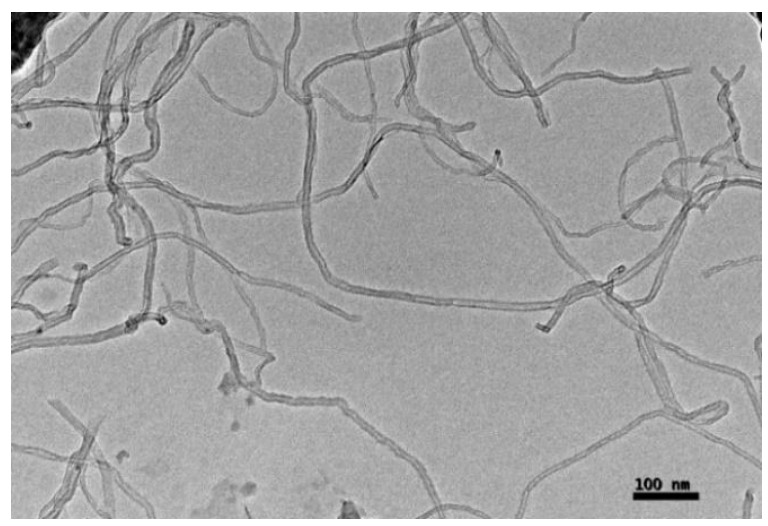

Figura 98. MWCNTs cortos preparado en dos etapas con sonda de ultrasonidos.

Si se evalúa la influencia del método de dispersión, sonda de ultrasonidos y homogeneizador, tampoco se aprecian diferencias significativas entre ambos métodos de dispersión mecánicos (Figura 99 y Figura 100). La longitud de los nanotubos no parece haber disminuido debido a roturas producidas durante el proceso de dispersión mecánica de los mismos.

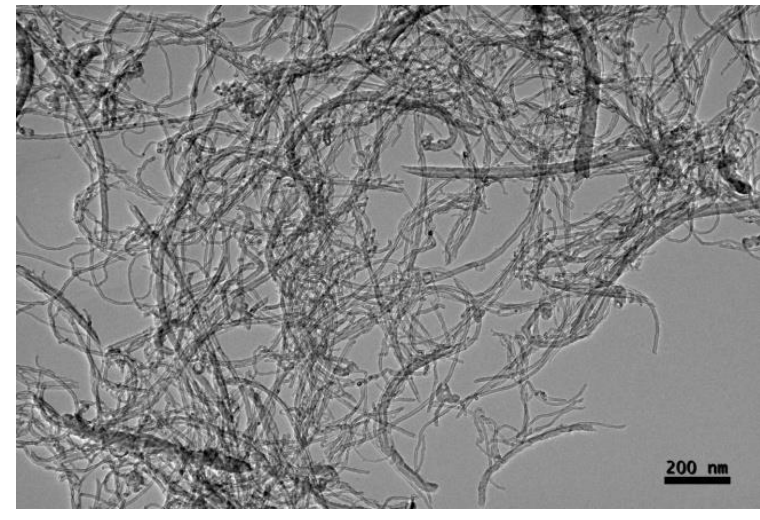

Figura 99. MWCNTs func.comercial preparado mediante la técnica el homogeneizador al $0,1 \%$.

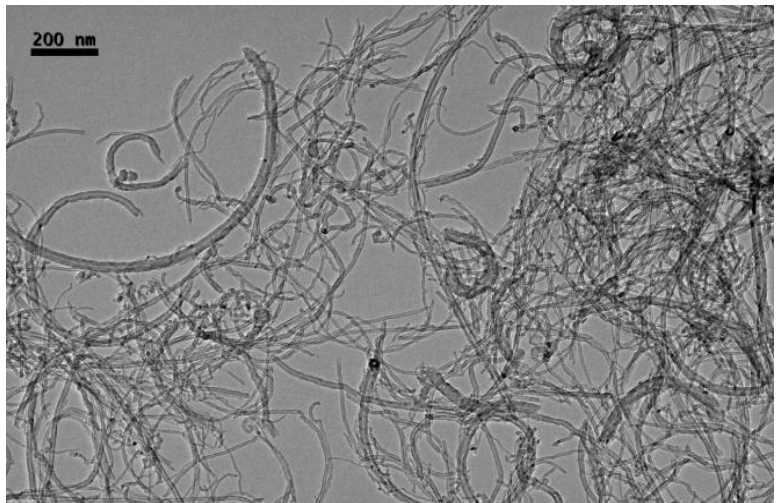

Figura 100. MWCNTs func.comercial preparado mediante la técnica de ultrasonidos al $0,1 \%$.

En las imágenes analizadas puede apreciarse que cuando se utilizó además del método de dispersión un surfactante como aditivo (en este caso surfactante SDS, Figura 101) para lograr dispersar mejor los MWCNTs func. comerciales en agua, los nanotubos se aprecian menos agrupados o aglomerados. En este análisis de imagen debe tenerse en cuenta que ver más 
agrupados o menos los nanotubos puede deberse a efectos de superposición de los nanotubos en la proyección de la imagen tomada en el TEM, por lo que resulta necesario utilizar otras técnicas adicionales que permitan caracterizar dicha dispersión.

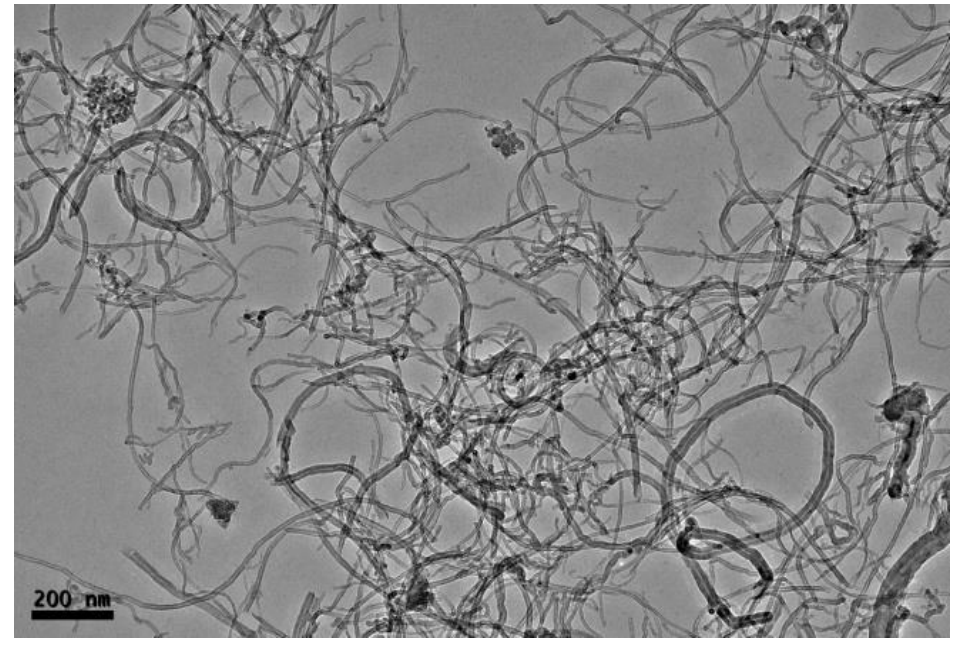

Figura 101. Nanofluido 0.1\% MWCNTs func.Comercial +SDS preparado mediante la técnica de ultrasonidos

Se puede concluir, que la técnica del TEM presenta algunos inconvenientes ya que por ejemplo al tomar una gota, colocarla sobre la gradilla y secarla, se puede producir una aglomeración de los nanotubos (durante su deposición sobre la gradilla o en el proceso de secado), no pudiendo la imagen tomada en el TEM plasmar la realidad de la dispersión de la suspensión. Para poder estudiar el estado de dispersión de las nanopartículas en el fluido base sería necesario utilizar un TEM vía húmeda (donde la celda contiene la suspensión en estado líquido) y a la cual no se ha tenido acceso, pues tan sólo hay equipos experimentales en EEUU (P.Garg tesis [22]). Con la técnica TEM utilizada, vía seca, tan sólo se ha podido apreciar si la longitud de los nanotubos se ha visto afectada.

\section{Caracterización del tamaño final de la nanopartícula dispersa en el fluido base}

Como información complementaria a las imágenes obtenidas mediante el TEM, se decidió analizar el tamaño de partícula o aglomerado mediante la técnica de difracción laser. Esta técnica de difracción por láser permite medir el tamaño de partícula o agregado que se encuentra en la suspensión.

Dicho ensayo se realizó con los nanofluidos preparados a partir de MWCNTs cortos func. Comerciales a una fracción volumétrica del 0,1\%, utilizándose las siguientes técnicas de dispersión descritas en el apartado 2.2 del capítulo III: 
- $\quad$ Agitación suave con pez magnético según procedimiento descrito en el apartado 2.2.1. Referenciada como "original".

- Homogeneizador (10 pasadas, 1250 bar) según procedimiento descrito en el apartado 2.2.2.

- $\quad$ Surfactante (SDS) + Homogeneizador (10 pasadas, 1250 bar) según procedimiento descrito en el apartado 2.2.2.

- $\quad$ Sonda de ultrasonidos $12 \mathrm{~min}$, según procedimiento descrito en el apartado 2.2.3.

- $\quad$ Surfactante (SDS) + Sonda de ultrasonidos 12 min, según procedimiento descrito en el apartado 2.2.3

Como se observa en la Figura 102 con ambas técnicas de dispersión (homogeneizador y sonda de ultrasonidos) se consigue reducir el tamaño de los agregados de nanotubos cuando estos se dispersan en agua si se comparan con los resultados obtenidos en una dispersión agitada por métodos convencionales y que se ha denominado "original". Aunque los nanotubos dispersados ya están funcionalizados comercialmente y por tanto han perdido en parte su carácter hidrófugo, se observa que estos no se dispersan en agua sino se aplica un mecanismo de disgregación enérgico como pueden ser los ultrasonidos o el homogeneizador.

Si además se añade en el agua un surfactante para que este actúe sobre la superficie de los nanotubos se observa como en ambos casos el diámetro medio disminuye. También puede concluirse a la vista de los resultados que la dispersión en todos los casos no ha conseguido individualizar totalmente a las partículas de nanotubos, ya que el diámetro medio detectado se corresponde a agregados, con tamaños superiores a los $100 \mathrm{~nm}$. 


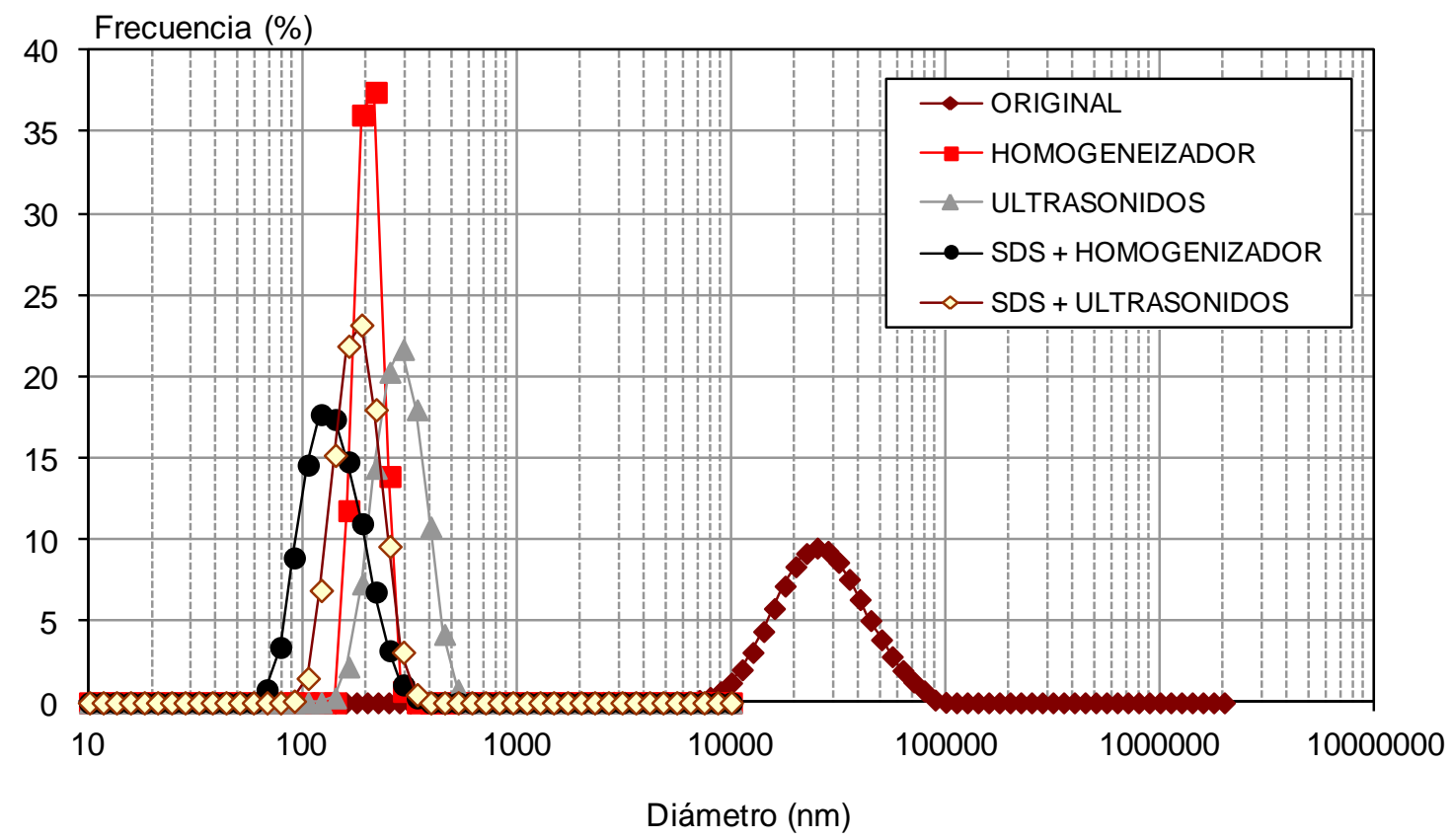

Figura 102. Análisis tamaño de partícula en nanofluidos (MWCNTs Func. Cortos $0,1 \%$ ) preparados con distintas técnicas

\subsubsection{Caracterización de la estabilidad de los nanofluidos preparados con nanotubos}

Para la caracterización de la estabilidad de las suspensiones con nanotubos se han utilizado tres técnicas: análisis mediante observación del frente de sedimentación, medida de la luz retrodispersada por la suspensión en el tiempo (medida con el Turbiscán según procedimiento 2.3.1. del Capítulo II) y caracterización de la absorbancia mediante espectrofotómetro, como ya se ha descrito en el procedimiento 2.3.2. del Capítulo III.

A continuación, se resumen los resultados de los ensayos de estabilidad realizados a las distintas suspensiones de nanofluidos preparadas a partir de nanotubos de carbono.

Análisis de la estabilidad de los nanofluidos mediante observación del frente de sedimentación Esta es una de las técnicas más simples para caracterizar la estabilidad de los nanofluidos en el tiempo frente a la sedimentación, pues si los nanotubos dispersados en el fluido base no permanecen estables y se van aglomerando, estos aglomerados de mayor tamaño sedimentarán siguiendo la ley de Stokes, permitiendo ver de forma visual el frente de sedimentación. En las siguientes figuras se muestra la comparativa en estabilidad de suspensiones de MWCNTs cortos Func.comerciales al $0,1 \%$ de fracción volumétrica 
preparados con distintos sistemªs de dispersión mecánica: agitación suave con pez magnético (Figura 103) y homogeneizador a presión (Figura 104).

Como se observa en las imágenes la dispersión de los nanotubos en el fluido base con el equipo homogeneizador logra mejorar la estabilidad de los nanofluidos preparados, comparado con el baño, pues no se observa un avance del frente de sedimentación transcurrido un mes desde la preparación de la muestra. Hay que señalar que, aunque el equipo proporciona una dispersión estable de los nanotubos en agua, el paso de la suspensión produjo un desgaste severo en la válvula, desaconsejándose dicho sistema para este tipo de nanofluidos.
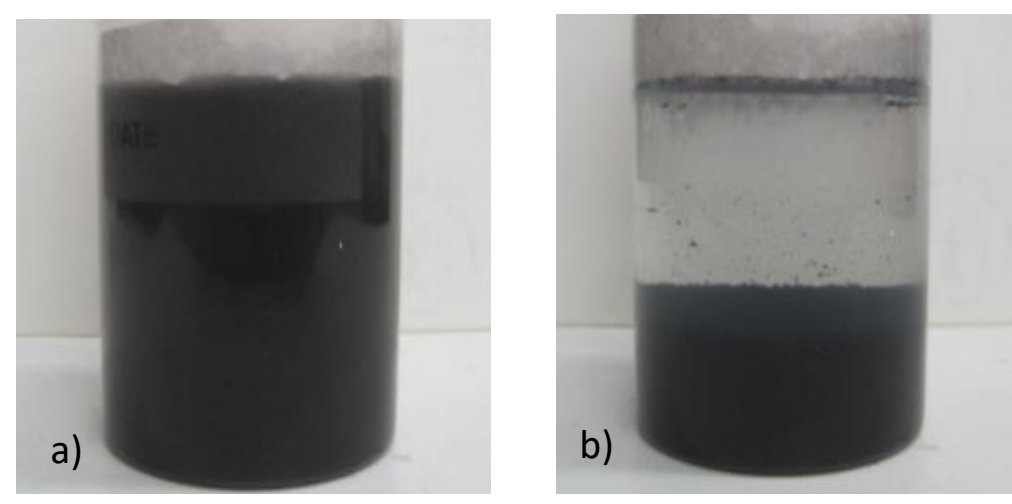

Figura 103. Nanofluido MWCNTs cortos Fun.comercial $\Phi=0,1 \%$ a) tras agitación b) tras un minuto en reposo

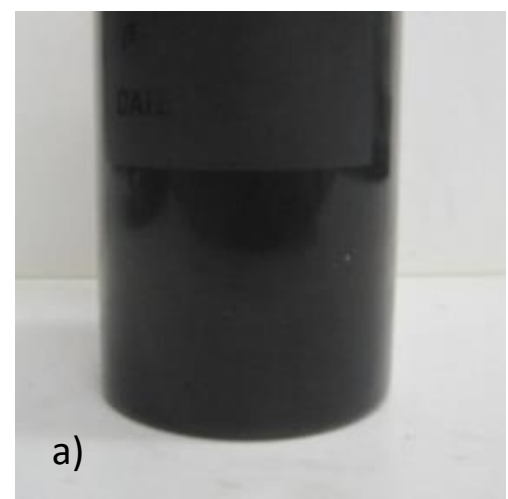

b)

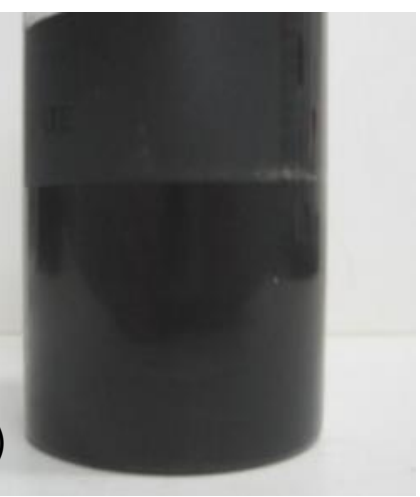

Figura 104. Nanofluido MWCNTs cortos Fun.comercial $\Phi=0,1 \%$ a) homogeneizada b) homogeneizada tras un mes

Esta técnica de observación del frente de sedimentación tan sólo es válida para determinar si la suspensión preparada de nanofluidos sedimenta rápidamente o permanece estable en el tiempo sin que se detecte acumulación de material en el fondo, pero no permite detectar cambios en la dispersión de los nanofluidos debido a efectos de aglomeración que no impliquen una sedimentación directa del material. Con esta técnica no se puede comparar el comportamiento tras la dispersión de muestras preparadas a distintas fracciones o con 
distintos métodos de preparación, pues los cambios producidos no se pueden apreciar visualmente.

En la Figura 105 se muestra la evolución en el tiempo de tres muestras (a tres fracciones volumétricas) preparadas con otra técnica de dispersión, la agitación con sonda de ultrasonidos durante 2 minutos. El frente de sedimentación aparece mucho más rápido en la muestra más diluida, con menor fracción volumétrica. Esta técnica no permite confirmar que las muestras de mayor fracción volumétrica sean más estables por aparecer más tarde el frente de sedimentación, ya que esto puede deberse a la mayor cantidad de nanotubos en la muestra que implica que el proceso de clarificación lleve más tiempo, aunque las partículas estén sedimentando a la misma velocidad. Resulta necesario utilizar otras técnicas que permitan medir la estabilidad del nanofluido con mayor sensibilidad.

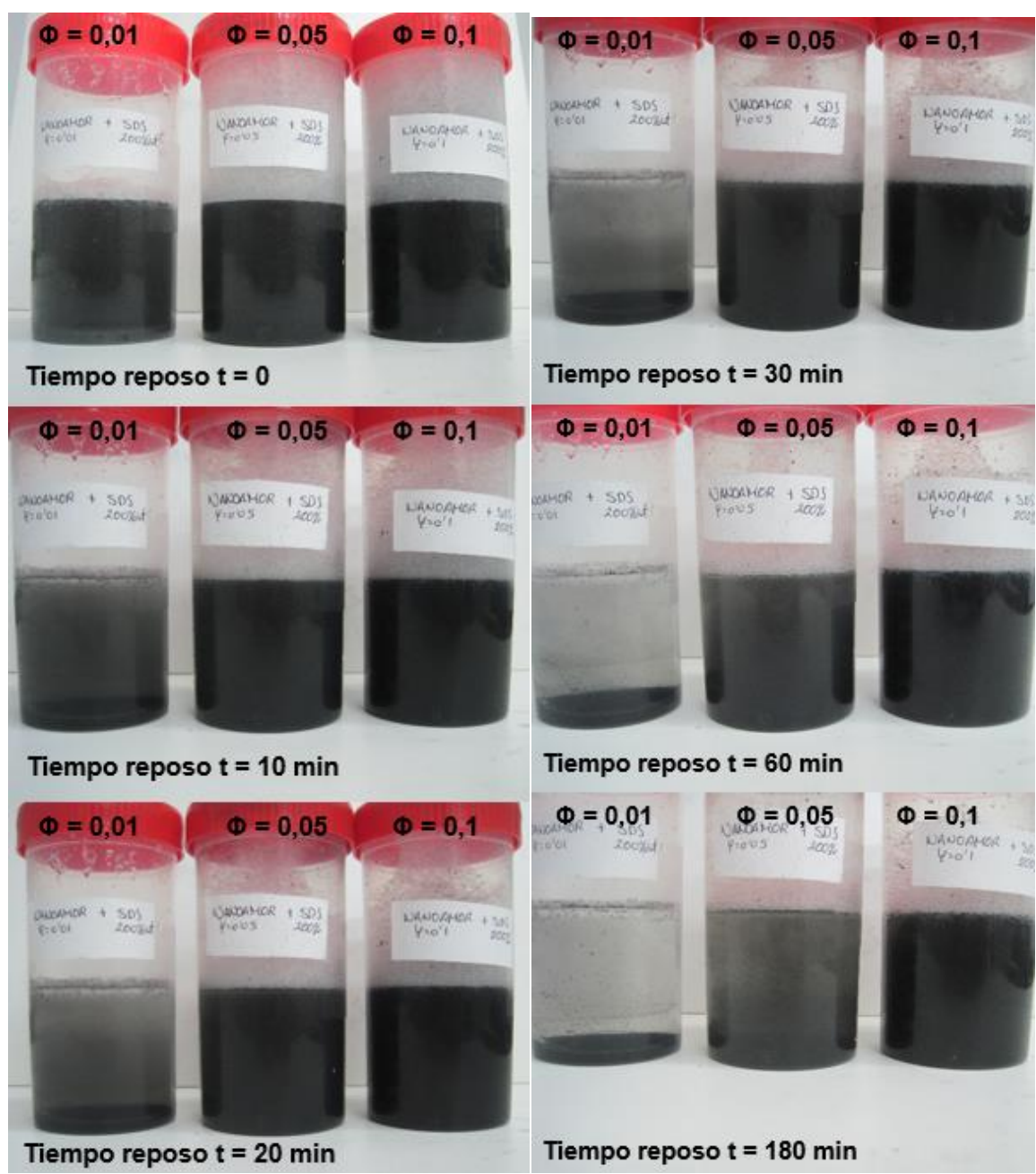

Figura 105. Evolución del frente de sedimentación de muestras de MWCNTs-cortos Func.Comercial a distintas fracciones volumétricas $(\%)(0,01,0,05$ y 0,1$)$ preparadas con sonda de ultrasonidos y surfactante SDS al $1 \%$ 


\section{Estabilidad de los nanofluidos medida en el equipo turbiscán}

La técnica de medida de la estabilidad del nanofluido mediante el turbiscán se basa en un sistema óptico de medida mediante dispersión múltiple de luz que permite analizar la dispersión de luz producida por las partículas en la suspensión tras la aplicación de un haz incidente de luz, según el método descrito en el apartado 2.3.1 Capítulo III. Con dicha técnica se obtiene como resultado la evolución en el tiempo del porcentaje de luz transmitida (T) o retrodipersada (BS) a lo lago de la altura de la celda donde se encuentra la suspensión.

En las siguientes figuras se muestran los resultados de los perfiles de BS (\%) y T (\%) obtenidos directamente del equipo Turbiscán en toda la altura de la cubeta (h) para varios tiempos de medida, para una muestra de nanofluido preparada con nanotubos de carbono. En la Figura 106 y la Figura 107 se observa la poca estabilidad de una muestra agitada en baño $(0.1 \%$ MWCTs-cortos Func. comercial), pues ni el perfil de transmisión ni el perfil de retrodispersión permanecen constante en el tiempo. Puede observarse como la transmisión a medida que pasa el tiempo va siendo cada vez mayor debido a la clarificación del nanofluido Figura 106.

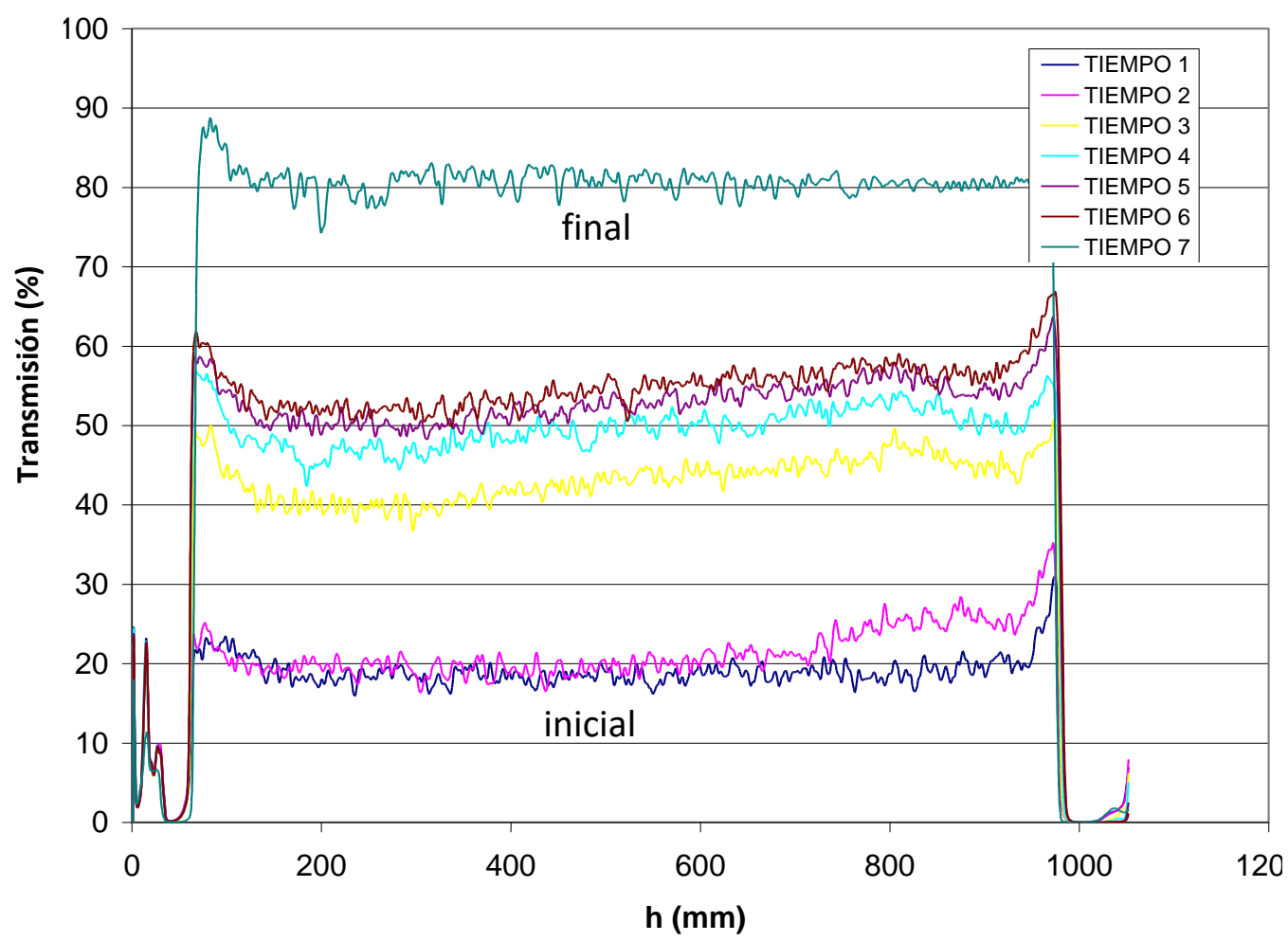

Figura 106. Perfil de Transmisión (\%) para el nanofluido MWCNTs cortos func.comercial al $0,1 \%$ agitada en baño 


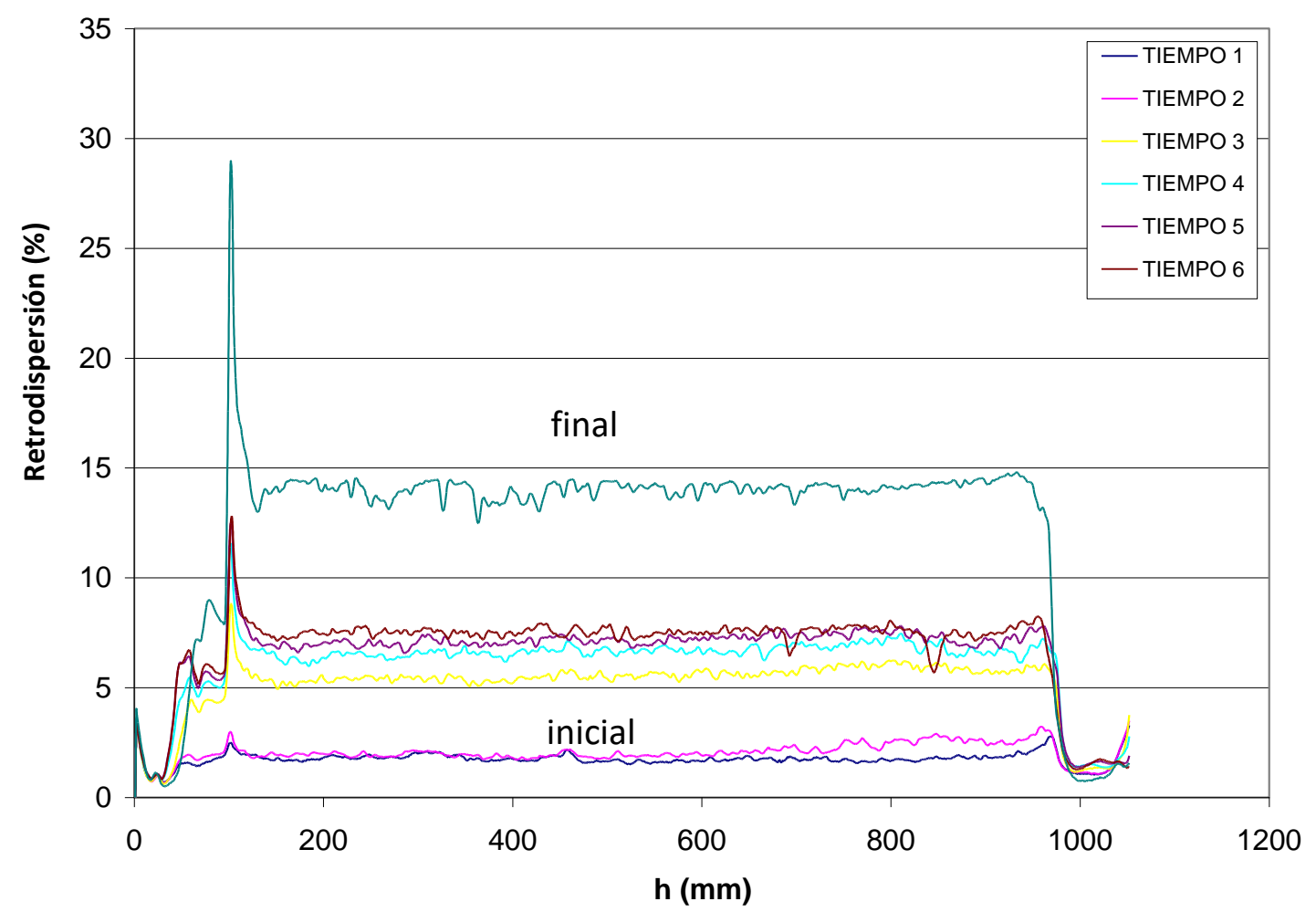

Figura 107. Perfil del B.S. (retrodispersión) (\%) para el nanofluido MWCNTs cortos func.comercial $0,1 \%$ agitada en baño

Cuando se utiliza un método de dispersión mecánica más fuerte como la sonda de ultrasonidos, con lo que se consigue dispersar mejor los nanotubos y éstos se desaglomeran, la caracterización de la estabilidad mediante la técnica del Turbiscán no se puede utilizar pues los resultados obtenidos están por debajo de su límite de detección. En la Figura 108 se recogen los perfiles de transmisión obtenidos para estas muestras y se puede observar como la transmisión de luz es prácticamente del 0\% y la cantidad de luz reflectada (BS), Figura 109, es de un $1 \%$. Ambas medidas permanecen estables en el tiempo, pero con unos valores medidos de transmisión y retrodispersión muy en el límite de detección. Esto puede deberse a que las muestras de nanotubos absorben prácticamente toda la luz incidente. 


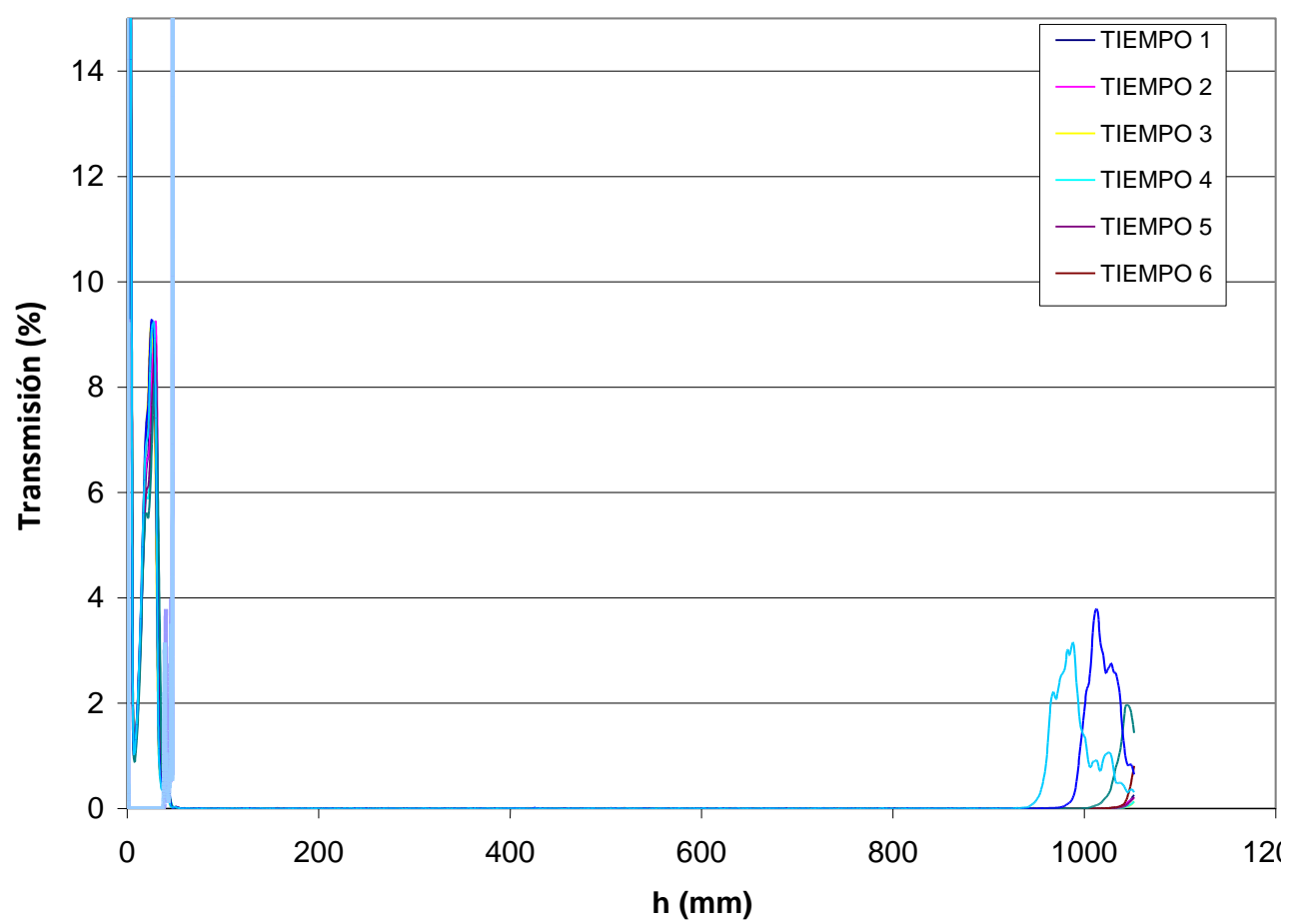

Figura 108. Resultados Transmisión para el nanofluido MWCNTs cortos func.comercial $0,1 \%$ dispersada mediante sonda ultrasonidos $12 \mathrm{~min}$

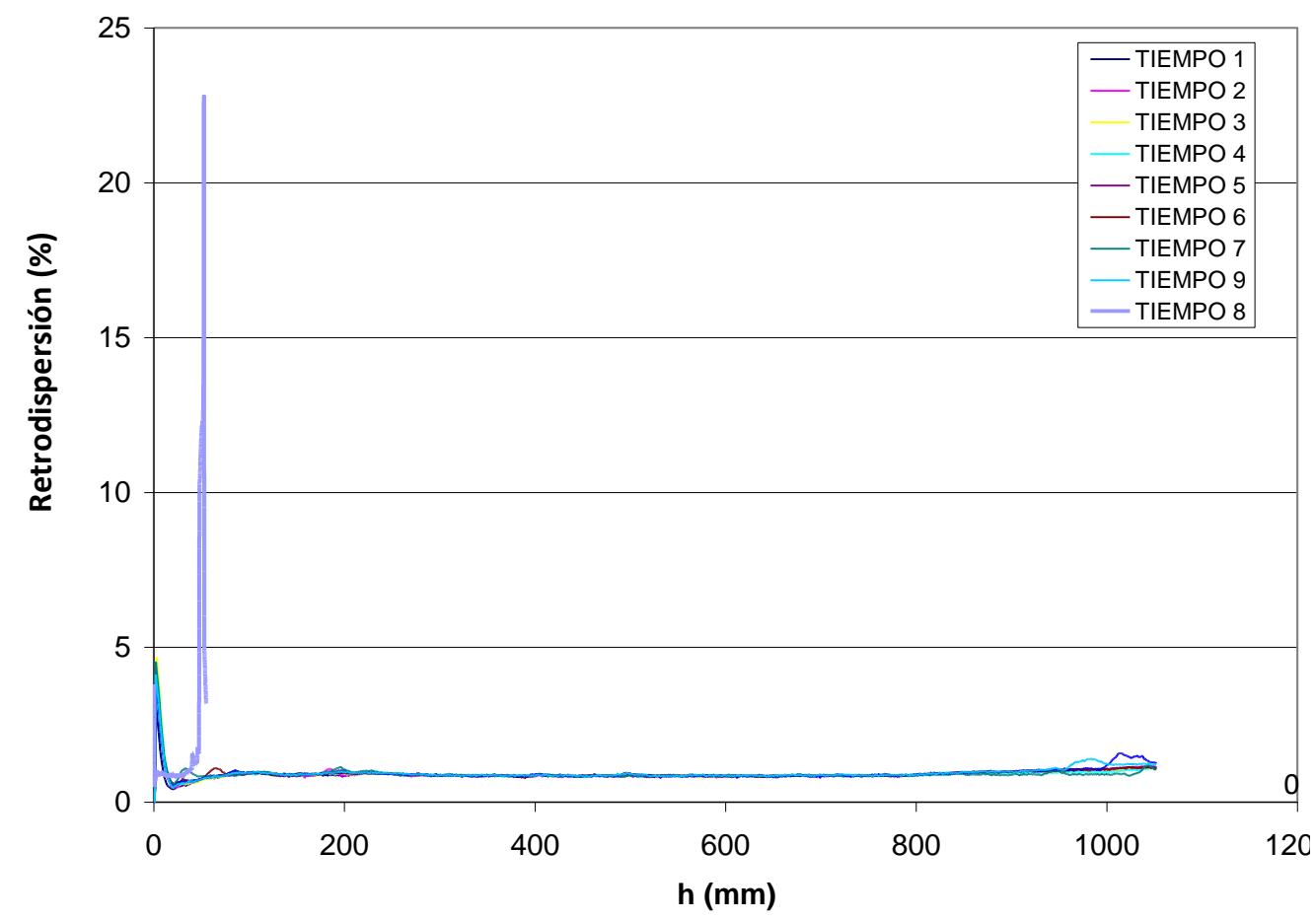

Figura 109. Resultados retrodispersión (\%) para el nanofluido MWCNTs cortos func.comercial 0,1\% dispersada mediante sonda ultrasonidos $12 \mathrm{~min}$ 
En la Figura 110, se ha representado el BS medido en función del tiempo para un punto central de la cubeta. Si se analiza la estabilidad de suspensiones preparadas en las mismas condiciones de dispersión mecánica (ultrasonidos) pero con distinta fracción volumétrica de nanotubos, se observa como a medida que aumenta la fracción volumétrica la retrodispersión medida es mayor, ya que el número de partículas en la suspensión es mayor aumentando la cantidad de luz retrodispersada. Estas suspensiones permanecen estables en el tiempo pues su BS apenas se modifica.

En la Figura 111 se observa la diferencia en los valores de retrodispersión (BS) de dos muestras de suspensiones preparadas, una con surfactante y otra sin surfactante, en las mismas condiciones de dispersión mecánica (ultrasonidos) y a una misma fracción volumétrica. Aunque el BS detectado es bajo, se observa como el nanofluido preparado con surfactante presenta una mayor dispersión de partículas, con un tamaño medio de agregado menor que la suspensión preparada sin surfactante y por tanto una menor reflexión o BS debido al pequeño tamaño.

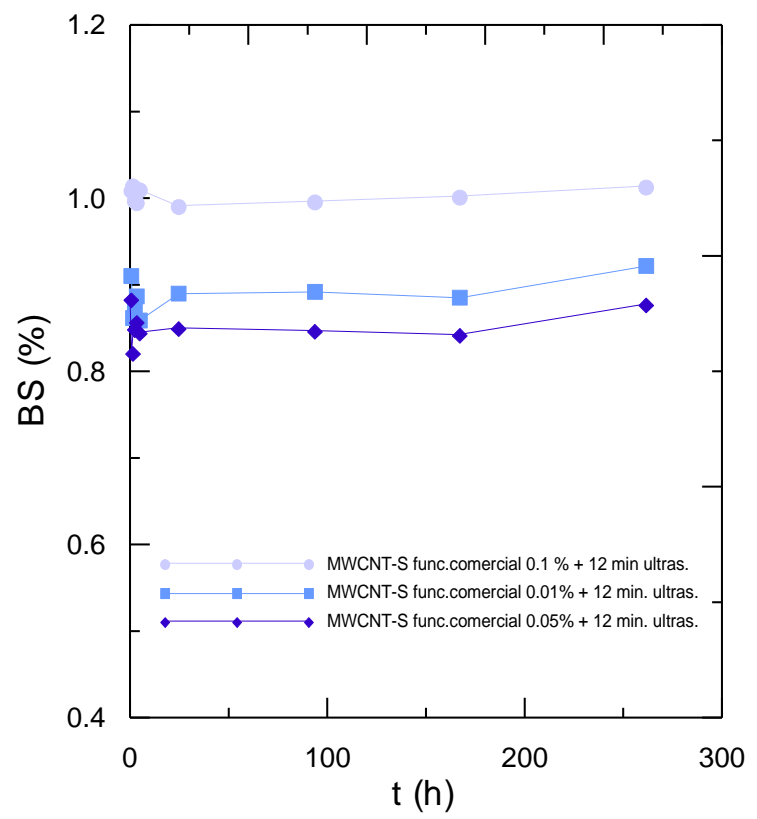

Figura 110. Estabilidad de suspensiones MWCNTs cortos funcionalizados comerciales preparadas a distinta fracción volumétrica con ultrasonidos

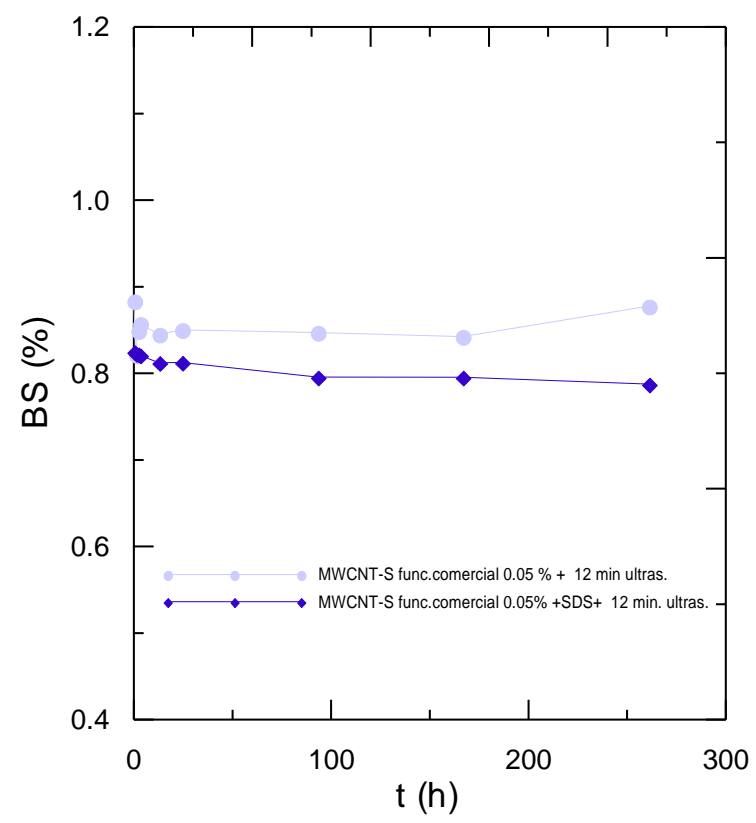

Figura 111. Comparación estabilidad de suspensiones MWCNTs cortos funcionalizados comerciales preparadas con y sin surfactante

Para todas las muestras analizadas puede concluirse que la estabilidad de las mismas se ha mantenido constante pues no se ha detectado cambios en BS a lo largo del tiempo. 
Para la mayor parte de los nanofluidos MWCNTs que se han ensayado en el Turbiscán los valores de retrodispersion, $\mathrm{BS}$, son menores del $1 \%$, y los valores de transmisión $0 \%$, es decir todo es absorbido o dispersado sin que lo detecte el receptor que mide el BS. Esta técnica de medida no es muy sensible para muestras de nanofluidos de MWCNTs pues recoge valores de BS muy bajos y por tanto las diferencias de dispersión entre suspensiones pueden no apreciarse o encontrarse dentro del error de medida. Para que el haz de luz incidente sea reflejado el diámetro de la partícula tiene que ser mayor que la longitud del haz incidente, que para el equipo Turbiscán es de $850 \mathrm{~nm}$. Como ya se ha observado en el gráfico de tamaño de partícula, Figura 102, las partículas o agregados están todos por debajo de $300 \mathrm{~nm}$. Como el tamaño es inferior a la longitud de onda del haz incidente no se produce la reflexión total, absorbiéndose toda la luz y obteniendo un valor de retrodispersión, BS, muy bajo.

\section{Estabilidad de los nanofluidos medida en espectrofotómetro}

Como el método de medida de la estabilidad mediante Turbiscán no resultó ser lo bastante sensible (pues se obtuvieron porcentajes muy bajos de BS y T) se utilizó otra técnica para la medida de la estabilidad de los nanofluidos preparados con nanopartículas en base carbono.

Siguiendo el procedimiento descrito en el apartado 2.3.2. del capítulo III, la estabilidad de los nanofluidos preparados a partir de nanotubos se midió mediante espectrofotómetro, obteniéndose la evolución de la absorbancia en el tiempo de una muestra tomada en la parte alta del recipiente que contiene la suspensión de nanofluido.

En el caso de los nanotubos de carbono la longitud de onda elegida para realizar los ensayos fue de $550 \mathrm{~nm}$. Para esta longitud de onda la sensibilidad o medida de absorción es máxima. Además, las medidas de absorbancia en esa zona implican un menor error frente a pequeñas variaciones en la longitud de onda que las realizadas en cualquier otra zona de la banda de absorción, según se ha observado en los resultados experimentales y se ha constatado en la bibliografía [84].

Los resultados de la evolución de la estabilidad de los nanofluidos preparados con aditivos, se muestran en la Figura 112, donde se ha representado la evolución de la absorbancia relativa de distintos tipos de nanofluidos de CNT con surfactantes. Se observa una clara diferencia en la pendiente decreciente de estabilidad relativa entre los nanofluidos CNT largos y cortos, independientemente de si estos nanotubos son de una única capa o de pared múltiple. El 
efecto de los surfactantes (Goma Arábica y Tritón X-100) sobre la estabilidad de nanofluidos es similar a la funcionalización, excepto en el caso de los MWCNT cortos. Para este tipo de material la estabilización de los nanofluidos con surfactante es ligeramente mejor que los nanofluidos preparados a partir de MWCNTs cortos funcionalizados (la absorbancia relativa fianl de los MWCNTs cortos con surfactantes presenta valores de 0,6 y 0,8, Figura 112 , mientras que en los MWCNTs cortos funcionalizados la absorbancia relativa final alcanza un valor de 0,2 (Figura 113).

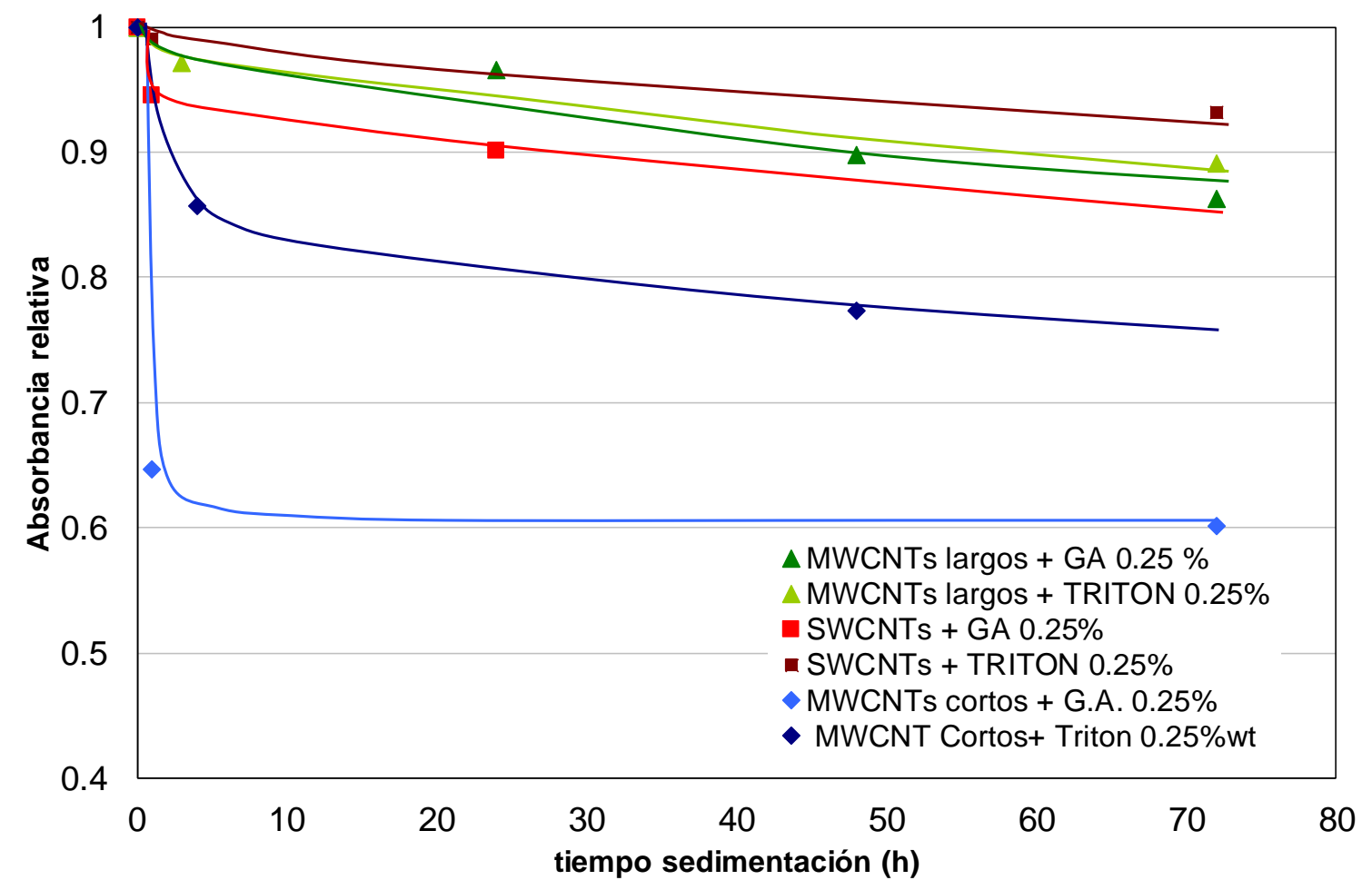

Figura 112. Evolución de la absorbancia relativa de los distintos tipos de nanofluidos MWCNTs + aditivo con el tiempo

Si se analizan los resultados obtenidos de evolución de la absorbancia relativa de MWCNTs funcionalizados (Figura 113) se observa que la evolución de la absorbancia de los nanofluidos muestra una clara diferencia entre los nanotubos funcionalizados cortos y los largos. La suave pendiente decreciente en la absorbancia relativa de los MWCNT funcionalizados largos demuestra que su estabilidad es más alta que los MWCNTs cortos e independiente del tipo de funcionalización aplicada (ácida o alcalina). Estos resultados indican que el éxito de la funcionalización y posterior dispersión en agua depende más de la longitud de los nanotubos y no tanto del método de funcionalización aplicado. 


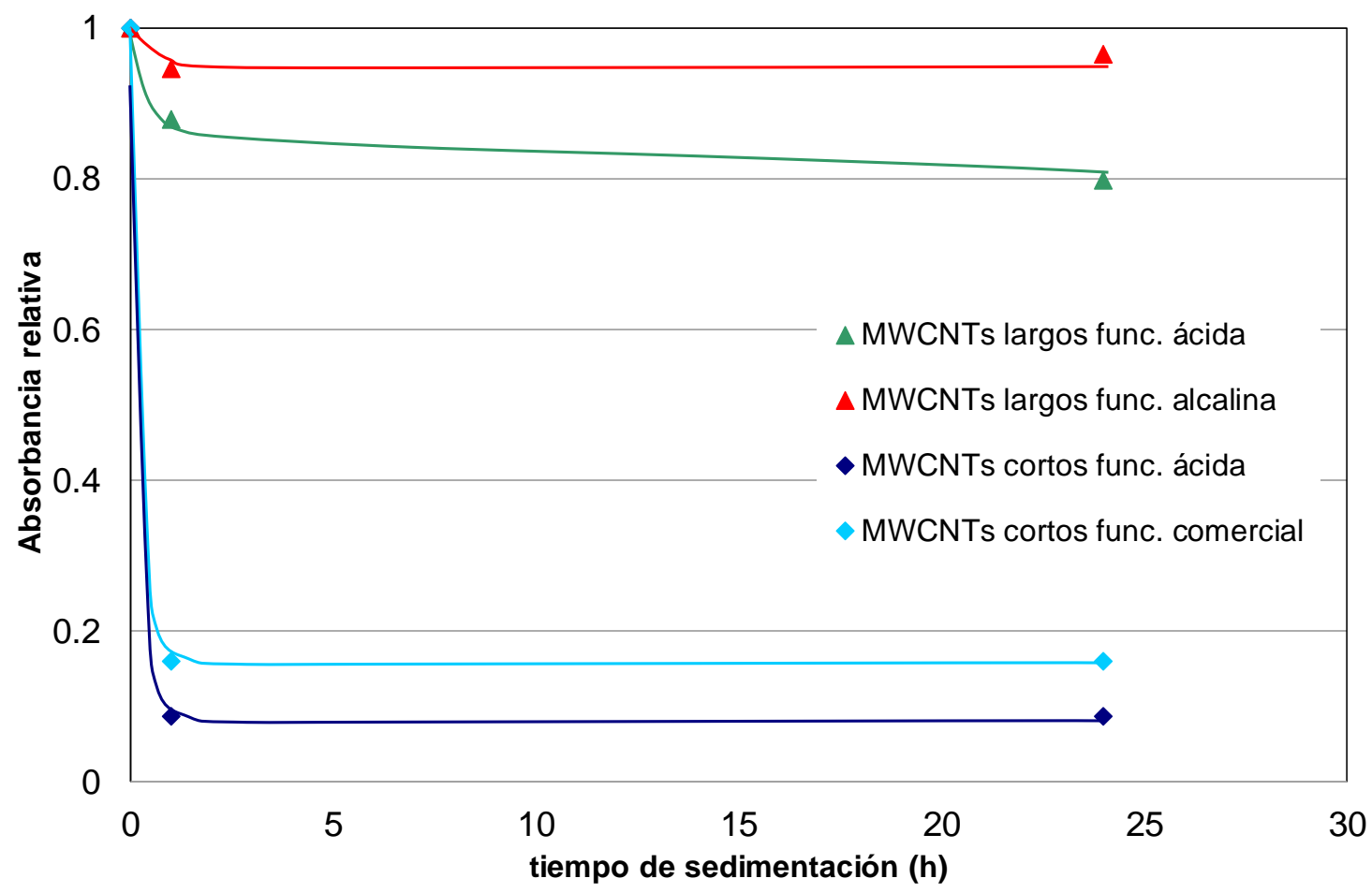

Figura 113. Evolución de la absorbancia relativa de los distintos tipos de nanofluidos de MWCNTs funcionalizados en el tiempo

Tras los resultados de estabilidad de los nanofluidos preparados con nanotubos analizados puede concluirse que los nanofluidos menos estables son los preparados con MWCNTs cortos, mejorándose dicha estabilidad si se utilizan aditivos como el Tritón. Los nanofluidos más estables se consiguen con los MWCNTs largos obteniéndose buenos resultados para ambos tipos de funcionalización, aunque con un resultado ligeramente mejor con la funcionalización alcalina.

\subsection{Resultados de la medida de la conductividad térmica de los nanofluidos preparados con} nanotubos

A continuación, se resumen los resultados de conductividad térmica obtenidos para los distintos nanofluidos de nanotubos de carbono preparados (Tabla 24 y Tabla 25). Los resultados se presentan conjuntamente en varios apartados para así analizar la influencia de las distintas variables estudiadas sobre el aumento en la conductividad térmica, con el objetivo de optimizar la preparación de los nanofluidos para su posterior aplicación térmica. 


\subsubsection{Influencia del método de dispersión mecánica sobre la conductividad térmica}

En primer lugar, se analizó la influencia sobre la conductividad térmica que tiene el método de dispersión mecánica aplicado a las nanopartículas para su dispersión en el fluido base agua. Se analizaron como se ha comentado tres métodos de dispersión:

- $\quad$ Baño de ultrasonidos

- Homogeneizador

- Sonda ultrasonidos

\section{Dispersión mecánica con baño de ultrasonidos}

Se ha analizado el efecto del tiempo de permanencia de la suspensión en el baño de ultrasonidos sobre los valores de conductividad térmica representándose la evolución de las medidas de conductividad térmica a $40^{\circ} \mathrm{C}$ (Figura 114). Se ha observado que a medida que se incrementa el tiempo de permanencia en el baño, los valores de conductividad térmica no se incrementan e incluso se aprecia una ligera disminución de estos. Esto puede indicar una deficiente dispersión de las nanopartículas, las cuales tienen tendencia a aglomerarse y posteriormente sedimentar en el medio, disminuyendo finalmente la conductividad térmica. Este efecto se repite para las dos fracciones volumétricas estudiadas $(0,05 \%$ y $0,1 \%)$ en los nanofluidos preparados a partir de MWCNTs cortos funcionalizados comercialmente $y$ dispersados con SDS. Este hecho se observó también con los otros tipos de materiales, por lo que se puede concluir que el baño de ultrasonidos no es un buen método de dispersión ya que carece de la suficiente energía para dispersar los nanotubos. Estos resultados concuerdan con los resultados obtenidos en el estudio de porcentaje de rotura del aglomerado del material inicial explicado en el apartado 2.1.1 del presente capítulo.

\section{Dispersión mecánica con homogeneizador}

En la Tabla 28 se muestran los resultados de conductividad térmica obtenidos para una muestra (MWCNTs cortos comerciales) dispersada en el homogeneizador a distintas presiones (cuanto mayor es la presión aplicada en el equipo homogeneizador, mayor es la energía aplicada en la dispersión de las partículas en el medio). Estos ensayos se realizaron todos con el mismo número de pasadas (10 pasadas) en el proceso de recirculación de la muestra en el equipo. 
Los estudios de dispersión en el homogeneizador se realizaron con muestras de nanofluidos preparadas a distintas fracciones, resultando óptima la presión de 1250 bar, con la que se obtuvieron los valores de conductividad térmica más altos, como puede observarse en la Tabla 28.

Tabla 28. Influencia de la presión aplicada en el homogeneizador en la dispersión de nanofluidos MWCNTs $\Phi=0,01 \%$

\begin{tabular}{cc}
\hline Presión aplicada en la homogeneización & Conductividad térmica a $40^{\circ} \mathrm{C}$ \\
( bar) & $k(\mathrm{~W} / \mathrm{m} \mathrm{K})$ \\
\hline 850 & $0,688 \pm 0,004$ \\
1250 & $0,693 \pm 0,005$ \\
1450 & $0,690 \pm 0,005$ \\
\hline
\end{tabular}

Una vez establecida la presión óptima en 1250 bar, se estudió el efecto del número de pasadas sobre la conductividad, (Figura 115). Estos ensayos se realizaron para los MWCNTs cortos funcionalizados comerciales a dos fracciones volumétricas, $(0,05 \%$ y 0,1\%) midiéndose la conductividad térmica a dos temperaturas ( 25 y $40^{\circ} \mathrm{C}$ ). Para los dos nanofluidos preparados en estas condiciones, a medida que se aumenta el número de pasadas en el homogeneizador (realizadas a 1250 bar de presión) se observa cómo se consigue un aumento en los valores de conductividad térmica, posiblemente por una mejor dispersión de los nanotubos en el agua. Tras el análisis de los resultados puede concluirse que los valores más altos de conductividad térmica se obtienen con una homogeneización de las partículas a presión mayor de 1200 bar y un número de pasadas alto (20 pasadas). Sin embargo, hay que añadir que en estas condiciones de trabajo se produce un desgaste excesivo de la válvula de paso del equipo haciendo inviable su aplicación técnica. Por este motivo este equipo no se considera óptimo para la dispersión mecánica de este tipo de nanofluidos con nanotubos. 


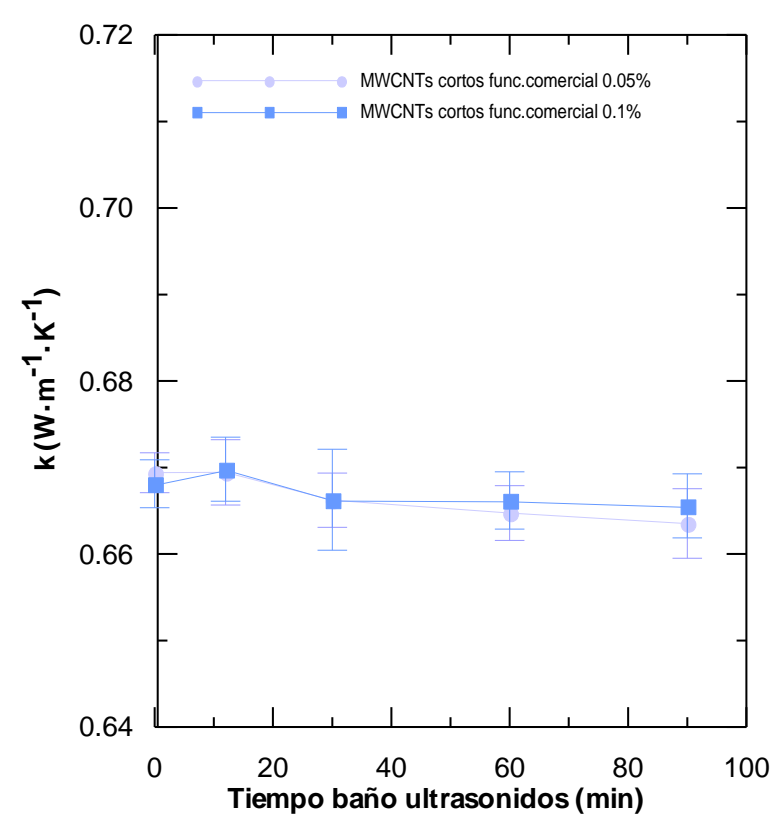

Figura 114. Conductividad térmica de nanofluidos en función del tiempo de agitación en el baño de ultrasonidos

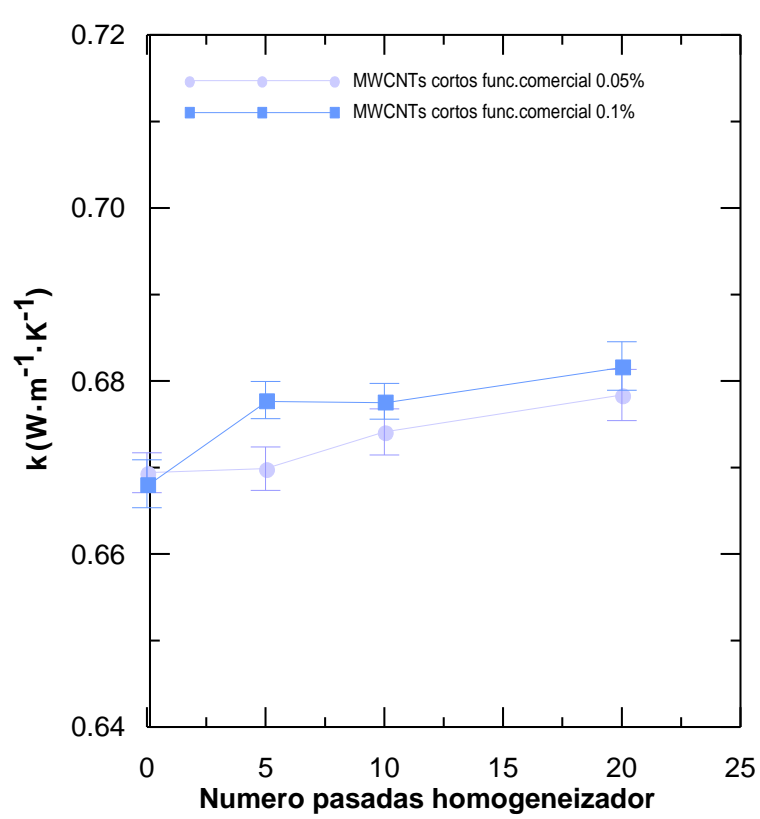

Figura 115. Conductividad térmica de nanofluidos en función del número de pasadas en el homogeneizador

\section{Dispersión mecánica con sonda de ultrasonidos}

La dispersión mecánica con sonda de ultrasonidos es el método más usado en la bibliografía consultada para la preparación de nanofluidos [5]. La elevada energía aplicada permite dispersar las nanopartículas en el medio, aunque en el caso de los nanotubos (material con un diámetro de tamaño nanométrico, pero con una longitud en el orden de las micras), un valor excesivo de energía aplicada puede conducir a una fragmentación de la longitud de los nanotubos ya dispersos y a una modificación final de sus propiedades. Por esta razón se decidió realizar un estudio del efecto del tiempo de aplicación de los ultrasonidos sobre las propiedades finales de los nanofluidos obtenidos en dichas condiciones.

En la Figura 116 se puede observar el efecto del tiempo de aplicación de la sonda de ultrasonidos sobre los valores de conductividad térmica. Estos ensayos se realizaron para los MWCNTs cortos funcionalizados comerciales a dos fracciones volumétricas $(0,01 \%$ y 0,05\%). Además, también se estudió el efecto de la utilización del surfactante SDS.

Cuando se utiliza como método de dispersión la sonda de ultrasonidos y se incrementa el tiempo de aplicación se observa como este tiempo es crítico pues, aunque se ha comprobado que aumentos de 2 minutos a 12 minutos mejoran la conductividad, tiempos largos de 
aplicación tienen un efecto negativo. Esta bajada en conductividad térmica puede deberse, según la bibliografía consultada [15 y 16], a dos posibles causas:

- Una rotura de los nanotubos debido a la elevada energía aplicada con los ultrasonidos.

- Una aglomeración de las nanopartículas dispersas debido al aumento de las interacciones entre ellas por la energía aplicada con los ultrasonidos.

Las muestras preparadas con la sonda de ultrasonidos a las que se les ha añadido un surfactante siempre muestran valores más altos de conductividad térmica si se comparan con los nanofluidos que no llevan el surfactante, Figura 116, pues dicho aditivo impide la reaglomeración de las nanopartículas ya dispersas. De esta forma el segundo efecto de aglomeración por un exceso de aplicación de energía se reduce.

En la Figura 117 se ha representado conjuntamente los aumentos relativos en conductividad térmica respecto al agua de los nanofluidos preparados con las tres técnicas de dispersión. EI estudio se realizó con los MWCNTs cortos funcionalizados comerciales a dos fracciones volumétricas $(0,05$ y $0,1 \%)$.

De los resultados en aumento de conductividad térmica representados pueden extraerse las siguientes conclusiones:

- Entre las técnicas de dispersión estudiadas los aumentos de conductividad térmica son mayores en el homogeneizador (en condiciones óptimas 1250 bar y 20 pasadas) y la sonda de ultrasonidos (tiempo de aplicación 12 min.).

- Los valores más altos se obtienen cuando además de las técnicas de dispersión (homogeneizador y ultrasonidos) se añade un surfactante a la suspensión (en este caso el SDS).

- A medida que se aumenta la fracción volumétrica de los nanotubos los aumentos en conductividad térmica son mayores.

Se puede concluir que la mejor técnica a utilizar para lograr una buena dispersión de los nanotubos y por tanto mayores aumentos relativos en conductividad térmica es la sonda de ultrasonidos, ya que, aunque con el homogeneizador se alcanzan resultados equivalentes, el desgaste producido en la válvula del equipo hace inviable su aplicación (Figura 118). La 
dispersión alcanzada con el baño de ultrasonidos es muy inferior, dando como resultado menores incrementos relativos por lo cual esta técnica no se considera adecuada para la preparación de nanofluidos con nanotubos.

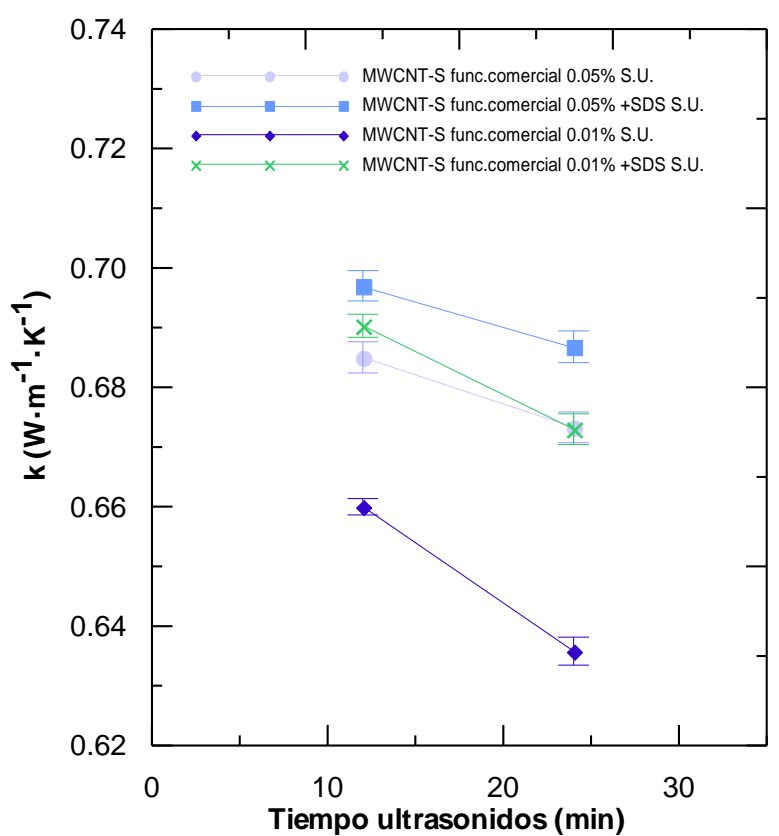

Figura 116. Conductividad térmica de nanofluidos MWCNTs cortos Func.comercial en función del tiempo de aplicación de la sonda de ultrasonidos

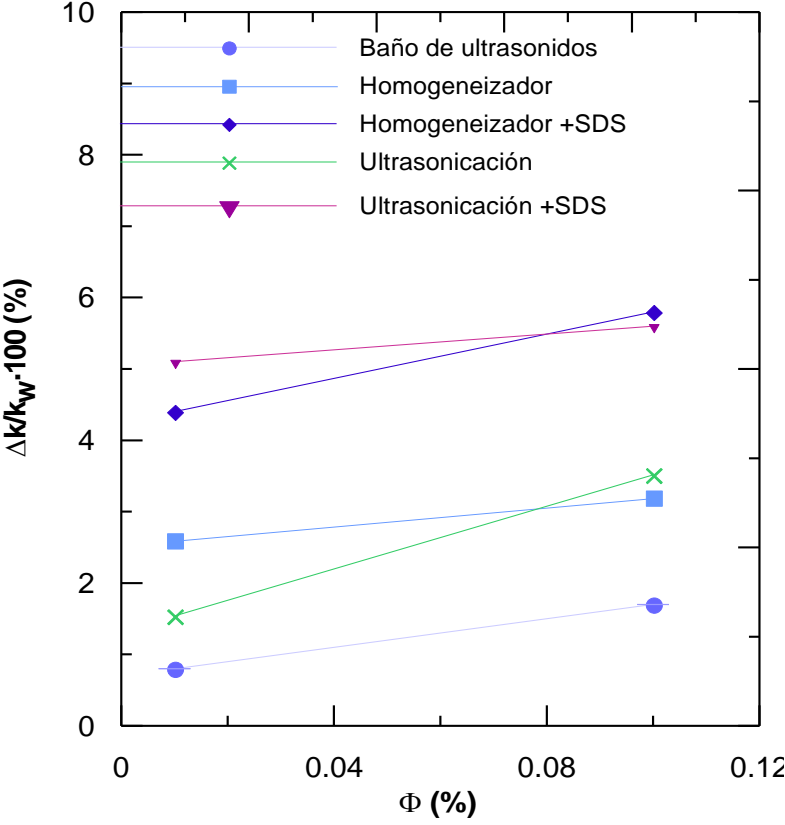

Figura 117. Incremento de conductividad térmica en nanofluidos preparados con MWCNTs cortos Func.comercial , según la técnica de dispersión utilizada

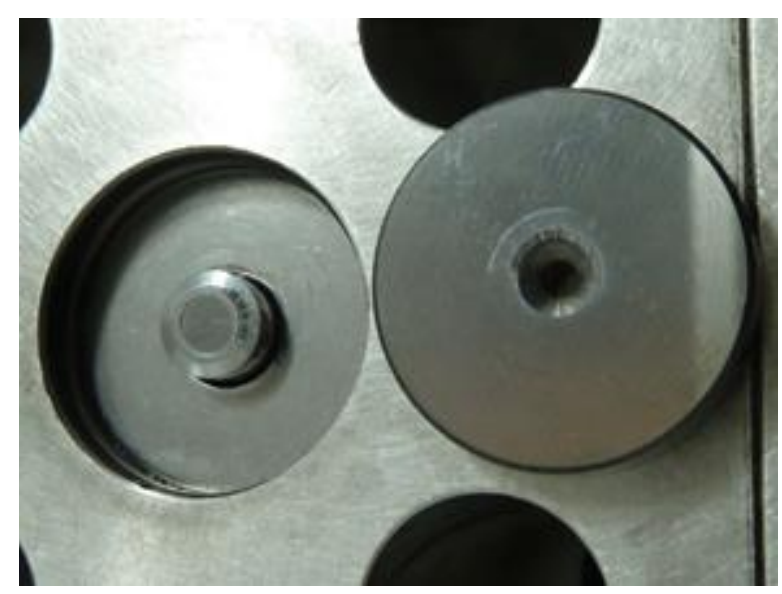

Figura 118. Imagen del desgaste de la válvula del equipo Homogeneizador 


\subsubsection{Influencia de la naturaleza del surfactante sobre la conductividad térmica}

En este apartado se resumen los resultados de conductividad térmica obtenidos en nanofluidos preparados mediante la adición de surfactantes y posterior dispersión mecánica en ultrasonidos. Los distintos tipos de surfactantes utilizados en la preparación de los nanofluidos de nanotubos han sido:

- $\quad$ Surfactante tipo no-iónico: Goma arábiga (G.A.)

- $\quad$ Surfactante tipo catiónico: Bromuro de cetiltrimetilamonio (CTAB)

- Surfactante tipo aniónico: Dodecilsulfato sódico (SDS)

En la Figura 119 se han representado los aumentos porcentuales de conductividad térmica

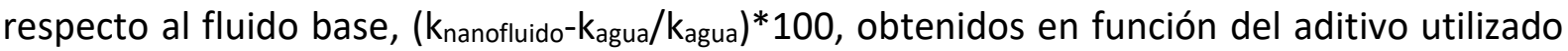
en la dispersión de los nanotubos. El estudio de la adición de surfactantes con el objetivo de modificar la superficie del material base se llevó a cabo con los nanotubos MWCNTs cortos. De entre los surfactantes estudiados el que mejores resultados ha dado en las cantidades adicionadas, ha sido la goma arábiga. Aunque el CTAB podría aumentar su efecto si se introduce en mayor cantidad, este presentó problemas de generación de espuma. Las cantidades de aditivo ensayadas han sido las documentadas en la bibliografía, [5, 17, 27 y 28], ya que cantidades insuficientes pueden no recubrir totalmente la superficie de las partículas.

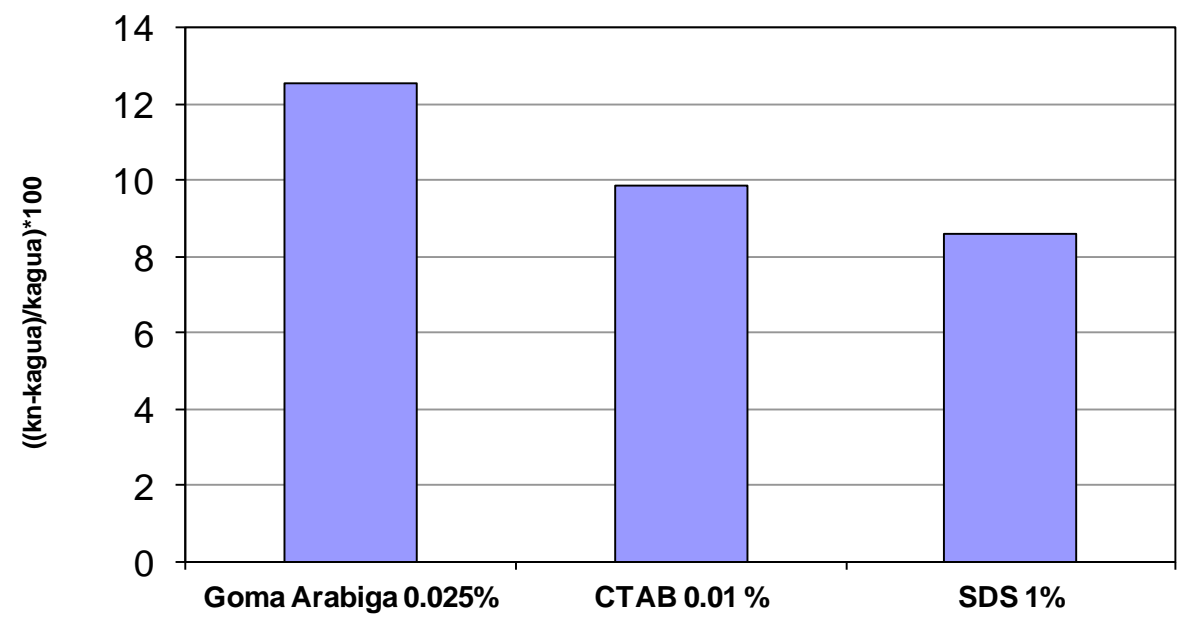

Figura 119. Aumentos relativos en conductividad térmica de los nanofluidos al $0,1 \%$ preparados con MWCNTs cortos en función del tipo de surfactante utilizado en la aplicación de ultrasonidos a $40^{\circ} \mathrm{C}$.

Un factor a considerar cuando se utilizan surfactantes es la degradación de su efecto con la temperatura (por ejemplo, a temperaturas mayores a $60^{\circ} \mathrm{C}$ ), ya que el enlace entre 
surfactante y nanopartícula puede dañarse [6]. Este problema puede darse también durante la preparación de los nanofluidos con sonda ultrasónica, donde las temperaturas alcanzadas son altas si no se refrigera la muestra durante la sonicación.

2.2.3 Influencia de la fracción volumétrica y la temperatura de trabajo sobre la conductividad térmica

Una vez fijado como sistema óptimo de dispersión la sonda de ultrasonidos, se procedió a analizar la influencia de otras variables susceptibles de aumentar la conductividad térmica de los nanofluidos. En primer lugar, se estudió el efecto que puede tener la temperatura de ensayo en la que se mide la conductividad térmica y la fracción volumétrica de nanopartículas en el nanofluido. Dicho estudio se llevó a cabo con dos tipos de nanofluidos preparados con la sonda de ultrasonidos:

- Nanofluidos preparados a partir de MWCNTs cortos, utilizando SDS como surfactante, referenciados como nanocyl.

- MWCNTs cortos funcionalizados comercialmente, referenciados como nanoamor.

Como se aprecia en los resultados de los gráficos, Figura 120 a) y b), cuando se aumenta la fracción volumétrica de los nanotubos en el fluido base se obtiene un aumento de la conductividad térmica, siguiendo la misma tendencia que en los aumentos teóricos obtenidos en los modelos teóricos como el de Maxwell [3]. Cuando la fracción volumétrica es mayor, hay más partículas en la suspensión, lo que implica mayor movimiento browniano, más contactos entre partículas y mayor conductividad térmica. La fracción volumétrica máxima que se pudo alcanzar con este tipo de nanotubos (MWCNTs cortos + SDS) sin tener sedimentación fue de $0,2 \%$, mientras que para los MWCNTs cortos funcionalizados comercialmente fue del $0,1 \%$.

Si se analiza el efecto de la temperatura del nanofluido durante la ejecución del ensayo, se puede observar que cuando la temperatura aumenta el movimiento browniano se incrementa también, pues hay muchos más contactos entre partículas favoreciéndose los mecanismos de transferencia de calor por conducción y por tanto, incrementando el valor de conductividad térmica del nanofluido. Dicho efecto se reproduce independientemente del tipo de nanotubo dispersado. 
El efecto combinado de ambas variables (fracción y temperatura) conduce a mayores valores de conductividad térmica.

a)

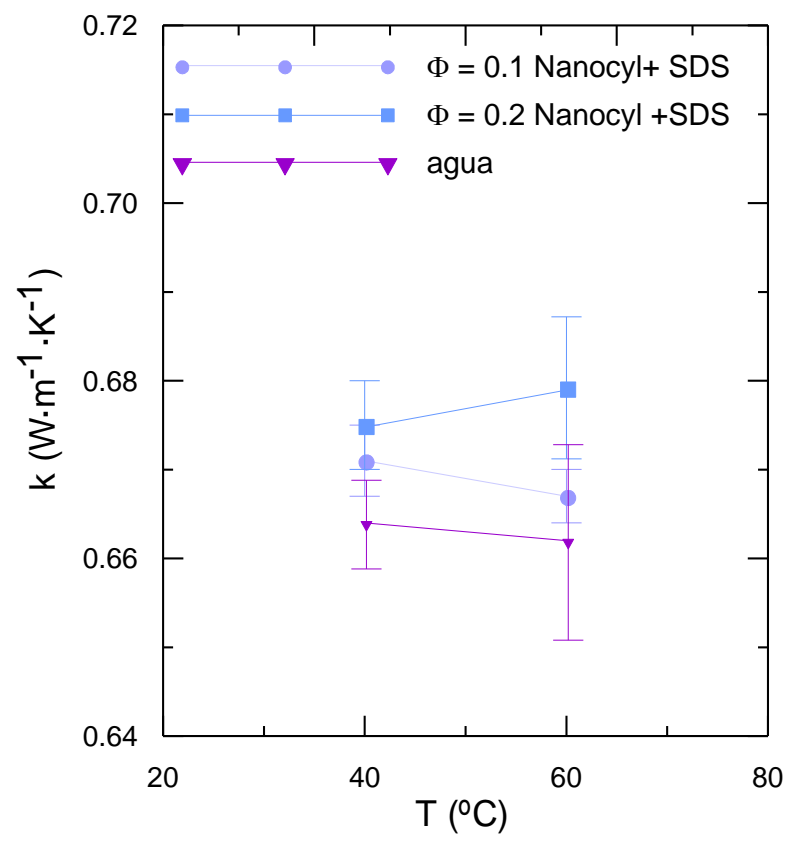

b)

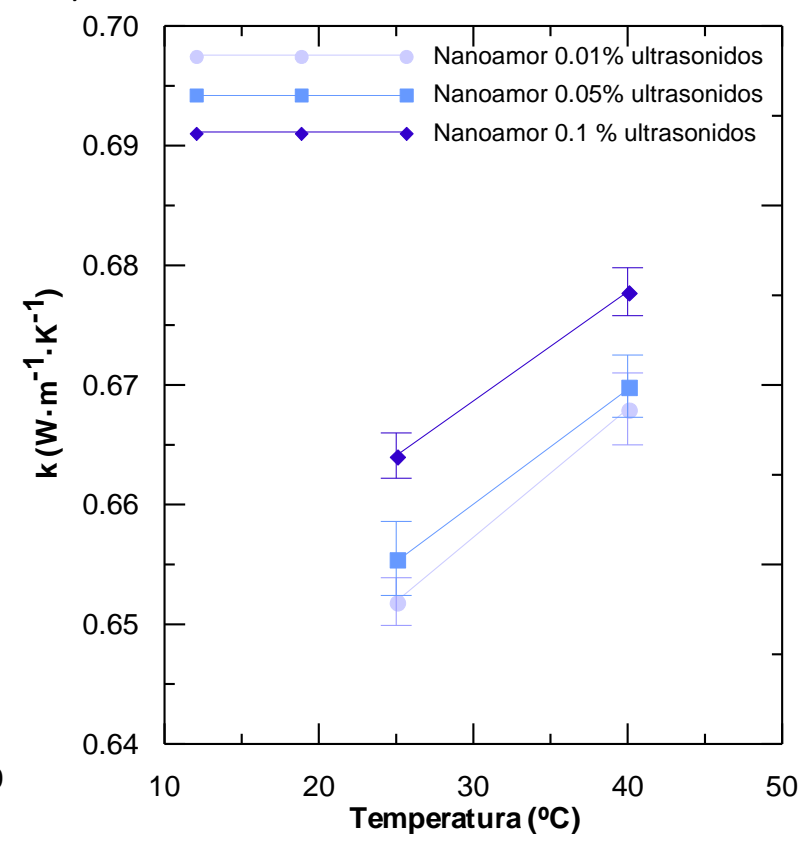

Figura 120. Conductividad térmica de nanofluidos de MWCNTs cortos a diferentes temperaturas y fracciones volumétricas a) con SDS b) funcionalizados

\subsubsection{Influencia de la tipología de nanotubo sobre la conductividad térmica}

Para realizar el estudio de la influencia de la naturaleza del nanotubo utilizado sobre el aumento en conductividad térmica del nanofluido, se han fijado las siguientes variables de preparación de los nanofluidos:

- $\quad$ Fracción volumétrica de los nanotubos en el fluido base agua $(0,1 \%)$.

- $\quad$ Sistema de dispersión mecánica (Agitación mediante sonda de ultrasonidos).

- $\quad$ Tiempo de aplicación de la sonda de ultrasonidos (12 min).

- $\quad \mathrm{pH}$ del nanofluido $(\mathrm{pH}=6)$.

- Temperatura de ensayo $\left(40^{\circ} \mathrm{C}\right)$.

- $\quad$ Tipo de surfactante (GA).

Se ha realizado el estudio de la naturaleza del material (tipo de pared múltiple o única, y longitud de los nanotubos de carbono), y del estado superficial (funcionalización de su 
superficie o modificación superficial mediante aditivo), obteniéndose los resultados que se muestran en la Tabla 29.

Como puede observarse en la Tabla 29 los peores valores de aumento relativo en conductividad térmica se han obtenido con los nanofluidos preparados a partir de MWCNTs cortos. Esto puede deberse a una incorrecta dispersión de los nanotubos en el fluido base, de hecho, los MWCNTs cortos sin funcionalizar necesitan la adición de un surfactante para evitar que sedimenten rápidamente. Esta tipología de nanotubo presentó un estado de aglomeración del material de partida elevado, con un tamaño de aglomerado de $500 \mu \mathrm{m}$. Además, al caracterizar el índice de rotura de aglomerado se observó que presentaban valores bajos, de un $83 \%$ tras 20 minutos de aplicación de ultrasonidos, con gran resistencia a romperse cuando se dispersa mediante agitación mecánica (Tabla 27). Con los MWCNTs cortos funcionalizados comercialmente no se obtienen mejores resultados como puede observarse en la tabla, pues como ya se ha demostrado en los espectros obtenidos en su caracterización con FT-IR, estos nanotubos presentaban una funcionalización muy baja por lo cual su dispersión en base acuosa es muy deficiente. Cuando a estos nanotubos cortos de pared múltiple se les adiciona un surfactante tampoco se consigue dispersar de forma correcta los nanotubos obteniéndose valores negativos en el aumento de conductividad.

Con los nanotubos cortos funcionalizados de forma experimental en laboratorio los resultados obtenidos han sido diferentes. Con ellos si que se han conseguido aumentos en la conductividad térmica respecto al fluido base debido a una mejor dispersión de los nanotubos en el fluido base, gracias a que durante el proceso de funcionalización ácida se logró introducir mayor cantidad grupos funcionales tipo $(-\mathrm{COOH})$ que en los MWCNTs funcionalizados comercialmente, (espectros FT-IR Figura 92 ). Como se observó en los espectros FT-IR los nanotubos con funcionalización comercial no mostraron dichos grupos (-COOH), por lo que en los nanofluidos preparados con estos materiales no se obtuvieron aumentos en conductividad térmica, obteniéndose resultados iguales a los nanofluidos preparados con nanotubos cortos no funcionalizados.

Cuando la naturaleza de los nanotubos es diferente (MWCNTs largos o de pared única SWCNTS) se aprecian cambios en la conductividad térmica de los nanofluidos. Se puede observar que con los nanotubos de pared múltiple largos se obtienen aumentos en 
conductividad térmica considerables tanto cuando se utiliza surfactante como cuando se funcionaliza su superficie. Sin embargo, los mejores aumentos se consiguen con los nanotubos de pared única (SWCNTs).

La funcionalización ácida de la superficie conlleva siempre aumentos en la conductividad del nanofluido preparado, posiblemente debido a la mejor dispersión de los nanotubos al cambiar su naturaleza hidrofóbica con la incorporación de grupos funcionales. Dicho comportamiento se observa en todos los tipos de nanotubos estudiados.

Tabla 29. Comparación de los aumentos en conductividad térmica medidos en los nanofluidos preparados al $0,1 \% \Phi$ con el mismo sistema de dispersión a partir de distintos tipos de nanotubos

Aumento relativo

Tipo de muestra Conductividad térmica a $40{ }^{\circ} \mathrm{C}$

(\%)

\begin{tabular}{lc}
\hline MWCNT cortos + GA 0,25\%wt & $-4,68$ \\
MWCNT cortos +Func. comerciales & $-7,85$ \\
MWCNT cortos + Func. Ácida & 5,68 \\
MWCNT largos + GA 0,25\%wt & 2,14 \\
MWCNT largos + Func. Ácida & 8,65 \\
MWCNT largos + Func. Básica & $-5,63$ \\
SWCNT GA 0,25\%wt & 7,06 \\
SWCNTs Func. Ácida & 10,29 \\
\hline
\end{tabular}

\subsubsection{Influencia del pH del nanofluido sobre la conductividad térmica}

Para medir el efecto del potencial zeta que presenta el nanofluido sobre la conductividad térmica del mismo, se modificaron las muestras de nanofluidos con un $\mathrm{pH}=6$ a un $\mathrm{pH}$ más básico $\mathrm{pH}=8$ y $\mathrm{pH}=10$, donde los potenciales de repulsión entre partículas son mayores y por tanto puede evitarse la formación de aglomerados, mejorando de esta forma la dispersión y estabilidad de los nanofluidos preparados.

Tras la modificación de pH se midió la conductividad térmica de los siguientes nanofluidos:

- Nanofluidos preparados a partir de MWCNTs cortos funcionalizados comercial, estudiándose dos fracciones volumétricas 0,01 y 0,05 \%. 
- Nanofluidos preparados a partir de MWCNTs cortos func. comercial, estudiándose dos fracciones volumétricas 0,01 y $0,05 \%$ y con aditivo surfactante SDS.

En la Figura 121 se observa como una modificación del pH hacia valores alejados del punto isoeléctrico de la suspensión de nanotubos $(\mathrm{pH}=2)$ ayuda a mantener a las nanopartículas más dispersas aumentando finalmente la conductividad térmica del nanofluido. Si además de la estabilización mediante pH se añade un aditivo en la etapa de dispersión, el efecto es algo mayor (Figura 121 b).
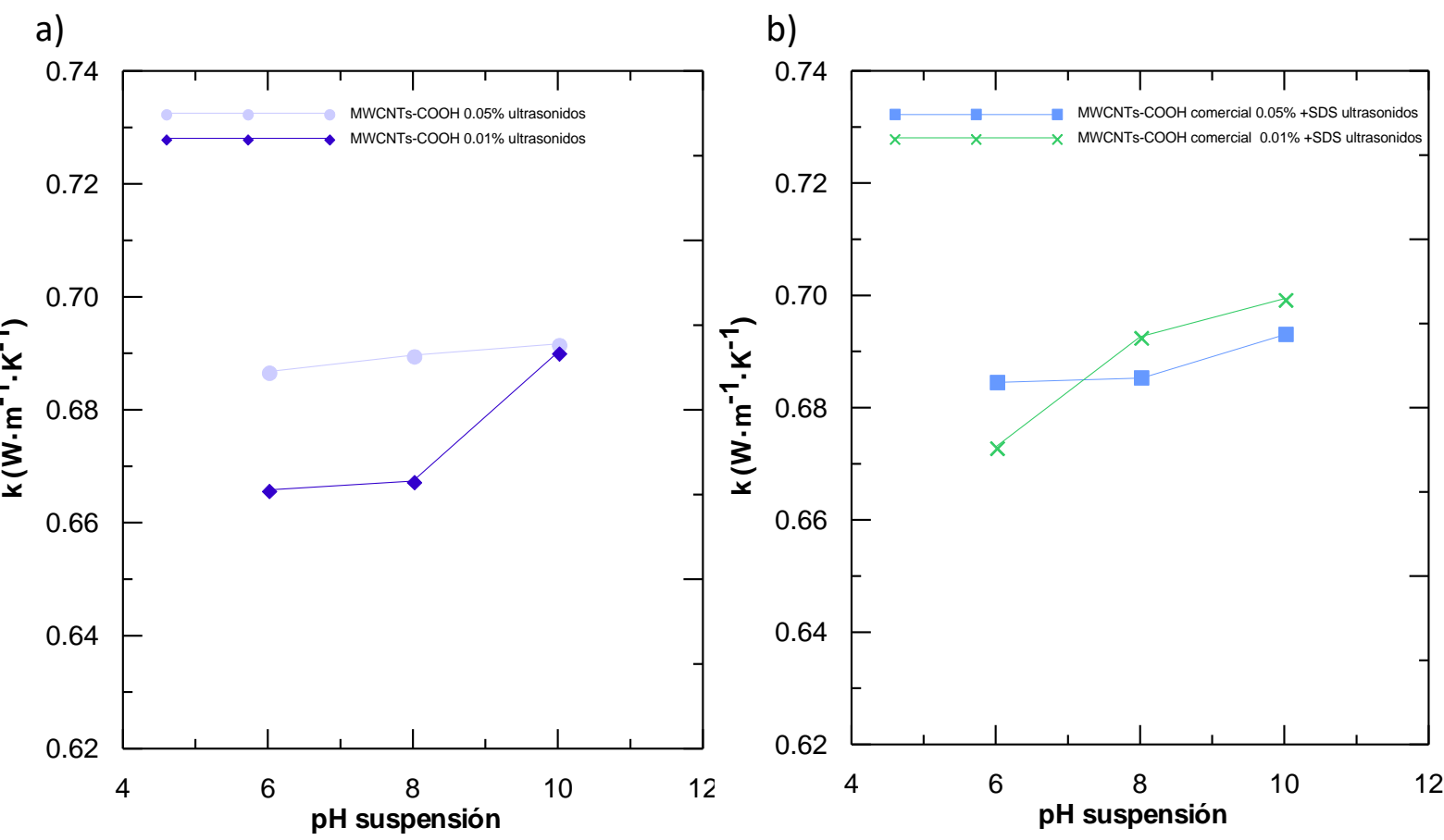

Figura 121. Influencia pH sobre la conductividad térmica de nanofluidos preparados con MWCNTs cortos funcionalizados comerciales a) sin aditivo b) con SDS

Tras la observación de los resultados en conductividad puede concluirse que un ajuste del pH de la suspensión a pH básicos $(\mathrm{pH}=10)$ alejados del punto isoeléctrico conducen a una mejor dispersión de los nanotubos y por tanto a unos valores de conductividad más elevados.

\subsection{Resultados de la medida de la viscosidad de los nanofluidos preparados con nanotubos}

La medida de la viscosidad de los nanofluidos preparados con nanotubos de carbono se ha llevado a cabo utilizándose un reómetro rotacional, siguiendo el procedimiento descrito en el apartado 3.3. del capítulo III. Se ha realizado un estudio con los resultados obtenidos para 
cada uno de los nanofluidos preparados con el objetivo de analizar la influencia que puede tener las variables de proceso (método de dispersión, fracción volumétrica, tipo de surfactante, tipología de material) sobre la viscosidad final del nanofluido, comparándose los reogramas medidos a una temperatura de ensayo de $40^{\circ} \mathrm{C}$.

2.3.1 Influencia del método de dispersión mecánica y del tipo de surfactante sobre la viscosidad del nanofluido

Como se puede observar en la Figura 122, el valor de la viscosidad medido en las suspensiones preparadas con los dos métodos de dispersión (sonda de ultrasonidos y homogeneizador) es muy similar. En suspensiones tan diluidas y bien dispersas el nanofluido presenta un comportamiento newtoniano hasta gradientes de velocidad de $300 \mathrm{~s}^{-1}$. A partir de estos gradientes de velocidad, se observa un ligero cambio en el comportamiento de los nanofluidos subiendo ligeramente los valores de viscosidad.

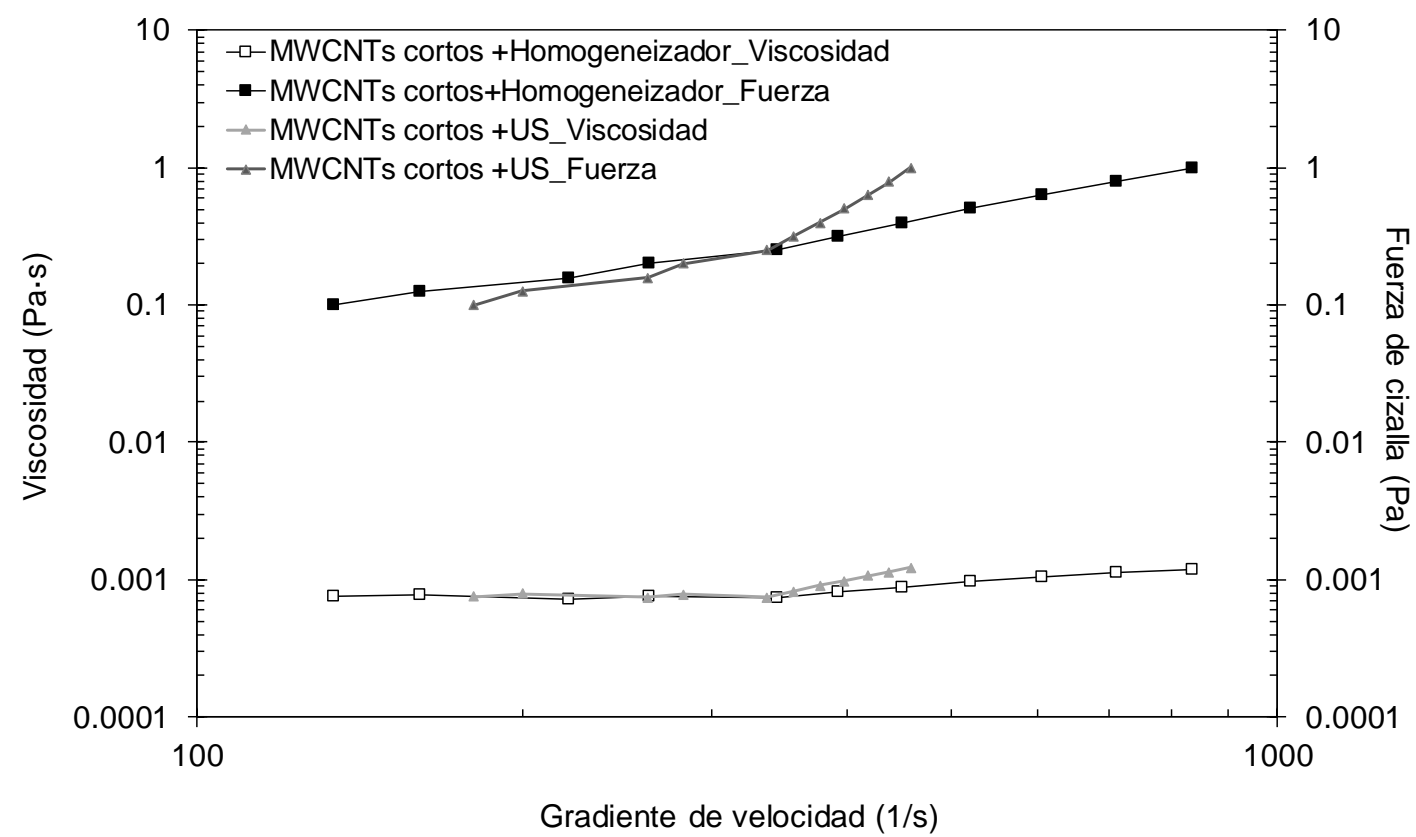

Figura 122. Comparación viscosidades de los nanofluidos preparados con sonda ultrasonidos y con homogeneizador. Nanofluido MWCNTs cortos func.comerciales $0,1 \%$ sin surfactante.

En la Figura 123 se ha analizado la influencia del tiempo de aplicación de la sonda de ultrasonidos sobre la viscosidad de los nanofluidos preparados con y sin surfactante. En los nanofluidos preparados sin surfactante, con una viscosidad muy por encima de la del agua, se observa como la viscosidad es menor a medida que se aumenta el tiempo de ultrasonidos, 
como se observa en la serie "cortos func 24 US" con 24 minutos de sonda de US al compararla con la serie "cortos func 12 US" con 12 minutos de sonda de US, debido a una mejor dispersión. El comportamiento que muestran esta tipología de nanofluidos de MWCNTs cortos func. comercial es pseudoplástico, debido posiblemente a la ruptura progresiva de los flóculos presentes a bajas cizallas a medida que se incrementa la velocidad [30].

Cuando los nanofluidos se preparan con la sonda de ultrasonidos con la adición de surfactante, estas suspensiones se comportan como fluidos newtonianos, bajando la viscosidad debido a la incorporación de cargas estáticas en la superficie de las nanopartículas con la adición del surfactante que favorecen el mecanismo de repulsión electrostática. Para suspensiones bien estabilizadas o con bajas fracciones volumétricas, $\Phi=0,01 \%$, la reología está gobernada por el movimiento browniano y por tanto el comportamiento del nanofluido en esos casos es newtoniano, con baja viscosidad.

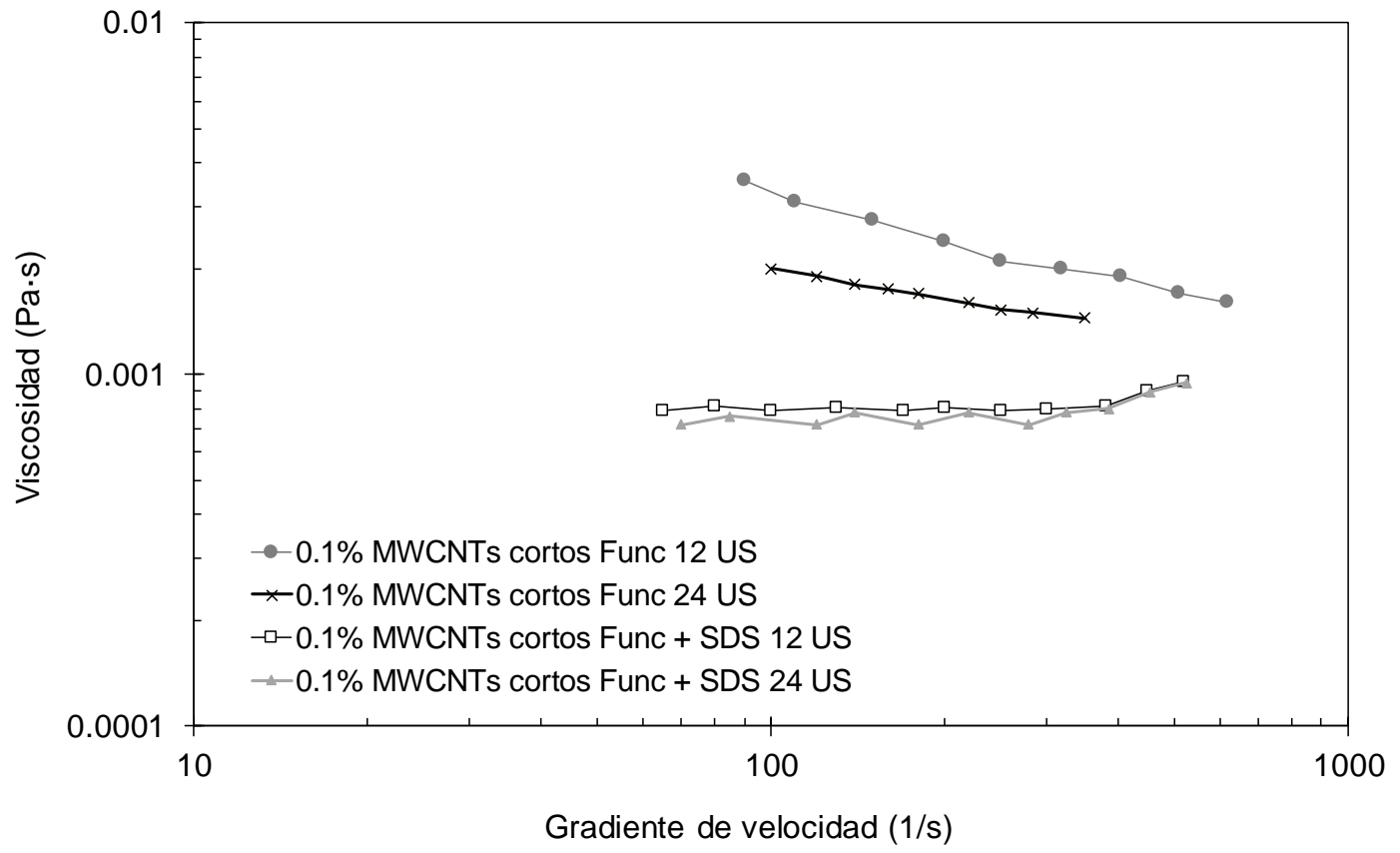

Figura 123. Influencia del tiempo de ultrasonidos sobre la viscosidad para nanofluido MWCNTs cortos func.comerciales $0,1 \%$ con y $\sin$ surfactante

Cuando se utilizan los surfactantes las partículas de nanotubos se encuentran más estables debido a esta repulsión electrostática por lo que con un tiempo de aplicación de ultrasonidos de 12 minutos se alcanzan viscosidades ya bajas y un incremento del tiempo de aplicación no 
conlleva a una disminución de la viscosidad como se había observado en los nanofluidos preparados sin surfactantes.

Cuando en lugar de la sonda de ultrasonidos se utiliza el homogeneizador, (Figura 124), los resultados obtenidos son similares. Los valores obtenidos de viscosidad permanecen constantes, pero cuando el gradiente de velocidad aplicado supera los $300 \mathrm{~s}^{-1}$, se observa un ligero incremento en los valores de viscosidad independientemente del método de dispersión utilizado.

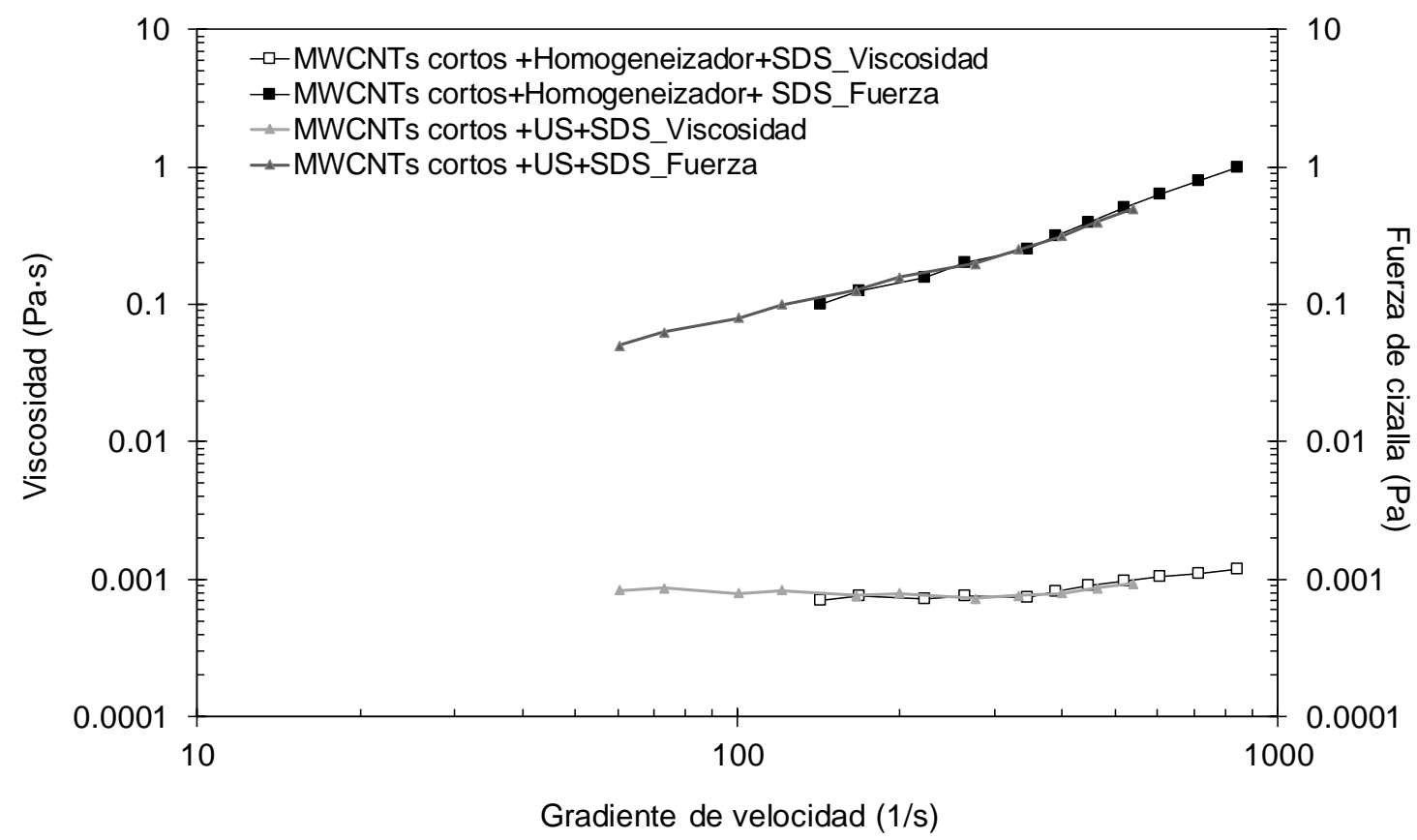

Figura 124. Comparación viscosidades de los nanofluidos preparados con sonda ultrasonidos y con homogeneizador. Nanofluido MWCNTs cortos func. Comerciales $0,1 \%$ con surfactante SDS.

En la Tabla 30 se muestran los aumentos relativos de viscosidad para los dos métodos de dispersión utilizados en el estudio. Ambas suspensiones, a una fracción volumétrica del 0,1 \%, presentan una viscosidad muy parecida al agua, obteniéndose un menor incremento en viscosidad en las suspensiones preparadas con sonda de ultrasonidos. 
Tabla 30. Aumento relativo de la viscosidad en función del sistema de dispersión para los MWCNTs cortos funcionalizados comerciales, medidas realizadas a $40^{\circ} \mathrm{C}$

\begin{tabular}{lcc}
\hline \multicolumn{1}{c}{ Tipo de muestra } & $\begin{array}{c}\text { Promedio de la viscosidad } \\
\text { (Pa.s) }\end{array}$ & $\begin{array}{c}\text { Aumento relativo respecto a la } \\
\text { viscosidad del agua (\%) }\end{array}$ \\
\hline Agua & $7,5 \mathrm{E}-04 \pm 0,9 \mathrm{E}-05$ & - \\
0,1_ultrasonidos+SDS & $8,2 \mathrm{E}-04 \pm 1,4 \mathrm{E}-05$ & 7 \\
0,1_homogeneizadorx10_SDS & $8,9 \mathrm{E}-04 \pm 1,9 \mathrm{E}-05$ & 15 \\
\hline
\end{tabular}

\subsubsection{Influencia de la fracción volumétrica sobre la viscosidad}

Se ha realizado el estudio del efecto de la fracción volumétrica del nanofluido sobre la viscosidad en nanofluidos preparados a partir de nanotubos MWCNTS funcionalizados comerciales (Nanoamor). Como se observa en la Figura 125 a medida que se incrementa la fracción volumétrica de nanotubos en el fluido, la viscosidad de la suspensión se incrementa ligeramente. Este aumento de viscosidad puede estar ocasionado por un mayor número de contactos entre las partículas y la influencia de estas interacciones no se puede despreciar pues la reología está gobernada por las fuerzas entre las partículas. [4,17].

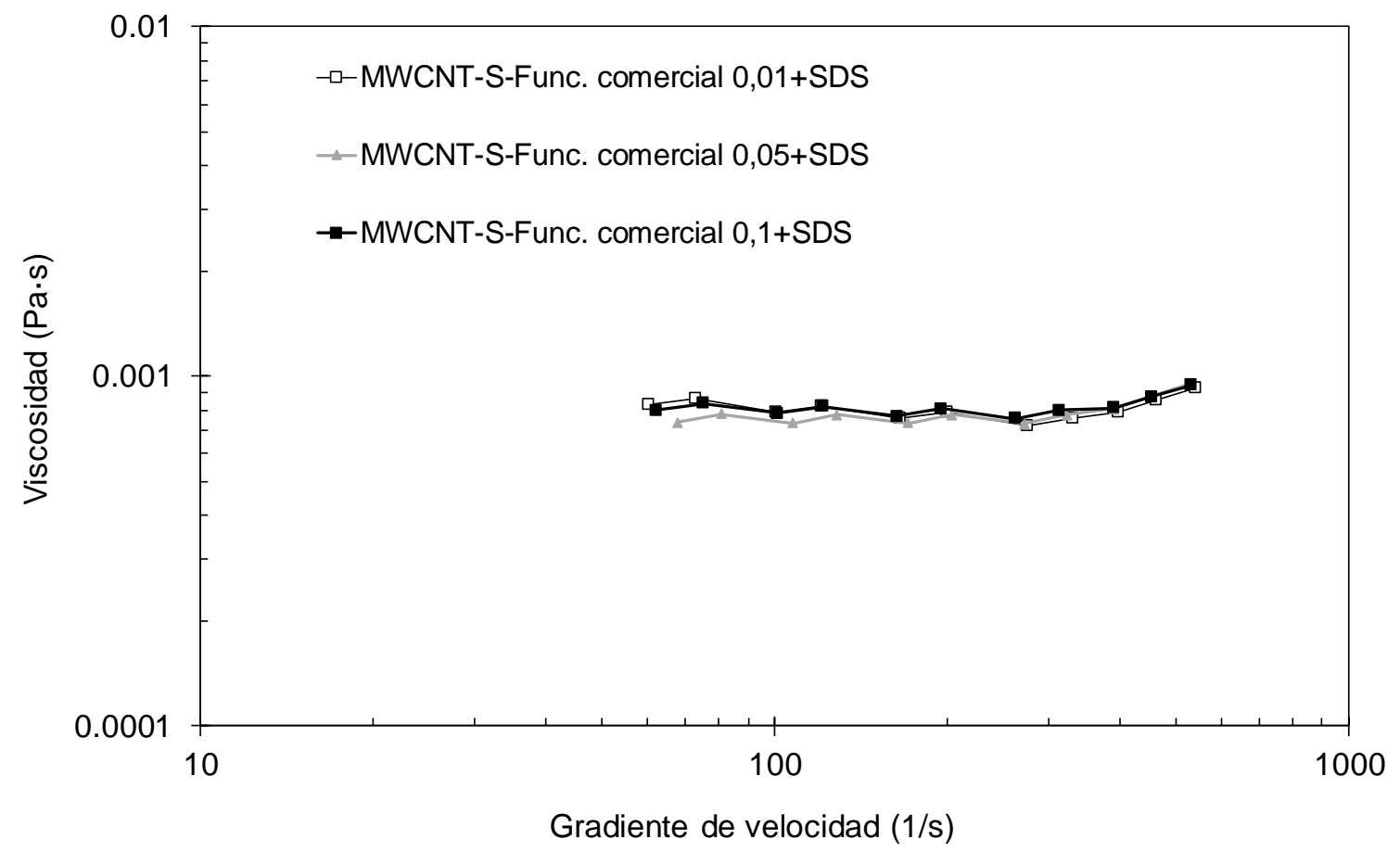

Figura 125. Comparación de los valores de viscosidad a distintas fracciones volumétricas para nanofluidos preparados por US a partir de MWCNTs cortos funcionalización comercial 
El efecto del aumento en fracción volumétrica en estos nanofluidos no ha ocasionado un incremento tan elevado en los valores de viscosidad como el observado con los nanofluidos preparados a partir de óxidos cerámicos, muy posiblemente porque no se han podido preparar nanofluidos con nanotubos a elevadas fracciones volumétricas ( 1 y $5 \%$ ).

\subsubsection{Influencia de la tipología de nanotubo sobre la viscosidad}

Para analizar el efecto del tipo de material en la viscosidad de los nanofluidos en primer lugar se han comparado dos tipos de nanotubos cortos (funcionalizados y no funcionalizados), utilizándose el mismo procedimiento de preparación (ultrasonidos U.S. más adición de surfactante SDS). Ambas suspensiones preparadas a una misma fracción volumétrica de 0,1\% y con la adición de surfactante presentan comportamiento newtoniano hasta gradientes de velocidad de $400 \mathrm{~s}^{-1}$, donde empiezan a mostrar carácter dilatante (Figura 126). Estos dos materiales presentan viscosidades parecidas en el tramo newtoniano (viscosidad constante) pero se puede apreciar que el material funcionalizado comercialmente tiene una viscosidad más baja debido posiblemente a que los grupos funcionales del material permiten una reducción de las fuerzas atractivas de Van der Waals, y una mayor separación de las partículas, sin aglomerados [31].

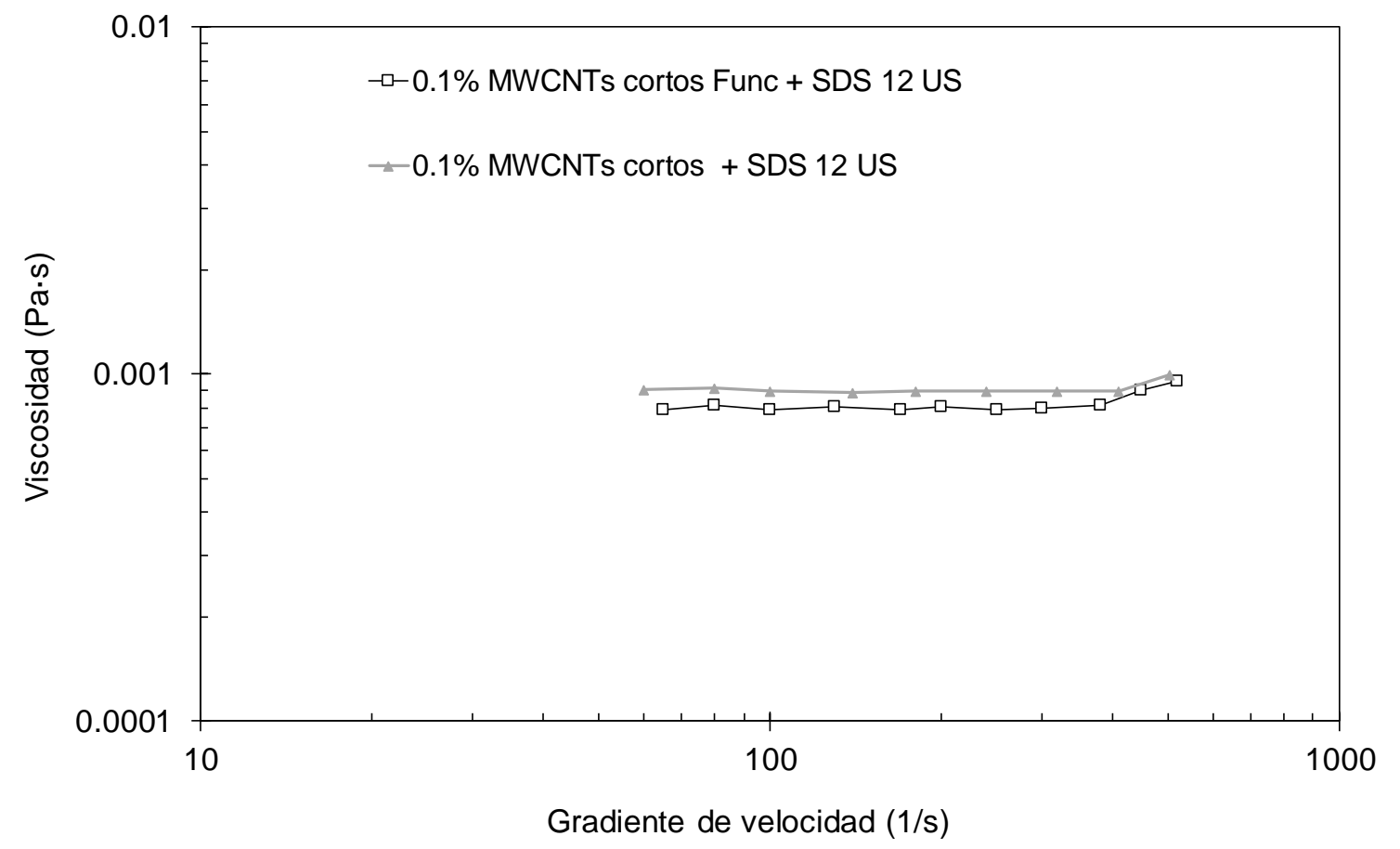

Figura 126. Influencia del tipo de material para suspensiones preparadas con la sonda ultrasónica 
En la Tabla 31 se muestran los aumentos relativos en viscosidad obtenidos con los distintos tipos de nanotubos comparados (todos a la misma fracción volumétrica $0,1 \%$ ). Los nanofluidos preparados con nanotubos de carbono de pared múltiple largos (MWCNTs largos) presentan una viscosidad mayor que los preparados con nanotubos cortos (aumentos de un $29 \%$ frente a un aumento del $18 \%$ ), posiblemente debido a que su mayor longitud implica un mayor número de contactos, como han constatado otros autores como Timofeeva et al. [52]. Cuando los nanofluidos se preparan a partir de nanotubos de carbono de pared única (SWCNTs) que también son largos, su viscosidad (23\%), también es mayor que la obtenida con los nanotubos cortos pero menor que los de pared múltiple, debido a que en un mismo volumen al tener solo una capa, la superficie de material de carbono para un mismo volumen es menor que en los nanotubos multicapa. Los aumentos en conductividad térmica obtenidos en los nanofluidos con esta tipología de nanotubos largos o de pared única preparados con surfactante han sido significativos (aumentos del $2 \%$ y $7 \%$ respectivamente, Tabla 29 ,) sin embargo los aumentos en viscosidad pueden dificultar su aplicación como fluido calotransportador.

Tabla 31. Aumento relativo de la viscosidad en función del tipo de material. Ensayos a $40^{\circ} \mathrm{C}$

\begin{tabular}{lcc}
\hline \multicolumn{1}{c}{ Tipo de muestra } & $\begin{array}{c}\text { Promedio de la } \\
\text { viscosidad (Pa.s) }\end{array}$ & $\begin{array}{c}\text { Aumento relativo } \\
\text { viscosidad (\%) }\end{array}$ \\
\hline Agua & $7,5 \mathrm{E}-04 \pm 0,9 \mathrm{E}-05$ & - \\
MWCNTs cortos 0,1+SDS & $9,2 \mathrm{E}-04 \pm 1,1 \mathrm{E}-05$ & 18 \\
MWCNTs cortos func.comercial 0,1+SDS & $8,1 \mathrm{E}-04 \pm 1.5 \mathrm{E}-05$ & 7 \\
MWCNTs largos 0,1 +SDS & $9,7 \mathrm{E}-04 \pm 1,4 \mathrm{E}-05$ & 29 \\
SWCNTs 0,1 +SDS & $9,3 \mathrm{E}-04 \pm 1,3 \mathrm{E}-05$ & 23 \\
\hline
\end{tabular}




\section{Preparación y caracterización de los nanofluidos preparados con} nanopartículas de grafeno

Debido a la naturaleza hidrofóbica de las nanopartículas de grafeno, la dispersión de este tipo de nanopartículas en base acuosa no resulta fácil, por lo que es necesario aplicar métodos adicionales a la agitación mecánica que ayuden a mejorar la dispersión. En este apartado se describen los resultados obtenidos tras la aplicación de distintos métodos para la preparación de los nanofluidos de grafeno, como la dispersión mecánica aplicada a diferentes intensidades y la funcionalización covalente y no covalente de las nanopartículas.

Para la preparación de los nanofluidos de grafeno se utilizaron los siguientes tipos de materiales;

- GFN750 láminas de longitud máxima 1-2 $\mu$ m y espesor entre capas 1-5 nm y superficie específica media, según el proveedor, de $750\left(\mathrm{~m}^{2} / \mathrm{g}\right)$

- GFN300, láminas de longitud máxima 1-2 $\mu$ m y espesor entre capas 1-5 nm y superficie específica, según el proveedor, de $300\left(\mathrm{~m}^{2} / \mathrm{g}\right)$.

Estos dos tipos de nanopartículas de grafeno presentan propiedades parecidas pero distinta superficie específica. Si se consigue dispersar bien las nanopartículas de grafeno en el fluido base, la superficie específica de las mismas puede jugar un papel crucial en el aumento de la conductividad térmica al favorecerse el área de transmisión. Por el contrario, dicho aumento de superficie puede incrementar las interacciones con el fluido base y dificultar la dispersión de las nanopartículas.

El proceso seguido para dispersar el grafeno hasta la fracción volumétrica deseada ha sido el siguiente:

- agitación mecánica mediante sonda de ultrasonidos

- funcionalización de la superficie de las nanopartículas

- estabilización de la suspensión mediante modificación del potencial zeta

Para poder estabilizar los nanofluidos de grafeno mediante estabilización electrostática resulta necesario que la suspensión tenga un $\mathrm{pH}=7$ para obtener un elevado potencial de 
repulsión entre partículas, Figura 127. Dicho $\mathrm{pH}$ se obtuvo al mezclar las nanopartículas de grafeno con el agua destilada, por lo cual no fue necesario un ajuste posterior del mismo.

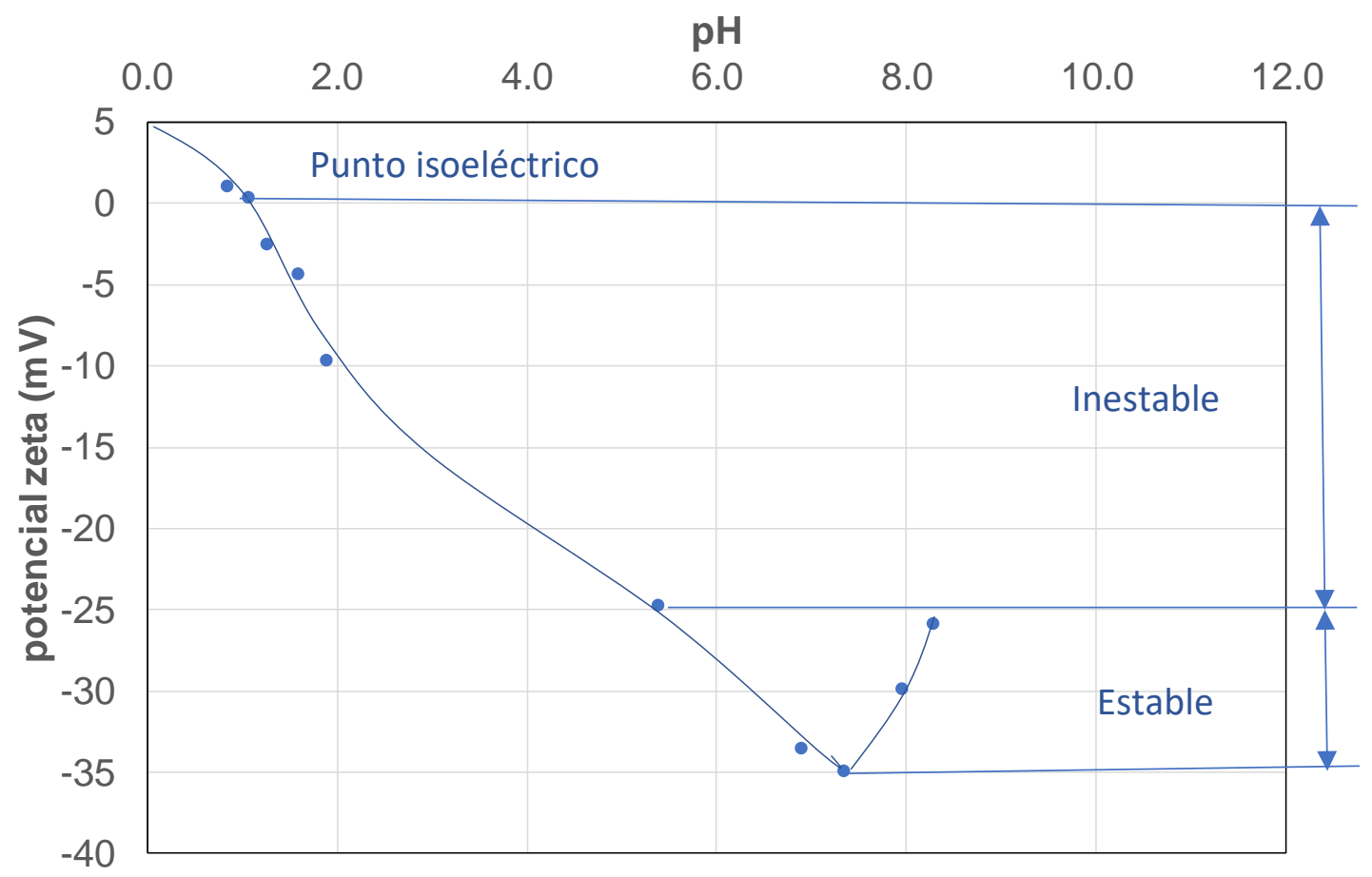

Figura 127. Potencial zeta en función del pH de la muestra GFN750 Y GFN300

En la Tabla 32 se resumen los distintos nanofluidos preparados con las nanopartículas de grafeno (GFN750 y GFN300 Capítulo III apartado materiales 1.5), indicando la fracción volumétrica, el sistema de dispersión y al proceso de estabilización aplicado. Se ha caracterizado la capacidad calorífica, viscosidad y conductividad térmica a distintas temperaturas, además de la estabilidad de los nanofluidos mediante espectrofotometría IR, así como el grado de dispersión mediante TEM y difracción láser (Malvern). 
Tabla 32. Tabla resumen de la preparación de los nanofluidos obtenidos con GFN750 y GFN300

\begin{tabular}{llcc}
\hline \multicolumn{1}{c}{ Muestra } & Sistema dispersión & $\begin{array}{c}\text { Fracción } \\
\text { volumétrica } \Phi\end{array}$ & $\begin{array}{c}\text { Relación aditivo } \\
\text { (g aditivo : g grafeno) }\end{array}$ \\
\hline GFN750 & Homogeneizador & 0,12 & - \\
GFN750 & Sonda Ultrasonidos & 0,025 & - \\
GFN750 & Sonda Ultrasonidos & 0,12 & - \\
GFN750 & Sonda Ultrasonidos & 0,25 & SDS (15:1) \\
GFN750 & Sonda Ultrasonidos & 0,025 & GA (15:1) \\
GFN750 & Sonda Ultrasonidos & 0,025 & TRITON (15:1) \\
GFN750 & Sonda Ultrasonidos & 0,025 & - \\
(*) GFN750 Fac. $1 \mathrm{~h}$ & Sonda Ultrasonidos & 0,025 & - \\
GFN750 Fac. $1 \mathrm{~h}$ & Sonda Ultrasonidos & 0,12 & - \\
GFN750 Fac. $3 \mathrm{~h}$ & Sonda Ultrasonidos & 0,025 & - \\
GFN750 Fac. $9 \mathrm{~h}$ & Sonda ultrasonidos & 0,025 & - \\
(**) GFN750 Falk. & Sonda Ultrasonidos & 0,12 & - \\
\hline GFN300 & Homogeneizador & 0,12 & - \\
GFN300 & Sonda ultrasonidos & 0,12 & - \\
GFN300 Fac. & Sonda ultrasonidos & 0,12 & - \\
\hline & Sonda ultrasonidos & 0,12 & - \\
\hline
\end{tabular}

(*)Fac : funcionalización ácida, con una duración del tratamiento de 1 hora, 3horas o 9 horas $\left({ }^{* *}\right)$ Falk:funcionalización alcalina

Para una mejor compresión de los ensayos realizados con las nanopartículas de grafeno se muestra en un diagrama de flujo el procedimiento seguido con cada tipo de óxido, Figura 128. 

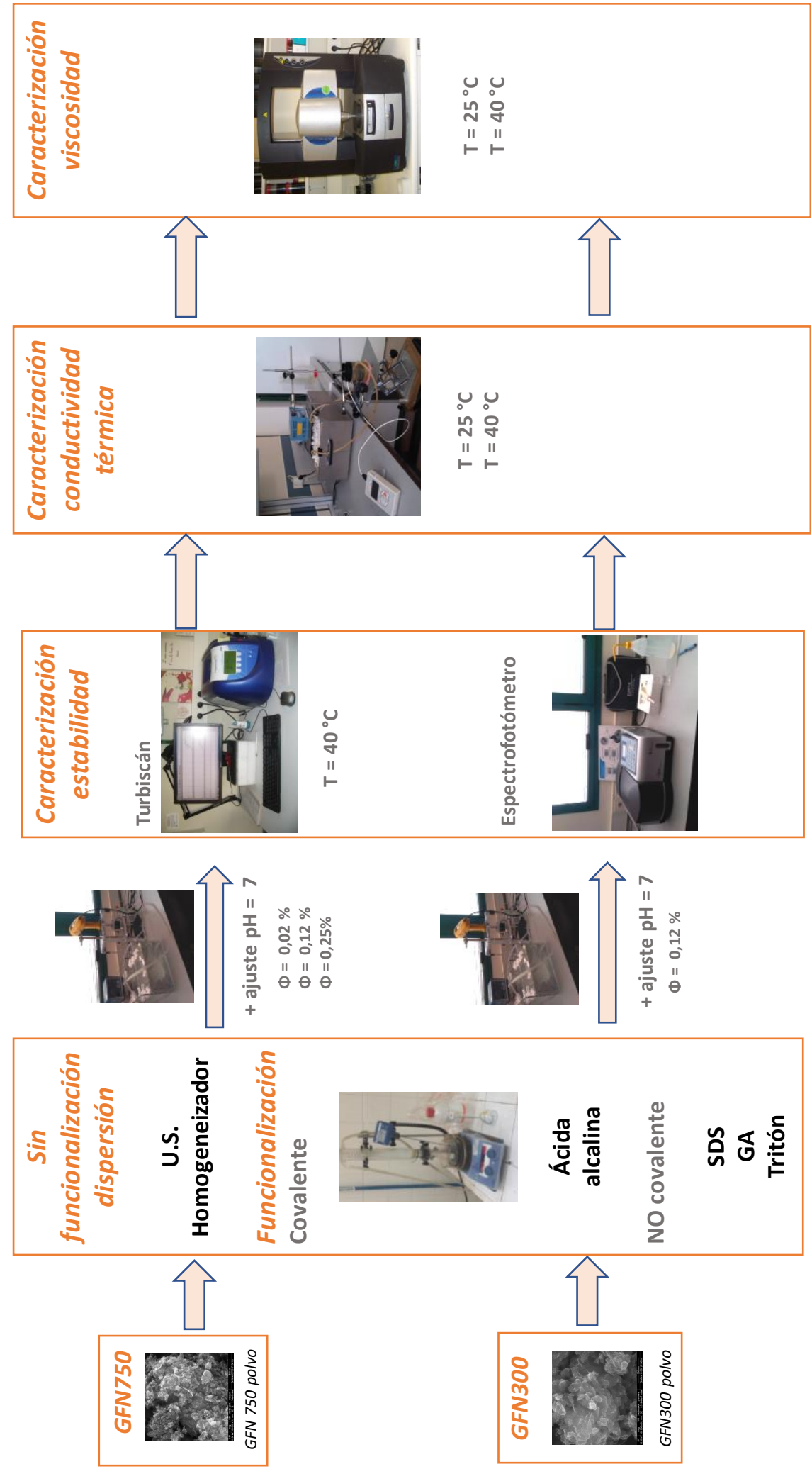

Figura 128. Diagrama de flujo donde se muestra el procedimiento seguido con cada tipo de material para la preparación y caracterización de los nanofluidos 


\subsection{Caracterización de la dispersión y estabilidad de los nanofluidos preparados con} grafeno

\subsubsection{Caracterización de las partículas de grafeno adquiridas}

El grafeno se caracteriza por presentar fuertes interacciones entre los orbitales $\pi$ de los átomos de carbono entre las láminas, por lo cual tiende a aglomerarse y a originar problemas en la dispersión del material en polvo debido a la alta resistencia de los aglomerados formados. Para poder analizar la influencia que puede tener el estado de aglomeración de las nanopartículas iniciales en la preparación de los nanofluidos se caracterizaron las nanopartículas de grafeno adquiridas (GFN750 y GFN300) y las funcionalizadas en laboratorio analizándose la forma y el tamaño de los agregados. Para dicho estudio se utilizaron dos técnicas, el análisis de imagen obtenida mediante microscopía de barrido (MEB) y el análisis de tamaño de partícula mediante difracción láser (equipo MALVERN).

\section{Análisis de imagen de las nanopartículas de grafeno}

En las figuras Figura 129 a Figura 132 se muestran las imágenes tomadas en el microscopio electrónico de barrido para cada uno de los materiales GFN750 y GFN300, a diferentes aumentos. En ellas se puede observar que en ambos tipos de material las nanopartículas se encuentran aglomeradas inicialmente (tamaños medios de aglomerado de $50 \mu \mathrm{m}$ ).

En la imagen de la Figura 132 se observan desniveles en superficie asociados a los límites de las monocapas de grafeno confirmando la disposición laminar en multicapas de la muestra. 


\section{Grafeno GFN750}

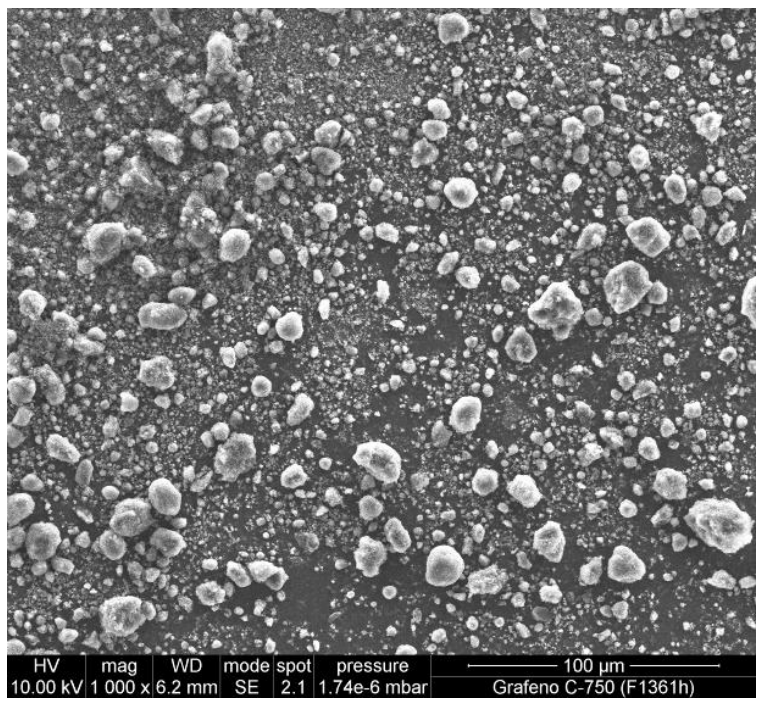

Figura 129. Imagen MEB Grafeno GFN 750 x1000 aumentos

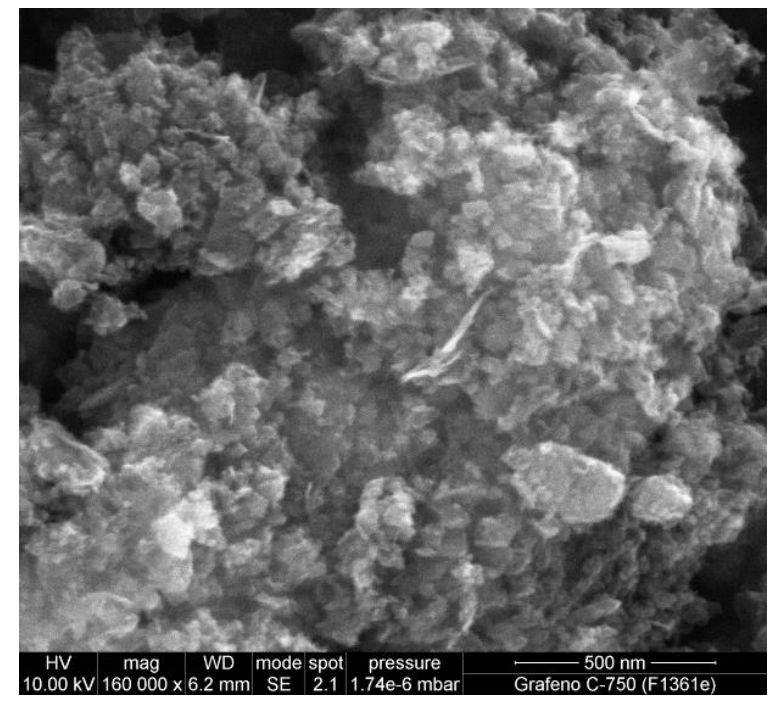

Figura 130. Imagen MEB GrafenoGFN750 x160.000 aumentos

\section{Grafeno GFN300}

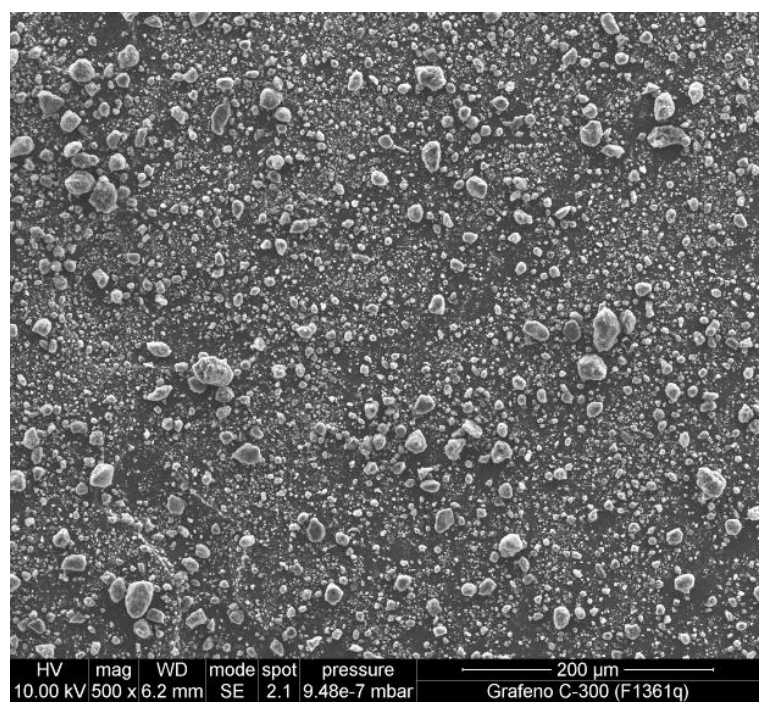

Figura 131. Imagen MEB Grafeno GFN300 x 500 aumentos

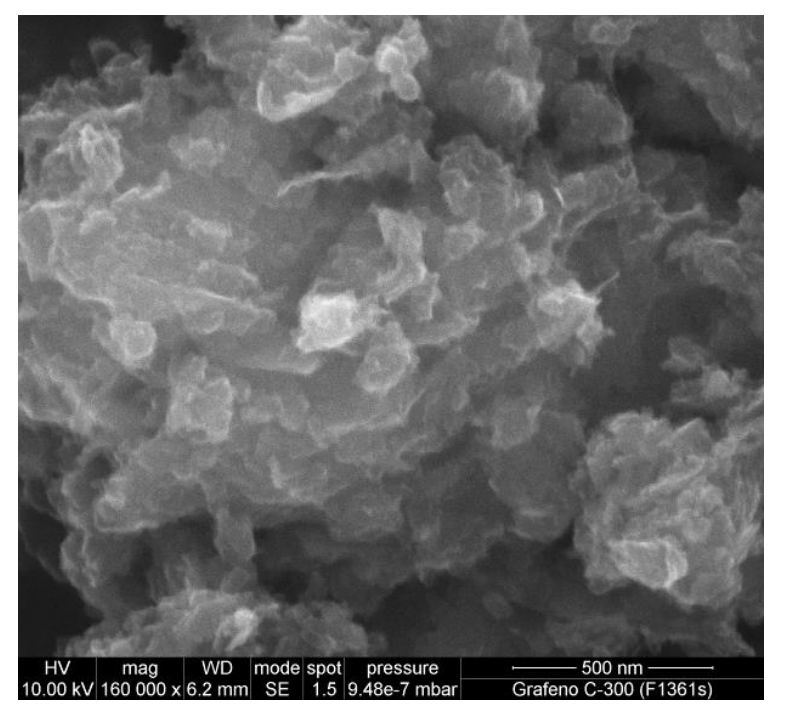

Figura 132. Imagen MEB Grafeno GFN300 x160.000 aumentos

Además de las imágenes en el microscopio electrónico de barrido, también se tomaron imágenes del grafeno en el microscopio electrónico de transmisión (TEM) donde los aumentos que se pueden alcanzar son mayores, con el objetivo de poder analizar la morfología de las láminas de grafeno adquiridas formando las monocapas.

Para la preparación de las muestras para el TEM se sonicaron los nanofluidos y se tómo una alícuota que se depositó sobre las gradillas. Los resultados más relevantes obtenidos en el 
TEM se muestran en las siguientes imágenes. En la Figura 133 se observa de forma individualizada una nanopartícula de grafeno en forma de lámina, con una longitud de $650 \mathrm{~nm}$ y una anchura de $450 \mathrm{~nm}$ (algo por debajo de las dimensiones máximas de 1 a $2 \mu \mathrm{m}$ en la información facilitada por el proveedor, presentando por tanto un tamaño menor). En la Figura 134 se pueden observar regiones más transparentes, que indica la presencia de monocapas y regiones más oscuras que indica la presencia de bicapa o tricapas.

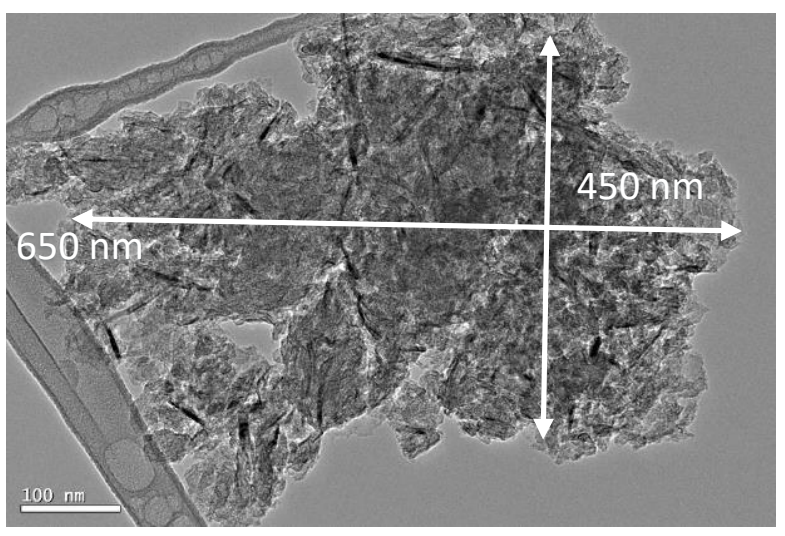

Figura 133. Imagen TEM Grafeno GFN750 ×30000 aumentos

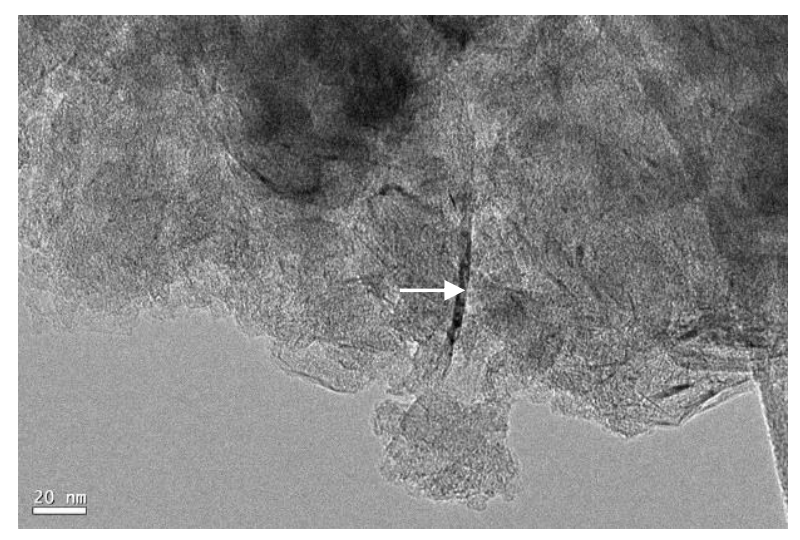

Figura 134. Imagen TEM Grafeno GFN750 × 80000 aumentos

\section{Análisis del tamaño de los agregados de las nanopartículas}

Tras el análisis morfológico de las nanopartículas de grafeno se llevó a cabo la determinación del tamaño del material de grafeno adquirido GFN750 y GFN300 por difracción láser. En la Tabla 33 se muestran los resultados del análisis de distribución de tamaños de aglomerados obtenidos para cada uno de los materiales de grafeno adquiridos. Se observa que las partículas de grafeno GFN750 presentan un tamaño de aglomerado mayor que las del grafeno GFN300, efecto ya observado en las imágenes en el MEB, (Figura 129 y Figura 131) y que puede tener un efecto negativo a la hora de lograr una perfecta dispersión de las mismas en medio acuoso para una misma energía aplicada.

Tabla 33. Distribución de tamaños de los aglomerados de Grafeno

\begin{tabular}{rccc}
\hline $\begin{array}{r}\text { Tamaño de los } \\
\text { aglomerados }\end{array}$ & $\begin{array}{c}d_{10} \\
(\mu \mathrm{m})\end{array}$ & $\begin{array}{c}d_{50} \\
(\mu \mathrm{m})\end{array}$ & $\begin{array}{c}d_{90} \\
(\mu \mathrm{m})\end{array}$ \\
\hline Grafeno GFN300 & 2,7 & 19 & 80,2 \\
Grafeno GFN750 & 3,2 & 23,8 & 131 \\
\hline
\end{tabular}




\section{Estudio de la dureza de los agregados de nanopartículas de grafeno}

Además de caracterizar el tamaño y forma de los aglomerados, también se realizó un estudio de dispersión de los aglomerados en agua con los distintos tipos de grafeno adquiridos. En este estudio se analizó la reducción de tamaño de los aglomerados una vez dispersados en agua tras la aplicación de una agitación suave o una agitación más enérgica con ultrasonidos.

En la Figura 135 se han representado conjuntamente el tamaño de aglomerado $\left(d_{90}\right)$ medido para cada material a distintos tiempos. Puede observarse como una agitación suave no consigue destruir apenas los aglomerados iniciales que presentan ambos materiales (GFN750 y GFN300). Resulta imprescindible aplicar ultrasonidos para llegar a reducir de forma considerable el tamaño de los aglomerados.

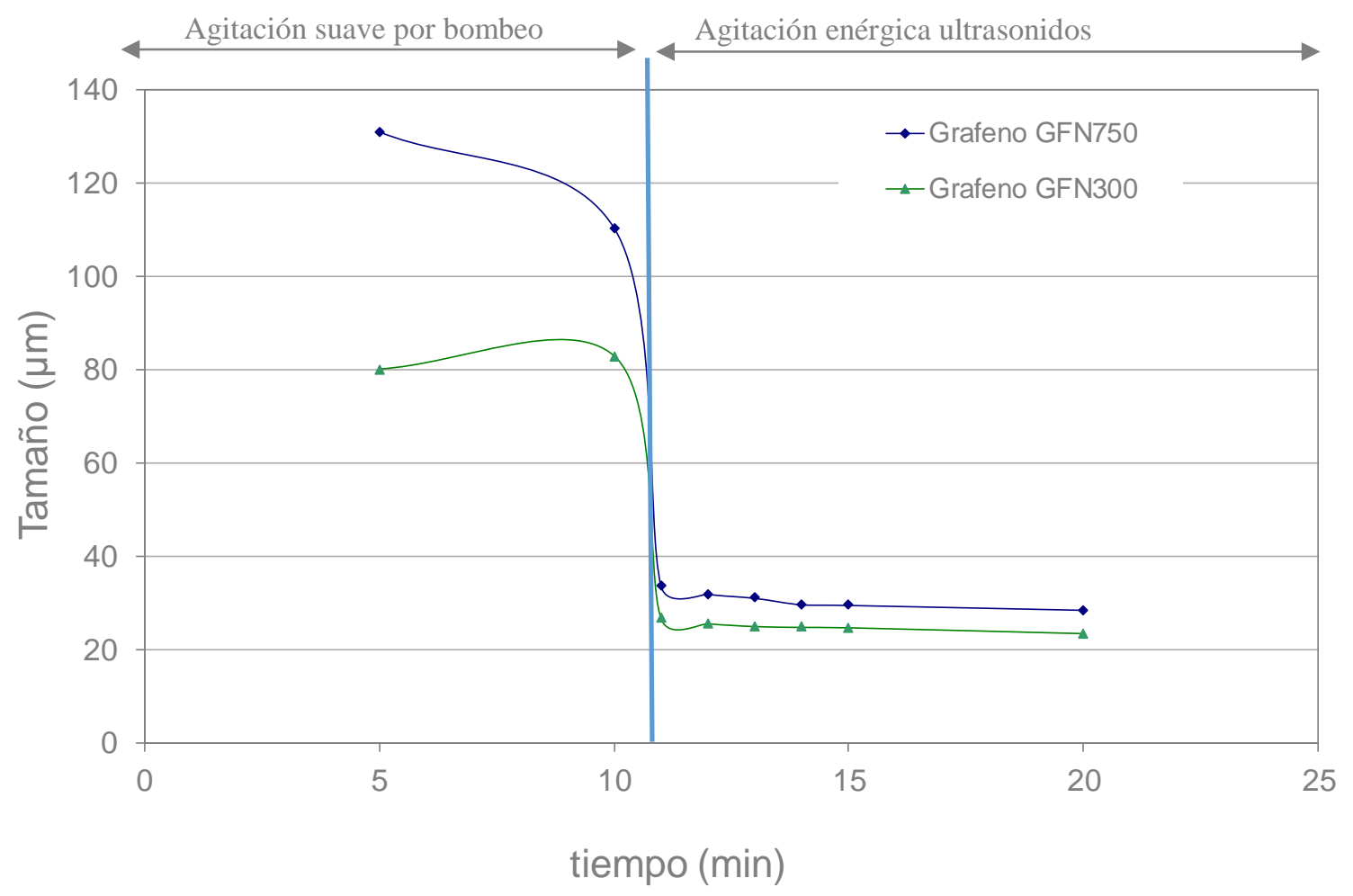

Figura 135. Estudio de la dispersión mediante la medida de la evolución del tamaño de aglomerado cuando se aplica agitación enérgica

Tras el estudio de dispersión de los aglomerados se calcularon los coeficientes de resistencia a la rotura de los mismos (expresados como porcentaje de reducción de tamaño conseguido tras la aplicación de agitación mecánica), Tabla 34. Del análisis de los resultados se constata que el GFN750 alcanza mayor porcentaje de rotura de los aglomerados, pudiendo concluir 
que lo aglomerados de GFN750 resultan ser menos resistentes que los aglomerados de GFN300. Los aglomerados GFN 300 no se rompen cuando se aplica una agitación suave y necesitan de una aplicación más enérgica como los ultrasonidos. Sin embargo, el tamaño final del producto dispersado GFN750 es ligeramente mayor que el alcanzado con el GFN300, debido posiblemente a que inicialmente el tamaño de aglomerado era mucho mayor.

Tabla 34. Evolución del coeficiente de resistencia a la rotura de los aglomerados de Grafeno en función del tipo de agitación aplicada

\begin{tabular}{ccccc}
\hline & \multicolumn{3}{c}{ Coeficiente de resistencia a la rotura del } \\
Tipo de material & \multicolumn{3}{c}{ aglomerado (\%) } & Tamaño final \\
& $\begin{array}{c}\text { agitación } \\
\text { suave }\end{array}$ & $\begin{array}{c}\text { agitación } \\
\text { Ultrasonidos }\end{array}$ & $\begin{array}{c}\text { agitación } \\
\text { Ultrasonidos }\end{array}$ & dispersado \\
& $10 \mathrm{~min}$ & $1 \mathrm{~min}$ & $20 \mathrm{~min}$ \\
GFN750 & 16 & 74 & 78 & $\mathbf{2 8 , 5}$ \\
GFN300 & 0 & 67 & 71 & $\mathbf{2 3 , 5}$ \\
\hline
\end{tabular}

\subsubsection{Funcionalización covalente de las nanopartículas de grafeno}

Como ya se ha comentado, la naturaleza hidrofóbica de las nanopartículas de grafeno dificulta su dispersión en medio acuoso. Una solución para mejorar la dispersión de las nanopartículas en el proceso de preparación de los nanofluidos consiste en la funcionalización de la superficie de las nanopartículas de grafeno, que puede llevarse a cabo de forma covalente o no covalente [apartado 2.1.3 del capítulo III]. La funcionalización covalente consiste en la adición de grupos funcionales enlazados covalentemente a la superficie de las partículas. Con este tipo de funcionalización se modifica el carácter hidrofóbico mejorándose la dispersión directa en medio acuoso y en cualquier otro solvente polar sin tener la necesidad de utilizar aditivos.

En el presente estudio se han utilizado dos métodos para la funcionalización covalente de las nanopartículas de grafeno: 
- $\quad$ Funcionalización ácida: se añaden grupos carboxilo a la superficie del grafeno mediante un tratamiento sencillo con ácidos. Para ello se adicionó 0,5 g de grafeno a una mezcla de ácidos $\left(\mathrm{H}_{2} \mathrm{SO}_{4}(96 \%)\right.$ y $\mathrm{HNO}_{3}(65 \%)$ en una proporción en volumen 3:1) y se mantuvieron en agitación a $55^{\circ} \mathrm{C}$ [7]. Se realizó un estudio para observar la influencia del tiempo de funcionalización sobre la cantidad de grupos carboxilo incorporados en la superficie. Los tiempos elegidos para el estudio fueron de: 1, 3 y 9 horas de agitación.

- Funcionalización alcalina o básica: se adicionó 0,1 g de grafeno a una suspensión de persulfato potásico (KPS) [23] en un baño agitado termostatado a $85^{\circ} \mathrm{C}$ durante 3 horas.

La caracterización de los grupos funcionales introducidos en las nanopartículas de grafeno con los tratamientos ácido y básico se llevó a cabo mediante espectroscopia infrarroja, FT-IR [apartado 3.10 del capítulo III]. Los espectros FT-IR obtenidos a partir de las nanopartículas de grafeno funcionalizadas se muestran en las siguientes figuras (Figura 136 a Figura 138). Los resultados de los perfiles FT-IR evidencian que los grupos hidrofílicos (hidroxílicos y carboxílicos) han sido introducidos sobre la superficie de las nanopartículas de grafeno con ambas técnicas de funcionalización.

\section{Funcionalización covalente Grafeno GFN750}

En la Figura 136 se muestra el efecto que tiene el tiempo de funcionalización (cuando se aplica la técnica de funcionalización ácida) sobre la cantidad de grupos carboxilos introducidos. Para tratamientos de funcionalización cortos de una hora apenas se logra introducir grupos carboxílicos. Si se aumenta el tiempo de ensayo de funcionalización a tres horas, la presencia de grupos carboxílicos comienza a ser significativa, aunque dicha tendencia no se mantiene para tiempos superiores de ensayo (nueve horas). Esto parece indicar que con las 3 horas de funcionalización ácida se logra ya prácticamente la máxima incorporación de grupos carboxílicos a la superficie de las partículas.

Si se compara la funcionalización ácida con la alcalina, Figura 137, se observa como la funcionalización ácida muestra mayores picos (mayor cantidad de grupos carboxílicos adicionados en la superficie) que la alcalina debido a que es una funcionalización mucho más agresiva. 


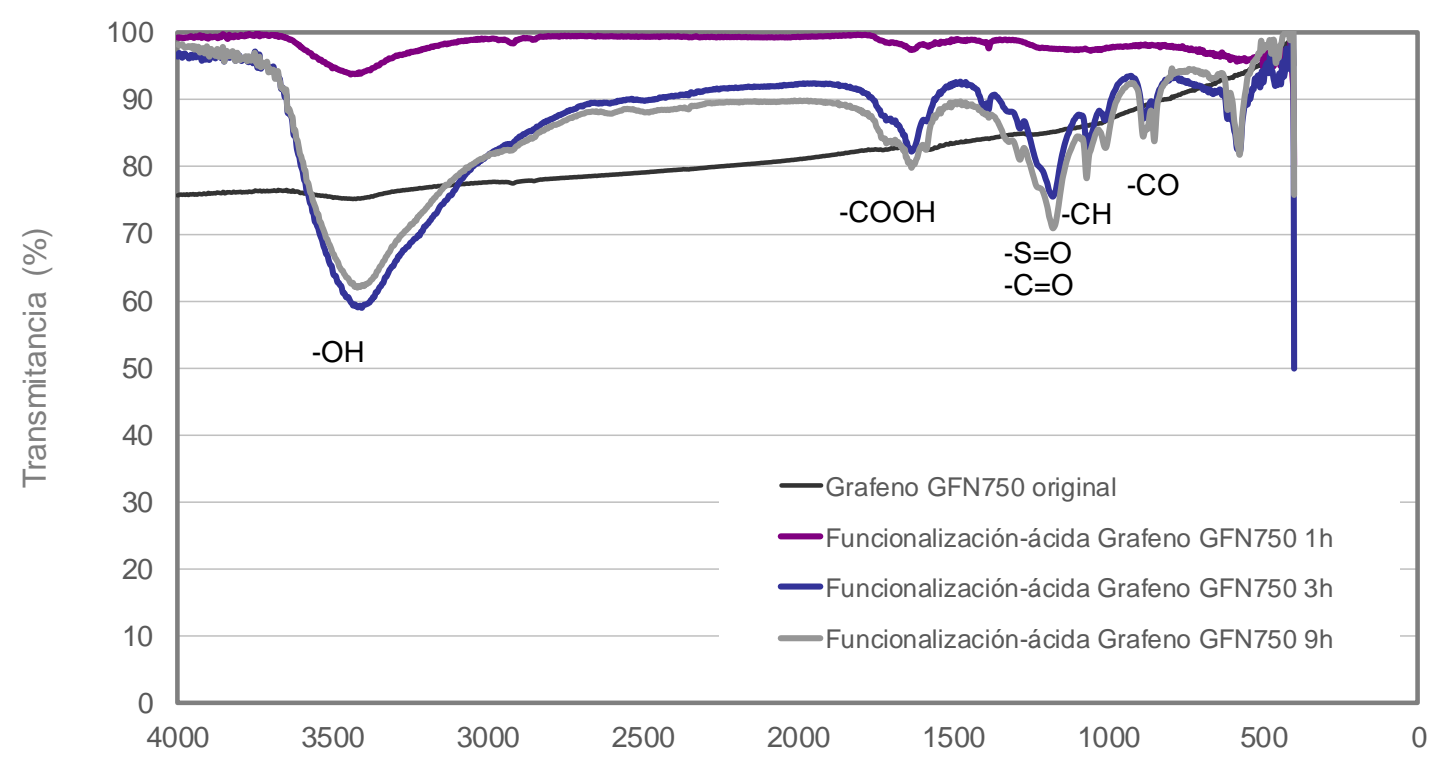

Longitud de onda $\left(\mathrm{cm}^{-1}\right)$

Figura 136. Resultados de FT-IR para GRAFENO GFN750 funcionalizado mediante el método ácido.

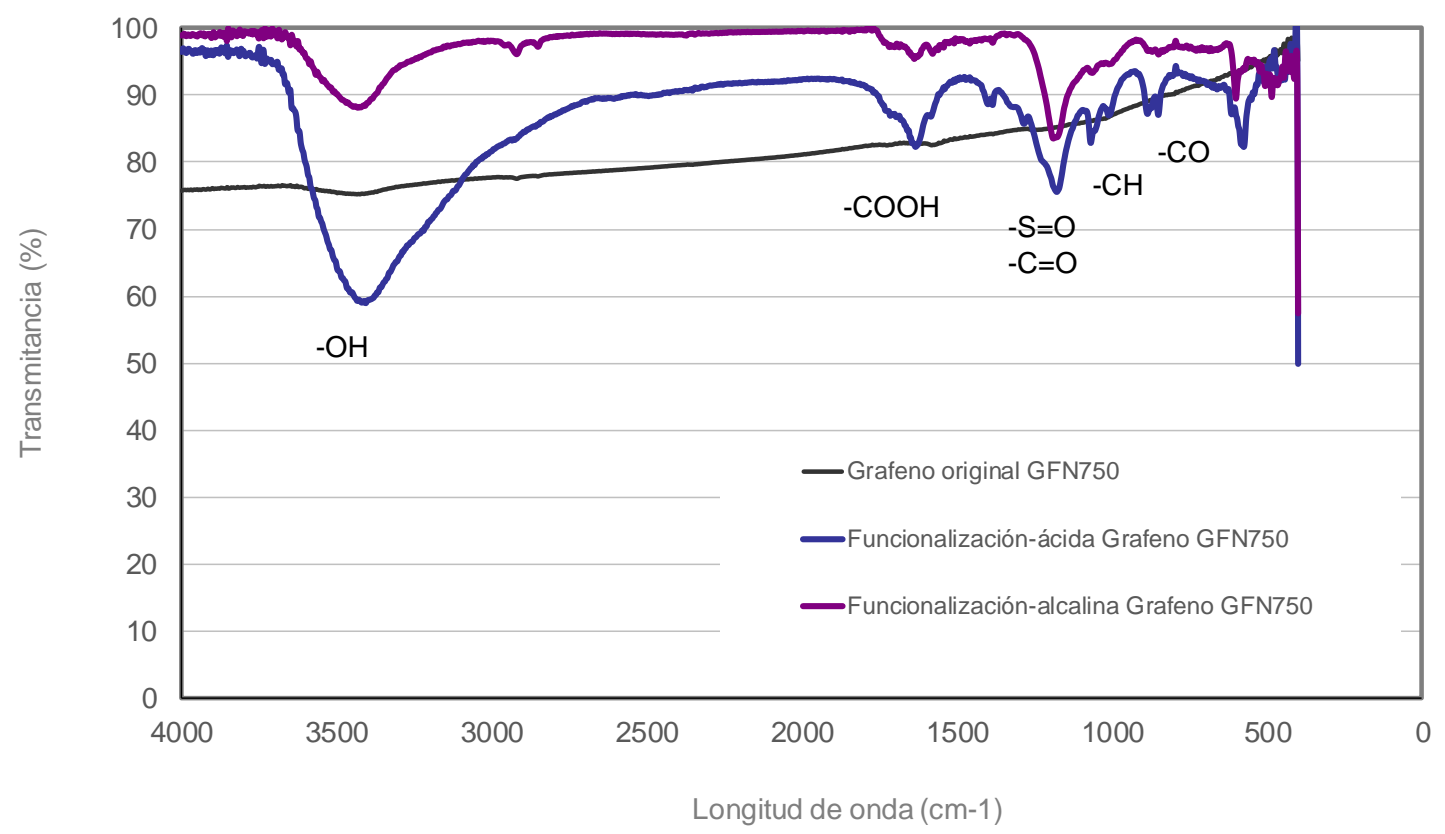

Figura 137. Resultados obtenidos en FT-IR para GRAFENO GFN750 funcionalizado por los métodos ácido y alcalino.

A la vista de los resultados analizados se puede concluir que el método óptimo para la funcionalización covalente de las nanopartículas de grafeno es el método ácido con un tiempo de permanencia de tres horas. 


\section{Funcionalización covalente Grafeno GFN300}

Para la funcionalización covalente de las nanopartículas de grafeno GFN300 se eligió como método para su funcionalización el método ácido, aplicándose durante un tiempo máximo de tres horas. En la Figura 138 se muestran los resultados del espectro FT-IR obtenidos con dicho método, comprobándose en el espectro obtenido que también se logró la introducción de grupos carboxílicos.

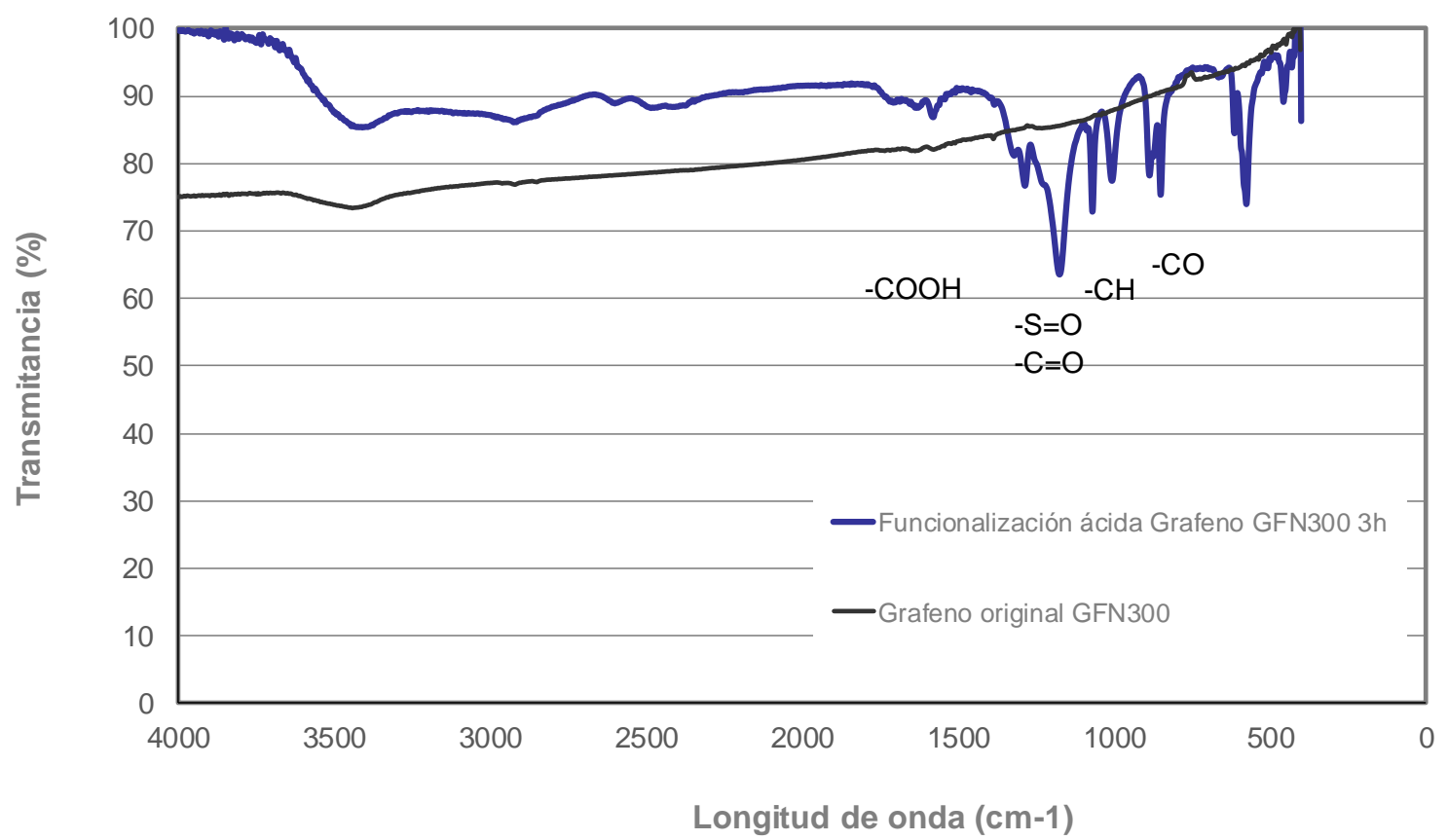

Figura 138. Resultados de FT-IR para Grafeno GFN300 original y funcionalizado vía ácida.

Como ya se ha descrito en el apartado 2.1.3 del capítulo III, tras la funcionalización de la superficie de las nanopartículas de grafeno por ambos métodos (ácido o básico) resulta necesario lavar las partículas para eliminar posibles restos de ácido o base. Tras el lavado, la suspensión de partículas se somete a un proceso de centrifugación para favorecer el proceso de separación y una vez precipitadas las nanopartículas se procede a su secado en estufa. Este proceso de secado puede ocasionar la aglomeración de dichas partículas, por lo que se consideró necesario evaluar de nuevo su morfología antes de proceder a la dispersión en agua para obtener el nanofluido. 


\section{Análisis de imagen por MEB de las nanopartículas de grafeno funcionalizadas}

El análisis de imagen del material tras la funcionalización en laboratorio se llevó a cabo en el MEB con el objetivo de observar posibles cambios en la morfología y en el tamaño de los aglomerados de partículas. Como muestran las imágenes (Figura 139 y Figura 140) el tratamiento de funcionalización genera aglomerados de mayor tamaño (del orden entre 100$500 \mu \mathrm{m}$ ) respecto a los aglomerados originales en las nanopartículas de grafeno adquiridas (20-100 $\mu \mathrm{m})$. Esta tendencia se observa en ambos métodos, tanto con el método ácido como con el método básico (Figura 139 izda. y dcha. para el grafeno GFN750 y Figura 140 para el grafeno GFN300). Como ya se ha comprobado experimentalmente el tamaño y dureza del aglomerado influye en el tamaño final de las nanopartículas dispersadas y también en la conductividad final del nanofluido, por lo que el resultado final de los nanofluidos preparados con nanopartículas funcionalizadas por el método covalente puede verse afectado por el tamaño de los aglomerados obtenidos tras dicho proceso de funcionalización.

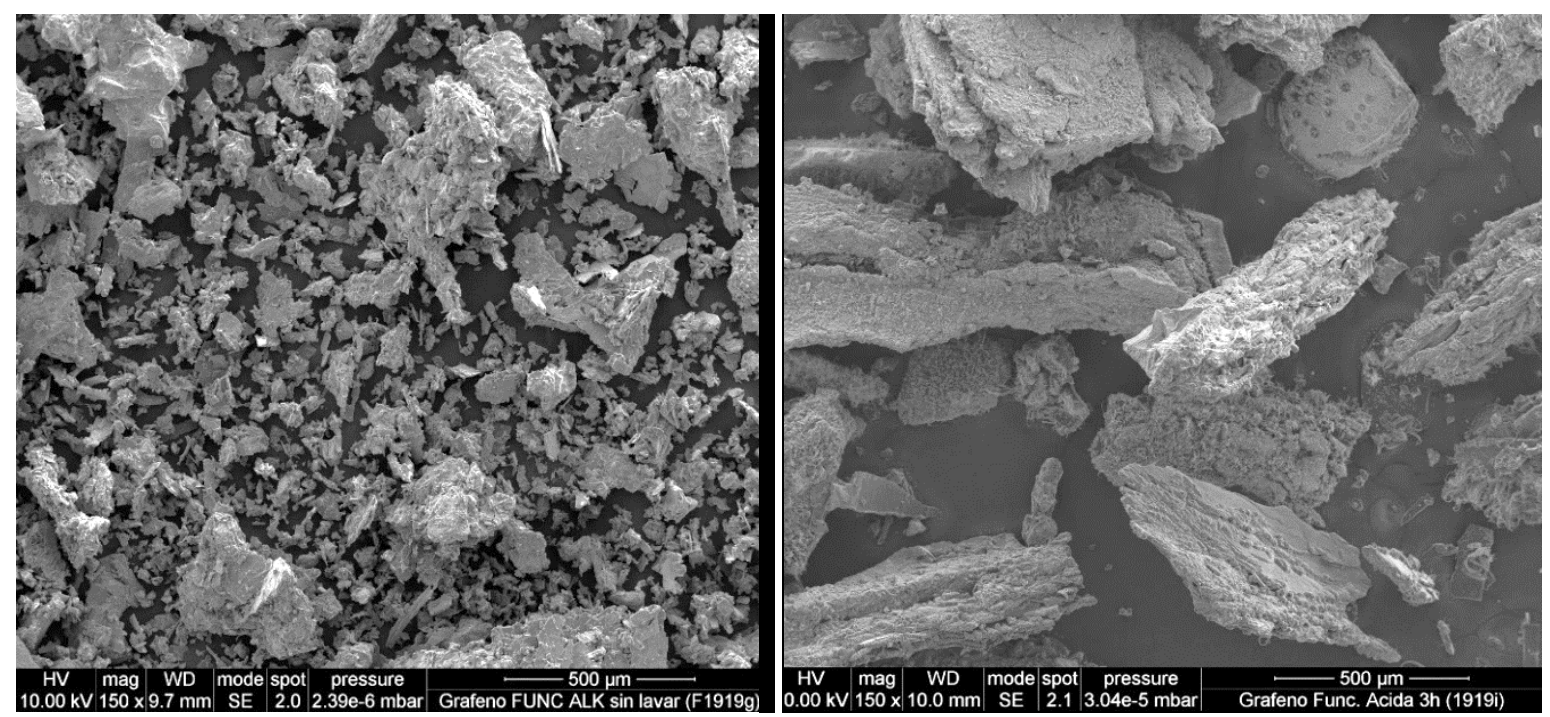

Figura 139. Grafeno GFN750 x150 aumentos a) funcionalización alcalina (izda.) b) funcionalización ácida (dcha.). 

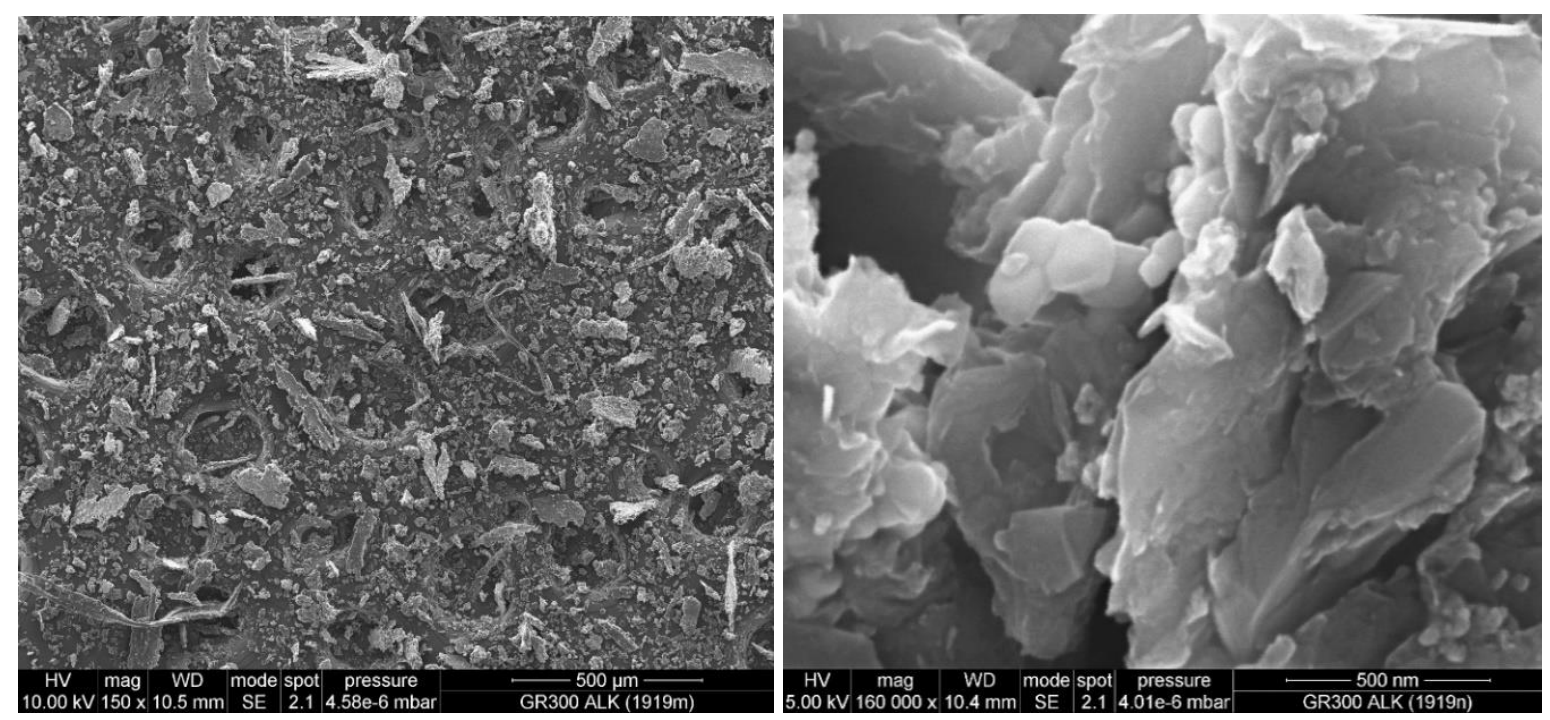

Figura 140. Grafeno GFN300 x150 aumentos a) funcionalización alcalina (izda.) b) funcionalización ácida (dcha.).

\subsubsection{Caracterización del estado de dispersión de las nanopartículas de grafeno en los} nanofluidos preparados

A continuación, se presentan los resultados obtenidos en la caracterización del estado de dispersión de las distintas suspensiones acuosas de grafeno preparadas mediante dispersión con sonda de ultrasonidos, utilizando nanopartículas de grafeno con superficie modificada mediante funcionalización covalente y no covalente.

Las técnicas utilizadas para caracterizar la dispersión de los nanofluidos preparados fueron las siguientes:

- técnica de análisis de imagen en microscopio electrónico de transmisión, TEM

- Análisis del tamaño de nanopartícula o agregado en la suspensión utilizando la técnica de difracción láser

Análisis del estado de dispersión de las nanopartículas de grafeno en los nanofluidos

\section{preparados con distinta energía de sonicación}

La técnica de análisis de imagen en microscopio electrónico de transmisión (TEM) requiere medir la muestra de nanofluido tras una operación de secado de la suspensión colocada en el portamuestras del equipo. Esta técnica en seco no permite visualizar el estado real de dispersión de las nanopartículas en el fluido base, pero sí que permite analizar el estado de agregación de los nanofluidos de grafeno tras la funcionalización covalente y dispersión 
mecánica con ultrasonidos. Dicha caracterización es importante pues ambos métodos pueden ser muy agresivos y modificar significativamente la morfología de las nanopartículas.

En la siguientes imágenes (Figura 141 a Figura 143 )se observa la morfología que presentan las nanopartículas de grafeno sin funcionalizar en las suspensiones de nanofluidos tras la aplicación de distintos tiempos y energías de sonicación con la sonda de ultrasonidos.

- Grafeno GFN750 Prueba 1 ( Referenciado como Optigraf 1). Suspensión de grafeno preparada a 0,01\% en fracción volumétrica y dispersada en sonda de ultrasonidos aplicando una Energía de sonicación del 30\% de amplitud durante $30 \mathrm{~min}$.

- $\quad$ Grafeno GFN750 Prueba 2 (Referenciado como Optigraf 2). Suspensión de grafeno preparada a 0,01\% en fracción volumétrica, y dispersada en sonda de ultrasonidos aplicando una Energía de sonicación del 50\% de amplitud durante $60 \mathrm{~min}$.

- $\quad$ Grafeno GFN750 Prueba 3 (Referenciado como Optigraf 3). Suspensión de grafeno preparada a 0,01\% en fracción volumétrica y dispersada en sonda de ultrasonidos aplicando una Energía de sonicación del 80\% de amplitud durante 180 min.

Cuanto mayor es la energía aplicada y el tiempo de aplicación de ultrasonidos se observa una mayor individualización de las nanopartículas de grafeno hallándose mejor dispersas, Figura 143; las nanopartículas son más transparentes indicando que se ha conseguido la presencia de monocapas. En las imágenes se observa las líneas paralelas características de la separación entre capas del orden de pocos nanómetros.

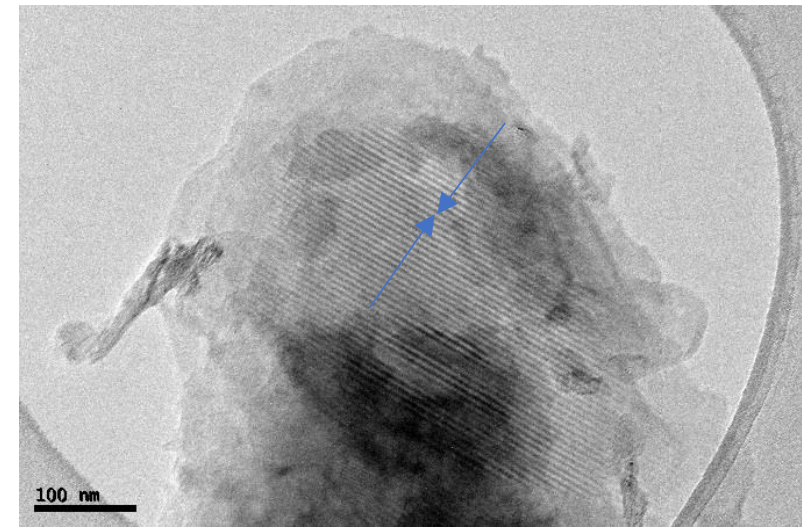

Figura 141. Grafeno OPTIGRAF 1 (30000 aumentos)

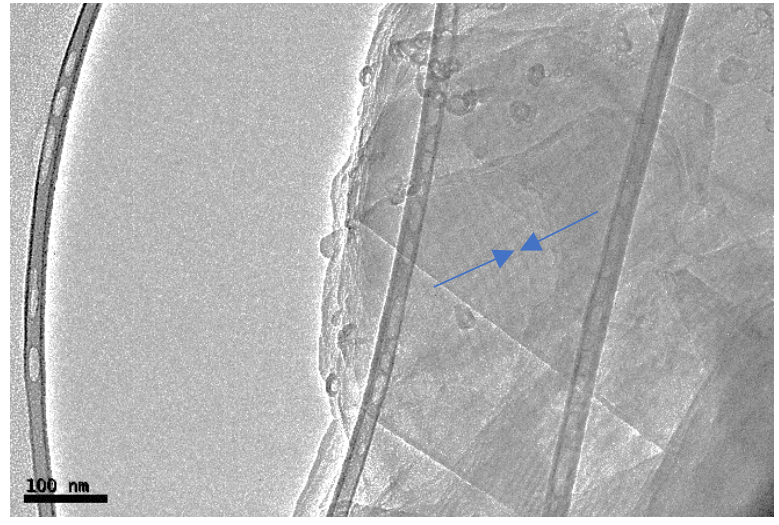

Figura 142. Grafeno OPTIGRAF 2 (30000 aumentos) 


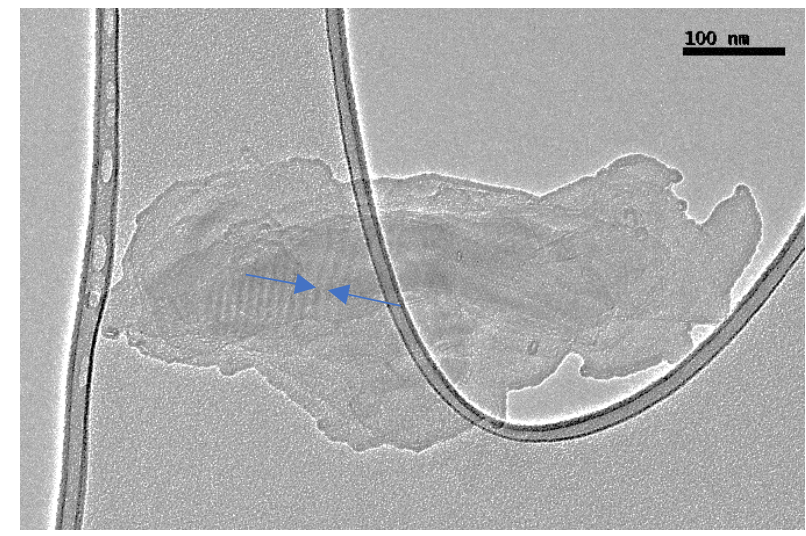

Figura 143. Grafeno OPTIGRAF 3 (30000 aumentos)

En la Figura 144 se muestra las distribuciones de tamaños de los aglomerados de partículas de grafeno obtenidas con cada uno de los tres métodos ensayados. Como puede observarse tanto en los gráficos como en la Tabla 37, al contrario de lo esperado a medida que se aumenta la intensidad de los ultrasonidos aplicada así como el tiempo de aplicación, las partículas de grafeno pueden llegar a aglomerarse obteniéndose una curva bimodal ( optigraf 3 en Figura 144).

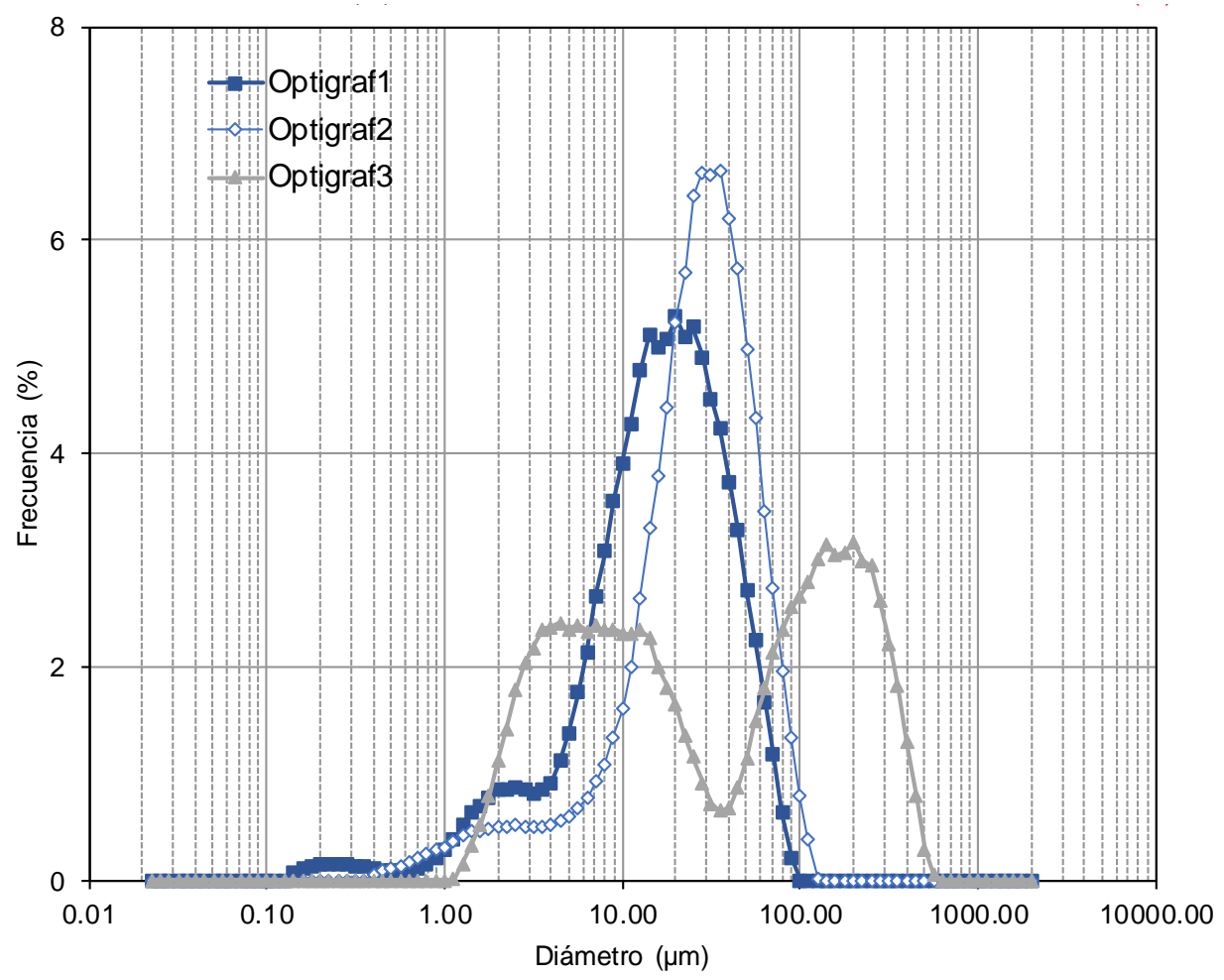

Figura 144. Distribución de tamaños de aglomerados en los nanofluidos de grafeno 
Tabla 35. Distribución de tamaños de los aglomerados de Grafeno

\begin{tabular}{cccc}
\hline Referencia muestra & $\begin{array}{c}d_{10} \\
(\mu \mathrm{m})\end{array}$ & $\begin{array}{c}d_{50} \\
(\mu \mathrm{m})\end{array}$ & $\begin{array}{c}d_{90} \\
(\mu \mathrm{m})\end{array}$ \\
\hline OPTIGRAF 1 & 3,5 & 15,9 & 42,3 \\
OPTIGRAF 2 & 7,1 & 27,1 & 56,4 \\
OPTIGRAF 3 & 3,17 & 31,70 & 252 \\
\hline
\end{tabular}

Se puede concluir que si se aplica una energía excesiva las partículas en lugar de dispersarse tienden a aglomerarse debido al elevado movimiento generado por la sonda y los choques entre ellas. Esta tendencia ha sido observada ya por otros autores $[55,58,69,75]$ por lo que la energía aplicada para dispersar las nanopartículas es crítica, dado que si es excesiva afecta negativamente a la dispersión. Tras el análisis de los resultados se estableció un tiempo de ultrasonicación de 30 minutos y una amplitud máxima de $30 \%$, pues con ese tiempo se ha logrado individualizar las partículas y se evitan los fenómenos de reaglomeración por aplicación de una energía de sonicación excesiva.

La caracterización de la dispersión de los nanofluidos de grafeno GFN750 mediante las técnicas de análisis de imagen TEM y análisis de tamaño de aglomerado por difracción laser ha permitido:

- Seleccionar la energía de sonicación en el equipo de ultrasonidos que permita alcanzar el mejor grado de dispersión: Aplicación de un 30\% de amplitud de energía y un tiempo máximo de sonicación de 30 minutos.

- Observar que las partículas de grafeno se encuentran menos aglomeradas.

Análisis del estado de dispersión de las nanopartículas de grafeno funcionalizado en los nanofluidos preparados

Cuando se observa al TEM la morfología de las nanopartículas de grafeno (GFN750 y GFN300) funcionalizadas mediante el método ácido aplicando distintos tiempos de funcionalización (1h, 3h y 9h), Figura 145 y Figura 146, se aprecia que dichas nanopartículas no se hallan tan individualizadas como cuando se han preparado nanofluidos a partir del material sin funcionalizar, Figura 141 a Figura 143. Esto puede deberse a que el método de funcionalización genera agregados de nanopartículas más difíciles de dispersar. 

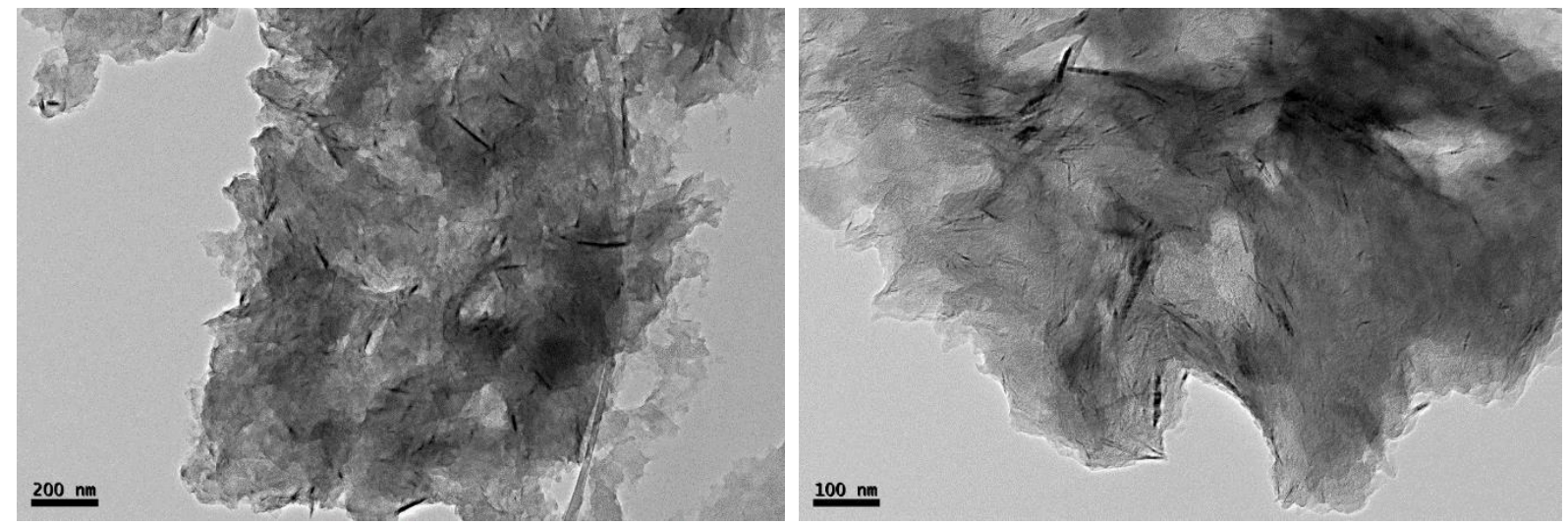

Figura 145. Grafeno GFN750 Funcionalizado 3h a) 10000 aumentos (izd.) y b) 20000 aumentos (dcha.)
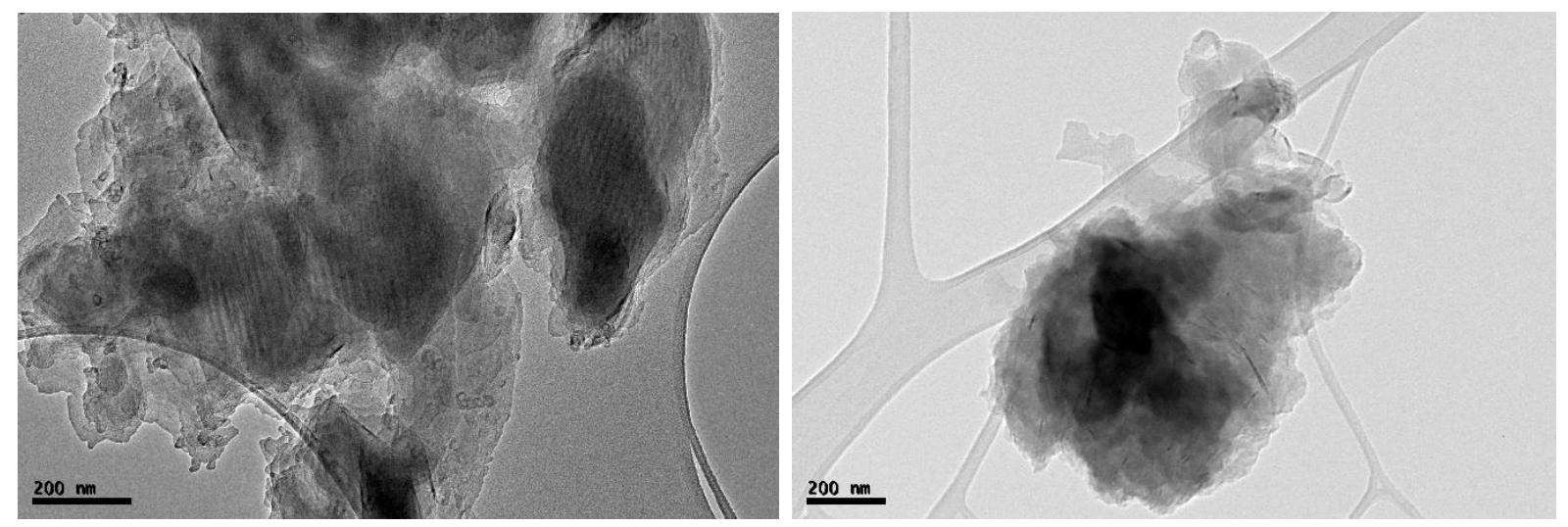

Figura 146. Grafeno GFN750 (15000 aumentos) a) Funcionalizado $1 \mathrm{~h}$ (izda.) y b) Funcionalizado $9 \mathrm{~h}$ (dcha.)

Con las imágenes del TEM, como ya se ha comentado en el estudio de otros materiales, no se puede determinar el estado de agregación o dispersión de las nanopartículas en el fluido base debido a que las imágenes que se recogen son una proyección por lo que podemos encontrar superposición de nanopartículas en la misma imagen. Tan sólo se puede observar si hay cambios entre la morfología de las nanopartículas al realizar la agitación o la funcionalización. Como ya se ha comentado en la caracterización de los nanotubos, la técnica indicada para poder ver el estado de dispersión es el análisis de imagen en húmedo sin secar las muestras (TEM Vía húmeda P.Garg [22]).

\subsubsection{Caracterización de la estabilidad de los nanofluidos preparados con grafeno}

Tras la dispersión de las nanopartículas en agua resulta imprescindible determinar la estabilidad de los nanofluidos preparados con el objeto de garantizar su aplicabilidad industrial, y así evitar que sus propiedades térmicas no varíen con el tiempo. 
A continuación, se resumen los resultados de los ensayos de estabilidad realizados a las distintas suspensiones de nanofluidos de grafeno preparadas. Las técnicas utilizadas para medir dicha estabilidad fueron tres: la estabilidad visual en el tiempo, la técnica de dispersión de luz (mediante el equipo Turbiscán) y el análisis por espectrofotometría visible.

\section{Estabilidad de los nanofluidos mediante observación visual del frente de sedimentación}

En la Figura 147 se muestra la comparativa en estabilidad de varias muestras preparadas con sonda de ultrasonidos con distintos tipos de material de partida (GFN 750 original, GFN750 funcionalizado por método ácido y funcionalizado por método alcalino) transcurridos 40 días tras su preparación.

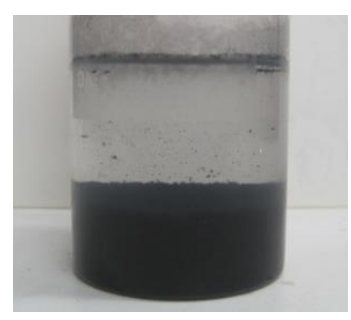

a) original GFN750

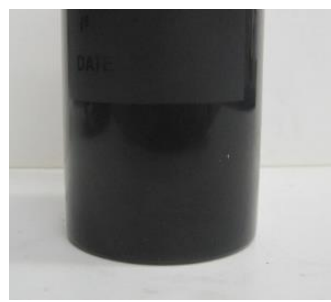

b) func.ácida GFN750 $3 \mathrm{~h}$

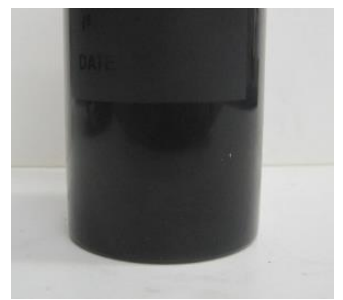

c) func.alcalina GFN750

Figura 147. Imagen del frente de sedimentación observado en muestras de nanofluidos de grafeno preparadas con sonda de ultrasonidos

Tras la observación de los resultados se puede concluir que la suspensión de grafeno preparada con el material original sin funcionalizar acaba sedimentando, mientras que las suspensiones en las que la superficie de las nanopartículas de grafeno se han funcionalizado (imágenes b y c) no se aprecia sedimentación. Esta técnica de sedimentación visual tan sólo es válida para determinar si la suspensión preparada de nanofluidos sedimenta rápidamente o permanece estable en el tiempo sin que se detecte acumulación de material en el fondo del recipiente que lo contiene, pero no permite detectar cambios en la dispersión de los nanofluidos debido a efectos de aglomeración. Tampoco permite comparar la dispersión entre muestras preparadas a distintas fracciones o con distintos métodos de dispersión. Para dicha caracterización resulta necesario utilizar otras técnicas, cuyos resultados se comentan a continuación. 


\section{Estabilidad de los nanofluidos de grafeno medida por retrodispersión, B.S.}

Al igual que sucedía con los nanotubos cuando se caracteriza su estabilidad utilizando la técnica de retrodispersión en el Turbiscan, los valores de retrodispersión (B.S.) para los nanofluidos de grafeno son menores del $1 \%$, y los valores de transmisión $0 \%$. Toda la luz es absorbida o dispersada sin que lo detecte el receptor que mide el B.S., tal y como puede observarse en el perfil de transmisión mostrado en la Figura 148. En este gráfico se ha representado el perfil de transmisión medido a distintos tiempos a lo largo de la altura de la probeta h para una muestra de nanofluido de GFN750 al 0,1\% de fracción volumétrica. Sólo se produce algo de clarificación y por tanto se detecta la transmisión de la energía incidente en la parte alta de la probeta $(40-55 \mathrm{~mm})$ debido a las burbujas de aire generadas al depositar la muestra de grafeno.

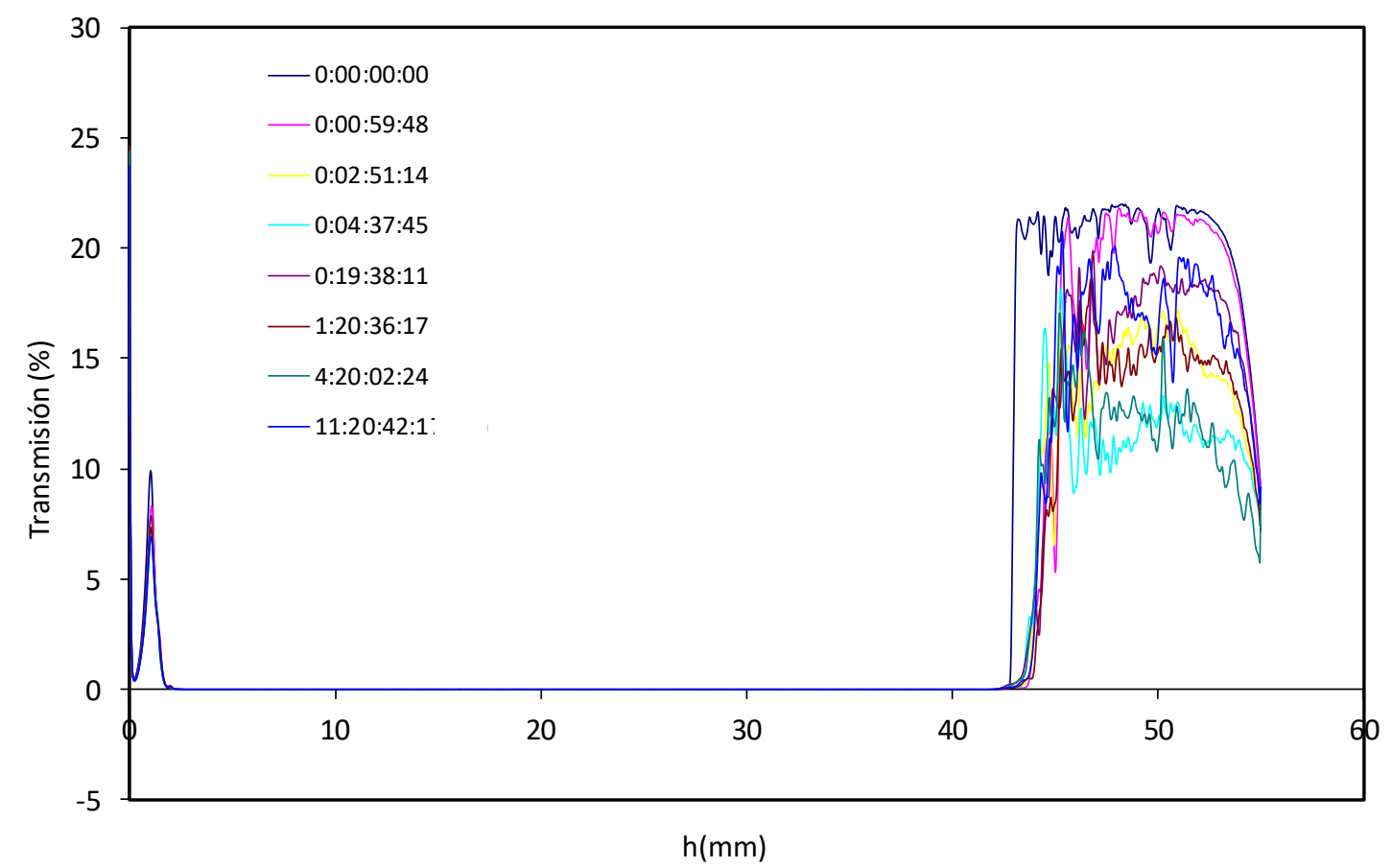

Figura 148. Perfil de Transmisión (\%) para el nanofluido de grafeno GFN750 0,1 \% $\Phi$

Esta técnica de medida de la estabilidad mediante B.S. no aporta suficiente resolución o sensibilidad para los nanofluidos de grafeno, ya que esta tipología de material presenta un elevado índice de absorción si lo comparamos con los óxidos metálicos y por tanto no puede utilizarse para caracterizar la estabilidad de estos nanofluidos. 


\section{Medida de la estabilidad de los nanofluidos de grafeno mediante espectrofotometría}

Para caracterizar la estabilidad de las suspensiones de grafeno mediante espectrofotómetro, se siguió el procedimiento descrito en el apartado 3.1.2, Capitulo III.

En primer lugar, para poder determinar la longitud de onda a la cual la absorbancia de las partículas de grafeno es máxima, se midió la absorbancia de las muestras a diferentes longitudes de onda, desde 380 hasta 500 nm, obteniéndose el espectro de absorción representado en la Figura 149 . Puede observarse como hay un incremento de absorbancia a medida que disminuye la longitud de onda del haz aplicado. A la vista de estos resultados, se determinó que la mejor longitud de onda para analizar la estabilidad de las suspensiones era $400 \mathrm{~nm}$, ya que permite obtener un valor alto de absorbancia sin encontrarse en el límite de la capacidad del espectrofotómetro.

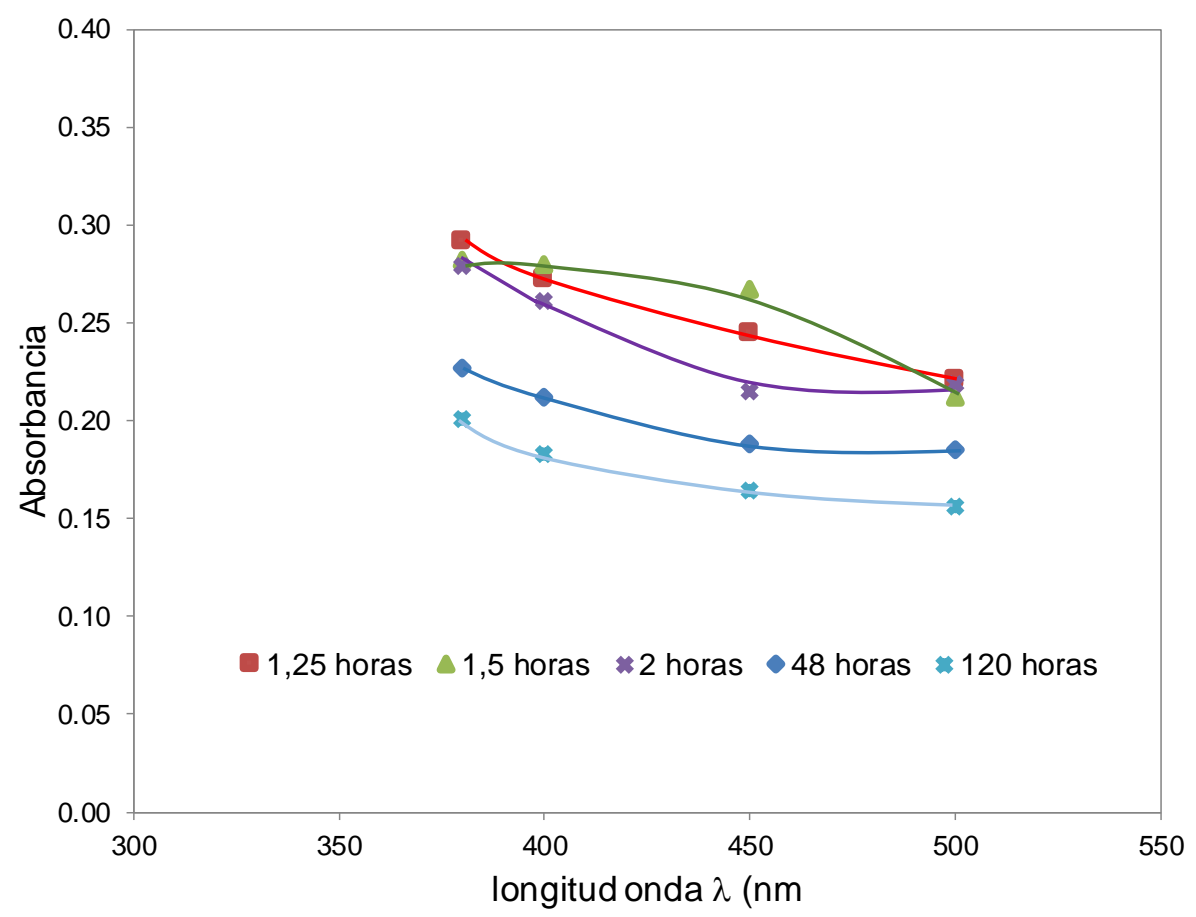

Figura 149. Espectro de absorción de las muestras con un $0,25 \%$ de fracción volumétrica de grafeno GFN750

Una vez fijada la longitud de onda óptima para realizar los ensayos de estabilidad a los nanofluidos de grafeno se procedió a ensayar los distintos tipos de nanofluidos preparados.

Al analizar el efecto que tiene la fracción volumétrica de grafeno presente en las suspensiones acuosas sobre la absorbancia medida, se observa que a medida que se aumenta la fracción volumétrica de nanopartículas en el medio las pérdidas de absorbancia debidas a una 
clarificación del líquido se dan más rápidamente indicando una menor estabilidad en este tipo de muestras (Figura 150). La mayor fracción de nanopartículas puede originar mayor número de colisiones y favorecer los mecanismos de sedimentación en estos tipos de nanofluidos ya que la superficie de las nanopartículas de grafeno no está funcionalizada para evitar la aglomeración de las mismas.

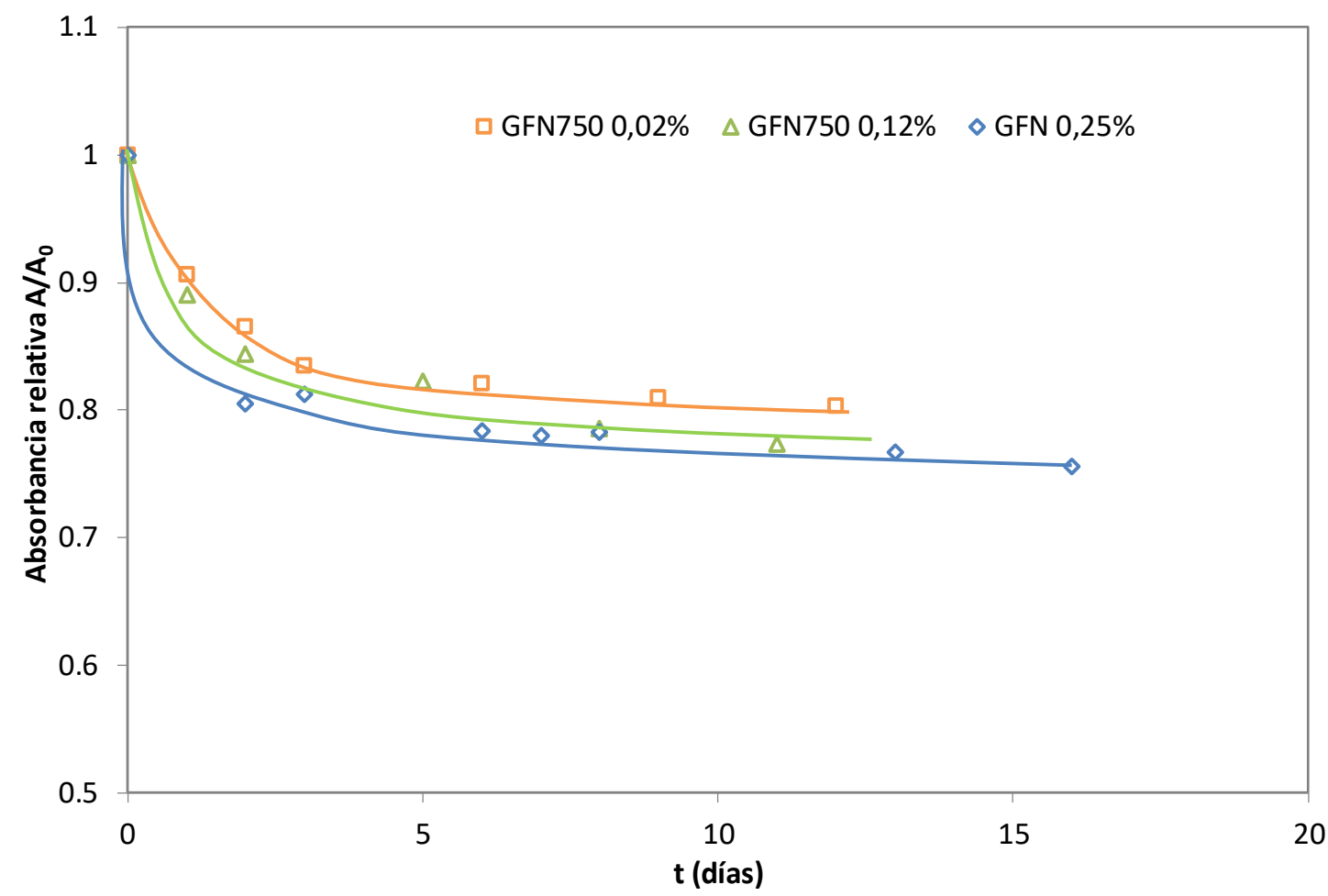

Figura 150. Variación de la absorción relativa con el tiempo para nanofluidos de GFN750 a distinta fracción volumétrica. Preparados sin aditivos con un tiempo de sonicación de $\mathbf{3 0}$ minutos.

También se analizó el efecto del tiempo de aplicación de ultrasonidos sobre la estabilidad de los nanofluidos de grafeno preparados mediante agitación en sonda de ultrasonidos y sin ningún tipo de funcionalización de la superficie de las nanopartículas (en la Figura 151). Se puede observar como al duplicar el tiempo de agitación en ultrasonidos se consigue ralentizar los procesos de sedimentación de las nanopartículas, pues la variación de absorbancia de las muestras debido a la clarificación del nanofluido es menor: tras tres días desde la preparación se observa una pérdida del $20 \%$ en absorbancia cuando se han sonicado las muestras durante 30 minutos, mientras que la perdida es tan solo del $10 \%$ cuando se han sonicado durante 60 minutos. 


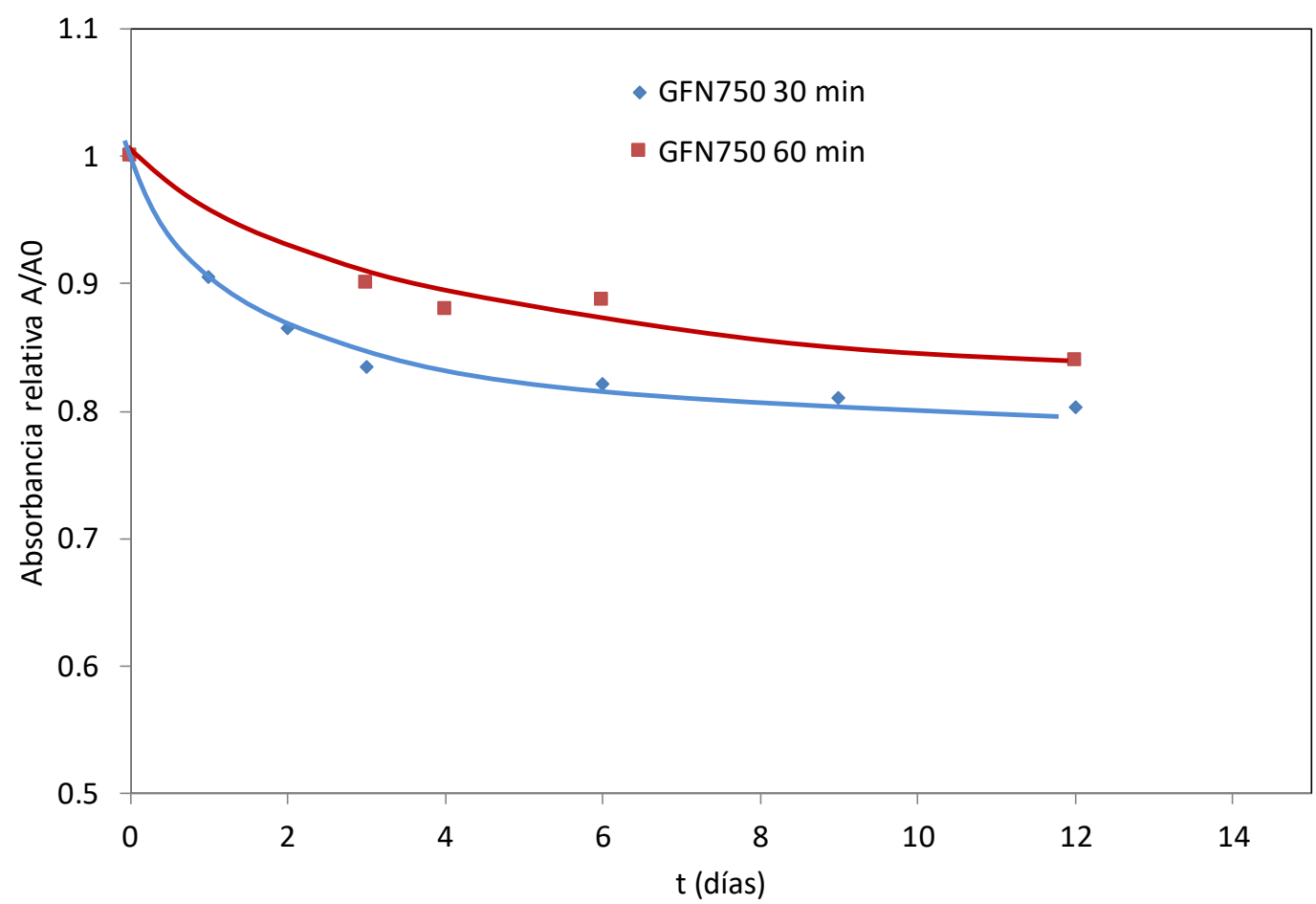

Figura 151. Variación de la absorbancia relativa frente al tiempo de reposo de las muestras con un $0,02 \%$ en volumen de grafeno GFN750 sin funcionalizar, sonicadas durante 30 y 60 minutos

Con objeto de mejorar la dispersión de las nanopartículas de grafeno en los nanofluidos preparados se modificó la superficie de dichas partículas mediante el método covalente y la adición de surfactantes (no covalente). La estabilidad de los nanofluidos así preparados se espera que sea mayor pues con una buena dispersión se consiguen agregados de partículas de menor tamaño y se evita la sedimentación de dichas partículas.

\section{Estabilidad de los nanofluidos preparados con GFN750 funcionalizado no covalente}

En la Figura 152 se muestran los resultados de absorbancia para los nanofluidos obtenidos utilizando distintos tipos de surfactantes, con una adición en peso respecto al peso de nanopartículas de grafeno de 10:1. La fracción volumétrica de grafeno GFN750 elegida fue alta, 0,25\%. En las series de datos representadas en el gráfico se observa una disminución de la fracción relativa con el tiempo en todos los casos, lo cual indica un proceso de sedimentación y/o agregación de las nanopartículas, aunque esta disminución es menos pronunciada, en comparación con el resto de las muestras, en la muestra de grafeno preparada con el surfactante tipo aniónico SDS. Los surfactantes tipo no-iónicos como el Tritón o la Goma arábiga no consiguen mejorar la estabilidad de las partículas de grafeno en la 
suspensión acuosa, obteniéndose en el caso de la goma arábiga peores resultados que los obtenidos en los nanofluidos preparados con GFN750 sin ningún tipo de aditivo.

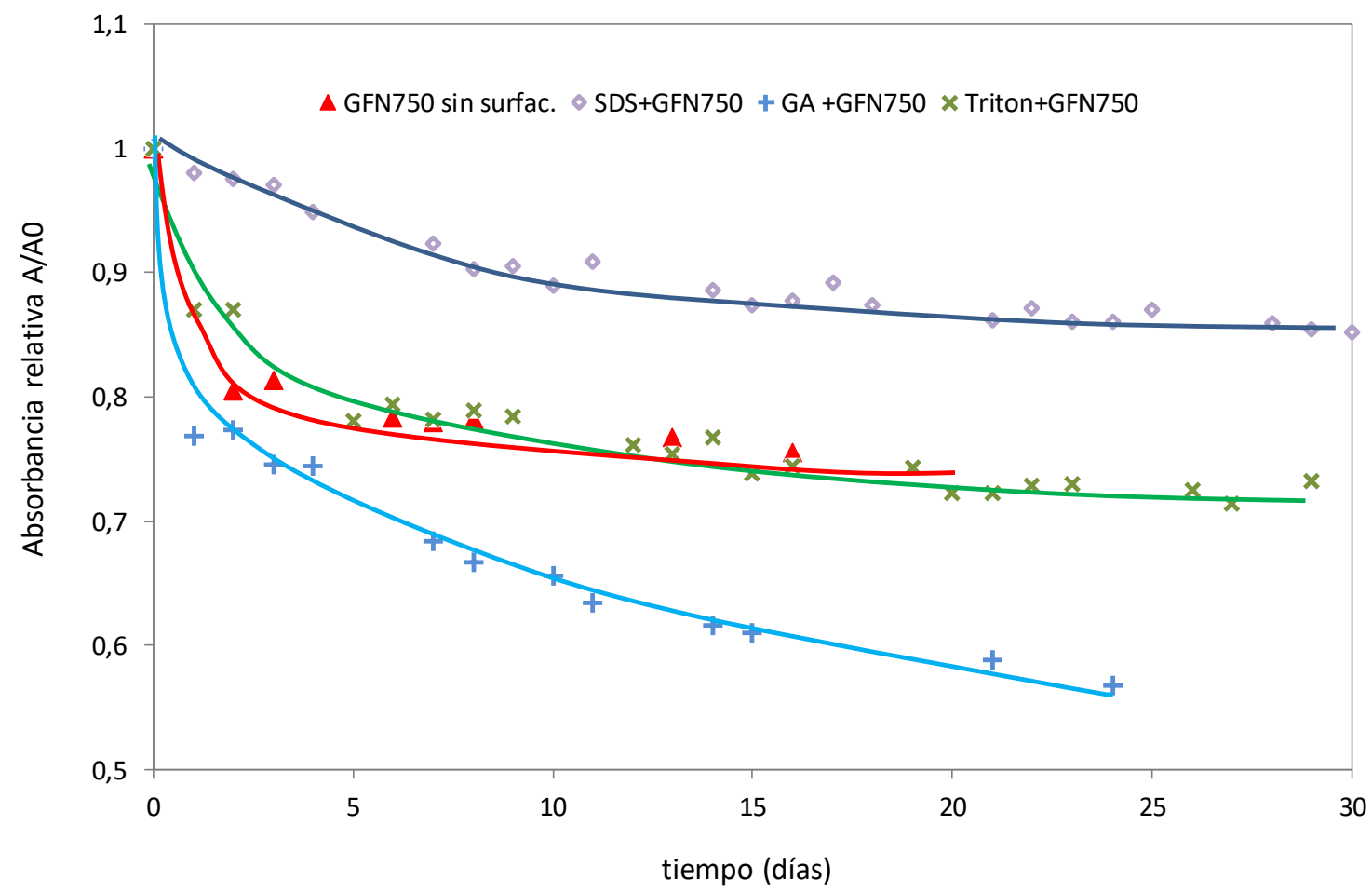

Figura 152. Variación de la absorbancia relativa frente al tiempo de las muestras con un $0,25 \%$ de grafeno y diferentes tipos de surfactantes.

Estabilidad de los nanofluidos preparados con GFN750 y GFN300 funcionalizado con el método covalente

En la Figura 153 se observa que los dos métodos utilizados para la funcionalización de las nanopartículas permiten mejorar la estabilidad de los nanofluidos de grafeno si se compara con una suspensión preparada con grafeno sin funcionalizar. Este efecto se observa tanto para las nanopartículas de grafeno GFN750 como para las de menor superficie específica (GFN300). 


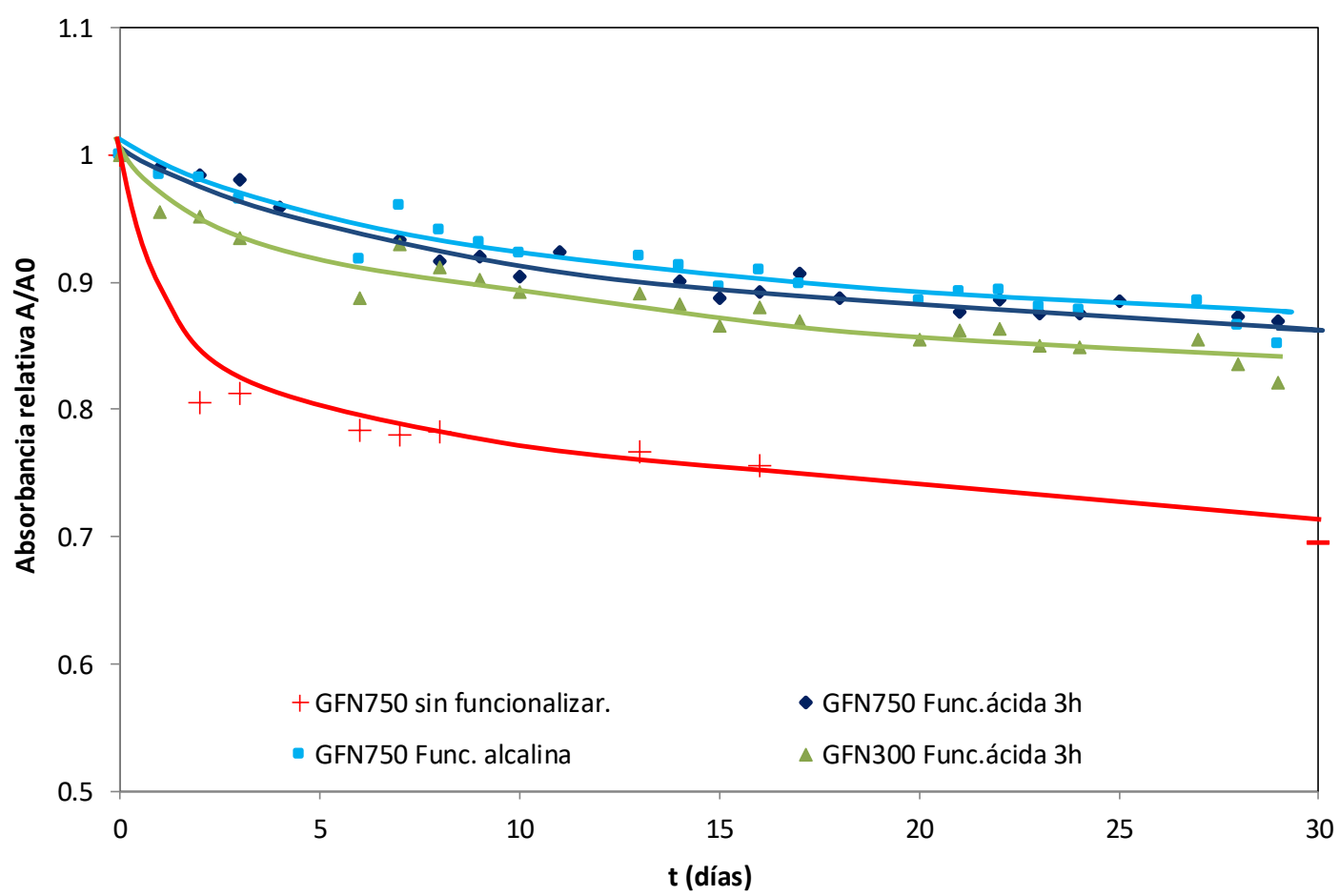

Figura 153. Variación de la absorbancia relativa frente al tiempo de las muestras con un $0.25 \%$ de grafeno 750 y 300 funcionalizado

Como puede observarse se obtiene valores similares para ambos tipos de funcionalización. Asimismo, se consigue una mayor estabilidad para las suspensiones de GFN750 func. ácida que para la suspensión de GFN300 debido posiblemente a la mayor superficie específica de las nanopartículas del grafeno GFN750 y por tanto con más grupos funcionalizados en su superficie que le confieren un mejor grado de dispersión en base acuosa.

Los resultados obtenidos en estabilidad mediante la funcionalización covalente ácida son parecidos a los obtenidos con la funcionalización no-covalente cuando se utiliza el surfactante SDS. Estos dos métodos mejoran la estabilidad alcanzada con los nanofluidos sin funcionalizar dispersados con ultrasonidos, como ya se había apreciado en la caracterización visual del frente de sedimentación. 


\subsection{Resultados de la medida de conductividad térmica de los nanofluidos preparados con} nanopartículas de grafeno

A continuación, se resumen los resultados de conductividad térmica obtenidos para los distintos nanofluidos de grafeno. Se han caracterizado los nanofluidos preparados directamente a partir de los dos tipos de grafeno adquiridos, junto con los tratados superficialmente (mediante funcionalización covalente o surfactantes). Los resultados se presentan conjuntamente en varios apartados con el objeto de analizar la influencia de las distintas variables de proceso sobre el aumento en la conductividad térmica que experimenta el nanofluido; tal es el caso del tipo de metodología de dispersión mecánica, la fracción volumétrica y la temperatura.

\subsubsection{Medida de la conductividad térmica en nanofluidos de grafeno sin funcionalizar}

Se midió en primer lugar la conductividad térmica de suspensiones acuosas de grafeno GFN750 sin funcionalizar preparadas a distintas fracciones volumétricas $0,025,0,12$ y $0,25 \%$ con la sonda de ultrasonidos. Se midió la conductividad térmica de los nanofluidos preparados a dos temperaturas 25 y $40^{\circ} \mathrm{C}$ para comprobar el efecto que esta variable ejerce en nanofluidos con distinta fracción volumétrica de sólidos. Los resultados obtenidos se muestran en la Figura 154 (imagen izquierda). En el caso de los nanofluidos de grafeno sin funcionalizar puede observarse como apenas se obtiene un aumento en conductividad térmica respecto al fluido base agua a $25^{\circ} \mathrm{C}$ siendo dicho aumento algo mayor a medida que aumentamos la temperatura. Cuando se aumenta la fracción volumétrica no se observa el aumento en conductividad térmica teóricamente esperado, posiblemente debido a la poca estabilidad de las nanopartículas de grafeno sin funcionalizar en el fluido base, como ya se ha comprobado en el apartado 3.1.4 del presente capitulo, en la observación del frente de sedimentación visual y en los gráficos de evolución de la absorbancia relativa de los nanofluidos preparados a distinta fracción (Figura 150).

El estudio también se realizó con las partículas de grafeno GFN300, con distinta superficie específica que el GFN750. Respecto a las conductividades medidas a $25^{\circ} \mathrm{C}$ en los nanofluidos de grafeno GFN300, Figura 154 (imagen de la derecha), no se aprecia un aumento de la 
conductividad al aumentar la fracción volumétrica, presentando un comportamiento muy parecido a los nanofluidos preparados con el GFN750.
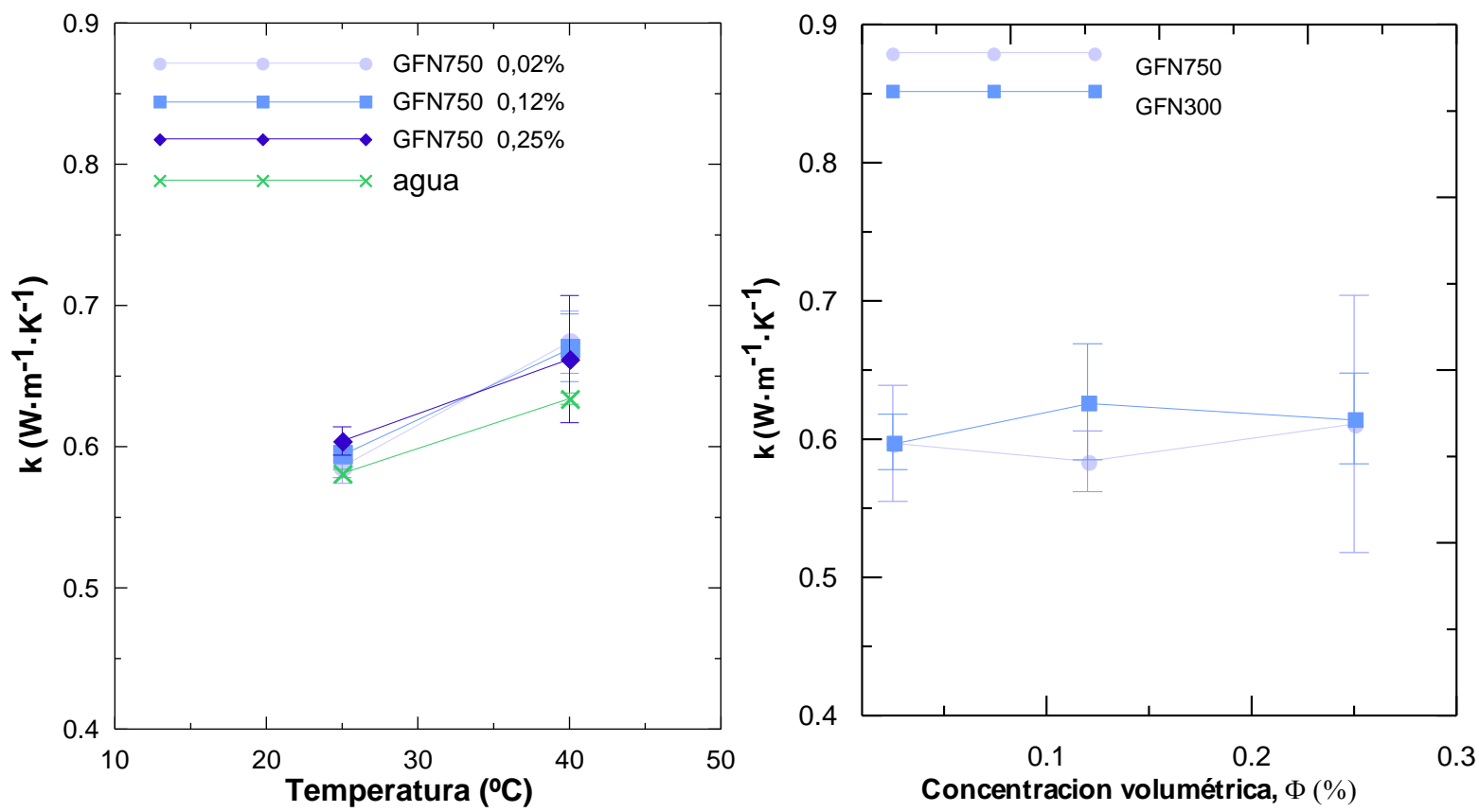

Figura 154. Conductividad térmica de las suspensiones de Grafeno GFN750 adquirido y sonicado en S.U, en función de la temperatura y la fracción volumétrica (izda.). Comparación con el grafeno GFN300 (dcha.).

3.2.2 Medida de la conductividad térmica en nanofluidos de grafeno funcionalizado con surfactantes

A continuación, se comparó la conductividad térmica de las muestras de nanofluidos preparados con GFN750 sin funcionalizar a una fracción volumétrica de 0,25 \% con la obtenida en nanofluidos de grafeno con la superficie de las nanopartículas funcionalizadas. Los surfactantes utilizados fueron Tritón X100 y SDS, pues como ya se comprobó en la caracterización de la estabilidad de los nanofluidos cuando se utiliza la Goma Arábiga como surfactante con las partículas de grafeno, la estabilidad de los nanofluidos es peor que cuando se intentan dispersar las nanopartículas de grafeno sin aditivo (Figura 152). En la Figura 155 se muestran los resultados obtenidos cuando los surfactantes se añaden en una proporción en peso de 15:1 respecto al grafeno en suspensión. Puede observarse como el Tritón X100 apenas mejora la conductividad respecto al fluido base en ninguna de las temperaturas estudiadas, posiblemente al bajo efecto como surfactante en la dispersión de las nanopartículas. Este hecho ya se apreció en los resultados de estabilidad, donde las muestras 
con Tritón sedimentaban rápidamente. Cuando se utiliza como surfactante el SDS, como ya se ha constatado en los resultados obtenidos de estabilidad, las suspensiones de grafeno preparadas con este aditivo mejoran su dispersión y esto influye directamente en los valores medidos de conductividad térmica. Con los nanofluidos preparados con el SDS como surfactante se obtienen los mayores aumentos de la conductividad térmica en los nanofluidos de grafeno, alcanzando a $40{ }^{\circ} \mathrm{C}$ un aumento del $7,5 \%$ respecto al fluido base.

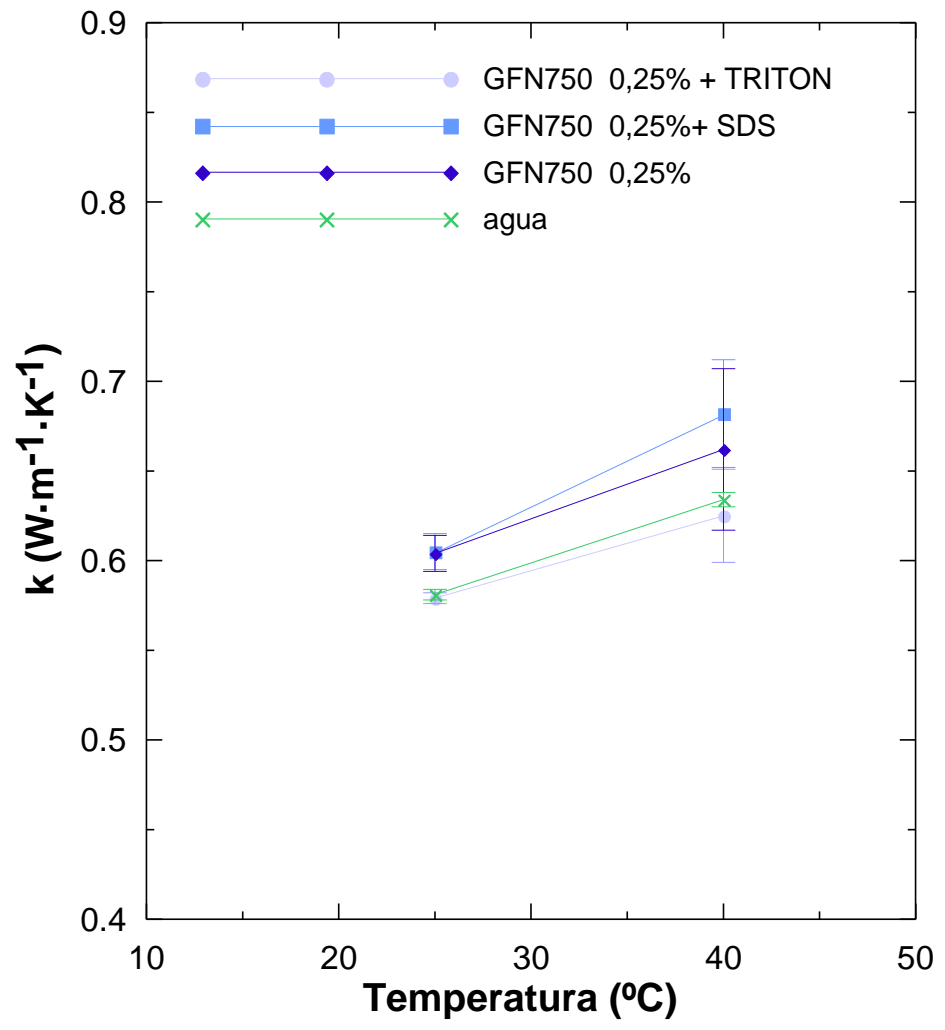

Figura 155. Conductividad térmica de las suspensiones de GFN750 al 0,25\% de fracción volumétrica y funcionalizados con aditivos en proporción 15:1

3.2.3 Medida de la conductividad térmica en nanofluidos de grafeno funcionalizado con método covalente

Los nanofluidos preparados con nanopartículas de grafeno funcionalizadas por el método covalente presentan una estabilidad muy buena. Dicha característica hace viable su aplicabilidad como fluido térmico si se consiguen aumentos de conductividad significativos. De forma general, cabe indicar que en todos los gráficos, (Figura 156 y Figura 157), se observan aumentos de conductividad respecto al fluido base, consiguiéndose los mayores aumentos (sobre el $9 \%$ ) a $40{ }^{\circ} \mathrm{C}$ y a fracciones elevadas de $0,12 \%$ cuando se ha realizado la 
funcionalización ácida o a una fracción volumétrica de 0,02\% cuando se ha efectuado una funcionalización alcalina.

A continuación, y en base también a los resultados presentados en las gráficas de las figuras Figura 156 y Figura 157 se especifica de forma más detallada el efecto de las diferentes variables de operación estudiadas sobre la conductividad térmica de los nanofluidos de grafeno dispersados.

\section{Efecto del tiempo de funcionalización del método ácido sobre la conductividad térmica}

El tiempo de funcionalización afecta directamente a la cantidad de grupos carboxilos introducidos. Para tratamientos de funcionalización cortos, de una hora, apenas se logra introducir grupos carboxílicos. Al aumentar el tiempo del ensayo de funcionalización (tiempo durante el cual las partículas están en contacto con la mezcla ácida) se consigue incrementar la cantidad de grupos carboxílicos, lo cual tiene un efecto positivo sobre la conductividad térmica de los nanofluidos, observándose aumentos de conductividad significativos, Figura 156 (izda.).

\section{Efecto del tipo de material sobre la conductividad térmica}

Se han estudiado dos tipos de materiales de grafeno funcionalizados con el método ácido, pero con distinta superficie específica, el GFN750 con mayor superficie específica y el GFN300, Figura 156 (dcha.). Los nanofluidos preparados con el grafeno con mayor superficie presentan valores de incremento en conductividad térmica más altos.

\section{Efecto de la fracción volumétrica sobre la conductividad térmica}

Si se analiza el efecto de la fracción volumétrica para la Figura 157 (izda.), cuando dicha fracción se aumenta se obtiene un aumento de la conductividad térmica, de acuerdo con lo esperado [3], pues cuando la fracción volumétrica es mayor, hay más partículas en la suspensión, lo que implica mayor movimiento browniano, más contactos entre partículas y mayor conductividad térmica.

Cuando la temperatura aumenta, el movimiento browniano se incrementa también, hay muchos más contactos entre partículas favoreciendo los mecanismos de transferencia de calor por conducción y por tanto el aumento del valor de la conductividad térmica del 
nanofluido. El efecto combinado de ambas variables (fracción y temperatura) conduce a mayores valores de conductividad térmica.

\section{Efecto del tipo de funcionalización covalente sobre la conductividad térmica}

Si se analiza el efecto que tiene el tipo de funcionalización covalente que se ha aplicado en este estudio (método ácido y método alcalino), sobre la conductividad térmica de los nanofluidos preparados con las nanopartículas preparadas a una fracción volumétrica de 0,02\%, Figura 157 (dcha.), se observa que se obtienen mayores incrementos con el método alcalino que con el método de funcionalización ácido. La cantidad de grupos carboxilos incorporados con la funcionalización ácida según los resultados obtenidos con el ensayo FTIR es mayor que los incorporados con la funcionalización alcalina, sin embargo, la estabilidad de los nanofluidos preparados con grafeno funcionalizado por el método ácido fue algo menor que por el método básico, por lo que puede que estén mejor dispersadas las funcionalizadas por el método alcalino generando un incremento en la conductividad térmica.
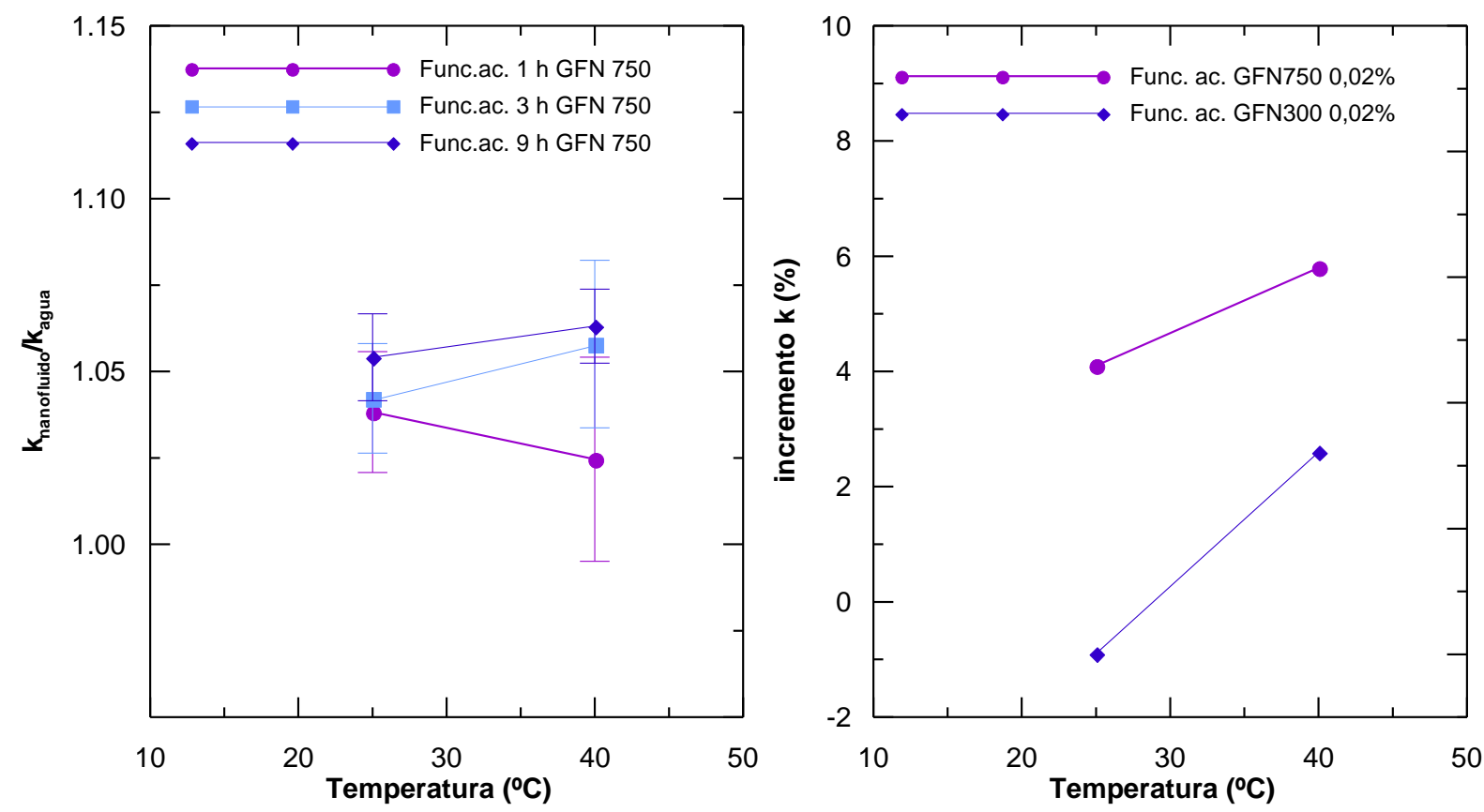

Figura 156. Aumento en la conductividad térmica de nanofluidos al $0.02 \%$ de GFN750 funcionalizado a distintos tiempos de permanencia en ácido (izda.). Comparativa materiales GFN750 y GFN300 (dcha.). 

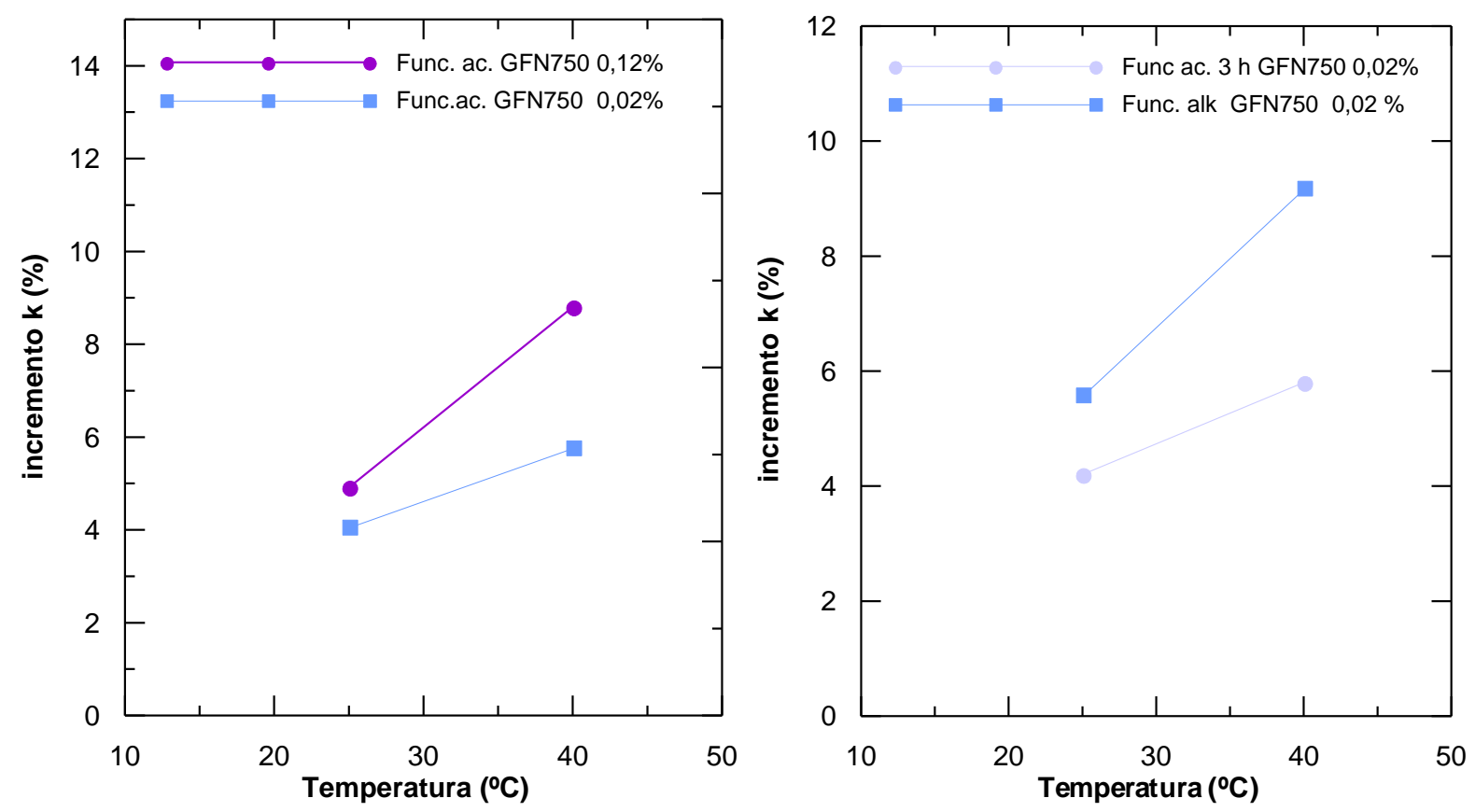

Figura 157. Conductividad térmica para el grafeno GFN750 Func. Ácida a distinta fracción volumétrica. Ensayos a dos temperaturas (izda.). Comparación métodos de funcionalización (dcha.).

\subsection{Resultados de la medida de viscosidad de los nanofluidos preparados con nanopartículas de grafeno}

El comportamiento reológico de los distintos nanofluidos preparados se ha medido con el reómetro Bohlin según el procedimiento descrito en el apartado 3.3.1 del capítulo III. Se han obtenido para cada uno de ellos la viscosidad dinámica del fluido para distintos gradientes de velocidad aplicados.

\subsubsection{Medida de la viscosidad en nanofluidos de grafeno sin funcionalizar}

En primer lugar, se midió la viscosidad de las suspensiones preparadas a partir de nanopartículas de grafeno dispersadas sólo con métodos mecánicos, concretamente con la sonda de ultrasonidos. Los reogramas obtenidos a partir de los cuales se obtiene la viscosidad absoluta, se muestran en las figuras Figura 158 y Figura 159. En la Figura 158 se ha representado la viscosidad obtenida con los nanofluidos de grafeno GFN750 preparados a distinta fracción volumétrica. Puede observarse como presentan un comportamiento newtoniano para gradientes de velocidad entre 100 y $400 \mathrm{~s}^{-1}$. Sin embargo, dicho 
comportamiento deja de ser newtoniano a gradientes de velocidad más altos (400-1000 s-1), obteniéndose valores de viscosidad cada vez mayores acordes a un comportamiento dilatante del nanofluido. Este tipo de comportamiento no newtoniano también se ha constatado en los artículos consultados [42], observándose que la viscosidad de los nanofluidos presenta una fuerte dependencia con el tamaño de la nanopartícula dispersada. Para analizar este fenómeno de forma más precisa sería necesario utilizar equipos que permitan el estudio de la reología a altas cizallas sin originar error de medida debido a la centrifugación de las muestras (Vórtices de Taylor).

De las tres fracciones estudiadas se observa como la viscosidad del nanofluido preparado a mayor fracción volumétrica $(0,25 \%)$ presenta el mayor aumento de viscosidad.

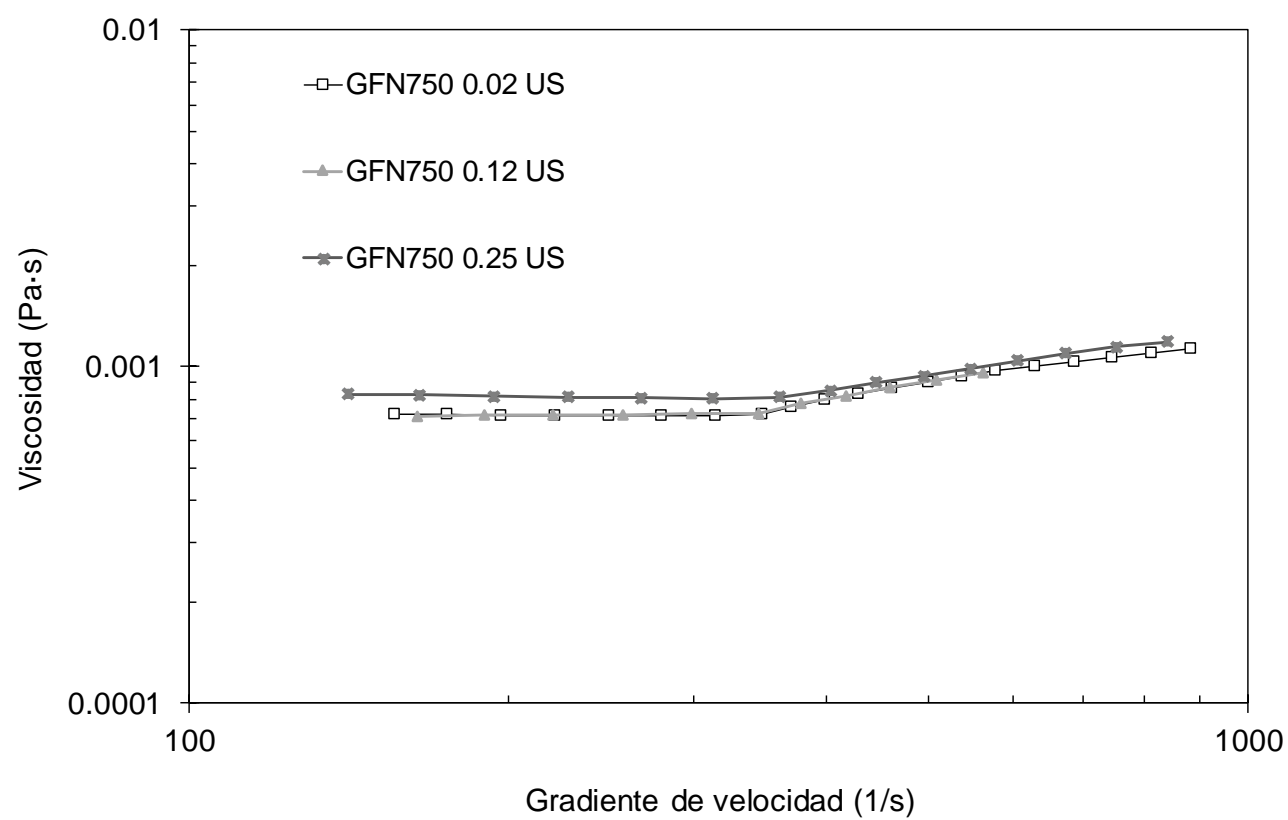

Figura 158. Viscosidad del nanofluido GFN750 a distinta fracción volumétrica preparado con sonda de ultrasonidos. Ensayo de viscosidad realizado a $40^{\circ} \mathrm{C}$

El comportamiento reológico de las suspensiones preparadas con el grafeno con menor superficie específica GFN300 es muy similar al observado con los nanofluidos con GFN750, Figura 159. 


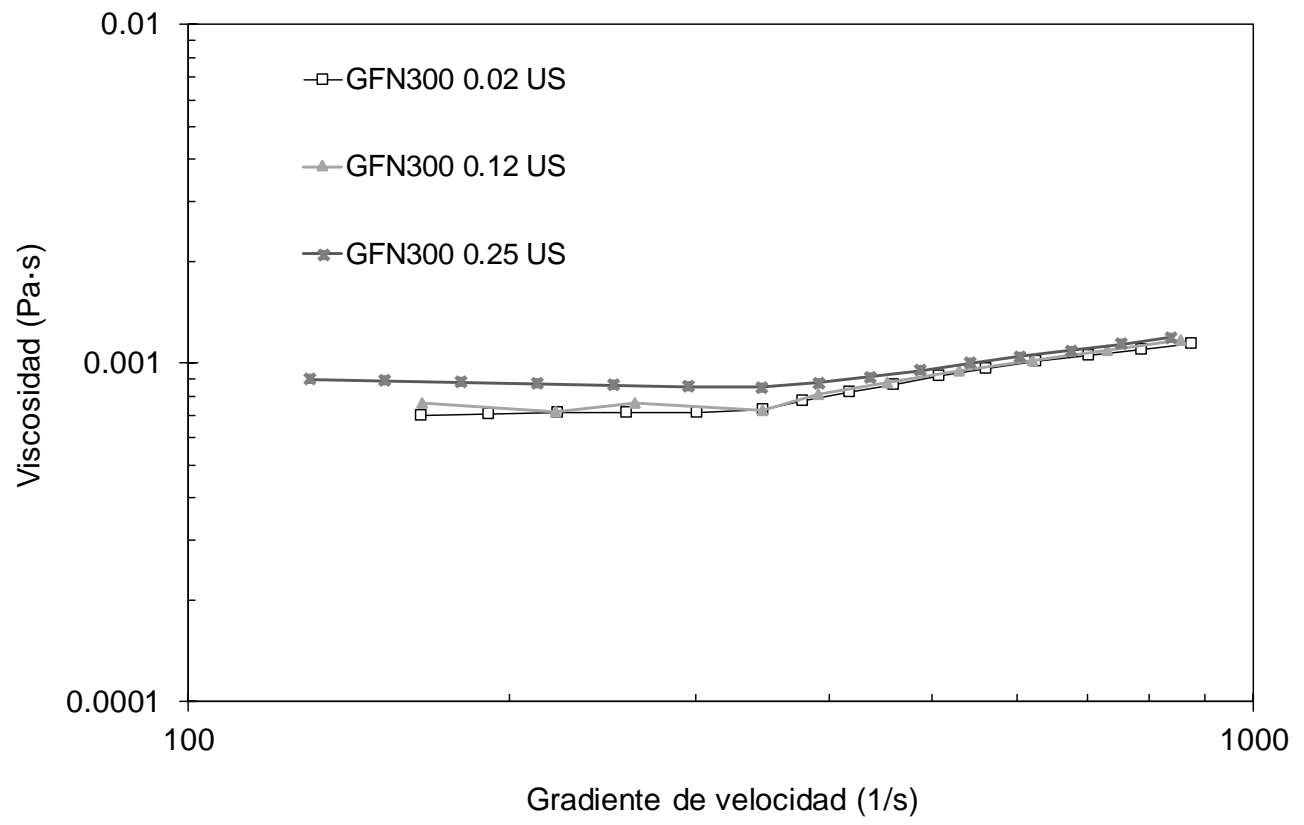

Figura 159. Viscosidad del nanofluido GFN300 a distinta fracción volumétrica preparado con sonda de ultrasonidos. Ensayo de viscosidad realizado a $40^{\circ} \mathrm{C}$

Estos nanofluidos de grafeno (tanto los preparados con GFN750 como los de GFN300) presentan una viscosidad absoluta mayor que la del agua, tal y como puede observarse en la Tabla 36, a medida que se aumenta la fracción volumétrica (alcanzando un $8 \%$ en el caso de suspensiones más concentradas). Estos aumentos no son muy significativos si se comparan con los aumentos en viscosidad obtenidos con los nanofluidos preparados a partir de óxidos, aunque la principal razón no es la naturaleza del material sino la baja fracción de sólidos a los que se preparan las suspensiones.

Tabla 36.Valores de viscosidad absoluta de los nanofluidos de grafeno preparados a distinta fracción volumétrica mediante sonda de ultrasonidos

\begin{tabular}{lcc}
\hline \multicolumn{1}{r}{ Tipo de muestra } & $\begin{array}{c}\text { Promedio de la } \\
\text { viscosidad (Pa.s) }\end{array}$ & $\begin{array}{c}\text { Aumento relativo respecto a la } \\
\text { viscosidad del agua (\%) }\end{array}$ \\
\hline Agua & $7,50 \mathrm{E}-04 \pm 0,9 \mathrm{E}-05$ & - \\
GFN750 0,02 \% & $7,55 \mathrm{E}-04 \pm 0,8 \mathrm{E}-05$ & 0,6 \\
GFN750 0,12 \% & $7,60 \mathrm{E}-04 \pm 0,9 \mathrm{E}-05$ & 1,3 \\
GFN750 0,25 \% & $8,14 \mathrm{E}-04 \pm 1,2 \mathrm{E}-05$ & 8,6 \\
GFN300 0,02 \% & $7,53 \mathrm{E}-04 \pm 0,7 \mathrm{E}-05$ & 0,4 \\
GFN300 0,12\% & $7,65 \mathrm{E}-04 \pm 0,9 \mathrm{E}-05$ & 2,0 \\
GFN300 0,25\% & $8,00 \mathrm{E}-04 \pm 1,1 \mathrm{E}-05$ & 6,7 \\
\hline
\end{tabular}




\subsubsection{Medida de la viscosidad en nanofluidos de grafeno funcionalizados}

Dada la poca estabilidad de los nanofluidos preparados con nanopartículas de grafeno con su superficie sin funicionalizar se optó por su funcionalización con el objetivo de mejorar la dispersión de las nanopartículas en el fluido base. Para ello se incorporaron aditivos surfactantes como el Sodiodecilsulfato SDS, la goma arábiga G.A. y el TRITON. Estos surfactantes se adicionaron en distintas fracciones, caracterizando el comportamiento reológico de los nanofluidos en el reómetro, según el procedimiento descrito en el apartado 3.3.1.

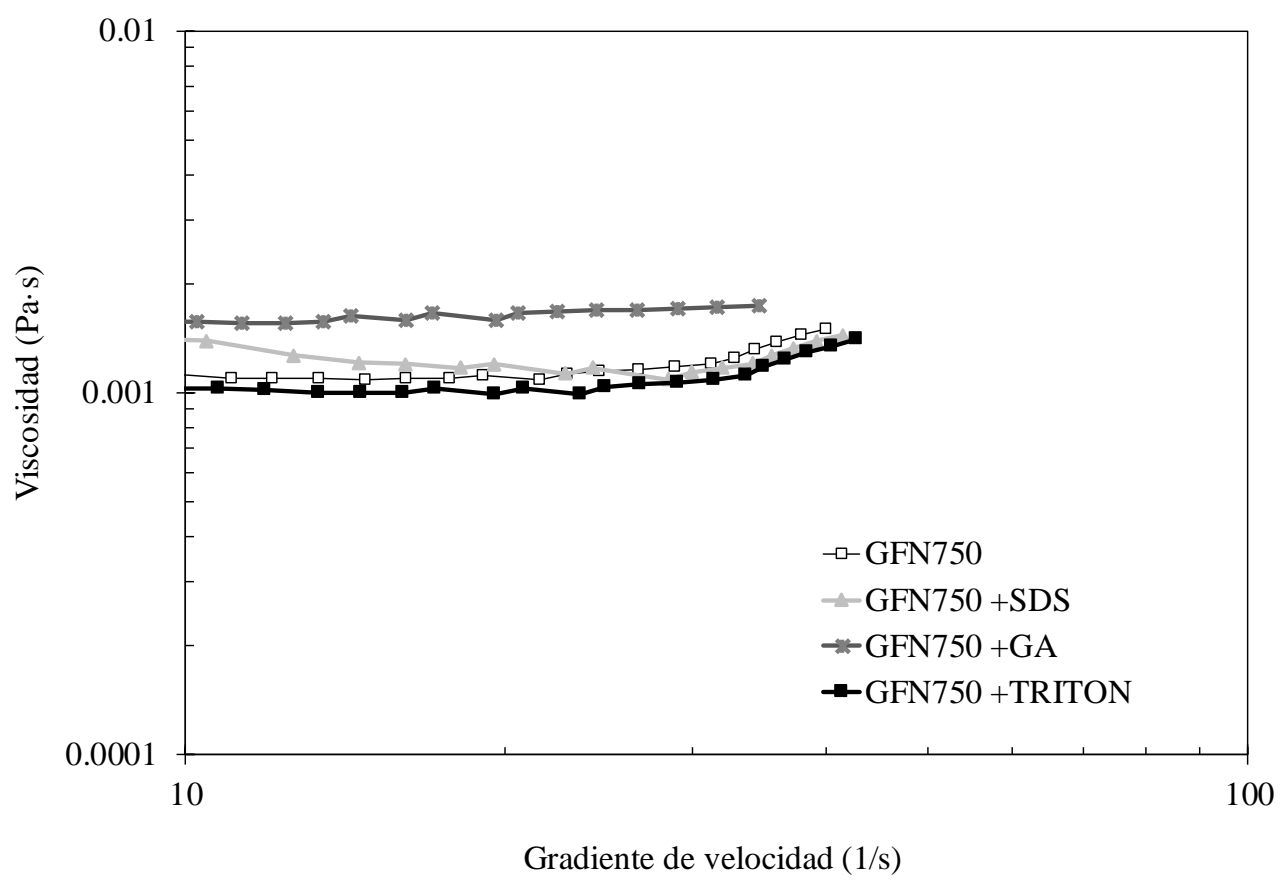

Figura 160. Efecto del tipo de surfactante utilizado sobre la viscosidad del nanofluido a una $T=40^{\circ} \mathrm{C}$

En la Figura 160 se aprecia que la viscosidad de las suspensiones de grafeno a fracciones volumétricas elevadas $(0,25 \%)$ al añadir surfactantes (en una proporción en peso surfactante:grafeno de $10: 1$ ) disminuye respecto de la que presenta la suspensión de grafeno sin aditivos en el caso del aditivo SDS y el tritón, no así para la GA.

Tomando únicamente los valores en el rango en el que el fluido se comporta de forma newtoniana se ha obtenido el valor de la viscosidad absoluta a $40^{\circ} \mathrm{C}$ para analizar el incremento de la misma respecto al fluido base agua a fracciones volumétricas bajas $(0,12 \%)$. Los datos se resumen en la Tabla 37. En este caso cuando se utilizan surfactantes para mantener los nanofluidos estables no se observa una menor viscosidad del nanofluido si se 
compara con el fluido base o con la suspensión de grafeno sin funcionalizar. De todos los aditivos estudiados, la goma arábica es el dispersante con el que se obtiene un mayor incremento en viscosidad, en suspensiones diluidas y concentradas, por lo que su aplicación no es aconsejable, en primer lugar, porque no mejora la conductividad ni la estabilidad (ver gráfico de Figura 152) e incrementa en gran medida la viscosidad. El aditivo Tritón lleva a incrementos en viscosidad similares al SDS, pero con el Tritón no se han observado incrementos significativos en la conductividad térmica tal y como ocurría con la utilización del SDS, como se ha observado en el apartado anterior de conductividad térmica. En consecuencia, se puede concluir que el mejor tipo de aditivo para los nanofluidos de grafeno de los ensayados es el SDS.

Si la funcionalización realizada a las nanopartículas es por el método covalente en lugar de la utilización de aditivos, los resultados de viscosidad de los nanofluidos son mejores. Tanto con el método alcalino como con el ácido, el incremento en viscosidad respecto al fluido base es sólo del 5\%.

Tabla 37. Comparación de las viscosidades de los nanofluidos de grafeno preparados con distintas fracciones de surfactantes a $40 \circ \mathrm{C}$

\begin{tabular}{lcc}
\hline \multicolumn{1}{c}{ Tipo de muestra } & $\begin{array}{c}\text { Promedio de la } \\
\text { viscosidad (Pa.s) }\end{array}$ & $\begin{array}{c}\text { Aumento relativo respecto a la } \\
\text { viscosidad del agua (\%) }\end{array}$ \\
\hline Agua & $7,5 \mathrm{E}-04 \pm 0,9 \mathrm{E}-05$ & - \\
GFN750 0,12 \% & $7,6 \mathrm{E}-04 \pm 0,8 \mathrm{E}-05$ & 1,3 \\
GFN750 0,12 \% +Triton X100 (10-1) & $7,9 \mathrm{E}-04 \pm 1,0 \mathrm{E}-05$ & 5,4 \\
GFN750 0,12 \% + GA (10-1) & $1,1 \mathrm{E}-03 \pm 1,2 \mathrm{E}-05$ & 47,3 \\
GFN750 0,12 \% + SDS (5_1) & $7,8 \mathrm{E}-04 \pm 0,9 \mathrm{E}-05$ & 4,0 \\
GFN750 0,12 \% + SDS (10-1) & $8,1 \mathrm{E}-04 \pm 1,1 \mathrm{E}-05$ & 8,1 \\
GFN750 0,12 \% + SDS (15-1) & $8,9 \mathrm{E}-04 \pm 1,2 \mathrm{E}-05$ & 18,9 \\
GFN750 0,12 \% Func.Acida & $7,8 \mathrm{E}-04 \pm 0,8 \mathrm{E}-05$ & 4,0 \\
GFN750 0,12 \% Func.Alcalina & $7,8 \mathrm{E}-04 \pm 0,9 \mathrm{E}-05$ & 4,7 \\
\hline
\end{tabular}

Puede concluirse que para el caso de los nanofluidos de grafeno su funcionalización por el método covalente permite obtener nanofluidos estables, con incrementos de viscosidad reducidos (5\%) y aumentos en conductividad del $10 \%$, resultando ser, en consecuencia, el mejor método para la preparación de los nanofluidos de grafeno. 


\section{Estudio comparativo y de viabilidad de los nanofluidos preparados}

Tras el análisis de los resultados de estabilidad, conductividad térmica y viscosidad, se ha llevado a cabo un estudio de los distintos modelos teóricos que predicen el comportamiento térmico final de los nanofluidos, para ver cuál de ellos se ajusta mejor a los resultados experimentales obtenidos. Con la modelización del comportamiento térmico de los nanofluidos será posible optimizar el nanofluido en futuras preparaciones.

Además del estudio de modelización, se ha llevado a cabo un estudio de viabilidad de aplicación de los nanofluidos preparados. Uno de los objetivos principales de la tesis ha sido validar si la dispersión de nanopartículas sólidas en un fluido base como el agua conducen finalmente a un aumento significativo de la conductividad térmica del nanofluido, que permita su posterior aplicación como fluido térmico. Las acciones propuestas para dicha validación fueron las siguientes:

- Realizar una comparativa de los nanofluidos preparados y caracterizados utilizando los módulos de Prandtl y Mouromtseff

- Validar la transferencia de calor de uno de los nanofluidos en un bucle experimental

Estos dos estudios indicarán las ventajas y desventajas de los distintos tipos de nanofluidos preparados a escala de laboratorio a lo largo de la tesis (óxidos metálicos, nanotubos de carbono y grafeno), permitiendo conocer que tipología de material y procedimiento de preparación es el más viable técnica y económicamente.

\subsection{Modelización de la conductividad térmica de los nanofluidos}

Tras la revisión bibliográfica efectuada sobre los estudios experimentales con nanofluidos realizados por distintos investigadores se ha constatado una relación no lineal entre la conductividad y la fracción volumétrica de nanopartículas en el fluido base. De hecho, se han observado incrementos anómalos a bajas fracciones respecto a los valores de conductividad que predicen los modelos teóricos, como puede observarse en la Figura 161. En esta figura aparecen representados junto al modelo teórico de Maxwell, los valores experimentales de la conductividad del nanofluido respecto a la conductividad del fluido base ( $\left.\mathrm{k}_{\mathrm{eff}} / \mathrm{k}_{\mathrm{bf}}\right)$, frente a $\beta \Phi$, donde $\beta \equiv\left[k_{p}-k_{b f}\right] /\left[k_{p}+2 k_{b f}\right]$, y $\Phi$ es la fracción volumétrica. 


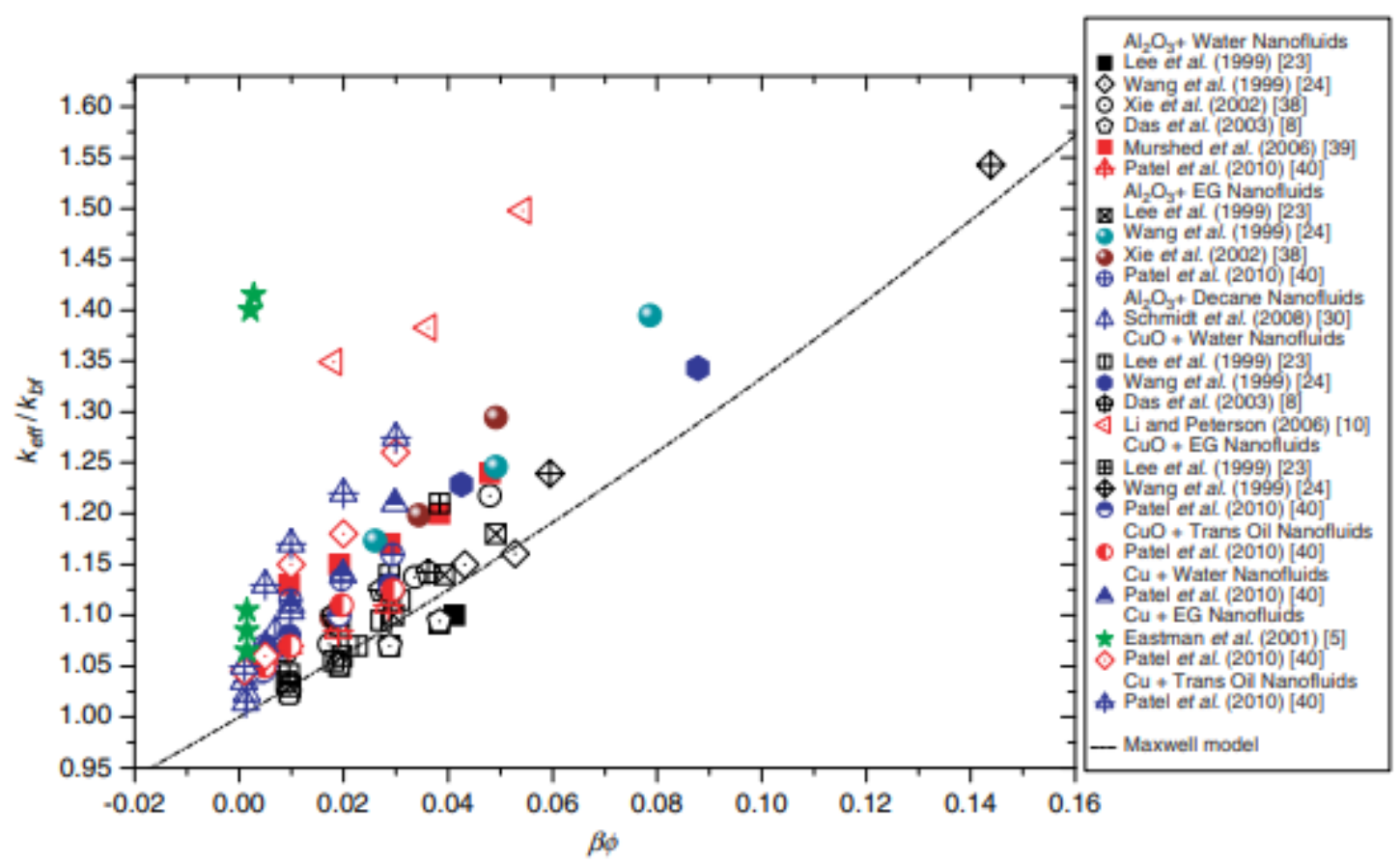

Figura 161. Comparación de los valores de conductividad efectiva experimentales obtenidos por diversos autores y los predichos por el modelo teórico de Maxwell [106]

Resulta imprescindible mencionar que dicho aumento anómalo no ha sido observado por otros grupos de investigadores [14]. Estas incongruencias en los valores experimentales obtenidos entre los distintos grupos investigadores pueden deberse a la distinta naturaleza de las nanopartículas (método de síntesis, pureza), al método de preparación del nanofluido (dispersión, estabilidad) y/o al error del método de medida. Tener un método normalizado de medida y trabajar con nanofluidos estándar para validar los métodos de preparación y caracterización, sería el camino adecuado para luego poder modelizar el comportamiento de los nanofluidos.

El primer modelo de Maxwell postula que la conductividad térmica depende linealmente de la fracción (Ec.1) Este modelo se ajusta bastante bien cuando la fracción volumétrica de nanopartículas es baja y la relación $\left(\mathrm{k}_{\mathrm{p}} / \mathrm{k}_{\mathrm{f}}\right)$ es alta.

Sin embargo, la mayor parte de los resultados experimentales analizados en la bibliografía no siguen esta tendencia y presentan dependencia de otros factores, como ya se ha comentado anteriormente. En los modelos clásicos hay ciertos mecanismos que no están considerados y que pueden contribuir a predecir los mecanismos de conducción si éstos se incluyen en los modelos. Das et al [106] fueron los primeros en demostrar una dependencia fuerte de la 
conductividad térmica con la temperatura, siguiéndoles otros investigadores como Ravikanth et al. y Li et al $[20,66]$. Cuando se incrementa la temperatura se produce un aumento en el movimiento browniano de las nanopartículas que afecta el estado de aglomeración de las mismas. Otros factores como el tipo de surfactante utilizado en la dispersión y estabilización de las nanopartículas [71 y 72] o la forma de partícula [30 y83], influyen sobre el resultado final de la conductividad térmica en el nanofluido, por lo que estos factores deben considerase en los modelos teóricos. Los nuevos modelos propuestos se dividen, en función del factor considerado, en dos grandes tipos:

- Mecanismos estáticos: se consideran factores asociados al estado de agregación de las nanopartículas, a la resistencia térmica de la interfase nanopartícula-fluido base, y a la forma de las partículas.

- Mecanismos dinámicos: relacionados con la colisión entre partículas como consecuencia de su movimiento browniano y la convección inducida debido al dicho movimiento. Este último mecanismo podría explicar la dependencia de los aumentos de conductividad térmica relacionados con la temperatura.

\section{Clasificación de los modelos de conductividad térmica para nanofluidos}

\section{$\underline{\text { Modelos clásicos }}$}

Son modelos basados en mecanismos estáticos, incluyendo la conductividad térmica de los componentes y considerando su fracción volumétrica, su forma, su distribución. Entre ellos podemos citar:

- Modelo de Maxwell.

- Modelo de Bruggman, parecido al de Maxwell pero adecuado a fracciones volumétricas altas.

- Modelo de Hamilton-Crosser, que introduce un factor de esfericidad $\Psi$, siendo dicho modelo igual al de Maxwell cuando el factor de esfericidad es igual a 1.

- Modelo de Rayleigh.

- Modelo de Nan.

- Modelo Hasselman, que incluye una barrera térmica. 


\section{Modelos basados en la teoría de la nanocapa}

Estos modelos basan su efecto en una nanocapa interfacial que actúa como puente entre la nanopartícula y el fluido. Dichos modelos tienen sentido para nanofluidos con nanopartículas con un diámetro menor a $10 \mathrm{~nm}$. Entre los modelos que consideran dicho factor podemos citar:

- Modelo de Leong

- Modelo de Yu and Choi

- $\quad$ Modelo de Xue

- Modelo de Murshed

\section{Modelos dinámicos basados en el movimiento browniano}

Como ya se ha comentado, dichos modelos consideran el factor de aumento de la conductividad térmica ocasionado por el choque entre partículas debido al movimiento browniano de las mismas. Estos modelos se pueden dividir a su vez en modelos clásicos o computacionales:

- Modelo de Jan and Choi

- Modelo de Xuan

- $\quad$ Modelo de Kumar

- Modelo de Prasher

- Modelo de Yang

- Modelo Keblinski, computacional.

Para la modelización de los nanofluidos preparados se han seleccionado varios modelos teóricos de cada grupo con el objetivo de ver qué mecanismo de los anteriormente citados reproduce mejor los resultados experimentales obtenidos. 


\subsubsection{Modelización y análisis de los resultados de la conductividad térmica de nanofluidos} preparados con nanopartículas esféricas (sílice, alúmina, oxido de cobre II)

A continuación, se definen los modelos teóricos utilizados para la modelización de los nanofluidos preparados a partir de óxidos. Estos modelos se han elegido en base a la bibliografía consultada $[18,61,106]$. En cada uno de ellos se mencionan los factores que se consideran en el cálculo del aumento en conductividad térmica del nanofluido.

\section{Modelo de Maxwell}

El primer modelo planteado fue el modelo de Maxwell (Ec.1) en 1873, uno de los modelos más populares, aunque presenta varias limitaciones ya que presupone que las partículas del nanofluido son esféricas y que la fracción volumétrica de las mismas en el fluido base es baja $(\Phi<1)$. Además, es un modelo estático, que no considera la interacción entre las nanopartículas. Es un modelo clásico elemental válido para cualquier medio heterogéneo, prediciendo el aumento en conductividad del nanofluido en base a factores convencionales: las conductividades específicas del fluido $\left(\mathrm{k}_{\mathrm{bf}}\right)$ y del sólido introducido $\left(\mathrm{k}_{\mathrm{p}}\right)$, y la fracción volumétrica del mismo ( $\Phi)$.

\section{Modelo de Rayleigh}

En 1892, Rayleigh [108] fue el primero en analizar la conductividad térmica efectiva de una mezcla con una distribución regular de partículas. El modelo de Rayleigh es un modelo estático que deriva del modelo de Maxwell.

$$
k_{n f}=k_{b f}+3 \Phi \frac{k_{p}-k_{b f}}{2 k_{b f}+k_{p}-\Phi\left(1+3,939 \Phi^{7 / 3}\left(\left(k_{p}-k_{b f}\right) /\left(4 k_{b f}-3 k_{p}\right)\right)\right)\left(k_{p}-k_{b f}\right)} k_{b f}
$$

\section{Modelo de Hamilton y Crosser}

Tal y como se ha comentado, una de las limitaciones del modelo de Maxwell es la de suponer partículas con geometría esférica. Una extensión a este modelo sería introducir un factor de forma, n, y deformar las esferas hasta convertirlas en elipsoides, que podrían considerarse 
como cuasi-cilindros. Esta modificación la plantearon Hamilton y Crosser en 1962, adoptando un factor de forma, $m=3 / \Psi$. Donde $\Psi$ es el factor de esfericidad de las partículas, que toma el valor 1 cuando éstas son totalmente esféricas y 0,5 para partículas alargadas [61, 111]. Cuando en el nanofluido las partículas son alargadas, en fracciones diluidas el efecto de la orientación de las mismas, si la dispersión es buena, puede obviarse y utilizar una aproximación similar al modelo de Maxwell. Por este motivo, para $m=3$, en partículas esféricas, el modelo de Hamilton se reduce al moldeo de Maxwell. Para partículas alargadas, el moldeo de Hamilton conduce a conductividades térmicas mayores.

$$
k_{n f}=\frac{k_{p}+(m-1) k_{b f}-(m-1) \Phi\left(k_{b f}-k_{p}\right)}{k_{p}+(m-1) k_{b f}+\Phi\left(k_{b f}-k_{p}\right)} k_{b f}
$$

\section{Modelo de Fricke}

Fricke en 1953 [109], obtuvo una ecuación para la conductividad del fluido con partículas con forma elipsoidal disueltas en una matriz. Para partículas alargadas en forma de aguja delgada, la ecuación se reduce a la siguiente expresión:

$$
k_{n f}=k_{b f}+\frac{1}{3} \Phi \frac{5 k_{b f}+k_{p}}{k_{b f}+k_{p}}\left(k_{p}-k_{b f}\right)
$$

Cuando las partículas son largas pero planas la ecuación a aplicar sería:

$$
k_{n f}=k_{b f}+\frac{1}{3} \Phi \frac{k_{b f}+2 k_{p}}{k_{p}}\left(k_{p}-k_{b f}\right)
$$

\section{Modelo de Nan et al.}

En 2003, Nan et al .[110] obtuvieron una ecuación equivalente a partir de la ecuación de Frike pero considerando una mezcla de nanotubos con fluido base.

$$
k_{n f}=\frac{3+\Phi\left(k_{p} / k_{b f}\right)}{3-2 \Phi} k_{b f}
$$




\section{Modelo de Krischer}

En 1963, Krischer [61] consideró una matriz de elementos con una resistencia específica distribuidos en el fluido base.

$$
k_{n f}=\left[\frac{1-f}{(1-\Phi) k_{b f}+\Phi k_{p}}+f\left(\frac{1-\Phi}{k_{b f}}+\frac{\Phi}{k_{p}}\right)\right]^{-1}
$$

Considera el estado de ordenación de las partículas mediante un factor " $f$ " equivalente a la fracción de resistencias paralelas en una matriz rectangular. Cuando $f$ tiene como valor 0 significa que la totalidad de las partículas están ordenadas en serie (generando una red de elevada conductividad térmica) y cuando f toma el valor 1 es porque las partículas están alineadas en paralelo (generando así una conductividad térmica baja).

\section{Modelos de mezclas}

También se han propuesto modelos para mezclas, en los cuales cuando el factor $n$ toma el valor 1 las partículas están alineadas en paralelo, y cuando $n=-1$ están alineadas en serie. Dichos modelos predicen la conductividad térmica del nanofluido mediante la siguiente expresión:

$$
\left(k_{n f}\right)^{n}=\Phi\left(k_{p}\right)^{n}+(1-\Phi)\left(k_{b f}\right)^{n} \quad-1<n<1
$$

\section{Modelo Yu y Choi}

En 2003 Yu y Choi propusieron un nuevo modelo a partir de la modificación del modelo de Maxwell considerando el efecto de la nanocapa. La teoría de la nanocapa considera que el líquido se ordena alrededor de las partículas formando capas. La expresión de la conductividad térmica se obtiene a partir de la siguiente expresión:

$$
k_{n f}=\frac{k_{p}+2 k_{b f}+2\left(k_{p}-k_{b f}\right)(1+\beta)^{3} \Phi}{k_{p}+2 k_{b f}-\left(k_{p}-k_{b f}\right)(1+\beta)^{3} \Phi} k_{b f}
$$


Donde $\beta$ es la relación de espesor de la nanocapa del líquido que envuelve la partícula respecto al radio de la nanopartícula. El espesor de la nanocapa de líquido que rodea a la partícula $\gamma$ puede calcularse a partir de la siguiente expresión:

$$
\gamma=0,01(T-273) r_{p}^{0,35}
$$

siendo T la temperatura en Kelvin, y $r_{p}$ el radio de la nanopartícula en nanómetros.

\section{Modelo Xue}

En 2005, Xue [113] consideró la forma especial de los nanotubos, que se caracterizan por tener una relación longitud/diámetro del nanotubo muy grande y una distribución espacial característica, proponiendo como modelo la siguiente expresión:

$$
k_{n f}=\frac{1-\Phi+2 \Phi \frac{k_{p}}{k_{p}-k_{b f}} \ln \left(\frac{k_{p}+k_{b f}}{2 k_{b f}}\right)}{1-\Phi+2 \Phi \frac{k_{b f}}{k_{p}-k_{b f}} \ln \left(\frac{k_{p}+k_{b f}}{2 k_{b f}}\right)} k_{b f}
$$

\section{Modelo Bruggeman y Murshed}

Bruggeman propuso un modelo que predice con bastante exactitud el aumento en conductividad para partículas completamente esféricas y homogéneas sin la limitación de aplicar a nanofluidos diluidos, que Murshed resolvió obteniendo la siguiente ecuación:

$$
k_{n f}=\frac{1}{4}\left[(3 \Phi-1) k_{p}+(2-3 \Phi) k_{b f}\right]+\frac{k_{b f}}{4} \sqrt{\Delta}
$$

donde $\Delta$ :

$$
\Delta=\left[(3 \Phi-1)^{2}\left(\frac{k_{p}}{k_{b f}}\right)^{2}+(2-3 \Phi)^{2}+2\left(2+9 \Phi-9 \Phi^{2}\right)\left(\frac{k_{p}}{k_{b f}}\right)\right]
$$

\section{Modelo Leong}

En 2006, Leong [86, 94, 61] propuso un novedoso modelo para nanopartículas esféricas basado en la teoría de la nanocapa. Este modelo sigue la siguiente expresión: 


$$
k_{n f}=\frac{\left(k_{p}-k_{l r}\right) \Phi k_{d r}\left(2 \gamma_{1}^{3}-\gamma^{3}+1\right)+\left(k_{p}+2 k_{l r}\right) \gamma_{1}^{3}\left[\Phi \gamma^{3}\left(k_{l r}-k_{b f}\right)+k_{b f}\right]}{\gamma_{1}^{3}\left(k_{p}+2 k_{l r}\right)-\left(k_{p}-k_{l r}\right) \Phi\left(\gamma_{1}^{3}+\gamma^{3}-1\right)}
$$

Donde:

$k_{/ r}$ es la conductividad térmica de la nanocapa interfacial

siendo

$$
\begin{gathered}
\gamma=1+\frac{h}{r_{p}} \\
\gamma_{1}=1+\frac{h}{\left(2 r_{p}\right)}
\end{gathered}
$$

h es el espesor de la nanocapa interfacial que se obtiene a partir de la ecuación:

$$
h=\sigma(2 \pi)^{1 / 2}
$$

Mientras que $\sigma$ es un parámetro que caracteriza la difusividad en el límite de la nanocapa y cuyo valor típico se encuentra entre 0,2-0,8 nm.

Cuando las nanopartículas disueltas en el nanofluido presentan forma cilíndrica la ecuación del modelo se expresa como:

$$
k_{n f}=\frac{\left(k_{p}-k_{l r}\right) \Phi k_{d r}\left(2 \gamma_{1}^{2}-\gamma^{2}+1\right)+\left(k_{p}+k_{l r}\right) \gamma_{1}^{2}\left[\Phi \gamma^{2}\left(k_{l r}-k_{b f}\right)+k_{b f}\right]}{\gamma_{1}^{2}\left(k_{p}+2 k_{l r}\right)-\left(k_{p}-k_{l r}\right) \Phi\left(\gamma_{1}^{2}+\gamma^{2}-1\right)}
$$

\section{Modelo Xuan}

En 2003, Xuan propuso un modelo que tiene en cuenta el movimiento Browniano y la agregación de las nanopartículas formando "clusters" [61, 112]. Habitualmente el movimiento browniano se desprecia en partículas con tamaño micrométrico, sin embargo, se ha demostrado que el efecto browniano puede afectar a la conductividad térmica de los nanofluidos ya que puede ocasionar movimientos de convección en el fluido base, y que van a depender de la temperatura, densidad y tamaño de las nanopartículas.

Basándose en estas premisas, propusieron un modelo que tiene en cuenta el movimiento Browniano y que se expresa como sigue:

$$
k_{e f f}=k_{f} \frac{k_{p}+2 k_{f}+2 \Phi\left(k_{p}-k_{f}\right)}{k_{p}+2 k_{f}-\Phi\left(k_{p}-k_{f}\right)}+\frac{1}{2} \rho_{p} c_{p} \Phi \sqrt{\frac{k_{B} T}{3 \pi \mu_{f} R_{c l}}}
$$


donde $R_{c l}$ es el radio aparente de los clusters y $K_{B}$ es la constante de Boltzmann.

Se puede ver que el modelo de Xuan et al., añade un término que contiene algunos factores de efecto específicos del movimiento browniano, como temperatura, viscosidad y tamaño de los aglomerados de nanopartículas.

Para ver que tipología de modelo se ajusta mejor a los resultados de conductividad térmica

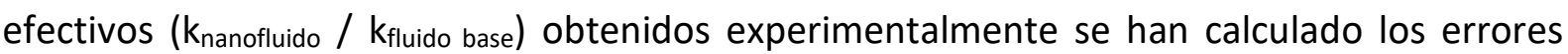
relativos en \% para cada tipología de nanofluido preparado (a partir de nanopartículas adquiridas en sólido u obtenido a partir de la dilución de una suspensión comercial).

Dicho error relativo $\left(e_{r}\right)$ se ha calculado según la siguiente expresión:

$$
e_{r}=\frac{\left|k_{m}-k_{\text {exp. }}\right|}{k_{\text {exp. }}} \cdot 100
$$

Donde $\mathrm{k}_{\mathrm{m}}$ es la conductividad obtenida con el modelo teórico aplicado y $\mathrm{k}_{\exp }$ la medida experimentalmente en laboratorio en los nanofluidos preparados. 
Tabla 38. Error relativo (\%) de la conductividad térmica teórica con la experimental a $40^{\circ} \mathrm{C}$.

\begin{tabular}{|c|c|c|c|c|c|c|c|c|c|c|c|c|c|c|c|}
\hline Nanofluido & $\begin{array}{c}\varphi \\
\text { [v\%] }\end{array}$ & Maxwell & Rayleigh & Fricke & $\begin{array}{l}\text { Nan } \\
\text { et al. }\end{array}$ & $\begin{array}{l}\text { Hamilton } \\
\text { and } \\
\text { Crosser }\end{array}$ & $\begin{array}{l}\text { Krischer } \\
(f=1)\end{array}$ & $\begin{array}{l}\text { Krischer } \\
(f=-1)\end{array}$ & $\begin{array}{c}\text { Mixture } \\
\text { model } \\
(n=1)\end{array}$ & $\begin{array}{c}\text { Mixture } \\
\text { model } \\
(n=-1)\end{array}$ & $\begin{array}{l}\text { Yu } \\
\text { and } \\
\text { Choi }\end{array}$ & Xue & Bruggeman & $\begin{array}{l}\text { Leong } \\
\text { at al. }\end{array}$ & $\begin{array}{l}\text { Xuan } \\
\text { et all }\end{array}$ \\
\hline \multirow{3}{*}{$\begin{array}{l}\text { Aerosil } \\
200\end{array}$} & 0,5 & 1,81 & 1,81 & 1,82 & 2,10 & 1,81 & 1,67 & 2,23 & 1,95 & 1,67 & 1,67 & 1,84 & 0,40 & 0,26 & 1,81 \\
\hline & 1 & 0,65 & 0,65 & 0,69 & 1,23 & 0,65 & 0,38 & 1,49 & 0,94 & 0,38 & 0,39 & 0,72 & 0,79 & 0,52 & 0,65 \\
\hline & 5 & 2,42 & 2,42 & 2,53 & 5,39 & 2,42 & 1,09 & 6,57 & 3,76 & 1,09 & 1,07 & 2,75 & 4,03 & 2,62 & 2,42 \\
\hline \multirow{3}{*}{$\begin{array}{l}\text { Ludox } \\
\text { TM-50 }\end{array}$} & 0,5 & 0,78 & 0,78 & 0,79 & 1,06 & 0,78 & 0,64 & 1,20 & 0,92 & 0,64 & 0,64 & 0,81 & 0,40 & 0,25 & 0,78 \\
\hline & 1 & 4,24 & 4,24 & 4,27 & 4,84 & 4,24 & 3,96 & 5,11 & 4,53 & 3,96 & 3,97 & 4,31 & 0,79 & 0,50 & 4,24 \\
\hline & 5 & 3,91 & 3,91 & 4,02 & 6,92 & 3,91 & 2,56 & 8,13 & 5,27 & 2,56 & 2,54 & 4,24 & 4,03 & 2,51 & 3,91 \\
\hline \multirow{3}{*}{$\begin{array}{l}\text { Aeroxide } \\
\text { Alu }\end{array}$} & 0,5 & 1,01 & 0,89 & 0,89 & 8,62 & 8,51 & 0,89 & 0,04 & 66,79 & 25,00 & 0,04 & 2,75 & 0,40 & 0,93 & 0,71 \\
\hline & 1 & 1,02 & 1,01 & 1,01 & 16,26 & 16,10 & 1,01 & 0,83 & 196,35 & 48,61 & 0,83 & 4,70 & 0,79 & 1,87 & 0,77 \\
\hline & 5 & 1,05 & 9,07 & 9,07 & 82,29 & 83,91 & 9,07 & 0,15 & 343,31 & 238,68 & 0,15 & 27,55 & 4,03 & 9,35 & 8,36 \\
\hline \multirow{3}{*}{$\begin{array}{l}\text { Aerodisp } \\
\text { W925 }\end{array}$} & 0,5 & 1,02 & 0,24 & 0,24 & 7,41 & 7,30 & 0,24 & 1,16 & 64,93 & 23,61 & 1,16 & 1,60 & 1,44 & 0,93 & 0,30 \\
\hline & 1 & 1,02 & 0,90 & 0,90 & 16,14 & 15,98 & 0,90 & 0,93 & 196,04 & 48,45 & 0,93 & 4,59 & 2,91 & 1,87 & 0,79 \\
\hline & 5 & 1,05 & 9,78 & 9,78 & 83,46 & 85,09 & 9,78 & 0,49 & 344,88 & 240,86 & 0,49 & 28,37 & 16,40 & 9,35 & 9,19 \\
\hline \multirow{3}{*}{$\begin{array}{l}\text { Óxido de } \\
\text { cobre }\end{array}$} & 0,5 & 0,03 & 0,03 & 4,05 & 3,95 & 0,73 & 0,90 & 31,7 & 13,09 & 0,90 & 0,48 & 0,53 & 0,02 & 0,53 & 0,03 \\
\hline & 1 & 1,84 & 1.84 & 6,08 & 5,91 & 0,34 & 3,52 & 71,9 & 23,58 & 3,52 & 2,72 & 2,81 & 1,74 & 2,81 & 1,83 \\
\hline & 5 & 1,64 & 1,64 & 38,04 & 38,59 & 8,87 & 6,51 & 729 & 119,54 & 6,51 & 2,96 & 3,38 & 2,82 & 3,33 & 1,64 \\
\hline \multicolumn{2}{|c|}{ Suma de errores } & 23,5 & 39,2 & 84,2 & 284,2 & 240,6 & 43,12 & 890,9 & 1386 & 646 & 20 & 91 & 41 & 38 & 37 \\
\hline
\end{tabular}


Tabla 39. Error relativo (\%) de la conductividad térmica teórica con la experimental a $60^{\circ} \mathrm{C}$.

\begin{tabular}{|c|c|c|c|c|c|c|c|c|c|c|c|c|c|c|c|}
\hline Nanofluido & $\begin{array}{c}\varphi \\
{[\mathrm{v} \%]}\end{array}$ & Maxwell & Rayleigh & Fricke & $\begin{array}{l}\text { Nan } \\
\text { et al. }\end{array}$ & $\begin{array}{l}\text { Hamilton } \\
\text { and } \\
\text { Crosser }\end{array}$ & $\begin{array}{c}\text { Krischer } \\
(\mathbf{f}=1)\end{array}$ & $\begin{array}{l}\text { Krischer } \\
(f=-1)\end{array}$ & $\begin{array}{c}\text { Mixture } \\
\text { model } \\
(n=1)\end{array}$ & $\begin{array}{c}\text { Mixture } \\
\text { model } \\
(n=-1)\end{array}$ & $\begin{array}{l}\text { Yu } \\
\text { and } \\
\text { Choi }\end{array}$ & Xue & Bruggeman & $\begin{array}{l}\text { Leong } \\
\text { at al. }\end{array}$ & $\begin{array}{l}\text { Xuan } \\
\text { et all }\end{array}$ \\
\hline \multirow{3}{*}{$\begin{array}{l}\text { Aerosil } \\
200\end{array}$} & 0,5 & 3,35 & 3,35 & 3,37 & 3,64 & 3,35 & 3,20 & 3,81 & 3,51 & 3,20 & 3,21 & 3,39 & 0,41 & 0,81 & 3,34 \\
\hline & 1 & 2,94 & 2,94 & 2,91 & 2,40 & 2,94 & 3,22 & 2,08 & 2,65 & 3,22 & 3,20 & 2,87 & 0,82 & 1,62 & 2,97 \\
\hline & 5 & 2,67 & 2,67 & 2,56 & 0,10 & 2,67 & 4,00 & 1,54 & 1,31 & 4,00 & 4,00 & 2,34 & 4,16 & 8,11 & 2,81 \\
\hline \multirow{3}{*}{$\begin{array}{l}\text { Ludox } \\
\text { TM-50 }\end{array}$} & 0,5 & 0,37 & 0,37 & 0,38 & 0,65 & 0,37 & 0,22 & 0,81 & 0,52 & 0,22 & 0,23 & 0,40 & 0,41 & 0,26 & 0,76 \\
\hline & 1 & 9,26 & 9,26 & 9,30 & 9,87 & 9,26 & 8,95 & 10,23 & 9,59 & 8,95 & 8,96 & 9,34 & 0,82 & 0,52 & 2,98 \\
\hline & 5 & 4,27 & 4,27 & 4,39 & 7,24 & 4,27 & 2,85 & 8,78 & 5,73 & 2,85 & 2,85 & 4,62 & 4,16 & 2,59 & 3,00 \\
\hline \multirow{3}{*}{$\begin{array}{l}\text { Aeroxide } \\
\text { Alu }\end{array}$} & 0,5 & 0,96 & 5,72 & 5,72 & 13,2 & 13,12 & 5,72 & 4,75 & 68,60 & 29,22 & 4,75 & 7,61 & 1,43 & 0,93 & 6,61 \\
\hline & 1 & 1,04 & 0,72 & 0,72 & 13,1 & 13,02 & 0,72 & 2,52 & 166,79 & 42,79 & 2,52 & 2,79 & 2,90 & 1,86 & 5,32 \\
\hline & 5 & 1,03 & 11,36 & 11,36 & 80,6 & 82,16 & 11,36 & 1,99 & 367,81 & 229,43 & 1,99 & 29,6 & 16,31 & 9,31 & 9,11 \\
\hline \multirow{3}{*}{$\begin{array}{l}\text { Aerodisp } \\
\text { W925 }\end{array}$} & 0,5 & 0,99 & 2,55 & 2,55 & 9,84 & 9,73 & 2,55 & 1,62 & 63,55 & 25,35 & 1,62 & 4,39 & 1,43 & 0,93 & 2,50 \\
\hline & 1 & 0,98 & 4,83 & 4,83 & 19,5 & 19,34 & 4,83 & 2,93 & 181,71 & 50,77 & 2,93 & 8,54 & 2,90 & 1,86 & 4,72 \\
\hline & 5 & 1,10 & 4,37 & 4,37 & 69,3 & 70,73 & 4,37 & 4,41 & 351,00 & 208,76 & 4,41 & 21,4 & 16,31 & 9,31 & 3,86 \\
\hline \multirow{3}{*}{$\begin{array}{l}\text { Óxido de } \\
\text { cobre }\end{array}$} & 0,5 & 1,27 & 1,27 & 2,74 & 2,64 & 0,52 & 2,13 & 29,86 & 11,61 & 2,13 & 1,72 & 1,76 & 1,26 & 1,76 & 1,27 \\
\hline & 1 & 3,04 & 3,04 & 4,72 & 4,55 & 1,59 & 4,71 & 69,25 & 21,92 & 4,71 & 3,93 & 4,01 & 3,00 & 4,01 & 3,04 \\
\hline & 5 & 1,05 & 1,05 & 34,17 & 34,7 & 5,88 & 8,99 & 723,7 & 113,10 & 8,99 & 5,54 & 5,94 & 0,09 & 5,90 & 1,05 \\
\hline \multicolumn{2}{|c|}{ Suma de errores } & 34,3 & 57,7 & 94,1 & 271 & 238,9 & 67,82 & 868,3 & 1369,4 & 624,59 & 51,86 & 109 & 56,41 & 49,78 & 53,34 \\
\hline
\end{tabular}


En las tablas Tabla 38Tabla 39 se muestra la suma de los errores obtenidos para todos los óxidos a distintas fracciones cuando se ajustan los datos experimentales a los teóricos de un mismo modelo (última fila). Puede observarse que los modelos que mejor se ajustan de forma global ya que presentan el menor error son:

You y Choi $<$ Maxwell $<$ Xuan $<$ Leong $<$ Rayleig $<$ Bruggeman $<$ Krischer $\mathrm{f}=1$, tanto a $40^{\circ} \mathrm{C}$ como a $60^{\circ} \mathrm{C}$, aunque a temperaturas altas los errores totales obtenidos son mayores. También se ha constatado mayor error a una fracción volumétrica mayor. Los resultados confirman que el modelo de You y Choi, que tiene en cuenta el efecto de la nanocapa actuándo como una resistencia al aumento de conductividad y el modelo de Xuan que considera el movimiento browniano y el efecto de aglomeración, junto con el modelo de Maxwell para fracciones más diluidas, son los modelos que reproducen mejor el comportamiento termodinámico de todos los nanofluidos de óxidos analizados. Se ajustan peor los modelos que incorporan factores de forma o matrices de redes (Krischer), debido a que muy posiblemente tanto las nanopartículas de óxidos (de forma esférica) como sus aglomerados no han llegado a establecer conexiones entre ellos generando un mecanismo de transmisión por conducción preferente en una determinada dirección y que conlleve un aumento en el valor de conductivdad.

De entre todos los nanofluidos preparados con óxidos el nanofluido de sílice es el material que más se ajusta a los valores calculados con los modelos teóricos, sobre todo a bajas fracciones, presentando unos errores bajos (señalados en azul los valores menores del 1\%). Puede que al tratarse de una suspensión comercial la dispersión y estabilidad del nanofluido sea mejor, y por tanto los valores de conductividad experimentales medidos con el KD2 son más similares a los valores de conductividad teóricos obtenidos con los distintos modelos analizados.

Como conclusión del estudio de modelización realizado cabe indicar que los modelos de Mawwell, y de You y Choi (modelo que tiene en cuenta el efecto de la nanocapa) parecen ser los más adecuados para predecir el aumento en conductividad en los nanofluidos preparados en dos etapas a partir de nanopartículas de óxidos, pues son los modelos que mejor se ajustan a los resultados experimentales de los tres tipos de óxidos estudiados. 


\subsubsection{Modelización y análisis de los resultados de la conductividad térmica de nanofluidos} preparados con nanopartículas de carbono

Los modelos elegidos para la predicción teórica de conductividad térmica efectiva de los nanofluidos preparados con partículas no esféricas (nanotubos) se han seleccionado en base a la bibliografía [61, 110, 114, y 115] siendo algunos de ellos modelos utilizados para los nanofluidos preparados a partir de óxidos, como:

- Modelo de Maxwell, modelo clásico utilizado para el estudio de nanofluidos preparados con nanopartículas esféricas (Ecuación1).

- Modelo nanotubos Hamilton Crosser Modelo según la expresión (Ecuación 28) pero con el factor de esfericidad de las CNTS de 0,5 para formas cilíndricas.

- Modelo de Xue et al. Modelo basado ya en la forma de los nanotubos (Ecuación 36).

- Modelo de Leong. Modelo basado en la teoría de la conductividad térmica de la nanocapa $\left(k_{\mid r}\right)$ pero aplicado a partículas cilíndricas (Ecuación 39)

- Modelo de Xuan modelo que tiene en cuenta el movimiento Browniano y la agregación de las nanopartículas formando "clusters" (Ecuación 44)

A partir de la bibliografía revisada, se han definido otros modelos específicos para nanotubos de carbono y grafeno como los que a continuación se especifican:

\section{Modelo nanotubos NAN y Liu}

Nan y Liu [110] desarrollaron en 2003 un modelo especial para los nanotubos considerando una conductividad térmica transversal y otra longitudinal siguiendo las siguientes expresiones:

$$
k_{n f}=\frac{3+\left(\beta_{11}+\beta_{33}\right) \Phi}{3-\beta_{11} \Phi} k_{b f}
$$

donde

$$
\beta_{11}=\frac{2\left(k_{11}^{c}-k_{b f}\right)}{k_{11}^{c}-k_{b f}} \quad \beta_{33}=\frac{k_{33}^{c}}{k_{b f}}-1
$$

$\mathrm{k}^{\mathrm{c}}{ }_{11} \mathrm{y}^{\mathrm{c}}{ }_{33}$ son la conductividad térmica transversal $\mathrm{y}$ longitudinal de los nanotubos, respectivamente:

$$
k_{11}^{c}=\frac{k_{p}}{1+\frac{2 a_{k} k_{p}}{d_{p} k_{b f}}} \quad k_{33}^{c}=\frac{k_{p}}{1+\frac{2 a_{k} k_{p}}{L_{p} k_{b f}}}
$$


donde

$d_{p} \quad$ es el diámetro del nanotubo

$I_{p} \quad$ es la longitud del nanotubo

$k_{p} \quad$ es la conductividad térmica del solido

$a_{k} \quad$ es el radio de Kapitza expresado como

$$
a_{\mathrm{k}}=\mathrm{R}_{\mathrm{k}} k_{b f}
$$

siendo $R_{k}$ la resistencia térmica en la interfase nanotubo-líquido, cuyo valor es $8,33 \times 10^{-8}$ $\mathrm{m}^{2} \mathrm{~K} / \mathrm{W}$.

Cuando se analizan los resultados predichos por el modelo de NAN se aprecia que son significativamente mayores que los datos obtenidos por el modelo de $\mathrm{CHOI}$. Esto es debido a que el modelo de NAN no tiene en cuenta los estados de agregación de los nanotubos. Cuando los nanotubos comienzan a aglomerarse la superficie efectiva decrece empeorando la transferencia térmica y reduciéndose la conductividad térmica del nanofluido $[61,66]$

\section{Modelo Nanotubos Jiang}

El investigador $\mathrm{H}$. Jiang desarrolló un nuevo modelo [114] que tiene en cuenta el modelo de Prasher sobre agregación de nanopartículas esféricas.

$$
k_{n f}=\frac{\left(k_{i n t}+2 k_{b f}\right)+2 \varphi_{a}\left(k_{i n t}-k_{b f}\right)}{\left(k_{i n t}+2 k_{b f}\right)-\varphi_{a}\left(k_{i n t}-k_{b f}\right)} k_{b f} \quad \varphi_{a}=\frac{\varphi_{p}}{\varphi_{\text {int }}}
$$

Donde $\phi_{p}$ es la fracción de volumen ocupada por la nanopartícula individual o nanotubo, $\phi_{\text {int }}$ es la fracción de volumen de los CNTs o partículas de grafeno en el agregado y $\phi_{a}$ la fracción de volumen de los agregados en todo el fluido. La fracción de volumen de los agregados $\phi_{a}$ disminuye al aumentar $\phi_{\text {int }}$ y $\phi_{\mathrm{p}}<\phi_{\text {int }}<1$.

El parámetro $\phi_{\text {int }}$ es un factor empírico, que está influenciado por la geometría CNT, la fracción de volumen CNT, el tipo de fluido, la interacción entre CNT y fluido base; mayor valor de $\phi_{\text {int }}$ significa un aumento de la fracción de CNT en el agregado.

- Cuando $\phi_{\mathrm{a}}=1$ y $\phi_{\mathrm{p}}=\phi_{\text {int }}$ (el nanofluido es una suspensión homogénea) $k_{\mathrm{nf}}=\mathrm{k}_{\text {int }}$, que implica un medio compuesto totalmente por agregados de CNT. 
- Cuando $\phi_{\text {int }}=1$ (el nanofluido es una suspensión bien dispersa), solo hay un CNT en cada agregado. Los datos experimentales se encontrarán entre estos dos límites.

\section{Modelo nanotubos YAMADA y OTA}

Otro de los modelos encontrados en la bibliografía de aplicación en partículas no esféricas es el modelo de Yamada y OTA [115]. Este modelo incluye el efecto del radio $\mathrm{R}$ y longitud $\mathrm{H}$ de los nanotubos

$$
k_{e f f}=k_{f} \frac{1+\frac{k_{f} H}{k_{p} R} \Phi^{0,2}+\left(1-\frac{k_{f}}{k_{p}}\right) \Phi_{\frac{H}{R}} \Phi^{0,2}}{1+\frac{k_{f} H}{k_{p} R} \Phi^{0,2}-\left(1-\frac{k_{f}}{k_{p}}\right) \Phi}
$$

En las siguientes tablas se muestran los errores (calculados como error relativo $\left(\varepsilon_{r}\right)$ según ecuación 45), obtenidos con cada uno de los modelos teóricos seleccionados para nanopartículas no esféricas. El estudio se ha llevado a cabo con distintos materiales (MWCNTs cortos, MWCNTs largos y MWWCNTs funcionalizados) y preparados a distintas fracciones volumétricas. La conductividad térmica se midió a varias temperaturas, para incluir de esta forma la influencia de dicha variable.

Tabla 40. Nanotubos MWCNTs cortos $+S D S T=40^{\circ} \mathrm{C}$

\begin{tabular}{cccccccccc}
\hline $\begin{array}{c}\text { Fracción } \\
\text { volumétrica } \Phi \\
{[\%]}\end{array}$ & Maxwell & Nan & Jiang & Xue $\begin{array}{c}\text { Hamilton } \\
\text { and } \\
\text { Crosser }\end{array}$ & $\begin{array}{c}\text { Yamada } \\
\text { y Ota }\end{array}$ & $\begin{array}{c}\text { Leong } \\
\text { al }\end{array}$ \\
\hline 0,1 & & & & & & & & \\
0,2 & 0,78 & 0,78 & 0,59 & 0,45 & 0,49 & 0,98 & 0,82 & 0,78 \\
0,5 & 1,01 & 1,00 & 0,61 & 1,45 & 0,42 & 1,41 & 1,23 & 1,01 \\
\hline Suma de errores & 1,14 & 1,16 & 0,37 & 1,52 & 0,02 & 1,96 & 1,70 & 1,17 \\
\hline
\end{tabular}


Tabla 41. Nanotubos MWCNTs cortos + SDS $\mathrm{T}=60^{\circ} \mathrm{C}$

\begin{tabular}{cccccccccc}
\hline $\begin{array}{c}\text { Fracción } \\
\text { volumétrica } \Phi \\
{[\%]}\end{array}$ & Maxwell & Nan & Jiang & Xue $\begin{array}{c}\text { Hamilton } \\
\text { and } \\
\text { Crosser }\end{array}$ & $\begin{array}{c}\text { Yamada } \\
\text { y Ota }\end{array}$ & Leong & $\begin{array}{c}\text { Xuan et } \\
\text { al }\end{array}$ \\
\hline 0,1 & & & & & & & & \\
0,2 & 0,34 & 0,33 & 0,14 & 0,90 & 0,04 & 0,54 & 0,37 & 0,34 \\
0,5 & 6,89 & 6,88 & 6,52 & 4,58 & 6,34 & 7,80 & 7,62 & 7,40 \\
\hline Suma de errores & 9,13 & 9,11 & 8,40 & 4,63 & 8,05 & 10,89 & 10,62 & 10,10 \\
\hline
\end{tabular}

Tabla 42. Nanotubos MWCNTs cortos funcionalizados comerciales $\mathrm{T}=25^{\circ} \mathrm{C}$

\begin{tabular}{ccccccccc}
\hline $\begin{array}{c}\text { Fracción } \\
\text { volumétrica } \Phi \\
{[\%]}\end{array}$ & Maxwell & Nan & Jiang & Xue $\begin{array}{c}\text { Hamilton } \\
\text { and } \\
\text { Crosser }\end{array}$ & $\begin{array}{c}\text { Yamada } \\
\text { y Ota }\end{array}$ & Leong & $\begin{array}{c}\text { Xuan et } \\
\text { al }\end{array}$ \\
\hline $\mathbf{0 , 0 1}$ & 1,63 & 1,63 & 1,65 & 1,76 & 1,66 & 1,61 & 1,63 & 1,63 \\
$\mathbf{0 , 0 5}$ & 1,21 & 1,21 & 1,31 & 1,84 & 1,36 & 1,12 & 1,15 & 1,22 \\
$\mathbf{0 , 1}$ & 0,04 & 0,05 & 0,24 & 1,29 & 0,34 & 0,16 & 0,09 & 0,05 \\
\hline Suma de errores & 2,88 & 2,89 & 3,2 & 4,89 & 3,31 & 2,89 & 2,87 & 2,90 \\
\hline
\end{tabular}

Tabla 43. Nanotubos MWCNTs cortos funcionalizados comerciales $\mathrm{T}=40^{\circ} \mathrm{C}$

\begin{tabular}{cccccccccc}
\hline $\begin{array}{c}\text { Fracción } \\
\text { volumétrica } \Phi \\
{[\%]}\end{array}$ & Maxwell & Nan & Jiang & Xue $\begin{array}{c}\text { Hamilton } \\
\text { and } \\
\text { Crosser }\end{array}$ & $\begin{array}{c}\text { Yamada } \\
\text { y Ota }\end{array}$ & $\begin{array}{c}\text { Leong } \\
\text { al }\end{array}$ \\
\hline $\mathbf{0 , 0 1}$ & 0,57 & 0,57 & 0,55 & 0,45 & 0,54 & 0,59 & 0,57 & 0,57 \\
$\mathbf{0 , 0 5}$ & 0,73 & 0,72 & 0,63 & 0,11 & 0,58 & 0,83 & 0,79 & 0,73 \\
$\mathbf{0 , 1}$ & 1,74 & 1,74 & 1,55 & 0,52 & 1,45 & 1,97 & 1,90 & 1,77 \\
\hline Suma de errores & 3,03 & 3,04 & 2,73 & 1,08 & 2,57 & 3,39 & 3,26 & 3,07 \\
\hline
\end{tabular}


Tabla 44. Nanotubos MWCNTs - $\mathrm{COOH}$ funcionalizados por método ácido a distintos tiempos $\mathrm{T}=40^{\circ} \mathrm{C}$

\begin{tabular}{|c|c|c|c|c|c|c|c|c|}
\hline $\begin{array}{c}\text { Fracción } \\
\text { volumétrica } \Phi \\
{[\%]}\end{array}$ & Maxwell & Nan & Jiang & Xue & $\begin{array}{l}\text { Hamilton } \\
\text { and } \\
\text { Crosser }\end{array}$ & $\begin{array}{c}\text { Yamada } \\
\text { y Ota }\end{array}$ & Leong & $\begin{array}{c}\text { Xuan et } \\
\text { al }\end{array}$ \\
\hline 0,1 F. ácida 3h & 0,0 & 0,0 & 0,20 & 1,24 & 0,30 & 0,20 & 0,03 & 0,00 \\
\hline 0,1 F. ácida 9h & 0,15 & 0,15 & 0,05 & 1,09 & 0,15 & 0,35 & 0,18 & 0,15 \\
\hline 0,2 F. ácida 9h & 1,33 & 1,32 & 0,94 & 1,12 & 0.74 & 1,75 & 1,57 & 1,35 \\
\hline Suma de errores & 1,47 & 1,48 & 1,19 & 3,45 & 1,19 & 2,30 & 1,80 & 1,50 \\
\hline \multicolumn{9}{|c|}{ Tabla 45. Nanotubos MWCNTs - $\mathrm{COOH}$ funcionalizados por método ácido a distintos tiempos, a $\mathrm{T}=60^{\circ} \mathrm{C}$} \\
\hline $\begin{array}{c}\text { Fracción } \\
\text { volumétrica } \Phi \\
{[\%]}\end{array}$ & Maxwell & Nan & Jiang & Xue & $\begin{array}{l}\text { Hamilton } \\
\text { and } \\
\text { Crosser }\end{array}$ & $\begin{array}{c}\text { Yamada } \\
\text { y Ota }\end{array}$ & Leong & $\begin{array}{c}\text { Xuan et } \\
\text { al }\end{array}$ \\
\hline 0,1 F.ácida 3h & 3,75 & 3,85 & 3,66 & 2,66 & 3,56 & 3,94 & 3,78 & 3,85 \\
\hline 0,1 F.ácida 9h & 6,29 & 6,29 & 6,11 & 5,13 & 6,01 & 6,48 & 6,32 & 6,29 \\
\hline 0,2 F.ácida 9h & 6,14 & 6,13 & 5,77 & 3,82 & 5,58 & 6,53 & 6,36 & 6,15 \\
\hline Suma de errores & 16,18 & 16,28 & 15,54 & 16,74 & 15,15 & 16,95 & 16,46 & 16,29 \\
\hline
\end{tabular}

Puede observarse que todos los modelos se ajustan bastante bien (con errores inferiores al 10\%) en la mayoría de los casos excepto para el caso de los nanotubos funcionalizados en laboratorio cuando la temperatura del ensayo es de $60^{\circ} \mathrm{C}$. Todos los nanofluidos se han preparado a fracciones muy bajas por lo cual era de esperar que los ajustes fueran buenos. El aumento de temperatura en el ensayo penaliza el ajuste, pues se obtiene mayor error.

De entre todos los modelos podemos concluir que para los nanotubos cortos sin funcionalizar (Tabla 40 y Tabla 41) los modelos que mejor se ajustan son el de Maxwell, Hamilton-Crosser y Xue, aunque el error de este último modelo se incrementa cuando la temperatura aumenta. Con los nanotubos funcionalizados comercialmente y puestos en suspensión en laboratorio ( Tabla 42 y Tabla 43) se ajustan mejor los modelos de Maxwell, Leong y Xue.

Para el caso de los nanotubos funcionalizados a escala de laboratorio con el método 1 y el método 2, ajustan muy bien los modelos de Maxwell, Jiang y Hamilton-Crosser ( Tabla 44 y Tabla 45). 
Cuando se utilizan nanopartículas con formas no esféricas como en el caso de los nanofluidos preparados con nanotubos de carbono en fracciones diluidas (fracción volumétrica $\Phi<0,2$ ) el modelo básico de Maxwell es el más adecuado para predecir el comportamiento termodinámico con un error bajo. Cuando las suspensiones se preparan a mayor fracción son los modelos de Xue y Hamilton-Crosser los que mejor se ajustan, pues estos modelos tienen en cuenta la forma de las nanopartículas.

\subsection{Aplicación de los nanofluidos como fluidos térmicos}

El número de Prandtl, el número de Reynolds y el número de Nusselt son función de las propiedades físicas de los nanofluidos y estos números adimensionales influyen en el coeficiente de transferencia de calor por convección. El rendimiento de los fluidos en la transferencia de calor está determinado por la combinación de estas propiedades y para seleccionar el mejor nanofluido resulta necesario comparar los coeficientes de transferencia de calor. En el apartado 3 del primer capítulo se han presentado las principales ecuaciones de transmisión de calor $(7,8,10$ y 11$)$ con sus correspondientes coeficientes.

El número de Nusselt aumenta cuando aumenta el número de Reynolds y el número de Prandtl, pero en los nanofluidos se ha observado que ambos parámetros tienen una dependencia inversa [104]:

- Cuando aumenta la fracción de nanopartículas y/o disminuye la temperatura el número de Prandtl aumenta, aumentando el número de Nusselt también.

- Cuando disminuye la fracción de nanopartículas y /o aumenta la temperatura el número de Reynolds aumenta, aumentando el número de Nusselt también.

Para evaluar los efectos de las propiedades físicas combinadas, en la bibliografía consultada los investigadores utilizan expresiones adimensionales que indican la capacidad de transferencia de calor del nanofluido respecto del fluido base. Simons introdujo el número de Mouromtseff (Mo) para evaluar los efectos de las propiedades de los fluidos combinados sobre el coeficiente de transferencia de calor convectivo del flujo turbulento interno basado en la correlación de Dittus-Boelter [132]: 


$$
M o=\frac{k^{a} \rho^{b} c_{p}^{d}}{\eta^{e}}
$$

Los valores de los exponentes $\mathrm{a}, \mathrm{b}, \mathrm{d}$, y e dependen del modo de transferencia de calor. La importancia del número de Mouromtseff radica en el hecho de que para un fluido a través de una geometría dada y a una velocidad especificada, cuanto mayor sea el número de Mouromtseff proporcionará una mayor tasa de transferencia de calor.

Donde

k conductividad térmica $(\mathrm{W} / \mathrm{mK})$

$\rho \quad$ densidad del sólido $\left(\mathrm{kg} / \mathrm{m}^{3}\right)$

$\mathrm{c}_{\mathrm{p}} \quad$ calor específico $(\mathrm{J} / \mathrm{kgK})$

$\eta \quad$ viscosidad dinámica (Pas)

4.2.1 Estudio comparativo mediante el módulo de Mouromtseff y de Prandtl de la efectividad de los nanofluidos

Aunque el parámetro que juega un papel muy importante para caracterizar la mejora de las propiedades térmicas de los nanofluidos es la conductividad térmica del nanofluido ( $\left.\boldsymbol{k}_{n f}\right)$, que consiste en la capacidad de transferir energía en forma de calor del nanofluido mediante el mecanismo de conducción [50], existe otro coeficiente, el coeficiente de película que constituye en general, la mejor forma de medir la eficiencia de un fluido de transferencia de calor, pues incluye las cuatro propiedades críticas de un fluido: viscosidad, calor específico, densidad y conductividad térmica.

Simons [132] presentó la eficacia de varios refrigerantes líquidos para la refrigeración electrónica según el concepto de Mouromtseff, Mo. Para flujo laminar la expresión del número adimensional de Mouromtseff (Mo) sigue la siguiente expresión, [103]:

$$
\frac{M o_{\text {nanofluido }}}{M o_{\text {agua }}}=\frac{k_{\text {nanofluido }}}{k_{\text {agua }}}
$$

Como se observa en la expresión (53), si se obtiene un aumento en la conductividad térmica en el nanofluido respecto a la conductividad térmica del fluido base, agua, tendremos un aumento en la transferencia de calor (valores de Mo mayores a la unidad). Sin embargo, para que este aumento sea efectivo no se debe considerar el aumento de conductividad de forma 
independiente. Resulta necesario considerar la viscosidad final del nanofluido en las condiciones de aplicación, ya que un aumento de la viscosidad conlleva un aumento en la energía de bombeo, que implicará finalmente una disminución de la eficiencia energética global.

Para comparar los nanofluidos en régimen laminar $(\mathrm{Re}<2300)$ se han utilizado dos coeficientes que relacionan tanto viscosidad $\left(C_{n}\right)$, como conductividad $\left(C_{k}\right)$, según la expresión (54). Un nanofluido será efectivo si dicha relación $\left(C_{\eta} / C_{k}\right)$ es inferior a cuatro, según Prasher $[132,134]$ :

$$
\frac{k_{n f}}{k_{\text {agua }}}=1+C_{k} \Phi \Rightarrow C_{k}=\frac{\left(\frac{k_{n f}}{k_{\text {agua }}}\right)-1}{\Phi} ; \frac{\eta_{n f}}{\eta_{\text {agua }}}=1+C_{\eta} \Phi \Rightarrow C_{\eta}=\frac{\left(\frac{\eta_{n f}}{\eta_{\text {agua }}}\right)-1}{\Phi} ; \Rightarrow \frac{C_{\eta}}{C_{k}}<4
$$

Para el flujo turbulento la transferencia de calor depende de las propiedades termofísicas del fluido. En este caso el coeficiente de Mouromtseff, según Simons [133] se obtiene como:

$$
\text { Mo }=\frac{\rho^{0,8} k^{0,67} c_{p}^{0,33}}{\eta^{0,47}} \quad \longrightarrow \quad \frac{\text { Mo } \text { nanofluido }}{\text { Mo agua }}>1
$$

Siempre que la relación del número de Mouromtseff del nanofluido respecto al agua sea mayor que la unidad se obtendrá un aumento en la transferencia del calor y por tanto dicho nanofluido será efectivo para su aplicación como fluido térmico.

Para comprobar que los nanofluidos preparados ofrecen el mejor comportamiento térmico, alta conductividad térmica y baja viscosidad, también se ha utilizado el número de Prandtl [104].

En las tablas sucesivas ( Tabla 46 a Tabla 51) se muestran los valores de los coeficientes para flujo laminar $\left(C_{n} / C_{k}\right)$ (ec. 54), coeficiente de Mouromtseff (ec. 55) y el número de Prandtl (ec.11), obtenidos con cada tipología de nanofluido preparado. Estos coeficientes ayudarán a evaluar la idoneidad del nanofluido para su aplicación como fluido térmico ya sea en régimen laminar o en régimen turbulento.

\section{Análisis de los coeficientes en flujo laminar}

Si analizamos el coeficiente definido para flujo laminar, $\left(C_{n} / C_{k}\right)<4$ (ec. 54), en el caso de los nanofluidos preparados con óxidos se observa que los nanofluidos preparados con sílice no 
mejoran las propiedades térmicas en flujo laminar para fracciones volumétricas mayores de 0,5\% (Tabla 46). Tan sólo los nanofluidos de alúmina y óxido de cobre a fracciones volumétricas de hasta un $1 \%$ presentan un comportamiento aceptable cuando la temperatura del ensayo es mayor de $40^{\circ} \mathrm{C}$, (Tabla 47 y Tabla 48 ). Con los nanofluidos preparados a partir de nanopartículas de carbono, sólo se consiguen buenos resultados con las partículas de grafeno, Tabla 51.

\section{Análisis de los coeficientes en flujo turbulento}

Como ya se ha indicado en la expresión (55) cuando el coeficiente de Mouromtseff del nanofluido sea mayor que el del fluido base agua, el nanofluido mejorará las propiedades térmicas en flujo turbulento. En el caso de los nanofluidos de sílice (Tabla 46) la relación Mo_nanofluido/Mo_agua no presenta incrementos, obteniéndose los mejores valores a fracción volumétrica baja (0,5\%). Para el caso de la alúmina y el óxido de cobre ( Tabla 47 y Tabla 48 respectivamente) los valores de Mouromtseff relativos son algo más altos, aunque dicho aumento no es muy significativo. Los mejores valores se obtienen a bajas fracciones volumétricas y temperaturas.

Al analizar los nanofluidos preparados con nanotubos o grafeno (Tabla 49, Tabla 50 y Tabla 51) sólo se obtiene valores relativos del número de Mouromtseff mayores que uno en el caso de los nanofluidos preparados con grafeno y los nanofluidos de MWCNTs cortos +SDS al 0,2\%.

\section{Análisis del número de Prandtl}

Los nanofluidos preparados ofrecen un mayor número de Prandtl que el fluido base en la mayoría de los casos, que conllevará a un aumento en el coeficiente de transferencia de calor. En los resultados obtenidos mostrados en las tablas Tabla 46Tabla 51) se observa cómo la adición de diferentes volúmenes de nanopartículas afecta al número de Prandtl, pues a medida que aumenta la fracción volumétrica de las partículas, el número de Prandtl aumenta más rápidamente para cada nanofluido por el aumento de viscosidad. Los aumentos en el número de Prandtl son mayores en los nanofluidos de óxido de cobre y los nanofluidos de nanotubos de carbono MWCNTs cortos. Si se analiza el efecto de la temperatura, se observa que el número de Prandtl de todos los fluidos disminuye con un aumento de ésta, pues en este caso, la variación de viscosidad tiene mayor peso que la variación en conductividad. El calor específico aumenta muy modestamente, y la conductividad térmica aumenta 
moderadamente con un aumento de la temperatura. Sin embargo, la viscosidad disminuye sustancialmente con el aumento de la temperatura. Por lo tanto, el efecto de la conductividad térmica se suma al efecto de la viscosidad que es el dominante contrastando el aumento del calor específico y como consecuencia se obtiene una disminución del número de Prandtl.

El valor del número de Prandtl determina qué fenómeno es más significativo en el proceso de convección (números bajos predomina mecanismo de conducción, con números altos predomina el mecanismo de convección). El mayor número de Prandtl para un nanofluido se obtiene a fracciones volumétricas altas y a temperaturas bajas, como puede observarse en las siguientes tablas.

Tabla 46. Módulos adimensionales utilizados para la caracterización de las propiedades termofísicas para los nanofluidos preparados a partir de sílice

\begin{tabular}{|c|c|c|c|c|c|c|c|}
\hline \multirow{2}{*}{$\begin{array}{c}\text { Fracción } \\
\text { volumétrica (\%) }\end{array}$} & \multirow{2}{*}{$\begin{array}{c}\text { Temperatura } \\
\left({ }^{\circ} \mathrm{C}\right)\end{array}$} & \multicolumn{3}{|c|}{ Régimen laminar } & \multirow{2}{*}{$\begin{array}{l}\text { Régimen } \\
\text { turbulento } \\
\text { Mouromtseff }\end{array}$} & \multirow{2}{*}{$\frac{M o_{n f}}{M o_{a g u a}}$} & \multirow{2}{*}{$\begin{array}{c}\text { Número } \\
\text { de } \\
\text { Prandtl }\end{array}$} \\
\hline & & $C_{\eta}$ & $C_{k}$ & $C_{n} / C_{k}$ & & & \\
\hline 0,5 & 40 & 0,01 & 0,02 & 0,23 & 6056 & 0,99 & 5,0 \\
\hline 1 & 40 & 0,26 & 0,00 & 187 & 5192 & 0,85 & 4,0 \\
\hline 5 & 40 & 2,19 & 0,00 & 706 & 2260 & 0,37 & 4,3 \\
\hline Agua & 40 & - & - & - & 6087 & 1,00 & 4,9 \\
\hline 0,5 & 60 & 0,05 & 0,06 & 0,93 & 6894 & 0,97 & 3,5 \\
\hline 1 & 60 & 0,39 & 0,04 & 10,2 & 5951 & 0,84 & 2,9 \\
\hline 5 & 60 & 1,19 & 0,01 & 85,29 & 3361 & 0,47 & 3,0 \\
\hline Agua & 60 & - & - & - & 7051 & 1,00 & 3,4 \\
\hline 0,5 & 80 & 0,29 & 0,04 & 7,76 & 7010 & 0,96 & 3,3 \\
\hline 1 & 80 & 0,22 & 0,00 & 49,63 & 6396 & 0,88 & 2,6 \\
\hline 5 & 80 & 0,25 & 0,02 & 14,26 & 5528 & 0,76 & 2,7 \\
\hline Agua & 80 & - & - & - & 7270 & 1,00 & 3,1 \\
\hline
\end{tabular}


Tabla 47. Número de Prandtl y Mouromtseff para los nanofluidos preparados a partir de alúmina

\begin{tabular}{|c|c|c|c|c|c|c|c|}
\hline \multirow{2}{*}{$\begin{array}{c}\text { Fracción } \\
\text { volumétrica (\%) }\end{array}$} & \multirow{2}{*}{$\begin{array}{c}\text { Temperatura } \\
\left({ }^{\circ} \mathrm{C}\right)\end{array}$} & \multicolumn{3}{|c|}{ Régimen laminar } & \multirow{2}{*}{$\begin{array}{l}\text { Régimen } \\
\text { turbulento } \\
\text { Mouromtseff }\end{array}$} & \multirow{2}{*}{$\frac{M o_{n f}}{M o_{a g u a}}$} & \multirow{2}{*}{$\begin{array}{c}\text { Número } \\
\text { de } \\
\text { Prandtl }\end{array}$} \\
\hline & & $C \eta$ & $C_{k}$ & $C \eta / C_{k}$ & & & \\
\hline 0,5 & 40 & 0,01 & 0,13 & 10,9 & 6244 & 1,02 & 4,8 \\
\hline 1 & 40 & 0,02 & 0,06 & 3,1 & 6314 & 1,04 & 4,5 \\
\hline 5 & 40 & 0,01 & 0,45 & 42,7 & 4496 & 0,73 & 11,6 \\
\hline Agua & 40 & - & - & - & 6087 & 1,00 & 4,9 \\
\hline 0,5 & 60 & 0,08 & 0,16 & 2,1 & 7149 & 1,01 & 3,4 \\
\hline 1 & 60 & 0,01 & 0,04 & 2,9 & 6936 & 0,98 & 3,5 \\
\hline 5 & 60 & 0,01 & 0,45 & 38,1 & 5063 & 0,71 & 9,3 \\
\hline Agua & 60 & - & - & - & 7051 & 1,00 & 3,4 \\
\hline 0,5 & 80 & 0,16 & 0,16 & 1,0 & 7191 & 0,99 & 3,5 \\
\hline 1 & 80 & 0,06 & 0,15 & 2,4 & 7265 & 0,99 & 3,6 \\
\hline 5 & 80 & 0,01 & 0,39 & 40,2 & 5771 & 0,78 & 7,1 \\
\hline Agua & 80 & - & - & - & 7270 & 1,00 & 3,1 \\
\hline
\end{tabular}

Tabla 48. Número de Prandtl y Mouromtseff para los nanofluidos preparados a partir de óxido de cobre II

\begin{tabular}{|c|c|c|c|c|c|c|c|}
\hline \multirow{2}{*}{$\begin{array}{c}\text { Fracción } \\
\text { volumétrica (\%) }\end{array}$} & \multirow{2}{*}{$\begin{array}{c}\text { Temperatura } \\
\left({ }^{\circ} \mathrm{C}\right)\end{array}$} & \multicolumn{3}{|c|}{ Régimen laminar } & \multirow{2}{*}{$\begin{array}{c}\text { Régimen } \\
\text { turbulento } \\
\text { Mouromtseff }\end{array}$} & \multirow{2}{*}{$\frac{M o_{n f}}{M o_{a g u a}}$} & \multirow{2}{*}{$\begin{array}{c}\text { Número } \\
\text { de } \\
\text { Prandtl }\end{array}$} \\
\hline & & $c_{n}$ & $C_{k}$ & $c_{n} / C_{k}$ & & & \\
\hline 0,5 & 40 & 0,03 & 0,16 & 6 & 6243 & 1,02 & 4,8 \\
\hline 1 & 40 & 0,05 & 0,01 & 0 & 6600 & 1,08 & 4,1 \\
\hline 5 & 40 & 0,02 & 54,88 & 2212 & 793 & 0,13 & 919,8 \\
\hline Agua & 40 & - & - & - & 6087 & 1,00 & 4,9 \\
\hline 0,5 & 60 & 0,05 & 0,18 & 3 & 7463 & 1,05 & 3,2 \\
\hline 1 & 60 & 0,06 & 0,10 & 2 & 7084 & 1,00 & 3,6 \\
\hline 5 & 60 & 0,03 & 59,16 & 1913 & 874 & 0,12 & 781,3 \\
\hline Agua & 60 & - & - & - & 7051 & 1,00 & 3,4 \\
\hline 0,5 & 80 & 0,09 & 0,16 & 2 & 7801 & 1,07 & 3 \\
\hline 1 & 80 & 0,02 & 0,02 & 1 & 7965 & 1,09 & 2,9 \\
\hline 5 & 80 & 0,03 & 70,15 & 2367 & 907 & 0,12 & 766,1 \\
\hline Agua & 80 & - & - & - & 7270 & 1,00 & 3,1 \\
\hline
\end{tabular}


Tabla 49. Número de Prandtl y Mouromtseff para los nanofluidos preparados a partir de Nanotubos MWCNTs cortos+SDS

\begin{tabular}{|c|c|c|c|c|c|c|c|}
\hline \multirow{2}{*}{$\begin{array}{c}\text { Fracción } \\
\text { volumétrica (\%) }\end{array}$} & \multirow{2}{*}{$\begin{array}{c}\text { Temperatura } \\
\left({ }^{\circ} \mathrm{C}\right)\end{array}$} & \multicolumn{3}{|c|}{ Régimen laminar } & \multirow{2}{*}{$\begin{array}{l}\text { Régimen } \\
\text { turbulento } \\
\text { Mouromtseff }\end{array}$} & \multirow{2}{*}{$\frac{M o_{n f}}{M o_{a g u a}}$} & \multirow{2}{*}{$\begin{array}{c}\text { Número } \\
\text { de } \\
\text { Prandtl }\end{array}$} \\
\hline & & $C_{\eta}$ & $C_{k}$ & $C_{n} / C_{k}$ & & & \\
\hline 0,1 & 40 & 0,19 & 03,09 & 16 & 5597 & 0,91 & 5,6 \\
\hline 0,2 & 40 & 0,12 & 3,27 & 27 & 5133 & 0,84 & 7,1 \\
\hline 0,5 & 40 & 0,06 & 497,62 & 7779 & 692 & 0,11 & 1051,3 \\
\hline Agua & 40 & - & - & - & 6087 & 1,00 & 4,9 \\
\hline 0,1 & 60 & 0,18 & 3,77 & 21 & 6099 & 0,86 & 4,7 \\
\hline 0,2 & 60 & 0,06 & 0,10 & 2 & 7084 & 1,00 & 3,5 \\
\hline 0,5 & 60 & 0,25 & 277,96 & 1098 & 1024 & 0,14 & 431,4 \\
\hline Agua & 60 & - & - & - & 7051 & 1,00 & 3,4 \\
\hline 0,1 & 80 & 0,01 & 4,61 & 346 & 6552 & 0,90 & 4,2 \\
\hline 0,2 & 80 & 0,15 & 2,67 & 18 & 6561 & 0,90 & 4,3 \\
\hline 0,5 & 80 & 0,29 & 12,25 & 43 & 3777 & 0,52 & 17,8 \\
\hline Agua & 80 & - & - & - & 7270 & 1,00 & 3,1 \\
\hline
\end{tabular}

Tabla 50. Número de Prandtl y Mouromtseff para los nanofluidos preparados a partir de nanotubos MWCNTs-COOH cortos por dilución de suspensión comercial

\begin{tabular}{|c|c|c|c|c|c|c|c|}
\hline \multirow{2}{*}{$\begin{array}{c}\text { Fracción } \\
\text { volumétrica (\%) }\end{array}$} & \multirow{2}{*}{$\begin{array}{c}\text { Temperatu } \\
\text { ra } \\
\text { (ํㅡ) }\end{array}$} & \multicolumn{3}{|c|}{ Régimen laminar } & \multirow{2}{*}{$\begin{array}{c}\text { Régimen } \\
\text { turbulento } \\
\text { Mouromtseff }\end{array}$} & \multirow{2}{*}{$\frac{M o_{n f}}{M o_{a g u a}}$} & \multirow{2}{*}{$\begin{array}{c}\text { Número } \\
\text { de } \\
\text { Prandtl }\end{array}$} \\
\hline & & $C_{\eta}$ & $C_{k}$ & $C_{n} / C_{k}$ & & & \\
\hline 0,1 & 40 & 5,10 & 0,12 & 42 & 5105,4 & 0,83 & 7,04 \\
\hline 1,0 & 40 & 45,9 & 0,06 & 779 & 1371,1 & 0,22 & 192,37 \\
\hline Agua & 40 & - & - & - & 6087 & 1,00 & 4,9 \\
\hline 0,1 & 60 & 4,80 & 0,01 & 927 & 5686,2 & 0,80 & 5,6 \\
\hline 1,0 & 60 & 38,52 & 0,08 & 490 & 1652,3 & 0,23 & 127,6 \\
\hline Agua & 60 & - & - & - & 7051 & 1,00 & 3,4 \\
\hline 0,1 & 80 & 2,62 & 0,19 & 14 & 6705,6 & 0,92 & 3,89 \\
\hline 1,0 & 80 & 20,16 & 0,09 & 215 & 2380,7 & 0,32 & 55,3 \\
\hline Agua & 80 & - & - & - & 7270 & 1,00 & 3,1 \\
\hline
\end{tabular}


Tabla 51. Número de Prandtl y Mouromtseff para los nanofluidos preparados a partir de GFN700

\begin{tabular}{|c|c|c|c|c|c|c|c|}
\hline \multirow{2}{*}{$\begin{array}{c}\text { Fracción } \\
\text { volumétrica (\%) }\end{array}$} & \multirow{2}{*}{$\begin{array}{c}\text { Temperatura } \\
\left({ }^{\circ} \mathrm{C}\right)\end{array}$} & \multicolumn{3}{|c|}{ Régimen laminar } & \multirow{2}{*}{$\begin{array}{l}\text { Régimen } \\
\text { turbulento } \\
\text { Mouromtseff }\end{array}$} & \multirow{2}{*}{$\frac{M o_{n f}}{M o_{\text {agua }}}$} & \multirow{2}{*}{$\begin{array}{l}\text { Número } \\
\text { de Prandt }\end{array}$} \\
\hline & & $c_{\eta}$ & $C_{k}$ & $c_{n} / C_{k}$ & & & \\
\hline 0,02 & 25 & 21,35 & 0,82 & 26,1 & 4952 & 0,93 & 7,7 \\
\hline 0,12 & 25 & 3,82 & 3,48 & 1,1 & 5467 & 1,02 & 6,5 \\
\hline 0,25 & 25 & 2,58 & 0,40 & 6,5 & 4973 & 0,93 & 7,7 \\
\hline Agua & 25 & - & - & - & 5324 & 1 & 6,4 \\
\hline 0,02 & 40 & 7,59 & 7,11 & 0,9 & 6184 & 1,04 & 4,7 \\
\hline 0,12 & 40 & 1,46 & 5,32 & 3,7 & 5775 & 0,97 & 5,6 \\
\hline 0,25 & 40 & 0,44 & 2,24 & 5,1 & 5759 & 0,97 & 5,5 \\
\hline Agua & 40 & - & - & - & 5917 & 1 & 5,1 \\
\hline
\end{tabular}

Las conclusiones obtenidas tras el análisis de los coeficientes en flujo turbulento y flujo laminar conducen a resultados muy parecidos, siendo los nanofluidos preparados a partir de sílice y los nanotubos de carbono con los que se obtienen peores resultados en ambos tipos de flujo. El coeficiente de Mouromtseff se obtiene mayor que el del fluido base agua, para el caso de los nanofluidos preparados con alúmina a fracciones volumétricas bajas $(0,5 \%)$ y bajas temperaturas $\left(40{ }^{\circ} \mathrm{C}\right)$ y para los nanofluidos preparados con óxido de cobre en fracciones volumétricas no muy altas (0,5 y $1 \%)$. En estos casos dichos nanofluidos mejorarán las propiedades térmicas en flujo turbulento. Respecto al número de Prandtl los mayores valores (nanofluidos de óxido de cobre al 5\% y nanofluidos MWCNTs cortos al 0,5\%) se corresponden siempre con coeficientes de Mouromtseff muy bajos (los cuales no mejoran las propiedades térmicas del fluido base) debido a la elevada viscosidad de los nanofluidos. La aplicación final de estos nanofluidos va a depender del balance entre la energía capturada gracias a ese aumento del coeficiente de calor y la energía utilizada para el bombeo del nanofluido, por lo que no puede considerarse el número de Prandtl de forma independiente para predecir el comportamiento térmico final del nanofluido. El número de Reynolds bajará bastante cuando la viscosidad sea muy alta disminuyendo el coeficiente de Nusselt y por tanto el coeficiente de transferencia de calor. Por tanto, si aumenta la viscosidad para mantener constante el Re se debe aumentar en la misma proporción la velocidad del fluido, incrementándose la presión de bombeo del equipo. 


\subsubsection{Estudio económico de los distintos tipos de nanofluidos}

\section{Análisis de mercado de los fluidos térmicos}

El agua es un fluido transmisor de calor muy económico para temperaturas hasta $100^{\circ} \mathrm{C}$. Para temperaturas superiores se debe presurizar el circuito para poder trabajar con el fluido en fase líquida, aumentando los costes, por este motivo su aplicación se limita a temperaturas inferiores a $100^{\circ} \mathrm{C}$ (Tabla 52).

Tabla 52. Aplicación de los distintos fluidos térmicos en el mercado

\begin{tabular}{ll}
\hline \multicolumn{1}{c}{ Fluido base } & Temperatura de operación \\
\hline Agua & Baja temperatura \\
Parafinas & Baja temperatura \\
Glycoles & Baja-media temperatura \\
Aceites térmicos & Media-alta temperatura \\
Sales fundidas & Alta temperatura \\
\hline
\end{tabular}

En el mercado la mayoría de los fluidos térmicos más utilizados y que pueden aplicarse a distintos intervalos de temperatura son los aceites térmicos. Estos fluidos térmicos en base no acuosa pueden clasificarse según su estructura química en tres tipos principales:

- Aceites sintéticos, con dos grandes subgrupos: de gama media y de alta gama

- Aceites minerales

- Otros, incluidas las siliconas.

Estos fluidos, aunque son capaces de trabajar a elevadas temperaturas por presentar un punto de ebullición elevado presentan como inconveniente la degradación de los aceites con su uso. Entre ellos se puede comparar su capacidad de transferencia de calor para ver que tipología de fluido permite reducir el área de transferencia de calor y por tanto el diseño del intercambiador, siendo los aceites minerales los que mejor comportamiento presentan. Otra característica de estos fluidos térmicos que no se da en los fluidos en base acuosa es que los aceites presentan una temperatura mínima de bombeo por debajo de la cual el sistema no puede trabajar pues se aumenta considerablemente la viscosidad del fluido siendo la viscosidad crítica para su bombeo correcto de 2000 cP. 
Si se evalua el precio, los aceites térmicos sintéticos (aplicación hasta $340^{\circ} \mathrm{C}$ ) son el doble de caros que los aceites minerales, mientras que los aceites térmicos sintéticos aromáticos (aplicación hasta $400^{\circ} \mathrm{C}$ ), lo son hasta cinco o seis veces más caros. Los precios medios de los aceites minerales oscilan como ya se ha comentado en función de sus propiedades, pero su precio medio se sitúa en 1,4 €/I (Pirobloc HTF-Mineral).

La comparación de las directrices ambientales y de seguridad personal es importante al seleccionar una determinada química de fluido. En estos fluidos térmicos hay que vigilar también su punto de inflamación que da una indicación de la presencia de compuestos volátiles en el fluido. El punto de inflamación desciende a medida que se forman moléculas más pequeñas y volátiles, degradándose el fluido y requiriendo de un cambio de carga cuando el punto de inflamación disminuye más de $50^{\circ} \mathrm{C}$ en comparación con el valor de origen del fluido nuevo. Estos temas de seguridad y degradación incrementan los costes al requerir de revisiones periódicas de mantenimiento y un cambio de carga tras 35000-40000 horas efectivas. La utilización de agua como fluido caloportador en aquellos procesos que no requieran de temperaturas elevadas presenta las siguientes ventajas:

- Es económica.

- No es tóxica.

- No es inflamable.

- Presenta elevada conductividad térmica si se compara con los aceites (conductividad térmica del agua a $25^{\circ} \mathrm{C} 0,55 \mathrm{~W} / \mathrm{mK}$ mientras que la de un aceite mineral es de 0,14 $\mathrm{W} / \mathrm{mK})$

El valor elevado de conductividad térmica del agua le confiere un valor diferenciador como fluido térmico, el cual puede incrementarse si se logra aumentar dicho coeficiente añadiendo nanopartículas al fluido base sin que dicho nanofluido supere los costes de los aceites $(1,4 € / I)$, generando así un producto competitivo.

En la búsqueda de nanofluidos comerciales con similares características se han localizado tan sólo dos productos (Ice Dragon Cooling Nanofluid Coolant y Cooler Zalman Reserator 3 Max Dual) con un coste de $(107,6 € / /$ y 67,1 €/equipo refrigeración con nanofluido) respectivamente. El hecho de que no se hayan localizado más nanofluidos comerciales puede deberse al elevado coste de las nanopartículas que incrementan considerablemente el precio 
del nanofluido y a otros tipos de barreras, como las que menciona el proyecto europeo nanoUPTAKE (Overcoming Barriers to Nanofluids Market Uptake) y entre las cuales se pueden citar como más importantes en la evaluación de mercado:

- Seguridad y salud, toxicidad de algunos materiales

- Elevado precio

- Elevada presión de bombeo en su aplicación con su correspondiente incremento de energía

- Falta de estabilidad, de reproducibilidad, y de durabilidad

- Producción a gran escala

- El impacto económico obtenido debido al ahorro energético no está suficientemente validado...

\section{Evaluación del coste de los nanofluidos}

Tras este breve análisis de los fluidos térmicos comerciales y que se sitúan como la competencia de los nanofluidos, se presentan los resultados obtenidos en el estudio económico llevado a cabo para los distintos tipos de nanofluidos preparados en el laboratorio. Dicho análisis ha incluido un estudio del coste del nanofluido expresado como $€ /$, además de un análisis de la eficiencia del mismo (analizando también el aumento en conductividad térmica obtenido con el nanofluido que está directamente relacionado con el aumento en el coeficiente de transferencia de calor).

Las tecnologías para la producción de nanopartículas son todavía a día de hoy muy costosas, además de presentar una baja productividad (producción en lotes pequeños); por este motivo, el coste de las materias primas es elevado y existe además una gran diferencia de precio según la tipología de las partículas. Si se analizan los resultados obtenido en el estudio del coste de adquisición de las materias primas utilizadas en la preparación de los nanofluidos (se han analizado cuatro empresas SSNano, US Research Nanomaterials, Nanoamorphus y Timesnano) se observa que los óxidos cerámicos son los de menor coste presentando siempre un precio menor de $2 € / g$ excepto para las suspensiones de sílice ,Ludox al $50 \%$ en peso, (Figura 162). Los nanotubos de carbono presentan la mayor oscilación de precios en el mercado en función de su pureza, resultando más económicos los nanotubos de pared múltiple (MWCNT) que los de una única capa (SWCNT). Dentro de los nanotubos de pared 
múltiple los nanotubos con una menor longitud se pueden adquirir a un precio menor que los de una longitud mayor, debido a que existe una mayor oferta al ser los más utilizados.

Precio materiales $€ / \mathrm{g} \circ € / \mathrm{ml}$

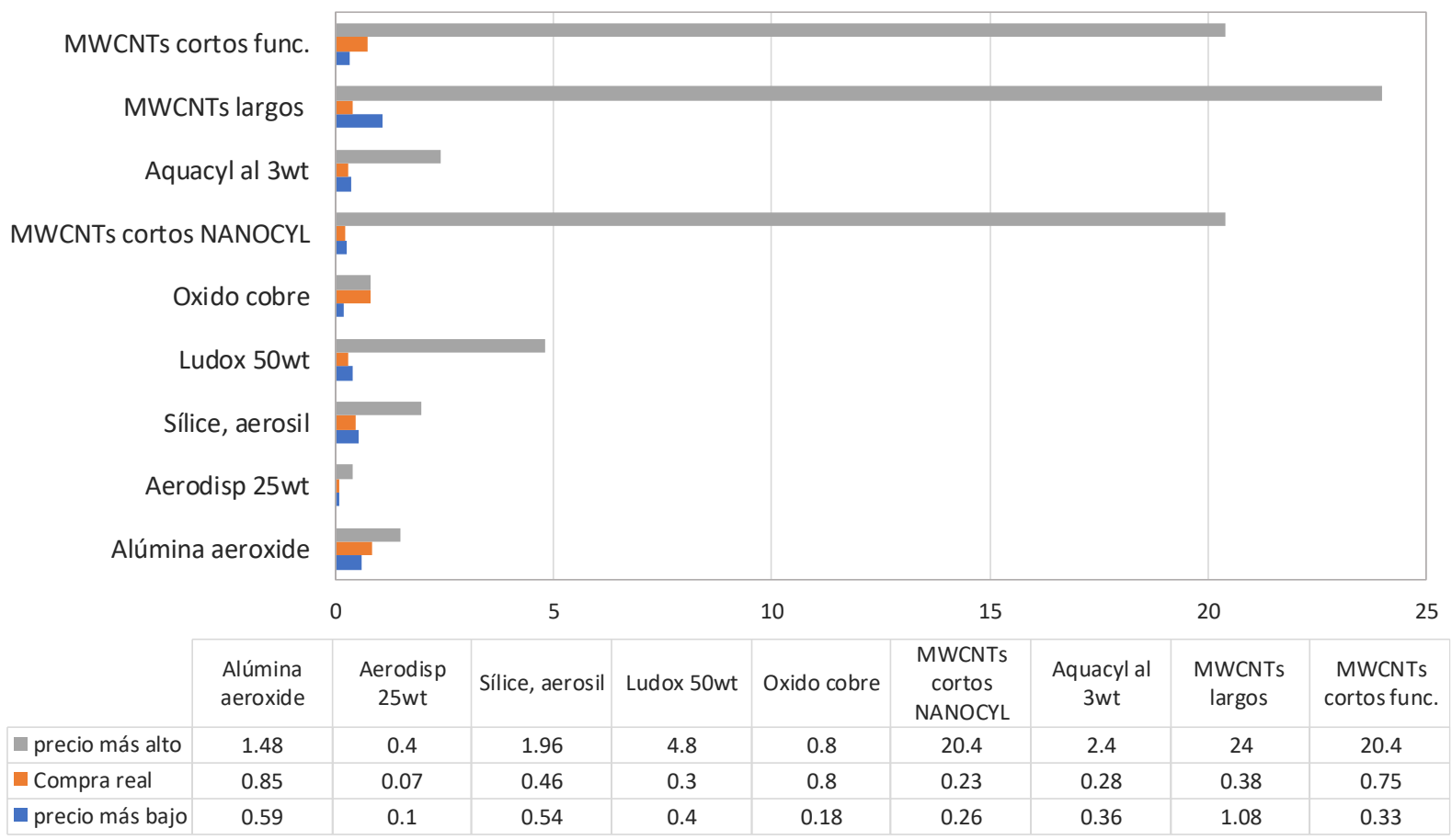

Figura 162. Gráfico comparativo de los precios de las distintas materias primas utilizadas en la preparación de los nanofluidos

Como ya se ha comentado los nanotubos de carbono de pared única (SWCNTs) junto con las nanopartículas de grafeno son las materias primas más caras por lo que se han comparado en un gráfico aparte (Figura 163). Las nanoplacas de grafeno son nanopartículas formadas a su vez de láminas de grafeno apiladas en forma de plaqueta. Cada tipología de grafeno contiene partículas con un grosor medio y una superficie similar. Las partículas de grado $\mathrm{C}$ que son las que se han utilizado, tienen un tamaño medio menor a 2 micras, con superficies específicas promedio que oscilan desde 300 a $750 \mathrm{~m}^{2} / \mathrm{g}$. El precio de las nanopartículas de grafeno varía en función de lo individualizadas que estén las plaquetas y de su pureza, obteniéndose diferencias del $200 \%$. 


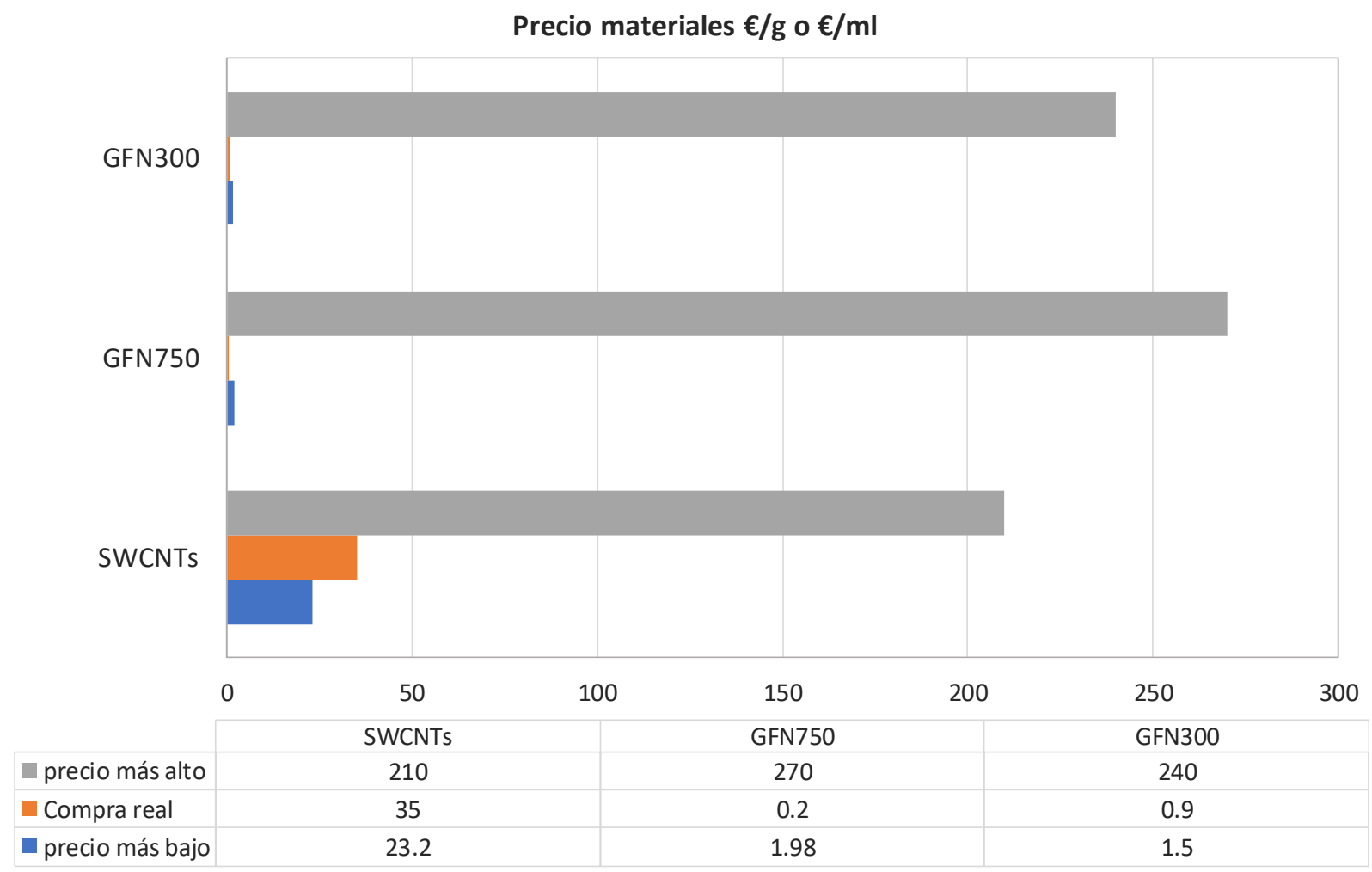

Figura 163. Precios de las materias primas más caras utilizadas en la preparación de los nanofluidos

Se ha calculado el coste de los nanofluidos preparados a partir del precio de dichas nanopartículas en el momento de su adquisición (referenciado en los gráficos como compra real), para realizar una comparativa de los precios a distintas fracciones volumétricas. En el caso de los nanofluidos a los cuales se les ha aplicado la técnica de funcionalización a nivel de laboratorio a las nanopartículas adquiridas, se ha estimado que el incremento en coste de dicha funcionalización supone un incremento del $40 \%$ del coste de adquisición. Dicho sobrecoste se ha calculado a partir del análisis de valores promedio de los precios de mercado. En primer lugar, se han comparado los óxidos cerámicos y metálicos a las tres fracciones volumétricas $(0,5,1$ y $5 \%)$ preparados a partir de nanopartículas adquiridas en polvo o a partir de las diluciones comerciales para el caso de los nanofluidos cerámicos de sílice y alúmina (Ludox y Aeroxide respectivamente), Figura 164. Los precios más bajos se corresponden con los nanofluidos preparados por el método de dilución de suspensiones comerciales, mientras que cuando preparamos los nanofluidos a partir de nanopartículas en polvo los precios se incrementan, al igual que cuando se aumenta la fracción volumétrica, siendo el nanofluido de óxido de cobre el de mayor precio $(252 € / I)$, seguido de la alúmina $(168 € / I)$ y el de sílice (33€/I) cuando se preparan a un $5 \%$ en volumen. Dichos incrementos de precio también se 
corresponden con incrementos en la conductividad térmica, por lo que la aplicación de dichos nanofluidos va a depender de la evaluación global de mejora de rendimiento térmico obtenido y eficiencia junto con el coste del sistema de refrigeración.

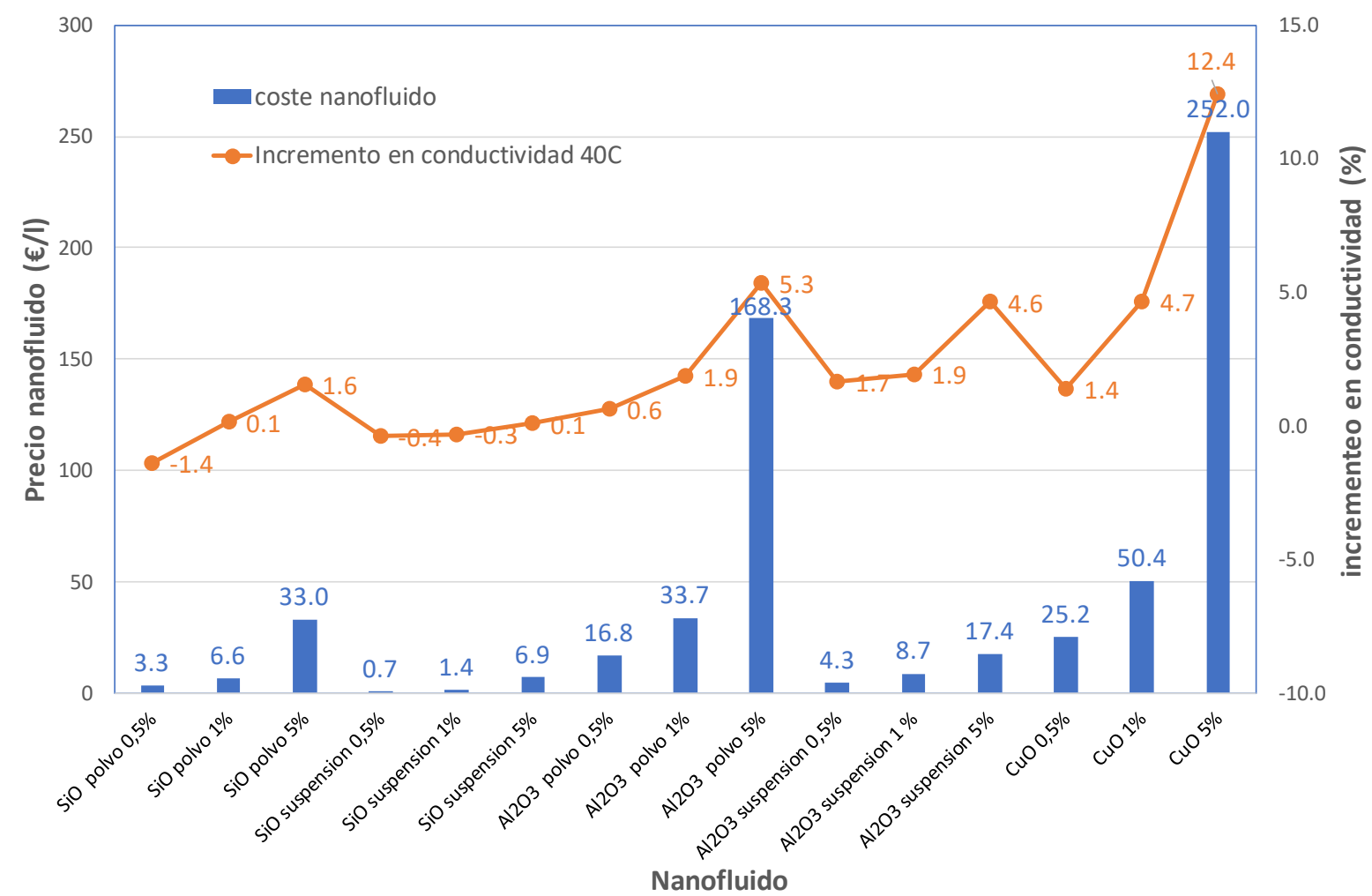

Figura 164. Estudio comparativo del coste de nanofluidos preparados con nanopartículas de óxidos cerámicos y metálico junto con el incremento en conductividad a una temperatura de $40^{\circ} \mathrm{C}$

El análisis de los nanofluidos de nanotubo de carbono se ha realizado a una única fracción volumétrica $(0,1 \%)$, pues la dispersión de esta tipología de material es complicada y dificulta la preparación a elevadas fracciones volumétricas. Se ha evaluado la influencia de la tipología de material, nanotubos multicapa cortos o largos, y el método de funcionalización de su superficie, funcionalizados por el método covalente y mediante aditivos surfactantes, sobre el coste final del nanofluido, representándose conjuntamente con el incremento en conductividad térmica medido (Figura 165). En el gráfico se observa que los nanotubos MWCNTs adquiridos no presentan un coste elevado y a tan baja fracción el incremento que experimentan debido al proceso de funcionalización y /o a la adición de surfactante no es muy significativo, presentando un mayor coste los preparados por dilución de la suspensión comercial Aquacyl, seguidos de los nanofluidos preparados con surfactante SDS y TRITON. EI 
nanofluido que presenta un menor coste y a su vez un aumento en conductividad térmica importante es el preparado con MWCNTs cortos y GA.

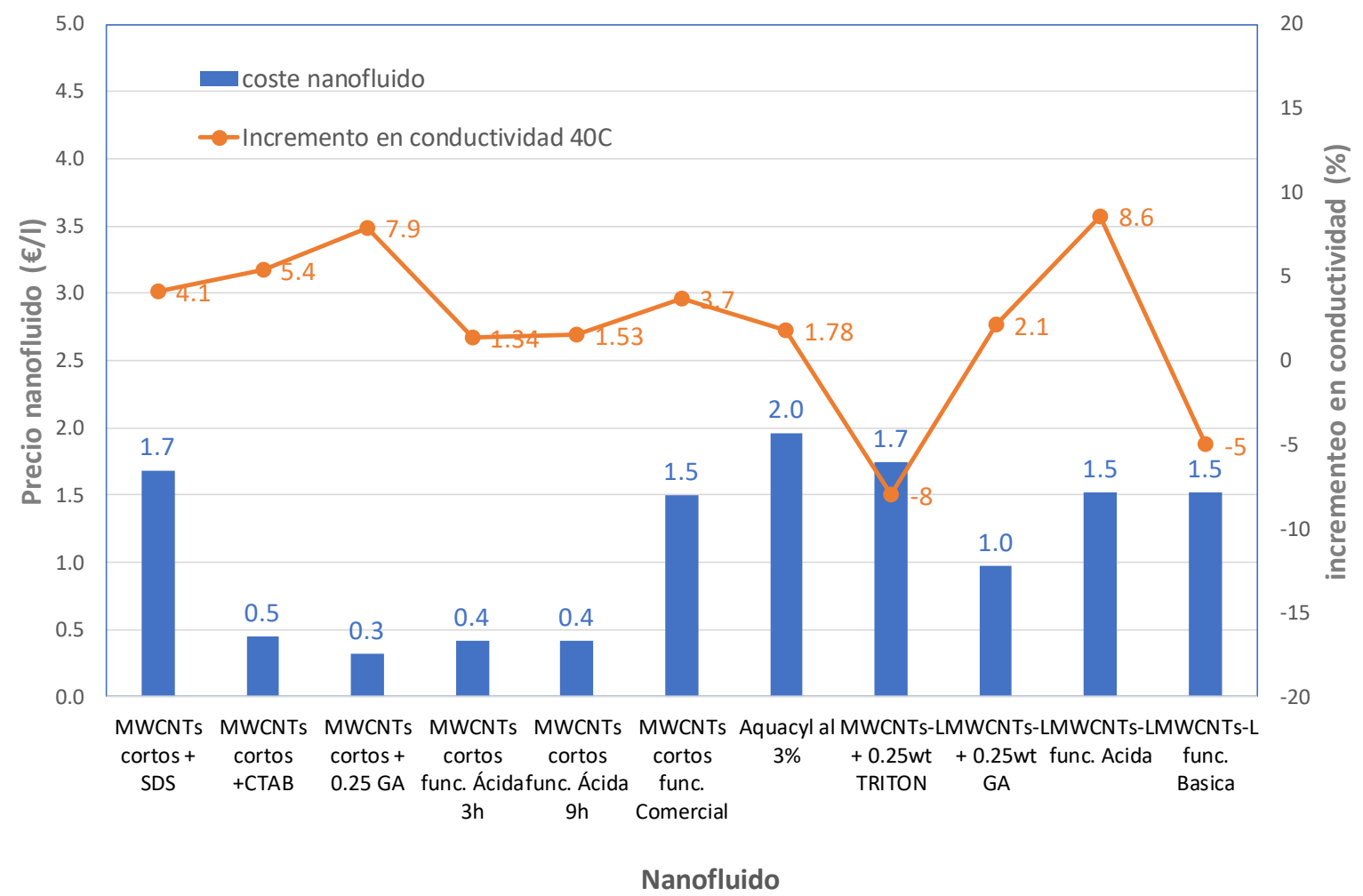

Figura 165. Estudio comparativo del coste de nanofluidos preparados con nanotubos de carbono de pared múltiple junto con el incremento en conductividad a $40^{\circ} \mathrm{C}$

Debido al elevado precio de los nanotubos de carbono de pared única (SWCNTs) adquiridos estos se han representado en un nuevo gráfico, Figura 166, comparándose con los (MWCNTs) a una fracción volumétrica de 0,1 \% y funcionalizados con dos tipos de surfactantes Tritón y goma arábiga (GA). En este gráfico también se observa que con Tritón como surfactante no se consiguen aumentos en la conductividad térmica, por lo que presentando como aditivo un precio superior a la $\mathrm{GA}(0,4 € / \mathrm{ml}$ frente a $0,08 € / \mathrm{g})$, su efecto como dispersante en esta tipología de material no resulta adecuada, ni en los nanotubos de pared única ni en los de pared múltiple. 


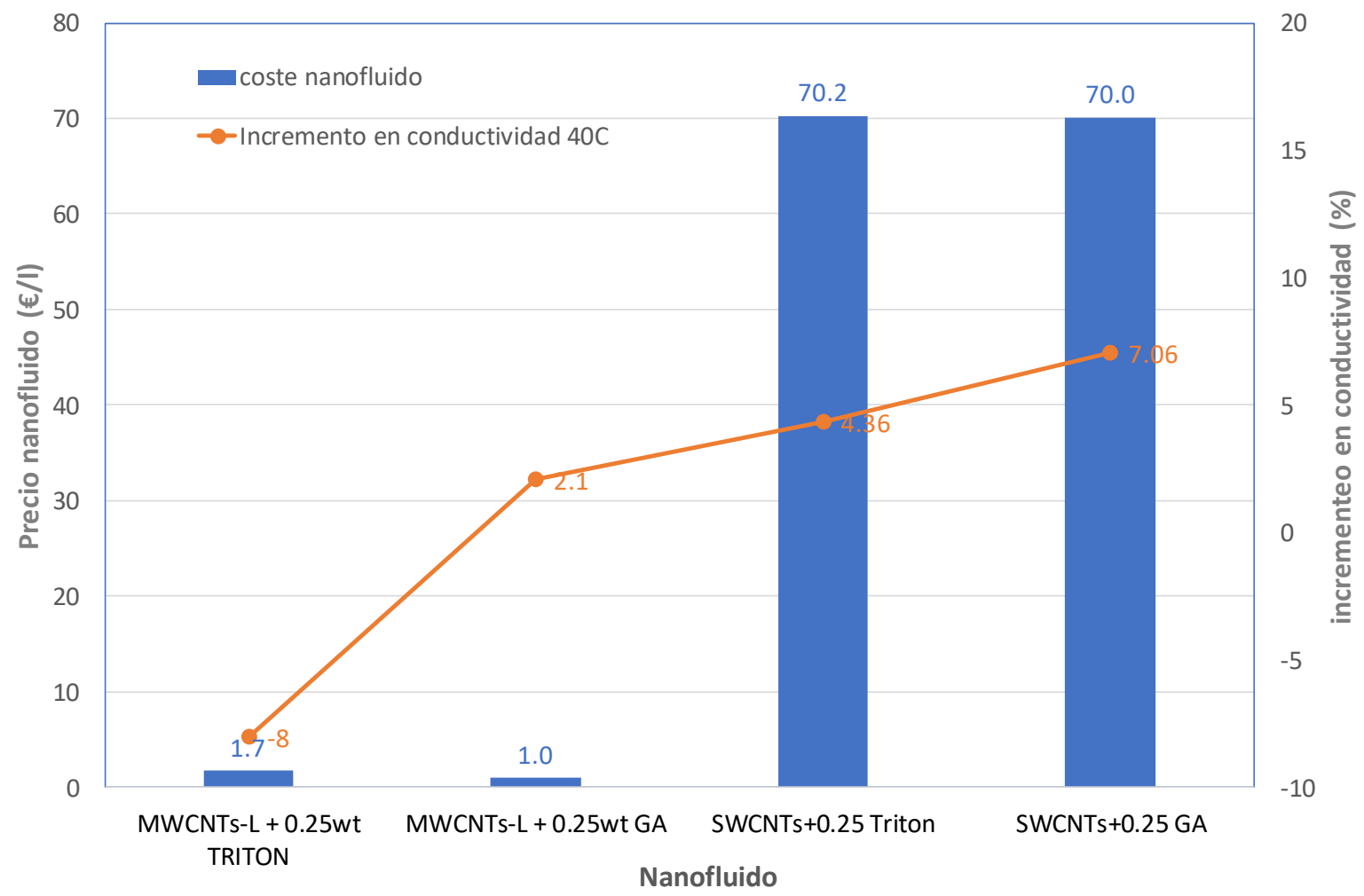

Figura 166. Estudio comparativo del coste de nanofluidos preparados con nantubos de carbono de pared única y múltiple y surfactantes (G.A. y Triton) junto con el incremento en conductividad a $40^{\circ} \mathrm{C}$

En la Figura 167 se ha comparado el diferente coste obtenido con los nanofluidos preparados a partir de grafeno. Si se compara el coste del grafeno 300 funcionalizado por el método ácido con el nanofluido de grafeno 750 preparado por el mismo método, se observa que el incremento en coste del grafeno 300 no implica un mayor incremento en conductividad térmica, siendo por tanto más viable el grafeno con mayor superficie, el grafeno 750. De entre los distintos métodos de funcionalización aplicados, la adición de surfactantes sí que incrementa en gran medida el precio ya que la fracción y superficie de nanopartículas a funcionalizar es mayor y por tanto se requiere mayor cantidad de aditivo. Respecto a los métodos de funcionalización covalente, que presentan un menor coste, resulta necesario comentar que dicho coste está calculado en base a los precios de mercado de materiales funcionalizados (considerándose un sobrecoste del $40 \%$ del precio base) y que podría diferir en función del método de funcionalización y del tiempo, por lo que dicho coste podría ser superior. Este método de funcionalización covalente con el análisis de coste efectuado es el más viable desde un punto de vista de aplicación como fluido térmico pues es con el que se 
consiguen mayores incrementos en conductividad térmica, aunque quedaría por demostrar su viabilidad técnica, en cuanto a temas de productividad.

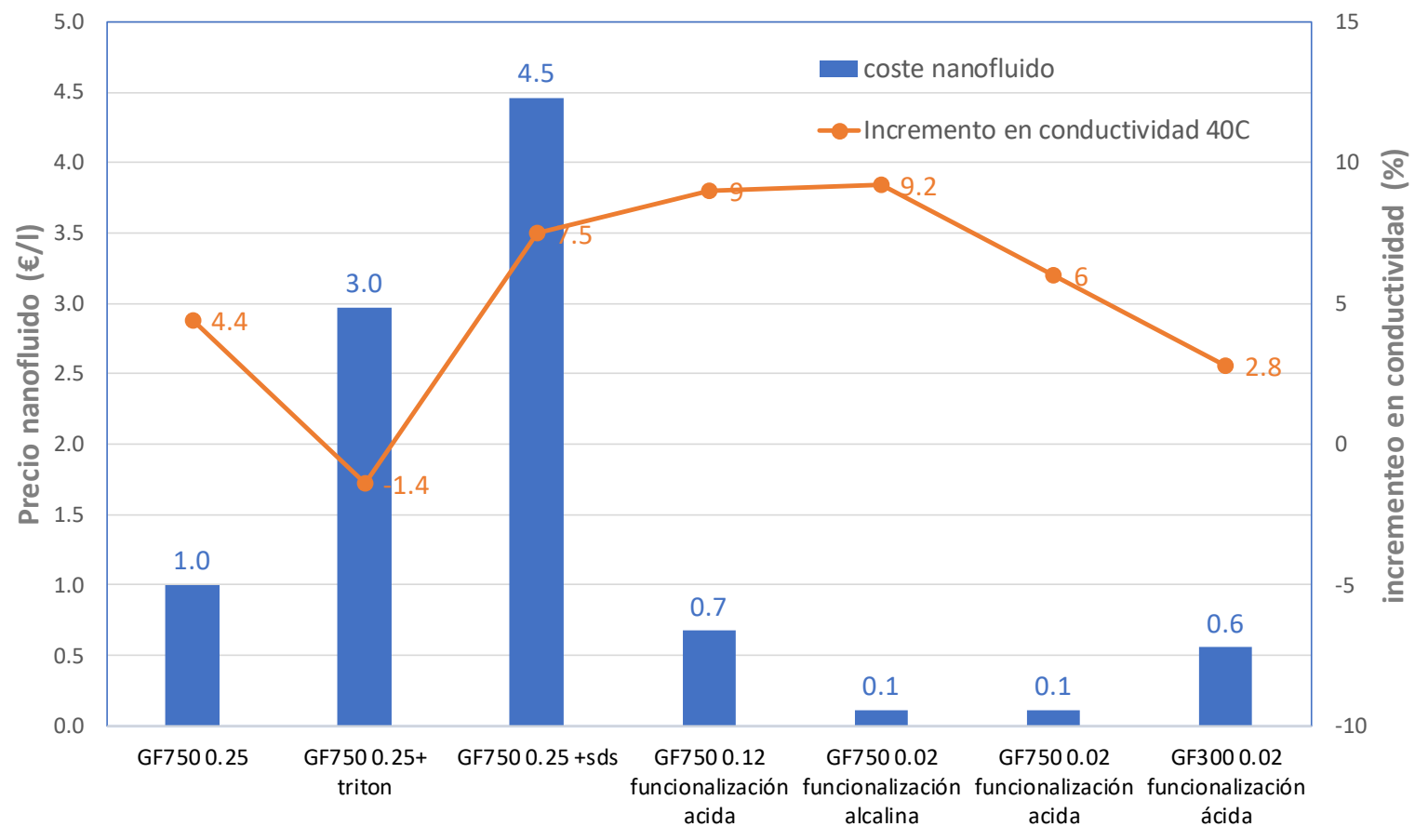

Nanofluido

Figura 167. Estudio comparativo del coste de nanofluidos preparados con nanopartículas de grafeno junto con el incremento en conductividad a $40^{\circ} \mathrm{C}$

Tras el estudio por familias del coste de los nanofluidos, para poder comparar entre los distintos tipos de nanofluidos preparados se ha definido un coeficiente (índice eficienciacoste, IEC) en el que se tiene en cuenta el incremento en conductividad obtenido y el coste de dicho nanofluido y que sigue la siguiente expresión:

$$
\text { IEC }=(\text { incremento } \mathrm{k} / \text { precio nanofluido }) * 1000
$$

En la Figura 168 se resumen los nanofluidos con un índice eficiencia-coste mayor de 1000, observándose que los nanofluidos de grafeno 750 funcionalizados por método covalente son con los que se consiguen mejores resultados, seguidos de los nanotubos de pared múltiple cortos dispersados con goma arábiga como surfactante. 


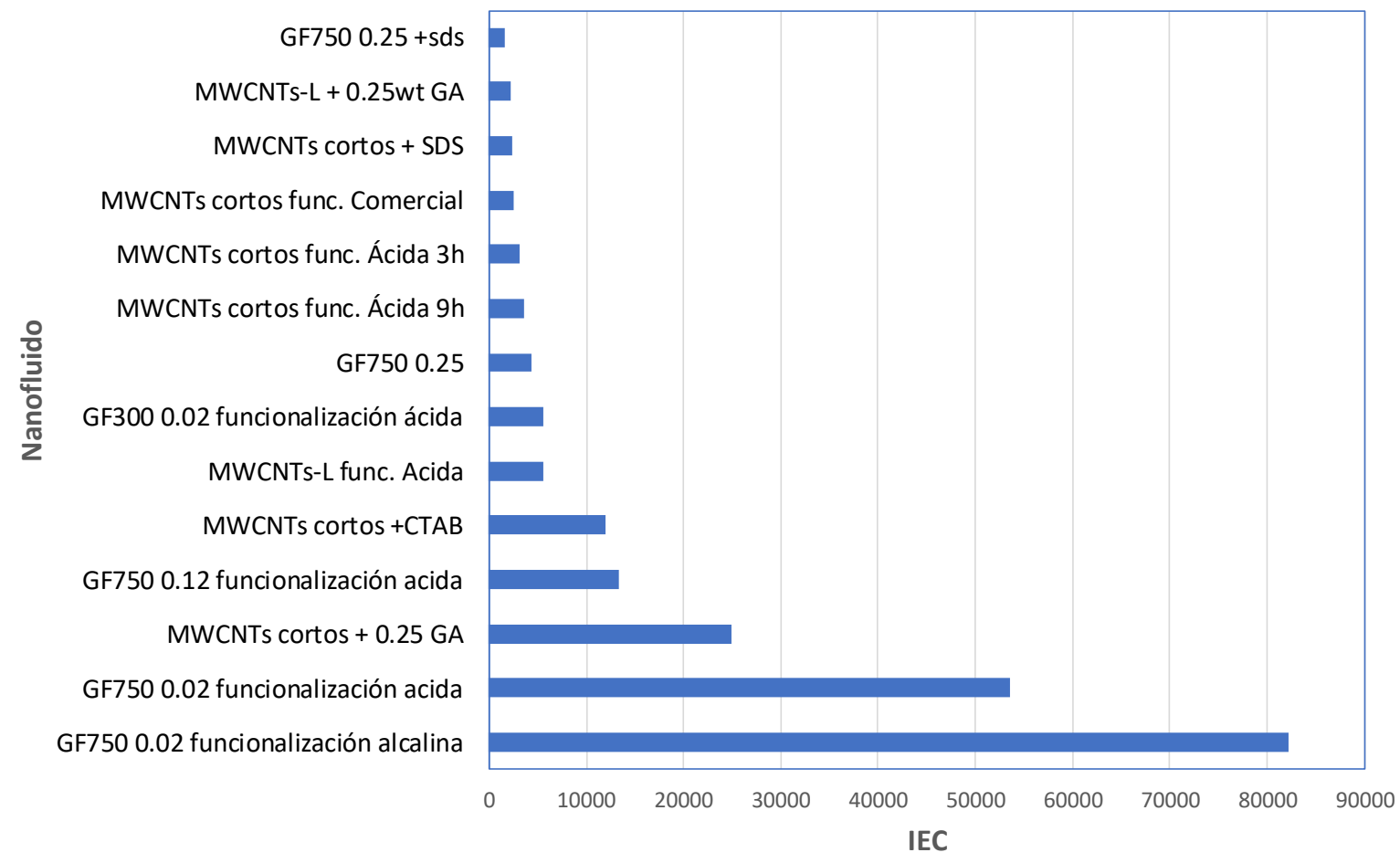

Figura 168. Relación de nanofluidos con mayor índice eficiencia-coste (IEC)

A modo de resumen se pueden extraer las siguientes conclusiones del estudio económico:

- El precio del material base utilizado en la preparación de nanofluidos es muy variable, en función del grado de pureza y tipología. Resulta necesario realizar más estudios para desarrollar procesos continuos y rentables que permitan fabricar económicamente las nanopartículas en grandes cantidades para su aplicación como fluido térmico, pues de lo contrario el coste de los nanofluidos resulta elevado si se compara con el fluido base (agua).

- De entre todos los nanofluidos preparados el que presenta un menor coste es el Grafeno 750 a baja fracción volumétrica (0,02\%), seguido de los MWCNTs cortos con GA como surfactante.

- El nanofluido de mayor coste se obtiene cuando se utilizan como nanopartícula el óxido de cobre a elevada fracción volumétrica $5 \%$, pero si ésta se baja a un $1 \%$ son los nanofluidos preparados con material SWCNTs los que presentan un mayor precio.

- Si se evalúa su índice de eficiencia IEC, el mayor valor se obtiene con el nanofluido preparado con nanopartículas de grafeno 750 funcionalizadas por el método covalente, preparado a una fracción volumétrica de $0,02 \%$. 
Tras el análisis de costes se ha decidido realizar un estudio de validación con los siguientes nanofluidos: alúmina, sílice y nanotubos de carbono MWCNTs cortos comerciales, estudiando el incremento de transmisión de calor obtenido en bucle experimental, para evaluar así su comportamiento global cuando entran en juego otros factores como viscosidad, temperatura y sedimentación. No se pudo incluir en este estudio el nanofluido preparado con grafeno 750 funcionalizado ya que la cantidad de material necesario para las pruebas en el bucle implicaba obtener una cantidad considerable de este material, de la cual no se disponía al realizarse la funcionalización a escala de laboratorio.

\subsubsection{Validación de la transferencia de calor de los nanofluidos en un bucle experimental}

Para la validación experimental de la aplicación de los nanofluidos para mejorar la transferencia de calor se ensayaron en un bucle experimental los siguientes nanofluidos producidos en las condiciones óptimas desarrolladas en el presente estudio:

- Nanofluido con nanopartículas de sílice en polvo (preparado a una fracción volumétrica de $1 \%$ y $5 \%$ )

- Nanofluido con nanopartículas de alúmina (preparado a una fracción volumétrica de $1 \%$ y $5 \%$ )

- Nanofluido con nanotubos (preparado mediante el proceso de dilución del material comercial Aquacyl a una fracción volumétrica de $0,1 \%$ y $1 \%$ )

Se prepararon un total de 10 litros de cada uno de los nanofluidos para su validación en el bucle termohidráulico de laboratorio diseñado por el departamento de mecánica de fluidos de la UJI, Figura 169 [144]. Este bucle ha permitido determinar de forma experimental el coeficiente de transferencia de calor conseguido por un fluido sin que este experimente cambio de fase. 


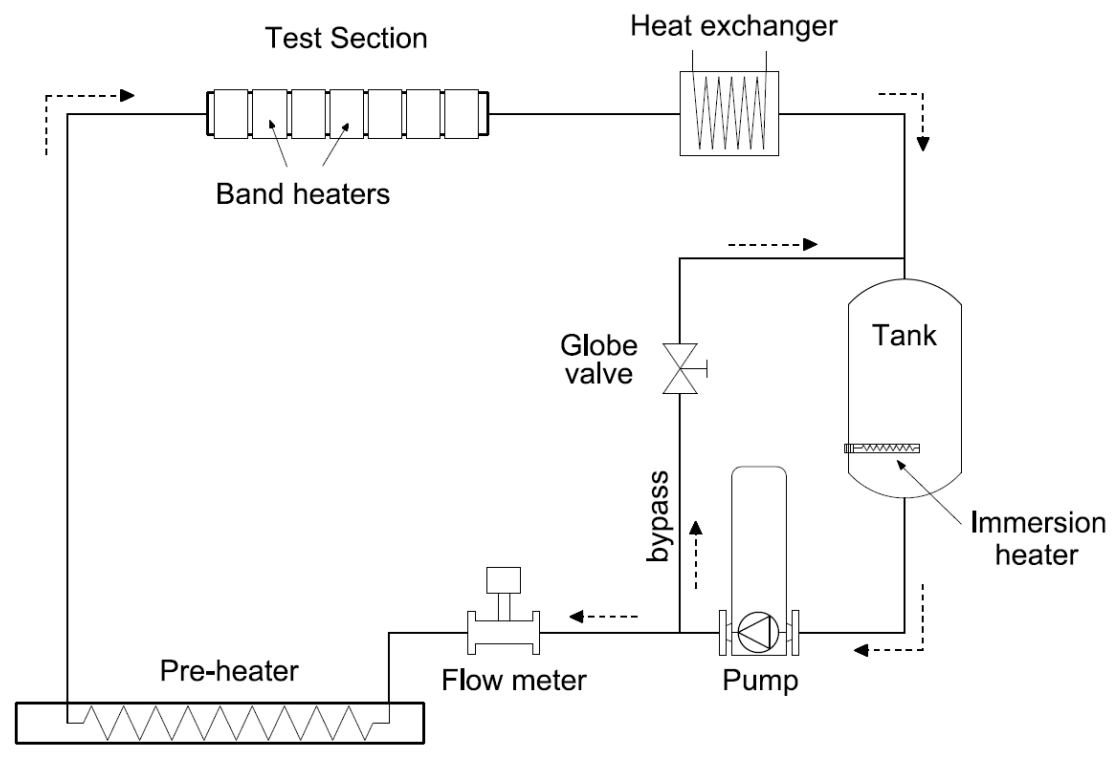

Figura 169. Esquema del bucle térmico de convección forzada de laboratorio

En el bucle el fluido objeto de estudio se puede calentar a distintas temperaturas y pasar a través del intercambiador a diferentes caudales modificando para ello la presión de bombeo. En la sección de testeo se instalaron termorresistencias para medir el aumento de temperatura además de un sensor de presión. El objetivo de esta monitorización fue obtener el coeficiente de transmisión de calor y la pérdida de carga que experimenta el nanofluido.

Además de obtener el coeficiente de transferencia de calor se ha evaluado la perdida de carga que se experimenta en el bucle y que está directamente relacionada con la viscosidad del nanofluido. Si el nanofluido es muy viscoso generará un aumento en la perdida de carga y será necesario aumentar la presión de bombeo para mantener la misma velocidad del nanofluido en el sistema, lo cual implica un aumento en el consumo de energía.

Se realizaron ensayos con tres tipos de nanofluidos a dos fracciones volumétricas ( $1 \%$ y $5 \%$ para sílice y alúmina y $0,1 \%$ y $1 \%$ para los nanotubos). Todos los ensayos se realizaron con un Re> 3000 (régimen turbulento) para evitar sedimentación de las nanopartículas a velocidades bajas de circulación excepto en el caso de los nanotubos de carbono, donde su elevada viscosidad a la fracción volumétrica del $1 \%$ impidió alcanzar dicho régimen con la energía de la bomba. Los ensayos se realizaron a una temperatura fija del fluido de entrada de $60^{\circ} \mathrm{C}$ y una temperatura máxima de pared del $65^{\circ} \mathrm{C}$, manteniéndose el número de Prandtl constante. 
Siguiendo el procedimiento descrito anteriormente y con los cálculos del balance energético aplicado al bucle (ver ecuaciones en artículo [144]) se obtuvieron los resultados de coeficiente de transferencia y caída de presión a distintas velocidades (distinto número de Re) para cada uno de los nanofluidos ensayados.

Tras los resultados obtenidos en el bucle experimental, puede concluirse que el coeficiente de transferencia de calor por convección forzada se incrementa en la alúmina y la sílice cuando los nanofluidos se preparan a fracciones elevadas (fracción volumétrica 5\%), presentando valores similares al fluido base, agua, a fracciones volumétricas del $1 \%$. También se ha demostrado en los ensayos realizados en el bucle que la caída de presión aumenta al utilizar los nanofluidos y su incremento está relacionado con la viscosidad del fluido, la cual es mayor cuando la fracción de nanopartículas dispersas es más elevada.

En la Tabla 53 se resumen los mejores datos obtenidos en aumento en coeficiente de transferencia de calor con los tres tipos de nanofluidos testeados en el bucle experimental junto con los coeficientes relativos de Mouromtseff, Prandtl y conductividad térmica que caracterizan térmicamente al fluido. Junto a estos coeficientes se ha incluido el aumento en la presión de bombeo aplicada en cada nanofluido para alcanzar un determinado número de Reynolds y el coste de preparación de los nanofluidos a escala de laboratorio (€/l).

Tabla 53. Estudio comparativo junto con el coste de producción de la eficiencia térmica de los nanofluidos

\begin{tabular}{|c|c|c|c|c|c|c|c|}
\hline Nanofluido & $\begin{array}{c}\text { Fracción } \\
\text { volumétrica } \Phi \\
(\%)\end{array}$ & $\begin{array}{c}\text { Incremento } \\
\text { en k a } 60{ }^{\circ} \mathrm{C} \\
(\%)\end{array}$ & $\frac{M o_{n f}}{M o_{a g u a}}$ & Prof. & $\begin{array}{c}\text { Incremento } \\
\text { en } h(\%) \\
\text { a un } \\
\operatorname{Re}=30000\end{array}$ & $\begin{array}{c}\text { Pbombeo } \\
\text { (bar) a un } \\
R e=30000\end{array}$ & $\begin{array}{r}\text { Coste } \\
(€ / I)\end{array}$ \\
\hline Alúmina & 1 & - & 0,98 & 3,5 & - & - & 33 \\
\hline Alúmina & 5 & 5,8 & 0,71 & 9,3 & 65 & 0,009 & 168 \\
\hline Sílice & 1 & 3,9 & 0,84 & 2,9 & 5 & 0,003 & 6,6 \\
\hline Sílice & 5 & 6,9 & 0,47 & 3,0 & 84 & 0,065 & 33 \\
\hline MWCNTs & 0,1 & 0,1 & 0,80 & 5,6 & 48 & 0,005 & 2 \\
\hline
\end{tabular}

El mayor aumento en el coeficiente de transferencia de calor (h) en el bucle experimental se ha obtenido con el nanofluido de sílice al 5\% de fracción volumétrica, obteniéndose un incremento del $84 \%$ debido al incremento en conductividad térmica del 6,9\%. Sin embargo, el 
número de Mo es bajo, debido a la elevada viscosidad, prediciendo un peor comportamiento térmico que se ve reflejado en el aumento de la presión de bombeo. La elevada viscosidad de los nanofluidos de sílice al $5 \%$ de fracción volumétrica ocasiona una elevada pérdida de carga en el circuito por lo que finalmente resulta necesario aplicar mayor presión de bombeo para mantener la misma velocidad. Por este motivo se concluye que para el estudio de viabilidad de los nanofluidos resulta imprescindible utilizar además de los valores de conductividad térmica, los números adimensionales como el de Mo junto con la evaluación del coste global. 


\section{CAPÍtulo V}

Conclusiones 

En el presente capitulo se resumen las conclusiones derivadas del estudio de dispersión llevado a cabo en la preparación de nanofluidos en base acuosa a partir de nanopartículas de distinta naturaleza y su posterior caracterización termo-física.

En primer lugar, se resumen las conclusiones generales obtenidas sobre la metodología utilizada en la preparación y en la caracterización de los nanofluidos, y que pueden ser de aplicación en posteriores estudios.

Las conclusiones más importantes obtenidas para cada tipología de nanofluido se resumen posteriormente en los apartados 2 y 3 del presente capítulo, que junto con las principales conclusiones obtenidas sobre modelización y viabilidad dan una visión global de los principales resultados alcanzados.

\section{Conclusiones obtenidas en la metodología aplicada en la preparación y caracterización de los nanofluidos}

- Se ha constatado que para la preparación de nanofluidos por el método de dos etapas resulta imprescindible realizar junto con la dispersión mecánica una modificación de la superficie de las partículas, ya sea por estabilización de la suspensión mediante la modificación del pH, o por funcionalización de la superficie de las nanopartículas por el método covalente o no covalente, para así evitar la aglomeración de las nanopartículas dispersadas.

- La caracterización inicial de las nanopartículas adquiridas para el estudio mediante métodos ópticos (TEM y MEB) permite concluir que ninguno de los materiales presenta nanopartículas individuales, sino que todos ellos presentan aglomerados de partículas de gran tamaño. Este grado de agregación elevado dificulta en gran medida su posterior dispersión, como ha podido comprobarse en el estudio de friabilidad realizado a los materiales adquiridos, en el que ninguno de los materiales aglomerados ha conseguido dispersarse sólo con agitación suave.

- La metodología de dispersión mediante baño de ultrasonidos no es suficiente para disgregar aglomerados por lo que no se recomienda su uso en la preparación de nanofluidos, ya que la baja energía aplicada no permite una correcta dispersión de las nanopartículas. Dicha metodología sólo se utilizó en la preparación de nanofluidos de 
nanotubos de carbono para evitar romper su relación diámetro-longitud demostrándose finalmente que los nanotubos no se dispersaron totalmente obteniéndose suspensiones poco estables debido a la sedimentación y sin aumentos en la conductividad térmica.

- Se ha constatado que resulta necesario aplicar una energía elevada como en la sonda de ultrasonidos para lograr la dispersión de los agregados de nanopartículas en agua, siendo el tiempo de aplicación una variable crítica en el proceso dependiente a su vez de la naturaleza del material a dispersar.

- Cuando se utiliza como técnica de dispersión el equipo homogeneizador se pueden obtener también nanofluidos bien dispersos (los aumentos de conductividad medidos han sido parecidos a los obtenidos con nanofluidos preparados con la sonda de ultrasonidos, presentando una viscosidad también similar), pero los problemas de desgaste por erosión de la válvula de paso del homogeneizador impiden su aplicación industrial.

- Se ha constatado que de entre todas las técnicas de dispersión estudiadas, la aplicación de la sonda de ultrasonidos es la que conduce a la obtención de mejores resultados, tras el ajuste del tiempo de aplicación.

- La metodología de funcionalización de la superficie de las nanopartículas por el método covalente utilizada ha permitido introducir grupos funcionales en la superficie de las nanopartículas de carbono, caracterizándose dicha funcionalización mediante los espectros FT-IR, en los cuales se ha observado que los picos más fuertes se han obtenido con la funcionalización ácida. Los nanotubos funcionalizados comerciales adquiridos presentaban un espectro muy suavizado sin apenas picos, indicando una presencia muy baja de grupos carboxílicos, por lo que el método de funcionalización aplicado en laboratorio resulta ser más adecuado que el comercial. Se ha observado que los procesos de lavado, separación por centrifugado y secado posterior a la funcionalización modifican el estado de agregación de las nanopartículas, obteniéndose aglomerados con una morfología laminar formando plaquetas y que pueden afectar al grado de dispersión final, aunque dichos aglomerados son muy parecidos a los aglomerados del producto comercial funcionalizado. 
- Se ha comprobado que el microscopio electrónico de transmisión (TEM) no resulta adecuado para medir el grado de dispersión de los aglomerados de nanopartículas en el fluido base tras la dispersión mecánica, ya que con esta técnica no se puede diferenciar si la imagen obtenida es la de una partícula aglomerada o una superposición de partículas que en estado original estaban individualizadas, pues el haz de electrones que atraviesa la fina capa pasa a través de todas estas partículas, observándose en la imagen únicamente una proyección global. Con la técnica del microscopio electrónico de barrido (MEB) se recoge información de la superficie de la partícula, siendo el tamaño obtenido más representativo. Hay que señalar que ninguna de las dos técnicas puede medir muestras líquidas por lo que resulta necesario acondicionar la muestra con un proceso de secado que puede cambiar el estado de agregación de las partículas, como se ha constatado en el presente estudio.

- El método de medida de tamaño de partícula por difracción laser ha permitido medir el tamaño de nanopartículas o aglomerados de nanopartículas en las muestras de nanofluidos, permitiendo comparar las distintas técnicas de preparación utilizadas. Este método de caracterización resulta indicado para estudios comparativos entre nanofluidos, pero hay que señalar que no es representativo del grado de dispersión real de las nanopartículas en el fluido base ya que para poder realizar las medidas se diluye la muestra en agua, por lo que podría cambiar el estado de agregación de los aglomerados al modificarse por ejemplo el pH y el potencial de repulsión.

- De entre los distintos métodos utilizados para caracterizar la estabilidad de las suspensiones, el avance del frente de sedimentación visual sólo permite detectar la poca estabilidad en nanofluidos que sedimenten rápidamente, siendo este método muy poco adecuado para materiales como los nanotubos de carbono o grafeno debido a la alta coloración que dan al fluido base incluso a baja fracción volumétrica y que impiden discernir de forma visual el avance del frente de sedimentación. El equipo Turbiscán ha permitido caracterizar la estabilidad de los nanofluidos preparados a partir de óxidos cerámicos. Sin embargo, este método de medida no es válido para materiales como los nanotubos o partículas de grafeno, pues apenas dan retrodispersión ni transmisión, debido al coeficiente de absorción elevado característico de estos materiales. Por este motivo se ha desarrollado una metodología 
para caracterizar la estabilidad de los nanofluidos basados en partículas de carbono utilizando para ello un espectrofotómetro y tomando a distintos tiempos una alícuota en la misma zona de la muestra para evaluar así la fracción relativa de nanopartículas con dicho equipo.

- De entre los dos métodos utilizados para la medida de la conductividad térmica en los nanofluidos, la medida de la conductividad por el método de placas (TCl de Netzsch) no ha permitido evaluar la conductividad a temperaturas superiores a la temperatura ambiente obteniéndose valores de conductividad térmica con un elevado error de medida. Si que ha sido posible analizar la conductividad a distintas temperaturas de ensayo por el método de hilo caliente con el equipo KD2, gracias al diseño y acople de su sensor en el dispositivo experimental desarrollado en este estudio, el cual ha permitido realizar las medidas en el interior de un baño termostatado con una buena reproducibilidad.

- Para la caracterización del comportamiento reológico de los nanofluidos se ha comprobado que resulta adecuado utilizar un reómetro con el husillo de dos cilindros, pues la elevada superficie del cilindro permite realizar medidas en fluidos con viscosidades bajas. Sin embargo, en estos reómetros el esfuerzo de cizalladura que puede aplicarse está limitado por esfuerzo de cizalladura máximo y por el error de medida obtenido a gradientes de velocidad mayores a $10^{2} \mathrm{~s}^{-1}$ debido a la centrifugación de las muestras (Vórtices de Taylor).

\section{Conclusiones obtenidas en el estudio de las propiedades de los nanofluidos}

\section{preparados}

\section{Conclusiones obtenidas para los nanofluidos preparados a partir de diferentes óxidos}

- En el análisis de las imágenes obtenidas en el Microscopio electrónico de barrido (MEB) se ha observado que a pesar de que las partículas de sílice, alúmina y óxido de cobre en origen tienen tamaño nanométrico, el estado de agregación de las mismas es elevado (aglomerados con tamaño medio superior a $200 \mathrm{~nm}$ ). Respecto a la morfología de las partículas dentro de estos aglomerados, las partículas de sílice en los nanofluidos 
preparados a partir de dilución de suspensión comercial LUDOX son esféricas, mientras que las de sílice en polvo (Aerosil), óxido de cobre y alúmina se observan aglomeradas.

- Se ha determinado con el coeficiente de friabilidad la facilidad de dispersión de los aglomerados de las nanopartículas en polvo adquiridas, observando que para todos los óxidos no se consigue romper los aglomerados con agitación suave, resultando necesario la aplicación de ultrasonidos, con un tiempo de aplicación inferior a 15 minutos, pues a tiempos mayores se ha comprobado que la energía de ultrasonidos aplicada tiene un efecto negativo ocasionando una reaglomeración de las nanopartículas.

- Se ha observado diferencias significativas en el grado de dispersión entre los nanofluidos preparados a partir de nanopartículas en polvo y los nanofluidos preparados mediante la dilución de las suspensiones comerciales tras la caracterización en el TEM. En los nanofluidos preparados por dilución de suspensiones comerciales las nanopartículas se observan individualizadas mientras que en los nanofluidos preparados a partir de nanopartículas en polvo se observan aglomerados de nanopartículas, es decir peor dispersadas. Para el caso de la alúmina, se ha observado que dichos agregados están formados por una cadena de nanopartículas con un tamaño de 5 a $10 \mathrm{~nm}$ y con una forma arracimada, no esférica. En la caracterización del tamaño final de nanopartícula dispersada mediante la técnica de difracción laser se ha observado que el tamaño medio de estos aglomerados en los nanofluidos preparados a partir de la sílice en polvo se encontraba en torno a $201 \mathrm{~nm}$, mientras que en todos los nanofluidos de alúmina preparados se ha alcanzado un tamaño medio de agregado de unos $100 \mathrm{~nm}$. En el caso de los nanofluidos de óxido de cobre se ha podido constatar que los aglomerados presentan un tamaño medio de unas 1,2 $\mu \mathrm{m}$. En consecuencia, el análisis de las imágenes de las muestras de nanofluidos, junto con la medida de tamaños por difracción láser ha permitido concluir que no se ha alcanzado la dispersión total de las nanopartículas en el fluido base, encontrándose estas formando aglomerados de mayor o menor tamaño.

- Aunque el grado de dispersión alcanzado no ha sido elevado, la medida de estabilidad de los nanofluidos mediante la técnica de turbiscán ha demostrado que todos los nanofluidos preparados a distintas fracciones volumétricas con los óxidos permanecen 
estables, pues no se ha detectado cambios en los valores de retrodispersión (BS) a lo largo del tiempo de ensayo (72 h), siendo algo más inestables los nanofluidos de óxido de cobre preparados a fracciones bajas (del 1\%).

- Tras el análisis de la caracterización térmica de los nanofluidos preparados con óxidos se ha constatado que al aumentar la fracción volumétrica de sólidos se incrementa la conductividad térmica, obteniéndose aumentos en conductividad del $2 \%$ para la sílice, del $5 \%$ para la alúmina y del $12 \%$ para el $\mathrm{CuO}$ a $40^{\circ} \mathrm{C}$. Los nanofluidos preparados a partir de la dilución de suspensión comercial no han mostrado aumentos significativos, a pesar de observar que las nanopartículas estaban mejor dispersas. De hecho, los mejores resultados se han obtenido con el material óxido de cobre a pesar de presentar los aglomerados de mayor tamaño tras su dispersión, aunque la estabilidad de estos nanofluidos se ha visto afectada por los fenómenos de sedimentación. Se puede concluir que el mecanismo predominante de transmisión de calor en estos casos es el que se basa en la conducción a través de las nanopartículas aglomeradas siguiendo la teoría de Keblinski, quien propuso que dicha aglomeración podía incrementar la conductividad térmica del medio debido a que proporcionan rutas locales por percolación que facilitan el transporte de calor.

- La caracterización reológica de los nanofluidos de óxidos ha puesto de manifiesto que a una mayor fracción volumétrica de nanopartículas el aumento de la viscosidad es significativo, excepto para el nanofluido obtenido a partir de la dilución de una suspensión comercial de sílice, Ludox. La viscosidad de los nanofluidos de alúmina es elevada tanto cuando se prepara a partir de nanopartículas de Aeroxide en polvo como cuando se prepara por el método de dilución del Aerodisp, obteniéndose el mayor incremento en viscosidad a una fracción volumétrica del $5 \%$.

Conclusiones obtenidas para los nanofluidos preparados a partir de nanopartículas en base carbono

- Los nanotubos de carbono y las nanopartículas de grafeno adquiridas también se encuentran agrupadas formando aglomerados como se ha podido apreciar en las imágenes obtenidas en el MEB. Se ha observado que los MWCNTs cortos presentan un tamaño de aglomerado mucho mayor que los otros tipos de nanotubos de carbono, 
tanto de pared múltiple como de pared única. Los nanotubos de pared múltiple cortos funcionalizados por el método comercial son los que presentan un tamaño medio de aglomerado menor. Respecto el grafeno, las nanopartículas de GFN750 presentan un tamaño de aglomerado mayor que las del GFN300. Sin embargo, estos aglomerados de GFN 750 son más friables y alcanzan mayor porcentaje de rotura de los aglomerados tras la dispersión en sonda de ultrasonidos. Este estado de aglomeración generalizado en los materiales adquiridos ha requerido de la aplicación de técnicas de dispersión mecánicas intensas, por lo que el baño de ultrasonidos no resultó suficiente para conseguir disgregar las nanopartículas en base carbono.

- En el análisis de las imágenes obtenidas en TEM y los resultados de tamaño de partícula medidos con el equipo de análisis por difracción láser se ha observado que el tamaño medio de los aglomerados de nanotubos de carbono o grafeno en los nanofluidos disminuye tras la dispersión con sonda de ultrasonidos, aunque finalmente no se ha conseguido individualizar totalmente a las partículas de nanotubos, ya que el diámetro medio detectado se corresponde a agregados con tamaños superiores a los $100 \mathrm{~nm}$.

- Se ha constatado que entre los distintos tipos de surfactantes utilizados para la funcionalización de la superficie de las nanopartículas de nanotubos de carbono, la goma arábiga es el que mejores resultados ha permitido alcanzar tanto en conductividad térmica como en estabilidad en el caso de los nanofluidos preparados con este método de funcionalización no covalente.

- Si se comparan las dos técnicas aplicadas en la funcionalización de la superficie de las nanopartículas (covalente y no covalente), la funcionalización por el método no covalente mediante surfactantes ha permitido obtener nanofluidos estables a una fracción volumétrica mayor que en los nanofluidos preparados con nanopartículas funcionalizadas por el método covalente comercial $(0,2 \%$ frente al $0,1 \%$ para el caso de los MWCNTs cortos).

- Se ha observado que entre los diversos tipos de nanotubos de pared múltiple (largos y cortos) funcionalizados por el método covalente, los primeros han presentado una estabilidad más alta que los MWCNTs cortos independientemente del tipo de funcionalización aplicada (ácida o alcalina) pudiéndose concluir que el éxito de la funcionalización aplicada con el objetivo de mejorar la dispersión de los nanotubos en 
agua depende más de la longitud de los nanotubos y no tanto del método de funcionalización aplicado.

- De entre todos los nanofluidos preparados con nanotubos de carbono los mayores aumentos en conductividad térmica se han obtenido con los nanotubos de pared única (SWCNTs) alcanzándose un incremento del $10 \%$ a $40^{\circ} \mathrm{C}$, debido a su mayor relación longitud-diámetro, seguidos de los nanotubos de pared múltiple largos. Los peores resultados se han obtenido con los MWCNTs cortos, obteniéndose tan solo incrementos en la conductividad térmica de los nanofluidos cuando se ha funcionalizado su superficie por método covalente en laboratorio.

- Cuando se funcionalizan las nanopartículas de grafeno por el método no covalente, el surfactante que mejor ha funcionado ha sido el surfactante tipo aniónico SDS. Los surfactantes tipo no-iónicos como el Tritón o la Goma arábiga no han conseguido mejorar la estabilidad de las partículas de grafeno en la suspensión acuosa. La estabilidad de los nanofluidos preparados con grafeno funcionalizado por método covalente ácido ha sido elevada, obteniéndose una mejor estabilidad con el grafeno GFN750 que con el grafeno GFN300 debido posiblemente a que su mayor superficie específica ha permitido incorporar mayor número de grupos funcionalizados consiguiendo un mejor grado de dispersión en base acuosa, al igual que se ha observado con los nanotubos largos.

- El mayor incremento en conductividad térmica cuando se utiliza grafeno, se ha obtenido con el grafeno GFN750 y preparado con el SDS como surfactante, alcanzando a una temperatura de $40^{\circ} \mathrm{C}$ un incremento del $7,5 \%$ respecto al fluido base.

- Los aumentos relativos en viscosidad con los materiales en base carbono son bajos para la mayoría de los nanofluidos estudiados independientemente del método de dispersión mecánica utilizado, debido a la baja fracción volumétrica a la que se han preparado $(<0,1 \%)$ por lo que las suspensiones presentan una viscosidad muy parecida al agua con un comportamiento típico newtoniano. Se ha constatado que los valores de viscosidad más elevados se han obtenido con los nanofluidos preparados con materiales funcionalizados. 


\section{Conclusiones obtenidas sobre modelización y viabilidad tras el estudio}

\section{comparativo entre nanofluidos}

- Los resultados obtenidos en el análisis de modelos realizado para los nanofluidos con óxidos confirman que el modelo de You y Choi, que tiene en cuenta el efecto de la nanocapa actuando como una resistencia al aumento de conductividad, y el modelo de Xuan que considera el movimiento browniano y el efecto de aglomeración, junto con el modelo de Maxwell para fracciones más diluidas, son los modelos que reproducen mejor el comportamiento termodinámico de los nanofluidos analizados. Se ajustan peor los modelos que incorporan factores de forma o matrices de redes (Krischer).

- Cuando se utilizan nanopartículas con formas no esféricas como en el caso de los nanofluidos preparados con nanotubos de carbono en fracciones diluidas (fracción volumétrica $\Phi<0,2 \%$ ) el modelo básico de Maxwell es el más adecuado para predecir el comportamiento termodinámico con un error bajo. Cuando las suspensiones se preparan a mayor fracción son los modelos de Xue y Hamilton-Crosser los que mejor se ajustan, pues estos modelos tienen en cuenta la forma de las nanopartículas.

- Se han utilizado los módulos de Mouromtseff y de Prandtl para predecir el comportamiento en régimen turbulento de los nanofluidos caracterizados, y un coeficiente que relaciona la viscosidad y la conductividad térmica $\left(c_{\mu} / c_{k}\right)$ para estudiar su comportamiento en régimen laminar. El análisis de los coeficientes en flujo turbulento y en flujo laminar conduce a resultados similares, siendo los nanofluidos preparados a partir de sílice y los nanotubos de carbono con los que se obtienen peores resultados en ambos tipos de flujo.

- El precio del material base utilizado en la preparación de nanofluidos es muy variable, en función del grado de pureza y tipología repercutiendo directamente en el coste final de los nanofluidos, que resulta ser elevado si se compara con el fluido base (agua). De entre todos los nanofluidos preparados el que presenta un menor coste es el nanofluido preparado con plaquetas de grafeno 750 a baja fracción volumétrica $(0,02)$, seguido del nanofluido preparado con nanotubos MWCNTs cortos con GA como surfactante. 
- El nanofluido con mayor coste se obtiene cuando se utilizan como nanopartículas el óxido de cobre a elevada fracción volumétrica (5\%). Aunque si se compara a una misma fracción volumétrica, (menor a un 1\%, por ejemplo), son los nanofluidos preparados con material SWCNTs los que presentan un mayor precio.

- Si se evalúa el índice de eficiencia de los nanofluidos estudiados, IEC, el mejor valor se obtiene con el nanofluido preparado con nanopartículas de grafeno 750 funcionalizadas por el método covalente, preparado a una fracción volumétrica baja del $0,02 \%$.

- Los ensayos realizados en el bucle han permitido validar los nanofluidos preparados a nivel de laboratorio. El mayor incremento en el coeficiente de transferencia de calor medido experimentalmente en el bucle se ha obtenido con el nanofluido de sílice al $5 \%$ de fracción volumétrica. Sin embargo, este nanofluido se caracteriza por presentar una viscosidad elevada que ocasiona una elevada pérdida de carga en el circuito del bucle, por lo que finalmente resulta necesario aplicar mayor presión de bombeo para mantener la misma velocidad dificultando su aplicación como fluido térmico. El número adimensional de Mouroutseff bajo ya predecía dicho comportamiento. 
Futuras líneas de investigación 

Como líneas futuras que pueden dar continuidad al trabajo de investigación sobre dispersión de nanopartículas desarrollado en esta tesis podemos citar:

- Desarrollo de un método de análisis de imagen vía húmeda que permita cuantificar la dispersión de nanopartículas alcanzada en el fluido base y que evite los procesos de secado que concentran o aglomeran las nanopartículas modificando el estado de dispersión real en el fluido base (como sería el caso del TEM en húmedo).

- Estudiar la dispersión de los mismos materiales con tamaño nanométrico en un fluido base distinto al agua, donde los incrementos en conductividad térmica obtenidos pueden ser mayores según se ha observado en la revisión bibliográfica realizada. Además, estos fluidos base facilitarían la dispersión de las nanopartículas de carbono caracterizadas por su naturaleza hidrofóbica.

- Se ha demostrado que la mayoría de los nanofluidos preparados a fracciones altas aumentan su conductividad térmica respecto al fluido base, pero estos nanofluidos se caracterizan por tener una viscosidad elevada, por lo que sería importante realizar un estudio para conseguir reducir en la medida de los posible los valores de viscosidad, ya que de esta manera no se aumentaría demasiado la potencia de bombeo del fluido y sería más viable su utilización como fluido térmico.

- Realizar un estudio para evaluar la aplicación de los nanofluidos en sistemas avanzados de captación, transporte y almacenamiento de energía, como por ejemplo fluidos con coeficiente de absorción elevado para su uso en los colectores solares

- En este estudio se han preparado nanofluidos a partir de la dispersión de un tipo de material de tamaño nanométrico en un fluido base, pero se podría plantear el estudio de nanofluidos híbridos (mezcla de distintos materiales), obteniendo de este modo nanofluidos con propiedades diferentes.

- Completar la caracterización térmica de los nanofluidos con otros estudios relacionados con la sostenibilidad de estos nanofluidos, como por ejemplo obtener su ACV (análisis de ciclo de vida) para ver si son medioambientalmente adecuados.

- Aplicar los conocimientos sobre preparación y caracterización de suspensiones de materiales de tamaño nanométrico a una fracción elevada para su aplicación en otras 
áreas como por ejemplo tintas conductoras a base de nanotubos de carbono o grafeno o como en tintas inkjet para obtener recubrimientos cerámicos con nuevas funcionalidades. 


\section{Publicaciones}



A continuación, se resumen las publicaciones científicas y comunicaciones a congresos a las que ha dado lugar el estudio realizado sobre la dispersión de nanopartículas en base acuosa para su aplicación como fluido térmico que ahora se presenta como Tesis Doctoral ordenadas cronológicamente,

\section{Artículos}

- Mondragón R., Segarra C., Martínez-Cuenca R., Juliá J.E., Jarque J.C. Experimental characterization and modelling of physical properties of nanofluids at high temperature conditions for heat transfer applications. Powder Technology Powder 249 (2013) 516-529

Powder Technology 249 (2013) 516-529 transfer applications

Rosa Mondragón ${ }^{\mathrm{b}}$, Carmen Segarra ${ }^{\mathrm{a}}$, Raúl Martínez-Cuenca ${ }^{\mathrm{b}}$, J. Enrique Juliáa ${ }^{\mathrm{b}}$, Juan Carlos Jarque ${ }^{\mathrm{a}, *}$

"Instibito de Tecno logía Cerúmica, Universitat Jaume L Compus de Riu S.C., 1207 I Castellán de la Plana Spain

b Departamento de Ingeniería Merúnica y Construcoún, Universitat faume L Campus de Riu Sec., 12071 Castellán de la Pana, Spain

A R T I C L E I N F O

\section{Artide histary:}

Received 12 Aprill 2013

Received in revised form 15 July 2013

Accepted 23 August 2013

Available online 31 August 2013

\section{Keywords:}

Namofluid

Conductivity

Heat transfer

Vismsiny

Viscosity
A B S T R A C T

The use of suspended nanoparticlesin a base fluid has been practiced in the last years to increase its heat transfer capabilities, In this work, water based nanofluids of silica, alumina and carbon nanotubes were characterized regarding its later use in heat transfer applications. Well dispersed nanofluids were prepared at different volume fractions (up to $5 \mathrm{v}$ ) bydispersing the powder into the base fluid or by diluting commercial nanofluids acquired in suspension form. The thermal conductivity, the specific heat and the viscosity of all the prepared nanofluids were measured in order to optimize the Prandtl number and the heat transfer performance, at high temperature conditions (up to $80^{\circ} \mathrm{C}$ ). Available modek for these variables have been used to predict experimental data and the suitability of each one for the different sort of tested nanofluids has been obtained. Finally, the stability of the nanofluids was also studied through the evolution of the amount of light scattered by the sample during a period of time. 
- Martínez-Cuenca R., Mondragón R., Hernandez L., Segarra C., Jarque J.C., Hibiki.T., Juliá J.E. Heat transfer coefficient and pressure drop in SiO2, Al2O3 and CNT-water based nanofluids in turbulent flow. Applied Thermal Engineering 98 (2016) 841-849.

Applied Thermal Engineering 98 (2016) 841-849

Research Paper

Forced-convective heat-transfer coefficient and pressure drop of water-based nanofluids in a horizontal pipe

R. Martínez-Cuenca a , R. Mondragón ${ }^{\text {a }}$, L. Hernández a , C. Segarra ${ }^{\text {b }}$, J.C. Jarque ${ }^{\text {b }}$, T. Hibiki ${ }^{\text {, }}$ J.E. Juliá a,*

a Departamento de Ingenieria Mecánica y Consmucción, Universirar Jaume L Castellán de la Plana 12071, Spain

'Insiruro de Tecrodogia Cerúmice, Universirar Jaume L Castellón de la Plana 12071, Spain

Nudear Engineering Depanmenr, Purdue Universiry, West Lafayerte, IN 47907, Lhired Srares

- Convective heat transer and pressure drop of six water-based nanofluids studied.

- Different nanoparticle material, concentration and shape included.

- Thermal conductivities, specific heat, cluster size and viscosities reported,

- Results compared in constant Reynolds number and constant pressure drop basis.

- Classical correlations are valid if measured thermophysical properties are used.

A R T I C L E I N F O

\section{Arricle histary:}

Received 31 July 2015

Accepted 12 November 2015

Available online 6 January 2016

\section{Keywards:}

Nanofluid

Nanother

$\mathrm{SiO}_{2}$

$\mathrm{Al}_{2} \mathrm{O}_{3}$

Convective heat rranster

Pressure drop

\begin{abstract}
A B S T R A C T
In this paper the heat transfer performance of $\mathrm{Al}_{2} \mathrm{O}_{3}, \mathrm{SiO}_{2}$ and multi-walled CNTs (MWCNTs) in a closed loop were investigated. Heat transfer coefficient and pressure drop were measured in a horizontal thermalinsulated test-section, Special care was taken in the loop calibration and the estimation of measurement uncertainties. The results show that the Gnielinski correlation can be used to predict the turbulent heat transfer coefficient as long as the proper experimental values for the thermophysical properties of each nanofluid are used. Also, the Colebrook-White correlation for the friction factor showed good agreement with the experimental results for pressure drop. The nanofluids showed an increased heat transfer coefficient with respect to that of water on a constant Reynolds number basis, but a reduced performance when compared on a constant pumping power basis. Note that some authors treat CNTs as nanofluids because one of their dimensions is in the nanoscale, but strictly speaking this dimension is not the one that is actually contributing to the changes in the thermal properties of the mixture. We include them in our analysis to demonstrate that this kind of suspension also follows conventional correlations.

O 2015 Elsevier Ltd, All rights reserved.
\end{abstract}




\section{Publicaciones a congresos}

\begin{tabular}{|l|l|}
\hline Autores & $\begin{array}{l}\text { Mondragón, R.; Segarra, C.; Jarque, J.C.; Julia, J. E.; Hernández, L. } \\
\text { Martinez-Cuenca, R. }\end{array}$ \\
\hline Título & $\begin{array}{l}\text { Characterization and modelling of physical properties of nanofluids } \\
\text { for heat transfer application. }\end{array}$ \\
\hline Tipo de participación & Poster \\
\hline Congreso & 6th European Thermal Sciences Conference, Eurotherm 2012 \\
\hline Lugar de celebración & Poitiers, Francia. \\
\hline Fecha & 2012 \\
\hline
\end{tabular}

\begin{tabular}{|l|l|}
\hline Autores & $\begin{array}{l}\text { Julia, J. E.; Hernandez, L.; Martinez-Cuenca, R.; Hibiki, T.; Mondragon, } \\
\text { R.; Segarra, C.; Jarque, J.C. }\end{array}$ \\
\hline Título & $\begin{array}{l}\text { Measurement and modelling of forced convective heat transfer } \\
\text { coefficient and pressure drop of } \mathrm{Al}_{2} \mathrm{O}_{3} \text { - and } \mathrm{SiO}_{2} \text { - water nanofluids. }\end{array}$ \\
\hline Tipo de participación & Poster \\
\hline Congreso & 6th European Thermal Sciences Conference, Eurotherm 2012 \\
\hline Lugar de celebración & Poitiers, Francia. \\
\hline Fecha & 2012 \\
\hline
\end{tabular}

\begin{tabular}{|l|l|}
\hline Autores & $\begin{array}{l}\text { Segarra, C.; Jarque, J.C.; Castello, J.; Mondragón, R.; Juliá, J.E.; } \\
\text { Hernández, L.; Martinez-Cuenca, R. }\end{array}$ \\
\hline Título & $\begin{array}{l}\text { Characterization of physical properties of nanofluids with carbon } \\
\text { nanotubes for heat transfer applications. }\end{array}$ \\
\hline Tipo de participación & \begin{tabular}{l} 
Poster \\
\hline Congreso
\end{tabular} \\
$\begin{array}{l}\text { 8th World Conference on Experimental Heat Transfer, Fluid } \\
\text { Mechanics, and Thermodynamics, ExFHT 2013 }\end{array}$ \\
\hline Lugar de celebración & Lisbon, Portugal \\
\hline Fecha & 2013 \\
\hline
\end{tabular}

\begin{tabular}{|l|l|}
\hline Autores & $\begin{array}{l}\text { Julia, J. E.; Hernandez, L.; Martinez-Cuenca, R.; Mondragon, R.; Hibiki, } \\
\text { T.; Segarra, C.; Jarque, J.C. }\end{array}$ \\
\hline Título & $\begin{array}{l}\text { Measurement of forced convective heat transfer coefficient of al2o3- } \\
\text { sio2- and cnt- water nanofluids in laminar flow conditions. }\end{array}$ \\
\hline Tipo de participación & $\begin{array}{l}\text { 8th World Conference on Experimental Heat Transfer, Fluid } \\
\text { Mechanics, and Thermodynamics, ExFHT 2013, }\end{array}$ \\
\hline Congreso & Lisbon, Portugal. \\
\hline Lugar de celebración & 2013 \\
\hline Fecha & \\
\hline
\end{tabular}




\begin{tabular}{|l|l|}
\hline Autores & Segarra,C; Jarque,J.C; Mondragón, R.;Juliá, J.E.; Hernández, L. \\
\hline Título & $\begin{array}{l}\text { Estudio de la infuencia del método de dispersion utilizado en la } \\
\text { preparación de suspensions de nanofluidos sobre las propiedades } \\
\text { térmicas y reológicas de los mismos. }\end{array}$ \\
\hline Tipo de participación & Poster \\
\hline Congreso & LIII Congreso de la Sociedad Española de Cerámica y Vidrio. \\
\hline Lugar de celebración & L'Alcora (Castellón), España. \\
\hline Fecha & 2013 \\
\hline
\end{tabular}

\begin{tabular}{|l|l|}
\hline Autores & Segarra,C; Jarque,J.C; Tiscar, J.M.; Barba, A. \\
\hline Título & $\begin{array}{l}\text { Comparative study of carbon nanotubes dispersion using chemical } \\
\text { functionalization and surfactants for thermical nanofluids. }\end{array}$ \\
\hline Tipo de participación & Poster \\
\hline Congreso & $13^{\text {Th }}$ Mediterranean Congress of Chemical Engineering(13MCCE) \\
\hline Lugar de celebración & Barcelona, España. \\
\hline Fecha & 2014 \\
\hline
\end{tabular}

\begin{tabular}{|l|l|}
\hline Autores & Segarra,C; Jarque,J.C; Tiscar, J.M.; Barba, A. \\
\hline Título & $\begin{array}{l}\text { Characterization of physical properties of nanofluids with } \\
\text { functionalized Graphene. }\end{array}$ \\
\hline Tipo de participación & Poster \\
\hline Congreso & LIV Congreso de la Sociedad Española de Cerámica y Vidrio \\
\hline Lugar de celebración & Badajoz, España \\
\hline Fecha & 2014 \\
\hline
\end{tabular}


Nomenclatura 

$A_{s}:$ área de la superficie de contacto $\left(\mathrm{m}^{2}\right)$

A : absorbancia (adimensional) ley de Lambert-Beer(adimensional)

$a_{k}:$ radio de Kapitza $(\mathrm{m})$

b : longitud del camino óptico $(\mathrm{cm})$

c : fracción de la sustancia (mol/l)

$C_{\eta}$ : coeficiente que relaciona que la viscosidad del nanofluido respecto al fluido base (adimensional)

$C_{k}$ : coeficiente que relaciona que la conductividad del nanofluido respecto al fluido base (adimensional)

$\mathrm{C}_{\mathrm{pnp}}$ : calor específico de la nanopartícula $(\mathrm{J} /(\mathrm{kgK}))$

$\mathrm{C}_{\mathrm{pnf}}:$ calor específico del fluido base $(\mathrm{J} /(\mathrm{kgK}))$

c.f.: coeficiente de friabilidad de aglomerado, expresado en (\%) de perdida de tamaño

d :diámetro del canal o tubería (m)

$\mathrm{e}_{\mathrm{r}}$ : error relativo

$f$ :factor de fricción de Fanning obtenido

$\mathrm{g}:$ aceleración de la gravedad $\left(\mathrm{m} / \mathrm{s}^{2}\right)$

$\mathrm{h}$ : coeficiente de transmisión de calor por convección o de película ( $\mathrm{W} / \mathrm{m}^{2} \mathrm{~K}$ )

$\mathrm{k}_{\mathrm{nf}}$ : conductividad térmica del nanofluido $(\mathrm{W} / \mathrm{mK})$

$\mathrm{k}_{\mathrm{p}}$ : conductividad térmica de la partícula sólida(W/mK)

$\mathrm{kf}_{\mathrm{b}}$ : conductividad térmica del fluido base $(\mathrm{W} / \mathrm{mK})$

$\mathrm{k}$ :conductividad térmica $(\mathrm{W} / \mathrm{m} \mathrm{K})$

$k_{l r}$ : conductividad térmica de la nanocapa interfacial $(\mathrm{W} / \mathrm{mK})$

$\mathrm{K}_{\mathrm{B}}$ : constante de Boltzmann

"I" : la distancia a la pared (m)

$\mathrm{L}$ : longitud de la tubería $(\mathrm{m})$ 
$\mathrm{m}_{0}$ : temperatura inicial de la etapa de calentamiento

$\mathrm{m}_{2}$ : gradiente de variación de la temperatura

$m_{3}$ : pendiente de la recta del incremento de temperatura frente al logaritmo del tiempo

Mo : número adimensional de Mouromtseff

$\mathrm{Nu}$ :coeficiente de transmisión o de película (adimensional)

Pr :número de Prandtl (adimensional)

q : cantidad de calor intercambiado entre fluido y pared por unidad de tiempo (kcal/h o W)

$r: \operatorname{radio}(m)$

$R_{c l}:$ radio aparente de los clusters $(m)$

Re :número de Reynolds (adimensional)

$R_{k}$ : resistencia térmica en la interfase nanotubo-líquido, valor $8,33 \times 10-8 \mathrm{~m}^{2} \mathrm{~K} / \mathrm{W}$

$\mathrm{S}$ : superficie de transmisión $\left(\mathrm{m}^{2}\right)$

$\mathrm{t}$ : tiempo de medición (s)

$T_{p}$ : temperatura de la pared $(K)$

$T_{f}$ : temperatura del fluido $(K)$

UE: Movilidad electroforética $(\mu \mathrm{mcm} / \mathrm{Vs})$

$\mathrm{u}_{\infty}$ y $\mathrm{v}$ : velocidad del fluido $(\mathrm{m} / \mathrm{s})$

$\mathrm{v}_{\mathrm{s}}$ : velocidad de sedimentación de las partículas (velocidad límite, $\mathrm{m} / \mathrm{s}$ ).

$X$ : espesor del material $(\mathrm{m})$

$\alpha$ : difusividad térmica $\left(\mathrm{m}^{2} / \mathrm{s}\right)$

$\rho:$ densidad del fluido $\left(\mathrm{kg} / \mathrm{m}^{3}\right)$

$\rho_{\mathrm{np}}$ : densidad de la nanopartícula $\left(\mathrm{kg} / \mathrm{m}^{3}\right)$

$\rho_{\mathrm{fb}}$ : densidad del fluido base $\left(\mathrm{kg} / \mathrm{m}^{3}\right)$

$\varepsilon_{\mathrm{r}}$ : Constante dieléctrica 
$\varepsilon$ : es la absortividad molar $(\mathrm{l} /(\mathrm{mol} \mathrm{cm})$

$\Phi$ : fracción volumétrica de nanopartículas (adimensional)

$\phi_{\text {int }}$ : fracción volumétrica de nanopartículas en un agregado (adimensional)

$\phi_{\mathrm{a}}$ : fracción de volumen de los agregados en todo el fluido (adimensional)

$\eta$ : viscosidad del fluido (Pa.s)

$\eta_{n f}:$ viscosidad del nanofluido (Pa.s)

$\eta_{f b}:$ viscosidad del fluido base (Pa.s)

$\sigma:$ tensión o esfuerzo cortante $(\mathrm{Pa})$

$\gamma:$ gradiente de velocidad $(1 / \mathrm{s})$

$\varsigma$ potencial zeta $(\mathrm{mV})$ 

BIBLIOGRAFÍA 

[1] R.Saidur, K.Y Leong, H.A. Mohammad. A review on applications and challenges of nanofluids., Malaysia: Renewable and Sustainable Energy reviews, 2010, Vol. 15, 1646-1668. doi:10.1016/j.rser.2010.11.035

[2] S.U.S Choi, J.A. Eastman, Enhancing thermal conductivity of fluids with nanoparticles. [ed.] Internatiomal Mechanical Engineering Congress and exhibition, 1995. Vols. 12-17 Nov 1995. pag 99-105.

[3] Sezer Ozerinc, Sadik Kakac, Almila Guvenc. Enhanced thermal conductivity of nanofluids; a state -of -the-art review. 145-170, Ankara, Turkey. Microfluid Nanofluid, 2009, Vol. 8. DOI 10.1007/s10404-009-0524-4.

[4] Murshed SMS, Leong KC, Yang C. Enhanced thermal conductivity of TiO2-water based nanofluids .367-373, s.I. Int J Therm SCi, 2005, Vol. 44. doi:10.1016.

[5] Zoubida Haddad, Cherifa Abid, Hakan F.Oztop, Amina Mataoui. A review on how the researches prepare their nanofluids. International Journal of Thermal Sciences, 2013, Vol. 76. 168-189, Turkey.

[6] A. Ghadimi, R.Saidur, H.S.C. Metselaar. A review of nanofluid stability properties and characterization in stationary conditions. 4051-4068, Malaysia : International Journal of Heat and Mass Transfer, 2011, Vol. 54.

[7] S.M.Abbasi, Alimorad Rashidi, Ali Nemati, Kaveh Arzani. The effect of functionalisation method on the stability and the thermal conductivity of nanofluid hybrids of carbon nanotubes/gamma alumina. Iran. Ceramics International, 2012. Review o heat transfer in nanofluids: Conductive, convective and radiative experimental results.

[8] Duarte, Saúl García. Medición de conductividad térmica de fluidos. s.l. : CENTRO NACIONAL DE METROLOGÍA, 2009.

[9] Martinez, Salvador alvarado. Técnica de hilo caliente para la caracterización térmica de líquidos. México : s.n., 2011.

[10] S. Lazzari a, L. Nicoud b, B. Jaquet b, M. Lattuada c, M. Morbidelli. Fractal-like structures in colloid science. Advances in Colloid and Interface Science 235 (2016) 113. http://dx.doi.org/10.1016/j.cis.2016.05.002 
[11] Tyagi H, Phelan P, Prasher RS . Predicted efficiency of a low-temperature nanofluid-based direct absorption solar collector. J Sol Energy Eng. 2009; 131 (4) 041004

[12] YU W, France DM, Choi SUS, Routbort JL, Review and assessment of nanofluid technology for transportation and other applications. Energy systems Division, Argone National Laboratory, 2007

[13] Sarit K. Das, Stephen U. S. Choi, Wenhua Yu. Nanofluids: Science and Technology. Editor: John Wiley \& Sons

[14] Yanjiajo Li, Jingen Zhou, Simon Tung, Eric Scheneider, Shengqi Xi. A review on development of nanofluid preparation and characterization. Powder Thecnology 196 (2009) 89-101 DOI:10.1016

[15] M. J. Assael, C.-F. Chen, I. Metaxa, and W. A. Wakeham. Thermal Conductivity of Suspensions of Carbon Nanotubes in Water. International Journal of Thermophysics, Vol. 25, No. 4, July 2004

[16] LIU, Jie, et al. Fullerene pipes. Science, 1998, vol. 280, no 5367, p. 1253-1256.

[17] R. Sadri, G. Ahmadi, H. Togun, M. Dahari, S, Newaz, E. sadeghinezhad, n. Zubir. An experimental study on thermal conductivity and viscosity of nanofluids containing carbon nanotubes. Nanoscale Research Letters 2014, 9:151

[18] R Mondragon, Carmen Segarra, Juan Carlos Jarque. Experimental characterization and modeling of thermophysical properties of nanofluids at high temperature conditions for heat transfer applications.Powder Technology 249 (2013) 516-529

[19] A.Nasiri, M.Shariaty-Niasar, A.Rashidi, A.Amrollahi, R.Khodafarin. Effect of dispersion method on thermal conductivity and stability of nanofluid. Experimental Thermal and Fluid science, Theran,Iran,2011.

[20] Ravikanth, K.Debendra, A review and analysis on influence of temperature and concentration of nanofluids on thermophysical properties, heat transfer and pumping power. USA, International Journal of Heat and Mass Transfer 55,pp.4063-4078, 2012.

[21] Y. Ding, H.Alias, D. Wen, R.Williams, Heat transfer of aqueous suspensions of carbon nanotubes (CNT nanofluids), University of Leeds,UK. International Journal of Heat and Mass Transfer, 49, pp.240-250, 2006 
[22] P.Garg, J.Alvarado, C.Mord, An experimental study on the effect of ultrasonication on viscosity and heat transfer performance of multi-wall carbon nanotube-based aqueous nanofluids USA. International Journal of Heat and Mass Transfer 52, pp.5090-5101, 2009

[23] Z. Talaei, A.Reza, A.Rashidi, A.Amrollahi, M.Emami, The effect of functionalized group concentration on the stability and thermal conductivity of carbon nanotube fluid as heat transfer media. Theran, Iran. International Communications in Heat and Mass Transfer 38, pp. 513-517,2011

[24] SUS. Choi, AG Chang, W Yu, FE Lockwood. EA Grulke. Anomalous thermal conductivity enhacement in nanotube suspensions. Appl Phys Lett 79 (14):22522254, 2001

[25] J. Buongiorno, DvaidC. Venerus, Naveen Prabhat, Thomas, A benchmark study on the thermal conductivity of nanofluids, Journal of applied physics 106,

[26] B. Munkhbayar, Munkhjargal Bat-Erdene, B. Ochirkhuyag, D. Sarangerel, B. Battsengel ,Hanshik Chung, Hyomin Jeong. An experimental study of the planetary ball milling effect on dispersibility and thermal conductivity of MWCNTs-based aqueous nanofluids. Materials Research Bulletin 47 (2012) 41874196

[27] Richa Rastogi, Rahul Kaushal , S.K. Tripathi , Amit L. Sharma , Inderpreet Kaur , Lalit M. Bharadwaj. Comparative study of carbon nanotube dispersion using surfactants. Journal of Colloid and Interface Science 328 (2008) 421-428

[28] F.Inam, A.Heaton, P.Brown, T.Peijs, M.J.Reece. Effects of dispersion surfactants on the properties of ceramic-carbon nanotube (CNT) nanocomposites. Ceramics International40(2014)511-516 Heat transfer characteristics of nanofluids: a review

[29] D. Quemada, Rheological modelling of complex fluids. I. The concept of effective volume fraction, Eur. Phys. J. Appl. Phys. 1 (1998) 119-127.

[30] Lee, J. H., Lee, S. H., Choi, C., Jang, S., \& Choi, S. A review of thermal conductivity data, mechanisms and models for nanofluids. International Journal of Micro-Nano Scale Transport, 1(4), 269-322, 2010 
[31] M.A. Khairul, Kalpit Shah, Elham Doroodchi, Reza Azizian, Behdad Moghtaderi, Effects of surfactant on stability and thermo-physical properties of metal oxide nanofluids. International Journal of Heat and Mass Transfer 98 (2016) 778-787. http://dx.doi.org/10.1016/j.ijheatmasstransfer.2016.03.079

[32] Xiang-Qi Wang and Arun S. Mujumdar A review on nanofluids - part I and part II: theoretical and numerical investigations. Vol. 25, No. 04, pp. 613 -630, October December, 2008

[33] "Guía práctica de Energía Solar Térmica" AVEN ,Agencia Valenciana de la Energía 2008.

[34] Libro verde sobre eficiencia energética o como hacer más con menos. Bruselas: Comisión de las Comunidades Europeas, 2005. [ref. de 25 de noviembre de 2005].

[35] Paul, G., Chopkar, M., Manna, I., \& Das, P. K. Techniques for measuring the thermal conductivity of nanofluids: a review. Renewable and Sustainable Energy Reviews, 14(7), 1913-1924. (2010).

[36] Thomas, S., \& Sobhan, C. B. P. (2011). A review of experimental investigations on thermal phenomena in nanofluids. Nanoscale research letters,6(1), 1-21.

[37] Koronaki, I. P., Nitsas, M. T., \& Papaefthimiou, V. (2014, November). A Review on the Thermal Conductivity and Viscosity Models of Nanofluids: Impact on Convection Coefficient Calculations. InASME 2014 International Mechanical Engineering Congress and Exposition (pp. V08BT10A087-V08BT10A087). American Society of Mechanical Engineers.

[38] Ali ljam, R. Saidur. Nanofluid as a coolant for electronic devices (cooling of electronic devices), Malaysia, Applied Thermal Engineering 32 (2012) 76e82

[39] S.M.SohelMurshed, C.A.NietodeCastro, Superior thermal feature sofcarbonnanotubes-based nanofluids. A review Renewable and Sustainable Energy Reviews 37(2014)155-167.

[40] AL-SHAMANI, Ali Najah, et al. Nanofluids for improved efficiency in cooling solar collectors-a review. Renewable and Sustainable Energy Reviews, 2014, vol. 38, p. 348-367. 
[41] Nor Azwadi Che Sidik, H.A. Mohammed, Omer A. Alawi, S. Samion. A review on preparation methods and challenges of nanofluids. International Communications in Heat and Mass Transfer 54 (2014) 115-125

[42] L. SyamSundar a,n, K.V.Sharma c, M.T.Naik c, ManojK.Singh. Empirical and theoretical correlations on viscosity of nanofluids: A review. Renewable and Sustainable Energy Reviews.25(2013)670-686

[43] J.M. Wu, Jiyun Zhao, A review of nanofluid heat transfer and critical heat flux enhancement Research gap to engineering application. Progress in Nuclear Energy 66 (2013) 13e24

[44] Vicenzo Bianco, Oronzo manca, Sergio Mardini, Kambiz Vafai, Heat Transfer Enhacement with nanofluids. Editorial: CRR Press 2015 by Taylor and Francis Group, LLC.

[45] Enrique Torrella, Ramón Cabello, Rodrigo LLopis, Daniel sanchez, Carlos Sanz, Transmisión de calor. Procesos y equipos intercambiadores. Editorial: Universitat Politècnica de València, Primera edición 2015.

[46] S.M. Sohel Murshed and C.A. Nieto de Castro. Nanofluids. Synthesis, Properties and applications. Editorial University of Lisbon, Portugal, Primera edición 2014.

[47] Rodrigo Moreno Botella, Reología de suspensiones cerámicas, Consejo superior de investigaciones científicas, Madrid 2005.

[48] Omid Mahian, Ali Kianifar, Soteris A, Kalogirou, loan Pop, Somchai Wongwises. A review of the applications of nanofluids in solar energy. International Journal of Heat and Mass Transfer 57 (2013) 582-594

[49] John Philip, P.D. Shima. Thermal properties of nanofluids. Advances in Colloid and Interface Science 183-184 (2012) 30-45.

[50] Gabriela Huminic, Angel Huminic. Application of nanofluids in heat exchangers: A review. Renewable and Sustainable Energy Reviews 16 (2012) 5625-5638. http://dx.doi.org/10.1016/i.rser.2012.05.023.

[51] R. Saidur a, S.N. Kazi a, M.S. Hossain a, M.M. Rahman b, H.A. Mohammed. A review on the performance of nanoparticles suspended with refrigerants and lubricating oils in refrigeration systems. Renewable and Sustainable Energy Reviews 15 (2011) 310-323. 
[52] R. Saidur, M.A. Amalina. Latest developments on the viscosity of nanofluids. International Journal of Heat and Mass Transfer 55 (2012) 874-885

[53] Wenhua Yu, David m. France, Jules I. Routbort, and Stephen U.S. Choi, Review and Comparison of Nanofluid Thermal Conductivity and Heat Transfer Enhancements. Heat Transfer Engineering, 29(5):432-460, 2008. DOI:10.1080/01457630701850851.

[54] Georgia Tertsinidou, Marc J. Assael, -William A. Wakeham. The Apparent Thermal Conductivity of Liquids Containing Solid Particles of Nanometer Dimensions: A Critique. Int J Thermophys 2015. DOI 10.1007/s10765-015-1856.

[55] Suhaib Umer Ilyas, Rajashekhar Pendyala, Narahari Marneni. Preparation, Sedimentation, and Agglomeration of Nanofluids. Chem. Eng. Technol. 2014, 37, No. 12, 2011-2021. DOI: 10.1002/ceat.201400268.

[56] Joohyun Lee, Hansul Lee, Young-Jin Baik, Junemo Koo. Quantitative analyses of factors affecting thermal conductivity of nanofluids using an improved transient hot-wire method apparatus. International Journal of Heat and Mass Transfer 89 (2015) 116-123. http://dx.doi.org/10.1016/j.ijheatmasstransfer.2015.05.064

[57] Wei Yu and Huaqing Xie. A Review on Nanofluids: Preparation, Stability Mechanisms, and Applications. Journal of Nanomaterials Volume 2012, Article ID 435873, doi:10.1155/2012/435873.

[58] Rosa Mondragon, J. Enrique Juliá, Antonio Barba, Juan Carlos Jarque. Preparación y caracterización de nanofluidos: Influencia de variables sobre su estabilidad, estado de aglomeración y propiedades físicas. Boletín de la Sociedad Española de Cerámica y Vidrio.Vol 53, 3, 101-110, Mayo-Junio 2014.

[59] Yujin Hwang, Jae-Keun Lee, Jong-Ku Lee, Young-Man Jeong, Seong-ir Cheong, Young-Chull Ahn, Soo H. Kim. Production and dispersion stability of nanoparticles in nanofluids. Powder Technology 186 (2008) 145-15. doi: 10.1016/j.powtec. 2007.11.020.

[60] Rodrigo Vidonscky Pinto, Flávio Augusto Sanzovo Fiorelli. Review of the mechanisms responsible for heat transfer enhancement using nanofluids. 2016 Applied Thermal Engineering $108 \quad$ (2016) 720739.http://dx.doi.org/10.1016/j.applthermaleng.2016.07.147. 
[61] R. M. Sarviyaa, Veeresh Fuskeleb. Review on Thermal Conductivity of Nanofluids, Materials Today: Proceedings 4 (2017) 4022-4031, 2017.

[62] Liu Yang, Jianyong Xu, Kai Dua, Xiaosong Zhang. Recent developments on viscosity and thermal conductivity of nanofluids. Powder Technology 317 (2017) 348-369. http://dx.doi.org/10.1016/j.powtec.2017.04.061

[63] Jacob Eapen, Roberto Rusconi, Roberto Piazza, Sidney Yip. The Classical Nature of Thermal Conduction in Nanofluids, Journal of Heat Transfer, october 2010, vol. 132 , doi: $10.1115 / 1.4001304$.

[64] Ravikanth S. Vajjha, Debendra K. Das A review and analysis on influence of temperature and concentration of nanofluids on thermophysical properties, heat transfer and pumping power. International Journal of Heat and Mass Transfer 55 (2012) 4063-4078.

[65] Siddharth Suman, Mohd. KaleemKhan, Manabendra Pathak. Performance enhancement of solar collectors $-A$ review. Renewable and Sustainable Energy Reviews 49 (2015)192-210.

[66] Mauro Lomascolo, GianpieroColangelo, MarcoMilanese, ArturodeRisi. Review of heat transfer in nanofluids: Conductive, convective and radiative experimental results. Renewable and Sustainable EnergyReviews 43 (2015)1182-1198. http://dx.doi.org/10.1016/i.rser.2014.11.086.

[67] Omer A. Alawi, Nor Azwadi Che Sidik, H.A. Mohammed . A comprehensive review of fundamentals, preparation and applications of nanorefrigerants. International Communications in Heat and Mass Transfer 54 (2014) 81-95.

[68] M.J. Pastoriza-Gallego, C. Casanova, R. Paramo, B. Baroes, J.L. Legido, M.M. Pineiro. Study on stability and thermo physical properties (density and viscosity) of Al2O3 in water nanofluids, J. Appl. Phys. 106 (2009) 06430.

[69] Rosa Mondragon, J. Enrique Julia, Antonio Barba, Juan Carlos Jarque, Characterization of silica water nanofluids dispersed with an ultrasound probe: a study of their physical properties and stability. Powder Technol. 224 (2012) 138 e146. 
[70] Rebay, Mourad; Kakac, Sadik; Cotta, Renato M; Microscale and Nanoscale Heat Transfer: Analysis, Design, and Application. CRC Press, 2016. Microscale and Nanoscale Heat Transfer:Analasysis, Design and Applications.

[71] Ahmad Ghozatloo, Ali Morad Rashidi, Mojtaba Shariaty-Niasar. Effects of surface modification on the dispersion and thermal conductivity of CNT/water nanofluids. International Communications in Heat and Mass Transfer 54 (2014) 1-7 http://dx.doi.org/10.1016/i.icheatmasstransfer.2014.02.013.

[72] Amin Asadi, Meisam Asadi, Marzieh Siahmargoi, Taghi Asadi, Majid Gholami Andarati. The effect of surfactant and sonication time on the stability and thermal conductivity of water-based nanofluid containing $\mathrm{Mg}(\mathrm{OH}) 2$ nanoparticles: An experimental investigation. International Journal of Heat and Mass Transfer 108 (2017) 191-198.

[73] Jang, Seok Pil; CHOI, Stephen US. Role of Brownian motion in the enhanced thermal conductivity of nanofluids. Applied physics letters, 2004, vol. 84, no 21, p. 4316-4318.

[74] I.M. Mahbubul , I.M. Shahrul , S.S. Khaleduzzaman, R. Saidur, M.A. Amalina , A. Turgut. Experimental investigation on effect of ultrasonication duration on colloidal dispersion and thermophysical properties of alumina-water nanofluid. International Journal of Heat and Mass Transfer 88 (2015) 73-81.

[75] I.M. Mahbubul , R. Saidur, M.A. Amalina, E.B. Elcioglu , T. Okutucu-Ozyurt Effective ultrasonication process for better colloidal dispersion of nanofluid Ultrasonics Sonochemistry 26 (2015) 361-369.

[76] Nor Azwadi Che Sidik , H.A. Mohammed, Omer A. Alawi, S. Samion A review on preparation methods and challenges of nanofluids. International Communications in Heat and Mass Transfer 54 (2014) 115-125.

[77] Azadeh Ghadimi, Ibrahim Henk Metselaar The influence of surfactant and ultrasonic processing on improvement of stability, thermal conductivity and viscosity of titania nanofluid. Experimental Thermal and Fluid Science 51 (2013) $1-9$.

[78] Wenhua Yu, David M. France, Jules L. Routbort \& Stephen U. S. Choi (2008) Review and Comparison of Nanofluid Thermal Conductivity and Heat Transfer 
Enhancements, Heat Transfer Engineering, 29:5, 432-460, Doi:10.1080/01457630701850851.

[79] Chan Hee Chon and Kenneth D. Kihm, Stephen U. S. Choi, Shin Pyo Lee. Empirical correlation finding the role of temperature and particle size for nanofluid „Al2O3 thermal conductivity enhancement. Aplied Physics Letters 87, 153107_2005.

[80] Yuanqiao Rao . Nanofluids: Stability, phase diagram, rheology and applications. Particuology 8 (2010) 549-555. Chinese Society of Particuology and Institute of Process Engineering, Chinese Academy of Sciences. Published by Elsevier B.V.

[81] Joohyun Lee, Kisso Han, Junemo Koo. A novel method to evaluate dispersion stability of nanofluids International Journal of Heat and Mass transfer 70 (2014) 421-429.

[82] Michael S. Saterlie, Huseyin Sahin, Barkan Kavlicoglu, Yanming Liu, and Olivia A. Graeved. Surfactant Effects on Dispersion Characteristics of Copper-Based Nanofluids: A Dynamic Light Scattering Study . Chemistry of materials. (2012) 24, 3299-3306 http://dx.doi.org/10.1021/cm203853f .

[83] Hyun Jin Kim, Seung-Hyun Lee, Ji-Hwan Lee, Seok Pil Jang. Effect of particle shape on suspension stability and thermal conductivities of water-based bohemite alumina nanofluids. Energy (2015), http://dx.doi.org/10.1016/i.energy.2015.06.084

[84] A. Ghadimi , R. Saidur, H.S.C. Metselaar. A review of nanofluid stability properties and characterization in stationary conditions. International Journal of Heat and Mass Transfer 54 (2011) 4051-4068.

[85] A. Nasiri, M. Shariaty-Niasar, A.M. Rashidi , R. Khodafarin Effect of CNT structures on thermal conductivity and stability of nanofluid. International Journal of Heat and Mass Transfer 55 (2012) 1529-1535

[86] Leong, K. C., C. Yang, and S. M. S. Murshed. A model for the thermal conductivity of nanofluids-the effect of interfacial layer. Journal of nanoparticle research 8.2 (2006): 245-254.

[87] Colangelo, G., Favale, E., de Risi, A., \& Laforgia, D.. A new solution for reduced sedimentation flat panel solar thermal collector using nanofluids. Applied Energy, (2013) 111, 80-93. 
[88] Colangelo, G., Favale, E., Miglietta, P., de Risi, A., Milanese, M., \& Laforgia, D. Experimental test of an innovative high concentration nanofluid solar collector. Applied Energy, (2015) 154, 874-881.

[89] Kim, C. K., Lee, G. J., Lee, M. K., \& Rhee, C. K. . A Study on dispersion stability of nickel nanoparticles synthesized by wire explosion in liquid media. Archives of Metallurgy and Materials, (2015) 60(2), 1379-1382.

[90] Kim, S., Kim, C., Lee, W. H., \& Park, S. R Shear-dependent thermal conductivity of alumina nanofluids. Rheologica acta 51.7 (2012): 609-621.

[91] Yanjiao Li, Jing'en Zhou, Simon Tung, Eric Schneider, Shengqi Xi. Review on development of nanofluid preparation and characterization. Powder Technology. (2009) 196 89-10. Journal ISSN : 0032-5910.

[92] Meybodi, M. K., Daryasafar, A., Koochi, M. M., Moghadasi, J., Meybodi, R. B., \& Ghahfarokhi, A. K. A novel correlation approach for viscosity prediction of water based nanofluids of Al2O3, TiO2, SiO2 and CuO. Journal of the Taiwan Institute of Chemical Engineers, (2016) 58, 19-27.

[93] C.T. Nguyen, F. Desgranges, G. Roy, N. Galanis, T. Mare, S. Boucher, H. Angue Mints. Temperature and particle-size dependent viscosity data for water-based nanofluids - Hysteresis phenomenon. International Journal of Heat and Fluid Flow 28 (2007) 1492-1506

[94] Murshed, S. M. S., Leong, K. C., \& Yang, C. Investigations of thermal conductivity and viscosity of nanofluids. International Journal of Thermal Sciences, 47(5), (2008) 560-568.

[95] Prasher, R., Song, D., Wang, J., \& Phelan, P. Measurements of nanofluid viscosity and its implications for thermal applications. Applied Physics Letters, 89(13), (2006) 133108.

[96] Duangthongsuk, W., \& Wongwises, S. Measurement of temperature-dependent thermal conductivity and viscosity of TiO 2-water nanofluids. Experimental thermal and fluid science, 33(4), (2009) 706-714.

[97] Aravind, S. J., Baskar, P., Baby, T. T., Sabareesh, R. K., Das, S., \& Ramaprabhu, S. Investigation of structural stability, dispersion, viscosity, and conductive heat 
transfer properties of functionalized carbon nanotube based nanofluids. The Journal of Physical Chemistry C, 115(34), (2011) 16737-16744.

[98] Azmi, W. H., Sharma, K. V., Mamat, R., Najafi, G., \& Mohamad, M. S. The enhancement of effective thermal conductivity and effective dynamic viscosity of nanofluids-A review. Renewable and Sustainable Energy Reviews,53, (2016) 1046-1058.

[99] M. Abbasi, et al., The effect of functionalisation method on the stability and the thermal conductivity of nanofluid hybrids of carbon nanotubes/gamma alumina, Ceramics International (2012).

[100] A. Ghadimi , R. Saidur, H.S.C. Metselaar. A review of nanofluid stability properties and characterization in stationary conditions. International Journal of Heat and Mass Transfer 54 (2011) 4051-4068.

[101] A. Nasiri, M. Shariaty-Niasar, A.M. Rashidi, R. Khodafarin Effect of CNT structures on thermal conductivity and stability of nanofluid. International Journal of Heat and Mass Transfer 55 (2012) 1529-1535.

[102] L. Colla, L. Fedele, M. Scattolini, and S. Bobbo Water-Based Fe2O3 Nanofluid Characterization: Thermal Conductivity and Viscosity Measurements and Correlation. Hindawi Publishing Corporation Advances in Mechanical Engineering Volume 2012, Article ID 674947, 8 pages doi:10.1155/2012/674947.

[103] Alina Adriana Minea, Oronzio Manca, Madalina Georgiana Moldoveanu. FOM comparison on $\mathrm{Al}_{2} \mathrm{O}_{3}, \mathrm{CuO}$ and $\mathrm{TiO}_{2}$ water based nanofluids in laminar and turbulent flow. Asme-ati-uit 2015 Conference on Thermal Energy Systems: Production, Storage, Utilization and the Environment 17 - 20 May, 2015, Napoli, Italy.

[104] Ravikanth S. Vajjha, Debendra K. Das A review and analysis on influence of temperature and concentration of nanofluids on thermophysical properties, heat transfer and pumping power. International Journal of Heat and Mass Transfer 55 (2012) 4063-4078.

[105] Lenert, Andrej, Youngsuk Nam, and Evelyn N. Wang. (Solar Thermal) Heat Transfer Fluids .Annual Review of Heat Transfer 15, (2012). 
[106] Sarit K. Das, Stephen U. S. Choi, Wenhua Yu, T.Pradeep, NANOFLUIDS Science and Technology. Libro.

[107] Alirezaie, A., Hajmohammad, M. H., Ahangar, M. R. H., \& Esfe, M. H. Priceperformance evaluation of thermal conductivity enhancement of nanofluids with different particle sizes. Applied Thermal Engineering, 128, 373-380,(2018).

[108] Rayleigh, L. LVI. On the influence of obstacles arranged in rectangular order upon the properties of a medium. The London, Edinburgh, and Dublin Philosophical Magazine and Journal of Science, 34(211), 481-502.

[109] H.Frike, The Maxwell-wagner in a suspension of ellipsoids J. Phys. Chem. 1953, 57, 9, 934-937 .September 1, 1953 .doi.org/10.1021/j150510a018.

[110] C-W Nan, Z.Shi, Y.Lin . A simple model for the termal conductivity of carbon nanotubed-based components. Chemical Physics Letters 375, 666-669 (2003). doi:10.1016/S0009-2614(03)00956-4

[111] Hamilton, R. L., \& Crosser, O. K. Thermal conductivity of heterogeneous twocomponent systems. Industrial \& Engineering chemistry fundamentals, 1(3), 187191. (1962)

[112] Xuan, Y., Li, Q., \& Hu, W. Aggregation structure and thermal conductivity of nanofluids. AlChE Journal, 49(4), 1038-1043(2003) doi.org/10.1002/aic.690490420

[113] Xue, Q. Z. Model for the effective thermal conductivity of carbon nanotube composites. Nanotechnology, 17(6), 1655. (2006) Doi.10.1088/0957$4484 / 17 / 6 / 020$

[114] Jiang, H., Zhang, Q., \& Shi, L. Effective thermal conductivity of carbon nanotubebased nanofluid. Journal of the Taiwan Institute of Chemical Engineers, 55, 76-81. (2015). https://doi.org/10.1016/i.jtice.2015.03.037

[115] Yamada, E., \& Ota, T. Effective thermal conductivity of dispersed materials. Wärme-und Stoffübertragung, 13(1-2), 27-37(1980).

[116] Ahammed,N., Godson, L., Titus,J. , Raja, J. , Wongwises,S. Measurement of thermal conductivity of graphene-water nanofluid at below and above ambient temperatures. International Communications in Heat and Mass Transfer 70 , 6674.(2016). 
[117] Ghozatloo A., Shariaty-Niasar M., Morad A., Preparation of nanofluids from functionalized Graphene by new alkaline method and study on the thermal conductivity and stability. Transport phenomena and Nanotechnology Laboratory, Department of Chemical Engineering, College of Eng., University of Tehran, Tehran, 11155/4563, Iran

[118] Pu, N. W., Wang, C. A., Liu, Y. M., Sung, Y., Wang, D. S., \& Ger, M. D. Dispersion of graphene in aqueous solutions with different types of surfactants and the production of graphene films by spray or drop coating. Journal of the Taiwan Institute of Chemical Engineers, 43(1), 140-146. (2012)

[119] S. S., \& Kim, N. J. Influence of the oxidation treatment and the average particle diameter of graphene for thermal conductivity enhancement. Journal of Industrial and Engineering Chemistry, 20(4), 1911-1915. (2014)

[120] R. Ebrahimi, D. de Faoite, D.P. Finn, K.T. Stanton. Accurate measurement of nanofluid thermal conductivity by use of apolysaccharide stabilising agent. International Journal of Heat and Mass Transfer 136 (2019) 486-500. (2019)

[121] Nurettin Sezer, Muataz A. Atieh, Muammer Koç . A comprehensive review on synthesis, stability, thermophysical properties, and characterization of nanofluids. PowderTechnology 344, 404-431. (2019).

[122] Sajid, M. U., \& Ali, H. M. Recent advances in application of nanofluids in heat transfer devices: a critical review. Renewable and Sustainable Energy Reviews, 103, 556-592. (2019).

[123] Wanga Y., Hussein A. I, Al-Saaidi ,Kong,M. , Alvarado.J Thermophysical performance of graphene based aqueous nanofluids. International Journal of Heat and Mass Transfer $119,408-417,(2018)$

[124] Alirezaie, A., Hajmohammad, M. H., \& Alipour, A. Do nanofluids affect the future of heat transfer?"A benchmark study on the efficiency of nanofluids". Energy, 157, 979-989. (2018)

[125] Esfe, M. H., Arani, A. A. A., \& Firouzi, M. Empirical study and model development of thermal conductivity improvement and assessment of cost and sensitivity of EG-water based SWCNT-ZnO (30\%: 70\%) hybrid nanofluid. Journal of Molecular Liquids, 244, 252-261. (2017) 
[126] Maji, N. C., Krishna, H. P., \& Chakraborty, J. Low-cost and high-throughput synthesis of copper nanopowder for nanofluid applications. Chemical Engineering Journal, 353, 34-45. (2018)

[127] Chamkha, A. J., Molana, M., Rahnama, A., \& Ghadami, F. On the nanofluids applications in microchannels: a comprehensive review. Powder technology, 332, 287-322. (2018)

[128] Tawfik, M. M. Experimental studies of nanofluid thermal conductivity enhancement and applications: A review. Renewable and Sustainable Energy Reviews, 75, 1239-1253. (2017).

[129] Yu, W., Xie, H., Wang, X., \& Wang, X. Significant thermal conductivity enhancement for nanofluids containing graphene nanosheets. Physics Letters A, 375(10), 1323-1328. (2011).

[130] Yoon, K. Y., An, S. J., Chen, Y., Lee, J. H., Bryant, S. L., Ruoff, R. S., ... \& Johnston, K. P. Graphene oxide nanoplatelet dispersions in concentrated $\mathrm{NaCl}$ and stabilization of oil/water emulsions. Journal of colloid and interface science, 403, 1-6. (2013).

[131] Alvarado, S., Marín, E., Juárez, A. G., Calderón, A., \& Ivanov, R. Sistema automatizado para la medición de la conductividad térmica de líquidos mediante el método del alambre caliente. Revista mexicana de física, 57(3), 259-265. (2011)

[132] Timofeeva, E. V., Yu, W., France, D. M., Singh, D., \& Routbort, J. L.. Nanofluids for heat transfer: an engineering approach. Nanoscale research letters, 6(1), 182. (2011)

[133] Simons, R. E. Calculation corner: comparing heat transfer rates of liquid coolants using the Mouromtseff number. Electronics Cooling, 12(2), 10. (2006).

[134] Kaombe, D. D., Lenes, M., Toven, K., \& Glomm, W. R. Turbiscan as a tool for studying the phase separation tendency of pyrolysis oil. Energy \& fuels, 27(3), 1446-1452. (2013).

[135] Formulaction, Stability of pigment inkjet inks. Application paper, 1-5, (2009).

[136] Lu, Y., Kang, W., Jiang, J., Chen, J., Xu, D., Zhang, P., ... \& Wu, H. Study on the stabilization mechanism of crude oil emulsion with an amphiphilic polymer using the $\beta$-cyclodextrin inclusion method. RSC advances, 7(14), 8156-8166, (2017). 
[137] Duarte, S. G., Cortés, L. L., \& Lango, E. M. Circuito de medición para operar el método transitorio del hilo caliente en la medición de la conductividad térmica de fluidos simples. In Simposio de metrología, Querétaro, México (Vol. 27). 